\title{
ROUTLEDGE
HANDBOOKS
}

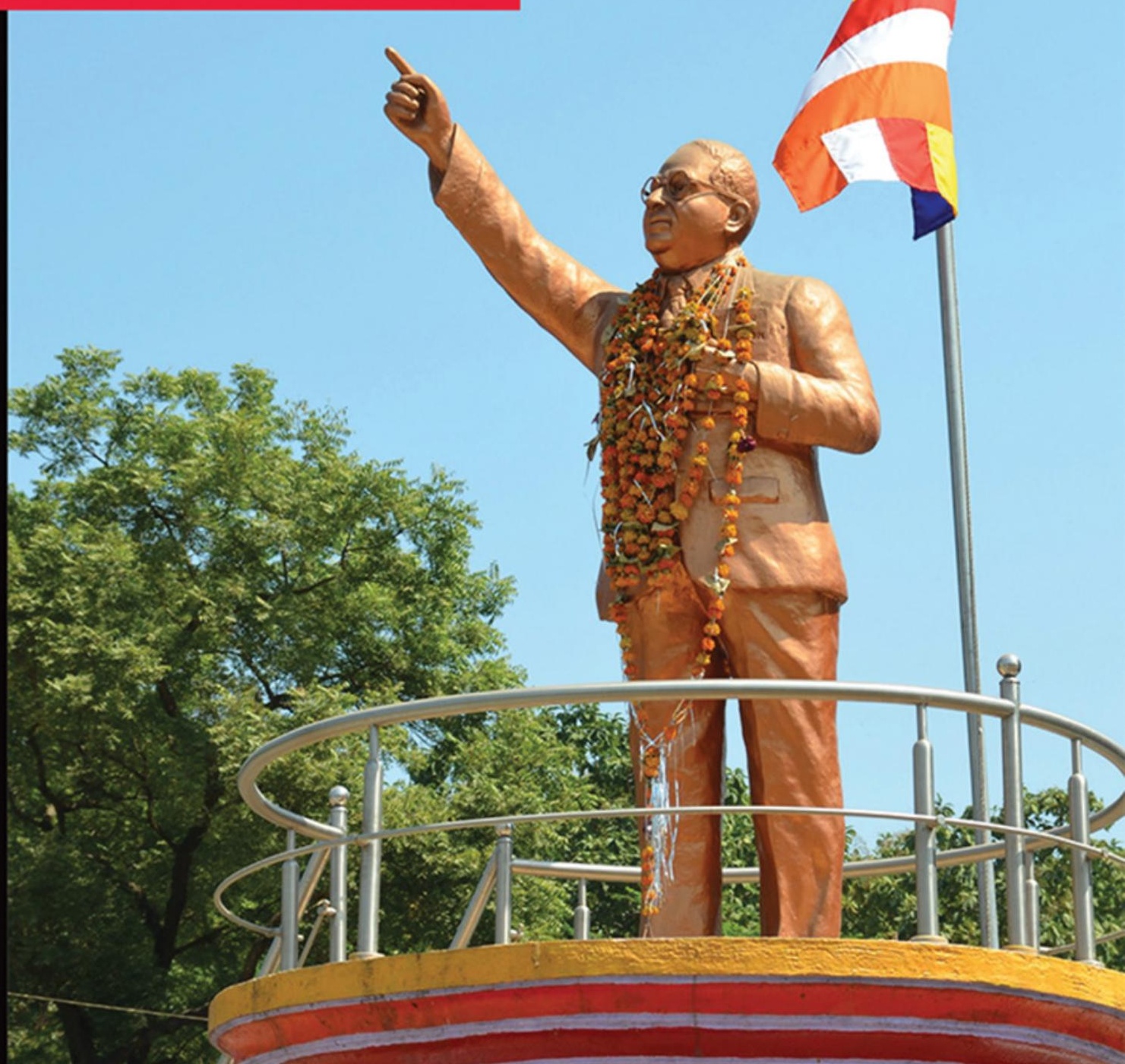

\section{Routledge Handbook of Contemporary India}

Edited by Knut A. Jacobsen 


\section{ROUTLEDGE HANDBOOK OF CONTEMPORARY INDIA}

India is the second largest country in the world with regard to population, the world's largest democracy and by far the largest country in South Asia, and one of the most diverse and pluralistic nations in the world in terms of official languages, cultures, religions and social identities. Indians have for centuries exchanged ideas with other cultures globally and some traditions have been transformed in those transnational and transcultural encounters and become successful innovations with an extraordinary global popularity. India is an emerging global power in terms of economy, but in spite of India's impressive economic growth over the last decades, some of the most serious problems of Indian society such as poverty, repression of women, inequality both in terms of living conditions and of opportunities such as access to education, employment, and the economic resources of the state persist and do not seem to go away.

Now available in paperback, this Handbook contains chapters by the field's foremost scholars dealing with fundamental issues in India's current cultural and social transformation and concentrates on India as it emerged after the economic reforms and the new economic policy of the 1980s and 1990s and as it develops in the twenty-first century.

Following an introduction by the editor, the book is divided into five parts:

- Part I: Foundation

- Part II: India and the world

- Part III: Society, class, caste and gender

- Part IV: Religion and diversity

- Part V: Cultural change and innovations.

Exploring the cultural changes and innovations relating a number of contexts in contemporary India, this Handbook is essential reading for students and scholars interested in Indian and South Asian culture, politics and society.

Knut A. Jacobsen is Professor of Religion at the University of Bergen, Norway. His previous publications include Yoga in Modern Hinduism: Hariharānanda Āranya and Sāmkhyayoga, and Pilgrimage in the Hindu Tradition: Salvific Space. He is the editor in chief of the six volumes Brill's Encyclopedia of Hinduism. 

$\because$ Taylor \& Francis http://taylorandfrancis.com 


\section{ROUTLEDGE HANDBOOK OF CONTEMPORARY INDIA}

Edited by Knut A. Jacobsen

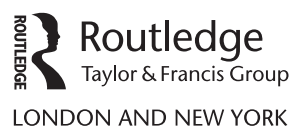


First published in paperback 2018

First published 2016

by Routledge

2 Park Square, Milton Park, Abingdon, Oxon OX14 4RN

and by Routledge

711 Third Avenue, New York, NY 10017

Routledge is an imprint of the Taylor E Francis Group, an informa business

(C)2016, 2018 selection and editorial matter, Knut A. Jacobsen; individual chapters, the contributors

The right of Knut A. Jacobsen to be identified as the author of the editorial material, and of the authors for their individual chapters, has been asserted in accordance with sections 77 and 78 of the Copyright, Designs and Patents Act 1988.

All rights reserved. No part of this book may be reprinted or reproduced or utilised in any form or by any electronic, mechanical,

or other means, now known or hereafter invented, including

photocopying and recording, or in any information storage or retrieval system, without permission in writing from the publishers.

Trademark notice: Product or corporate names may be trademarks or registered trademarks, and are used only for identification and explanation without intent to infringe.

British Library Cataloguing-in-Publication Data

A catalogue record for this book is available from the British Library

Library of Congress Cataloging-in-Publication Data

Jacobsen, Knut A., 1956-

Routledge handbook of contemporary India / Knut A. Jacobsen. pages $\mathrm{cm}$

1. India-Social conditions. 2. India-Economic conditions.

3. India-History-Partition, 1947. I. Title.

HN683.5.J33 2015

$306.0954-\mathrm{dc} 23$

2015005886

ISBN: 978-0-415-73865-1 (hbk)

ISBN: 978-1-138-31375-0 (pbk)

ISBN: 978-1-315-68257-0 (ebk)

Typeset in Bembo

by Apex CoVantage, LLC 


\section{CONTENTS}

List of figures ix

List of tables $x$

Notes on contributors $\quad x i$

Contemporary India: foundation, relations, diversity and innovations $\quad 1$

Knut A. Jacobsen

\section{PART I}

Foundation

1 Dreams, memories and legacies: partitioning India

Pippa Virdee

2 Symbiosis and resilience: the dynamics of social change and transition to democracy in India

Subrata Kumar Mitra

3 Foundations for a sustainable growth: India's Constitution and its

Supreme Court

Ananth Padmanabhan

4 Economic foundation of India

Kunal Sen

5 Equity, quantity and quality: the precarious balancing act in India's schools

Vimala Ramachandran 
6 Agriculture and the development burden

Rajeswari S. Raina

\section{PART II}

\section{India and the world}

7 Politics, security and foreign policy

Rajat Ganguly

8 Is India a South Asian or an Asian power?

Manjeet S. Pardesi

9 India's role as an international development actor

Emma Mawdsley

10 Dispersals, migrations, diversity of communities and the notion of an Indian diaspora

Brij V. Lal and Knut A. Jacobsen

11 Yoga and physical culture: transnational history and blurred discursive contexts

Mark Singleton

12 Modernised Ayurveda in India and the West

Maya Warrier

\section{PART III}

Society, class, caste and gender

13 The politics of economic reforms in India Diego Maiorano

14 Divided we stand: the Indian city after economic liberalisation Nandini Gooptu

15 India's middle classes in contemporary India

Leela Fernandes

16 Caste: why does it still matter?

Surinder S. Jodhka

17 Corruption and anti-corruption in modern India: history, patronage and the moral politics of anti-colonialism

William Gould 
18 Regional perspective: Gujarat and the contradictory co-existence of economic enterprise and political illiberalism

Harald Tambs-Lyche and Nikita Sud

19 Intimate spaces of struggle: rethinking family and marriage in contemporary India

Mallarika Sinha Roy

20 Adivasis and contemporary India: engagements with the state, non-state actors and the capitalist economy

Uday Chandra

\section{PART IV}

Religion and diversity

21 Myth as history and history as myth: the instructive case of India

Gerald James Larson

22 Matters that matter: material religion in contemporary Hinduism Vasudha Narayanan

23 Hindu pilgrimage sites and travel: infrastructure, economy, identity and conflicts

Knut A. Jacobsen

24 Ambedkar's life and his Navayana Buddhism

Eleanor Zelliot

25 Religion, identity and empowerment: the making of Ravidassia Dharm (Dalit religion) in contemporary Punjab

Ronki Ram

26 Muslims in contemporary India: socio-religious diversity and the questions of citizenship

R. Santhosh

27 Religious violence, crime statistics and India's Muslim minority Marika Vicziany

28 Christians in India: living on the margins with a diverse and controversial past

John C. B. Webster 


\section{PART V}

\section{Cultural change and innovations}

29 Combative constructions of femininity in the late twentieth-century narratives of India

Nandita Ghosh

30 The new Indian male: muscles, masculinity and middle classness Michiel Baas

31 Changing food habits in contemporary India: discourses and practices from the middle classes in Chennai (Tamil Nadu)

Michaël Bruckert

32 Coping with the diseases of modernity: the use of siddha medical knowledge and practices to treat diabetics

Brigitte Sébastia

Index 


\section{FIGURES}

2.1 A dynamic neo-institutional model of state-society-economy interaction

22.1 Sarasvatī image in Embassy Row in front of Indonesia's embassy

22.2 'Matter' and spirit in the larger scheme of things

23.1 Srāddha ritual as a collective ritual for a large group in contemporary Siddhpur

23.2 The pilgrims sitting in rows with the material items of the śrāddha ritual in front of them

24.1 Statue of Ambedkar with the Buddhist flag

24.2 Buddhists with picture of Ambedkar above the front door as a mark of their identity as follower of Ambedkar's tradition of Buddhism

30.1 The 'new Indian male', lean and muscular on the cover of health magazines 


\section{TABLES}

5.1 National gross enrolment ratios, all communities, scheduled castes and scheduled tribes, India

5.2 Dropout rates of all categories, ST and SC students (2001-02 to 2010-11) 82

5.3 Current attendance rates by social groups (NSSO Rounds) 84

6.1 Indian agriculture - the current profile 108

6.2 Calorie poverty increases as consumption poverty declines 109

6.3 Distribution of number of operational holdings by major size-groups for all social groups: all India

15.1 Households by possession of assets (\%) 235

27.1 Number of communal riots, incidents of tension and deaths in India in various states in 2012 and 2013

27.2 Proportion of employees in public order and safety activities in India at the Government of India Level and the State Governments Level 


\section{CONTRIBUTORS}

\section{Editor}

Knut A. Jacobsen is Professor in the History of Religions at the University of Bergen, Norway and author and editor of many books and numerous articles in journals and edited volumes on various aspects on religions of South Asia and in the South Asian diasporas. He is the author of Prakrti in Sāmkhya-Yoga: Material Principle, Religious Experience, Ethical Implications (Peter Lang, 1999), Kapila: Founder of Sāṃkhy and Avatāra of Viṣnu (Munshiram Manoharlal 2008) and Pilgrimage in the Hindu Tradition: Salvific Space (Routledge, 2013). Jacobsen is the Editor-in-Chief of the six volume Brill's Encyclopedia of Hinduism (2009-2015) and the Brill's Encyclopedia of Hinduism Online.

\section{Editorial Board}

Barbara Harriss-White, Oxford University, UK

Surinder S. Jodhka, Jawaharlal Nehru University, India

Gerald James Larson, University of California at Santa Barbara and Indiana University, USA Vasudha Narayanan, Florida University, USA

Rowena Robinson, Indian Institute of Technology, Bombay, India

\section{Contributors}

Michiel Baas is currently a Research Fellow with the Asia Research Institute (NUS). Previously he was a Fellow with the new Nalanda University (Delhi and Rajgir, India); Coordinator with the International Institute for Asian Studies (Amsterdam and Leiden, the Netherlands); Lecturer with the Anthropology Department of the University of Amsterdam; Coordinator with the Eutopia Institute; and Coordinator with the Amsterdam Institute for Social Sciences Research. He holds a PhD from the University of Amsterdam and has published extensively on the topic of migration and transnationalism. His book Imagined Mobility. Migration and Transnationalism among Indian Students in Australia was published in 2010 (Anthem Press). 
Michaël Bruckert is a PhD candidate and Lecturer in human geography, University Paris Sorbonne. His research interests are the economic, cultural and environmental aspects of food change and meat consumption. Bruckert's publications include 'La transition alimentaire de l'Inde: une hypothèse erronée?', Cahiers d'Outre-Mer (2014).

Uday Chandra is a Research Fellow at the Max Planck Institute for the Study of Religious and Ethnic Diversity, Göttingen. His research interests lie at the intersection between agrarian studies, political anthropology, postcolonial theory and South Asian studies. His articles have appeared in the Law \& Society Review, Contemporary South Asia and Social Movement Studies.

Leela Fernandes is Glenda Dickerson Collegiate Professor of Women's Studies and Professor of Political Science and South Asian Studies at the University of Michigan. She is the author of Transnational Feminism in the United States: Knowledge, Ethics, Power, India's New Middle Class: Democratic Politics in an Era of Economic Reform, Transforming Feminist Practice and Producing Workers: The Politics of Gender, Class and Culture in the Calcutta Jute Mills and editor of the Routledge Handbook of Gender in South Asia.

Rajat Ganguly is a Senior Lecturer in Security Studies and International Relations at Murdoch University, Australia. He is the author of several books and papers dealing with ethnic conflict, armed insurgency and security and foreign policy in Asia. His most recent book (ed.) is Autonomy and Ethnic Conflict in South and Southeast Asia (Routledge, 2012). He is the Editor-in-Chief of the Journal of Asian Security and International Affairs (http://aia.sagepub. com) and is a former editor and current editorial board member of the Journal of South Asian Development (http://sad.sagepub.com). He can be contacted at: R.Ganguly@murdoch.edu.au

Nandita Ghosh completed her BA, MA and MPhil degrees in English Literature from the University of Delhi, India, in the years 1984, 1986 and 1989. She then worked on her PhD in Postcolonial Literature specializing in South Asia at Fordham University in New York City, United States. She is currently teaching at Fairleigh Dickinson University in Madison, NJ as an Associate Professor of English. She has published articles in Jouvert, South Asian Review, Journal of Commonwealth and Postcolonial Studies, International Feminist Journal of Politics and Working USA: The Journal of Labor and Society.

Nandini Gooptu is a Fellow of St Antony's College, Oxford, and currently Head of the Oxford Department of International Development. Her publications include The Politics of the Urban Poor in Early-Twentieth Century India and India and the British Empire (edited with Douglas Peers), Enterprise Culture in Neo-liberal India, and Persistence of Poverty in India (edited with Jonathan Parry).

William Gould is Professor of Indian History at the University of Leeds. His current research explores the politics of corruption and anti-corruption in India, notions of Indian citizenship and adivāsi histories among 'nomadic' communities. Among his publications are Bureaucracy, Community and Influence: Society and the State in India, 1930-1960s (London: Routledge, 2011) and Hindu Nationalism and the Language of Politics in Late Colonial India (Cambridge: Cambridge University Press, 2004).

Surinder S. Jodhka is Professor of Sociology at the Jawaharlal Nehru University, New Delhi. He has published widely on the subjects of rural and agrarian change; caste 
in contemporary India; and social/cultural identities. His publications include Caste in Contemporary India (Routledge, 2015); Interrogating India's Modernity (Oxford University Press, 2013); Caste: Oxford India Short Introductions (Oxford University Press, 2012). He is a recipient of the ICSSR-Amartya Sen Award for Distinguished Social Scientists (2012).

Brij V. Lal, Fiji-born grandson of an Indian indentured labourer, is Professor of Pacific and Asian History at the College of Asia and the Pacific at the Australian National University. He has published widely on the history and politics of his native country and on the history and culture of the plantation diaspora. He is the author of Girmitiyas: The Origins of the Fiji Indians (1983), and General Editor of The Encyclopedia of the Indian Diaspora (2006). Among his semi-fictional books are Mr Tulsi's Store: A Fijian Journey (2001) and Turnings: Fiji Factions (2008). He lives in Canberra and counts among his hobbies walking in the Australian bush and, when time permits, watching cricket.

Gerald James Larson is Professor Emeritus, Religious Studies, UC Santa Barbara, and Tagore Professor Emeritus of Indian Cultures and Civilization, Indiana University, Bloomington. He is the author or editor of some twelve books and well over 100 scholarly articles on cross-cultural philosophy of religion, history of religions, classical Sanskrit and South Asian history and culture. His recent books include India's Agony Over Religion (SUNY Press, 1995), Religion and Personal Law in Secular India: A Call to Judgment (Indiana University Press, 2002), and Yoga: India's Philosophy of Meditation (Delhi: Motilal Banarsidass, 2008, co-edited with the late Dr Ram Shankar Bhattacharya). A collection of essays has been published in his honour, Theory and Practice of Yoga: Essays in Honour of Gerald James Larson, edited by Knut A. Jacobsen (Leiden: Brill, 2005; paperback edition by Motilal Banarsidass, 2008).

Diego Maiorano is a Research Fellow at the School of Politics and International Relations, University of Nottingham. His work is currently focused on India's political economy and on poverty reduction strategies in emerging economies. He is the author of Autumn of the Matriarch - Indira Gandhi's Final Term in Office (Hurst\&Co./Oxford University Press, 2015)

Emma Mawdsley is a Reader in the Geography Department, University of Cambridge. As well as research on Indian environmental and regional politics, she has worked on many aspects of international development. Her recent research is concerned with the 'emerging powers' as development actors, and she is the author of From Recipients to Donors: Emerging Powers and the Changing Development Landscape (Zed, 2012).

Subrata Kumar Mitra, Director, Institute of South Asian Studies (ISAS), National University of Singapore (NUS) and Emeritus Professor of South Asian Politics at Heidelberg University, was educated at Delhi University, Jawaharlal Nehru University (Delhi) and the University of Rochester (United States). South Asian Area studies and comparative politics, rational choice, governance, citizenship and re-use are his main interests. His publications include Politics in India: Structure, Process and Policy (Delhi: Oxford University Press, 2014).

Vasudha Narayanan is Distinguished Professor in the Department of Religion at the University of Florida and a past president of the American Academy of Religion. She is the author or editor of seven books and over a hundred articles, chapters in books, and encyclopedia entries. Her books include The Life of Hinduism (2007, with J. Stratton Hawley), 
Hinduism (2004, 2009), The Vernacular Veda: Revelation, Recitation, and Ritual (1994), The Way and the Goal: Expressions of Devotion in the Early Srivaișnava Tradition (1987) and The Tamil Veda: Pillan's Interpretation of the Tiruvāymoli. She is currently working on research into Hindu traditions in Cambodia.

Ananth Padmanabhan is currently a doctoral student at the University of Pennsylvania Law School. His general research interests are in the field of Indian constitutional law, administrative law and intellectual property rights. He is the author of the leading treatise, Intellectual Property Rights: Infringement and Remedies, published by LexisNexis Butterworths Wadhwa, 2012.

Manjeet S. Pardesi is a Lecturer in International Relations at Victoria University of Wellington. His research interests include great power politics, Asian security and Indian foreign policy. He is co-editor of India's Military Modernization (Oxford, 2014) and the author of 'China's Nuclear Forces and Their Significance to India' (Nonproliferation Review).

Rajeswari S. Raina is a Principal Scientist with the National Institute of Science, Technology and Development Studies (NISTADS), CSIR, New Delhi. As a keen student of the interface between development policy and scientific knowledge, she publishes and advises on agricultural science and technology and policy, rural development and related social and environmental changes.

Ronki Ram is currently a Fellow, Dean (Arts Faculty) and Shaheed Bhagat Singh Professor of Political Science at Panjab University, Chandigarh (India). He is also an Honorary Director, Indian Council of Social Science Research, North-Western Regional Centre at Chandigarh and was the first holder of the ICCR Chair of Contemporary India Studies at Leiden University, the Netherlands (September 2011-June 2013). A recipient of various awards both at home and abroad, Professor Ram is the author of two books in Gurmukhi script, and several book chapters. His research articles are published in reputed peerreviewed international journals like Modern Asian Studies, Journal of Asian Studies, Asian Survey, Contributions to Indian Sociology and Journal of Punjab Studies among others.

Vimala Ramachandran is National Fellow and Professor at the National University for Educational Planning and Administration (NUEPA), New Delhi and has been working on elementary education, girls' education and women's empowerment. She was involved in the conceptualization of Mahila Samakhya (Education for Women's Equality) - a pioneering Government of India programme - and served as the first National Project Director from 1988-1993. She has been engaged in research on elementary and secondary education focusing on gender and equity issues, teacher status and motivation and systemic barriers to realizing the equity goals of national policies and programmes for elementary education; adult literacy and continuing education; and most recently has been engaged in researching the educational needs of out of school youth, especially girls.

Mallarika Sinha Roy is an Assistant Professor at the Centre for Women's Studies, Jawaharlal Nehru University, New Delhi. Her book Gender and Radical Politics in India: Magic Moments of Naxalbari (1967-1975) (London and New York: Routledge) was published in 2011. She has published articles in peer-reviewed journals like Feminist Review, Indian Journal of Gender Studies, Contemporary South Asia, Feminism and Psychology and Journal of South Asian 
Development. Her research interests include social movement studies, gender and political violence, history and politics of South Asia.

R. Santhosh is an Assistant Professor in the Department of Humanities and Social Sciences, Indian Institute of Technology Madras, India. His broad research interests include questions of multiple modernity, ethnic relations and religious identity, in particular. He is interested in the articulation of Islamic and Hindu religious identities in the Indian subcontinent. $\mathrm{He}$ is currently engaged in research on religious civil society with a special emphasis on Islamic activism and charity.

Brigitte Sébastia is a Medical Anthropologist Researcher at the French Institute of Pondicherry and an associate member of the EHESS (CEIAS and LISST). She specializes in mental health, siddha medicine and diseases related to food and agricultural changes. She is the author of Les Rondes de Saint Antoine, Paris: Aux Lieux d'Etre, 2007 and the editor of Restoring Mental Health in India. Pluralistic Therapies and Concepts, Delhi: Oxford University Press, 2009. She has published twenty-five papers on her three medical specialisms.

Kunal Sen is Professor of Development Economics in the Institute of Development Policy and Management (IDPM), University of Manchester, and Professorial Fellow of the Brooks World Poverty Institute. His current research examines the political economy determinants of inclusive growth, and the role of institutions in economic development. Professor Sen's recent books are the edited volumes State Business Relations and Economic Development in Africa and India (Routledge, 2012); Institutions and Governance in Developing Countries (Edward Elgar, 2013); and The Politics of Inclusive Development: Interrogating the Evidence (Oxford University Press, 2014). He has been awarded the Sanjaya Lall Prize in 2006 and the Dudley Seers Prize in 2003 for his publications. He is member of the elite South Asia Area Panel of the British Academy.

Mark Singleton is a Senior Researcher at the School of Oriental and African Studies in London. His current work focuses on the textual and ethnographic history of hathayoga. He has a PhD from Cambridge University's Divinity Faculty. His books include Yoga in the Modern World (Routledge, 2008, ed.), Yoga Body, The Origins of Modern Posture Practice (OUP, 2010), Gurus of Modern Yoga (OUP 2014, ed.) and Roots of Yoga (Penguin, 2016, with James Mallinson).

Nikita Sud is Associate Professor of Development Studies at the University of Oxford. She researches the Indian state, state-market interactions under economic liberalisation, and the politics of natural resources, especially land. She is author of Liberalisation, Hindu Nationalism and the State: A Biography of Gujarat (Oxford University Press, 2012).

Harald Tambs-Lyche is Professor Emeritus at the Université de Picardie, Amiens. After working on Indians in Europe, he turned to Gujarat (Power, Profit and Poetry, 1997; The Good Country, 2004). With Nikita Sud he edited a special number of South Asia, 'Religion in the making of a region' (2011).

Marika Vicziany (BA Hons, University of Western Australia; PhD SOAS, University of London) has written some fifteen books and over 100 scholarly papers. She is Professor Emerita/Director of the National Centre for South Asian Studies at Monash University 
(Melbourne, Australia). Her work focuses on long-term economic development in South Asia and China and how this intersects with regional security, especially the situation of minorities.

Pippa Virdee is Senior Lecturer in South Asian History at De Montfort University, UK. Her research interests include the history of the Punjab, the South Asian diaspora in Britain and women's history in Pakistan. She is the Convenor of the Punjab Research Group. Her publications include Coming to Coventry: Stories from the South Asian Pioneers (2006) and the co-edited Refugees and the End of Empire (2011).

Maya Warrier is Reader in Religious Studies at the University of Winchester, UK. Her research and publications focus on themes related to the construction and transformation of Hindu identities and traditions in modern transnational contexts. She is author of Hindu Selves in a Modern World: Guru Faith in the Mata Amritanandamayi Mission (Routledge-Curzon, 2005), and co-editor of Public Hinduisms (Sage, 2012). Her work on transnational Ayurveda, funded by a grant from the Wellcome Trust, has been published in the form of journal articles and chapters in edited volumes.

John C. B. Webster, now retired, has taught history in the Punjab and Bangalore as well as at Pittsburgh Theological Seminary and Union Theological Seminary in the United States. His books include The Dalit Christians: A History, A Social History of Christianity: North-West India since 1800 and Historiography of Christianity in India.

Eleanor Zelliot, Laird Bell Professor of History Emerita, Carleton College, 1969-1997, is a specialist on the movement among Untouchables in India led by Dr B. R. Ambedkar. She has also edited books on saint-poets of the medieval period, and on current Hinduism: Untouchable Saints: An Indian Phenomenon (2005), The Experience of Hinduism: Essays on Religion in Maharashtra (1999), From Untouchable to Dalit: Essays on the Ambedkar Movement (2005), An Anthology of Dalit Literature (Poetry) (1992). She has also written over eighty articles and received a Distinguished Service Award from the American Association of Asian Studies. 


\title{
CONTEMPORARY INDIA Foundation, relations, diversity and innovations
}

\author{
Knut A. Jacobsen
}

The name India was, before 1947, a designation of a large part of South Asia, which is now divided into several nation states, one among which is India. 'Contemporary India' in the title of this Handbook refers to this nation-state that gained independence in 1947. India is by far the largest country in South Asia both in terms of geographical size (the seventh largest in the world) and in terms of population (the second largest in the world). India is one of the most diverse and pluralistic nations in the world in terms of official languages, cultures, religions and social identities. It has throughout history been a meeting place for a large number of different cultures, languages, religions, traditions of art and ideologies that have continually been transformed and adapted to new circumstances. The geographical landscape of India is very diverse as well and divided into three main parts, the Himalayan mountains in the far north, the Indo-Gangetic plain that includes most of north and east India, and the Deccan in the south. The greatest population concentrations are in the plain in the north and east, and along the coast in the Deccan in the south. The unique weather pattern in India and the rest of South Asia is the annual monsoon, which has enormous environmental and economic as well as cultural significance. The settlement patterns and the largest population concentrations have historically been shaped by the monsoon patterns as well as trade routes. India's geographical size is only one-third of China's, a country that India is often, unfairly, compared to (for the India-China relationship see Chapter 8 in this book). Around 1,300 million people live in India, 1,400 million in China. However, India's population is growing faster and India will within a few years become the most populous country in the world. Around 17.5 per cent of humanity lives in the nation-state of India. Its annual population growth is around 1.2 per cent, an annual increase of around 15 million. ${ }^{2}$ India has one of the youngest populations in the world. In 2012, India had the youngest population in terms of the number of people under thirty, around 704 million, ${ }^{3}$ and in about five years, the median age in India will be twenty-nine years, 'making it the youngest country in the world'. ${ }^{4}$ The worldwide Indian diaspora is thought to number between 30 and 40 million people and is one of the largest and fastest growing (Rai and Reeves 2008; see Chapter 10). ${ }^{5}$ India is the world's largest receiver of remittances from its diaspora, around US $\$ 70$ billion annually. ${ }^{6}$ India is an emerging global power not least because of its geographical and demographic size but in recent years it has in particular been the growth of the Indian economy that has been in focus. The 
Indian economy has been growing for several decades (see Chapter 4) and especially during the last two, India has seen strong economic growth compared to earlier decades (see Chapter 13). In contrast to some common Western images, India has been a provider of development assistance to other countries since the early 1950s, soon after independence (see Chapter 9). However, the economic growth is unequal among the Indian states and union territories and among social groups and classes (see Chapter 18). The Indian middle classes have especially benefited (see Chapter 14 and Chapter 15, and also Chapter 30 on new middle-class 'male ideal type' body and Chapter 31 on new middle-class food habits). The economic growth has created problems of increasing inequality, particularly within the cities and between urban and rural areas. Agriculture has become a victim of development ideology and economically development has benefited especially the urban bureaucrat elite (see Chapter 6). The green revolution favoured mainly rice and wheat and is partly responsible for the dramatic increase in cases of diabetes in India (see Chapter 32). The economic growth has also created serious environmental problems, especially water pollution, refuse and air pollution.

India gained independence from British colonial rule, the British Raj, on 15 August 1947 and became a sovereign republic when the Constitution came into effect on 26 January 1950. These two dates have thereafter become the most important public celebrations of the Indian nation, remembered as Independence Day and Republic Day. However, these celebrations hide the fact that the birth of India was marked by extreme violence, Punjab and Bengal in particular suffered, and there was a partitioning of people whose prime identifier afterwards became their different religious identities (see Chapter 1). The inability of a post-conflict reconciliation between India and Pakistan (see Chapters 7 and 8) has led to an absence of any form of official recognition of what happened during partition. No memorial or annual ritual has been established for the victims. This lack of closure has added to the suffering.

An important source of pride in India, something that also fuels its ambition of becoming a global power, is that the country is the world's largest democracy. Democracy is no doubt an enormous achievement. Very few post-colonial nations have had continuous democratic rule from the period of independence until today, as has India (with the exception of the emergency declared by the then Prime Minister Indira Gandhi from 1975 to 1977; see Chapter 2). India has enjoyed free elections, which have not been easy to organize given the number of candidates and voters, and has developed a well-established democratic culture. However, the state has not always worked well, and there are a number of threats to the democratic system (see Chapter 7). Democracy was tested only six months after independence with the killing of the father (Bapu) of the nation, Mahatma Gandhi (by a Hindu nationalist). Two prime ministers, Indira Gandhi and Rajiv Gandhi, were assassinated, for opposing regional independence movements in South Asia (the Khalistan movement in Indian Punjab in the case of Indira Gandhi and the Liberation Tigers of Tamil Eelam in northern Sri Lanka in the case of Rajiv Gandhi). Communalism (see Chapters 7 and 27) as well as corruption (see Chapter 17) are considered major problems, but no one is predicting the downfall of the democratic system. Democracy has nevertheless to be considered a success not least because of its stability. The Constitution and India's federal structure have been important for the survival of democracy (see Chapter 3) and Bhimrao Ramji Ambedkar, who was the leader of the Drafting Committee of the Constitution and its prime architect, should be recognized for having given Indian democracy a strong foundation (see Chapter 24). The Constitution laid down the fundamental rights of the individual and gave India a federal structure; each state and union territory has its own government, a Governor/Lieutenant and a Chief Minister. 
India has a large presence in the world outside of South Asia, not only due to migration of people, but also in terms of cultural influence, India transcends the South Asian geographical space. Indians have exchanged ideas with other cultures globally for centuries and some traditions have been transformed in those transnational and transcultural encounters and become successful innovations with an extraordinary global popularity. Two such examples, Yoga and Ayurveda, are covered in this book (see Chapters 11 and 12). The idea of India as the teacher of spirituality to the West was important for developing modern Yoga traditions. ${ }^{7}$ Interestingly, within decades, Yoga became a phenomenon mostly dedicated to the body, with bodily health as its prime focus, probably because of influences from global gymnastics and body-building movements as well as nationalism and the international sports movement. Yoga has been one of the main Indian cultural exports of the last few decades not least because Yoga had blended with new traditions of gymnastics and sports that were popular worldwide. Similarly, Ayurveda has become a global phenomenon, but only after the blending of traditional Ayurveda with elements of Western biomedicine.

In spite of India's impressive economic growth over the last decades, some of the most serious problems of Indian society persist and do not seem to go away. Some of these problems are poverty, the repression of women (see Chapters 19 and 29), and inequality both in terms of living conditions and of opportunities such as access to education (see Chapter 5), employment and the economic resources of the state (see Chapter 20). Caste in India, although no longer functioning as a social system, has nonetheless not disappeared (see Chapters 16 and 25), and inequalities caused by caste seem to overlap with new forms of inequality. Poverty and uneven access to the resources of the state may become a threat to democracy, a large proportion of the world's poorest people live in India, which contrasts with the large annual economic growth India has achieved in the last decades as well as with the image of India as an emerging world power.

India has a long and complex history. The dynamic interaction of communities, traditions and technologies is a main feature. India was the home of several ancient and medieval civilizations: the ancient Buddhist civilization of the Mauryans, the early medieval Hindu civilization of the Guptas, the Delhi Sultanate and Mughal Islamic culture. The long presence of the British colonial power added further complexity. Buddhism was dominant during the Mauryan empire (322-185 $\mathrm{BCE})$, which was one of several formative periods of Indian civilization, although its institutions gradually disappeared from India. However, in the twentieth century a new Buddhism became re-established by Bhimrao Ramji Ambedkar as a religion for social justice (see Chapters 24 and 25). Christianity in India, for several centuries associated with colonial rule, but with a presence in India at least a thousand years before the colonial period, has increasingly become a religion of the poor and repressed in India (see Chapter 28). Muslims are still suffering from the aftermath of partition that deprived them of most of their leadership and they are also victims of discrimination in Hindu-dominated society (see Chapter 26) as well as of religious violence (see Chapter 27). Hinduism is an immensely diverse and pluralistic phenomenon and should not be mistaken for the political movement that uses a homogenized idea of Hindu identity (Hindutva) to mobilize for a hinduization of India and produces fear among the minorities. Hinduism is often, especially from the time of Vivekananda, promoted as spiritual in contrast to the materialism of the West. India was superior to the West in spirituality, while the West was superior in materiality, Vivekananda suggested this, probably because he was looking for funding for his education, health and social improvement projects from Western supporters, but nevertheless hoped that there could be an equal exchange: money in return for spiritual wisdom. This dualism between a postulated spiritual India and materialistic West has no scientific basis, but is still 
important for Indian national identity, and a selling point for sections of Indian industry such as tourism and health industries. Hinduism is a quite materialistic religion (as are all religions), and recent research increasingly focuses on the material side of Hinduism. The exchange of material objects between priests and worshippers is a notable, even dominant feature in the rituals, and displaying objects of worship and being physically present at the sacred places are important (see Chapters 22 and 23). In contemporary political Hinduism there is an emphasis on history, ${ }^{8}$ but this emphasis is contrary to some of the fundamental philosophical presuppositions of Hinduism (see Chapter 21).

Some of the issues of cultural change dealt with in chapters in this book are the new visibility of women, new ideal male body types, changing food habits and innovations in traditional medicine as response to new diseases. The new visibility of women on the political stage in the last decades has challenged the story of India's emergence as a modern nation-state by calling attention to the invisibility of women in the construction of that story. The public outrage over the rape of Nirbhaya in December 2012 was also about this right to visibility and in this case, in particular the right of women to inhabit public spaces without endangering themselves (see Chapter 29). Another form of new visibility is the new male lean and muscular bodies in public spaces such as billboards and popular media as well as in the statues of Hindu gods, especially Siva and Hanumān, which have in the recent years increasingly been portrayed as muscular gods. The statues are getting bigger and bigger, reflecting perhaps the new ideals of masculinity and male socio-economic success as well as Hindu dominance (see Chapter 30). Innovation in the food traditions in India, which typically are thought to change slowly, do happen, but often at the margins of society, but such innovations can potentially lead to new changes such as the emancipation from ethnic, religious or caste rules, since food in India is a marker of a person's position in society (see Chapter 31). However, food changes in the recent past have led to new diseases, most dramatically those caused in part by the green revolution's favouring of wheat and white rice, which make medical innovations necessary even among practitioners of traditional medical traditions such as Siddha medicine who have no traditional means to deal with such diseases and have to improvise (see Chapter 32).

This Handbook deals with a number of the important issues for understanding contemporary India. It brings together emerging and leading scholars on various aspects of contemporary India. Many academic disciplines study India and the global Indian presence: History, Anthropology, Sociology, Political Science, Economy, Religious Studies, Literature, South Asian Studies and all these disciplines have increasingly focused on the traditions and transformations of contemporary India. India is rapidly changing, and researchers have wanted to understand these current transformations. The Routledge Handbook of Contemporary India contains essays by the field's foremost scholars who study the current transformations of Indian culture and society. The volume concentrates on India as it has developed in the twenty-first century. India is perhaps the world's most complex and intricate society, and this complexity makes the production of knowledge of this nation intellectually challenging but also fascinating and absorbing.

The Handbook has five parts and each part deals with separate themes, though all the themes are related.

\section{Foundation}

The first part of this book is called 'Foundation' because it deals with some of the fundamental issues of India as a society and nation-state, such as the experience of partition, 
the Constitution, India's political system, economy, agriculture, education and security. Part I starts with Pippa Virdee's chapter on the violent beginning of the nation-state of India with the division of Pakistan and India during which at least 1 million people were killed and millions displaced. Virdee correctly notes that it was particularly Punjab that bore the brunt of the partition violence and displacement. She argues that the violence of partition has overshadowed the pain of displacement and loss of identity. One consequence of partition was that the shared cultural roots and traditions of the Punjabi identity were replaced with a partitioning of people who now became identified on the basis of religion, as Sikhs, Muslims and Hindus. The mix of Muslim-Hindu-Sikh in Punjabi society ceased to exist when Punjab was divided. Other regions in India have often united on linguistic identity, but not so in Punjab; it has shunned its linguistic identity in favour of a national and religious identity. As the poet Balraj Sahni writes in his poem, quoted by Virdee in her article, 'What of our becoming human beings, We have turned into Hindus, Sikhs, and Muslims' (p. 32). Punjab is now associated with these three 'unmixed' religious communities.

The second chapter is about the survival of democracy in India. Subrata Kumar Mitra asks, 'What makes India's democracy work?' Mitra notes 'elections are necessary but not sufficient to make democracy work' (p. 45). Compared to many other post-colonial states democracy in India is quite an achievement. India's democracy, writes Mitra, 'is the outcome of general variables like path dependency, adroit institutional arrangement, political management and strategic policy reform' (p. 35). It survives, he argues, in competition with its competitors such as anti-system parties and extremist ideologies, 'because it delivers, if not for all and all the time, then, at least for most, and most of the time' (p. 35). Not least does it work because the underprivileged groups at the margins of the hierarchical society of India 'have learnt to use the ballot for upward mobility' (p. 36). Mitra explains the successful transition to democracy using a dynamic neo-institutional model and argues that the indigenous elite with social legitimacy was important. The party system was the result of six decades of development prior to independence under British rule, and political representation and social mobilization were present from the start. To answer the question of why Indian democracy works, Mitra elaborates three arguments: one, electoral mobilization and unfettered participation, two, election-reinforcing institutional arrangements and countervailing forces, and three, asymmetric but cooperative federalism.

The chapter on democracy is followed by a chapter on the Constitution and the Supreme Court. The Constitution was a fundamental document, coming into force on 26 January 1950. It describes India as a sovereign, secular, socialist, democratic republic and guarantees a number of civil liberties as well as supporting affirmative action to help groups that are disadvantaged because of past and present injustice. In his chapter Ananth Padmanabhan focuses on three aspects of the Constitution and the Supreme Court's considerations: first, its guarantee of fundamental rights and its contribution to the rights based on citizen-state interaction. Here Padmanabhan notes that the Court has had success in the rights against the state but that this success has been largely in the realm of language rather than in terms of achieving objectives through actual implementation. Second, its federal structure and its role in accommodating diversity in Indian society. Padmanabhan analyses the federal structure along the multidimensional axis of retaining India's national unity while at the same time securing its diversity and concludes that the design of the federal structure has not proven very strong in balancing the goals of national unification and diversity. Third, it is in the separation of powers between different branches of government that the Supreme Court has attained remarkable success, both in terms of language and practice, argues Padmanabhan. He concludes that national unity and the self-preservation of the Constitution have 
emerged as extremely important normative concerns for the Supreme Court, and that it has especially succeeded with respect to values such as individual freedom, self-development and sustainable growth.

Chapter 4 analyses the economic foundation of India. Kunal Sen notes that in the years before independence India suffered stagnation in living standards caused by 'deglobalization', a collapse of world trade volumes, and a marked intensification of poverty because of the stagnation of agricultural production and the collapse of artisanal industry. The gross domestic product started to rise again only in the late 1970s and it has risen steadily since, an achievement, Sen argues, that is paralleled by few countries except China. The growth in the last decade has been strong especially in the service sector, while agriculture since the 1980s has been developing very slowly. The service sector has grown from 19 per cent of GDP in 1955 to 40.7 per cent in 2008, while agriculture has been reduced from 57 per cent of GDP in 1955 to 19.8 per cent in 2008. In the chapter Sen analyses the history and development of the policies of the macroeconomic, trade, industrial and financial sectors, which are of particular importance for understanding the economy since the 1950s and the patterns of development of the core economic sectors, agriculture, industry and services. Finally, he analyses the diversity in economic performance between the regions and argues that here the political and economic institutions have played a key role.

Education makes up the foundation of modern nation states on many levels, not least in creating equality, quality of life and the ability to contribute to society. Chapter 5 deals with the urgent issue of education in India, and the most urgent of all, the quality of primary education. Vimala Ramachandran shows that while access to primary education has improved significantly in the last ten years, close to 97 per cent of children aged between six and eleven are enrolled in primary schools, the number drops to 39.3 per cent in upper-primary level and classes 11 and 12. While large drop-out rates are worrying, the biggest worry, argues Ramachandran, is that many children, especially in the government schools, learn very little. 'Mere access to schooling, without commensurate focus on quality and learning outcomes is meaningless' (p. 79), Ramachandran points out. Since the social and economic status of the child's family is one of the strongest determinants of their educational attainment, the 'fight for equity is ultimately a struggle for quality education' (p. 86). In India today, complains Ramachandran, the spatial segregation of the rich from the middle class and from the very poor implies that children go to schools with widely varying levels of quality and have very different schooling experiences. Many from the most deprived communities drop out of school because the schools do not teach them skills or give them confidence. After independence, higher education institutions had priorty, and not education for all. And when an increasing number of children started enrolling at school, there was a gradual growth in private schools with people with means taking their children out of government schools. Today the rich and the middle class have more or less moved their children out of the government schools. In a study in which Ramachandran interacted with teachers in eight states, she found that not one of these teachers sent their own children or grandchildren to government schools. The author believes that the lack of quality in primary education is a threat to democracy. India is increasingly becoming more polarized and schools no longer provide a shared space for children of different backgrounds and communities. Ramachandran in the final part of her chapter suggests a number of ways to improve the situation.

The last chapter of Part I, deals with the state of agriculture in India. At the time of independence India was an agricultural society. In 1955, almost ten years after independence, 57 per cent of GDP was from agriculture. Today, key features of Indian agriculture are record food production, increasing industrial investments, booming exports, persistent hunger, 
worsening malnutrition, escalating natural resource degradation and unprecedented distress within the farming community. Rajeswari Raina argues that the intermediate regime, or the state, along with its ideological and functional allies, has imposed its own articulation of development on agriculture and in that process the rich diversity, production potential and robustness of India's agriculture and diverse farming communities have been hindered. Raina divides the history of agriculture after independence into three phases. In the first phase centralized public investment with a wide range of public sector enterprises and policymaking mechanisms for agricultural growth was established. The state was characterized as a benevolent technocratic provider of public goods for agricultural growth, which was seen as the main driver of all development. The second phase (mid-1960s to the late 1990s) started with the green revolution and culminated with the acknowledgement that the green revolution did not reduce hunger or malnutrition, but did add to degradation of soil and water systems and loss of biological diversity. This phase reinforced centralization and added the voice of science and technology for productivity to the legacy inherited from the first phase. The current and third phase, beginning around 1998-2000 is marked by disillusionment with modernization and concern about increasing malnutrition. Raina argues that by 'legitimising and renaming the reinforcement of the green revolution approach as the alternative', the intermediate regime 'forecloses the opportunities for several other decentralised locationspecific alternatives' and that what is needed is a paradigm that celebrates the diversity of agro-ecological and social systems and is based on principles that have ecological and social feedback loops (p. 112). This paradigm sees the connection between agriculture and health on the one hand and between agriculture and the environment on the other.

\section{India and the world}

The topic of the first chapter in Part II, is the issue of security and wellbeing in India with a focus on three areas: the ethnic conflicts, the Maoist insurgency and foreign policy. Rajat Ganguly starts this chapter by calling attention to the immense ethnic, religious, linguistic and regional diversity in India. He then analyses the ethnic violence in India that has centred on the creation of new states exemplified by militant nativist movements in Tamil Nadu, Maharashtra, Assam, Mizoram, Punjab and Kashmir. He looks at communal and sectarian conflicts as threats to security and to the secular democracy and notes especially the failure of the justice system to deliver justice to victims of ethnic and communal violence and to arrest and punish those guilty of instigating mass murder. Ganguly then turns to the Maoist insurgency that traces its roots to earlier peasant struggle and is caused by poverty and castebased exploitation and discrimination. The Maoist insurgency is often named Naxalites after the peasant uprising that took place in Naxalbari in West Bengal in 1967. The movement was crushed in the 1970s but emerged, slowly, in the 1980s and has since spread to the forested tribal areas in West Bengal, Bihar, Odisha, Uttar Pradesh, Madhya Pradesh, Maharashtra, Karnataka and Andhra Pradesh, where it is currently based. Finally, Ganguly looks at the insecurity caused by India's external powers. India's military is the fourth largest in the world and India is a nuclear power. India has in the last twenty-five years, after the break-up of the Soviet Union and the loss of a crucial ally, been transformed, writes Ganguly, into 'a modern fighting machine' due to changes on regional and global levels and to a reappraisal by political, military and bureaucratic elites who urged India to consolidate 'its strategic autonomy' ( $\mathrm{p}$. 129). In this process, argues Ganguly, India has moved from a policy of 'non-alignment' to 'poly-alignment' establishing defence-specific agreements and strategic partnerships with a large number of countries. 
While many talk about India as a superpower or emerging superpower, it is notable that India is currently not a regional power in South Asia in spite of its demographic and material advantage. In his chapter Manjeet Pardesi looks at India's foreign, especially military, relations with South Asia and with the rest of Asia. Pardesi argues that after 1947 India was an Asian power, which was in line with Nehru's expectations that India would play a leading role in Asia and in interpreting Asia to the wider world. However, this ended with the SinoIndian war in 1962. After that war, India was reduced to a South Asian power. Due to the China-Pakistan nexus, because of the weapon transfer from the United States to Pakistan in the aftermath of the Soviet invasion of Afghanistan in 1979, and because of India's domestic economic weakness, India was incapable of projecting power outside of South Asia. Pardesi argues that due to the gradual economic rise of India over the past two decades India is in the process of developing into a great power in Asia and has become a significant actor in the emerging balance of power politics in East Asia and especially in Southeast Asia, although it has not managed to emerge as the regional power in South Asia.

Emma Mawdsley writes about how India is challenging the Western-led norms, modalities and institutions of the international development regime. The chapter first gives an overview of India's development cooperation history. India was already a provider of development assistance in the 1950s, but the last decade has seen an acceleration in India's development cooperation flows. Mawdsley analyses the discourse of development cooperation. The discourse typically emphasizes the shared experience of colonial exploitation and solidarity between the nations that have this experience, a win-win outcome of mutual opportunity and equality. The Western development discourse is patronizing, while the Indian development discourse frames the development cooperation in a language of mutual respect. However, the Indian discourse of mutual respect between nations risks inattention to justice within states. Mawdsley points out that as India increasingly becomes a part of development cooperation a number of difficult issues arise and that how these issues are dealt with will have implications in the future.

In the fourth chapter of Part II, Brij V. Lal and Knut A. Jacobsen analyse how the idea of an Indian diaspora developed, the role of the Indian diasporas, and the place of religion and diversity in the Indian diasporas. The authors note that the growth of, as well as the notion of, a large Indian diaspora is a phenomenon of the late twentieth century. The Indian state wanted to tap into the economic resources of the diaspora and attempted an active engagement with the Non-Resident Indian (NRI) community. The government of India set up a High Level Committee to gain a deeper understanding of the aspirations, attitudes, strengths and weaknesses of the Indian diasporas and their expectations of India and to 'recommend a broad but flexible policy framework and country-specific plans for forging a mutually beneficial relationship with the PIOs and NRIs and for facilitating their interaction with India and their participation in India's economic development' (p. 161). Lal and Jacobsen emphasize that the Indian diaspora is an extremely diverse and plural phenomenon. It is divided not only into old and new, once and twice migrant diaspora communities, and a large number of regional and linguistic cultures, but also into a number of different religious identities as well. They argue that religion has been important for the preservation of personal dignity in the diaspora, as well as maintaining identities and traditions, especially for the first-generation migrants. Religion has also been a main resource in the attempts to transfer the diasporic project of the first-generation migrants to their children, the so-called 'second generation'. While the first generation were eager to transfer their own diaspora consciousness to their children, the second generation, on the other hand, typically have felt at home in the new country. They have thus grown up in-between cultures and experienced 
not only the clash of values between generations but also between the Indian (regional) cultures and the cultures of the new country. They were not Indian in the same way as their parents, and from the point of view of the new country they are British, Norwegian, Swedish and so on, and at home in the new country. Finally, the chapter deals with an important part of the religious diversity in the Indian diaspora, the religious institutions of Dalits. Some Dalits do not want to be part of the Indian diaspora but seek to escape from the Indian environment. Significantly, however, the Dalit religious institutions in the diaspora reflect similar efforts in India of Dalits organizing themselves around separate religious symbols in order to attain justice.

In Chapter 11, Mark Singleton takes the transnational and transcultural flows and negotiations that have characterized the development of Yoga in contemporary India and the world. He explores Yoga in a transnational and global context and explores some of the ways in which Yoga has mutated and adapted in the encounter with discourses alien to 'traditional' Yoga contexts. The author argues that as a result of a tangled and on-going history of borrowing, addition, exchange and excision, it is not sufficient to identify Yoga's purported origins in 'tradition' in order to understand its modern manifestations. With particular reference to physical culture, it is demonstrated that Yoga as it is popularly practised around the world today owes a debt to discourses of health, fitness, beauty and spirituality that began to permeate new, mainly anglophone modes of Yoga from the late nineteenth century onwards. Singleton shows that transcultural flows and negotiations have characterized the development of modern Yoga. One of the most important strands of the transnational development is the traditions of women's gymnastics which arose during the nineteenth century in Europe and America, and notes Singleton, 'the typical transnational Hatha Yoga class of today owes more to these traditions of women's gymnastics than it does to the hathayoga systems handed down in the history of India' (p. 179).

The last chapter in Part II deals with the status of the Ayurveda system of medical knowledge and practices in contemporary India. ${ }^{9}$ In this chapter, Maya Warrier examines the changes undergone by Ayurveda in modern times. She divides the chapter into the development of Ayurveda in the colonial period, in Independent India and Ayurveda as a global health tradition. In the colonial period Ayurveda was heavily influenced by Western biomedicine and the history of modern Ayurveda can be read as a history of gradual biomedicalization. Revivalists wanted to establish Ayurveda as India's national medicine and Ayurveda became a symbol of nationalist aspirations. Late twentieth-century popular accounts of Ayurveda, writes Warrier, are in essence accounts of 'Indianness'; they are trenchantly nationalistic and often anti-Western in tone. They depict India as a land of "traditional" wisdom, mystical and esoteric insight, and "spiritual" prowess' (p. 190). Warrier argues that Ayurveda has become a heritage product. Claims are made for its value as a spiritual tradition - ancient and uniquely Indian - with a basis in science and rationality. In practice, Warrier shows, mainstream Ayurveda has assimilated the methods and paradigms of biomedicine. Ayurveda has gained popularity in the last three decades in the West, and here it is promoted mainly as a holistic spiritual tradition that can enable self-understanding and self-expression. The emphasis is on promoting wellbeing and optimizing human potential, and this form of Ayurveda has a strong self-help dimension. The chapter provides the context for these different developments and provides important insights into the multiple faces of Ayurveda in the modern world. In conclusion, the author asks if the new emphasis on a cosmopolitan and individualistic form of 'spirituality' could 'serve as a corrective to Ayurveda's excessive preoccupation both with nationalistic chauvinism and with science and biomedicine in postcolonial India' (p. 197). 


\section{Society, class, caste and gender}

The chapters in Part III examine Indian society with a focus on class, caste and gender. In the opening chapter of this part, Diego Maiorano gives a detailed analysis of the complex dynamics that prompted the government of India to liberalize its economy in the 1990s and the consequences of these reforms for contemporary Indian society. Maiorano shows that the combination of exceptional circumstances due to a severe balance-of-payment crisis with the ability of politicians' proponents to implement economic reforms 'by stealth' to a large extent explain why liberalization was possible. The chapter then explores the consequences of the economic reforms in terms of their distributional outcomes. Maiorano observes that poverty did decline, 'but at a frustratingly slow pace, while non-income dimensions of poverty remain among the most severe in the world' (p. 211). Agriculture is also, as Rajeswari Raina likewise shows in her chapter, one of the losers, 'witnessed by the very high number of farmers' suicides'. On the other hand, the big business community, 'able to colonise highly profitable areas hitherto reserved for the public sector, benefited from substantial tax incentives and received massive amounts of implicit and explicit subsidies' (p. 211). And likewise the middle classes benefited. Maiorano notes that 'the economic reforms and the greater role played by the private sector contributed to expand further the middle class that is now the main protagonist of the "new" India' (p. 212), and, significantly, the elections in India now tend to be determined by issues raised by the middle class(es). Maiorano concludes that India's economic reforms show the enduring power of elite groups in India's politics.

In her chapter, Nandini Gooptu analyses the extensive transformation of urban India following economic liberalization. This transformation encompasses the built environment, governance, politics, class relations, lifestyles, and personal and social identities. Gooptu argues that two contradictory trends characterize the changing Indian city. First, the city development is exclusionary and provides an opportunity for private capital accumulation and the fulfilment of middle- and upper-class aspirations in privatized spaces, at the cost of the poor. And second, the city is projected as inclusive in top-down participatory governance discourse, though with limited achievement in actual practice. Gooptu shows that the Indian cities as a result of these contradictions have become increasingly politically contested, spatially unequal, economically stratified and socially divided.

Leela Fernandes in Chapter 15 analyses the middle classes in India. Fernandes notes at the outset that the 'realities of the lives, identities, and politics of India's vast middle classes bear little resemblance to the heightened public rhetoric about this group' (p. 232), and argues that India's middle classes are characterized by variations based on factors such as socio-economic standing, caste, religion and region, and that this diversity coexists with a distinctive public middle-class identity where various actors make claims about a uniform middle-class identity. Fernandes argues that such claims have been heightened in the post-liberalization period and that the result is a paradoxical relationship between political claims regarding a singular middle class and a differentiated social group that ranges from very elite English urban uppermiddle classes to lower-middle classes that struggle to maintain their socio-economic status. Fernandes analyses this paradox and argues that the tensions produced by such fractures within the middle classes play an increasingly central role in shaping contemporary politics in India. Fernandes notes that the middle classes have always engaged in politics aimed at differentiating their socio-cultural identity from subaltern social groups and emphasizes that some of the central trends in contemporary India have been shaped by the politics of the middle classes.

In Chapter 16, Surinder S. Jodhka analyses a traditional aspect of inequality, caste, which tend to overlap with newer forms of inequality caused by liberalization of the economy. $\mathrm{He}$ 
first shows that the practice of caste 'on the ground' has always been diverse and very different from the 'book-view' of caste. In addition, the mainstream social science perspectives on Indian society have tended to look at caste as an institution, which would disintegrate and disappear with secularization and modernization. Indeed, as Jodhka argues, many in middle-class urban India would emphatically argue that caste would and should have disappeared from public life by now had it not been kept alive by the actors in India's electoral politics. Jodhka, however, argues that despite considerable changes in social and economic life, caste continues to overlap with the newer forms of inequalities and that besides its persistence as a system of social inequality, it also survives as a value that ranks people on a scale of honour and humiliation.

Corruption has been an enduring phenomenon in India, but in Chapter 17 Gould argues that the rise of large-scale anti-corruption movements in India reveals more than simply public dissatisfaction with apparently ever increasing corruption scandals. Instead, he argues, public debate on corruption in India is related to two long-term political concerns since the 1940s. The first concern is a popular critique of the (post)colonial state derived from the moral politics of anti-colonialism. The second is the survival of a practical politics of anti-corruption in forms of patronage politics in Indian parties. Gould explores these ideas by examining the relationship between large-scale scandals and routine practices through three phases of political critique of corruption, the 1930s-1950s, the 1980s-1990s and the post-2006 period. Corruption and anticorruption in Indian politics have not been static, but Gould suggests that it is the specific experience and history of the colonial state that is key to the particular characteristics of the role of corruption in Indian politics. Gould writes that the 'modern anti-colonial critique of corruption sets up the notion of the "ordinary" citizen's struggle against autocracy and the state, which has become a key feature of post-colonial anti-corruption movements' (p. 257). Gould shows that anti-corruption movements happen when the political system is unable to contain the working of certain kinds of capital or resource accumulation. He suggests viewing corruption as an alternative political economy that maintains its own forms of social and administrative stability. When that stability is threatened, 'social and political competition produces anti-corruption protest' (p. 257).

In Chapter 18, Harald Tambs-Lyche and Nikita Sud explore a regional perspective of the current social and cultural development by investigating Gujarat. Gujarat is the home state of the current Prime Minister Narendra Modi, and a state that for two decades has been dominated politically by the Bharatiya Janata Party (BJP). Since 1995, when the party gained power in Gujarat, the state has been promoted as the 'showcase' of the Hindu right-wing party. Gujarat is characterized by the economic liberalism of the BJP government that favours local and foreign investment while its illiberal politics inspired by Hindutva and the ideal of the Hindu nation severely limit political opposition and minority rights. Tambs-Lyche and Sud note that the situation of the Muslims has worsened under the BJP regime. This pattern is partly explained by historical reasons. Gujarat has a long tradition of trade, partly due to its coastal location. Merchants have had a strong social, cultural and political influence in the area. In the colonial period, indigenous capital built a competitive textile industry, and Gujarat was among the most advanced states in India at the time of independence. The dominance of the bourgeoisie largely explains the present situation, argue Tambs-Lyche and Sud. With the 2014 national election Modi became the prime minister, and it remains to be seen whether this pattern of economic liberalism and illiberal politics inspired by Hindutva, which increases social inequality and severely limits minority rights, will become an all-India model.

Mallarika Sinha Roy notes in her chapter that the fascinatingly diverse sources of family studies, ranging from religious tracts and printed domestic manuals from the nineteenth century to ethnography of kinship systems and literary texts, unveil the complexity in discourses 
of family and marriage in India. Her chapter builds on Rajeswari Sunder Rajan's observation that feminist interventions in exploring questions of conjugality, widowhood, sexual labour and nationalism have expanded the horizon of the women's movement. The chapter takes up these issues to understand the significance of the link between feminist scholarship and the women's movement in contemporary India. Instead of evaluating the success and failure of legal reforms concerning family and marriage initiated by the women's movement, she argues that reforms and backlashes, often in cyclical regularity, exist in the life of every movement and that the women's movement is no exception to this pattern. But she argues that newer thoughts and writings on these intimate spaces of struggle have helped the women's movement to address the legal gridlock from new angles. Feminist scholarship continues to work on the kinship networks formed through marriage, inter-caste and inter-religion marriages, violence inside familial and marital relations, access to education and health, but in addition has brought in questions of lesbianism and disability and these have considerably expanded the orders and borders of family studies. The enormous significance accorded to family and marriage in contemporary India contains subversion, and her chapter revisits the contested fields of intimacy from subversive locations by exploring the margins of family studies.

In the last chapter of Part III, Uday Chandra first asks what it means to be 'adivasi' (a category used to unite groups who are characterized as 'tribes' or 'scheduled tribes') in contemporary India. He thereafter examines the 'adivasi' interactions with the modern state, non-state actors such as missionaries, extreme right- and left-wing organizations, indigeneity activists and the capitalist economy. Chandra questions the stereotypical image of the adivasi as a hapless victim of modern political and economic processes, and offers instead nuanced, down-to-earth empirical accounts of different aspects of contemporary adivasi life. Chandra notes that the politics of land and forests, work and livelihoods, and migration to cities create opportunities as well as challenges for adivasis. There are differences between adivasi elders and youth, dominant and subordinate lineages, and men and women in adivasi villages, and the capitalist economic processes sharpen these differences. Chandra argues that these differences call the notion of an adivasi 'community' into question, and he emphasizes that the adivasi communities are part and parcel of modern life without a possibility of a return to a state of innocence in which 'all were equal and nature's abundance ensured plenty for all' (p. 305). Instead, argues Chandra, adivasis are subaltern individuals and 'communities' embedded in and grappling with modernity at large.

\section{Religion and diversity}

Diversity is a main characteristic of contemporary India, not only in terms of class, caste, gender, regions and languages but also in terms of religious traditions, practices and communities. Several religious traditions, some with a worldwide presence, have originated in India. In the first chapter of Part IV, Gerald James Larson notes that layers of cultural development in the South Asian region going all the way back to the second millennium BCE have left significant cultural residues and valuations even in twenty-first-century India. Larson argues that what is crucial to understand in order to appreciate Indic notions of 'history' and 'myth' is that Indic traditions themselves appear to exhibit as 'myth' what modern scholars attempt to construe as 'history'. This in turn makes possible an interesting mirror reversal, namely, that what modern scholars appear to construe as 'history' is what Indic traditions themselves would for the most part consider to be 'myth'. According to Larson this reversal of myth and history is due to different understandings of the unfolding of time, or different mindsets: "The mind-set is one of falling backwards, of "precessing", and, hence, at least in the classic 
Indic formulation, of the present and future always becoming the past (or, in other words, karma and rebirth)' (p. 326). The current Hindu nationalist attempts of turning myths into history ${ }^{10}$ will consequently run into a number of contradictions.

The religious traditions called Hinduism have manifested themselves in massive prestigious temples all over the world, and their divinities in their material form as statues are worshipped with elaborate material exchanges of food, liquids, flowers and money, in great festivals and on a daily basis. According to Hinduism, spirituality is expressed in materiality. In her chapter Vasudha Narayanan explores this material aspect of Hinduism. Narayanan investigates the multiple connections between 'material' substances, 'spirit' and liberation from the cycle of rebirth, and asks if 'matter' is opposed to the categories of 'spirit/soul/God'. In Hinduism, it is not. Matter, she argues, is fluid. It is sometimes concrete and sometimes hypermaterial. She uses the Sarasvatī statue outside the Indonesian Embassy in Washington DC to enter into a discussion on material religion in the Hindu traditions. A tall statue, she argues, may be a symbol of political clout, cultural capital, a deity who grants desires, a manifestation of ultimate reality, and moves between the states. She argues that Sarasvatī's attributes suggest networks of affordances connected with materiality and performativity, and paths to liberation through them and transcending them. Narayanan concludes that the significance of the materialities arises in part from their affordances to give, on the one hand, learning, happiness and prosperity on this earth, and on the other, detachment and liberation from the cycle of life and death, and that according to most Hindu schools our bodies are pervaded with souls, and both bodies and souls are pervaded by brahman.

Religion is grounded not only in myth and materiality, but also in geography and so too the religious traditions in India. A central feature of the Hindu traditions is the conceptions of salvific space and the institutions of pilgrimage travel to these places. The last hundred years has seen an enormous increase in pilgrimage travel in India, and this is the topic of the chapter by Knut A. Jacobsen. After dealing with the historical origin and growth of Hindu pilgrimage in India, the chapter delineates changes in infrastructure and technology that have led to changes in pilgrimage patterns. The chapter thereafter analyses the close relationship between pilgrimage and economy, and argues that Hindu pilgrimage has expanded not least because of successful marketing. One reason for the current peak in pilgrimage travel is that the religious and economic institutions have a shared interest in the growth of pilgrims and both participate in the marketing of the places. Finally, the chapter discusses the contemporary concern of religious and political powers with places of pilgrimage. This concern illustrates the way establishment and expansion of pilgrimage spaces can be a means to secure land for one's own religion. The practice of connecting mythology and geography is an efficient promotion device, and indicates the connection of pilgrimage space to the desire of political dominance. However, Hindu sacred narratives are often presented as describing events of previous yugas involving ideas that are removed from contemporary conceptions of history.

In Chapter 24 Eleanor Zelliot presents one of the most influential persons of modern India, Bhimrao Ramji Ambedkar, the leader of the untouchables, who together with Mohandas Karamchand Gandhi and Jawaharlal Nehru is considered one of the three makers of modern India. The chapter focuses in particular on Ambedkar's Navayana Buddhism. Zelliot points out that there was in the period before Ambedkar an increasing interest in Buddhism among Indian intellectuals. She shows how Ambedkar was able to build on an earlier revival of Buddhism in southern India associated with Lakshmi Narasu and Iyothee Trass, on the Maha Bodhi Society in India founded by Dharmapala, and on previous leadership in the Marathi-speaking area such as the two Mahars, Kisan Fagoji Bansode and Shivram Janba Kamble, as well as the high caste Vital Ramji Shinde and Jyotirao Phule. The chapter further 
analyses Ambedkar's satyagrahas and his relationship to Mahatma Gandhi. While Gandhi focused on changes of the heart, Ambedkar maintained that political and legal rights were essential. Ambedkar argued that the untouchables were treated as they were because they had the misfortune of calling themselves Hindus. He thought that if the untouchables had been members of another religion the caste Hindus would have treated them better, and he declared that he would not die a Hindu. He chose to convert to Buddhism. The chapter presents some of the contradictions Ambedkar saw in Buddhism and which he struggled to resolve when developing his own interpretations of the teaching of the Buddha. The final part presents the flourishing of Navayana Buddhism in contemporary India, and the author concludes that there is a need for the Buddhist conversions in India to be recognized in the larger Buddhist world outside of India.

While Zelliot focuses on Ambedkar and Buddhism in the Marathi-speaking areas, in Chapter 25 Ronki Ram concentrates on Punjab and the Ad Dharma and Ravidassia traditions. Ram explains that the Dalits in the state of Punjab have long been struggling hard to escape from the social exclusion that is grounded in the discriminatory social structures of Punjab's agrarian society. After experimenting with conversion and sanskritization as agencies of upward social mobility and as means to improve their situation, they now attempt to establish their separate Dalit identity based on a distinct Dalit religion. In Punjab, the Ad Dharm movement was the originator of the idea of a separate Dalit religion. However, argues Ram, Dalit religion has attained its current shape in Punjab through the agency of numerous Ravidassia Deras ('centres'). Ravidassia is founded on the popular sayings and teachings of Guru Ravidass, a Sant from an untouchable caste and his poems are included in the Guru Granth Sahib, the sacred book of the Sikhs. Ronki Ram explains that the Ravidassias hope that their religion will help them to become differentiated from the well-established religions in the region and to demonstrate a unique and separate Dalit identity.

In Chapter $26 \mathrm{R}$. Santhosh provides a broad overview of Muslim communities in contemporary India. India is the third largest Muslim country in the world. Much of the research on Muslims in India has focused on the encounter with modernity in the geopolitical landscape during colonial and post-colonial contexts. Santhosh highlights the enormous diversity among Muslims in India by focusing on the diverse theological and organizational schools representing reformist and traditionalist orientations, forms of social stratification and recent mobilization based on caste. He points out the fallacy of treating Muslims in India 'as a "community" with given socio-political dispositions due to their shared religious identity" (p. 394). The chapter also discusses the socio-economic conditions of Muslims and examines the Sachar Committee report, which demonstrated their backwardness in terms of economic development, but Santhosh also notes that the emergence of new middle classes is redefining the character of the Indian Muslims. The final part of the chapter looks at the question of Muslim citizenship in the context of increasing religious polarization, communal violence and the advent of a Hindu nationalist government in 2014. Santhosh concludes that Muslims in India are currently passing through some of the most momentous phases of their recent history.

Marika Vicziany, in Chapter 27, investigates religious violence in the conflict between Hindus and Muslims, the two largest religious communities in India, a conflict that in South Asia is called 'communalism'. She argues that the contours of the Hindus' fears need to be understood as a starting point for any discussion of religious violence in India. Hindu nationalism (Hindutva) is based on perceived threats to Hindu demographic, cultural and political dominance, and she therefore first asks, 'Who is a Hindu?' In the second part of the chapter, she examines the nature of the violence and the extent to which the official crime statistics of India can be relied on as a way of understanding the position of India's 
Muslim minority. The author argues that the under-representation of Indian Muslims in India's administrative and security institutions contributes to religious violence and to the unreliability of Indian crime statistics, and that 'the police form part of a wider governance structure that under-represents the interests of India's Muslim citizens' (p. 411).

In Chapter 28, John C. B. Webster focuses upon Christians as immersed in Indian culture and civil society. The author shows that while diverse in their social origins and geographical distribution, the Christians in India have been drawn mostly from low caste and tribal groups with which they continue to identify. He explains how this is reflected in their patterns of conversion, their varied relations to the caste system, their commitments to both Christ and modernity, their brands of political and cultural nationalism, their struggles for recognition as well as in claiming and safeguarding their constitutional rights, and in the kinds of opposition they have had to face, particularly from proponents of Hindutva. As Webster notes: 'The ancestors of the vast majority of Christians converted in order to escape from the experienced consequences of the kind of religio-cultural homogenization that the Sangh Parivar seeks to impose' (pp. 422-423).

\section{Cultural change and innovations}

Part $\mathrm{V}$ focuses on the cultural changes and innovations relating to the body in a number of contexts in contemporary India. In the first chapter, Nandita Ghosh writes about the gendered body and especially sexual violence against women in contemporary India. Ghosh notes at the outset that 'women's bodies are central to any understanding of unequal gender relations' (p. 430). The author further argues that the 1970s and 1980s marked a period of crises of the state with a proliferation of women's groups, interlinked regionally, locally and nationally, that battled discriminatory practices in domestic and public domains' grassroots movements. From the 1990s, these groups focused on the gendered impact of free market capitalism, religious fundamentalism, changes in democratic culture and problems of the national economy. The visibility of women on the political stage in these decades challenged the story of India's emergence as a modern nation-state by calling attention to the invisibility of women in the construction of that story. She analyses four works of fiction (In Custody, Days of the Turban, English August and Imaginary Maps), which present differing female experiences of oppression. Ghosh shows that the authors of the works explore constructions of femininity through a variety of female characters that modify or subvert the roles they are required to play. Finally she argues that literature has the power to unsettle dominant narratives and expose new possibilities, and she sees evidence of such new possibilities in the public outrage over the rape of Nirbhaya in December 2012 when various sections of civil society united to assert the right of women to safely and freely inhabit public spaces.

In Chapter 30 Michiel Baas analyses new images of the Indian male body. These images focus on muscles and masculinity. The author asks how we can understand this ostensibly new Indian male. Invoking Weberian typology the chapter analyses what the arrival of this 'ideal type' (lean, muscular) male body articulates about contemporary India in relation to socio-economic developments. He tries to show that recent Indian economic growth has come with new and specific ideas on the 'ideal' male body. Baas argues that the dramatic increase in visibility of men with lean, muscular bodies in public spaces (billboards) and popular media (Bollywood, TV series) in India indicates that increasingly the physical appearance of the male body is imagined to be an indicator of, and facilitator towards, socio-economic success. As a result, the number of gyms specifically targeting the Indian middle class has increased dramatically. The author builds his chapter upon various fields of scholarly research as well as his own ethnographic 
work and argues that the male body has become a new site of contestation and meaningmaking in the context of increasing globalization and middle-class formation.

The body is dependent on food as nutrition, but food is also embedded in systems of meaning, and in India, notes Michaël Bruckert in Chapter 31, 'food patterns differ according to region, religion, caste, financial means, habitat (rural or urban) and also to the age and gender of the individuals' (p. 458). Portraying changes on the national scale within such a fragmented mosaic is an impossible task. The author therefore addresses the changing food habits in contemporary India through the specific case of Chennai in Tamil Nadu, and in particular the discourses and practices of the middle classes. Bruckert shows that food consumption patterns renew and recast the links between diet, identity, hierarchy, purity and morality. In India, he argues, food change does not follow the alleged pattern of 'food transition' theorized by nutritionists. Bruckert suggests that one main factor that makes India an exception to this pattern is moral values: 'Incomes not only pertain to purchasing power, but to ways of life as well. Moral values matter as food is always socially and symbolically constructed' (p. 460). An expanding economy, mass consumption, a globalized way of life and the habit of eating out have diversified both offer and demand of food for the urban middle classes, but the author observes that many people nevertheless still face restrictions in terms of accessibility and availability, and concludes that food change mostly occurs at the margins of contemporary Indian society. In particular, food eaten out is often the frontrunner of transformations and 'paves the way for new patterns of sociability as it potentially emancipates from ethnic, religious or caste rules' (p. 468).

In Chapter 32 Brigitte Sébastia looks at the use of Siddha medical knowledge and practices to treat diabetes, perhaps the number one disease of modernity in India. There has been a tenfold increase of this disease in India in the last four decades, and in 2014 around 25 per cent of the population in the cities of Delhi and Chennai over twenty years of age are diabetics. ${ }^{11}$ In Chennai, 38 per cent of persons over forty are diabetics. Sébastia observes that type 2 diabetes has emerged in India since the 1980s as the result of rapid changes in diet and lifestyle. Unchecked consumption of white rice and lack of physical activity have been identified as two major reasons for this increase. In her fieldwork with practitioners of Siddha medicine Sébastia discovered that Siddha practitioners are increasingly consulted for the treatment of patients with this disease. While college-trained Siddha doctors are equipped to treat diabetes as their training incorporates biomedical disciplines and the study of emerging diseases, traditional Siddha practitioners have to juggle with their own methods and medication, as they did not inherit the knowledge to treat this disease, which was rare in the past. Based on the ethnography of two traditional Siddha practitioners, opposite in many aspects, her chapter demonstrates their ability in dealing with different aspects of diabetes care which qualifies them to contribute to the fight against a disease considered as a major public health issue.

Finally, a note on transliteration from Indian languages; I have chosen to include diacritics in a few chapters that deal with Indological topics (Chapters 11, 21, 22, 23 and 32, and in the reviews of these chapters in this introduction). However, in these chapters I have not used diacritics on geographical names [Varanasi and not Vāraṇāsī) and modern names [Vivekananda and not Vivekānanda). Apart from those chapters, the simplified transliteration system of Indian languages is used, allowing for some differences between chapters. To avoid confusion of words with similar spelling, Brahman refers to the caste, brahman to the supreme deity.

This is a single-volume collection of essays and although a number of the most important issues and themes have been included, there are nevertheless significant issues that I have not been able to incorporate because of size limitations of the volume and other restraints. I nevertheless believe that the volume will be helpful to those seeking academic knowledge about contemporary India. 


\section{Notes}

1 The other South Asian countries are Bangladesh, Bhutan, the Maldives, Nepal, Pakistan and Sri Lanka.

2 http://data.worldbank.org/indicator/SP.POP.GROW, accessed 2.12.2014.

3 http://blog.euromonitor.com/2012/02/special-report-the-worlds-youngest-populations-. html\#sthash.DPlCqig5.dpuf, accessed 6.12.2014.

4 http:/www.thehindu.com/news/national/india-is-set-to-become-the-youngest-country-by-2020/ article4624347.ece, accessed 6.12.2014.

5 The diaspora has in the last decades been actively engaged by the Indian state and, partly because of that effort, an awareness of a larger global Indian community, the Indian diaspora, was created. The categories Non-Resident Indian (NRI) and People of Indian Origin (PIO) are now well known and somehow included in thoughts about India, as the diaspora has become an important aspect of the current globalization development. Indians, in fact, live in almost every county in the world.

6 'Bridging the gulf: bilateral remittance estimates for 2012', Times of India, 1.12.2014. The largest amount of remittances, about half, came from Qatar, Bahrain, Oman, Saudi Arabia and Kuwait.

7 Vivekananda probably saw this as an opportunity to build national confidence in the face of British colonialist humiliation.

8 '6 times more "Puranas" in hand, RSS puts 100 on job for new history', http://indianexpress.com/ article/india/india-others/6-times-more-puranas-in-hand-rss-puts-100-on-job-for-new-history/, accessed 16.12.2014.

9 AYUSH (Ayurveda, Yoga and naturopathy, unani, Siddha and homeopathy), which was previously a department in the Ministry of Health, was assigned a separate ministry under Narendra Modi's government in 2014 (Department of Ayurveda, Yoga and naturopathy, unani, Siddha and homeopathy).

10 See Note 8.

11 'Diabetes cases increase tenfold in Chennai, Delhi in four decades', Times of India, 12.11.2014.

\section{References}

Euromonitor International (2014) 'Special report: the world's youngest populations', Euromonitor International, http://blog.euromonitor.com/2012/02/special-report-the-worlds-youngest-populations-.html [accessed 6.12.2014].

Rai, R. and P. Reeves (2008) The South Asian Diaspora: Transnational Networks and Changing Identities. Routledge, London.

Sampath, J. (2014) 'Diabetes cases increase tenfold in Chennai, Delhi in four decades', Times of India, Chennai, 12.11.2014.

Shivakumar, G. (2013) 'India is set to become the youngest country by 2020', The Hindu, Chennai, 17.4.2013, http://www.thehindu.com/news/national/india-is-set-to-become-the-youngest-countryby-2020/article4624347.ece [accessed 6.12.2014].

Times of India (2014) 'Bridging the Gulf: bilateral remittance estimates for 2012', New Delhi, 1.12.2014.

World Bank (2014) 'Population growth (annual \%)', http://data.worldbank.org/indicator/SP.POP. GROW [accessed 2.12.2014].

Yadav, S. (2014) '6 times more "Puranas" in hand, RSS puts 100 on job for new history', The Indian Express, New Delhi, 18.8.2014, http://indianexpress.com/article/india/india-others/6-times-morepuranas-in-hand-rss-puts-100-on-job-for-new-history/ [accessed 16.12.2014]. 

$\because$ Taylor \& Francis http://taylorandfrancis.com 


\section{PART I}

\section{Foundation}



$\because$ Taylor \& Francis http://taylorandfrancis.com 


\title{
1 \\ DREAMS, MEMORIES AND LEGACIES Partitioning India
}

\author{
Pippa Virdee
}

After nearly seventy years of independence, the partition of India, the creation of Pakistan, and their wider ramifications continue to resonate and reverberate today. This is particularly palpable in the region of Punjab, which bore the brunt of the associated partition violence, resulting in millions of people being forced to migrate and forever severed from their homelands. The generation that witnessed this grand project in history, which informs and defines the region, is fading away in numbers, but the small numbers that survive still talk about the events as if they were a recent memory. During a trip to Lahore at the end of 2013, I was constantly reminded of the events of 1947 and taken back in time by a generation that had known Punjab before it was partitioned. During a conversation with Najum Latif, who had migrated from Jullundar as a child in 1947, he emotionally recited this poem by Ustad Daman:

We may not speak, but deep in our hearts we know That you have lost, as we too have lost in this divide With this false freedom, towards destruction

You ride, and so too do we ride

There was some hope, there is life to be found But you died, and so we too died.

Ali 2011

The painful loss and the lack of closure continue to haunt. The remnants of this bygone era are everywhere, from the often-crumbling buildings to the often-melancholic memories. The food, the language, the dress, the vibrant and hearty Punjabi and the plains of the Punjab that connected people and are now divided by hostile boundaries. There is a constant reminder of these divided histories while travelling between the two Punjabs; one only needs to casually observe the place names of shops which are frequently located in the 'other' Punjab. These are the small ways in which those who fled in 1947 have preserved their own ancestral histories, passing them through the generations that will be unfamiliar with the other half. The strict visa controls by both governments ensure they remain divided and foreign. 
The transfer of power in India was essentially planned, however, in the closing days there was a collapse of law and order, especially in the province of Punjab. This highly militarised area $^{1}$ responded with some of the worst violence seen in the history of the subcontinent. And so the smooth transfer of power and the creation of two states was forever tainted with the blood of civilians. By tracing this extraordinary period through personal experiences of violence, forced migration and finally rebuilding torn lives highlights the fact that this was not just a moment in history but instead it was a decision which impacted millions of lives and lasted for years; and for some they are still wandering in the streets of their childhoods. Although lives were rebuilt, the memory of ancestral homelands and lost childhoods remained with the people. The fractures caused by imperial collapse and the partition became permanent and so for many refugees their former homes remained with them only in memory. It is perhaps for this reason why some people, especially in Punjab, have not reconciled to the idea of partition; the lack of closure is equally evident in the response of the two new states and their inability to have any form of an open postconflict reconciliation.

This chapter deliberately stays away from the wider political legacies associated with independence and the partition of British India because these are better documented elsewhere (Hasan 1997, Kamra 2002, Talbot and Singh 1999, Pandey 2001). The volatile and emotive issue of Kashmir and its bloody shadow continue to dominate the discourse of Indo-Pak relations. The security concerns have consequently fuelled the race for both India and Pakistan to become nuclear nations, which prominent writers such as Ashis Nandy, trace back to partition (Tan and Kudaisya 2000: 211). The broader questions surrounding the accession of Princely States (other than from a conflict and security perspective) have also not generated that much scholarly discussion given that they formed two-thirds of India at independence. The Princely States remained excluded from the Radcliffe Boundary Commission discussions; yet they were to form an integral part of the new nation-states and had to accede their autonomy. Politically then, partition has been fundamental in shaping the political and security landscape of post-colonial India and Pakistan. However, this chapter will focus on the region of Punjab, which was partitioned in 1947 and has been transformed by the decisions taken in Delhi and London. It was the last region to be annexed following the second Anglo-Sikh war in 1849, and following the mutiny in 1857 Punjab played a pivotal role in the British imperial machinery. It was a region that was transformed under colonial rule and then divided. Today Pakistani Punjab is the most populous province and dominates the tripartite power base (military, bureaucracy and feudal) in Pakistan. Indian Punjab has also been at the forefront of India's green revolution but politically the separatist movement of the 1980s has overshadowed much of its recent history. But underlying this is the scar and trauma of partition; the dreams of independence and creation of Pakistan that very quickly transformed into bitter legacies. It is here that Daman's poem acts as a powerful reminder of the loss and evokes nostalgia of a lost age.

\section{Handing over the reins of power}

As independence drew closer and the idea of a separate homeland for India's Muslims became a reality, the Punjab, which Jinnah termed the 'cornerstone' of Pakistan, effectively became the battleground. The Unionist Party, which had dominated Punjabi politics for the past twenty years, was able to block the Muslim League's attempts to form a Ministry, due to the fragile balance of votes. But tensions were mounting outside the legislature 
as communal organisations in the region all laid claim to the historic land. Neeti Nair (2011) argues that contrary to popular perception, some high profile Hindus also preferred the partition option in the decades preceding independence. There is, she argues, a convergence taking place of politics of communalism with anti-colonialism in Punjab during this period (257). Evidently the Indian National Congress which refused to share power with the Muslim League in the United Provinces following the 1937 provincial elections is seen as a major turning point in changing the fortunes of the Muslim League that ultimately laid claim to speak for all of India's Muslims. By 1946 the Muslim League had been transformed and so the journey towards a separate and new entity of Pakistan became a real possibility.

When the British decided to hand over the reins of power in India, the result was not a smooth transfer of power from colonial rule to two independent countries of India and Pakistan. The reality was much more chaotic, with widespread lawlessness creating the space for unprecedented levels of communal violence between Hindus and Muslims and in the case of Punjab, the Sikhs too. The toxic mix of large numbers of demilitarised personnel and weaponry, the militarised Punjab (Sikh) States, and law and disorder as the British exit, and at stake for the average masses was their livelihoods, their homelands and their lives. In the case of the Sikhs this was also their spiritual homeland. Most were taken by surprise at the levels of violence, chaos and mass forced migration that followed.

The result, an estimated death toll of approximately 1 million people, though the true human cost can never be measured. The Punjab and Bengal were the two regions most affected by the division, which drew the new boundaries between India and Pakistan. The all-consuming violence which engulfed these regions resulted in one of the largest forced migrations in the twentieth century, with an estimated 15 million people crossing the newly created borders by Sir Cyril Radcliffe. The dislocation was at its peak in the Punjab between August and December 1947. It was estimated by the Indian government that, by June 1948, 5.5 million non-Muslims and 5.8 million Muslims crossed the border in Punjab (After Partition 1948:50).

It was in the wake of the Unionist government's resignation on 2 March 1947 that the Punjab slid into communal violence (see further Talbot 1996). Until this time, the province had escaped the communal violence that had earlier engulfed Calcutta, Noakhali in East Bengal and then spread to Bihar (Nanda 1948: 16). The disturbances of March 1947, in Rawalpindi division, in the wake of Khizr's resignation marked an alarming trend towards increased use of violent means to achieve political goals and thus legitimatising violence as a political tool. The demarcation of territory in response to the impending British departure, combined with the highly militarised nature of Punjabi society, made the situation qualitatively different from previous 'communal riots' (Aiyar 1995). Crucially the March violence $^{2}$ set the benchmark for further and more gruesome reprisal hostility, or as Paul Brass has termed 'retributive genocide' (2003), in August 1947.

The Punjab violence was a factor in the last Viceroy Mountbatten's decision to bring forward the date of departure from India. Initially planned for June 1948, the date changed to August 1947, which effectively left no time to prepare a smooth transfer of power and even less time to consider how the country would be divided. Partition was now seen as the only way forward. The Mountbatten Plan was announced on 3 June 1947 and accepted by the main leaders, Jawaharlal Nehru, Muhammad Ali Jinnah and the Sikh leader Sardar Baldev Singh. And so on 14 August 1947 Pakistan came into being (though the two wings were divided by 1,000 miles of landmass) and the following day at the stroke of midnight on 15 August, India finally got its independence after a long struggle. 


\section{Porous borders to permanent fractures}

Sir Cyril Radcliffe was given the unenviable task of chairing the Boundary Commission. One of Radcliffe's virtues was apparently his lack of any familiarity with Indian politics and more importantly, any previous knowledge of the region that he was going to divide (Yong 1997: 7). This was supposed to ensure that he appeared as a neutral figure and dealt even-handedly with the conflicting territorial claims. Based on previous census material, the partition line, known as the Radcliffe Line, was eventually drawn in six weeks establishing the fate of millions of people. What is more astonishing is that the actual boundary between the countries was announced on 17 August, three days later (see further Chester 2002, Yong 1997). The majority of people remained oblivious to the political wrangling over the boundaries and most, until the violence and chaos spread, remained in their homes regardless of the new international boundaries reluctant to leave (and abandon) their homes.

Curiously, Radcliffe's relationship with Mountbatten continues to raise questions over the extent to which Mountbatten influenced the boundary award. Lucy Chester suggests that Radcliffe was not as ignorant as he is often portrayed, however, it is difficult to quantify the level of 'influence' Mountbatten had on the outcomes of the Boundary Commission, who allegedly influenced the line in Gurdaspur and Ferozepur, despite some tehsils having Muslim majority populations (Kamran 2007: 203). Arguably this is one of the most bitter legacies of the boundary, which is intertwined with the Kashmir issue as it provides a corridor to India (Abid and Abid 2011). While the controversies surrounding Mountbatten's role will continue, Chester does offer an interesting insight into how Radcliffe felt when leaving India:

I station myself firmly on the Delhi airport until an aeroplane from England comes along. Nobody in India will love me for my award about the Punjab and Bengal and there will be roughly 80 million with a grievance who will begin looking for me. I do not want them to find me. I have worked and travelled and sweated - oh I have sweated the whole time.

Chester 2009:100

This is a rare insight because the enigmatic Radcliffe was obsessive about destroying his personal papers and so his role is left mostly to speculation and conjecture; however, it does show his own awareness of the repercussions in drawing the lines and perhaps he also sensed that he would be blamed for this unpopular award.

It is interesting to note that all three key leaders, Mountbatten, Jinnah and Nehru, failed to anticipate the mass migration of peoples. During the months of August to December 1947, almost all the Sikhs and Hindus of West Punjab left Pakistan and similarly nearly all the Muslims of East Punjab and many from adjoining areas left to create new homes in the Dominion of Pakistan. Prior to independence there was hardly any mention of a planned exchange of population, the Government of India felt it was inconceivable that people would just leave their ancestral lands and property and migrate (Rai 1965: 72). This was despite the warning signs of violence-related migration in Noakhali (October 1946) and Bihar (November 1947) that contained elements of ethnic cleansing, and the fact that some non-Muslims started to migrate in the wake of riots and violence in Rawalpindi in March 1947. Jinnah on the other hand had also envisaged a Pakistan that included other religious minorities as is evident in his Presidential Address to the Constituent Assembly of Pakistan on 11 August 1947. Indeed the Muslim League leadership vowed to protect the 
minorities in Pakistan and thus prevent a mass exodus (Singh 1962: 9). Yet the idea was not completely inconceivable because Jinnah had also suggested an exchange of population as early as 10 December 1945 and Ghazanfar Ali Khan, who was one of Jinnah's close aides, considered an 'exchange of population a necessary corollary' to the establishment of a Muslim state (Rai 1965: 72). While the secular orientated Indian National Congress could accept a territorial division, a division of peoples would totally negate its ideology and force it to accept that India was indeed made up of 'two nations' with irreconcilable differences (Address by Jinnah 1983). The colonial government alternatively was completely focused on leaving India at this point and had neither anticipated nor planned for a mass transfer of population as a result of its policies. Yet the idea of planned exchanges of populations and the so called 'unmixing' of ethnic communities was something used extensively following World War II in Europe so it is surprising that it does not feature in the discussions in the exit plan for India (Frank 2011).

Once the violence reached uncontrollable levels and chaos engulfed the Punjab region, the two new dominions had to accept that the exchange of populations was an inevitable outcome of partition. It was therefore recommended by the High Commissioner to Nehru, that a 'transfer of population should take place', although the nature of that exchange was less clear (Singh 2006: 502). Many people still resisted migration, for example in Lyallpur the sizable Sikh population were forced to leave in September after appeals made by the Sikh leader, Master Tara Singh, and the West Punjab Governor, Sir Francis Mudie; others saw the migration as a temporary measure due to the uncertainty and had planned to come back to their ancestral lands. Even the leadership of the two countries had anticipated that the refugees would return to their homes once the situation had improved. Mahatma Gandhi's view on this was that 'the migrant must eventually return to their homes and lands that the two Dominion Governments must extend the fullest protection of their minorities' (After Partition 1948: 59). The newly created international border should have functioned as a porous border (which it did in the early period) but in reality it gradually began to limit and restrict people's movement and thus entrench the division. Zamindar's (2007) research has also shown how during the early years the border was quite fluid and there was much more flexibility in movement of people, indeed people were coming back and forth to make arrangements for their possessions and properties until the permit system was introduced.

For many fleeing refugees though, the traumatic and often violent journey across the new border marked a sense of relief, Keller makes the analogy with the feeling of having reached the 'promised land' (Keller 1975: 59). Yet, the longer-term legacy of this migration has not always represented that analogy of the 'promised land'. Saadat Hason Manto, a short story writer, most poignantly touches upon this space that became 'no mans-land' in this Urdu fictional account of Toba Tek Singh (see Bhalla's translation, 1999: 565-573). The short story is set in a lunatic asylum, overcast by the looming partition but with little knowledge of how this will impact them. The madness of partition is offset by the madness in the lunatic asylum and the story of Bishan Singh, more popularly known as Toba Tek Singh, which is an old town in what would become Pakistan. Manto, a migrant from India, was never completely at ease in Lahore and died shortly afterwards in 1955. The confusion of identity and citizenship are themes which resonate in his work and as the ending of Toba Tek Singh unfolds we find the remnants of the many migrants that were torn between two spaces in no man's land. It is perhaps the legacies of these amorphous lines in the minds and memories of the victims of partition that have left a most bitter legacy, which has eventually translated into a bitter relationship between the two nations. 


\section{For the love of cities}

The mass migration of people following partition also fundamentally altered the physical landscape. Delhi, the colonial capital, was transformed from an Urdu speaking Muslim city in character to a city that housed the incoming Punjabi refugees that now lend much of their character to the city. Delhi retains its Mughal links through the extensive architecture that dominates the city but the people are heavily influenced by the Punjabi migrants (Kaur 2007). Shaista Ikramullah, a prominent female Pakistani politician, after leaving the city wrote, 'For millions of people like me, to whom Delhi was synonymous with Muslim culture, a Pakistan without Delhi was a body without a heart' (Rumi 2013: 49). The economic and demographic reconfiguration of the cities in Punjab was also to have a significant impact on the divided Punjab; it transformed small towns to cities and cities into regional and international economic centres.

Demographically, the communally mixed Punjab was after independence unceremoniously 'unmixed' of 'other' communities. Historically Punjab had a strong pluralist and composite cultural tradition that statistical data and simple religious categorisation does not reveal. Furthermore there is much debate about the role of colonialism and the formation of these fixed religious categories (Bhasin-Malik 2007). According to the 1941 Census of India, Punjab consisted of 29 per cent Hindus, 53 per cent Muslims, 15 per cent Sikhs and 3 per cent others. By 1951, Pakistan Punjab was overwhelmingly Muslim with 98 per cent and only 2 per cent other. Indian Punjab on the other hand became dominated by the 66 per cent Hindus and 30 per cent Sikhs, with a small 2 per cent of Muslims and 1 per cent other. The reality prior to August 1947 was that some localities, especially in Central Punjab, were much more diverse, while others were dominated by one community. After the partition, the impact of the total out-migration of 'other' communities had a huge impact on the local and regional economy because of the skills and contribution of these people. For example in Ludhiana, skilled Muslim workers dominated employment in the flour and rice mills with 83 per cent of workers; in the hosiery sector, Muslims accounted for 61 per cent; and in the textiles industry they accounted for 78 per cent of the workforce. ${ }^{3}$ For many cottage industries the result was closure. Furthermore, the new migrants coming from West Punjab, who had a different set of skills, did not compensate the skills that were lost with the migration of these workers.

Prior to independence Lahore was the leading commercial and cultural heartland of the Punjab (and indeed in north India) with an influential and affluent non-Muslim population, while Amritsar, only a short distance from Lahore, depended much on the Muslim artisans that contributed to the vibrancy of the city. During their deliberations of the Boundary Commission, Chester asserts that they were 'driven by the need to preserve Amritsar's economic and strategic position' (2009: 75), hinting that perhaps no one had anticipated the demographic and economic consequences of partition on Amritsar city (see further Talbot 2006). The reality was that Amritsar suffered more than Lahore due to its geographic positioning as a border city; the large Muslim artisan class had left a big void in the labour market thus leading to its decline (Luthra 1949). Furthermore, the sensitive international border between India and Pakistan ensured that the border areas, such as Amritsar, Gurdaspur and Ferozpur now experienced economic decline. Conversely Lahore, partly due to the lack of alternatives in Pakistan and its political importance, retained much of its former imperial glory; though it also suffered in the short term from the complete out-migration of the economic dominance of Hindus and Sikhs.

Equally provincial towns like Ludhiana and Lyallpur became industrial heartlands of divided Punjab (Virdee 2007). Both these towns previously had majority 'other' populations 
and consequently attracted fleeing refugees from the other side. Interestingly there is a history of migration between Ludhiana and Lyallpur prior to independence. The development of the new Lyallpur Canal Colony in the late nineteenth century and the social engineering that went along with the project has received relatively little attention, given its dramatic impact on the region (see further Ali 1988, Gilmartin 2004). Farmers, artisans and even some professionals from Central and East Punjab, including Ludhiana, were drawn by the economic opportunities in these newly irrigated colonies that came to represent the most fertile lands in India (Darling 1925 [1977]). Fifty years later at the time of partition, the non-Muslims re-migrated eastwards once again to their 'original' ancestral homes from which their grandparents and parents had earlier departed (see further Tatla 1995). Adding to the attraction of Ludhiana was, however, the fact that it was on the main artery of north India, the Grand Trunk Road. It was therefore connected to all the major cities (Delhi, Amritsar and Lahore) and thus was an important stop for refugees who were on the move and consequently attracted many refugees.

Internal migration has historically therefore played an important role in the development of Punjab. Following partition, refugees and migrants have played a significant role in providing the basis of creating new industrial heartlands that have shaped new emerging cities like Lyallpur and Ludhiana and in regenerating the economy post-1947. However, it was the dominance of small-scale industry in Ludhiana, which in 1952 stood at 452 small-scale units compared to Amritsar's 239, that enabled the city to achieve a competitive advantage over its rivals. Through this, Ludhiana emerged as East Punjab's leading industrial centre, surpassing Amritsar and Jullundar. Indeed, the development and the necessity of small-scale units was praised by India's first Prime Minister, Jawarharlal Nehru:

One of my colleagues had recently made a quick survey of the small-scale industries started in the Punjab since independence and was much impressed with what had been done both by the permanent residents there and those who had come from Pakistan as refugees. I believe he listed 20,000 small enterprises that had grown up in the last few years in the Punjab with a relatively small capital but with a great deal of energy and enterprise. That is the kind of thing which heartens one and increases self confidence ... It is the Government's business to create conditions for the rapid spread of medium and small-scale industries all over India. The example of Ludhiana, where such industries have thrived shows that this kind of thing could be done everywhere. It would be better for such industries to be started away from big cities.

Dhiman 1962:28

While small towns like Ludhiana eventually benefited from the mass human displacement of 1947, there was also another side effect, which continues to resonate in contemporary India. Refugees from all communities faced similar problems of rehabilitation and those who had access to influence and money used their connections to ease that process. Satya Rai notes that nepotism, corruption and bribery were rampant in the administration. Money, power and influence were important factors in the speedy evacuation of friends and family, 'refugees could not get equal justice or attention' (Rai 1965: 87). Some individuals took advantage of the chaos and lack of administrative control and used the misery of others to make money, 'one trip with the refugees or with their kin was equal to an ordinary months earnings' (Rai 1965: 87-88) for the riksha wallas. Sardar Ishar Singh Majhail, the East Punjab Minister for Refugees and Rehabilitation, was well aware of some of the corruption that 
was going on. He is reported to have declared in December 1947 that he would take every effort to prevent shops and factories from falling into the hands of rich people (Tribune 13 December 1947). This was in response to reports of members of the Legislative Assembly attempting to acquire factories and workshops in their names or in collusion with other notables (Tribune 13 December 1947). The process of granting loans and allocating evacueeabandoned property was almost inevitably open to abuse. Bribery, land grabbing and extortion were especially prevalent due to fierce competition for resources coupled with abandoned properties but Talbot notes that the 'border cities provided additional opportunities for crime' (Talbot 2006: 68). The legacy of this is also evident in present-day India and Pakistan, where institutionalised corruption is endemic. Ilyas Chattha (2012) has recently been unearthing this connection between corruption during the rehabilitation of refugees and its impact on the post-colonial states.

While the urban landscape changed dramatically, lives were rebuilt and new homes were made, the emotional attachment that people had with cities such as Lahore and Delhi was a source of much literature. The following poem by Prem Kirpal who was a Lahori migrant to Delhi is about how his beloved city became a foreign land:

\author{
Spirit's Musings \\ My beloved City of Lahore \\ Still Standing not far from Delhi \\ Within quicker reach by air or train, \\ Suddenly became a forbidden land \\ Guarded by a sovereign state \\ Of new ideologies, loves and hates. \\ Homes were lost and hearts were bruised \\ In both unhappy parts of Punjab.
}

Nevile 2006: xxix

Pran Nevile, a retired diplomat and writer in his later life, never forgot Lahore, the city of his youth. He reminisces, 'Even after a lapse of over five decades, my emotional attachment to this great city is as deep as ever. My memories of boyhood and youth are still fresh in my mind and are often a subject matter of conversation whenever I sit together with exLahorias of my generation' (2006: xxix). However, Rumi in his eulogy to Delhi, notes how many prominent writers from Lahore never came back to visit the city after migrating. These included figures such as, Krishan Chander, Rajinder Singh Bedi, Balwant Singh and Balwant Gargi; the trauma of seeing their beloved city transformed in the new world was perhaps too much for them (2013: 51).

Similarly Afzal Tauseef, a writer and journalist based in Lahore, moved to Quetta, after her family were killed, unable to come back to Punjab and Lahore until much later in life. The carnage left many members of her family dead during August 1947 and Tauseef is still puzzled about the root cause that led to such a painful division. She was forced to migrate following this massacre; displaced from her ancestral land, she has not to this day come to terms with being uprooted from her home.

my father was so bitter about it. He opted for Baluchistan and left Punjab forever. So for me, my Punjab was my village, which then became a part of India ... Living in Baluchistan made me forget Punjab and Punjabi language. But then I started rediscovering the Punjab ... I was only nine years old and was too young to develop 
any personal opinion about such circumstances. I was just like a scared child simply following the instructions. My father was so disheartened and disappointed. He left it straightaway saying that: 'I don't want to live in here'.

Interview in Lahore, 22 April 2007

Though a child at the time, the irrationality of partition shaped Tauseef's views and it was only later on in life that she was able to come back and live in the Punjab. There was much bitterness in her experiences, understandably shaped by the massacre of her family, but then subsequently shaped by the new state of Pakistan. The expectations of the new state were high and millions had paid the price for the creation of Pakistan and so the gradual deterioration of state institutions has created a class critical of the regime; a class that is trying to understand and reconcile itself to a bitter legacy of partition that has persisted for nearly seventy years.

\section{Reimagining the land, language and religion}

While the partition of Punjab addressed the needs of the Muslims of India, the territorial division itself has created a much more unintended outcome that of a more communalised and fractured post-colonial Punjabi identity. As noted earlier, Punjab was made up of three main communities, Hindus, Muslims, Sikhs and a smaller number of other minorities. Rammah powerfully argues that the Muslim-Hindu-Sikh mix in Punjabi society ceased to exist once Punjab was divided (2006: 215). The 1947 Partition and subsequently the linguistic reorganisation and further division of East Punjab in 1966, has created territories which are now associated with three 'unmixed' religious communities. Thus Pakistan Punjab is predominately Muslim; Indian Punjab is dominated by Sikhs; and Haryana and Himachal Pradesh (previously part of eastern Punjab) are now dominated by the Hindus. Post-1947 Punjab(s) today reflect the fault lines created in colonial India and remain divided religiously and linguistically. However, recent scholarly work has started to challenge this dominant discourse of Punjabi society that is still quite complex given the huge population transfers that have taken place.

One of the most important features of any ethnic group is language which binds and brings the cultural history of those people together to form a cohesive group of people with a shared sense of its past. Punjabi interestingly was never given state patronage; this is true for the Mughal period, Ranjit Singh's reign and also under the British. The preferred state or official languages were Persian and Urdu (Malhotra and Mir 2012: xxix). Mir argues that part of the problem under the British was the plurality of the scripts used to write Punjabi; all three scripts (Indo-Persian, Gurmukhi and Devanagari) were used but none of them dominated (2010). Yet despite this anomaly, Punjabi continued to be the language of the masses and reached into wider Punjab (from Peshawar to Delhi), albeit in different dialects but broadly comprehensible. But it is the plurality in written Punjabi that causes friction and provides the space for further divisions in the post-colonial context. It is within this context that the language, the people and the land become further sub-divided to reflect both national and in the case of Sikhs, sub-national, identities. This produces three distinct outlooks: Hindi, Hindu, Hindustan; Urdu, Muslim, Pakistan; and Punjabi, Sikh, Khalistan (Kalra 2014: 3). The Hindu Punjabi has therefore been absorbed into the wider Hindutva project; the Muslim Punjabi (in West Punjab) has abandoned the Punjabi language in favour of the more 'Islamic' Urduised identity; and interestingly it is the Punjabi owning and speaking Sikhs that have become synonymous with the Punjab and Punjabi identity. Yet in reality it is also the mother tongue of the majority of Pakistanis and many Hindu Punjabis. 
The connection of language and religion has therefore come to define the post-colonial landscape in Punjab. While these are simplified stereotypes of the divided people, more broadly they are symptomatic of the communalised politics of the sub-continent and more specifically, they are much more peculiar to the Punjab region. For example Tariq Rehman has shown how 'Soon after the creation of Pakistan, Punjabi vanished as a University subject. Because of its association with Sikhs and due to the state's promotion of Urdu, Punjabi was relegated to the periphery' (Rammah 2006: 216). It is difficult to think of another region in the sub-continent that has shunned its own linguistic and ethnic history in favour of a national or religious identity. People like my own parent's generation who epitomised the pluralistic land of Punjab are fewer and fewer. There are hardly any people of my father's generation left in Indian Punjab; as child I never found it strange that my father made most of his notes in the Indo-Persian script despite being a Sikh. As Bhardwaj (2012) notes, 'in East Punjab, Urdu became a casualty of Punjabi.' The prescriptive orthodoxy symbolising Sikhism today is also unfamiliar to many, including myself. My mother, who was a practising Sikh, had embraced 'other' practices to epitomise the pluralistic tendencies associated with the Punjab that I am familiar with. Similarly Bhardwaj has tried to unearth some of the hidden histories of a composite Punjab, which belies the dominant narrative. He recalls this story:

Behind my grandparents' house in our village Akalgarh, in district Ludhiana, is a narrow street. To this day it is called Rajputan de Gali (the street of the Rajputs). This is where the influential community of 'Rajput Muslims,' as they were addressed, lived before Partition. The villagers' reference to the Maseet Wala Gurdwara (literally the mosque turned gurdwara) is yet another symbol of the once powerful presence of Muslims in Akalgarh. Similarly, there is a pond called Taru Shah da Toba, named after a wandering fakir Taru Shah, who preferred to stay on in our village. Over the years his shrine in the old graveyard has grown in size and stature. Yet there are no Muslims in the village.

Partition has enabled this rewriting of history that is now constructed through a lens that is linear and mono-religious in its outlook. Both India and Pakistan have been trying to erase and rewrite their shared past; the forced migration resulted in the separation of people and lasted a few months but the project to rewrite these histories has been more complex and subtle. Churnjeet Mahn, in a recent project, has been exploring this cultural amnesia towards contested sites and how Sikh and Muslim sites co-exist in post-1947 along the Grand Trunk Road (see the project website: www.thegtroad.com). Retelling this story in the post-1947 Punjab also means erasing 'other' histories. But as Bhardwaj highlights, these new imagined localities still retain a connection with their previous history despite renaming of places. For example in Lyallpur, old Sikh localities are still known as Gurunanak Pura and Gurugobind Pura, despite the out-migration of all the Sikh community. Malhotra and Mir's work interestingly tries to delve into some of these complexities which have shaped contemporary Punjab(s). Memory and nostalgia for a glorious past continue to resonate beyond the divided boundaries, as they note, 'For many of the Partition's refugees, while the physical relationship with land/people was irrevocably lost, their "Punjab" would live on in their imaginaries, and in the new world they constructed for themselves.' For example names given to refugee colonies of Delhi: Gujranwala, Bhera or Punjabi Bagh...or the other is conversation opener, 'tussi pichhon Kithon de ho?' (where are you from?), which is a clear 
reference to where were you from before partition (Malhotra and Mir 2012: xxv-xxvi). Naming places after former villages, towns or cities helps embed and memorialise the past in the present and Bhardwaj's work alludes to the presence of the past in the present. Yet both these highlight the complex history of migrations in Punjab and moreover the mixing and unmixing of people before and after 1947.

\section{Making new histories}

This regional history, highlights the transformation and legacies of that moment in time, when as Mushirul Hasan says; 'never before, in South Asian history did so few decide the fate of so many and rarely did so few ignore the sentiments of so many in the subcontinent ... never before in South Asian history did so few divide so many, so needlessly' (1993: 4243). The longer-term repercussions of this violent beginning for India and Pakistan have overshadowed the trauma and dislocation felt by millions of innocent people who were forced to flee their homes. While the process of carving up India was pre-planned, the exchange of population was not; though disruption and violence were expected, the ability to deal with them was inadequate and while New Delhi and Karachi celebrated their new existence, neither thought this would be the source of such hostility between the two countries. The legacy of decolonisation in India has therefore had ramifications far beyond merely transferring power. This was not just a physical separation but a division of people, emotions, ancestral lands and properties; it was a partitioning of people whose primary identifier now was their religious identity, while their caste, class, linguistic or ethnic identity had been receded, albeit temporarily. In reality the process had started in colonial Punjab, with increasing communalisation of identities. Revivalist groups were important in awakening and constructing essentialised religious identities among people who had previously adopted a more pragmatic attitude. And it is within this context that more broadly it is about the transformation of a region which has not just been demographically altered but that it also now tells us a different history. It is now a revised post-1947 history that fails to adequately acknowledge the shared cultural roots and traditions of the broader ethnic identity.

It is of course impossible to talk about independence and partition without mentioning the accompanying violence, at its height in August 1947. The bitter legacies of this have developed into bitter memories and relationships. Interestingly though, this is much more prevalent at the national and 'official' level rather than at a human level. The people, however, are most bitter about the lack of contact and travel restrictions, which keep them separated. Furthermore, given the levels of violence in 1947, it is interesting that in post-colonial India, the communal violence that has overshadowed much of the secularist history has largely been absent in Punjab. Though in Punjab, the militancy period of 1980s and the movement for Khalistan has been particularly violent and bitter; some would trace the history of this back to the unresolved aspirations of a Sikh State and 1947.

Finally in the making of these new histories, one aspect that stands out in the new globalised world is the widespread impact of migration. Earlier in the chapter there was a brief discussion of how refugees often find small ways of preserving their histories and memories in their 'new' homes. This has allowed them to remain connected with a past, which is forever fractured. Others, however, decided to completely break with history and chose to migrate abroad. There is evidence that this great migration led to further migrations, both internally to other states and abroad like post-war Britain, which at the time was short of labour and was an attractive option for those looking to escape the trauma of partition (Tan and Kudaisya 2000: 231-232). According to estimates by Tan and Kudaisya, 
between 8 and 10 per cent of all Sikhs had migrated overseas by the end of the 1950s and another 30 per cent were living within India but outside Punjab in towns and cities of adjacent provinces and in the capital of Delhi.

And it is within the diaspora that much of the recent scholarship on memory, trauma and partition has been emerging. Though they escaped the immediateness of the sites that were associated with the violence and dislocation, the memory associated with the land has not escaped. The generation that has grown up listening to stories of partition has prompted some people to at least explore this history. Bhalla, a US-based physicist, 'grew up listening to these stories from her grandmother who remained traumatized till her death. She regretted not having recorded them and this prompted her to start the 1947 Partition Archive' (Arshad 2013). The oral history project has been busy collecting first-hand accounts from a fading generation.

The loss associated with partition is also made worse by any lack of closure or any form of official recognition for what happened. People were forced to flee and many thought they would return to their home but most never did and this sudden fracture was never allowed to heal properly. The suffering therefore has largely been a private matter, until more recently with the digital revolution allowing people to share their stories across the borders and religious boundaries. But it is the dreams, memories and legacies of partition that Balraj Sahni, a prominent Indian actor and a migrant from Rawalpindi, captures so evocatively in his poem and continues to haunt many. It was written during his visit to Amritsar in 1951 and it draws on much of the pain and loss associated with partition:

You are those with a country; you are those with homes

We are homeless; we are estranged

You smiled and took us to your breast

We cried and took consolation

The faded stars, twinkled once again

What we did not hope for, was made possible by your warmth

May my city live, and its people thrive

We came and pray for this as we now depart

All our pockets are empty!

We carry nothing with us as we leave.

Half a heart repines here

Half a heart lies neglected there.

The paths, for which our hearts once beat

For those paths we became strangers.

What of our becoming human beings,

We have turned into Hindus, Sikhs, and Muslims.

Sahni 1963 [2006]:89

\section{Notes}

1 The Punjab region was the major recruitment area for the Indian Army during colonial rule. By the time of World War I, over 50 per cent of the army recruitment was from Punjab (Yong 2005).

2 In the lead up to the violence in March 1947, the Muslim League had been pursuing a campaign, 'Direct Action Day', against the incumbent Khizr Ministry in the Punjab. When the Ministry resigned on 2 March it was amid growing unrest in the district. Aiyar (1995) suggests that the 
March violence showed signs of a move towards organised violence and the emergence of 'private armies' in carrying out formulated plans.

3 These figures are for the district, but most of the industry was located in the city. In Amritsar, Muslim workers accounted for 90 per cent of workers in scientific engineering, 83 per cent of wood workers and 79 per cent in the glassware sector. In Jullundhar, 90 per cent of the workers in the hosiery industry were Muslim and in Ferozepur 80 per cent of the workers in the textiles industry were Muslims (Luthra 1949: 32).

\section{References}

1947 Partition Archive (n.d.) http://www.1947partitionarchive.org/ [Accessed July 2014]

Abid, Q. and Abid, M. (2011) 'Boundary Commission tilting in favour of "other factors"', Pakistan Vision, 12 (2): 36-65.

Address by Quaid-i-Azam Mohammad Ali Jinnah at Lahore Session of Muslim League, March, 1940, Islamabad (1983) Directorate of Films and Publishing, Ministry of Information and Broadcasting, Government of Pakistan, Islamabad, 5-23.

After Partition (1948) The Publication Division, Ministry of Information and Broadcasting, Government of India, 59.

Aiyar, S. (1995) “August anarchy” the partition massacre in Punjab 1947', South Asia, 18 (1): 13-36.

Ali, I. (1988) The Punjab Under Imperialism 1885-1947, Princeton, NJ: Princeton University Press.

Ali, N. (2011) 'The poets we forgot', Tribune, 31 December, http://tribune.com.pk/story/314225/thepoets-we-forget/. [Accessed July 2014]

Anon. Tribune (Simla) 13 December 1947

Arshad, S. (2013) 'Partition stories, in first person', The Times of India, 27 October, http://timesofindia. indiatimes.com/home/stoi/deep-focus/Partition-stories-in-first-person/articleshow/24771616.cms. [Accessed July 29 2014]

Bhardwaj, A. (2012) 'The absence in Punjabiyat's split universe', The Hindu, 15 August, http:// www.thehindu.com/opinion/lead/the-absence-in-punjabiyats-split-universe/article3772133.ece. [Accessed July 29 2014]

Bhasin-Malik, K. (2007) In the Making. Identity formation in South Asia, Gurgaon: Three Essays Collective.

Brass, P. (2003) 'The partition of India and retributive genocide in the Punjab 1946-47: means, methods and purposes', Journal of Genocide Research, 5 (1): 71-101.

Census of India (1941) Delhi: Manager of Publications.

Census of India (1951) Delhi: Office of the Registrar General.

Census of Pakistan (1951) Karachi: Manager of Publications, Government of Pakistan.

Chattha, I. (2012) 'Competitions for resources: partition's evacuee property and the sustenance of corruption in Pakistan', Modern Asian Studies, 46 (5): 1182-1211.

Chester, L. (2002) 'The 1947 partition: drawing the Indo-Pakistani boundary', American Diplomacy, 7 (1), Published online. [Accessed 29 July 2014]

Chester, L. (2009) Borders and Conflict in South Asia. The Radcliffe Boundary Commission and the Partition of Punjab, Manchester: Manchester University Press.

Darling, M.L. (1925 reprint 1977) The Punjab Peasant in Prosperity and Debt, Delhi: Manohar.

Dhiman, R. (1962) Punjab Industries, Ludhiana: Dhiman Press of India.

Frank, M. (2011) 'Fantasies of ethnic unmixing: population transfer and the collapse of empire in Europe' in P. Panayi and P. Virdee (eds), Refugees and the End of Empire: Imperial Collapse and Forced Migration during the Twentieth Century, Basingstoke: Palgrave Macmillan.

Gilmartin, D. (2004) 'Migration and modernity: the state, the Punjabi village, and the settling of the canal colonies', in I. Talbot and S. Thandi (eds), People on the Move: Punjabi Colonial and Post-colonial Migration, Karachi: Oxford University Press.

Hanson, A.B. (2002) 'The Punjab 1937-47 - a case of genocide?', International Journal of Punjab Studies, 9 (1): 9-12.

Hasan, M. (ed.) (1993) India's Partition: Process, Strategy, Mobilisation, New Delhi: Oxford University Press.

Hasan, M. (1997) Legacy of a Divided Nation: India's Muslims since Independence, Delhi: Oxford University Press.

Kalra, V.S. (2014) 'Punjabiyat and the music of Nusrat Fateh Ali Khan', South Asian Diaspora, 6 (2): 179-192. 
Kamra, S. (2002) Bearing Witness. Partition, Independence, End of the Raj, India: Roli Books.

Kamran, T. (2007) 'The unfolding crisis in Punjab, March-August 1947: key turning points and British responses', Journal of Punjab Studies, 14 (2): 187-210.

Kaur, R. (2007) Since 1947: Partition Narratives among Punjabi Migrants of Delhi, Delhi: Oxford University Press.

Keller, S. (1975) Punjab Uprooting and Social Change: The Role of Refugees in Development, Delhi: Manohar.

Luthra, K.L. (1949) Impact of Partition in Border Districts of East Punjab, East Punjab: Board of Economic Inquiry.

Malhotra, A. and Mir, F. (eds) (2012) Punjab Reconsidered: History, Culture, and Practice, New Delhi: Oxford University Press.

Manto, S.H. Toba Tek Singh (1955) trans. A. Bhalla (ed.) (1999) Stories about the Partition of India, New Delhi: HarperCollins.

Mir, F. (2010) The Social Space of Language: Vernacular Culture in British Colonial Punjab, London: University of California Press.

Nair, N. (2011) Changing Homelands: Hindu Politics and the Partition of India, Cambridge, MA: Harvard University Press.

Nanda, J. (1948) Punjab Uprooted: A Survey of the Punjab Riots and Rehabilitation Problems, Bombay: Hind Kitab.

Nevile, P. (2006) Lahore. A Sentimental Journey, India: Penguin.

Pandey, G. (2001) Remembering Partition. Violence Nationalism and History in India, Cambridge: Cambridge University Press.

Rai, S. (1965) Partition of the Punjab: A Study of its Effects on the Politics and Administration of the Punjab 1947-56, Bombay: Asia Publishing House.

Rammah, S. (2006) 'West Punjabi poetry: from Ustad Daman to Najm Hosain Syed', Journal of Punjab Studies, 13 (1 and 2): 215-228.

Rumi, R. (2013) Delhi by Heart, New Delhi: HarperCollins.

Sahni, B. (1963) Mera Pakistani Safarnama, trans. G. Schreffle (2006), Journal of Punjab Studies, 13 (1 and 2): 89.

Singh, K. (ed.) (2006) Select Documents on Partition of Punjab - 1947, Delhi: National Book Shop.

Singh, R. (1962) The Military Evacuation Organisation 1947-48, New Delhi: Government of India.

Talbot, I. (1996) Khizr Tiwana: The Punjab Unionist Party and the Partition of India, Surrey: Curzon.

Talbot, I. (2006) Divided Cities: Partition and its Aftermath in Lahore and Amritsar 1947-57, Karachi: Oxford University Press.

Talbot, I. and Singh, G. (eds) (1999) Region and Partition. Bengal, Punjab and the Partition of the Subcontinent, Karachi: Oxford University Press.

Tan, T.Y. and Kudaisya, G. (2000) The Aftermath of Partition in South Asia, London: Routledge.

Tatla, D.S. (1995) 'The sandal bar: memoirs of a Jat Sikh farmer', The Panjab Past and Present, 29 (1 and 2): 160-175.

The Grand Trunk Road: www.thegtroad.com. [Accessed 29 July 2014]

Virdee, P. (2007) 'Partition in transition: comparative analysis of migration in Ludhiana and Lyallpur', in A. Gera and N. Bhatia (eds), Partitioned Lives: Narratives of Home, Displacement and Resettlement, Delhi: Pearson.

Yong, T.T. (1997) “'Sir Cyril goes to India”: partition boundary-making and disruptions in the Punjab', International Journal of Punjab Studies, 4 (1): 1-20.

Yong, T.T. (2005) The Garrison State. The Military, Government and Society in Colonial Punjab, 1849-1947, New Delhi: Sage.

Zamindar, V.F. (2007) The Long Partition and the Making of Modern South Asia: Refugees, Boundaries, Histories, India: Penguin. 


\title{
2 \\ SYMBIOSIS AND RESILIENCE
}

\section{The dynamics of social change and transition to democracy in India}

\author{
Subrata Kumar Mitra
}

India's democracy, with its vast spread, astounding depth and resilience, is remarkable. ${ }^{1}$ By the standard of post-colonial states and transitional states, this is a relatively rare achievement. The centrality of democratic competition in the political process - all political positions in India are elective and nearly all the political forces of the country compete on equal terms in general elections, supervised by an independent Election Commission - is comparable to Western liberal states. With sixteen, largely fair and free general elections already to its credit, few would question India's status as a consolidated democracy. What makes India's democracy work? Why has a common origin from British colonial rule led to dissimilar outcomes in India's neighbours which have found it difficult to sustain democratic regimes.

I argue in this chapter that India's democracy is neither a sham ${ }^{2}$ nor idiosyncratic. ${ }^{3}$ Rather than being sui generis, India's successful transition to democracy is the outcome of general variables like path dependency, adroit institutional arrangement, political management and strategic policy reform. India's democratic process comprising elections, political campaigns, social movements, political contestation through the judicial process and indigenous forms of protest, conflates Western liberal forms and indigenous political traditions. This has created a hybrid political system that fosters a sense of enfranchisement, empowerment and entitlement among the citizens, who have legislative and judicial means to hold the government accountable. India's democracy generates - and feeds off - a widely dispersed sense of social justice, efficacy, legitimacy and political trust. It survives in open competition against its competitors - anti-system parties and extremist ideologies - because it delivers, if not for all and all the time, then, at least for most, and most of the time.

Following decolonization, India in 1947 faced the challenge of transforming subjects into citizens and a poor, diverse and hierarchical society with low literacy and fresh memories of Partition violence into a democratic political system. Though the country sorely lacked the 'pre-conditions of democracy', it still made a successful transition to parliamentary democracy. In India today, support for the ballot rather than bullet, cuts across social classes, castes and party affiliations. The scale, regularity and effectiveness of India's elections have shown the initial apprehensions about the sustainability of democracy in an illiberal context 
to have been baseless. ${ }^{4}$ Despite continued insurgency in Jammu and Kashmir and in the North East, sporadic terrorist attacks with the support of local sympathizers, no one seriously questions the main foundation of Indian democracy, namely elections as the exclusive basis of power and legitimacy.

The reciprocal relation of dynamic social change and democratization of power, and popular elections as the great leveller, are the most significant facts of modern Indian politics. Building on the legacy of social mobilization and the largely non-violent struggle for Independence under the overall leadership of Mahatma Gandhi, the underprivileged groups at the margin of India's hierarchical society have learnt to use the ballot for upward mobility. In consequence, democracy and social change, deeply entangled in a symbiotic process, have become an integral part of the agenda of the modern state, regardless of which political party happens to be in power at a given point of time. Democracy has thus emerged as the most effective method to weave the many strands of the country's complex heritage together in order to produce a nation. The process has become self-sustaining as new generations have replaced those who were part of the anti-colonial agitation, and has become a constitutive element of the post-colonial institutional arrangement.

\section{Transition to democracy and its consolidation}

Ironically, the seeds of a modern democratic system were first planted in India by the British colonial rulers. Sustaining effective rule over a country of continental dimensions with a diverse population required two elements indispensable to a colonial regime, namely, law and order, and some form of representation to generate consent by the subject population. Both of these eventually became the building block of post-colonial democracy. A series of acts of the British Parliament facilitated an increasing involvement of the Indian population through restricted franchise. Colonial rule guaranteed property rights for the elites and recourse to judicial redress in civil and criminal issues for all. The Indian middle class, urban and English educated, grew steadily in numbers and constantly clamoured for representation in various advisory institutions to British colonial rulers, and jobs in colonial bureaucracy. From 1885, the Indian National Congress established by Sir Alan Octavian Hume, a retired civil servant, gave an organizational focus to India's struggle for eventual independence from British rule. Gradually, its leadership passed from the hands of the liberal urban middle classes to leaders from the provinces, who were more adept with the vernacular idioms of politics, and to peasants and workers which broadened the scope of the social agenda. Thus, gradually, though very limited in nature, the modern ideas of individual rights including the right to property and proper legal redress, rudimentary representation and the right to association became part of India's political discourse.

This had deep implications for India's social structure which was organized on the basis of status, and reciprocal social obligations between holders of land and service castes. A new, political linkage made its appearance whereby rural society got steadily polarised between owners of the means of production and workers, creating fissures in the traditional jajmani system, based on status, and structured along the lines of exchange of services. A new sense of aspiration for upward mobility above and beyond station at birth set in, giving rise to the new social function of the broker between the modern state and traditional society. When Independence finally arrived and a new Congress government took power in Delhi, a rudimentary democratic structure was already in place.

This brief incursion into the history of the entanglement of the incremental devolution of power and social change under British rule is important for a comparative understanding 


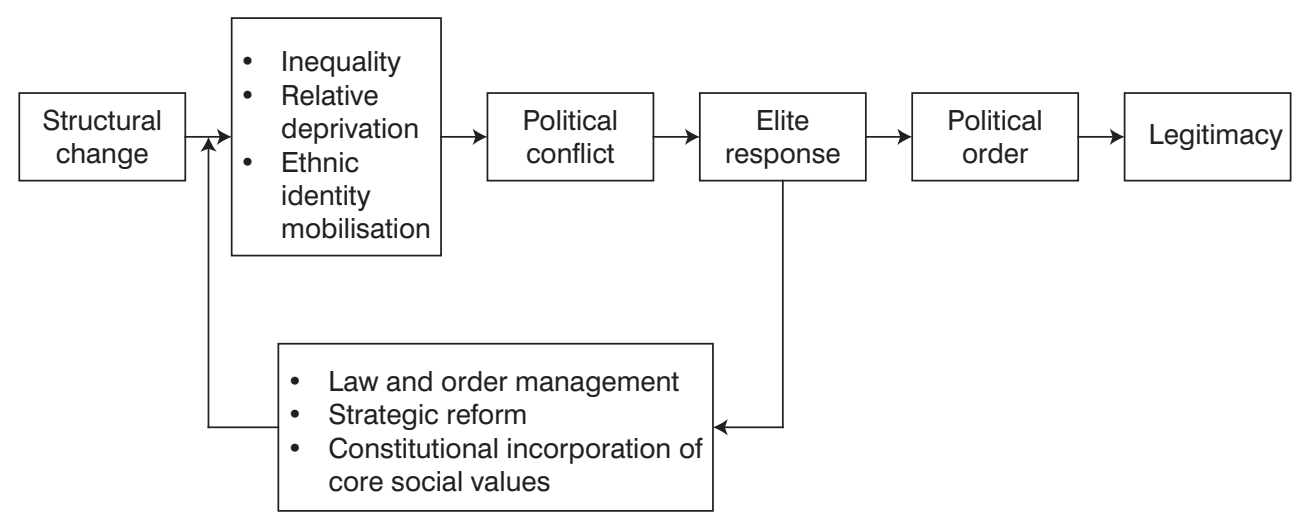

Figure 2.1 A dynamic neo-institutional model of state-society-economy interaction

of the resilience of Indian democracy. To explain India's successful transition from colonial rule to electoral democracy I offer a dynamic neo-institutional ${ }^{5}$ model of economy-society-state interaction (Mitra 2005, 2011a, 2011b, 2012). In this model, the new social elites, themselves the outcome of a process of fair and efficient political recruitment through democratic elections, play a two-track strategy and institute processes of law and order management, strategic social and economic reform and accommodation of identity.

The model seeks to explain why structural changes, from colonial, semi-colonial or communist rule to popular democracy, socialism to capitalism or upper-caste hegemony to multi-caste competition, do not always result in political anarchy. The presence of decisionmaking elites with deep social roots in charge of institutional arrangement of the state, and with an eye for governance, can make the difference. A comparable process was not at work in successor states like Pakistan and Sri Lanka where political elites, in the absence of the need to establish political bonds with workers and peasants, could not play the role of intermediating between state and society effectively. The absence of an indigenous elite with social legitimacy and ministerial experience led to a crisis of authority in transitional societies once the colonial rulers depart which causes the army and the bureaucracy to move in to fill in the void. This can have disastrous consequences for post-colonial democracy. ${ }^{6}$

In contrast to Pakistan, such was not the case in India. Political representation and social mobilization were present in Indian politics towards the last stage of colonial rule in an embryonic form. Both got a boost with the introduction of universal adult franchise in 1947. Since then, electoral participation has steadily increased; more important, the nature of power at the disposal of local and regional bodies has grown dramatically since Independence. Under the overall supervision of an independent Election Commission, Indians today vote in elections to the centre, State and local governments, and at each level, decision-making power is increasingly in the hands of elected politicians. In a calculated move, India's leaders put everything on the auction block of electoral politics right at the outset, in the first general election of 1951-1952. Even the very definition of the nation, its physical boundaries, and the basic principles of its economic organization were not considered over and above politics. The result, as we shall see below, was that the great school of democracy quickly multiplied the numbers of its enthusiastic pupils and continued to produce both knowledge and skill even when the first generation, identified with the coming of Independence, left the scene. 
The first general election to the Lok Sabha was a veritable adventure in democracy. This was the first time that a mammoth electorate of 173.2 million electors was going to the polls. The voter registration, identification and, finally, the conduct of the polls were all to be conducted by the recently established independent Election Commission, with an electoral organization staffed by men and women drawn from many different branches of the public services because no specialized bureaucracy had been foreseen by the Constitution for this purpose. Subsequent elections have maintained the largely peaceful character of the polling process though the deployment of the army has become routine in recent elections. India's elections have assumed gigantic proportions, and have earned an international reputation for being largely free and fair. The level of participation in India's parliamentary elections which has stabilized around 60 per cent is lower than the longer-established and more affluent democracies of Europe. There is, however, considerable regional variation in levels of participation. These trends are particularly visible in elections to the lower houses in the federal States. The level of participation in these elections has also gone up from the modest 45 per cent turnout of the first election to over 60 per cent in more recent elections. Electoral participation in the politically disturbed North East is among the highest in India. In the elections held during 2002-2006, the level of electoral participation in some of them - such as Manipur (90.2 per cent), Nagaland (87.9 per cent), Mizoram (78.7 per cent), Tripura (78.7 per cent), Assam (75.7 per cent) - has produced spectacular results.

Elections and political parties generate a tandem effect between them: one tends to reinforce the other. The introduction of limited franchise by the colonial government towards the end of the nineteenth century had spurred political competition for the seats, leading to the mobilization of the electorate on communal lines. This has an important legacy for contemporary Indian politics. The party system of contemporary India is the result of the six decades of growth under British rule prior to Independence. It is a complex system with the continuous presence of the Congress party in the national political arena, the emergence of a powerful Hindu-nationalist movement, the world's longest elected communist government at the regional level and the occasional lapse into authoritarian rule which, nonetheless, did not become terminal as in the case of the majority of post-colonial societies. The picture becomes much clearer if we divide the post-Independence period into the 'one-dominantparty system' period (1952-1977) and its subsequent transformation into a multi-party system. The relative ease with which India developed electoral democracy and a competitive party system might appear puzzling to those unfamiliar with the pre-Independence record of the Indian National Congress with regard to taking part in elections and its legacy of sharing ministerial office under the 'Government of India Act', 1935. Should the individual be the basis of political representation, or should organic groups based on religion, caste and ethnicity form the basis of representation, and as such, the exercise of power, is a question that had created heated debate among sections of Indians when the notion of restricted franchise was first mooted towards the end of the nineteenth century. The leaders of the Congress party deeply schooled in Locke and Mill had opted early for the same norms of electoral representation as in the British Parliament that they were familiar with and which they much coveted. However, politicians from outside the group of Hindu, upper-caste groups that dominated the Congress party thought otherwise. They feared the tyranny of the majority which they suspected would be the likely outcome of the introduction of electoral democracy based on majority rule. Not surprisingly, political parties which drew their main support from among Muslims and the untouchable groups were keen on proportional representation, which they thought would be a safer basis for the protection of their interests and identities. 
In the event, British policy makers were caught in a double bind - between majority voting rules that they were familiar with - and respect for minority rights, which enjoined the adoption of proportional representation. However, even as the Indian National Congress resented the adoption of proportional representation as the basis of restricted franchise, it nevertheless participated in the elections under colonial rule, gaining in the process valuable experience of electioneering. The issue was finally settled through two fortuitous events. The Partition of India removed the Muslim League as a main player in the Indian political arena and a trenchant advocate of proportional representation. The second event was the famous 'Poona Pact' of 1936 between Gandhi and Ambedkar - the celebrated leader of India's 'untouchable' castes, so called because of their ritually 'polluted' status who was one of the main advocates of proportional representation. The agreement finally led to the setting aside of a quota of seats for the untouchables, and subsequently, tribal communities, under a rule known as 'reservation of seats'. There were thus no obstacles against the principle of majority voting after Independence. The 'Representation of People Act' of 1947 gave due recognition to this rule as the basis of all elections in India except those to the Presidency and the upper house in the central Parliament and State legislatures.

India's electoral campaigns are an excellent demonstration of how political parties develop their strategies to cope with elections based on single member constituencies and franchise based on individual preferences with the existence of castes, tribes and other groups based on collective identities. Factions, short-term alliances of individuals and increasingly, broad-based coalitions are some of the consequences of this complex process of electoral mobilization. Elections and party competition have played a double role by empowering both individuals and groups leading to the continuous creation of new groups and coalitions. The paradoxical co-existence of modern elections and caste alliances and caste consciousness is yet another outcome of the process of electioneering. ${ }^{7}$

Rather than inhibiting the growth of party competition, social conflict, interwoven with political conflict, deepens political partisanship. However, elections based on first-pastthe-post (FPTP) electoral rules, operating in large, single member constituencies which are usually multi-caste and often multi-religious in character, ultimately lead to political moderation on the part of competing parties. Elections with limited franchise under British rule had facilitated political transition by acting as the institutional context in which power was transferred to elected Indian leaders. This experience had become an integral part of the culture and tradition of the Congress party which was able to transform a minority of votes to a majority of seats in the early elections - thanks to a divided opposition. However, that was no longer possible towards the end of the 1960s in State legislative elections and from 1977 in parliamentary elections at the national level because in the meantime, the idea of political coalitions - an efficient method of transforming votes to seats - had become common currency among parties opposed to the Congress party. Its inability to come to terms with this new development cost its electoral prospects dearly as one can see from the electoral outcomes in the 1990s. However, the Congress party eventually learnt to play the coalitional game and was handsomely rewarded for its efforts in the parliamentary elections of 2004, and in 2009 winning enough parliamentary seats in order to form the government.

Post-Independence acceleration of social change led to a smooth transition of leadership when the generation from the freedom movement was replaced by younger leaders, many of whom came from upwardly mobile, newly enfranchised, lower social classes. The entry of the peasant-based, backward caste parties in the 1960s and the Bharatiya Janata Party, widely seen as the party of business and industry, into government brought these groups closer to power. All sections of Indian society thus have links to the structure of power 
at one time or another, if not in the national arena, then at least in one or more regional governments. Drawing on survey data provides the basic information about the distribution of support to the main political parties across social formations.

The social base of the Congress party cuts across all social groups and cleavages of India, making it India's quintessential catch-all party. Nevertheless, Congress has relatively greater support in the lower social classes and among religious minorities. The social profile of the Hindu-nationalist BJP presents a sharp contrast. Initially, it was very much a party of the 'Hindu-Hindi-belt' which normally indicates the north Indian Gangetic plains. Of late, it has spread out of this regional base and formed government in the West (Gujarat), and the South (Karnataka). The BJP continues to be a party of the upper social order and Hindu upper castes, but has nevertheless already succeeded in extending its reach to the former untouchables, backward classes, tribals and even to a small section of Muslim voters as well. By the standards of its national support base, the Left consisting of both the Communist parties (CPM and CPI) attracts proportionally more support from the lower social classes as well as support from the more educated voters. The rise of India's regional parties is a comparatively recent phenomenon. Like the Congress, in the regional context these parties cut across all social groups and compete with the Congress for the same social base, except for the Other Backward Classes (OBCs), a social group sandwiched between the Hindu upper classes and the former untouchables. The leaders of many of India's regional parties are drawn from the OBCs which correspond to the service castes (shudra in terms of the varna category). At Independence, the introduction of universal adult franchise empowered underprivileged social groups with a new political resource. The right to vote by secret ballot, exercised at a polling booth conveniently located at a public place where one could vote freely, created an environment which was helpful for political participation. The right to vote in secrecy and without coercion acted as a direct challenge to social dominance posed by newly mobilized lower castes and religious minorities who felt empowered thanks to the value of the vote.

Social mobilization and its political containment, largely though not exclusively, within the framework of political institutions appear to have taken place in India as two independent but ultimately convergent processes. The pace of social change has accelerated through social reform legislation, recruitment of new social elites into the political arena and the political mobilization through electoral participation. Their overall impact on the stability of the political system has been moderated by intermediary functions and parties at the regional and local levels. Lloyd and Susanne Rudolph have described the process as vertical, differential, and horizontal mobilization. ${ }^{8}$ Typically, as the marginal social groups discovered the negotiable value of the vote during the early years after Independence, they became avid players in the political arena at the local and regional levels. Established Jajmani systems reciprocal social bonds based on the exchange of service and occupational specialization - broke down to create new groupings. Finally, caste associations, based on shared social and economic interests emerged as links between parties and the society. ${ }^{9}$ This has created useful room to manoeuvre in the hands of national, regional and local elites. ${ }^{10}$

In sum, based on the previous discussion, one can ask, what makes Indian democracy work, and why does it fail, sometimes? What significance does India's counter-factual democracy hold for general theories of democracy transition and consolidation? Three arguments that follow help us understand how India's democratic process has acquired the capacity to learn from its lapses and take corrective measures which makes it self-sustaining. 


\section{Electoral mobilization and unfettered participation}

Regular and effective elections, based on universal adult franchise to all important offices and institutions at the central, regional and local levels of the political system are one of the most significant factors to explain the success of India's electoral democracy. India's powerful and independent Election Commission, ${ }^{11}$ ably supported by the Supreme Court ${ }^{12}$ and a watchful and litigious civil society, ensures that elections remain largely free and fair. Elections have helped induct new social elites in positions of power, and replace hereditary social notables. The electoral process from its early beginnings about six decades before Independence has grown enormously, involving a massive electorate of about 815 million men and women (2014), of whom, roughly 60 per cent (66 per cent in the 2014 election) take part in the polls. The fact that terrorist attacks and insurgency have not been able to thwart competitive elections speaks to the strength of India's electoral processes.

While the constitutional structure of India's elections has remained more or less constant over the past six decades, the electoral process - evidence of the dynamism of social empowerment - has undergone significant changes. The general elections of the 1950s were dominated by traditional leaders of high castes. However, as the logic of competitive elections sank in, cross-caste coalitions replaced 'vote banks' that were based on vertical mobilization, where dominant castes dictated partisan preferences to lower social groups. 'Differential' mobilization of voters, which refers to the coming together of people from different status groups, and 'horizontal' mobilization, where people of the same status group coalesce around a collective political objective, have knocked vertical social linkages out of the electoral arena. Today, sophisticated electoral choices based on calculations that yield the best results for individuals and groups are the rule. Electoral empowerment has brought tribes and religions in all social strata into the electoral fray.

Differential and horizontal electoral mobilization of socially marginal groups has resulted in policy changes that further demonstrate the deepening of democracy in India. Successive governments have introduced laws to promote social integration, welfare, agrarian relations and social empowerment. Over the past two decades, broad-based political coalitions have forced more extreme forms of Indian politics, such as the champions of Hindu, Sikh, Muslim, or for that matter, linguistic and regional interests, to moderate their stance.

\section{Election-reinforcing institutional arrangements and countervailing forces}

India's record at successful state formation and, more recently, the progressive retreat of the state from controlling the economy, but without the ensuing chaos seen in many transitional societies caught in similar situations, speak positively of the validity of the country's institutional arrangements which effectively protect India's electoral democracy. These institutional mechanisms are based on constitutional rules that allow for elections at all possible levels and areas of governance, and therefore promote, articulate and aggregate individual choice within India's federal political system. Since the major amendment of the Constitution in 1993 that created an intricate quota system, India's 600,000 villages have become the lowest tier of the federal system, bringing direct democracy to the doorstep of ordinary villagers and guaranteeing the representation of women, Dalits, backward castes and tribal members.

The juxtaposition of the division and separation of powers, the fiercely independent media and alert civil rights groups, and a pro-active judiciary, have produced a level playing 
field to facilitate democratic politics. Many of these are colonial transplants that have been adapted by repeated use and re-use to local custom and need (Mitra 2011a). It is significant to note that India's main political parties do not question the legitimacy of India's modern institutions. Although they differ radically in their ideological viewpoints, parties such as the Communist Party, Hindu-nationalist parties like the Shiv Sena and the Bharatiya Janata Party, all share the norms of democracy. Not even parties that draw their strength from mobilizing religious cleavages or class conflict issues object to democracy. Therefore the right to democratic participation is no longer considered an exotic idea.

\section{Asymmetric but cooperative federalism}

India's federation has simultaneously succeeded in differentiating the political and administrative landscape of India, while holding on tightly to the unity and integrity of the state as a whole. Cooperation among units widely different in size rather than the dominance of large regions or, indeed, of an almighty central government is a striking feature of the Indian federation. The boundaries of the federal States have been re-drawn on the lines of mother tongue, making regions coherent cultural and political units. The fears of 'balkanization' (Harrison 1960) that marked the rise of language movements in the 1950s have not borne out. Meanwhile the regional arena has emerged as the most crucial unit of India's electoral arena and has endowed regional parties with an extra measure of power.

The Indian state has devised an ingenious system of enhancing stability of the political system through a combination of federalisation and other forms of power-sharing. By creating new regional and sub-regional governments, federal units can be rearranged. Short-term, constitutionally permitted central or even army rule can substitute representative government when the regional political system is unable to sustain orderly rule. Such emergency rule at the regional level is usually withdrawn when the need for the suspension of the normal functioning of parliamentary politics is no longer tenable. The legal responsibility for law and order rests primarily with the regional government, but is under the watchful eye of the centre. While the State governments control the regional police, the Constitution of India provides for their superseding by direct rule from Delhi when they fail to maintain lawful governance.

In brief, the successful transformation of a colonized population into citizens of a secular, democratic republic, has contributed to the sustainability of electoral democracy. The main strategy has consisted in the encouraging of rebels, the alienated and the indifferent to become national stakeholders. The strategy's components are: (a) India's institutional arrangement (the Constitution), (b) laws meant to implement the egalitarian social visions underlying the Constitution, (c) the double role of the state as a neutral enforcer and as a partisan supporting vulnerable social groups in producing a level playing field, (d) the empowerment of minorities through law and political practice, including India's personal law which guarantees freedom to religious minorities to follow their own laws in the areas of marriage, divorce, adoption and succession, and, finally, (e) judicialization which safeguards individual and group rights.

Such is the power of electoral dynamics in India and so deep-rooted is the process that even when democracy fails as in the case of violent riots, insurgency or governmental instability, these remain localized and soon enough, electoral democracy bounces back. In response to such cases three points deserve our attention. First, so far, India has been generally successful in containing, if not solving such protracted issues as the secessionist movements in many of India's regions, including Jammu and Kashmir, within the structure of the democratic 
constitution. Second, the cleavages and conflicts tend to be local and regional rather than national. They also tend to be cross-cutting where those who are opposed to one another on one cleavage might find themselves in alliance on a different issue, rather than cumulative where advantages as well as disadvantages cumulate in specific social groups. Finally, the rhetoric of the leaders of such movements, even when radical and strident, is deeply ensconced within the conceptual framework of electoral democracy. Rather than leaning towards religious fundamentalism, they point more towards power-sharing, in sharp contrast to millenarian-totalitarian movements such as Afghanistan's Taliban or Sri Lanka's LTTE.

\section{Institutions and social mobilization as the twin bedrocks of democracy}

While India's democratic achievements are impressive, the size of the electorate or regularity of elections are necessary but not sufficient conditions for a functioning, democratic society. What matters much more in global ranking today is the ability of democratic regimes to sustain good life. In the age of global flow of culture, the very definition of good life itself has changed. More than merely the basic needs, dignity of the individual, sanctity of the sacred, and cultural freedoms have emerged as additional criteria for basic minimum material needs. India's record on basic needs is quite dismal, bypassed by several Sub-Saharan African countries that do not boast democratic rule, not to talk of East Asian 'tigers' (Drèze and Sen 2013). However, as we have seen, the widespread discontent arising out of these issues rather than cumulating in a revolutionary movement to overthrow the system, is transformed by India's competitive political system into political resources at the disposal of competing political parties which in the long run enhances the legitimacy of the democratic political system. The biggest challenge that India's democracy faces today is how to achieve these goals without reneging on the very premises of electoral democracy.

Strategic social and economic reform, within the framework of the Constitution as suggested in Figure 2.1, can vastly enhance administrative efficiency and political legitimacy. Of course, measures like 'direct cash transfer' or the 'Mahatma Gandhi National Rural Employment Guarantee Act' where the state guarantees at least 100 days of paid work to at least one member of families below the poverty line have helped broaden the social base of democratic rule. A further armoury in the repertoire of the state is the discovery of what people in their localities consider sacred, and to weave that into the larger structure of the modern state.

The management of religious institutions and practices, under the federal division of powers, is currently on the State List under the federal division of powers. However, it is high time to move that to the Concurrent List so that national legislation and a national coordinating body for the country as a whole, responsible for orderly management of religious affairs for each religion in the country, can be put up. The authorities responsible for law and order management can then have proper interlocutors within each religion to negotiate issues like construction of new places of worship or renovation of existing ones, regulating practice when it impinges on the public sphere and, most important of all, in negotiating acceptable solution when it comes to conflict on ownership of places of worship. Appropriate, functional, innovative institutions, seamlessly connecting the modern state and traditional society, conflating time tested wisdom with new, global knowledge can deepen and broaden the scope of electoral democracy.

Three factors - an awareness of the usefulness of political parties, overlapping social bases and overall value consensus among party supporters - explain why this unusual combination of partisanship, governmental coherence, and policy continuity despite governmental change 
has been possible in India. In addition to the modern forms of interest articulation, there are also indigenous variations of this as well. The tradition of unconventional direct action has spawned many variants. Demand groups supplement their political repertoire with several modes of direct action. These include forms of direct collective protest action which include satyagraha, hartal, bandh, dharna gherao, jail bharo and rasta roko. ${ }^{13}$ These are supplemented by social movements. For example, the Chipko-movement in northern India fought for the protection of the Himalayan forests. ${ }^{14}$

This has led to the emergence of a new social class of mediators in the political process, generally called the 'social activists', who are often upper and middle class in their social origin but who identify themselves with the lower orders of society, a whole variety of social strata ranging from the untouchable castes to the destitute among the tribes and ethnic minorities. There is a new genre of 'movements' in India which, while having an economic content, are in practice multidimensional and cover a large terrain. This includes the highprofile environmental movements, the women's movement, the civil liberties movement, movements for regional self-determination and autonomy and the peasants' movement. Other groups focus on peace, disarmament and denuclearization. Movement politics has appeared as the 'power of the powerless'. The synergy between political mobilization of potential beneficiaries and vote-seeking political parties has become the engine for change in India, leading to game-changing social legislations. ${ }^{15}$

\section{Conclusion: institutional re-arrangement to deepen electoral democracy}

Despite its continental dimensions, massive elections, its social context of ethnic and conflict-ridden diversity and deeply embedded inequalities based on caste, gender, religion and tribe, India has succeeded in the consolidation of electoral democracy. This has been brought about through a political process ensconced in a hybrid political culture that dovetails modernity and tradition. At the heart of the political process are hinge institutions like the Supreme Court, the Election Commission, the Parliament and a few others that seek to generate a level playing field where power can be shared by a constantly increasing body of stakeholders who constitute India's political community. But, what can be done about democracy-corroding pathologies such as corruption, terrorism, policy paralysis and hard core poverty, without compromising the canons of democracy in the process?

As one can see in the contained but enduring insurgency in Kashmir and the North East, Maoist violence in Central and Eastern India, and sporadic Hindu-Muslim conflict, India still faces the challenge of how to reconcile democracy, governance and collective identity. India's social and economic cleavages sometimes manifest themselves in complex combinations of ethnic conflict, secessionist movements, inter-community violence and terrorist attacks. There is nothing inherently anti-democratic about the vast majority of such political acts. In India, even putatively anti-democratic actors like convicted terrorists appeal through normal channels of judicial redress for their democratic rights. ${ }^{16}$ If one overlooks the element of rank opportunism in the use of democratic means by those opposed to parliamentary democracy and takes into consideration the vigorous defence put up for them by India's active civil society and judiciary, one can understand how this eventually deepens and broadens the scope of the democratic political system and process. Context matters. After all, politics in India, as indeed politics anywhere, is about the relentless quest for power. But, for reasons of path dependency and the other factors discussed above, more than in most transitional societies it is in the Indian context that democracy has become the fortuitous side-effect of the normal competition for power. We 
learn from the Indian case that electoral democracy can turn rebels into stakeholders. ${ }^{17}$ The crisis of electoral democracy can be an opportunity to engage in some serious institutional redesigning to keep the ball rolling, and protect the gains of democratization.

Indian democracy has made great strides in terms of the expansion of participation from the core groups to whom the British had transferred power and generated an inclusive community where different social groups can compete under equal conditions for the exercise of power. The success of India's democracy, properly understood, has important significance for democracy in South Asia, as well as for broader democracy theory. It shows that strategic reform, accountability and social policies that balance efficiency with justice, can sustain the progress in democracy and development in a post-colonial context. India's successful conflict-resolution, compared to other new democracies has been immensely helped by the fact that social groups tend to overlap, and that key intermediaries for conflictresolution such as the judicial system and party politics have been available for a considerable length of time prior to Independence.

In the final analysis, elections are necessary but not sufficient to make democracy work. One needs a continuous adaption of institutions to the changing environment so as to make them relevant and appropriate to sustain a level playing field. This is the general lesson to be learnt from the Indian experiment.

\section{Acknowledgments}

I am grateful to Radu Carciumaru, Knut A. Jacobsen and Jivante Schöttli for their comments on an earlier draft. The technical assistance of Ayesha Wijayalath is deeply appreciated.

\section{Notes}

1 For many, as Niraja Gopal Jayal and Pratap Bhanu Mehta argue, India's democracy remains a 'curiosity' and an 'outlier', when seen in the light of 'most theories of democracy that look at structural variables - such as class structure, extent of ethnic diversity, level of income and education - to predict the prospects of a country instituting and remaining a democracy' (Jayal and Mehta 2010: xv).

2 Indicators of the success of India's democracy such as the sense of political efficacy on the part of ordinary citizens, a widely spread sense of legitimacy and trust in political institutions, garnered from meticulous survey-based evidence are seen as the main assets of democracy in India (Kohli 2001, State of Democracy in South Asia (SDSA) 2008, Mitra and Singh 2009).

3 'The default explanation' is to argue that Indian democracy is a sui generis phenomenon, a case of Indian exeptionalism (Jayal and Mehta 2010: xv). See Mitra (2013a) for my critique of Indian exceptionalism.

4 Most prominent among them are Selig Harrison (1960) who predicted the end of parliamentary democracy in a miasma of ethnic strife and balkanization, Barrington Moore (1966) who anticipated peaceful paralysis or worse, and Ayesha Jalal (1995) who saw dangerous common trends of authoritarianism, based either on personal rule or party ideology, in both India and Pakistan.

5 Neo-institutionalism is a theory, which explains the way institutions emerge in certain contexts as well as the way they interact with and affect the society. See North (1990).

6 For a dissection of the paths not taken that lowered the chances of democracy transition and consolidation in Sri Lanka and Pakistan, see Sahadevan and DeVotta (2006); Spencer (2005) Oldenburg (2010); El-Khawas (2009).

7 For party system and elections in India see: Mitra (2011a, 2013b); Sridharan (2010); Adeney and Saez (2005).

8 Vertical mobilization refers to political linkages that draw on and reinforce social and economic dominance. Horizontal mobilization takes place when people situated at the same social and 
economic level get together to use their combined political strength to improve their situation. Differential mobilization refers to coalitions that cut across social strata. See Rudolph and Rudolph (1967).

9 For the formulation of these ideas in terms of an analytical framework on elections and social change in India based on a model of electoral norms and organizational structures corresponding to them, see Mitra (1994), 49-72.

10 For an application of this concept as a framework for strategic protest as a form of political participation in India, see Mitra (1991).

11 See McMillan (2010).

12 See Rajamani and Sengupta (2010).

13 Satyagraha means in Sanskrit 'holding the truth', and was employed most famously by Gandhi against British colonial rule; hartal means strike action; bandh - collective cessation of public activities; dharna - a form of sit-in strike; gherao means 'to surround a decision-maker'; jail bharo to fill the jails in a form of radical protest; rasta roko - Hindi for stopping the vehicular traffic as a part of a protest movement (see Mitra 2011a).

14 See T. S. Bankoti (2008) or Nepal (2009).

15 The following, a small sample of the enormous body of legislation - levellers of the political playing field - will give an idea of the ever-increasing scope of democratic politics, and the deep roots of political dynamics in India. Industrial Disputes Act, 1947; Untouchability Offences Act, 1955; Hindu Code Act, 1956; Muslim Women (Protection of Rights on Divorce) Act, 1986; The Scheduled Castes and Scheduled Tribes (Prevention of Atrocities) Act, 1989; The 73rd Amendment of the Constitution, 1992; National Commission for Minorities Act, 1992; The National Commission for Backward Classes Act, 1993; Maintenance and Welfare of Parents and Senior Citizens Act, 2007; Mahatma Gandhi Rural Employment Guarantee Act, 2005; National Food Security Act, 2013.

16 The Supreme Court of India commuted the death sentence of 1993 Delhi bomb blast case convict and Khalistani terrorist Dvenderpal Singh Bhullar to life terms on the grounds of delay in deciding on the mercy petition filed by his wife. See 'Supreme Court commutes Bhuller's death sentence', in The Hindu, March 31, 2014. http://www.thehindu.com/news/national.

17 The transformation of the anti-corruption movement led by Anna Hazare into the Aam Aadmi Party (AAP) which won the assembly elections in Delhi and formed the government is a good example of the power of India's electoral democracy to induct new values and leaders into the political arena. The victory of the Hindu-nationalist Bharatiya Janata Party (BJP) in the parliamentary elections of 2014 has similarly transformed right-wing, conservative and radical nationalists into an accountable and moderate party of government. See Mitra (2013b) and Mitra and Schöttli (forthcoming).

\section{References}

Adeney, K. and L. Saez (eds) (2005) Coalition Politics and Hindu Nationalism, London: Routledge.

Bankoti T. S. (2008) Chipko Movement, New Delhi: Global Vision Publishing House.

Brown, J. (1985) Modern India: The Origins of an Asian Democracy, Delhi: Oxford University Press.

Brown, J. (1989) Gandhi: Prisoner of Hope, New Haven, CT: Yale University Press.

Drèze, J. and A. K. Sen (2013) An Uncertain Glory: India and its Contradictions, London: Allen Lane.

El-Khawas, M. A. (2009) 'Musharraf and Pakistan: Democracy Postponed', Mediterranean Quarterly, 20 (1): 94-118.

Harrison, S. S. (1960) India: The Most Dangerous Decades, Princeton, NJ: Princeton University Press.

Huntington, S. (1968) Political Order in Changing Societies, Yale, CT: Yale University Press.

Jalal, A. (1995) Democracy and Authoritarianism in South Asia: A Comparative and Historical Perspective, Cambridge: Cambridge University Press.

Jayal, N. G. and P. B. Mehta (eds) (2010) The Oxford Companion to Politics in India, Delhi: Oxford University Press.

Kohli, A. (ed.) (2001) Success of India's Democracy, Cambridge: Cambridge University Press.

Kothari, R. (1970) Politics in India, Boston, MA: Little Brown.

Lipset, S. M. (1959) 'Some Social Requisites of Democracy: Economic Development and Political Legitimacy', American Political Science Review, 53: 69-105. 
McMillan, A. (2010) 'The Election Commission', in Niraja Gopal Jayal and Pratap Bhanu Mehta (eds), The Oxford Companion to Politics in India, 98-116, Delhi: Oxford University Press.

Mitra, S. (1991) 'Room to Maneuver in the Middle: Local Elites, Political Action and the State in India', World Politics, 43 (3): 390-413.

Mitra, S. (1994) 'Caste, Democracy and the Politics of Community Formation in India', in Mary Searle-Chatterjee and Ursula Sharma (eds), Contextualising Caste, 49-71, Oxford: Blackwell.

Mitra, S. K. (2005) Puzzle India's Governance: Culture, Context and Comparative Theory, London: Routledge.

Mitra, S. K. (2011a) Politics in India: Structure, Process and Policy, London: Routledge.

Mitra, S. K. (2011b) 'Democracy's Resilience: Tradition, Modernity and Hybridity in India', Harvard International Review, 32 (4): 46-52.

Mitra, S. K. (ed.) (2012) Citizenship and the Flow of Ideas in the Era of Globalization: Structure, Agency and Power, Delhi: Samskriti.

Mitra, S. K. (2013a) 'How Exceptional is India's Democracy? Path Dependence, Political Capital, and Context in South Asia', India Review, 12 (4): 227-244.

Mitra, S. K. (2013b) 'The Ambivalent Moderation of Hindu Nationalism in India', Australian Journal of Political Science, 48 (3): 269-285.

Mitra, S. K. and J. Schöttli (forthcoming) 'India's 2014 General Elections: A Critical Realignment in Indian Politics?', Asian Survey.

Mitra, S. K. and V. B. Singh (2009) When Rebels become Stakeholders, Delhi: Sage.

Moore, B. (1966) Social Origins of Dictatorship and Democracy: Lord and Peasant in the Making of the Modern World. Chapter VI 'Democracy in Asia. India and the Price of Peaceful Change', 314-385, Boston, MA: Beacon Press.

Nepal, P. (2009) Environmental Movements in India: Politics of Dynamism and Transformations, Delhi: Authorspress.

North, D. C. (1990) Institutions, Institutional Change and Economic Performance, New York: Cambridge University Press.

Oldenburg, P. K. (2010) India, Pakistan, and Democracy: Solving the Puzzle of Divergent Paths, London and New York: Routledge.

Putnam, R., with R. Leonardi and R. Y. Nanetti (1994) Making Democracy Work: Civic Traditions in Modern Italy, Princeton, NJ: Princeton University Press.

Rajamani, L. and A. Sengupta (2010) 'The Supreme Court', in N. G. Jayal and P. B. Mehta (eds), The Oxford Companion to Politics in India, 80-97, Delhi: Oxford University Press.

Rudolph, L. I. and S. H. Rudolph (1967) The Modernity of Tradition. Political Development in India, Chicago: University of Chicago Press.

Sahadevan, P. and N. DeVotta (2006) Politics of Conflict and Peace in Sri Lanka, New Delhi: Manak Publications.

Scott, J. (1985) Weapons of the Weak: Everyday Forms of Peasant Resistance, New Haven, CT: Yale University Press.

Spencer, J. (ed.) (2005) Sri Lanka: History and the Roots of Conflict, New York: Routledge.

State of Democracy in South Asia: A Report (SDSA) (2008) SDSA Team, New Delhi: Oxford University Press.

Sridharan, E. (2010) 'The Party System', in Niraja Gopal Jayal and Pratap Bhanu Mehta (eds), The Oxford Companion to Politics in India, 117-135, Delhi: Oxford University Press. 


\title{
3
}

\section{FOUNDATIONS FOR A SUSTAINABLE GROWTH}

\section{India’s Constitution and its Supreme Court}

\author{
Ananth Padmanabhan
}

The legal system plays a significant role in any country's growth trajectory, and within this system, that fundamental of all laws, the Constitution, assumes highest importance. Not only does this document reveal the normative values suffusing the nation's visualisation but it also puts in place structures of governance to actualise this vision. The preamble to the Indian Constitution envisages a 'sovereign, secular, socialist, democratic, republic' and its 400 odd articles and 12 Schedules work together, and sometimes in contradiction, to achieve these five goals. In line with the objectives of this volume on contemporary India, this chapter examines three important constitutional themes essential to the stable and inclusive growth of the nation today, and the Supreme Court's role in giving them meaning and effect. While one eye is trained on the past, the other keenly awaits the future with predictions in store.

Before embarking on this narrative, a few words on the Constitution's framing are in order. The Constituent Assembly, responsible for drafting the document, consisted of members elected by the people's representatives in the provincial assemblies. This indirectly elected body began its first session on 9 December 1946, but became seriously involved with its job after the formal grant of Independence. In January, 1948, a draft Constitution was made available for public response within a period of eight months from then. On 4 November, 1948, the general discussions on the draft commenced in the Constituent Assembly, followed by a clause-centric discussion for about 32 days. This process culminated in the adoption and signing of the Constitution of India on 26 November 1949, and its coming into force on 26 January 1950 (Sridhar n.d.).

It is true that the Constituent Assembly depended substantially on its task of structural design, on the Government of India Act, 1935, passed by the British Parliament. The parliamentary system, the centralised federation, the vast administrative detail for governmental structure and the provision for elections to the provinces, all found presence in the Constitution. Similarly, the document and its framers drew heavily upon the wellspring of ideas offered by the rights discourse in the United States of America. The idea of enumerating a set of non-justiciable directive principles also received impetus due to similar provisions existing elsewhere, including in the Irish Constitution (Austin 1999: 5).

Above all, one indigenous document gave the Indian Constitution its distinctive vision, identity and character, all of which would in turn be instrumental in building the 
foundations of the newly born nation state. This was the Objectives Resolution adopted during the December 1946 Constituent Assembly session. This Resolution, drafted by India's first Prime Minister, Jawaharlal Nehru, itself drew from Congress Party documents two decades past. It later found presence in the constitutional text too through the preamble, and can be understood as uncovering three different normative goals: protecting and promoting national unity and integrity, seeding democratic structure and spirit in the polity, and triggering a social revolution to uplift the citizenry, a vast majority of whom personified an impoverished predicament (Sridhar n.d.: 5-6). These three purposes have interacted at cross-purposes to shape the Indian experience of working its Constitution, rendering the Objectives Resolution the most important document in strengthening the foundation of the country's political and legal system.

Because the most unique and original feature of the Indian Constitution over the earlier constitutional documents such as the two Government of India Acts of 1919 and 1935 and ones preceding those is the clear and unequivocal guarantee of fundamental rights, the first part of this chapter examines the signal effect of these provisions in strengthening the foundations of contemporary India. Here, I shall also address specifically the Supreme Court's role in contributing to, and shaping, this rights-based dialogue of citizen-State interaction. The voluminous expanse of literature on fundamental rights makes it impossible to give a comprehensive overview of all provisions. For the purpose of throwing light on the Court's role in strengthening the foundations of a rights-based discourse, I will focus on Articles 14, 19 and 21, referred to often as the golden triumvirate, and show how a largely proactive judicial approach has been instrumental in protecting and nurturing the freedom of citizens.

The next part of the chapter looks into the federal structure of the Constitution and how it attempts, through this design, to bring about a sound system of Centre-State relations. The rationale for introducing a federal system of governance was largely administrative convenience, but post the linguistic division of States, this structure has played an important role in accommodating diversity in the Indian polity. At the same time, concerns abound as to the unequal development of States and increasing regional parochialism, fuelled in most cases by self-seeking political actors. Another worrisome feature lies in the design itself, which carries over the colonial idea of centralisation being a necessary feature to govern and keep united a country this large and diverse. As a consequence, the nation has been witness to unbridled imposition of State emergency on the ground of breakdown of constitutional machinery. The territorial identity of States has also come under attack from internal forces, many of them appealing to the federal structure and the vast powers vested with the Centre to seek separate Statehood. The asymmetric model of federalism, designed to respond to the factum of inequitable development that such claims peg themselves on, has not worked too well either. The second part broadly explores these different ideas and the possibility of the federal structure propelling and hindering, by turns, India's future growth.

An important feature of any constitutional foundation, perhaps the most important when it comes to self-preservation of a democratic polity, is the separation of powers between different branches of Government. Without constitutional provisions that formalise such separation, there is always the danger that any one authority will usurp all power and use the democratic route to eventually put in place a form of despotic governance. Severe onslaught in the 1970s on the separation of powers, especially through the 42nd Constitution (Amendment) Act, 1976, and the practical interference with the judiciary and its functioning, has led to counteracting responses from the judiciary, enshrining this principle and the related idea of judicial independence as part of the unamendable basic structure of the Constitution. 
The last part of the chapter analyses the significance of this principle in providing a sound foundation for India's future growth.

In addition to the three normative goals mentioned above that present us with a convenient prism to locate and observe the nuances of the doctrinal development and structural features in the three themes chosen for this chapter, there is a bi-dimensional axis of language and practice that drives the analysis here. The strength of any legal foundation depends both on language, namely the conversation that provides meaning to the foundation, and on practice, that is the extent to which such language achieves its objectives through actual implementation. Both are important, yet separate, frames from which the strength of a constitutional foundation can be tested, as this chapter will seek to do.

\section{The fundamental rights story and the Supreme Court's PIL (public interest litigation) jurisprudence}

Part III of the Constitution enumerates the different fundamental rights guaranteed to citizens and other persons. Most of these rights are available only against the State, though a few exceptions exist where rights are horizontally enforced against non-State actors. However, the definition of "State" itself has received a fairly broad interpretation by the Court, resulting in a situation where many fringe actors such as Government companies, ${ }^{2}$ cooperative societies ${ }^{3}$ and public sector undertakings ${ }^{4}$ engaged in pure commercial activity are brought within the purview of State. Thus, in terms of spread, the Supreme Court has been actively responsible for expanding the foundation of the rights-based discourse by including all 'agencies or instrumentalities' ${ }^{5}$ of the State within the reach of Part III. Apart from a direct guarantee of fundamental rights in many cases, this move by the Court has been responsible in constitutionalising the actions of purely private actors by internalising an expectation of fairness in the minds of the citizen. This is sufficiently borne out by the exercise of writ jurisdiction by various High Courts under Article 226 of the Constitution. These writs being entertainable on the ground of violation of any legal right, Courts have expanded protection to citizens by intervening so long as private actors commit breach of any statutory duty or, sometimes, even a public duty.

It is in the domain of substantive content, though, that the Court has made serious inroads into the initially one-sided State-citizen relationship. The Court has redrawn the terrain to guarantee a better balance and higher protection. The best example of this is the Article 21 jurisprudence ${ }^{6}$ and the Court's expansionism over the years when interpreting this provision and bringing newer rights within its fold. In A.K. Gopalan v. State of Madras, ${ }^{7}$ the Supreme Court dismissed a writ filed by a detenu because 'procedure established by law', required under Article 21 to deprive a person of his right to life or personal liberty, could include any legally prescribed procedure. Additional considerations such as the fairness, reasonableness or justice behind these statutory mandates were held irrelevant while gauging the constitutionality of the State action. Interestingly, Gopalan called into question a balancing of two of the important normative goals envisaged by the Objectives Resolution. On the one hand, the liberty of a political activist advocating an alternative viewpoint was at stake. On the other, the ability of the State to keep in check possibly divisive ideologies and thus protect national unity was being put to test. This balance is best articulated by Justice Mukherjea in his opinion, as follows:

Ordinarily, every man has the liberty to order his life as he pleases, to say what he will, to go where he will, to follow any trade, occupation or calling at his pleasure 
and to do any other thing which he can lawfully do without let or hindrance by any other person. On the other hand, for the very protection of these liberties the society must arm itself with certain powers ... The society, therefore, has got to exercise certain powers for the protection of these liberties and to arrest, search, imprison and punish those who break the law. If these powers are properly exercised, they themselves are the safeguards of freedom, but they can certainly be abused ... What the Constitution, therefore, attempts to do in declaring the rights of the people is to strike a balance between individual liberty and social control.

The Court leaned in favour of the latter, and the reason could well have been the nascent character of the Indian State. Justice Patanjali Sastri, while explaining the unusual constitutional status conferred on preventive detention by Article 22 of the Constitution, observed:

This sinister-looking feature, so strangely out of place in a democratic constitution which invests personal liberty with the sacrosanctity of a fundamental right and so incompatible with the promises of its preamble is doubtless designed to prevent an abuse of freedom by anti-social and subversive elements which might imperil the national welfare of the infant Republic.

Even Justice Fazl Ali, though holding in the petitioner's favour and striking down the Prevention Detention Act, 1950, as unconstitutional, trod with caution. The learned Judge captured the delicate balance at play here in the last paragraph of his opinion, reproduced below:

I am aware that both in England and in America and also in many other countries, there has been a reorientation of the old notions of individual freedom which is gradually yielding to social control in many matters. I also realise that those who run the State have very onerous responsibilities, and it is not correct to say that emergent conditions have altogether disappeared from this country. Granting then that private rights must often be subordinated to the public good, is it not essential in a free community to strike a just balance in the matter? That a person should be deprived of his personal liberty without a trial is a serious matter, but the needs of society may demand it and the individual may often have to yield to those needs. Still the balance between the maintenance of individual rights and public good can be struck only if the person who is deprived of his liberty is allowed a fair chance to establish his innocence, and I do not see how the establishment of an appropriate machinery giving him such a chance can be an impediment to good and just government.

The perils of tilting the balance towards greater social control were unleashed in full spate during the National Emergency. By then, the nation had fought three major wars, acquired the property of its citizens to bring about social justice, and nationalised important industries to equalise economic wealth. Though all these policies brought the fundamental rights of citizens under direct curtailment, none of them evoked the same sense of injustice as did the Emergency. The proclamation of Emergency at the midnight hours of June 25, 1975 and the excesses that followed were seen as an attempt by Indira Gandhi, India's then Prime Minister, to unlawfully hold on to power in the face of judicial annulment of her 
parliamentary election. The last straw was when the judiciary too failed to protect opposition leaders placed under detention. In what can be termed the worst decision of the Indian Supreme Court in Additional District Magistrate, Jabalpur v. Shivakant Shukla, ${ }^{8}$ the Court held that once fundamental rights were suspended in the wake of Emergency, no right to life would survive under common law. In other words, citizens were stripped of all their basic human rights during the period of Emergency. The bold Justice Khanna who dissented here was soon superseded from the post of Chief Justice of India, paving the path for the Executive to appoint a more pliant Chief Justice.

There could be no better explanation for what followed than the mystical phenomenon of unintended consequences. The Supreme Court, in an attempt to redeem its glory, started placing greater emphasis on the language of rights (Baxi 1985: 108). The crushing defeat inflicted on the Congress Party in the parliamentary elections of 1977 aided this transformation and soon enough, the nation experienced its first foundational shift in constitutional discourse in Maneka Gandhi v. Union of India. ${ }^{9}$ The rather simplistic set of facts here - the impounding of the petitioner's passport by the Union without revealing the reasons thereof - coupled with a concession to grant a post-decisional hearing by the Attorney General of India, lent themselves to a short order disposing the legal action on these very terms. Yet, the Seven Judge Bench of the Court chose to delve in much greater detail on the meaning and scope of the expressions 'personal liberty' and 'procedure established by law' under Article 21. Justice Bhagwati, in what has gone down in the annals of Indian constitutional law as a defining moment of sorts, sagaciously opined that

[T] he principle of reasonableness, which legally as well as philosophically, is an essential element of equality or non-arbitrariness pervades Article 14 like a brooding omnipresence and the procedure contemplated by Article 21 must answer the test of reasonableness in order to be in conformity with Article 14. It must be 'right and just and fair' and not arbitrary, fanciful or oppressive; otherwise, it would be no procedure at all and the requirement of Article 21 would not be satisfied.

Going beyond the specific outcome for the petitioner therein, Maneka crafted the syntax for a language of rights. Personal liberty soon became the mantra for metamorphosis of the judiciary from a sentinel on the que vive to an active benefactor of positive rights. Taking Maneka as the foundation for a renewed rights jurisprudence, and building on it by expanding the meaning of both 'life' and 'personal liberty' in Article 21, the Court set new benchmarks for judicial activism. The Court had the suffering of several millions of people and the degrading human conditions in which they lived in mind as it proclaimed - with the mission of upliftment - that the right to life included the right to live with human dignity. ${ }^{10}$ The Court listed within the fold of this expansive interpretation, necessities such as adequate nutrition, clothing and shelter, facilities for reading, writing and expressing oneself in diverse forms, and freely moving about and commingling with fellow human beings. ${ }^{11}$ While there is well-justified caution expressed by constitutional theorists about branding Maneka an activist decision (Khosla 2009: 87), it certainly ushered in a whole new language of positive rights, and along with it, higher expectations from the judiciary on the citizen welfare front. Article 21, post Maneka, has found its way into the judicial conversation on solitary confinement and bar fetters on under-trials, ${ }^{12}$ handcuffing of citizens on the way to court, ${ }^{13}$ custodial torture, ${ }^{14}$ the imposition of the death penalty only in the rarest of rare cases, ${ }^{15}$ the delay in execution as an extenuating factor even when the death penalty is ordered under such rare circumstances ${ }^{16}$ right to privacy, ${ }^{17}$ right to information, ${ }^{18}$ access to legal aid, ${ }^{19}$ sexual 
harassment at the work place, ${ }^{20}$ the right to die,${ }^{21}$ the award of monetary compensation as relief in cases of torture, ${ }^{22}$ the constitutionality of anti-terror legislation containing draconian exceptions to established rules of evidence and criminal procedure, ${ }^{23}$ and, most recently, the legality of the inhuman manual scavenging practice going on in several parts of the country ${ }^{24}$ and the legal recognition of transgender people. ${ }^{25}$

Even more unconventional than the inclusion of Article 21 in the discourse on civil and political rights is its influence in the fashioning of rights and remedies in the socioeconomic realm. However, this trend in judicial reasoning cannot be viewed in isolation and has to necessarily be understood in conjunction with another important part, Part IV, of the Constitution. Though the Directive Principles of State Policy, enumerated in Articles 38 to 51 of this part, were meant to be non-justiciable, the Court has correlated the scope of some of these principles with the expansive content of Article 21 to guarantee their availability as fundamental rights under Part III (Jain 2000: 98). It is when expounding on these socioeconomic principles under Part IV and their availability as rights under Part III that the Court has significantly pushed the barriers of thinking that traditionally perceived fundamental rights to be negative liberties against the State. The Court, recognising the importance of primary education in guaranteeing a meaningful life, conferred the directive in Article 45 exalted status as a protected right under Article 21, eventually leading the path to the insertion of Article 21-A and supporting legislation. ${ }^{26}$ Along similar lines, the Court has also read in multifarious rights such as to a healthy life, ${ }^{27}$ access to medical facilities,${ }^{28}$ shelter and housing, ${ }^{29}$ food security ${ }^{30}$ a clean and unpolluted environment, ${ }^{31}$ sustainable development, ${ }^{32}$ and effective remedies built on the polluter pays principle, ${ }^{33}$ the precautionary principle, ${ }^{34}$ and the public trust doctrine. ${ }^{35}$

Finally, no narrative on this theme is complete without a look, brief as it may be, into the Supreme Court's public interest litigation (PIL) jurisdiction and its attempt at inclusion of voices from different walks of life through the relaxation of legal standing. In fact, the Bombay High Court can be considered the pioneer in this area because the first such unconventional relaxation of standing took place in a writ filed before this Court in Piloo Mody v. State of Maharashtra (Desai and Muralidhar 2000). ${ }^{36}$ The petitioners here were ordinarily placed residents of Mumbai who sought to challenge disposal of Government property at abysmally low prices. The High Court responded to the State's challenge to the locus standi or legal standing of these petitioners by reasoning that the petitioners, as residents of Bombay, had an interest in the orderly development of the city in harmony with a proper layout. Subsequent judicial development in this area, spearheaded by several important decisions of the Supreme Court, essentially build on the same philosophy: discarding the regular bipolar, adversarial structure of a lawsuit to entertain legal challenges by a wider variety of constituents who can be considered 'interested' or 'aggrieved' persons ${ }^{37}$ in the dispute at hand. Three broad trends can be identified even within this common philosophy: first, the trend of allowing special interest groups to advocate the cause of those incapable of defending their own, largely overlapping with the Court's jurisprudence on expansion of Article 21 to guarantee additional civil and political rights protection to the meek and the downtrodden. ${ }^{38}$ Second, the relaxation of locus standi to substantially intervene in matters of environmental protection and ensure protection of the rights of citizens to a clean and healthy environment, guaranteed under Article $21 .^{39}$ The third is a trend to relax locus standi with the instrumental idea of enhancing probity in public affairs, again by reading in a right to corruption-free governance within Article 21 (Sudarshan 2005: 24-25) or by recognising a legally enforceable public interest in matters relating to the three branches of Government. ${ }^{40}$ The Court has, while exercising its PIL jurisdiction, devised novel procedures for the purpose of ascertaining facts ${ }^{41}$ and overseeing enforcement of its orders. ${ }^{42}$ 
It goes without saying that the Court's expansive PIL jurisdiction and its broadening of Article 21 to cover socio-economic rights has left lawyers and academics divided on the correctness of this approach, both from a conceptual standpoint and in terms of its actual efficacy. Attempts have also been made to cut through the rhetoric and understand the real nature of the discourse, including whether the Court has fashioned broadly available socioeconomic rights or merely intervened in a conditional sense, i.e. to enforce a set of benefits already in place but not implemented thus far by the Executive (Khosla 2010 and Tushnet 2011). These and other debates on the Court's exercise of judicial review and assumption of power over a wide variety of subjects with procedural restrictions ranging from little to none, are outside the scope of this chapter. However, before leaving this part and proceeding to discuss India's federal structure, an important concern comes to mind. The practice of the Supreme Court over time has given way to practices of different Benches of this Court. This has come at the cost of consistency in outcomes and even worse, in the kind of judicial reasoning to arrive at such outcomes. The same Court that progressively recognised the right to selfdetermination of transgenders ${ }^{43}$ has affirmed the criminalisation of homosexuality ${ }^{44}$ through a different Bench. Similarly, the Court has upheld hard-hitting anti-terror legislation ${ }^{45}$ and given imprimatur to the Armed Forces (Special Powers) Act, $1958,{ }^{46}$ while at the same time protecting private citizens from recruitment into private policing organisations such as Salwa Judum. ${ }^{47}$ Through these different views and approaches of different Benches, the Court adds much murkiness to the essential line drawing between two core foundational objectives writ large in the Constitution, namely, preservation of national unity and identity, and protection of the individual against State excesses. The Court has to put in place internal mechanisms to avoid such inconsistency on basic and foundational questions, if the Constitution and specifically, Parts III and IV therein, have to continue serving as a dependable bedrock for the country's future growth in a sustainable manner. Moreover, the Court's success has largely been in the realm of language, to reference the bi-dimensional axes analysis introduced at the beginning of this chapter. It is important to ensure that the limited success in this axis is not diluted, while the institutions of power work towards a better ordinate on the practise axis.

\section{The federal structure}

The federal structure India inherited from the British through the Government of India Act, 1935, was a product of two different instrumental concerns: one, the heady task of administering a large and diverse country, and two, projecting a compromise in the larger theatre called the Indian independence movement by permitting provincial autonomy. When transplanting this structure on to the Indian Constitution, a large part of the "colonial hangover' - to borrow a clichéd phrase - was unfortunately retained. The centrist character of the resultant federal structure has led to the oft used, and sometimes misused, aphorism: 'federal in character, unitary in spirit'. In this part, I examine how the federal structure has played out, along the multi-dimensional axes of retaining India's national unity and integrity, while at the same time, securing its diversity and multiculturalism. Clearly, there is a delicate balance at play here because too much assertion of national identity and imposition of 'Indian-ness' could arguably result in the collapse of sub-national identities and a backlash. On the contrary, promoting sub-nationalism at the cost of weakening the nation state can be detrimental to the very existence of democratic spirit, and lead to possible anarchy.

This part picks three important themes to try and explain the competing concerns in this legal and political thicket, and the judicial responses and trends therein. While it is wishful to consider that these themes shall capture the complexities of the debate(s) in entirety, they 
will show how the foundation is currently set and more ambitiously, propose realignments in the structure that strike an optimal balance between the normative goals of preservation of national identity and respect for the multicultural heartbeat. The three themes are: (i) the Centre's power to declare emergency in any particular State, (ii) the carving out of separate States, and (iii) India's asymmetric federalism.

\section{Article 356 and its unwise use}

The Constitution permits the Centre, in a situation where the Government of the State cannot be carried on in accordance with the provisions of the Constitution, to take over the governance of that State vide a proclamation of emergency that satisfies the requirements laid out in Article 356. There are many issues that this provision presents, but I shall focus on the most important of these: the extent of power vested with the Union to declare such emergency in the first place.

The issue came up before the Supreme Court for its consideration the first time in State of Rajasthan v. Union of India. ${ }^{48}$ This case has an interesting political context to it, being the massive defeat of the Congress Party at the hands of the then opposition - a motley group of parties with ideologies ranging from the left to the right - cobbled hurriedly to face the parliamentary elections held immediately after the infamous National Emergency of 1975. The drubbing faced by the Congress Party at the Centre emboldened the new political dispensation to advise the nine States governed at that point by the Congress Party. The convoluted, yet ingenious, advice went thus: because your party has lost at the Centre, there is a clear misalignment between your Ministry and the people who you govern. This could lead to law and order concerns. Therefore, advise your Governor to consider recommending the imposition of Article 356.

The State Ministries immediately initiated legal proceedings against this advice. So, there was no formal proclamation of emergency under challenge here. Yet, the Court examined the permissibility of judicially reviewing such a proclamation. In an opinion that placed absolute primacy on the Centre's stand in this matter, the Supreme Court held that the Court would only intervene if the proposed action was 'so completely outside the purview of Art. 356 or so clearly in conflict with a constitutional provision that a question of excess of power could have apparently arisen' - a rather weak standard of review once we realise that most political decisions find justification, tenuous or otherwise, in some constitutional principle. Justice Chandrachud, in his concurring opinion, added that it was entirely left to the President to judge whether a situation necessitating the imposition of emergency under Article 356 had arisen, and that the Court, though expectant of his fairness in arriving at this decision, could not sit in judgment over his subjective satisfaction. The only matter for the Court's consideration was whether the reasons, if any disclosed, for the action proposed or taken, bore a reasonable nexus with the exercise of the particular power. This observation left open the ominous possibility of no reasons being disclosed whatsoever, and the Court, and the State Governments, being left high and dry in such an event. Moreover, even if reasons were disclosed, the President could be subjectively satisfied that such reasons bore reasonable nexus with his decision to invoke Article 356 except in extreme cases - possibly those vitiated by mala fides - and the Court would still defer to his decision.

The Court's abdication of responsibility to safeguard the federal structure inevitably led to unbridled, and often vicious, invocation of Article 356. This ultimately compelled the Supreme Court to intervene in S.R. Bommai v. Union of India ${ }^{49}$ despite the contentious issue of wrongful invocation of Article 356 being rendered infructuous due to intervening 
elections. This case too had an interesting background story, as three State Governments were dismissed because of inability to control rioting that followed the Babri Masjid demolition, a watershed event in post-independence India. However, the petitions before the Court were motley and not confined to these three instances of invocation of Article 356. In a classic exercise of its balancing power, the Court broadly found the dismissals connected with the rioting to be constitutionally valid and the rest to be infirm. Though this finding had no practical implication, the Court's restatement of the law drew the line differently, safeguarding the federal structure way better than its earlier verdict in Rajasthan, and possibly placing the clamps on misuse of Article 356. This restatement is best reflected in the following observation of Justice Jeevan Reddy:

[t] he exercise of power by the President under Article 356(1) to issue Proclamation is subject to judicial review at least to the extent of examining whether the conditions precedent to the issuance of the Proclamation have been satisfied or not. This examination will necessarily involve the scrutiny as to whether there existed material for the satisfaction of the President that a situation had arisen in which the Government of the State could not be carried on in accordance with the provisions of the Constitution. Needless to emphasise that it is not any material but material which would lead to the conclusion that the Government of the State cannot be carried on in accordance with the provisions of the Constitution which is relevant for the purpose. It has further to be remembered that the article requires that the President 'has to be satisfied' that the situation in question has arisen. Hence the material in question has to be such as would induce a reasonable man to come to the conclusion in question.

Bommai had two major implications for the federal scheme. First, though the Court, in accordance with Article 74(2), would not concern itself with the advice tendered to the President by the Council of Ministers, it would still examine the material on the basis of which such advice was given, including the Governor's report. Second, the subjective satisfaction arrived at by the President would have to independently satisfy the 'reasonable man' test, thus in effect being amenable to objective standards of review. Though the Court would not second guess the sufficiency of the material placed before it, it could well question the legitimacy of the inferences drawn by the President from such material.

There was a third idea that Justice Jeevan Reddy expressed, which went to the structural foundations of the federal structure. He observed that so long as the States were not mere administrative units but constitutional potentates in their own right, the mere labelling of the Constitution as unitary or quasi-federal or a mixture of federal and unitary structure would not vest the President with unrestricted powers to invoke Article 356. However, the Court placed high value on the principle of secularism, thereby signalling that were any State Government to act in contravention of constitutional principles that safeguarded the integrity of the nation - such as the three Governments dismissed post the Babri Masjid incident - its dismissal would be justifiable under the constitutional scheme. That Bommai had, in this fashion, struck a balance by distinguishing between acts threatening national integrity or stability, and acts that perhaps went against political morality but were best left to the normal route of trial and error as played out in the State political arena, only became evident much later, when the Court struck down the imposition of Presidential rule in Bihar.

In Rameshwar Prasad v. Union of India,${ }^{50}$ Article 356 was invoked when the elections to the Bihar State Legislative Assembly did not produce a decisive winner. The political chicanery 
and unethical practices behind the scene in contravention of the anti-defection provisions in the Tenth Schedule, with the objective of cobbling up a majority, seemingly motivated the Governor to prepare his report advising declaration of emergency. Hence, as Justice Balakrishnan's dissent stated, there was ample reason on the face of the record to justify invocation of Article 356. The majority still found the invocation unconstitutional, and the best way to understand this is that the unethical conduct alleged was of the kind truly internal to the political system of that State with no ramifications for national unity or integrity. The majority expressly relied on the three proclamations found unconstitutional in Bommai and the factual background therein - each of them involved solely questions of internal political morality - to inductively reason the unconstitutionality of the proclamation here.

Based on the above, rather limited, flashes of reasoning and judicial trends, we can hypothesize an attempt on the part of the Court to realign the centrist posture of the federal structure by instilling a healthy respect for the democratic choices made by the electorate in that State. This may be necessary, but still not sufficient, to consider the foundations of the federal structure strong enough to resist fissiparous tendencies while simultaneously accommodating genuine concerns of diversity. This is evident from the discussion that follows.

\section{Creating separate States: all in the centre's hands}

In the matter of carving out separate States, again the constitutional design displayed strong features of centrism. Article 3 conferred a limited right to the States to 'express their views' on the creation of a new State formed through the redrawing or modification of their territory. Parliament remained the final arbiter on the issue as the Bill providing for such a measure had to be voted on only in its two houses. Again, the question of balancing competing considerations loomed large. The important concern of ensuring that the nation's territorial unity was not left to the mercy of special interest groups at the State level had to be balanced with genuine demands of multiculturalism or administrative efficiency. This is where the Court's role becomes important, though sadly, as matters currently stand, the whole field is a political mess.

In Babulal Parate v. State of Bombay,${ }^{51}$ the Court was called upon for the first time to decide the scope of the proviso to Article 3, which provides for the solicitation of views from the States whose territories stood impacted by the proposal. The nuance here was that the State's views were sought, and given, the first time but there was a subsequent amendment to the proposal, which was not placed before the State Legislature for its views. The Court's response to this contention, and its interpretation of Article 3, virtually handed over a carte blanche to the Centre. Interpreting the proviso, the Court held that its underlying purpose was only to furnish an opportunity to the State Legislature to express its views within the time allowed and not to bind Parliament in accepting or acting upon the State Legislature's views. Parliament was free to deal with the Bill in any manner it thought fit, including a subsequent modification of the proposal without any fresh reference to the State Legislature. The Court, in two strokes, rendered toothless the requirement of referring to the State Legislature. One, it reduced the proviso to a mere procedural formality, instead of compelling the Centre to adduce strong reasons why the views of the State were not accepted. Two, it permitted amendments that may have completely deviated from the original proposal, except that this time, the State Legislature would not even be called upon to express its view. All of this can ultimately be traced to a weak conception of Indian federalism, as evident from the following passage from the decision: 
None of the constituent units of the Indian Union were sovereign and independent in the sense the American colonies or the Swiss Cantons were before they formed their federal unions. The Constituent Assembly of India, deriving its power from the sovereign people, was unfettered by any previous commitment in evolving a constitutional pattern suitable to the genius and requirements of the Indian people as a whole. Unlike some other federal legislature, Parliament, representing the people of India as a whole, has been vested with the exclusive power of admitting or establishing new States, increasing or diminishing the area of an existing State or altering its boundaries, the Legislature or Legislatures of the States concerned having only the right to an expression of views on the proposals. It is significant that for making such territorial adjustments it is not necessary even to invoke the provisions governing constitutional amendments.

To summarise, the already centrist design became even more so, post Babulal Parate. The later decisions of the Court stand testimony to this conclusion. For instance, in Pradeep Chaudhary v. Union of India, the Court held that even a substantial amendment to the Bill as originally passed on to the State Legislature for its views, would not in any manner call for a second opinion from the State in question.

As the recent controversies surrounding the creation of the State of Telangana after bifurcation of Andhra Pradesh reveal, the demand for separate Statehood can have extremely divisive implications for the Indian State. Unfortunately, with every new State being created, we see an exponential increase in the demand for many more. Most of these demands are at the behest of special interest groups that perceive the appeal to the Centre as a convenient ploy to get their own private fiefdoms. The Court, by enfeebling the State's voice in the matter, has indirectly lent more potency to such ploys. Its approach in Babulal Parate has ended up validating the earlier mentioned aphorism about Indian federalism, and resulted in a top-down approach where the Centre, less aware of the ground realities in a particular State, can bypass those administering the State who are better placed to assess the validity of bifurcation claims. Because Article 3 provides no real safeguards against an overarching Central exercise of authority, we need to examine whether the balance of power can still be kept alive through limited reliance on this provision and greater resort to India's asymmetric model of federalism.

\section{Asymmetric federalism: the case of unequals treated unequally}

Though all sub-national entities within the nation are equal, some are more equal than the rest. This is the underlying premise behind the design of asymmetric federal structures within the Constitution. The rationale for such unequal treatment could be either the unique cultural specificities or historical past that necessitates more autonomy to the unit in question, or the unequal development of the unit compared to other units or of parts of the unit compared to the rest of it that necessitates differential treatment of the unit or its less developed parts respectively. The constitutional design of asymmetric federalism is fairly complex and nuanced, and not fitting within one homogenous trend or thought. Hence, this sub-part focuses on two parts of the model, namely the fifth and the sixth Schedules, and the special provisions for differential treatment of regions within the same State. The debates on special status to Jammu and Kashmir and the provisions that purportedly enhance the autonomy of Meghalaya and Nagaland are outside the scope of this chapter. 
The Fifth Schedule, when read with Article 244(1) of the Constitution, provides for the administration and control of scheduled areas and tribes in States other than Mizoram, Tripura, Assam and Meghalaya. The Sixth Schedule provides for the administration and control of the same subject matter in these four States. The reason for a separate schedule was in recognition of the divergence between the religious and cultural practices of the scheduled tribes in these States and in the remaining parts of the country. When debated before the Constituent Assembly, some members expressed worry about the potential of these provisions to create a Tribalstan of sorts but better sense prevailed, in realisation of the truism that special occasions demanded special responses.

There is very little secondary literature on the impact of these provisions in practical terms. A better way of understanding the impact would be to merely look at the scheduled areas and see how far behind the rest of the country they still are, in terms of economic and human development indices. Drawing a direct correlation between such backwardness and the failure of these provisions may be a tad unfair. However, we could safely conclude that the provisions have not promoted the interests of these areas in the manner, and to the extent, imagined by the fathers of the Constitution. To take a simple example from the few that we have with us, consider the decision in Samatha v. State of Andhra Pradesh ${ }^{52}$ and its aftermath. The Supreme Court had categorically laid down in Samatha that non-tribals could not acquire land in the tribal areas covered within the Fifth Schedule whether through direct voluntary transfers or through indirect ones effected by the State grant of mining leases in these areas. This was a progressive and protective decision for the tribals, as rampant mining had emerged as a threat to their cultural diversity and way of life. Unfortunately, the accepted national development paradigm soon took over, and the same Court in BALCO Employees' Union v. Union of India ${ }^{53}$ questioned the Samatha ruling and resorted to hyper-technical distinctions to distinguish this decision. ${ }^{54}$ Over time, land issues have become unmanageable in at least a few of the nine Fifth Schedule States, with this in turn resulting in law and order problems including naxalism (Malhotra 2013). Though the Panchayats (Extension to the Scheduled Areas) Act, 1996 was introduced to ensure that Panchayats and Gram Sabhas are specifically vested with managerial powers over land resources, it has achieved scant results (Upadhyay n.d.).

The story with the Sixth Schedule is marginally better, inspiring some scholars to recommend extension of these set of provisions to the Fifth Schedule Areas as well (Malhotra 2014). Sadly, on closer analysis, the Sixth Schedule is a failure when weighed on the scale of constitutional expectations. The Autonomous District Councils set up thereunder have not succeeded in guaranteeing the optimal level of operational freedom required to address the cultural and historical specificities of the regions covered under the Sixth Schedule (North East India 2012). ${ }^{55}$ Some of the problems highlighted in the functioning of these Councils are the concentration of power and capture of the councils' functioning by a few individuals, poor quality of governance, financial dependency and indiscipline, and inability to protect tribal lands and promote healthy land management systems. ${ }^{56}$

In an unhappy twist, the Schedules have also led to more centralisation of power, including to the point where draconian, rather than beneficial, legislation are crafted for these regions taking umbrage under their special status. ${ }^{57}$ This is quite contrary to the original intent, wherein laws passed by Parliament and the State Legislatures were not meant to automatically apply so that the Governor would enjoy the power to adapt the legislation with the specific needs of the scheduled areas in mind. In short, the model of a single legal order which permits differential treatment of regions and groups (Khosla 2012: 84) has just added one more tier to the governance structure at extreme bureaucratic cost and with little results to show. 
Now we proceed to examine whether a different model, in which special provisions are carved out for certain regions of the State to tackle specifically articulated problems without as general a sweep as the two Schedules discussed above, has worked. Again, the provisions are a handful, with some less important than others, so it would be best to confine the enquiry to Article 371-D. This special provision relates to the State of Andhra Pradesh prior to its bifurcation, and was introduced with the objective of addressing the backwardness in the Telangana region. This provision was the outcome of dissatisfaction with the earlier constitutional formula of separate development Boards and equitable allocation of development expenditure, prescribed by Article 371 to guarantee intra-State equity when integrating the Telangana region of the former princely State of Hyderabad with parts of the erstwhile Madras province. Part of the dissatisfaction was due to a 'Gentleman's Agreement' signed in 1956 that promised way more in the form of safeguards for the Telangana region when compared with Article 371 (Forrester 1970). To rectify this mismatch between expectations and the provisioning, the Central Government introduced the Andhra Pradesh Public Employment (Requirement as to Residence) Rules, mandating continuous residence of fifteen years to be eligible for appointment to Government jobs in Telangana. The invalidation of these Rules by the Supreme Court in A.V.S Narasimha Rao v. State of Andhra Pradesh ${ }^{58}$ was the final nail in the coffin, leading to the 1969 agitation for separate Statehood for Telangana region.

Article 371-D was a compromise solution introduced to resolve the agitation, and vested power with the President to provide for equitable opportunities and facilities for people belonging to different parts of the State, in matters of public employment and education. Having regard to the requirements of the State as a whole, its various parts could receive differential treatment. Subsequently, the Supreme Court has upheld various Presidential orders under Article 371-D providing for public sector recruitment on zonal, rather than intra-State, basis. ${ }^{59}$ The Court has also affirmed the inapplicability to Andhra Pradesh, of its earlier decisions restricting the imposition of residence requirements in the matter of medical admissions. ${ }^{60}$ Despite this, the compromise solution failed miserably, with the Centre finally granting Telangana's claims of separate Statehood. In fact, the unfortunate incidents surrounding the creation of this State go to the root of national unity and integrity, forcing us to conclude that the asymmetric model of federalism has done little both in terms of the language and practice of national unity. The failure of the Fifth and the Sixth Schedules, on the other hand, show its failure, again in terms of both language and practice, in the multiculturalism project.

To sum up the federalism story, the design has not proven very strong in balancing the normative goals of national unification and preservation of multicultural identities. While the Supreme Court has attempted to provide some strength to the foundation, as seen from the shifting judicial approach with respect to the invocation of Article 356, such efforts have not borne much fruit overall. A rethink of the federal structure is necessary to resolve the competing considerations that prop up from time to time, if contemporary, and young, India has to emerge a global superpower in the years to come.

\section{Self-preservation and an independent judiciary}

If there is an area in Indian constitutional law where the Supreme Court has met with remarkable success on both the axes, namely of language and practice, it is where matters of constitutional self-preservation are involved. The Court has guarded its independence quite strongly in the last couple of decades and prevented the Constitution from being attacked from within, that is through amendments to the document, using the basic structure doctrine. 
Judicial independence is constitutionally enshrined as a directive principle in Article 50, but that is quite an understatement of the prominence it has assumed in the constitutional discourse. Judges today appoint their own, and they enjoy wide powers to enforce their orders, including the power to haul up bureaucrats and Ministers for contempt of court in the event of non-compliance with their orders. Their salaries are drawn from the Consolidated Fund of India and hence not open to a vote in Parliament. Their conduct is not open to discussion in Parliament except when a motion for impeachment, seeking the removal of any particular judge, is pending before the Parliament. The Supreme Court and the various High Courts can strike down any legislation passed by any of the legislative bodies as being unconstitutional, and the law would then have no effect whatsoever. And last but most important of all, the constitutional courts can stop Parliament from amending the Constitution if such amendment falls foul of the basic structure doctrine. And this is where we start the story of judicial independence in India.

In the path taken by the principle of judicial independence in India, Indira Gandhi v. Raj Narain $^{61}$ is a landmark moment. But its implications cannot be understood without a brief word about the earlier, and by far the most groundbreaking, decision of the Supreme Court: Kesavananda Bharati v. State of Kerala. ${ }^{62}$ Shorn of all technical detail, Kesavananda asked one question of the greatest constitutional significance, and this was whether there existed any substantive limitations on the amending power of Parliament once the procedure prescribed in Article 368 had been satisfied. The Court answered in the affirmative. It held that the power to amend the Constitution cannot take a destructive turn. Therefore, the basic structure of the Constitution would not be open to change. Simple as this sounds, the basic structure doctrine befuddled legal scholars and invited strong criticism. There was considerable confusion even among the judges forming the majority in Kesavananda as to what the basic structure really was. The Constitution did not expressly brand some of its provisions or features as part of its 'basic structure' while leaving out the others. Facially, all provisions were important with the only distinction being that ratification by half of the State Legislatures was required for amendments to some of the provisions, notably the ones touching upon the federal structure and powers of the higher judiciary. Also, the doctrine was seen as an attempt at judicial usurpation of power; especially so because the Court had seemingly been antagonistic to the social welfare agenda pushed by the Executive and declared quite a few legislations as unconstitutional and falling foul of the right to property, a fundamental right prior to 1978. Therefore, the basic structure doctrine was perceived as a last ditch attempt on the part of the Court to assert its dominance over the other two branches of Government.

However, the doctrine has come to stay and assumed stellar status in terms of the Court's contribution to the growth of constitutional law both domestically and from a comparative law perspective. And Indira Gandhi is an important chapter in this narrative. For this decision exposed the nation to the ominous possibilities surrounding the grant of unbridled powers to amend the Constitution. The facts of this case were indeed stark, and revealed complete disrespect for constitutionalism and a healthy institutional separation of powers. The constitutional amendment under challenge here was effected with the ulterior objective of overriding the judicial annulment of Indira Gandhi's election to the Parliament by the Allahabad High Court. This was already served by the retrospective modification to the Representation of Peoples Act. But the constitutional amendment went far beyond and attempted to immunise the Prime Minister's election to the Parliament from judicial scrutiny for posterity, and regardless of the egregiousness of the electoral misconduct. Clearly, this overreach of power shocked the conscience of the Court and it used the basic 
structure doctrine to hold the amendment unconstitutional. Judicial review was held to be an important guarantee of judicial independence, and as a result, part of the unamendable basic structure. Justice Mathew considered the original scheme formulated in the Constitution, under which the validity of elections had to be adjudicated using the judicial process, to be a part of the basic structure. Justice Khanna reasoned that the amendment violated the principle of free and fair elections, a major structural feature fashioned to preserve the democratic character of the Constitution. Justice Chandrachud found the amendment to violate the basic feature of the right to equality, sequestering as it did the election of the Prime Minister for differential and favourable treatment. Thus, though three of the five judges in Indira Gandhi relied on different conceptions of the basic structure to invalidate the amendment, all three were unanimous in the acceptance of this doctrine as an important safeguard against the abuse of power and an essential vehicle of self-preservation.

The Court has expanded on this doctrine to bring in other features of judicial independence within its purview. Here too, the beginning of the tale is beset with judicial deference, as the Court in S.P. Gupta v. Union of India ${ }^{63}$ gave a virtual carte blanche to the Executive in the matter of transfer and appointment of judges to the higher judiciary. Article 124, the constitutional provision dealing with the appointment of judges to the Supreme Court, and Article 217, the pari materia provision for appointment to the High Courts, came up for interpretation here. Both these provisions required the President to consult the Chief Justice of India and the vexing interpretive question was whether concurrence with the Chief Justice's choices had to necessarily follow from this consultative process. In other words, who had the final say in the matter of judicial appointments, the Executive or the Chief Justice of India? S.P. Gupta responded that consultation would not require concurrence, thereby placing the last word with the Executive, which could freely differ with the Chief Justice's recommendation of candidates for the high judicial office.

In similar fashion to the abuse of power that followed the meek subservience in State of Rajasthan, discussed above in the section 'the federal structure', S.P. Gupta threw open the doors wide to rampant interference with the functioning of the higher judiciary. Again, akin to the Court finding its Bommai to clamp down on improper invocation of Article 356, about a decade later came along the decision in Supreme Court Advocates-on-Record Association v. Union of India. ${ }^{64}$ Here, the Court used the basic structure doctrine and the principle of judicial independence to preserve its institutional health. Justice Verma acknowledged the self-preservation at play here, right in the beginning of his lead opinion, by observing thus:

These questions have to be considered in the context of the independence of the judiciary, as a part of the basic structure of the Constitution, to secure the 'rule of law' essential for the preservation of the democratic system. The broad scheme of separation of powers adopted in the Constitution, together with the directive principle of 'separation of judiciary from executive' even at the lowest strata, provides some insight to the true meaning of the relevant provisions in the Constitution relating to the composition of the judiciary. The construction of those provisions must accord with these fundamental concepts in the constitutional scheme to preserve the vitality and promote the growth essential for retaining the Constitution as a vibrant organism.

With this agenda, the Court rolled out an elaborate framework for appointment of judges, and heralded the collegium system to replace the Executive's primacy in this realm. Though this decision envisaged a collegium consisting of the Chief Justice and his two seniormost 
colleagues in the Court, a subsequent Presidential reference under Article 143 has expanded the strength of the collegium to include the four seniormost judges along with the Chief Justice, who would recommend candidates to the Executive. ${ }^{65}$ The Executive, in turn, would be bound by the choices of the collegium. The concerns with the collegium system, and the recent, and not-so-recent, attempts at streamlining the process to introduce higher transparency and accountability, are outside the purview of this chapter. It would suffice, therefore, to conclude the discussion by observing that the Court has had, at its heart, the objective of preserving itself and, through such an act of self-preservation, protecting the Constitution from ending up as a one-sided document with all significant powers in the hands of the Executive. Thus far, the basic structure doctrine and the principle of judicial independence have been areas where the Court's attempts have met with moderate success both along the language and the practice axes. Of course, some aberrations exist, such as the Court's approach to tribunalisation, where it has, in many ways, responded with an attempt to make the best of a bad situation rather than take a principled stand on the constitutionality of such bodies against the anvil of judicial independence. ${ }^{6}$ In such instances, both the language and the practice of self-preservation through the basic structure doctrine suffer. Yet, overall, the basic structure doctrine, subsuming within it the dual principles of separation of powers and judicial independence, has played a significant role in ensuring that the constitutional foundations passed on to us have remained preserved in their most essential form, readying the country to face new challenges.

\section{Conclusion}

The narrative that has unfolded through this chapter speaks of a country, and its apex Court, struggling to negotiate the several challenges thrown up by its diversity. The response mechanisms have worked in varying degrees, when we look back and analyse their efficacy using the bi-axial frame of language and practice. In a dominant sense, national unity and the self-preservation of the Constitution have emerged as extremely important normative concerns for the Court to keep in mind when laying the bricks and setting the mortar for the constitutional foundations. At the same time, the Supreme Court has also succeeded in infusing fundamental values such as individual freedom, self-development and sustainable growth into the constitutionalism conversation. How much of this has translated into reality is a separate issue, and one very important for the growth path of the country. Yet, that is a question best responded to by those entrusted with the working of the Constitution. There are certainly flaws in the constitutional model too, as seen from the discussion on India's federal structure, but they are relatively less egregious than those in the realpolitik model of governance that pervades contemporary India. If reform is needed, it has to start with the latter, and with the rise of an attitude that respects constitutional values rather than degrade them. Having said so, it is still imperative to relook, from time to time, the three important themes addressed in this chapter, and several more, to see how much of the Constitution, and the Court's practices with respect to the same, provide a linguistic and operational framework much required for the future growth of the nation.

\section{Notes}

1 Article 12 reads: 'In this Part, unless the context otherwise requires, "the State" includes the Government and Parliament of India and the Government and the Legislature of each of the States and all local or other authorities within the territory of India or under the control of the Government of India.' 
2 Central Inland Water Transport Corpn. v. Brojo Nath Ganguly, (1986) 3 SCC 156.

3 Pradeep Kumar Biswas v. Indian Institute of Chemical Biology, (2002) 5 SCC 111.

4 Sukhdev Singh v. Bhagat Ram, (1975) 1 SCC 421.

5 Ajay Hasia v. Khalid Mujib, (1981) 1 SCC 722.

6 Article 21 reads: 'No person shall be deprived of his life or personal liberty except according to procedure established by law.'

7 AIR 1950 SC 27. Hereinafter referred to as Gopalan.

8 AIR 1976 SC 1207.

9 AIR 1978 SC 597.

10 Francis Coralie Mullin v. Administrator, Union Territory of Delhi, (1981) 1 SCC 608.

11 Ibid.

12 Sunil Batra v. Delhi Administration, (1978) 4 SCC 494.

13 Prem Shankar Shukla v. Delhi Administration, (1980) 3 SCC 526.

14 DK Basu v. West Bengal, (1997) 1 SCC 416.

15 Bachan Singh v. State of Punjab, AIR 1980 SC 898.

16 V. Sriharan@Murugan v. Union of India, (2014)4 SCC 242; Shatrughan Chauhan v. Union of India, (2014) 3 SCC 1.

17 Mr. X v. Hospital Z, (1998) 8 SCC 296; Peoples' Union for Civil Liberties v. Union of India, AIR 1997 SC 568; R. Rajagopal v. State of Tamil Nadu, AIR 1995 SC 264.

18 Dinesh Trivedi $\mathrm{v}$. Union of India, (1997) 4 SCC 306.

19 Hussainara Khatoon (IV) v. State of Bihar, (1980) 1 SCC 98; M.H. Hoskot v. State of Maharashtra, (1978) 3 SCC 544; Suk Das v. Union Territory of Arunachal Pradesh, (1986) 2 SCC 401.

20 Vishaka v. State of Rajasthan, AIR 1997 SC 3011.

21 Aruna Shanbaug v. Union of India, (2011) 4 SCC 454; Gian Kaur v. State of Punjab, (1996) 2 SCC 648; P. Rathinam v. Union of India, (1994) 3 SCC 394.

22 Shakila Abdul Gafar Khan v. Vasanth Raghunath Dhoble, AIR 2003 SC 4567; Nilabati Behera v. State of Orissa, (1993) 2 SCC 746.

23 Peoples Union for Civil Liberties v. Union of India, AIR 2004 SC 456; Kartar Singh v. State of Punjab, (1994) 3 SCC 569.

24 Safai Karamchari Andolan v. Union of India, 2014 (4) SCALE 165.

25 National Legal Services Authority v. Union of India, (2014) 5 SCC 438.

26 Society For Un-Aided Private Schools Of Rajasthan v. Union of India, (2012) 6 SCC 1; Unni Krishnan v. State of Andhra Pradesh, (1993) 1 SCC 645.

27 Murli Deora v. Union of India, AIR 2002 SC 40; Consumer Education and Research Centre v. Union of India, AIR 1992 SC 922.

28 Parmanand Katara v. Union of India, AIR 1989 SC 2039; Paschim Banga Khet Mazdoor Samity v. State of West Bengal, AIR 1996 SC 2426.

29 Olga Tellis v. Bombay Municipal Corporation, (1985) 3 SCC 545; PUCL v. Union of India, 2012 (1) SCALE 735.

30 Chameli Singh v. State of Uttar Pradesh, (1996) 2 SCC 549.

31 Virender Gaur v. State of Haryana, (1995) 2 SCC 577; In Re: Noise Pollution, (2005) 5 SCC 733.

32 Indian Council for Enviro-Legal Action v. Union of India, (1996) 3 SCC 212; Vellore Citizens Welfare Forum v. Union of India, (1996) 5 SCC 647; M.C. Mehta v. Kamal Nath, (1997) 1 SCC 388.

33 Vellore Citizens Welfare Forum v. Union of India, (1996) 5 SCC 647.

34 A.P. Pollution Control Board v. M.V. Nayadu, (1999) 2 SCC 718.

35 M.C. Mehta v. Kamal Nath, (1997) 1 SCC 388.

36 Misc. Petition No. 519 of 1974 (Unreported).

37 State of Uttaranchal v. Balwant Singh Chaufal, AIR 2010 SC 2550.

38 Bandhua Mukti Morcha v. Union of India, AIR 1984 SC 802; Dr. Upendra Baxi v. State of Uttar Pradesh, (1983) 2 SCC 308; Hussainara Khatoon v. Home Secretary, State of Bihar, AIR 1979 SC 1360; People's Union for Democratic Rights v. Union of India, AIR 1982 SC 1473.

39 T.N. Godavarman Thirumulpad v. Union of India, AIR 1997 SC 1228; M.I. Builders v. Radhey Shyam Sahu, AIR 1999 SC 2468; Subhash Kumar v. State of Bihar, AIR 1991 SC 420; M.C. Mehta v. Union of India, (1992) 3 SCC 256; Virendra Gaur v. State of Haryana, (1995) 2 SCC 577.

40 S.P. Gupta v. Union of India, AIR 1982 SC 149; Shiv Sagar Tiwari v. Union of India, (1996) 6 SCC 558; Vineet Narain v. Union of India, (1996) 2 SCC 199, (1998) 1 SCC 226; Manohar Lal Sharma v. Principal Secretary, (2014) 2 SCC 532. 
41 Narmada Bachao Andolan v. State of Madhya Pradesh, AIR 2011 SC 1989 (strict rules of pleading not applicable); Rural Litigation and Entitlement Kendra, Dehra Dun v. State of Uttar Pradesh, AIR 1988 SC 2187 (letter sufficient to entertain a PIL without a formal writ petition being filed); Ratlam Municipality v. Vardhichand, AIR 1980 SC 1622 (judicial visits to the site); Bandhua Mukti Morcha v. Union of India, AIR 1984 SC 802 (appointing judicial commissions); Indian Council for EnviroLegal Action v. Union of India, AIR 1996 SC 1446 (reliance placed on reports prepared by National Environment Engineering Research Institute, Nagpur); T.N. Godavarman Thirumulpad v. Union of India, AIR 1997 SC 1228 (the Central Empowered Committee used as a mechanism to assist the Court in its 'green bench' jurisdiction); Shivarao Shantaram Wagle v. Union of India, AIR 1988 SCC 952 (independent scientific expert committee).

42 Vineet Narain v. Union of India, AIR 1997 SC 1228, AIR 1998 SC 889 (continuing mandamus).

43 National Legal Services Authority v. Union of India, (2014) 5 SCC 438.

44 Suresh Kumar Koushal v. NAZ Foundation, (2014) 1 SCC 1.

45 Peoples Union for Civil Liberties v. Union of India, AIR 2004 SC 456; Kartar Singh v. State of Punjab, (1994) 3 SCC 569.

46 Naga People's Movement of Human Rights v. Union of India, (1998) 2 SCC 109.

47 Nandini Sundar v. State of Chhattisgarh, (2011) 7 SCC 547.

48 (1977) 3 SCC 592. Hereinafter Rajasthan.

49 (1994) 3 SCC 1. Hereinafter Bommai.

50 (2006) 2 SCC 1.

51 AIR 1960 SC 51. Hereinafter Babulal Parate.

52 (1997) 8 SCC 191. Hereinafter Samatha.

53 (2002) 2 SCC 333.

54 Instead of going with the spirit of the Fifth Schedule protections, the Court reasoned that the grant of a mining lease to BALCO in a scheduled area of Chhattisgarh was permissible because it was governed (at that point in time) by the law of Madhya Pradesh and not Andhra Pradesh (whose law governed the situation in Samatha).

55 North East India: Status of Governance in the Sixth Schedule Areas, available at http://socialissuesindia. files.wordpress.com/2012/10/sixthschedule.pdf [last accessed on August 26 2014].

56 Ibid.

57 For instance, the beneficial provisions of the Code of Criminal Procedure, 1973, have not been extended to the scheduled areas in Andhra Pradesh, which continue to be governed by the colonial criminal procedure code of 1898. See K. Bojji Reddy v. State of Andhra Pradesh, 1995 (1) ALT (Cri.) 43.

58 AIR 1970 SC 422.

59 Govt. of A.P. v. Mohd. Ghouse Mohinuddin, (2001) 8 SCC 416; Govt. of A.P. v. Suryanarayanarao, 1991 Supp (2) SCC 367.

60 C. Surekha v. Union of India, (1988) 4 SCC 526; Dr. Fazal Ghafoor v. Principal, Osmania Medical College, (1988) 4 SCC 532.

61 AIR 1975 SC 2299. Hereinafter Indira Gandhi.

62 AIR 1973 SC 1469. Hereinafter Kesavananda.

63 AIR 1982 SC 149. Hereinafter S.P. Gupta.

64 (1993) 4 SCC 441.

65 In Re: Appointment and Transfer of Judges, (1998) 7 SCC 739.

66 See Union of India v. R. Gandhi, (2010) 11 SCC 1.

\section{References}

Austin, G. (1999) Working a Democratic Constitution: The Indian Experience, New Delhi: Oxford University Press.

Baxi, U. (1985) 'Taking Suffering Seriously: Social Action Litigation in the Supreme Court of India', Third World Legal Studies 4: 107-132.

Bhagwati, P. N. (1985) 'Judicial Activism and Public Interest Litigation', Columbia Journal of Transnational Law 23: 561-577.

Desai, A. and S. Muralidhar (2000) 'Public Interest Litigation: Potential and Problems', in B.N. Kirpal, A.H. Desai, G. Subramanium, R. Dhavan and R. Ramachandran (eds) Supreme but not Infallible: Essays in Honour of the Supreme Court of India, New Delhi: Oxford University Press. 
Forrester, D. (1970) 'Subregionalism in India: The Case of Telangana', Pacific Affairs 43 (1): 5-21.

Jain, M.P. (2000) 'The Supreme Court and Fundamental Rights', in S.K. Verma and Kusum Kumar (eds) Fifty Years of the Supreme Court of India: Its Grasp and Reach, New Delhi: Oxford University Press.

Khosla, M. (2009) 'Addressing Judicial Activism In The Indian Supreme Court: Towards An Evolved Debate', Hastings International and Comparative Law Review 32: 55-99.

Khosla, M. (2012) 'Making Social Rights Conditional: Lessons from India', International Journal of Constitutional Law 8: 739-765.

Khosla, M. (2012) The Indian Constitution, New Delhi: Oxford University Press.

Malhotra, S.G. (2013) 'Right Place, Wrong Arrangement', The Hindu, June 18, 2013, available at http://www.thehindu.com/opinion/op-ed/right-place-wrong-arrangement/article4823988.ece [accessed 25 August 2014].

Malhotra, S.G. (2014) 'Tribal Autonomy Undermined: Fifth Schedule Areas', available at http://www. epw.in/web-exclusives/tribal-autonomy-undermined.html-0 [accessed 25 August 2014].

North East India: Status of Governance in the Sixth Schedule Areas, available at http://socialissuesindia.files. wordpress.com/2012/10/sixthschedule.pdf [accessed 26 August 2014].

Sridhar, M. (n.d.) 'Evolution and Philosophy behind the Indian Constitution', Political Concepts and Constitution of India, available at http://www.hrdiap.gov.in/87fc/images11/4.pdf [accessed 1 August 2014].

Sudarshan, A. (2005) 'Constitutional Perspectives on Good Governance’, Student Bar Review 17: 15-37.

Tushnet, M. (2011) 'Reflections On Judicial Enforcement of Social and Economic Rights In The Twenty-First Century', NUJS Law Review 4: 177-187.

Upadhyay, S. (n.d.) 'Tribals And Their Lands: Legal Issues and Concerns with Special Reference to Madhya Pradesh and Andhra Pradesh', available at http://siteresources.worldbank.org/INTINDIA/ Resources/sanjay_upadhyay-paper.doc [accessed 26 August 2014]. 


\title{
4 \\ ECONOMIC FOUNDATION OF INDIA
}

\author{
Kunal Sen
}

\section{Introduction}

When India became a republic in 1950, the economy was primarily agrarian, with threefifths of output originating from agriculture. In the sixty years since independence, there has been a significant transformation of economic activity away from agriculture, with less than one-fifth of output now originating from agriculture and the rest from manufacturing and services. Since the 1980s, along with structural change, there has been strong economic growth, till 2010, followed by a period of declining growth. In this chapter, we describe India's economic foundation, paying particular interest to the processes of economic growth and structural change. We begin with a brief discussion of the patterns of growth and structural change since independence. We then discuss the economic policies that have underpinned India's economic development. Next we discuss the evolution of the three main economic sectors - agriculture, industry and services. We end with a summary of India's regional performance.

\section{Historical roots}

India went through two very different growth phases in the first half of the twentieth century, prior to independence. In the first period, up to 1914, global trade increased to unprecedented levels due to dramatically decreasing transport costs and the 'common currency' effect of the gold standard (Findlay and O'Rourke 2007). During this period, India had a liberal trade regime imposed on it by its colonial master, the British. In this period, India benefited from increased integration with a Europe-centred world economy (Roy 2011). In the second period, 1914-1947, following the outbreak of the First World War and leading up to the Great Depression, transport costs started rising, the gold standard was on the demise and protectionism was on the increase. This led to a phase that the economic historians Findlay and O'Rourke describe as 'deglobalisation' as world trade volumes collapsed. India, with its dependence on the world economy for its growth impulse in the colonial period, suffered a protracted stagnation in standards of living.

By the end of the colonial period, there had been a marked intensification of poverty, as agricultural production stagnated and there was a collapse of artisanal industry (Roy 2011). 
There were pockets of growth, however, in trade and large-scale industry, especially textiles. Much of the growth in the economy occurred in regions favoured by colonial investments in irrigation and infrastructure, and the economy was unbalanced, both spatially and sectorally, at the time of independence.

\section{Growth and structural change in the Indian economy}

In this section, we set out the 'stylised facts' of India's economic development. We begin with an overview of India's record in economic growth, and then move on to a description of the process of structural change in the economy.

\section{Economic growth}

After a long period of stagnation, especially from the mid-1960s to the late 1970s, GDP (gross domestic product) per capita started rising in the late 1970s, and has kept on steadily increasing over the last two decades of the twentieth century and in to the first decade of the twenty-first century. This is a remarkable achievement in terms of increases in average standards of living, and one paralleled by few other countries in the same period, except for China. However, the process of economic growth has not been balanced, at least across the major sectors of the economy - agriculture, manufacturing and services. The average annual rate of economic growth accelerated from 2.9 per cent in 1965-1979 to 5.8 per cent in 1980-1990. This was mostly due to an increase in the rates of growth of the service sector (which rose from an annual average of 4.3 per cent in 1965-1979 to 6.5 per cent in 19801990), and the manufacturing sector (which grew from an annual average of 4.1 per cent in 1965-1979 to 6.9 per cent in 1980-1990). In the most recent period, 2001-2008, the annual average rate of economic growth has been 7.3 per cent, the highest since independence and in large measure due to very strong growth in the service sector (8.7 per cent annually over this period). By contrast, the annual average rate of growth of the agricultural sector has been around 3 per cent over 1991-2008. Since the early 1980s agriculture has been the laggard in economic growth in India.

\section{Structural change}

There has been significant change in the structure of the Indian economy in the six decades since independence. Whereas in 1955, agriculture comprised 57 per cent of output, in 2008 , it comprised a mere 19.8 per cent. While in 1955, manufacturing comprised 9.9 per cent of output, in 2008, it was 15.6 per cent. This was mostly due to the growth in the output of the organised or formal manufacturing sector, from 4.9 per cent in 1955 to 10.6 per cent in 2008 . Perhaps the most remarkable feature of the Indian economy's structural change has been the increase in the share of the service sector - from 19 per cent of GDP in 1955 to 40.7 per cent in 2008. It is well known that India's pattern of economic development has been atypical, in that the service sector has comprised a far higher share of economic activity than should have been the case, given India's level of per capita income (Sen 2008).

\section{Economic policies}

The economic policy of a nation is crucial in understanding its economic foundation. This is particularly true for a country like India where a highly interventionist government has 
followed a complex set of economic policies in a wide variety of areas and sectors since independence. In this section, we provide an introduction to the macroeconomic, trade, industrial and financial sector policies prevailing in India since independence.

\section{Macroeconomic policy}

One of the key features of India's post-independence economic policy until the midseventies was the strong emphasis on maintaining a conservative stance with respect to monetary and fiscal policy. Unlike many other developing countries, the Indian government kept a tight rein on the budget deficit and its monetisation during this period. From the mid-1970s, there was, however, a gradual erosion of fiscal conservatism resulting in a steady increase in the fiscal deficit. This remarkable shift in fiscal policy stance can be traced to the changing political economy of the country, as socio-economic groups (such as public-sector workers, small-scale industrialists and medium and large farmers) that were dormant in the past began to be increasingly assertive and asked for a greater share of government subsidies. At the same time, with the weakening of political power at the Centre, the Indian state became increasingly populist as it resorted to settle the claims of various 'pressure-groups' through the budgetary process. The increasing fiscal deficits of the central government were an important contributing factor behind the severe balance-of-payment crisis of 1991. Since 1991, the Indian government has attempted to keep the fiscal deficit under control, with varying degree of success.

The expansionary fiscal policies coupled with the limited measures to liberalise the economy in the mid-1980s contributed to a discernible increase in output (GDP) growth in the economy from the early 1980s. This growth momentum, however, turned out to be unsustainable as the widening budget deficit and rapid increase in imports unmatched by export growth soon began to be reflected in a widening current account deficit. Despite rapid increase in inward remittances by expatriate Indians, the widening current account deficit began to reflect a rapid erosion in the nation's external reserve position. The situation was aggravated by the abrupt fall in remittance inflows and oil price increases caused by the Gulf War leading to the mid-1991 balance-of-payments crisis. The crisis proved to be the harbinger of a significant structural adjustment-cum-liberalisation reform implemented under the supervision of the IMF.

The crisis led to a temporary decline in GDP growth in 1991 and 1992. Since then there has been a rebound of the economy, with annual growth rates comparable to or ever higher than those of the 1980s. The average annual growth rate during 1993-1999 was 6 per cent compared to 5.5 per cent for the $1980 \mathrm{~s}$.

As a consequence of expansionary macroeconomic policy the rate of inflation witnessed an upsurge in the 1980s. The annual rate of inflation (measured by the GDP deflator) in the 1980s was 6 per cent, up from less than 3 per cent in the 1970s. Inflation peaked at over 10 per cent during the 1991 crisis, but has subsequently come down, falling below 8 per cent since 1995. This was primarily the result of monetary tightening but also of a freeze on all administered prices including food and fuel. Despite declared policy commitments, the government has not been able to achieve the fiscal consolidation required for successfully combining sustained rapid growth with low inflation. The very small improvement in the fiscal deficit since 1991 has been achieved by a fall in public investment, rather than through broadening the revenue base or pruning current expenditure. Continued reliance on tight monetary policy on inflationary consideration at a time when the budget deficit is running high continues to thwart long run growth through continuing high interest rates. Moreover 
the reliance on cuts in public investment expenditure for want of reducing the budget deficit has not led to the provision of infrastructure needed for rapid growth under the marketoriented policy reforms (Joshi and Little 1997).

\section{Trade policy}

From the mid-1950s till the late 1970s, India had a highly restrictive trade regime. Nearly all imports were subject to discretionary import licensing or were channelled by government monopoly trading organisations. The only exceptions were commodities listed in the Open General Licence (OGL) category. Capital goods were divided into a restricted category and the OGL category. While import licences were required for restricted capital goods, those in the OGL could be imported without a licence subject to several conditions. The most important of these were that the importing firm had to be the 'actual user' of the equipment and could not sell the latter for five years without the permission of the licensing authorities and that the resulting change in capacity must be compatible with the capacity approved by the industrial licensing authorities. Intermediate goods were divided into the banned, restricted and limited permissible categories plus an OGL category. As these names suggest, the first three lists were in order of import licensing stringency. OGL imports of intermediate goods were also governed by the 'actual user' condition. The import of consumer goods was, however, banned (except those which were considered 'essential' and could only be imported by the designated government canalising agencies).

Beginning with the export-import policy of 1977, there was a slow but sustained relaxation of import controls. Several capital goods, which until then remained under stringent import licensing, were steadily shifted to the OGL category.. These changes were made with the intention of allowing domestic industries to modernize and OGL status was usually accompanied by reduced customs tariff rates. Moreover, during the 1980s the import licensing of capital goods in the restricted list was administered with less stringency. In the case of intermediate goods too, there was a steady shift of items from the restricted and limited permissible categories to the OGL category. However, in the case of both capital and intermediate goods, in most cases these goods were placed in the OGL list if they were not being domestically produced. Thus, import liberalisation during this period may not have led to immediate direct competition to established producers of intermediate and capital goods in India (though in several instances, the goods that were allowed to be imported were imperfect substitutes of domestically produced goods). Furthermore, the average effective tariff rate for capital goods increased from 37 per cent in 1973 to 63 per cent in 1988. Also, consumer goods remained on the banned list for the entire duration of the 1970s and 1980s. Like imports, exports were also subject to an elaborate licensing regime. There were goods whose export was 'not allowed', goods whose exports were considered on a case-by-case basis, goods whose export was allowed within an export quota announced and allocated each year, goods whose export was canalised, and goods on the OGL list that could be exported subject to prescribed conditions.

The pace of the trade reforms - in particular, the shift from quantitative import controls to a protective system based on tariffs - initiated in the mid-1970s was considerably quickened by the new government (led by Rajiv Gandhi) that came into power in November 1985. Also, beginning in the mid-1980s, there was a renewed emphasis by the new administration on export promotion. The number and value of incentives offered to exporters were increased and their administration streamlined. Export licensing was also not generally implemented in a manner that became a significant deterrent to exports. 
In 1991, as a part of the structural adjustment programme, quotas on the imports of most machinery and equipment and manufactured intermediate goods were removed. Furthermore, the 'actual user' criterion for the imports of capital and intermediate goods was removed. There was also a significant cut in tariff rates, with the peak tariff rate reduced from 300 per cent to 150 per cent and the peak duty on capital goods cut to 80 per cent. There was, however, little change in trade policy with respect to consumer goods, which remained on the 'negative' (banned) list. After the 1990s, consumer goods industries, which continued to benefit from these continuing import bans, accounted for over 40 per cent of domestic manufacturing value added (Joshi and Little 1997).

\section{Industrial policy}

The two key components of the regulatory framework were the Industries (Development and Regulation) Act of 1951 and the Industrial Policy Resolution of 1956. The first piece of legislation introduced the system of licensing for private industry. The licensing system governed almost all aspects of firm behaviour in the industrial sector, controlling not only entry into an industry and expansion of capacity, but also technology, output mix, capacity location and import content. The principal aim of this Act was to channel investments in the industrial sector in 'socially desirable directions'. The Industrial Policy Resolution classified industries into three categories, based on the role the state was expected to play in each category. The divisions were: a) industries in Schedule A, mostly public utilities, basic and strategic industries, which were exclusively reserved for the state to develop; b) industries listed in Schedule B, mostly heavy industries that were to be progressively owned by the state but private firms were also allowed to enter; and c) industries outside the Schedules A and B which were open to private firms.

The system of controls was reinforced in the 1970s with the introduction of the Monopolies and Restrictive Trade Practices (MRTP) Act in 1970 and the Foreign Exchange Regulation Act (FERA) in 1973. The MRTP Act stipulated that all large firms (those with a capital base of over Rs.200 lakhs) were permitted to enter only selected industries and that too on a case-by-case basis. In addition to industrial licensing, all investment proposals by these firms required separate approvals from the government. The FERA provided the regulatory framework for commercial and manufacturing activities of branches of foreign companies in India and Indian joint-stock companies with a foreign equity holding of over 40 per cent. The Act specified a list of industries where such firms would be allowed to operate and all new investments and substantial expansions required separate approval from the government.

The industrial licensing system in conjunction with the import licensing regime led to the elimination of the possibility of competition, both foreign and domestic, 'in any meaningful sense of the term' (Bhagwati and Desai 1970: 272). As it became increasingly complex over time, it led to 'a wasteful misallocation of investible resources among alternative industries and also accentuated the under-utilisation of resources within these industries' (Bhagwati and Srinivasan 1975: 191) thus, contributing to high levels of inefficiency in the industrial sector. As Bhagwati (1993) pointed out, 'the industrial-cum-licensing system ... had degenerated into a series of arbitrary, indeed inherently arbitrary, decisions where, for instance, one activity would be chosen over another simply because the administering bureaucrats were so empowered, and indeed obligated, to choose' (p. 50).

In the mid-1980s, there were some half-hearted liberalisation measures such as the dilution of licensing requirements as regards entry and expansion of capacity. The list of 
industries open to large firms was also extended and the asset threshold above which firms were subject to monopoly regulation raised. Substantial deregulation occurred in 1991 with the industrial licensing system abolished altogether, except for a select list of environmentally sensitive industries (Mookherjee 1995). Sections of the MRTP Act that restricted growth or merger of large business houses were eliminated. The list of industries reserved for the public sector was reduced from seventeen to six and private investment actively solicited in the infrastructural sector. Foreign ownership up to a certain limit was 'automatically' approved for a wide range of industries deemed to be of national importance. Therefore, the policy regime since 1991 provided a far more conducive environment for private-sector firms to diversify and grow (Panagariya 2008). However, certain aspects of the old regulatory framework remained in place, in particular, labour laws that prohibit firms over a certain size from firing workers who have been in employment with the firm for more than one year, and bankruptcy procedures that do not allow firms to liquidate their assets easily.

\section{Financial sector policy}

In the 1950s and 1960s, the Indian financial sector operated in a fairly liberal environment. This period saw the consolidation of the Reserve Bank of India (RBI) in its role as the agency in charge of the supervision and control of banks. An important feature of the banking sector during the period 1951-1968 was that a large proportion of bank credit went to the industrial sector and. within it, to the large borrowers, with the agricultural sector getting a little over 2 per cent of bank credit. Thus, there was a growing realisation among Indian policy-makers that there was a need for extensive social control of the Indian banking system. In July 1969, as a consequence, fourteen of the largest commercial banks were nationalised.

Evolution of the Indian financial sector beginning in 1969 can be divided into three distinct sub-periods: first, a period of increasing financial repression from the early 1970s to the mid-1980s; second, a period of mild reforms until 1991; and finally, from 1991, a period of an increasingly liberalised financial sector. In the first period, the bank nationalisation of 1969 was followed by the nationalisation of six more Indian commercial banks in 1980 . Banks were increasingly pressurised to lend to the 'priority sector', comprising agriculture and allied activities, small-scale industry, retail trade, transport operators, professionals and craftsmen. While this meant that more credit was available to small-scale firms, medium and large firms may have received a decreasing share of bank credit in the process. At the same time, there was an increasing recourse to the banking sector via the statutory liquidity ratio to finance the ever-widening budget deficits of the central government in the 1970s and the 1980s, possibly crowding out bank financing of private investment. While the commercial banks essentially provided short-term credit to the manufacturing sector, long-term loans were provided by All India Development Banks like the Industrial Development Bank of India and Industrial Credit and Investment Corporation of India. These term-lending institutions depended a lot on the government for resources (usually subsidised heavily) and their allocation of long-term loans to firms was strictly monitored by the government according to plan priorities. The government with respect to pricing, quantum and timing of new issues controlled the stock markets.

While social control of the banking sector might have led to increasing inefficiency in the financial intermediation process, there was significant growth in the commercial banking system in the country both in geographical coverage and amount of resources mobilised (Sen and Vaidya 1997). This was in great part due to a strictly enforced branch licensing policy followed by the RBI. Under this policy, the RBI restricted banks from opening branches 
in urban and metropolitan areas. Instead, the thrust of branch expansion was mostly to the 'under-banked' districts in rural and semi-urban areas. This led to an increase in bank deposits as a percentage of national income from 15.3 in 1969 to 51.8 in 1994, and significant financial deepening in the Indian economy.

In the second period, from the mid-1980s, there was a gradual set of reforms in the money markets with little or no change in policies relating to the provision of credit to firms in the industrial sector. Some attempts were made to develop the government securities period during this time. More radical reforms had to wait till 1991 when, as part of the structural adjustment programme, the statutory liquidity ratio was substantially reduced. The interest rates on short-term loans (provided predominantly by the commercial banks) have also been deregulated in a phased manner since 1992 and by 1994 commercial banks were completely free to set their own lending rates. The interest rates on long-term loans (predominantly provided by All India Development Banks like Industrial Development Bank of India and Industrial Credit and Investment Corporation of India) were also deregulated in a phased manner and by 1992 were freed of all controls. Interest rate deregulation, softening of consortium lending arrangements, and the opening up of the banking sector to the entry of new private banks have set the stage for the emergence of a more competitive financial sector.

Since 1991, there has been a substantial deregulation of the stock market, especially the operation of the new issues market and relaxation of restrictions on the entry of foreign portfolio investors. Transparency of stock trading practices has improved as a result of the introduction of screen-based trading and the establishment of the National Stock Exchange that compete with the Bombay Stock Exchange, the premier exchange in the country. Indian firms with good track records have been allowed to issue bonds and equity in foreign capital markets. On balance, the financial liberalisation measures implemented since 1991 have led to a relatively easier access to capital markets, both at home and abroad, for firms and may have eased borrowing constraints on their investment decisions under the new policy regime.

To summarise our discussion, the evolution of economic policies in India in the postindependence period can be classified into three phases. The first phase was one of control and command, which stretched from the mid-1950s to the early 1980s. The second phase from the early 1980s to the early 1990s was a period of slow and uneven reform, with the liberalisation measures occurring mostly in the trade and industrial sector. The third phase from 1991 to the present was one of rapid and radical reforms, with the reforms encompassing almost every aspect of the policy regime.

\section{Economic sectors ${ }^{1}$}

In this section, we discuss patterns of growth and development in the core economic sectors - agriculture, industry and services - in turn.

\section{Agricultural sector}

After a period of slow growth in the 1950s, the new Borlaug seed-fertiliser technology introduced in the mid-1960s had a significant impact on raising yields and output levels of some crops and ushered in the Green Revolution and a rise in India's aggregate agricultural production. In the beginning, the new technology was initiated for wheat in the irrigated north-western region of India, but by the1970s, the Green Revolution had covered rice and other crops, and had spread to many other parts of the country and to small producers (Farmer 1977, Bhalla and Singh 2009). The growth rate of agricultural output at the All-India level 
accelerated from 2.24 per cent per annum in 1962-1983 to 3.37 per cent per annum between 1980 and 1993. Most of the output growth was due to productivity, with yields accounting for 85.2 per cent of output growth. In the 1980-1993 period, agricultural growth kicked off in the previously stagnant states of Eastern India (Rogaly et al. 1999). By 1992-1993, the diffusion of High Yielding Varieties of seeds which formed the basis of the Green Revolution was more or less complete, with about 90 per cent of wheat area and 70 per cent of rice area occupied by them (Kotwal et al. 2011). There was a strong association between agricultural growth and rural poverty decline in this period (Palmer-Jones and Sen 2003).

However, since 1993, output growth has decelerated to 1.74 per cent per annum, a slowdown observed in most states of India. At the same time, there was a shift in cropping pattern changes towards high-value crops compared to the period 1980-1993 before the agricultural reforms. In addition, the land/labour ratio has increased in most regions in India, in part due to the weak demand for labour from the non-farm sector and in part, due to the decline in agricultural productivity in the post-reform period, which implied falling productivityinduced demand for labour from the farm sector. The exhaustion of the possibility of an increase in the gross cropped area of most parts of India meant that agricultural development relied heavily on intensive growth. It is not clear what led to the decline in agricultural productivity in the post-reform period - a decline in public investment in agriculture may have been a contributing factor, though input subsidies to agriculture increased during the 'reforms' (Harriss-White and Janakarajan 2004). In addition, expenditure on the publicsector agricultural research system for agriculture faltered, as did the productivity of the research system (Kotwal et al. 2011).

The economic reforms themselves were not directly targeted to the agricultural sector, though there were indirect effects working through changes in the credit system for agriculture, with a weakening of the mandatory requirements for commercial banks to open rural and semi-urban branches, as well as an improvement in the terms of trade for agriculture in the 1990s as protection for industry was removed (along with higher minimum support prices for rice and wheat), leading to a fall in industrial prices (Balakrishnan et al. 2008). While the decrease in bank density in rural areas may have had an adverse effect on the financing of private agricultural investment, rising real prices for agricultural commodities in the post-reform period seemed to have a positive effect on output growth in the agricultural sector (Joshi et al. 2006).

\section{Industrial sector}

As we have noted earlier, the sector that has witnessed the largest set of reforms is the industrial sector. Prior to the reforms, the licensing policy served to divorce marketdetermined investment decisions from any guidelines that international opportunity costs might have otherwise provided (Bhagwati and Srinivasan 1975). In this environment, as we have observed earlier, there was little incentive for firms to export, given the high profitability of producing for the domestic market, and it thus contributed to high levels of inefficiency in the industrial sector.

Following the 1991 reforms, domestic deregulation has had surprisingly little effect on productivity and innovation. Trade liberalisation, especially in the form of access to imported intermediate goods, has been the dominant factor behind the increase in productivity growth in Indian manufacturing (Chand and Sen 2002). But there has been little evidence of creative destruction or product churning since the reforms of 1991 (Goldberg et al. 2010). The industrial sector is still dominated by incumbents - state-owned firms and business groups - 
and there is limited new firm entry in the formal manufacturing sector (Alfaro and Chari 2009). The reasons for this appear to be first, significant impediments to firm exit in form of stringent bankruptcy laws which still favour restructuring of existing loss-making firms rather than closure, and second, the political connections that incumbents have which allow them to prevent entry of new firms, especially in concentrated, profitable industries and in industries dominated by state-owned corporations (Mody et al. 2010).

\section{Services sector}

The service sector had the fastest growth rate of all three sectors in the post-1991 period. Between 1993 and 2004, the two fastest growing service sectors were business services and communications. This was mostly due to the advent of cellular technology as the government opened telecommunications to the private sector by relinquishing its monopoly control over communication services (Kotwal et al. 2011). Economic reforms that relaxed the entry of foreign firms into the services sector were also directly behind service sector growth as the share of services in foreign direct investment increased from 10.5 per cent in the early 1990s to nearly 30 per cent in the second half of the decade (Chanda 2007). As a consequence of the entry of outward-oriented foreign direct investment (FDI) into the information technology sector after 1992, software exports grew substantially - at nearly six times the rate for world exports of services.

It is often observed that the service sector in India is commonly skill intensive, and that its growth has mostly required skilled labour. This is certainly true for export-oriented information technology related sectors, e.g. communications and business services. However, other fast growing segments of the service sector are intensive in unskilled labour, the most important of which are the trade, hotel and restaurants sector. These services have rapidly increased their share in GDP from 9.1 per cent in 1955 to 16.7 per cent in 2008. Kotwal et al. (2011) show that the trade, hotel and restaurants sector grew rapidly in the 1990s, and was an important sector for the creation of unskilled labour-intensive jobs. Therefore, services sector growth was also driven by the unskilled labour-intensive hospitality and construction sectors, and not just by the skill-intensive information technology sector.

\section{Regional growth}

As we have discussed, economic growth in India has been strong since the mid-1980s. However, not all regions in India have benefited equally from the improvement in overall economic performance. States like Andhra Pradesh, Gujarat, Karnataka, Kerala and Tamil Nadu have grown at a rate of per capita income which has exceeded 4.5 per cent per annum during the period. On the other hand, states such as Assam, Bihar and Madhya Pradesh have grown at around 2 per cent or less in the same period. In contrast to the experience of China where geographical factors such as land-lockedness and access to the sea explain to a large extent the patterns of regional economic performance, there has been no clear correlation between geography and regional growth in India. Land-locked states such as Punjab and Haryana have exhibited strong economic growth and coastal states such as Orissa have shown significantly weaker economic performance.

India's federal structure and the significant political autonomy and independence in legislative powers enjoyed by state governments, along with regional variations in the collective strength of the economic and political elite. have allowed for the variation in regional institutional quality that has been important for explaining the differences in 
regional performance. As Sinha (2003) has argued, subnational states in India followed very different strategies with respect to the private sector, with differing outcomes with respect to economic growth. Cali and Sen (2011) have shown where synergistic state-business relations have emerged in Indian states, economic growth has followed. In addition to differences in institutional quality, initial conditions such as differences in agro-climatic factors have led to the uneven impact of the Green Revolution, and consequently, divergence in agricultural growth (Palmer-Jones and Sen 2003). This has also contributed to the differences in regional economic performance across India.

The economic growth trajectories of the states of Andhra Pradesh and West Bengal provide strong support for the argument that far more than geographical factors, political and economic institutions played a key role in the differing economic performance of these two states. West Bengal had favourable initial conditions at independence with a relatively large industrial sector, and a large professional class. However, West Bengal has witnessed slow economic growth, especially since the late 1960s, and a gradual decline in its manufacturing sector. This can be attributed in part to the adversarial relationship that successive state governments had with private capital that led to an insecurity of private property rights, and in part to the fragmented relationship that the state political elite has had with the national elite that led to under-investment in infrastructure and a lower allocation in industrial licences during the Licence Raj period (Sinha 2005, Chakravarty and Bose 2013). In contrast, for the Indian state of Andhra Pradesh, Alivelu, Reddy and Srinivasulu (2013) identify the coming to power of Chandrababu Naidu as Chief Minister of the state government in 1995 as the 'critical juncture' that explains the rapid improvement in state-business relations (that was sustained in the following Congress regime) as being important in Andhra Pradesh's subsequent successful record in economic growth. In addition, they attribute the emergence of a market savvy agrarian class and a modern middle class as a result of the expansion of modern education; and the proclivity on their part to look for alternative avenues of investment, as being crucial to Andhra Pradesh's growth success story.

\section{Concluding observations}

The Indian economy has shown considerable growth and structural transformation since independence. Starting out with a mostly agrarian economy with a small modern industrial sector and an insignificant services sector, the Indian economy currently is one of the largest in the world in terms of gross domestic product, with many modern industries and an export-oriented dynamic information technology sector. However, challenges remain, and in particular, the performance of the agricultural sector in the recent years has been disappointing. India also has not done well enough in formal manufacturing, especially in export-oriented industries. Regional performance has also been uneven. Therefore, while the economic foundation of the Indian economy is significantly stronger in the 2000s as compared to at the time of independence, not all sectors or regions of the economy have shown strong performance.

\section{Note}

1 This section draws from Sen (2014). 


\section{References}

Alfaro, L. and A. Chari (2009) 'India Transformed? Insights from the Firm Level 1988-2005', NBER Working Papers 15448, National Bureau of Economic Research, Inc.

Alivelu, G., G. Reddy and K. Srinivasulu (2013) 'State Business Relations and the Performance of the Manufacturing Sector in Andhra Pradesh', in K. Sen (ed.), State Business Relations and Economic Development in Africa and India, 198-214, London: Routledge.

Balakrishnan, P., R. Golait and P. Kumar (2008) 'Agricultural Growth in India since 1991', Reserve Bank of India Department of Economic Analysis and Policy Study, 27.

Bhagwati, J. (1993) India in Transition: Freeing the Economy, Oxford: Clarendon Press.

Bhagwati, J. N. and P. Desai (1970) India: Planning for Industrialization, Oxford: Oxford University Press.

Bhagwati, J. N. and T. N. Srinivasan (1975) Foreign Trade Regimes and Economic Development: India, New York: Columbia University Press.

Bhalla, G. S. and G. Singh (2009) 'Economic Liberalisation and Indian Agriculture: A Statewise Analysis', Economic and Political Weekly, 44 (52): 34-44.

Cali, M. and K. Sen (2011) 'Do Effective State Business Relations Matter for Economic Growth? Evidence from Indian States', World Development, 39 (9): 1542-1557.

Chakravarty, D. and I. Bose (2013) 'Industrialising West Bengal? The Case of Institutional Stickiness', in K. Sen (ed.), State Business Relations and Economic Development in Africa and India, 181-197, London: Routledge.

Chand, S. and K. Sen (2002) 'Trade Liberalization and Productivity Growth: Evidence from Indian Manufacturing', Review of Development Economics, 6 (1): 120-132.

Chanda, R. (2007) 'Services', in K. Basu (ed.), Oxford Companion to Economics in India, 472-479, New Delhi: Oxford University Press.

Farmer, B. H. (ed.) (1977) Green Revolution? Technology and Change in Rice Growing Areas of Tamil Nadu and Sri Lanka, London: Macmillan.

Findlay, R. and K. H. O'Rourke (2007) Power and Plenty: Trade, War and the World Economy in the Second Millennium, Princeton, NJ: Princeton University Press.

Goldberg, P., A. Khandelwal, N. Pavnik and P. Topalova (2010) 'Multi-Product and Product Turnover in the Developing World: Evidence from India', Review of Economics and Statistics, 92 (4): 1042-1049.

Harriss-White, B. and S. Janakarajan (2004), Rural India Facing the 21st Century: Essays on Long Term Village Change and Recent Development Policy, London: Anthem Press.

Joshi, P. K., Pratap Singh Birthal and Nicholas Minot (2006) 'Sources of Agricultural Growth in India: Role of Diversification towards High-Value Crops', International Food Policy Research Institute Markets, Trade and Institutions Division Discussion Paper 98.

Joshi, V and I. M. D. Little (1997) 'India: Reform on Hold', Asian Development Review, 15 (2): 1-42.

Kotwal, A., B. Ramaswami and W. Wadhwa (2011) 'Economic Liberalization and Indian Economic Growth: What's the Evidence?' Journal of Economic Literature, 49 (4): 1152-1199.

Mody, A., A. Nath and M. Walton (2010) 'Sources of Corporate Profits in India - Business Dynamism or Advantages of Entrenchment?', IMF Working Paper 11/8.

Mookherjee, D. (1995), 'Introduction', in D. Mookherjee (ed.), Indian Industry: Policies and Performance, 1-43, Oxford: Oxford University Press.

Palmer-Jones, R. and K. Sen (2003) 'What Has Luck Got to Do with It? A Regional Analysis of Poverty and Agricultural Growth in Rural India', Journal of Development Studies, 40 (1): 1-31.

Panagariya, A. (2008) India: The Emerging Giant, New York: Oxford University Press.

Rogaly B., B. Harriss-White and S. Bose (eds) (1999) Sonar Bangla: Agricultural Growth and Agrarian Change in West Bengal and Bangladesh, New Delhi, Sage.

Roy, T. (2011) The Economic History of India, 1857-1947, Oxford: Oxford University Press.

Sen, K. (2008) Trade Policy, Inequality, and Performance in Indian Manufacturing, London: Routledge Advances in South Asian Studies.

Sen, K. (2014) 'The Indian Economy: Growth Without Structural Transformation', in D. Devlin and B. Harriss-White (eds), China-India: Pathways of Economic and Social Development, Oxford: Oxford University Press.

Sen, K. and R. R. Vaidya (1997) The Process of Financial Liberalization in India, Oxford: Oxford University Press.

Sinha, A. (2003) 'Rethinking the Developmental State Model: Divided Leviathan and Subnational Comparisons in India', Comparative Politics, 35 (4): 459-476.

Sinha, A. (2005) The Regional Roots of Developmental Politics in India: A Divided Leviathan, Bloomington, IN: Indiana University Press. 


\title{
5 \\ EQUITY, QUANTITY AND QUALITY The precarious balancing act in India's schools ${ }^{1}$
}

\author{
Vimala Ramachandran
}

\section{Introduction}

Enrolment in primary schools recorded impressive growth in the 1990s and 2000s (Table 5.1). Government and non-government surveys confirm that close to 97 per cent of children between the age group of 6 to 11 years are enrolled in primary schools. While access to primary education has improved significantly in the last 10 years, the same cannot be said for upper-primary and secondary education. For example, in 2010-2011, GER (Gross Enrolment Ratios) at primary level was 116 with little gender gap, but at the upper-primary level, it drops to 85.5 (boys 87.7 and girls 83.1). It further drops to 65 (boys 69 and girls 60.8) in classes 9 and 10 and to 39.3 (boys 42.2 and girls 36.1) in classes XI and XII. In fact, the situation in higher education remains quite worrisome with a GER of 16 per cent, far below the global average of 27 per cent (Twelfth Five Year Plan, Planning Commission, Government of India [GOI], 2011). A recent survey of out-ofschool children commissioned by the Government of India reveals that only 2.97 per cent of children are 'officially' out of school (IMRB-MHRD 2014). Many more girls are in school as are many more children from socially and economically deprived communities. A large number of teachers have also been appointed in the last five years. In fact, if we are to go by the numbers published by the government, there is much to be upbeat about the primary education scenario in India.

Yet, despite the impressive data generated every year, there is a sense of disquiet when we talk of education. Recently my colleagues were conducting focus group discussions with parents of children who had dropped out after class VIII. In almost all the villages, parents said that their children had learnt little. For example, a student of class VIII of today cannot read what a child in class IV could twenty-five years ago. Many of them enrol in secondary school but drop out early because they are unable to cope. Parents also agree that children today can barely read and have rudimentary skills in mathematics and science. What is the use of such schooling, they asked. 
Gross Enrolment Ratios is a misleading indicator. Over the last ten years, the primarylevel GER among all communities tends to be more than 100 (as evident in Table 5.1 below). This essentially means that the numbers of children enrolled in the primary classes are higher than the child population of the concerned age group - telling us that many more over age and under age children are enrolled, thereby pushing the GER above 100 . As educational participation in a community improves and almost all children are enrolled in age-appropriate grades, the GER would come down and be closer to 100 . Therefore very high GER is not a positive sign; it tells us that our children are not enrolled in the ageappropriate grade as mandated by the Right to Education Act of 2009. Formal enrolment also means little. The key issue is whether the enrolled children are actually attending school, and if they are then how regular are they?

Let us take the example of indigenous tribes of India. They are known as Scheduled Tribes (ST). If we are to take the last ten years, the GER of ST at primary (6-10 years, classes 1 to 5) steadily increases from 116.90 in 2000-2001 to 136.18. This increase is comparable to that of the Scheduled Castes (SC) communities - indicating that formal enrolment in primary school went up sharply and a large proportion of over age as well as under age children are enrolled in primary schools. As we move from primary to upper-primary (11-13 years, classes 6 to 8) the picture gets worrying - GER (upper-primary) for ST drops to 40.70 (53.90 male, 26.70 female) in the year 2000 and gradually climbs to 88.88 (90.69 male, 86.97 female) in 2010-2011. As children proceed to classes 9 and 10 (age 14-15 years) the GER in 20102011 drops to 53.26 (57.11 male, 49.15 female) and it further drops in higher secondary (age 16-17 years, classes 11 and 12) to 28.80 (32.68 male, 24.81 female). The picture that emerges from the analysis of GER is further reinforced by available data on dropout rates (source: SES MHRD, GOI Various Years).

If we look at dropout rates of ST communities as a whole in India for 2010-2011, 35.6 per cent (37.2 male, 33.9 female) drop out by the time they finish class $V$ (Table 5.2). This data is significant, especially in the light of the RTE Act of 2009. It is indeed noteworthy that the dropout rates in 2001-2002 were much higher at 52.3 per cent (51 male, 54.1 female), and today the dropout rate of boys is higher than girls. The situation looks more worrying if we are to take the elementary cycle as a whole (Classes 1 to 8), 55 per cent of ST children (54.7 male and 55.4 female) drop out before they complete class VIII. Further at the end of class X the cumulative dropout rate stands as 70.9 per cent in 2010-2011 (70.6 male, 71.3 female). Essentially, what official statistics reveal is that barely 30 per cent of the ST children who enrol in class I actually reach class X - with the majority dropping out at various stages. There is also a noticeable gap between ST, SC and All Communities, with the status of ST being most challenging.

High dropout rates reflect a deeper malaise in the Indian education system. Mere access to schooling, without commensurate focus on quality and learning outcomes is meaningless. For ten years now (since 2005) independent surveys and also government-sponsored surveys have called their bluff and declared loud and clear that all children are not learning the way they should be. In India, on a test of reading comprehension administered to grade 5 students across the country, only 46 per cent of students were correctly able to identify the cause of an event (NCERT 2011). Only a third of students could compute the difference between two decimal numbers (NCERT 2011). Another recent study found that about 43 per cent of grade 8 students could not solve a simple division problem. Even recognition of two-digit numbers, supposed to be taught in grade 2 , tends to be achieved only by grade 4 or 5 (ASER 2011; Dundar et al. 2014). This is not all - careful scrutiny of the data reveals huge rural-urban, male-female, inter-state and inter-community differences. We now know that 


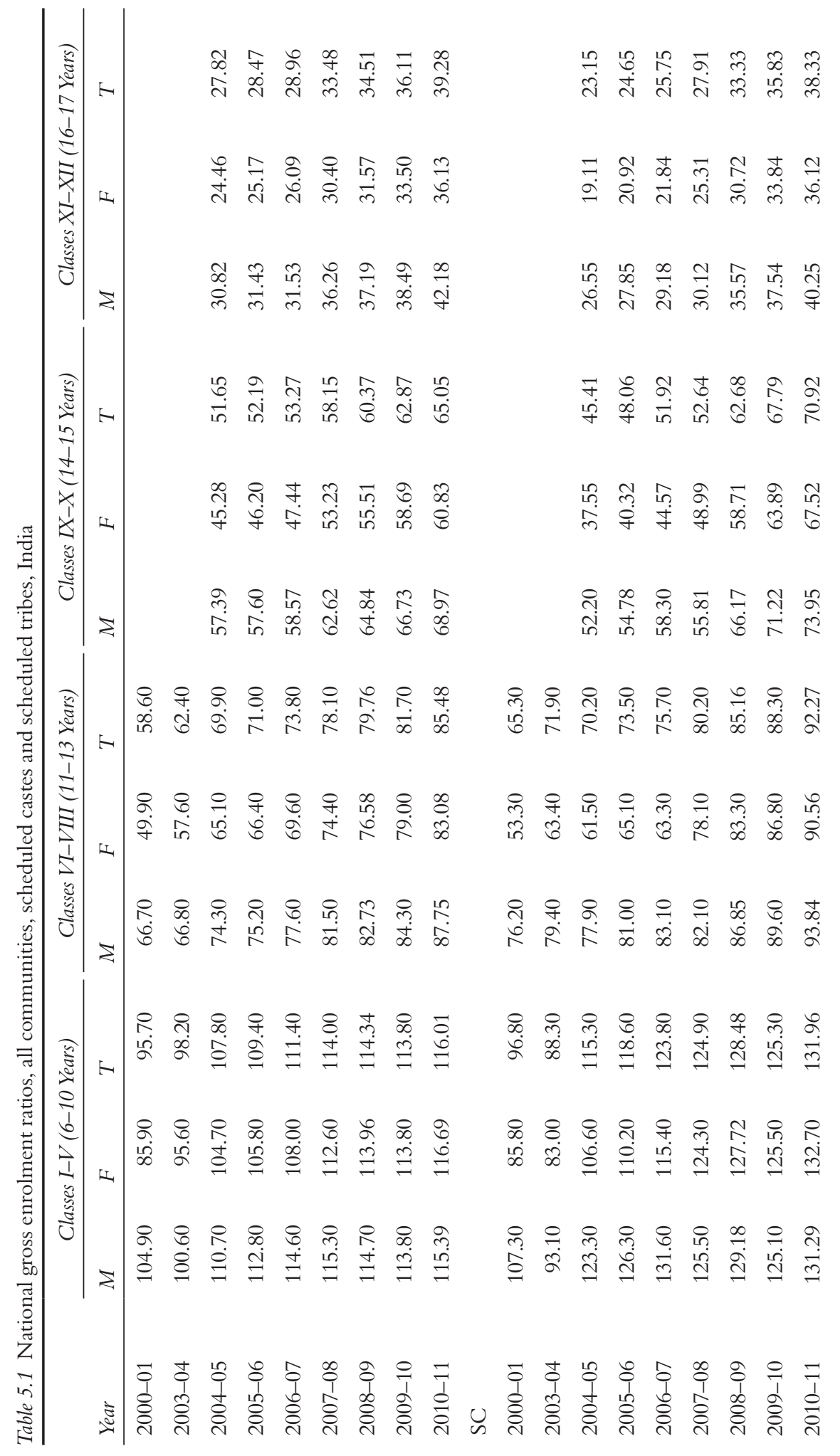




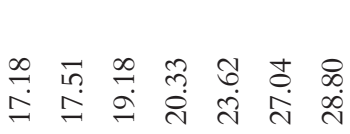

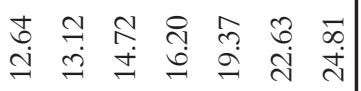

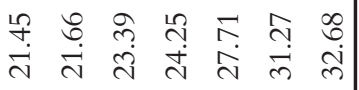

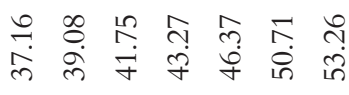

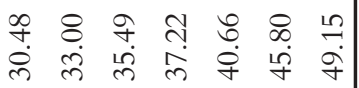

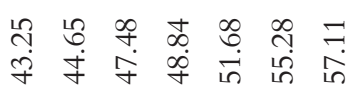

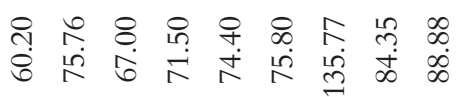

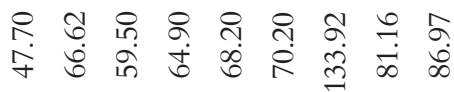

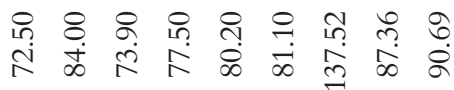

$$
\begin{aligned}
& \text { 을 \& }
\end{aligned}
$$

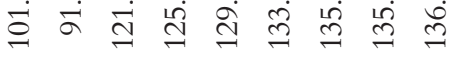

$$
\begin{aligned}
& \text { กิ } \\
& \text { ம }
\end{aligned}
$$

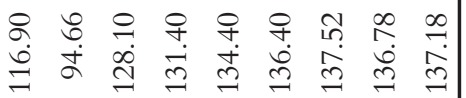

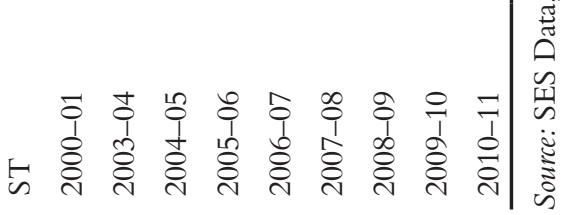




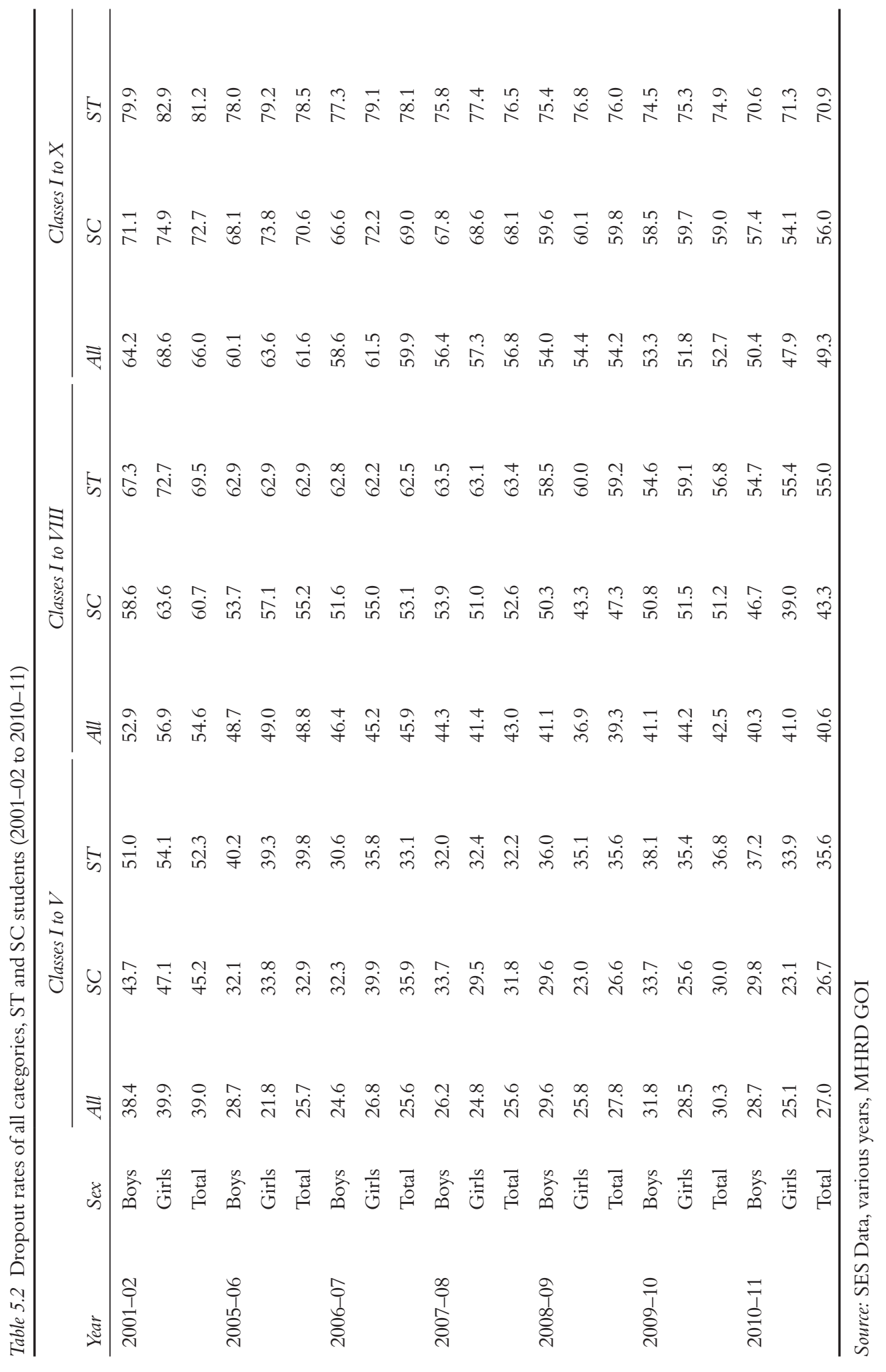


one of the biggest markers is the kind of school a child attends - alongside poverty, social status and location that effectively determines the kind of school a child would attend.

For many decades now we have known that the social and economic status of a child's family is one of the strongest determinants of a child's educational attainment. The last sixty years of educational data as well as other socio-economic surveys (like NSS, NFHS) have demonstrated this link.

Let us go back to our example of Scheduled Tribes of India. Various rounds of the National Sample Survey (NSSO, GOI) give us information on the educational status of ST communities. This national sample survey 55th Round (1999-2000), 61st Round (2004-2005) and 66th Round (2009-2010) gathered information (by social group) and therefore these three rounds give us valuable information on the comparative status of ST and other communities. These three rounds record current attendance in any educational institution (school, college, university, institute). As an indicator, it gives us information on the percentage of persons of different communities (disaggregated by gender) attending any educational institution. The picture that emerges from a perusal of NSSO data confirms the trends visible in education data of MHRD, GOI discussed above. As evident in Table 5.3, current attendance in any educational institutions in all the three age groups has been increasing as we move from 1999-2000 to 2009-2010 - and this is the case for all communities, rural and urban STs and for men and women. Yet, there is an appreciable gap between different social groups, with the status of STs being the most worrisome, followed by SC. Equally - as we move from 5-14 years to 15-19 years, there is an appreciable drop in the percentage of ST youth attending any educational institution. Let us take the latest round (2009-2010, 66th Round) data, while 81.4 per cent (81.4 male, 81.4 female) ST persons in the 5-14 age group reported attending schools in rural areas, this drops to 43.0 per cent (47.8 male, 37.3 female) when we look at 15-19 age group respondents. There is a further drop to 9.1 per cent (13.2 male, 5.8 female) when we look at 20-24 age group respondents (Table 5.3). This confirms the trends visible in both GER and dropout rates as discussed in the preceding paragraphs.

In fact, this is valid not only for India but is a global phenomenon. There is considerable evidence to show that the educational mortality of different social classes is different and the cumulative burden of poor learning and exclusion becomes most visible in higher education (Deshpande 2013). Bourdieu and Passeron, in their seminal work, also point out that

The combination of the educational chance of the different classes and the chances
of subsequent success attached to the different sections and types of schools
constitutes a mechanism of deferred selection which transmutes a social inequality
into a specifically educational inequality, i.e., an inequality of 'level' or success,
concealing and academically consecrating an inequality of changes of access to
higher levels of education.

Bourdieu and Passeron 1977: 158

The gap in achievement levels continues to grow as the child moves from primary to high school and university, with the cumulative burden of non-learning pushing children out at different stages. ${ }^{2}$ Reardon has argued that, 'The relationship between family socioeconomic characteristics and student achievement is one of the most robust patterns in educational scholarship, yet the causes and mechanisms of this relationship have been the subject of considerable disagreement and debate' (Reardon 2011: 3). In India, the mix of family poverty, location (rural, tribal, urban slum, etc.), caste / community identity, gender 


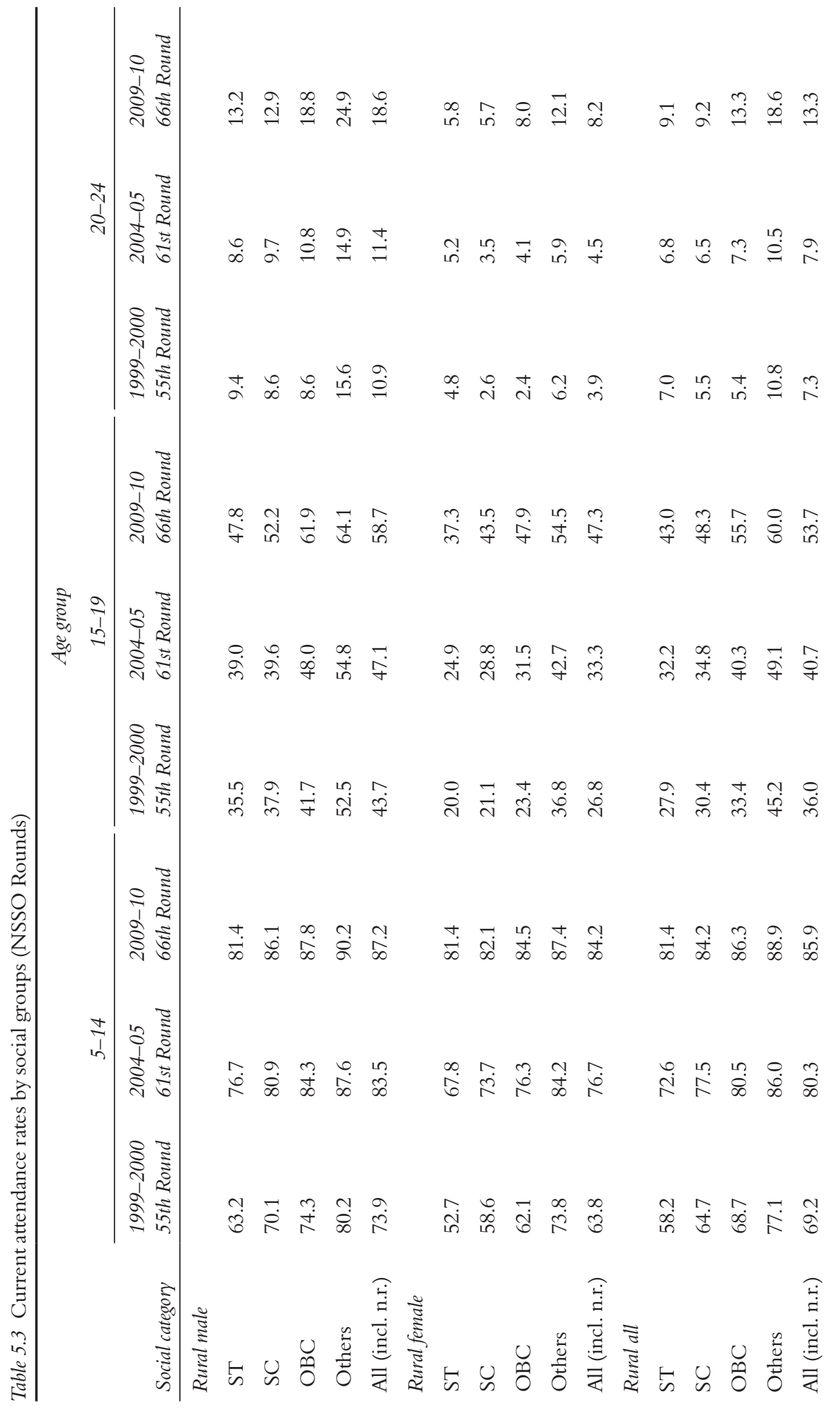




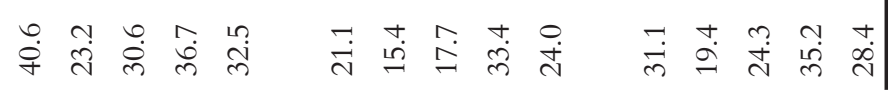

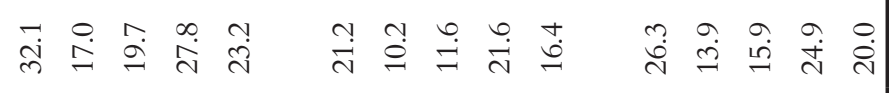

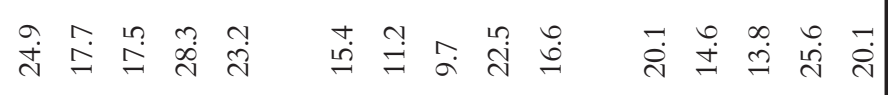

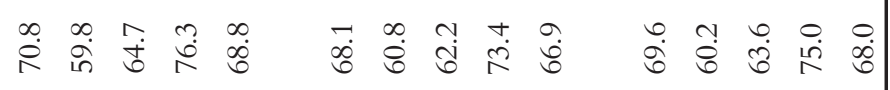

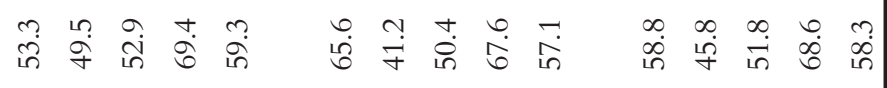

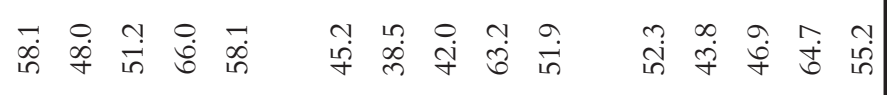

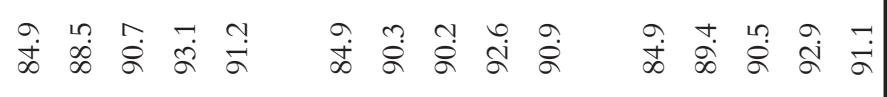

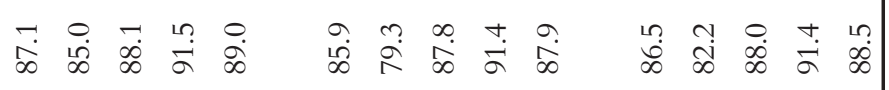

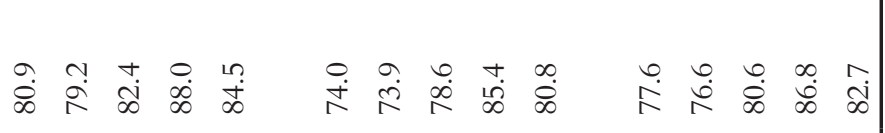

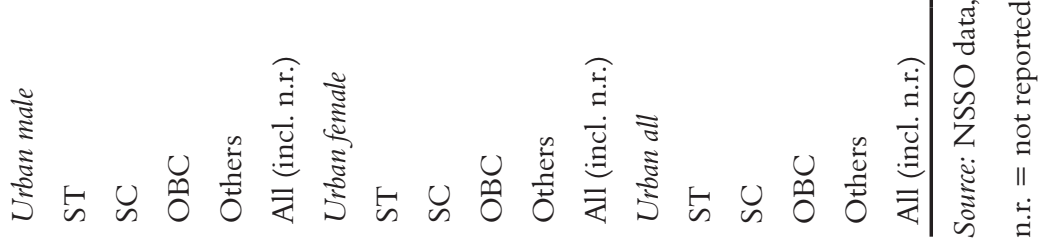


and parental occupation is known to be a significant predictor of education achievement among children (Ramachandran 2009).

Let us get back to the example of indigenous tribes that live in the heartland of India. This area is also known as Scheduled V area where the population of ST is more than 25 per cent. Recent discussions on the number of out-of-school children (OOSC) and of working children / child labour also reveal that the Schedule V states are particularly vulnerable. A recent study on multiple deprivations of ST population that did a detailed analysis of availability of schooling facilities in Jharkhand, Odisha, Chhattisgarh and MP revealed that

the difference in provisioning of education in tribal dominated areas to villages where they are negligible is remarkable in Odisha and Chhattisgarh. The gap in availability of schooling facility between villages that are tribal dominated and others increased as one goes up from primary to middle to secondary school levels, with the tribal concentrated villages having very low proportion of secondary schools per village ...

Rustagi et al. 2011: 4

This insight is confirmed when we look at GER rates and also the dropout rates of ST students at various levels of schooling. As evident in the table on GER at different stages, the GER drops as we move from primary to upper-primary to secondary and higher secondary. The situation in the states of Jharkhand and Odisha are perhaps the worst with the ST GER dropping to a low of 10.11 in Jharkhand (11.12 boys and 9.12 girls) and 17.22 in Odisha at higher secondary (boys 20.13 and girls 14.19). This picture is confirmed when we look at dropout rates.

It is therefore important for planners and administrators to understand the reasons behind poor educational participation beyond elementary. This is where there are significant data gaps - while we have overall estimates of the number of high schools / higher secondary schools to elementary (primary and upper-primary) schools, it would be valuable to calculate this for all the educational blocks with a high percentage of tribal populations. This may give us a clearer picture of access. Second, we need to also estimate the percentage of single- and two-teacher schools, schools with less than 30 to 50 students and the actual physical presence of teachers in rural habitations. A ground-level analysis of the schools, their facilities, availability of teachers, how frequently these schools are inspected / visited and the percentage of women teachers, could perhaps give us greater insights into the actual functioning of the school system in these areas.

All this points to the fact that the fight for equity is ultimately a struggle for quality education. Equally, our socio-economic identity often determines the quality of education that is accessible to us.

\section{Yet, why and how did equity and quality get disjointed?}

It is commonly believed that parents who are well off invest more resources and devote a larger proportion of their financial and social resources on their children's cognitive development. It is also argued that the rich have greater access to educational resources. The question, which then arises, is whether differentiation in the kind of schools that children attend, the quality of schooling and opportunities that are available reflects differences in income. Similarly, is it fair to assume that more educated parents (especially mothers) devoted more time and energy to the overall development of their children (Reardon 2011)? 
At another level, is there so much differentiation in the kind of schools children attend that it makes a significant difference to overall development and learning? Until the 1970s, we had heard about and met professionally successful people who had studied in a modest rural school or an urban municipal school. ${ }^{3}$ We also heard of numerous instances where a good school or a motivated teacher had been able to neutralise the odds that very poor children come with and enabled them to learn. Equally we have known of headmasters and teachers who made a big difference in the lives of very poor children, through encouragement and, most importantly, active academic support and guidance. Sadly, in the current scenario, such instances are becoming increasingly rare and in the last two to three decades, the difference in the ability of a child attending a rural primary school compared with children attending private school or a government school with a lot of resources is increasing.

The more worrying trend is that the higher number of children who are poor and those from disadvantaged communities (SCs, STs, new migrants, Muslims) end up attending schools that are more likely to have very poor facilities, indifferent teachers (in government schools), poorly qualified teachers (in low cost private schools) or are multi-grade schools with two or more classes sitting together with one teacher. Such schools are now referred to as high-poverty schools and exist in both the government sector as well as the private sector. Further, income inequality has led to an increasing spatial segregation of high-income families from middle-income and low-income families with the poorest often relegated to the outskirts of cities, inner-city slums or specific habitations in rural areas. This spatial segregation of the rich from the middle class and from the very poor essentially implies that children are going to different kinds and differentially endowed schools.

Government data also reveal another side of the picture. According to NSS 66th round data (2009-2010), a startling 14.25 million children aged between 6 and 14 years were estimated to be 'not attending'. According to District Information System for Education (DISE) data, 135.2 million students are enrolled in primary schools (an increase of 10 million children between 2005-2006 and 2010-2011). While more and more children move from primary to upper-primary, only 57.8 million children were enrolled at upper-primary level in 2009-2010. Further, these numbers drop sharply in high school and secondary school and age specific attendance ratio decreases sharply. ${ }^{4}$

The 64th round of the National Sample Survey Organisation also confirmed that close to 84 per cent of children from the poorest economic quartile attend government and government-aided schools. As we go up the economic ladder, the proportion of children attending government schools comes down and those attending private schools goes up. If we look deeper, even among the poor who are able to attend private schools go to the 'low cost' private schools where the quality of instruction is, at best, marginally better than in government schools and infrastructure is far worse.

It is indeed noteworthy that more than 90 per cent of rural as well as urban households reported having a school with primary classes within $1 \mathrm{~km}$. But availability of schools with middle- or secondary-level classes differed considerably between rural and urban sectors. Only 61.6 per cent of rural households, compared to 82.5 per cent of urban households, had a middle school within $1 \mathrm{~km}$. For secondary-level classes, the proportion was 30.7 per cent for rural as compared to 68.6 per cent for urban households. Further, about 33 per cent of rural households did not have any secondary school within a distance of $3 \mathrm{~km}$ (Report 532, NSSO 64th Round, 2009). Hence, it is fair to say that access is not equal and the ability of children to continue with their education is largely determined by location and availability of public transport. 
Crossing the secondary education barrier is a major hurdle before young people can hope to enrol at colleges and universities. Quality of secondary education exerts a huge influence on opportunities after school. Thomas Weisskopf points out that, in India around 40 per cent of higher education students are enrolled in low prestige arts programmes / bachelor's programmes. The percentage is 60 for SC and 75 for ST and it has to be questioned what kind of higher education they have access to. Their academic performance and estimates of how many finish their degree in the stipulated time vary, but in professional courses the percentages are far lower than the general category, and Weisskopf asks why many SC / ST students fall behind during the courses (Weisskopf 2013). In fact, this is not a new revelation. Way back in 1972 Suma Chitnis's work in Maharashtra revealed that the overwhelming majority of SC students (in the sample she was tracking) were 'studying in grade D colleges' and their performance throughout the course was poor and dropout rates were also high. She also found that a higher percentage of SC students were enrolled in non-professional courses and in non-science courses (Chitnis 1972). Reviewing the higher education terrain in India, Jandhyala B. G. Tilak argues that the emphasis is laid either on quantity or quality or equity, not on all three at the same time and that the result is a triangle of three unequal sides (Tilak 2013).

Going forward, having overcome the first barrier of access to primary schooling, there is no guarantee that attending school can guarantee learning. As discussed above, ASER $2011^{5}$ revealed that nationally only 48.2 per cent of class $V$ children could read simple class II level texts and only 29 per cent of class children could solve a two-digit subtraction problem. These findings reflect a mere tip of the iceberg and the reality on the ground is quite sombre. While many more children may be enrolling in school, the big question before us is whether they are learning, and to what extent, does the kind of school they attend influence this learning. The recent PISA test results $\left(2011^{6}\right)$ have also raised similar issues.

When most administrators, educationists (even those working in government institutions) and the larger education community agree that measuring inputs and enrolment is inadequate, the question that arises is why does government data focus so much on enrolment, retention, teacher appointments, teacher training, infrastructure and supplies and to a far lesser extent on learning? Why is it that we, as a nation, do not shrug at the thought that millions of our children attend school and emerge barely literate! What does it say about our education system? And how did we reach this situation?

\section{Quality, the heart of equity ${ }^{7}$}

India attained Independence in 1947. Mahatma Gandhi had dreamed of a school system that was rooted in the social and cultural context while at the same time ensuring good quality secular education that was accessible to all children in the country. But as the first government assumed office, 'education for all' was quickly forgotten. We plugged along with the colonial system, partly because there were more pressing economic and political issues to tackle. Gandhiji's plea for 'Nai Taleem' (a fresh approach) in education was lost in the din of building a command economy, which meant focusing on heavy / basic industries, institutions of higher technical education, and so on.

It is not that education was neglected. In addition to regular schools, the government did set up a chain of 'central schools' that were fairly well endowed and of good quality. But the real attention was reserved for higher education, as the ruling elite was committed to building quality institutions for professional and technical education. National institutes of technology, science, medicine and management produced graduates, who compared with 
the best in the world. It is no surprise that India had managed to ride the current global information technology wave in the 1990s with confidence. In this rarefied world, excellence and quality are key words.

However, the euphoria of India being a knowledge-driven economy was short lived. An independent non-governmental organisation facilitated a nation-wide sample survey on learning outcomes of children in 2005. The results were shocking. Close to 35 per cent of children in the 7-14 age group could not read a simple paragraph (grade 1 level) and almost 60 per cent of children could not read a simple story (grade 2 level). Sixty-five-and-a-half per cent of children in the 7-14 age group could not tackle simple arithmetic problems and more worrying was the fact that 47 per cent of children from 11 to 14 years could not solve grade 2 level arithmetic problems (ASER 2005). That is not all. In the same year, the government admitted that out of all children who enter grade 1, 52.8 per cent of children drop out before they reach grade 8 (SES, GOI 2005). Among them, children coming from the most deprived communities and from rural and remote areas constitute an overwhelming majority of dropouts. Education meant little to these children since they acquire few skills and little confidence. For all the official claims, close to half of all children in the appropriate age group receive less than the constitutionally mandated eight years of schooling.

How can two entirely different systems coexist in the same space? In the early 1950s, education and quality were seen as coterminous, in part because education was a privilege of the few who could afford it. Most children, even from upper middle-class families, studied in government schools. With modernisation and escalated demand for education, pressure for rapid expansion of the public education system increased. By the mid-1960s, as increasing numbers of children started enrolling in school, the country also witnessed a gradual increase in the number of private-aided and unaided schools. As the 1960s rolled by, people with means moved out of public (government) schools and a feeling developed that quality was, perhaps, better pursued in private schools. This was also the time when competitive language politics led to the political decision to adopt the vernacular medium and postpone or withdraw the teaching of English to high school. This further quickened the exit of the middle classes from government schools (except of course the special government schools like Kendriya Vidhyalaya). This movement of the children from economically better off families from government schools to private schools has continued to gain momentum through subsequent decades. ${ }^{8}$ The socially and politically significant minority, namely the middle classes and the rich, have more or less fully moved out of government schools. Interestingly, even those who remain in government schools attend better-endowed government schools.

Officially, in 2012, 54.8 per cent of schools were run by the education department of the government, 29 per cent by local bodies (panchayat / municipality), 8.9 per cent were privately aided and 7.3 per cent were private unaided. The distribution changes quite dramatically when we look at secondary and higher secondary schools: 31.3 per cent by government, 8.5 per cent by local bodies, 24 per cent private aided and 36.2 per cent private unaided (School Education Statistics, GOI 2012). If we look at the above distribution of schools alongside dropout rates, it is noteworthy that 27 per cent of children drop out by the end of class V (28.7 boys and 25.1 girls). Further 40.6 per cent drop out by class VIII (40.3 boys, 41 girls). It is worrying that government data does not tell us who (meaning by location, income group, family education status, type of school they attend) drops out. Micro studies / field-based studies point to the very poor, among them socially disadvantaged groups like SC, ST and Muslims and within them first-generation school goers, as the ones who drop out. 
In the 1990s, data on enrolment and retention took precedence over the painstaking process of monitoring the functioning of schools. The inspectorate system gave way to databased monitoring. As a result, as long as the local education authorities could show high enrolment rates, the work was seen as having been done. Even though the dropout rates were alarming, the ability of the system to retain children was not really seen as an important indicator of achievement till almost the middle of the last decade. It is no coincidence that a majority of children from the most deprived communities attend government schools and dropout rates calculated essentially pertain to government schools.

With growing pressure to meet globally accepted levels of school enrolment India joined the great numbers race. Issues of access and quality were analytically separated and the focus shifted to somehow getting children into schools with the belief that the government could worry about quality later. Statistics acquired an unprecedented status and we started searching for simple measures like enrolment, transition and completion rates to show progress, forgetting that a highly complex webs of issues are responsible for poor quality of government schools.

First, the school system is not accountable to anyone. When the government is satisfied with monitoring numbers (number of students enrolled, teachers appointed, textbooks distributed, midday meals supplied, buildings constructed, toilets built, etc.), there is very little motivation to do or look for anything else. Until 2012 (this may be about to change), the academic support institutions at cluster and block levels were preoccupied with gathering data from schools. Old-time inspectors no longer monitor what happens inside the schools or, for that matter, what the children are learning. Therefore, according to the old maxim, 'what is monitored is what gets done'. Our school system has perfected the skill of enrolling children and showing them on the rolls.

Second, given the no-detention policy (whereby children are not detained in class if they have not achieved the grade-specific competence), schools just promote children from one grade to the next without bothering to find out if they have indeed acquired the gradespecific knowledge and skills. As a result, we now have a situation where many children reach grade 5 without learning to read or write. There is another danger that looms large. The RTE Act has extended the no-detention policy right up to grade 8 . This essentially means that we may have children who have been in school for eight years but have not learnt language or mathematics or science.

Third, the numbers of days the schools actually work vary across the country. According to the ASER survey (2011) student attendance has been falling. For example, the average attendance of students in Bihar has declined from 59 per cent in 2007 to 50 per cent in 2011, whereas in Uttar Pradesh it fell from 67 per cent to 57 per cent in the same period. Several studies have also shown high teacher absence rates (Kremer et al. 2004; Muralidharan 2013). In our own field studies, we found that teachers in rural schools keep an undated leave application ready and take turns to attend class. Therefore, if there are indeed five teachers appointed for a primary school, on any given day only two or maybe three are likely to be present (Ramachandran 2004; Sharma and Ramachandran 2009). They rotate their 'French-leave' and as a result, one teacher ends up managing more than one class. Over the last ten years I have found that the actual time spent on teaching-learning in any one grade / class could be as little as twenty-five minutes a day. A recent study commissioned by the government's Sarva Shiksha Abhiyan also found that the actual teaching-learning time (time-on-task) was low and student attendance was also a matter of concern. ${ }^{9}$ Why then are we surprised that our children do not learn?

Fourth, the RTE has stipulated norms for basic infrastructure and facilities, for teacherpupil ratio, and other academic matters that determine quality. The Sarva Shiksha Abhiyan 
of today, the District Primary Education Programme of the 1990s, Operation Black Board of the 1980s and so on also developed elaborate guidelines and notified norms. The unfortunate reality is that many of these wonderful plans remain on paper. Often lofty intentions announced through policy are not followed up with concrete action. As a result, even after three decades of government-sponsored, central sector schemes for universal elementary education, a majority of our government schools located in rural areas and also in urban areas (the abysmal state of MCD-run schools is a case in point) have crumbling infrastructure and poorly maintained facilities. If there are toilets, there is no water; if there are toilet and water facilities, cleanliness is an issue. Apart from problems of basic maintenance, quality of construction is also poor. As a result, our schools are neither attractive nor safe.

The situation is not very different at the secondary level. Government secondary schools in many educationally backward states have poor infrastructure, inadequate teachers in some subjects, extremely poor science labs, no library, and so on. This list is fairly long. In addition, in many schools in rural and remote areas, a large number of girls-only schools do not offer science or commerce. Students are left with little option and end up doing languages or arts. In a study that I undertook in 2008-2009 in New Delhi, I found that girls' schools in some of the poorer areas did not offer science. When we asked the students of classes IX and X what they would like to do, many of them wanted to enrol in ITIs or in nursing schools, but they were unable to do so as their school did not offer science.

The problem is not lack of financial resources or of lack of good policies or strategies. The basic issue is that no one really cares if government schools function or not. Our political leaders, administrators, media and the middle classes have all abandoned government schools for their own children. In a recent study (Ramachandran et al. 2009), we had an opportunity to interact with teachers across eight states of India. I was shocked to note that not one of them sent their children/grandchildren to government schools. All of them said that they wanted their children to go to a functioning school that teaches English and 'maintains discipline'. They all wanted English medium for their own families even though they enforce vernacular medium in government schools. They want to see their own children go to schools that function, with proper classrooms and desks, with trained teachers, while at the same time they look the other way when government school children are cramped into small windowless spaces, are made to sit on the floor, have no lights or fans and, what is worse, are not sure if they will see the teacher every day.

This is a warped system! Official numbers tell us that all is well with our education while our eyes and ears tell a different story. India has created parallel structures of education governed by different norms and playing by different rules. In the process, the education system has got more differentiated, namely, public, aided and private; formal and alternative; permanent, transitional, pedestrian coexisting with institutions of excellence. The poorer and the more disadvantaged are pushed into schools with poor facilities, teachers and overall learning environment. This has given rise to a new trend of 'hierarchies of access', whereby, paradoxically, the democratisation of access to schools is accompanied by a reaffirmation of a child's caste, community and gender in defining which school she or he attends (Ramachandran 2004). Having pushed the socially excluded into educational ghettos, the government wants to neutralise the inequalities of past centuries through affirmative action in the form of reservation of a certain percentage of admissions of specific social groups in higher and technical education institutions. It is cruel to offer reservations at higher levels while paying little attention to education quality and learning in school. Are we not perpetuating or even deepening inequalities by not giving our children equal opportunities in school? 
The economic cake is expanding fast for some people in India. New opportunities are available to those who have been able to access quality education. There is a clamour for better schools, English education and new technologies. Quality is the new battleground.

Yet we are at a loss to define what we mean by 'quality'. At the heart of this concern are questions related to the goal of education. Is it to enhance the capabilities of people to negotiate an increasingly unequal, divisive and polarised world from a position of strength? Is it to enable people to reflect critically on their life situation and understand the world they live in to make informed choices? Good quality education, in essence, involves creating a system that enables children to learn to know, learn to do, learn to live with others and appreciate interdependence and diversity, and above all learn to 'act with ever greater autonomy, judgment and personal responsibility' (Delors et al. 1996).

The segregation in education with different social classes enjoying differential access to different kinds of schools cuts at the root and poses a real threat to democracy. As Joel E Cohen points out,

little has been done to address questions about the universality of educational content, which varies across countries and regions. Universal could mean that all children get the same education. Or it could mean that all children get some education, but the content differs by place, type of school, or technology of instruction. Or it could mean that there are universal principles that apply everywhere but that the implementation and specification of these principles in practice depend on the local context. If content differs, there may be some or no common elements for all children. Or it could mean that education is the same for everybody except for those children who are disabled, remote, rural, minority, or otherwise handicapped.

Cohen and Malin 2010: 10

An inability to address the fundamental goals of education does not augur well for democracy. In an increasingly polarised society, caste, religion and language identities are reinforced in politics and political parties mobilise along caste and community lines, pitting one group against the other to capture votes. Schools no longer provide a common shared space for children of different backgrounds and communities. Children today are growing up without getting an opportunity to mix with children from other social groups. While children from middle-class and affluent families with greater access to the world media may potentially be exposed to different viewpoints, the majority of poor children not only attend school where they mix with their own kind but have little access to the media (print and visual). They are thus doubly disadvantaged, by poverty and by poor quality education.

Given the segregation and given that those who can access reasonable quality education opt for higher end careers, teaching as a career is increasingly becoming a last resort. The last three decades have witnessed a sharp decline in the quality of teachers. The further one moves away from the metropolis and well-endowed schools, the greater the decline in educational level, skills and confidence of teachers. With the base of the educational pyramid remaining poor and the inability of our system to attract competent teachers, we are only reinforcing the quality divide.

As we peel away the layers of the education system, more contradictions reveal themselves. Larger governance issues like corruption, rent seeking and patronage make an already difficult situation even more resistant to reform. ${ }^{10}$ Even well-meaning reformers are at a loss about where to begin. Lofty goals are set every few years, new documents released (the most recent being the nation-wide effort to draft a national curriculum framework [NCERT 
2005]) and institutions are revamped to regulate quality (NCTE). Yet, institutions that are expected to set standards and provide academic leadership at different levels (national, state and district) have been reduced to petty fiefdoms that are least concerned about larger issues, such as the purpose of education. And unfortunately, the larger political debate on education continues to centre primarily on writing and re-writing history and peculiar manifestations of affirmative action that only reinforce social divisions and existing inequalities.

The crisis faced by Indian education reflects a global concern. Be it rioting youth of migrant communities in Europe, the exasperated students in South and Southeast Asia and the Middle East, or the palpable unrest in the Americas and Africa, all these are telling something. An education system that emerged in the early industrial period is no longer able to meet the growing aspirations and needs of people across the world. The 'best' are happy with the Ivy League, Oxbridge, Sorbonne, Indian Institutes of Technology and Indian Institutes of Management, their stepping-stone to money, fame and power. Simultaneously, the media have equalised aspirations and raised hopes that education could indeed be the great equaliser. Yet, the education that the poor receive adds little real value. The real world is harsh and those on the margins are being pushed further out into the wild.

At the heart of all this is the content of education:

- Who gets to learn what and how much?

- What confidence and capabilities does it endow?

- Who decides what is taught in school and later on in colleges?

- What accountability systems are in place to make sure that children who come to school are taught with love and care, in a non-discriminatory environment and in a manner that enables them to realise their potential?

- Who ensures that caste, gender, race and community prejudices are not reinforced in school and in colleges?

- Is anyone monitoring to see if a playing field is being created in schools and colleges?

All these questions are about quality, of learning, of environment, of relationships and of experience. Quality is the heart of the struggle for equality and justice. The unwillingness or inability to define what we really mean by quality and institutional mechanisms, necessary to realise standards of quality, is ultimately a political question. Unfortunately, the communist parties, the social democrats, the centrist liberals and the right-wing ideologues are all on the same side in the education quagmire, together contributing to the growing schism between the rhetoric and reality.

The situation may seem grim. But as we look closer and listen carefully, young people across the world are not in a mood to take this lying down. Maybe there is a silver lining. There is an urgent need to re-imagine education, overhaul the system and link education to life, livelihood, peace and social justice. While striving for equality, the education system should be able to respond to both aspirations and opportunities while enhancing choices. A farmer should be able to enhance her productivity, weigh the pros and cons of traditional and modern technologies and make informed choices. Children living in a multicultural environment should have an opportunity to learn about each other while creating bonds of shared experiences and at the same time, learning from the catastrophic consequences of racism, parochialism and communalism on humanity. Skilled and unskilled workers should be able to negotiate just wages and resist gender and age inequalities that exist. The education system should have the depth as well as the range to span different worlds that people live in and also create bridges. A child born into a community that is rooted in a 
traditional occupation must have the opportunity to move out if she so wishes or infuse modern technologies or marketing opportunities into a traditional occupation. This has implications for the education system. We may have to reconstruct education in such a way that it provides multiple points of entry and exit, accommodates varying paces of learning and enables people to stand tall where they are and reach out to the world with confidence. Young people who do not want to pursue formal schooling after grade 8 or 10 should have the opportunity to pursue learning in a different stream. Equally, a young person who may have dropped out when she was just 14 should be able to pick up the threads at a later stage, if she so desires. There is a need to rethink the value of linear progression from primary right up to higher education. This can happen only if people who are committed to an alternative vision have the courage to put an end to the mindless pursuit of numbers (also known misleadingly as 'goals') and call the bluff. This is the only way we can strengthen the voices clamouring for meaningful education.

\section{What can we do?}

It is universally accepted that three factors influence the performance of a school system, namely: inputs (facilities, teacher-pupil ratios, student enrolment, no-detention policy, incentives, midday meals), pedagogical process employed in the classrooms and the overall governance of the school system. We know that expenditure on inputs has been going up steadily, and (especially under DPEP and SSA) teacher training has been given importance. Research done in the last ten years does not show any positive correlation between the above inputs and student learning (Muralidharan 2013). For almost two decades now (since 19931994), educational planners and administrators are pushing for more of the same and many of them refuse to acknowledge reality. It is time the education community started thinking differently and be prepared for sweeping reforms - however painful it may be.

Maybe we need to start with teachers, initiate a dialogue with them and take them on board to reform the recruitment, academic support, monitoring and teacher management system. There is something fundamentally wrong with the way we have managed teachers as a cadre, teachers as professionals, teachers as individuals, teachers as experts and teachers as government servants. We have swung like a pendulum - from one strategy to another. Some state governments / administrators thought hiring local contract teachers was the way to manage absenteeism, but some others thought that this was a bad idea and that protecting teacher tenure was the key. Some thought mandatory training would do the trick ... we in India have tried many things at different points in time. Given that teachers have been seen as a powerful constituency, accountability systems were never designed or implemented seriously.

Maybe the best way to move forward is to announce that learning outcomes will be the primary and most important goal in elementary education. This has to be made a non-negotiable ground rule that informs the entire education system. This is what the Twelfth Plan document says, but does not go into how this would be done. I am not arguing for mechanical testing of all children and adding to the burden of tests; but I am arguing for an effective system that will rescue children from the cumulative burden of non-learning. We need to evolve a system whereby the learning levels of children are ascertained at periodic intervals in the school and presented to parents and other stakeholders in the immediate environment of the school. We still may not know how to do this, but it is high time we actively involved the parents, the education community, civil society organisations, local leaders and the media to keep the spotlight on what and how much children are learning. Yes, as many educational researchers would caution, testing cannot be an 
end in itself and that there is no guarantee that measuring learning outcomes and presenting them would automatically lead to improvement. It is the active interaction between teachers, parents and academic support structures that might help us arrive at a balance.

What are teachers expected to do? Cover the syllabus and go through the motion of completing it - never mind if the children are learning or not? Planners and administrators assume that all children in a class are at the same level and that teachers have to adhere to a time frame to complete the syllabus. They are accountable to completing the prescribed textbook and not to ascertain what their students know. Should we not turn the system on its head and start with what children know and who is at what level? Should not our schools have adequate autonomy with powers delegated to headmasters as school leaders to work out what is best for the students? The dividing line between the syllabus oriented teaching and remedial teaching need to go. The two need to become a seamless process which allows children to learn at their pace and enables teachers to work with groups of children at different levels - even evening classes for children who may not get support at home. This means that we just have to reduce pupil-teacher ratios in primary to around 1:20 - so that from classes I to V teachers have the space to innovate and work with every child. At the same time, teachers need to be made accountable to their children. The headmaster as the leader needs to have adequate authority (power) to manage teachers, including sanctioning leave, determining the annual increment, withholding salaries of those who absent themselves or do not teach, plan for their academic improvement and so on. They should also have adequate budget to hire additional local teachers to provide remedial instruction and support slow learners and children with disabilities.

This is essential to build a strong foundation at the primary stage - it is difficult for children to catch up at a later stage. There is a lot of global evidence to show that children who learn to read well in childhood have the potential to become autonomous learners at a later stage. Building a strong foundation is critical at pre-primary and primary levels.

We need to make sure every single school in the country comes up to a basic minimum acceptable level: one teacher for each class should be non-negotiable; the pupil-teacher ratio has to be calculated for every school (not every district); and a robust independent mechanism should be in place to audit the functioning of schools (through toll free help lines for students and parents to lodge complaints).

Further, teachers should be appointed to a school (and not to a state or district cadre) and they should be made accountable to the children. Maybe all teachers should first work in a school for a period of five to eight years - before they can ask for a change. Many countries require teachers to renew their licence - periodically prove their knowledge and teaching skills. I do not know if such a system can be implemented in India, but it is worth exploring ways and means to enable teachers to update their knowledge and skills; show that they have the aptitude to continue as teachers and demonstrate their commitment to learn and grow. The initiative has to come from the school and the teachers - they have to ask for training and also decide what they want, how and where. We just cannot continue with this mandatory 20-day training in SSA that has now become the norm in India. Maybe promotions and increments could be linked to a mechanism that acknowledges good teachers and discourages those who do not have the aptitude or interest. I know these are controversial in India ... nevertheless we just have to search for ways to overhaul our school system.

What and how much do our teachers know is as important a question as what and how much are our children learning. There is a lot of evidence - in India and in the region as a whole - that point to the poor subject knowledge of teachers (Kingdon and Banerji 2009; Banerji and Kingdon 2010). ${ }^{11}$ Poor teacher competencies translate into poor learning 
among students, and this underscores not only the importance of knowing the subject but also the skills to teach and transmit that knowledge. Transfers, promotions and other career opportunities could be linked to the overall learning level of the children a teacher is responsible for. Equally, teacher training should also be based on ability and subject knowledge of teachers. Training-related decisions need to be taken at school level and supported by cluster or block-level institutions. This will happen only if the block and cluster-level academic bodies created by the government are made accountable for the learning levels of children in their respective areas - and are made to take the cue from headmasters and not some official sitting in the state capital. In a nutshell, educational administrators have to take responsibility for learning.

The bottom line is that the entire education system - starting from pre-school (an essential prerequisite for school readiness) to higher secondary - has to make sure children realise their right to be taught and their right to learn in a non-discriminatory environment. Like in all other sectors, governance is the key. A school-upwards governance structure is critical to make education quality the heart of our equity strategy.

\section{Notes}

1 This chapter is based on the Nehru Memorial Museum and Library Teacher's Day public lecture that was given by the author on 5 September 2013 entitled 'Equality and quality are two sides of the same coin in India's School Education'.

2 A recent World Bank report (Dundar et al. 2014) captures the situation succinctly: 'Students from poor backgrounds have difficulty accessing education, and those who do enter tend to drop out early. More importantly, while gaps in enrolment between disadvantaged groups and the population averages have narrowed, historically disadvantaged and economically weaker children still have significantly lower learning outcomes ... Large and growing learning gaps threaten the equity gains in enrolment because children who learn less are more likely to drop out. School-age children who miss out on educational opportunities rarely have many opportunities to remedy this later in life. Poor-quality primary education also hinders access to, and performance in, higher education. Thus, an early focus on learning outcomes and bridging gaps in learning levels are essential to meet the equity and efficiency goals of education policy in South Asia.'

3 What happened through the 1970s to 1990s that the government school system lost focus on educating children and started chasing numbers? The 1960s were turbulent and the political system was adjusting to a unique Indian model of electoral politics. Teachers working in rural areas became assets to political parties. At the same time, as people's aspirations changed more and more, poor and marginalized communities started sending their children to school. When this happened, the middle class and the rich started pulling their children out of government schools and sending them to private or private-aided schools. Gradually as the years rolled by, people whose voices count and those with political or administrative clout no longer cared about government schools - especially the 'ordinary' ones in rural and urban areas. They had no 'stake' left in government schools (except of course the special ones like Kendriya Vidhyalaya or Navodaya Vidhyalaya). At the same time, especially in the 1980s and 1990s, the government started chasing numbers - enrolment rates. They believed that once all children are enrolled, they will then worry about quality. For a more detailed discussion see Ramachandran 2007.

4 The ASAR is 88 per cent (all) and 87 per cent in rural in age 6-10 to 86 per cent and 85 per cent in age 11-13, to 64 per cent and 61 per cent in 14 to 17 years and 18 per cent and 15 per cent in age 18-24. The NAR for classes I to $\mathrm{V}$ is 88 per cent for all (87 per cent rural, 91 per cent urban); for classes VI to VIII it comes down to 59 per cent (57 per cent rural and 65 per cent urban), decreases sharply to 41 per cent in classes IX and X (38 per cent rural and 51 per cent urban) and to a low of 27 per cent in classes XI and XII (23 per cent rural and 40 per cent urban) (Source: Report No. 532, NSSO, 64th Round, 2009).

Age Specific Attendance Ratio (ASAR): for each age group this measure gives an idea of the proportion of persons of a particular age group currently attending educational institutions, irrespective of the level or class in which they are studying. For example, for age group 6-10, 


\section{Equity, quantity and quality}

this attendance ratio is $=$ Number of persons in age group 6-10 currently attending educational institutions x (multiplied) 100 / (divided by) Estimated population in the age group 6-10 years (Report 532, NSSO, 64th Round).

Net Attendance Ratio: for each education class-group, this is the ratio of the number of persons in the official age group attending a particular class-group to the total number persons in the age group. For example, for class group $I-V$ the ratio (in per cent) is $=$ Number of persons of age 6-10 years currently attending classes $\mathrm{I}-\mathrm{V} \times 100 /$ Estimated population in the age group 6-10 years. Similarly it can be obtained for the remaining class groups of school education, i.e. VI-VIII, IX, $\mathrm{X}$ and XI-XII, with the corresponding official age groups as 11-13, 14-15 and 16-17 respectively (Report 532, NSSO, 64th Round).

5 ASER: The Annual Status of Education Report (ASER) is a national survey that collects information regarding children's schooling status and basic reading and maths abilities. Conducted every year since 2005, ASER is facilitated by Pratham and conducted by local institutions in every rural district of the country, reaching about 3 lakh households and 7 lakh children each year. ASER results show that at the national level, there has been no improvement in children's ability to read simple texts and do basic arithmetic in the seven years for which data are available.

6 PISA and recent findings.

7 A longer version of this section appeared in Ramachandran 2010.

8 ASER reports show increasing trends in private school enrolment from 18.7 per cent in 2006 to 25.6 per cent in 2011.

9 TSG, Government of India, 2010. Teachers and Students Time-on-Task in primary and upperprimary schools - a synthesis report. Research, Evaluation and Studies Unit, Ed CIL. New Delhi.

10 'In a survey of 2,350 teachers in three large states in India - Rajasthan, Madhya Pradesh, and Karnataka - depending on the state, 12 to 25 per cent of teachers reported often being harassed directly and indirectly by politicians for reasons unrelated to teaching. Harassment included threat of transfer to a remote area, demand for bribes to avoid transfer, and the expectation that school administrators would cooperate with local politicians in hiring contractors for school construction projects and issue no-objection certificates even if the construction was visibly substandard with only a fraction of the budget actually spent on it. Harassment did not end with politicians and their middlemen. It also included having to cultivate connections with government clerks in order to be reimbursed for claims owed to the teacher' (Béteille 2009) - quoted from Dundar et al. 2014.

11 Using SchoolTELLS data Kingdon and Banerji (2009) found that in rural India at the grade 5 level of difficulty only 28 per cent of the teachers could solve an area problem, and only 25 per cent could work out a percentage problem. About 60 per cent of the teachers made spelling mistakes in their two-sentence summaries of a section from the textbook. As many as 80 per cent admitted to having difficulty in responding to math queries from students ... Of particular concern in both Bihar and UP, two of the most educationally and economically disadvantaged states, is the limited teaching ability of math teachers (Banerji and Kingdon 2010). The best-scoring teachers - the regular teachers - scored only 55 per cent in Bihar, and 51 per cent in UP on a maths test based on the primary mathematics curriculum they are supposed to teach, in which the authors tested not only the teachers' content knowledge, but also their ability to explain topics in simple terms and spot mistakes in written student work (Dundar et al. 2014).

\section{References}

ASER Centre and Pratham (2005 to 2012) Annual Status of Education Reports, New Delhi.

Banerji, R. and G. Kingdon (2010) How Sound Are Our Mathematics Teachers? Insights form the SchoolTELLS Survey, Learning Curve, Bangalore: Azim Premji Foundation.

Béteille, T. (2009) Absenteeism, Transfers and Patronage: The Political Economy of Teacher Labour Markets in India, $\mathrm{PhD}$ Thesis. Stanford University.

Bourdieu, P. and J-C. Passeron (1977) Reproduction in Education, Society and Culture, London: Sage Publications.

Chitnis, S. (1972 [2013]) 'Education for Equality: The Case of Scheduled Castes in Higher Education', reprinted in Jandhyala B. G. Tilak (ed.) (2013) Higher Education in India: In search of Equality, Quality and Quantity, New Delhi: Orient Blackswan.

Cohen, J. and M. Malin (eds) (2010) International Perspectives on the Goals of Universal Basic Education, American Academy of Arts and Sciences, New York: Routledge. 
Delors, J. et al. (1996) Learning: The Treasure Within: Report to UNESCO of the International Commission on Education for the Twenty-first Century, Paris: UNESCO Publishing, available at http://unesdoc.unesco. org/images/0010/001095/109590eo.pdf [accessed 10 January 2015].

Deshpande, S. (2013) 'Introduction', in S. Deshpande and U. Zacharias (eds), Beyond Inclusion: The Practice of Equal Access in Indian Higher Education, New Delhi: Routledge.

Dundar, H., T. Béteille, M. Riboud and A. Deolalikar (2014) Improving Learning Outcomes in South Asia: Challenges, Opportunities and Policy Priorities in School Education, Directions in Development, Washington, DC: World Bank.

Government of India, MHRD (2012) School Education Statistics, Ministry of Human Resource Development, New Delhi.

Government of India, Ministry of Statistics and Programme Implementation, NSSO (2009) Report Number 532 on the NSSO 64th Round.

Government of India, Ministry of Statistics and Programme Implementation, NSSO (2011) Report Number 537 on the NSSO 66th Round.

Government of India, Planning Commission (2011) Twelfth Five-Year Plan, Government of India, New Delhi.

Government of India, SSA TSG and Ed CIL (2010) Teachers and Students Time-on-Task in Primary and Upper Primary Schools - a Synthesis Report, Research, Evaluation and Studies Unit, Ed CIL, New Delhi.

IMRB-MHRD (2014) 'National sample survey of estimation of out-of-school children in the age 6-13 in India', 2014, available at http://ssa.nic.in/pabminutes-documents/NS.pdf [accessed 17 April 2015].

Kingdon, H. Gandhi and R. Banerji (2009) 'Addressing School Quality: Some Policy Pointers for Rural North India', RECOUP Policy Brief No. 5, Faculty of Education, University of Cambridge, UK.

Kremer.M., N. Chaudhury, F. H. Rogers, K. Muralidharan and J. Hammer (2004) 'Teacher Absence in India: A Snapshot' http://siteresources.worldbank.org/DEC/Resources/36660_Teacher_absence_in_ India_EEA_9_15_04__South_Asia_session_version.pdf [accessed 8 December 2014].

Muralidharan, K. (2013) Priorities of Primary Education Policy in India's 12th Five-Year Plan, NCAERBrookings India Policy Forum 2013.

NCERT (National Council of Educational Research and Training) (2005) Government of India: National Curriculum Framework, New Delhi .

NCERT (National Council of Educational Research and Training) (2011) What Do They Know? A Summary of India's National Achievement Survey, Class V, Cycle 3 2010/11, New Delhi: NCERT.

Ramachandran, V. (2004) Hierarchies of Access: Gender and Equity in Primary Education, New Delhi: Sage Publications.

Ramachandran, V. (2007) 'The Great Number Race and Challenge of Education', Economic and Political Weekly, September 29: 3917-3919.

Ramachandran, V. (2009) Towards Gender Equality in Education: EFA Mid-Decade Assessment, New Delhi: NUEPA.

Ramachandran, V. (2010) 'Quality, The Heart of Equity', in Joel Cohen and Martin Malin (ed.) International Perspectives on the Goals of Universal Basic Education, American Academy of Arts and Sciences, New York: Routledge, 104-112.

Ramachandran, V., S. Bhattacharjea and K. M. Sheshagiri (2009) Primary School Teachers in India - The Twists and Turns of Everyday Practice. AzimPremji Foundation Mimeograph, Bangalore, available at http://azimpremjifoundation.org/Reports_Papers_and_Articles [accessed 17 April 2015].

Reardon, S. F. (2011) 'The Widening Academic Achievement Gap between the Rich and the Poor: New Evidence and Possible Explanations', available at http://cepa.stanford.edu/sites/default/files/ reardon\%20whither\%20opportunity\%20-\%20chapter\%205.pdf [accessed 10 January 2015].

Ripley, A. (2013) The Smartest Kids in the World: And How They Got That Way, New York: Simon \& Schuster.

Rustagi, P., S. K. Mishra and B. S. Mehta (2011) 'Scheduled Tribe Children in India: Multiple Deprivations and Locational Disadvantages', No 8, IHD-UNICEF Working Paper Series Children in India: Rights and Opportunities, New Delhi. Available at http://www.ihdindia.org/IHD-Unicefwp-PDF/IHDUNICEF\%20WP\%208\%20preet sunil balwant.pdf [accessed 10 January 2015].

Sharma, R. and V. Ramachandran (2009) The Elementary Education System in India: Exploring Institutional Structures, Processes and Dynamics, New Delhi: Routledge.

Tilak, J. B. G. (ed.) (2013) Higher Education in India: In Search of Equality, Quality and Quantity, New Delhi: Orient Blackswan.

Weisskopf, T. E. (2013) 'Impact of Reservations on Admissions to Higher Education', in J. B. G. Tilak (ed) Higher Education in India: In Search of Equality, Quality and Quantity, New Delhi: Orient Blackswan. 


\title{
6
}

\section{AGRICULTURE AND THE DEVELOPMENT BURDEN}

\author{
Rajeswari S. Raina
}

\section{Introduction}

Indian agriculture in the twenty-first century is mired in a context of rapid economic growth and widening income inequality. Record food production, increasing industrial investments, booming exports, persistent hunger, worsening malnutrition, escalating natural resource degradation and unprecedented distress within the farming community, are its key features. This chapter explores how the intermediate regime, or the state along with its ideological and functional allies, imposes its own articulation of development on agriculture. In the process it stifles the rich diversity, production potential and robustness of India's agriculture and diverse farming communities.

Agrarian movements, academics and activists accuse visible multinational and domestic industry, specific technologies, and unfavourable terms of trade or resource deprivations for the plight of Indian agriculture. Here, we discuss how agriculture as a sector of the economy and a way of life for over a quarter of the population and half the workforce of the world's largest democracy, is shaped by the power and persistence of a relatively small faction of the population. This population, the intermediate class of domestic businesses, large and middle peasantry and the public sector workforce, seeks and enables state-led development (Raj 1973; Mody 2005; Vaidyanathan 2007). Theoretically, the 'intermediate regime' emerges in societies where the feudal class has disappeared or is replaced, but capitalism led by big businesses is not fully established. The evidence comes from developing countries that gained independence in the post-war period, where an industrial bourgeoisie failed to emerge, and assorted strata of lower-middle class, rich peasants, and managers and professionals of the state wield political power (Kalecki 1976). While the emergence and pathways of power maintenance differ between countries, the prevalence of state capitalism with economic policy goals, structures like state enterprises, and a managerial class of professionals and administrators are common to all, be it Peru, Bangladesh, India or Egypt (Fitzgerald 1976; Imam 1980; Sawyer 1985; Streeten 1997). In this regime, major investments have to be carried out by the state. The interests of the lower-middle class, the professionals (technical and executive openings for the ambitious young men of the ruling class), and businesses (small and some big domestic industrial houses) converge with the state's interests and investment options. ${ }^{1}$ That the intermediate regime nurtures the multi-nationals and domestic businesses, 
and works nonchalantly against the disenfranchised rural poor, especially the beleaguered small farmers and rural labour, is not surprising. But the ways in which the latter are used for legitimising the development agenda that suits accumulation by the intermediate class, and the ways in which these goal posts of development policy then govern the resources and production systems of the majority of the rural poor, is alarming.

India, a country once celebrated for a successful green revolution, is now home to the largest number of hungry people, under-nourished children and anaemic women anywhere in the world. Major policy concerns of food and nutritional security, environmental degradation, rural employment and farm incomes have been articulated at least over the past four decades. Solutions ranging from new legislations and schemes for food security, enhanced food production and assured rural employment (National Food Security Bill (NFSB), 2012; National Food Security Mission (NFSM), 2007; Mahatma Gandhi National Rural Employment Guarantee Act (MGNREGA), 2005), to specific technologies and techniques (pesticide free and organic production, biofortification, genetic engineering, integrated nutrient management or micronutrient supply to soils, systems of rice intensification, drip and sprinkler irrigation, processing technologies), infrastructure (electricity, roads, storage spaces), and services, organisations for services or organisational formats (microfinance, farmer field schools, farmer producer companies, co-operatives, women's self-help groups) have been recommended. Some have been accepted and implemented as part of the state's development agenda. A rule of thumb for rejection seems to be the extent to which the solution threatens or alters the prevalent centralised supply driven administration of agriculture (Raina 2014a).

It does surprise many that India's first agriculture policy statement came in the year 2000. The National Agriculture Policy (NAP) 2000, proclaimed its goal for agriculture as 4 per cent growth rate (DoAC 2000). The NAP and the National Policy on Farmers (NPF) 2007, a more farmer focused variant of the NAP, are now available on the website of the Union Government's Ministry of Agriculture. They have never been tabled or debated in the Parliament. In order to govern agriculture in the absence of a policy, the Union Ministry has several Acts and rules that help develop the administrative and programme guidelines. These Acts and rules (some dating back to the 1950s and 1960s, with a few amendments) conforming to 'the new strategy' (Subramaniam 1972) guide the programmes or schemes designed and implemented by the Union Government's Department of Agriculture and Cooperation (DoAC) mainly as Central Sector Schemes and Centrally Sponsored Schemes. Though the absolute centralisation has seen some reform, the state, mainly the Union Government, continues to be the key actor setting the agenda in Indian agriculture. Private corporate sector growth in Indian agriculture is mainly in the agri-input industry and in the rapidly growing agro-processing; the recent corporate farming initiative and FDI in retail launched by the state will bring more private capital into agriculture.

Indian agriculture can be classified into three phases, based on the place and role it found in development as articulated by the state or, specifically, the intermediate regime that simultaneously constitutes and is nurtured by the state. It was 'the basis of all development', has been subjected to 'modernisation for development', and has been appropriated by strong contenders for 'alternatives in development'. The centralising tendencies of the intermediate class and the capacity to exploit the state to their own advantage, is evident in all these phases. But the demand for local authority, decentralised knowledge and policy support for agrarian alternatives is growing. This may change the meanings of development and the burden on agriculture imposed by development as articulated by the intermediate regime. 


\section{Three phases of Indian agriculture}

The picture of Indian agriculture poses several puzzles. There is pride in touching the desired agricultural growth rates; also concern about degradation and loss of natural resources, and the presence of over 200 million hungry people. Obviously, the marginal and small farmers and the agricultural labourers, who are the majority stakeholders, have no say in framing the development discourse. What is not obvious is the technocratic articulation of development used effectively by the intermediate regime, whose control over the state may now have reached its limit.

In this section we trace the evolution of Indian agriculture in three phases of development articulation, and new relationships between the state and agriculture. Other classifications (for instance, Bhalla and Singh 2010) present the evolution of Indian agriculture in three phases - the first phase of the green revolution with increasing productivity growth rates (18 years, from 1962-1965 to 1980-1983), the second phase of maturity of the green revolution with increasing production growth rates of major cereals but overall slower growth rates of productivity (about 10 years, 1980-1983 to 1990-1993), and the post liberalisation (post1991) phase of retrogression of production and productivity growth rates (13 years, 1990 1993 to 2003-2006). The growth rates may speak for the performance of the sector. But they mask the development agenda and the crucial changes in the relationship between the state and agriculture.

\section{Phase 1: Agriculture - the 'basis of all development'}

The political and economic logic that shaped agriculture in the immediate post-independence period (till the mid-1960s) is evident in Nehru's statement that agriculture was the 'basis of all our development work'. In keeping with this spirit, and contrary to what the NehruMahalanobis strategy of investing in capital goods industry had many to believe, the first three Five Year Plans allocated over 22 per cent of the total investment to agriculture (including irrigation), while industry accounted only for 17 per cent (Balakrishnan 2010, quoting V.K.R.V. Rao 1982: 72). Irrigation accounted for a significant share in this public investment for agriculture, along with investments (both foreign and domestic) in agri-inputs industry like fertilisers and machinery. This was enabled by a Nehruvian worldview of development, where agricultural growth was necessary for food and for the generation of surpluses for industrial growth (ibid.). Public sector research on food crops doubled in many provincial research stations under the State Governments (Raina 1999). These public investments did have an impact and agricultural growth rate rose to 2.6 per cent (1950-1951 to 1964-1965) compared to 0.4 per cent (1900-1901 to 1946-1947) in the colonial period (Sivasubramanian 2000). While area expansion did occur, it was expansion of irrigated area that contributed significantly to this growth (Vaidyanathan 2010).

Besides the 'big push' of public investments in agriculture and rural India, the 'problem of development' demanded new ways to address the institutional constraints that stood in the way of adoption of new techniques and increased productivity and production growth rates. Increasing evidence of the inverse size-productivity relationship led to redistributive land reforms (Vaidyanathan 2010), tenancy security, and Community Development (CD) programmes to enable knowledge and technological services for farmers. But land reforms were constrained by the Nehruvian approach to creating and nurturing an intermediate class that would participate in democratic governance and gain from state capitalism (Raj 1964; Mody 2005). Moreover, the stability and participation of the rich peasantry and lower middle 
class in governance was threatened by inflation and food crises, a consequence of shortfall in production, two drought years, and state attention diverted to the Indo-China war. By the end of this first phase, centralised public investment including a wide range of public sector enterprises and workforce, and policy-making mechanisms for agricultural growth were established; a powerful political commitment of state support for the poor farmer. The intermediate class had come of age.

\section{Phase 2: Agriculture - modernisation for development}

The second phase of Indian agriculture (mid-1960s to the late 1990s) takes off with the green revolution, a national and global political commitment to modernisation for food production. It culminates with the acknowledgement that the green revolution did increase food production but did not reduce hunger. To the 'poor farmer' legitimisation of state support (inherited from the first phase), it adds centralisation and science and technology (S\&T) for productivity.

With increasing dependence on food grain imports from the USA, and evidence that new planting material was available to complement the irrigated, chemical fertiliser-led crop production systems (already promoted in India by philanthropic organisations - the Ford, Rockefeller and Kellogg Foundations), the mid-1960s witnessed a major change in the rationale of agriculture in development. Agriculture was to ensure national food security. Marked by the world's biggest transfer of genetic material, the green revolution was launched in India, with the Union Government's import of 18,000 tons of Mexican wheat for sowing, in 1966. Wheat yields shot up by a record $6.5 \mathrm{~m}$ tons in one year (1967-1968); and the newly reorganised Indian Council of Agricultural Research (ICAR) took the credit for the success. The national 'strategy for agriculture' (Subramaniam 1972) formulated a few years after the launch of the green revolution, legitimised the centralisation and consolidation of agricultural S\&T (Raina 2011), and the two major policy planks of output price support and subsidised input supply (Ray 2007) that continue to date.

The technocratic vision of development dates back to the pre-independence period (Mody 2005). But with the appearance of the miracle seeds, agriculture's relationship with the larger rural economy, employment and industrial growth was no longer the focus; the focus was exclusively on linear transfer of production technologies. Within the state's agricultural S\&T and administration establishments, institutional reform of social and economic structures (say land reform), and capacities for local decision-making for agricultural development were no longer important.

India's planners had given specific attention to agriculture in the capital goods investments, with massive investments in the fertiliser industry (some plants established entirely with FDI and international technology) (Mahalanobis 1955; Sivaraman 1991) and irrigation that accounted for almost 90 per cent of public capital formation (Vaidyanathan 2007). Rice and wheat gained the most from these investments and public support (Barker and Herdt 1985; Rao and Gulati 1994), the unique convergence of technological and production capacities. Farmers responded to these capital investments by changing land use patterns, increasing cropping intensity and devoting more land to the cultivation of irrigated rice, wheat, cotton and sugarcane, with a massive reduction in the area devoted to pulses and coarse cereals.

The first phase of the green revolution ending around 1980-1983 (Bhalla and Singh 2010) witnessed the end of the rapid expansion of public capital formation in agriculture. The mid1980s witnessed increasing private investments in irrigation (tube wells expansion - with over 70 per cent of irrigated cereal production depending on groundwater by the end of the 
1980s), accompanied by increasing subsidies for tube wells, electricity and diesel, agricultural chemicals - fertilisers and pesticides, and seeds. The share of gross capital formation (GCF) in agriculture in total GCF fell from 20 per cent in 1980-1981 to 10 per cent in 1999-2000.

With increasing public and private corporate investments in agri-inputs industry and public enterprises for seeds, domestic trade, food, land reclamation, and irrigation and power, capital formation for agriculture, had outpaced capital formation in agriculture (see Ministry of Agriculture 2003, and Rao and Gulati 1994). The positive and direct relationship between public and private capital formation in agriculture during the 1970s (until 1979-1980) (Mishra and Chand 1995) turned negative in the next decade. As estimates of public financing of private capital in agriculture became available, it was clear that private investment promoting capital-intensive production practices and policy instruments, were maintained by 'politically conscious and interest seeking middle and large farmers' (Mishra and Chand 1995). Public financing of private capital during the early years of the green revolution was 35 per cent, and went up to 60 per cent in the later years of maturity, with stagnation in yield growth rates of staple cereals, and declining incremental yield response to unit irrigation and fertiliser use (Mishra and Chand 1995: A-78; ICAR 1998; Vaidyanathan 2010). Political capture of subsidies and inputs like electricity (Dubash 2007; Gulati and Narayanan 2003) became the norm. For the middle and rich farmers the state's investments and input supply had become a necessity; partly driven by the limited incremental response to expensive inputs (fertilisers, since the mid1970s) and partly by the limited local capacities for experimentation and learning because of a preconceived linear supply of knowledge and technologies from the centralised research and extension systems (Raina and Sulaiman 2007). Public investments and public policy support continued with increased flow of agricultural credit (enabled by bank nationalisation and more specific functions for rural banks), price support mechanisms based on cost of production for at least thirteen major crops, subsidies for all modern agricultural inputs - especially fertiliser, electricity and irrigation equipment, and increasing industrialisation for agri-input supply (Balakrishnan 2010; Birner et al. 2007; Dubash 2002; Gulati and Naryanan 2003). Modernisation through centralised public investments that subsidised private investments was no longer for development; it became an end in itself.

Two major features that mark agriculture to this day, were initiated in the second phase with agricultural development defined as technological modernisation. The first was the state's unquestioning acceptance and exclusive attribution of success in food production to S\&T. The second was the technocratically legitimate demand for centralisation and consolidation of all technical aspects of the sector, whether it was the conduct of research, dissemination of technologies generated, or the formulation and implementation of public programmes or schemes for agriculture (almost all of them embodying one or more technologies) (Raina 2011; 2014a). Together, these two features (i) policy making driven by a faith in technology, and (ii) centralised knowledge and policy decisions, created a supply driven agriculture sector (Raina 2014a).

The governance of agriculture is dictated by the development norms of the intermediate regime. For them, centralisation is an essential policy mechanism; it keeps the schemes and public services under control. Since they are the executive arm of the state, their articulation of 'development schemes', with specifications of where and what type of interventions, who should implement or manage the intervention, who the beneficiaries of the subsidy should be, and the processes of actual disbursement of entitlements, becomes the substance of development disbursed by the state (Vaidyanathan 2007; Raj 1973). The supply of knowledge and technologies as public goods becomes a key instrument of the intermediate regime. Straitjacketed and centralised to enable the irrigated, chemical based cereal production 
systems, they are the technical support for the supply syndrome - production policies, schemes and their subsidies (Raina 2011, 2014a).

Even critics who vehemently disagreed with Raj's application of the (Kaleckian) analytical category of intermediate regimes to the Indian state, did agree that 'it was a regime of increasing burdens being put on the shoulders of the rural as well as urban poor...' (Namboodiripad 1973: 2135). In the intermediate regime, the urban and rural poor, the working class, had no voice to articulate and use the state to serve their interests (Robinson 1976). The economic policy of the intermediate regime or the business interests that stand to gain were not very evident in the early 1970s, when public spending was still not exclusively for subsidising private capital. The rich and middle peasantry and industry could direct policy instruments, especially specific embodied technologies, to their own gain; be it attractive minimum support prices for major cereals, subsidies for chemical inputs, electricity and fossil fuels (for groundwater access), and loan waivers every once in a while. By the mid-1980s the public subsidisation of private capital for agriculture had come to stay.

This, the political appropriation of knowledge and policy, legitimised by modernisation for development, is the worst and lasting burden on agriculture. In this regime, formal S\&T does not need capacities to understand the production contexts and voices of marginal and small farmers or agricultural labour. Also, with technocratic interests in maintaining status quo, and limited space for even discussing the institutional reforms that were left unfinished in the first phase, there is limited scope for inclusion and participation of the majority of India's farmers and diverse agri-food systems in knowledge and policy decision-making.

\section{Phase 3: Agriculture - alternatives in development}

Disillusionment with modernisation of agriculture and concern about increasing malnutrition mark the current and third phase of Indian agriculture beginning around 1998-2000. By the late 1990s, the state - its planners and public sector economists - started using the term 'postgreen revolution' and questioning the decline in yield growth rate. This on-going phase is witness to a consolidation of forces by the established actors of the intermediate regime, in the face of several alternative conceptualisations and practice of agriculture and development. This phase may turn out to be either the most creative or the most violent and disruptive phase in Indian agriculture.

In industry, structural reform and liberalisation were initiated immediately in the post1991 era; but not so in agriculture (Ghosh 2010; Storm 1997; and Mittal 2011 agree despite different theoretical frameworks). The intermediate regime took time (almost a decade) to reshape the relationship between the state and agriculture. The linked decline in public capital formation and expansion of irrigation continued well into the post-reform era (Balakrishnan 2010). Unlike industry, in agriculture there was reluctance and resistance to reform even the most redundant extension departments, public sector labs, and resource degrading subsidies and non-performing services because all of them were legitimised by the existence of the massive number of poor farmers (see Raj 1973) and the state's responsibility to provide modern technologies and inputs to them (Planning Commission 2008, 2012). Following the global financial crisis of the late 1990s state support for private capital (global and domestic) and rallying slogans like public-private partnerships (PPP) gained acceptance as norms for efficient economic growth. Given public sector rigidities, redundancy and inadequate efforts to reform existing organisations and systems, the state chose to strengthen the prevalent model with new administrative mechanisms like regulatory bodies (quasi-public led by selected experts and bureaucrats) and business models (new public-private partnerships 
and skill development corporations). This was an affirmation of the post-crisis relationship between the state and agriculture. Armed with a policy goal of 4 per cent growth rate, and strategies supporting private (MNCs included) capital for agriculture, the intermediate regime crafted a new development agenda which was contested by various stakeholders.

The first decade of the twenty-first century was a happening phase in Indian agriculture. Though the stagnation in productivity growth rates and the unfavourable incremental capital output ratio (ICOR) were acknowledged (ICAR 1998; Golait and Lokare 2008), the mechanisms to correct these were spelt out as a policy for targeted growth rates in the National Agricultural Policy (NAP) (DoAC 2000). The share of GCF in agriculture in total GCF which had fallen to 6 per cent in 2007-2008, rose marginally to 10 per cent in 2009-2010 and 7.2 per cent in 2011-2012. Though all major policy instruments were deployed for food production, the average rate of growth of yield per year fell from 4.4 per cent (between 1980-1990) to 2.8 per cent (between 1991-1998) and further to 0.6 per cent (between 1999-2009) (Gillespie et al. 2012). The post-green revolution stagnation in yield growth rates in the rice-wheat cropping systems and in other well-endowed agricultural tracts, was soon related to major equity challenges (marginal and small farmers, disadvantaged caste groups), and demands made for further technological solutions to address these challenges (Murgai and Howes 2003; Jain 2006; Erenstein and Thorpe 2011). The increasing dependence of agriculture on groundwater and energy (free electricity) and fertiliser subsidies became major concerns for political bargains (Dubash 2007; Gulati and Narayanan 2003; and Birner et al. 2007). The chemical inputs, fertilisers and pesticides, electricity and fuel subsidies were questioned for their limited contribution to productivity gains and for the political bargaining associated with the supply of these technologies to farmers (Planning Commission 2008; Vaidyanathan 2010; PMEAC 2012). But election campaigns that were fought and won on the promise of free electricity since the late 1970s, had attained a political maturity by the turn of the century, to capture political space in the world of agricultural modersnisation and development. The political demand was to intensify the green revolution technologies in areas where it had an impact, and expand into areas that it had bypassed in the 1970s and 1980s. Alternatives to the public sector-led supply driven agriculture were necessary. The alternative, the new global articulation of the second or double green revolution (Conway, 1997) was accepted, which avowed public-private partnerships and new markets as absolute necessities.

Domestically, the demand for dismantling fertiliser subsidies was the most vociferous, when the subsidy bill touched a record Rs. 76,603 crores (766 billion) in 2008-2009 and maintained course till 2013-2014 (Planning Commission, Data Book, 2014). Though these soaring fertiliser subsidies were driven by global fossil fuel price rise and food price volatility, it was painful to realise that between 21.43 per cent to 32.01 per cent of agricultural GDP was being spent on subsidies (food, fertiliser, electricity and petroleum) every year since 2008-2009 (ibid.). The political debates ranged from dismantling all subsidies and enabling market mechanisms in the input sector, to installing regulatory authorities and more targeted technologies including precision cultivation methods and genetically modified (GM) crops.

Seeds were at the centre of the more targeted technologies to use chemicals most effectively. Seeds became the most contested agricultural input of the twenty-first century. Reform in the seed sector started in the 1980s (the maturity phase of the green revolution, Bhalla and Singh 2010), when industry or specifically Monopolies and Restrictive Trade Practices (MRPT) and Foreign Exchange Regulation Act (FERA) companies were granted permission to invest in and market seeds. With the National Seeds Act of 2004, the seed industry became an equal on many counts with the chemical industry; all seeds and planting material sold under a brand name had to be registered with the state, and all foreign seeds 
imported or foreign certification granted would be recognised by the state. Farmers were allowed to breed and exchange their own seeds, as long as they did not sell them under a brand name, and maintained the quality standards of registered seeds. But by this very Act, they were excluded from the seed industry. Cotton, fruits, vegetables and maize gained the most from this industry in terms of productivity per hectare. These and the cultivation of public sector generated cotton hybrids appropriated and sold as private produce with international IPR protection for specific Bt genes and processes of insertion, with no acknowledgement or profit sharing mechanisms with the public sector geneticists, plant breeders, agronomists, entomologists and pathologists (see Vennila 2006; Ramasundaram and Vennila 2013) mark a point of departure in the role of knowledge in agriculture. The political articulation of generation of public sector knowledge and technologies for modernisation of agriculture in phase 2, was replaced in phase 3 by the pro-active facilitation mechanisms for appropriation by or partnership and subservience to private (domestic or multinational corporate) sector for commercialisation (see, ICAR 2007; FICCI 2012). Centralised regulation and structures (a Seed Act or a proposed BRAI) were considered essential.

As it is globally, the state-led alternative of strengthening the green revolution paradigm co-exists with other alternatives. Many agro-ecosystems, diverse food cultures, and social and ecological movements (some since the 1970s) articulate alternatives to the green revolution approach. ${ }^{3}$ Contradicting the centralisation characteristic of the state-led alternative, these alternatives are being developed and promoted as decentralised location-specific programmes, in many cases (like Sikkim, Uttarakhand and Karnataka) with the support of the State Governments. ${ }^{4}$

A major institutional innovation for decentralisation came in 2007, when the Union Government launched the Rashtriya Krishi Vikas Yojana (RKVY) granting 25 per cent of the plan allocations to the State Governments. The RKVY funds were to be used by State Governments for planning (including district agricultural plans) and executing locationspecific programmes relevant to each agro-ecosystem, technology and natural resource. It ended the 100 per cent centralised planning, programme design and funding in agriculture. But the expectation that it would ensure flexibility and autonomy at the state level to engage with context-specific production and distribution problems remains unrealised. Some State Governments did design and use RKVY for organic agriculture and specific schemes for conjunctive use of water or groundwater sharing or pest surveillance and control. But the emergence of new guidelines and regulatory authorities for decision-making within and by the Union Government stifles these fledgling attempts for autonomy.

The social and political contestations about alternatives came alive in the seed sector. The constitution of national regulatory authorities like the Genetic Engineering Approvals Committee (GEAC) in the midst of protests over the Dunkel Draft in the early 1990s, and the rapid growth of India's private seed industry (domestic and multinational owned) supported by a World Bank loan during a phase of stagnation in industrial growth, sparked a series of protests, a rapid sprout of alternatives like community seed banks, in-situ seed conservation systems, ${ }^{5}$ and two important national legislations which were brewing over the 1990s (the Protection of Plant Varieties and Farmers Rights Act 2001, and the National Biological Diversity Act in 2002). The centre-state antagonisms built up with the leaking of genetically engineered cottonseeds for cultivation in Gujarat even before formal approval by the GEAC (regulatory lapse which led to burning of the 'illegal' cotton fields). Cases were filed by State Governments against the seed industry (Monsanto) and the Union Government, under the MRTP Act. Civil society responses and doubts about scientific credibility and expertise were fuelled by the public interest litigations and public hearing of 
evidence on GM crops (led and supported by a learned Union Minister of Environment and Forests). The Minister's demand for sound science to assess the GM crops debate resulted in a scientific report (Indian Academy of Sciences 2010), which was found plagiarised and eventually discredited. The moratorium on genetically modified crop trials (recommended by the Supreme Court and supported by a highly qualified group of scientists in 2013) till requisite biosafety mechanisms and protocols were put in place, and the approval granted for GM crop trials by an out-going government, a month before the national elections in 2014, raised questions about the politics of technology, and the nature of democracy and development in the country. Despite several such opportunities, the state, true to its intermediate class interests, strives to maintain status quo.

The state continues to provide the subsidies needed and strives to generate more Foreign Direct Investment (FDI) for agriculture, in industry, transport, infrastructure, processing and retail businesses. The empowered intermediate regime strives to maintain status quo even in the face of massive public losses. It feeds on the state's resources. It legitimises (a) the second green revolution as an alternative and (b) the policy instruments that offer opportunities for accumulation by the middle class.

\section{The development burden: evidence and options}

The intermediate regime's articulation and appropriation of the development agenda is now being questioned; whether seen as the configurations of agrarian and rural distress in an uncaring political regime (Vasavi 2012), the indifference of the collectivity of grossly statist policies (Drèze and Sen 2011), or the state elites wedded to growth and unwilling to address state capacities to deliver services to the poor (Kohli 2012). The current status of agriculture reveals how the intermediate regime is now incapable of seeing the evidence of distress caused by its articulation of agricultural development.

For the state, it is a matter of pride that agricultural growth rate was 3.75 per cent over the period 2004-2005 to 2012-2013 (Chand 2014); this approaches the policy goal of 4 per cent annual growth rate. Yet, this impressive growth rate pales in the context of overall growth rates of the Indian economy, which was 6.1 per cent in the decade 1991-1992 to 2000-2001, with growth rates above 9 per cent for the period 2005-2008 (Balakrishnan 2010). Table 6.1 here offers a brief profile of agriculture in the economy. That favourable terms of trade, increase in real prices of agricultural commodities, and consequent increase in profitability contributed over 50 per cent of the growth rate in agricultural GDP (Chand 2014), despite massive increases in use of inputs (Ministry of Finance 2014) is worrisome. That growth rates of productivity did not keep pace with growth rates of input use (chemicals, irrigation - mainly groundwater, HYV and hybrid seeds, and electricity consumption) bothers policy makers and other stakeholders (NDC 2007; Planning Commission 2012). Agriculture and allied sectors grew at 4.7 per cent in 2013-2014 (higher than the 3 per cent growth rate from 1999-2000 to 2012-2013), accounted for 13.5 percentage of the national GDP, and provided livelihoods for 263 million people - cultivators and workers, hosting 54.6 per cent of the national workforce (Ministry of Finance 2014; DoAC Census 2011). The relative stagnation of growth in productivity keeps the massive un- and under-employed workforce in agriculture, the poorest. Given the jobless growth in Indian industry and limited skilled jobs open to the rural population in the services sector, agriculture bears the burden of structural unemployment in a rapidly growing economy. Given the policy goal of 4 per cent growth rate the state spends more than a third of agricultural GDP on subsidies when the sector barely accounts for 14 per cent of the value-added in the economy (in 2012-2013). 


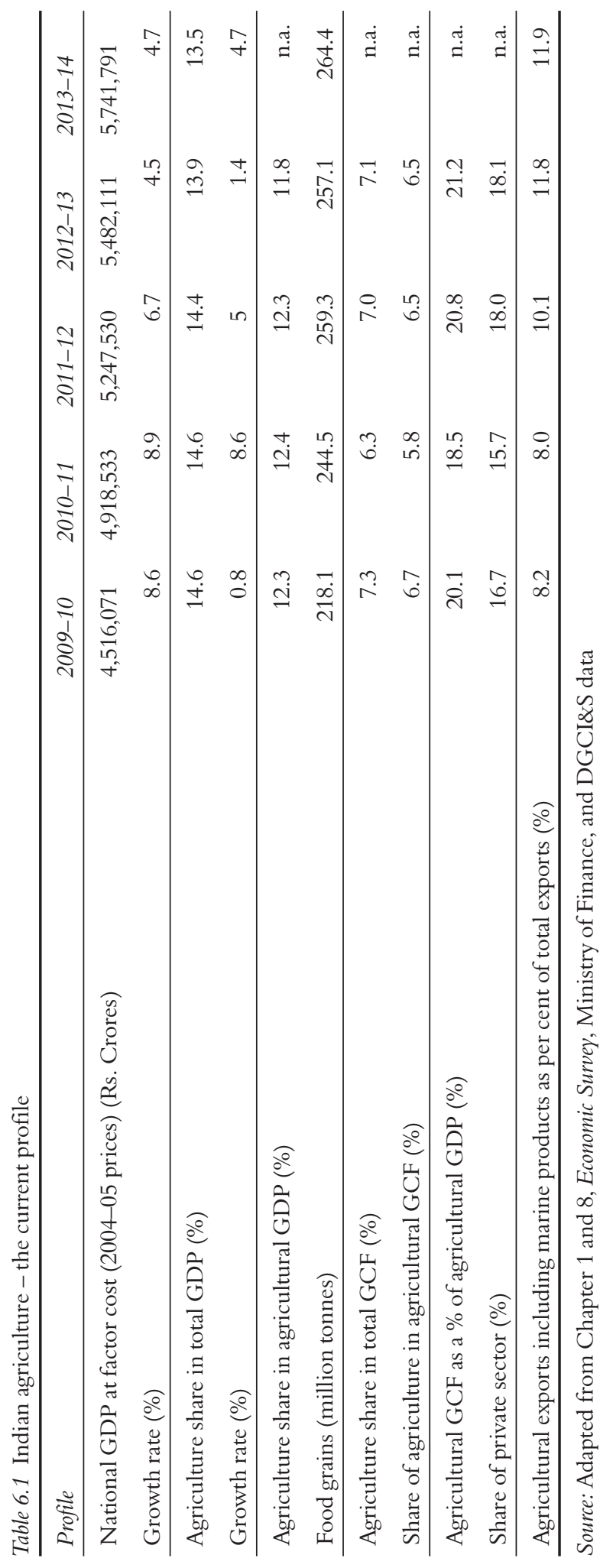


Table 6.2 Calorie poverty increases as consumption poverty declines

\begin{tabular}{llllll}
\hline & \multicolumn{3}{c}{ Consumption poverty (\%) } & & \multicolumn{2}{c}{ Calorie poverty (\%) } \\
\cline { 2 - 3 } \cline { 5 - 6 } Year & Rural & Urban & Rural & Urban \\
\hline 1983 & 46.5 & 42.3 & 66.1 & 60.5 \\
$1987-88$ & 39.3 & 39.2 & 65.9 & 57.1 \\
$1993-94$ & 36.8 & 32.8 & 71.1 & 58.1 \\
$1999-2000$ & - & - & 74.2 & 58.2 \\
$2004-05$ & 28.1 & 25.8 & 79.8 & 63.9 \\
\hline
\end{tabular}

Note: Consumption as measured by Monthly Per Capita Expenditure (MPCE) and calorie intake (2400 and 2100 kilo calories per day for rural and urban populations respectively) measured at the minimum level associated with the poverty line

Source: World Bank team (2011: 50), based on Deaton and Drèze (2009) Table 5, and World Bank staff estimates

Effectively, the intermediate regime transfers income to agri-business and industry from the shrinking share of the economic pie that agriculture generates.

India has achieved record food grain production, an all-time high of 264.4 million tonnes (2013-2014) (Table 6.1), with an almost equal volume of horticultural produce. Field agriculture, mainly crop production, contributes far less (at 11.8 per cent) to agricultural GDP (Table 6.1) than in the latter half of the twentieth century, with horticulture and livestock accounting for an increasing share (30.4 per cent from horticulture and 4.1 per cent from livestock, in 2012-2013). In addition, fruits, vegetables and meat and dairy products are gaining in their share of consumer expenditure on food, with cereals (rice and wheat) declining in their share in the consumption basket. In 2013-2014, India's cereal exports accounted for 46.8 per cent of the total value of agricultural exports.

However, the successes in food production are marred by increasing calorie poverty in the country, the most deficient in calorie intake being the rural poor (Table 6.2). The trend of calorie poverty continues; India is in 2013 home to a quarter of the world's hungry people, a third of all the malnourished children in the world (Welthungerhilfe et al. 2013; WFP-MSSRF 2009). Nearly half of its children under three years of age are underweight and under-nourished. One child dies of malnutrition every eight seconds, and over 87 per cent of pregnant women are anaemic (NFHS 2008; Jose and Navaneetham 2008). Given that the national agricultural production and distribution system is built to ensure food security, or at least one dimension of food security, namely food availability, this prevalence of hunger and malnutrition speaks of strategic fault-lines between agriculture, food and nutrition.

Historically, the green revolution, a food production strategy combining irrigation with chemical inputs and high yielding varieties, was one of the most successful attempts at increasing food production. But the production successes have not been sustained nor translated into consumption of adequate and safe food for all Indian citizens. Of the 54.6 per cent of the total workforce (DoAC Census 2011) that depends on agriculture, many are marginal and small farmers themselves, and workers who have been displaced or lost their land. They account for at least half of the 44 per cent increase in male agricultural workers and 24.5 per cent increase in female agricultural labour between 2001 and 2011 (DoAC Census 2011). 
Table 6.3 Distribution of number of operational holdings by major size-groups for all social groups: all India

\begin{tabular}{lllll}
\hline Year & Total ('000 numbers) & $\begin{array}{l}\text { \% of marginal and } \\
\text { small (together) to total } \\
\text { number of holdings }\end{array}$ & Total ('O00 hectares) & $\begin{array}{l}\text { \% of marginal and } \\
\text { small (together) to total } \\
\text { area of holdings }\end{array}$ \\
\hline $1970-71$ & 70,493 & 69.67 & 162,124 & 20.86 \\
$1980-81$ & 88,883 & 74.47 & 163,797 & 26.19 \\
$1990-91$ & 106,638 & 78.28 & 165,507 & 32.46 \\
$2000-01$ & 119,930 & 81.80 & 159,436 & 38.86 \\
$2005-06$ & 129,222 & 83.29 & 158,323 & 41.14 \\
$2010-11$ & 137,757 & 84.98 & 159,180 & 44.32 \\
\hline
\end{tabular}

Note: Marginal holding - less than 1 hectare. Small holding - 1-2 hectares

Source: Estimated from DoAC, various years, and Census of India

The shrinking size of operational holdings, with the average holding size falling from 2.28 hectares in 1970-1971 to 1.23 hectares in 2005-2006 (DoAC 2008), is noticeable. There is also a significant decline in the number of cultivators (down by 8.6 million between 2001 and 2011); a 3.2 per cent decline (ibid.). Though the percentage may vary depending on the food crops produced, caste and gender of the cultivators, it is estimated that less than 44 per cent of all cultivator households are net sellers of main food crops (Vishwanath and Serajuddin 2010). This makes these cultivator households and labour households vulnerable to food inflation, and worsens the disconnection between food production and nutrition (Gillespie et al. 2012).

Among the producers, marginal and small farmers are vulnerable to various risks. Handling over 44 per cent of all the sown area and 85 per cent of all operational holdings (Table 6.3), they remain the most under-nourished and vulnerable to price shocks (Ministry of Finance 2014). Given the fact that the number of operational holdings they handle has increased by 48.83 per cent and the average operational area has declined by 46.05 per cent between 1970-1971 and 2010-2011 (Table 6.3), their vulnerability to various other production risks is already high with each producer handling several diverse tiny parcels of arable land. The decline in the number of cultivators adds to vulnerability due to a decline in the share of self-produced and processed foods in the food basket of these marginal and small producers. Though they are efficient and more productive than medium and large farmers, their vulnerability to food price shocks increases (Dev 2012). They are likely to remain in chronic poverty (Gangopadhyay et al. 2010; McKay et al. 2004; Planning Commission 2010), given limited opportunities to participate in and gain from local value-added production systems. The diverse opportunities for sustainable agriculture and poverty reduction using local knowledge (GTZ Sustainet 2006), once lost, becomes irretrievable.

The state does acknowledge the stressed natural resources resulting from prevalent production practices and inadequate rural infrastructure (Planning Commission 2008; 2011a). But the centralised agricultural S\&T and administration can only proffer solutions to selective problem definitions, which often add to the natural resource degradation (Raina et al. 2006). For instance, depletion of micronutrients and minerals (nine major ones recorded thus far) due to chemical-intensive production practices is acknowledged, and fortification of 
soil systems and food-grains with the missing micronutrients (especially zinc [Zn] deficiency which is known to be a major cause of diarrhoeal deaths among infants) recommended (Prasad 2010, Srinivasarao and Rani 2013). There are several methods to enrich soils with biomass based, micronutrient and mineral retaining manures. But they rarely receive policy support or public investment; they cannot be designed into a central scheme and produced and supplied in standard (subsidised) doses for the entire country given the diversity of nutrient content in diverse green manures and farm yard manure mixtures. Options for public investments in location-specific soil rejuvenation and agricultural production systems do exist (Planning Commission 2011a), but they would demand a shift from the policy instruments of centralised input subsidy and output price support systems.

There is clear evidence of technology fatigue, run-down delivery systems in credit, extension and marketing services and insufficient agricultural planning at the district and lower levels (Planning Commission 2011b: 89, quoting the NDC meeting 2007). The state does acknowledge the explosive diversity of agriculture and food systems, and the administrative inefficiencies involved in over 55 central schemes (designed and implemented) by the Union Government's DoAC in the Ministry of Agriculture (streamlined into six National Missions in the XII Five Year Plan). But the demand for decentralised planning, public investments and production capacities at the district or lower levels remains on paper. The DoAC has issued guidelines for the allocation of RKVY funds by State Governments (DoAC 2007); this undermines the RKVY as an institutional innovation and debilitates the State Government's capacities to plan and implement programmes in diverse agro-ecosystems.

The persistence of technologies, investment patterns and centralised administration is best illustrated in the state's understanding of and solutions for rainfed agriculture. Rainfed production tracts cover 60 per cent of India's net sown area (Katyal and Farrington 1995; Shah 2006) and produce 34 predominant crops (NRAA 2009). There is evidence of stunning yield growth rates of millets, fruits and vegetables, livestock and dairy, from these tracts (Ministry of Finance 2014). They gain little from the centralised schemes and the massive subsidies (mainly fertiliser, and fuels and electricity) ${ }^{6}$ that enable production of 3-4 major irrigated chemical-intensive crops with assured minimum support prices (announced by the government). The rainfed farming systems (crops, livestock, horticulture and inland fisheries systems) that depend on rainwater harvesting, soil moisture management, and soil biomass based fertilisation, produce anywhere between 60 to 90 per cent of important food, fibre, fodder, and fuel. Increasing growth rate of food-grain production in the rabi season ${ }^{7}$ (in the period 2005-2006 to 2012-2013) is mainly due to impressive productivity growth rates achieved by these rainfed crop tracts and the rapid increase in groundwater withdrawal in these tracts, increasing private market channels and transport investments in rural and peri-urban areas. There is awareness that increasing irrigation (groundwater in particular) and fossil fuel dependent agriculture in rainfed tracts are not sustainable solutions (Vijayshankar 2006; Raina 2013), especially given the diversity of biophysical and social contexts even within one state (Vijayshankar 2005). Farmers in the rainfed farming districts (the 'Big 5' rainfed farming states of Maharashtra, Andhra Pradesh, Madhya Pradesh, Karnataka and Chhattisgarh) account for nearly two-thirds of the annual average of 16,000 farmer suicides between 1995 and 2012 (Raina 2014b). It is not that the state has been caught unaware; this slow and consistent disaster is a consequence of the inability and unwillingness to see the evidence, and to enable differentiated policy options and decentralised governance mechanisms.

Public policy changes and commensurate investment in decentralised capacities for production, processing and consumption systems have been recommended in the rainfed farming blocks and districts where more than 80 per cent of the rural poor live. The XII Five 
Year Plan, includes a National Rainfed Farming Programme (Planning Commission 2012: 46-47), designed to strengthen and build capacities in local organisations (block level) to provide complementary and integrated support for rainfed farming and non-farm activities, including leveraging funds and support from a range of on-going public schemes. ${ }^{8}$ But even with specific designs to operationalise decentralised public investment and support to achieve food and nutrition security through sustainable agro-ecosystems in different rainfed agriculture typologies (FAO, RRA and CRIDA 2013), little has changed. The intermediate regime is unwilling to acknowledge that there is no sustainable growth without inclusion, and unable to create the decentralised norms or institutions that will ensure such opportunities for inclusion. By legitimising and renaming the reinforcement of the green revolution approach as the alternative, it forecloses the opportunities for several other decentralised location-specific alternatives that the rural poor can participate in and gain from.

\section{Development, decentralisation and diversity}

A demand was made about three decades ago for a national policy for food, agriculture and nutrition, with the 'policy objective of minimising nutritional inequalities' (Rao 1982: 137). This is an entirely different policy goal compared to the prevalent goal of 4 per cent growth rate. The green revolution paradigm of genetics-led production knowledge and support (subsidies) has outlived its potential; there will only be diminishing returns to this paradigm (Ruttan 2005). What is needed is an alternative paradigm that celebrates the explosive diversity of agro-ecological and social systems. Agrarian alternatives based on principles that have ecological and social feedback loops, which will be based on 'building secure bridges between agriculture and nutrition/health on the one hand, and between agriculture and the environment on the other' are necessary (ibid.). Many alternatives in India have demonstrated a different epistemology of development and different policy goals. The question today is whether the middle class that enjoys the benefits from rapid economic growth will push for reform of the intermediate regime. Will it mobilise different fiscal and financial allocations, and educated and articulate decision-makers who can design and implement regionally differentiated production and distribution policies?

This chapter has discussed how an empowered intermediate regime articulates development, the role of agriculture in development and policy instruments. For the regime, agriculture has been fundamental to all development (phase 1), the driver of modernisation for development (phase 2), and is now a game of contending alternatives (phase 3). That an alternative development paradigm and policy framework is necessary for agriculture, food and nutrition is obvious. When contending alternatives (like systems of rice intensification (SRI), non-pesticidal management, and organic farming) seek scientific and political legitimisation from the existing knowledge and policy paradigm the response from the entrenched actors is to co-opt the alternatives into the prevalent approach (Raina 2013). The intermediate regime has used centralised target and control mechanisms to implement innovations like the RKVY; these policy solutions come as technological packages, without mobilising the decentralised capacities or functional devolution needed for the small farmers to participate effectively in these solutions. These centralised bureaucratic strangleholds on agriculture prevail. Whether it is the formulation of central guidelines for the RKVY, national authorities for specific technologies (say GM crops), or central subsidies disbursed for chemicals, fuel and food, the intermediate regime is aware that this centralisation and bureaucratisation leads to inefficiencies and corruption much like the bureaucratisation of co-operatives did in the past (Jodhka 1995). 
Today, many constituencies of Indian agriculture which were excluded in the green revolution strategy, like small farmers, agricultural labour, minor millets, consumers of diverse staples, rainfed and mountain agro-ecosystems, and the environment with all the flora and fauna associated, soil and water systems, and local food cultures, are gaining voice and presenting alternative problem statements. Several State Governments who had unquestioningly accepted the centralised development agenda for agriculture in the latter half of the twentieth century are asserting their constitutionally guaranteed authority to make specific technological choices, to promote their regional agri-food systems. The policy options here are public investment in education and health care and promotion of decentralised regional production systems, and domestic markets with short energy efficient value chains (Drèze and Sen 2011; Singh 2012). Contradicting these are the globally accepted development norms and their reaffirmation of programmes for centralised public subsidisation of market-led export oriented agriculture. Here the state accounts for, subsidises and ultimately legitimises the energy, nutrition and environmental deficits, all in the name of the poor farmer and malnourished children. The wealth of India's billionaire community increased twelvefold in fifteen years; enough to eliminate absolute poverty in the country twice over (PTI 2014). The legacy of past development trajectories, evident as climate change and several political-social conflicts may not permit this kind of accumulation; at least not for long. The intermediate regime has to confront its obsessions with vacuous growth rates to start with. It has to find ways of addressing questions of income and nutritional inequalities by acknowledging and promoting the diversity of Indian agriculture, seeking alternative decentralised knowledge and policy paradigms for development.

\section{Acknowledgements}

I acknowledge the comments and suggestions made by Dominic Glover, Knut A. Jacobsen, a friend who wishes to remain anonymous, and the participants in conferences in Yale University in April 2012, Nehru Memorial Museum and Library in December 2012, and the Indian Institute of Public Administration in November 2013, on new questions about land, a longer and broader view of the Indian economy, and knowledge and governance of agriculture and food, respectively. The usual disclaimer applies here too.

\section{Notes}

1 There were serious Marxist critiques (Namboodiripad 1973) of Raj's application of Kalecki's intermediate regime theory to understand India's middle class nurtured by state capitalism (Raj 1973). But what Kalecki and Raj were pointing out was how the intermediate regime weakened the working class and the poor peasant, using Marx's own methods of analysis on problems that have come up since (Robinson 1976).

2 Quoting Nehru (1968), from a speech delivered to the National Development Council in 1963 (see Balakrishnan 2010).

3 The Timbaktu Collective, Deccan Development Society, Centre for Sustainable Agriculture, The Keystone Foundation, Foundation for Ecological Services, Sewa Mandir, Central Himalayan Rural Action Group, Samaj Pragati Sahyog, Centre for Indigenous Knowledge Systems, Agriculture, Man and Ecosystems Foundation, and Watershed Support Services and Activities Network are a few examples of organisations that this author has known or collaborated with in the civic space. These organisations have demonstrated dynamic agrarian alternatives that are profitable, equitable and sustainable (socially and ecologically).

4 They include organic agriculture policies formulated, debated and approved in the state legislative assemblies of eleven states of the Indian Union. This is surprising in a country with little that is available as national policy or state level policies for agriculture. Also, the Ministry of Rural 
Development of the Union Government and several State Governments pro-actively enabling SRI (Systems of Rice Intensification), Integrated Pest Management, agri-horticulture programmes led by Women's Self Help groups, area based technology and development approaches with emphasis on employment and social entrepreneurship for ecological and economic returns, hundreds of civil society organisations or community based agro-ecosystem specific production and marketing networks and local and fair trade food systems that shun chemicals, pesticides and child labour (for some examples, see www.indiaenvironmentportal).

5 See Malik et al. (2013), the scientific manual for creating and managing community seed banks published by the NBPGR; the scientific validation of the work of several local biodiversity and seed conservation efforts say, by Muniyamma in Karnataka, a Sarangi in Orissa, or organisations like CIKS, Gene Campaign or Navdanya.

6 Total subsidies (including food, fertiliser, petroleum, import of food items - sugar, edible oils, etc.) amount to 2.19 per cent and 21.43 per cent respectively of the national GDP and agricultural GDP in 2009-2010; rising to 2.57 per cent and 32.02 per cent respectively in 2013-2014 (Estimated from Planning Commission, 2014: 34).

7 Rabi is the winter cropping season, harvested in spring.

8 The Working Group on Natural Resource Management and Rainfed Farming (Planning Commission 2011a) recommends a National Rainfed Farming Mission with three policy instruments, that would enable an iterative process of action, interaction and learning among critical actors in the system. The proposed Mission will involve:

i a National Rainfed Farming Program to be piloted in 1,000 Blocks,

ii creation of 'rainfed windows' within all other line departments and ministries relevant to rural/ agricultural development, energy, natural resources, and science and technology ( $\& \& T)$, and

iii specific policy support within central, state and district administrations to develop an institutional architecture for sustainable development of rainfed agriculture, fragile ecosystems and complex, diverse livelihoods.

It is not surprising that of this three pronged strategy, only the NRFP has been included in the XII Five Year Plan document (Planning Commission 2012). A Mission-mode piloting of the paradigm is an idea that prioritises a development problem that is at the core of India's economy, and demands a political willingness to reconsider and weigh macro-economic choices.

\section{References}

Balakrishnan, P. (2010) Economic Growth In India: History and Prospect, New Delhi: Oxford University Press.

Barker, R. and R.W. Herdt (1985) The Rice Economy of Asia, Washington, DC: Resources for the Future.

Bhalla, G. S. and G. Singh (2010) Final Report on Planning Commission Project Growth of Indian Agriculture a District Level Study, New Delhi: CSRD, Jawaharlal Nehru University.

Birner, R., S. Gupta, N. Sharma and N. Palanswamy (2007) The Political Economy of Agricultural Policy Reform in India: The Case of Fertilizer Supply and Electricity Supply for Groundwater Irrigation, New Delhi: IFPRI.

Chand, R. (2014) 'Dissecting Agricultural Performance Since Mid-1990s', Yojana, June 2014: 10-15.

Conway, G. (1997) The Doubly Green Revolution - Food for all in the 21st Century, New York: Penguin.

Deaton, A. and J. Drèze (2009) 'Food and Nutrition in India: Facts and Interpretations', Economic and Political Weekly, 44 (7): 42-65.

Dev, S.M. (2012) Agriculture-Nutrition Linkages and Entry Points in India, Working Paper No. 6, Mumbai: IGIDR.

DoAC (2007) Guidelines for National Agriculture Development Programme (NADP), Rashtriya Krishi Vikas Yojana (RKVY), New Delhi: Department of Agriculture and Cooperation, Ministry of Agriculture, Government of India.

DoAC (2008, and various years) All India Report on Agriculture Census (Various Years), New Delhi: Department of Agriculture and Cooperation, Agricultural Census Division, Ministry of Agriculture, Government of India.

Drèze, J. and A. Sen (2011) 'Putting Growth in its Place', Outlook, Nov. 14, 2011.

Dubash, N. (2002) Tubewell Capitalism: Groundwater Development and Agrarian Change in Gujarat, New Delhi: Oxford University Press. 
Dubash, N. (2007) 'The Electricity-Groundwater Conundrum: Case for a Political Solution to a Political Problem', Economic and Poltical Weekly, 42 (52): 45-55.

Erenstein, O. and W. Thorpe (2011) 'Livelihoods and Agro-ecological Gradients: A Meso-level Analysis in the Indo-Gangetic Plains India', Agricultural Systems, 104 (1): 42-53.

FAO, RRA and CRID (2013) Evolving an Operational Framework for Rainfed Farming Systems Program under the 12th Five Year Plan - Proceedings of the National Workshop, 14-15 May 2013, sponsored by FAO, organized in CRIDA, Hyderabad.

FICCI (2012) Seeding Success through Innovation and Technology, Knowledge Paper I: Food 360. Hyderabad: ICRISAT and FICCI.

Fitzgerald, E.V.K. (1976) 'The Political Economy of an Intermediate Regime', Journal of Latin American Studies, 8 (1): 53-71.

Gangopadhyay, S., P. Lanjouw, T. Vishwanath and N. Yoshida (2010) 'Identifying Pockets of Poverty: Insights from Poverty Mapping Experiments in Andhra Pradesh, Orissa and West Bengal', Indian Journal of Human Development, 4 (1): 5-28.

Gillespie, S., J. Harriss and S. Kadiyala (2012) The Agriculture Nutrition Disconnect in India - What Do We Know? IFPRI Discussion Paper 01187, Washington, DC: IFPRI.

Ghosh, J. (2010) 'The Political Economy of the Enabling State', Macroscan, March 10, 2010, www. macroscan.org [accessed 8 December 2014].

Golait, R. and S.M. Lokare (2008) Capital Adequacy in Indian Agriculture: A Riposte, RBI Occasional Papers, 29 (1, Summer 2008).

Gulati, A. and S. Narayanan (2003) The Subsidy Syndrome in Indian Agriculture, New Delhi: Oxford University Press.

GTZ Sustainet (2006) Sustainable Agriculture: Pathways out of Poverty for India's Rural Poor, Eschborn: GTZ.

ICAR (1998) Decline in Crop Productivity in Haryana and Punjab: Myth or Reality? New Delhi: ICAR.

ICAR (2007) ICAR-Industry Meet: Agricultural Transformation through Public Private Partnership - An Interface (by S. Ayyappan, P. Chandra, S.K. Tandon), New Delhi: ICAR.

Imam, K.K. (1980) 'Public Enterprise in an Intermediate Regime', The Bangladesh Development Studies, 8 (4): 75-83.

Indian Academy of Sciences (2010) 'Inter-Academy Report on GM Crops', available at http://www. indiaenvironmentportal.org.in/content/316933/inter-academy-report-on-gm-crops/ [accessed 17 April 2015]

Jain, V. (2006) 'Political Economy of the Electricity Subsidy', Economic and Political Weekly, 41 (38): 4072-4080.

Jodhka, S. (1995) 'Bureaucratisation, Corruption and Depoliticisation: Changing Profile of Credit Cooperatives in Rural Haryana', Economic and Political Weekly, 30 (1): 53-56.

Jose, S. and K. Navaneetham (2008) 'A Fact Sheet on Women's Malnutrition in India', Economic and Political Weekly, 43 (33): 61-67.

Kalecki, M. (1976, reprint) Essays on Developing Economies, Brighton: Harvester Press.

Katyal, J.C. and J. Farrington (1995) Research for Rainfed Agriculture, New Delhi: ICAR.

Kohli, A. (2012) Poverty amid Plenty in the New India, Cambridge: Cambridge University Press.

Mahalanobis, P.C. (1955) 'Draft Plan Frame for the Second Five-Year Plan 1956-57 to 1960-61', Samkhya, 16 (1 and 2): 63-110.

Malik, S.K., P.B. Singh, A. Singh, A. Verma, N. Ameta and I.S. Bisht (2013) Community Seed Banks: Operation and Scientific Management, New Delhi: National Bureau of Plant Genetic Resources.

McKay A., M. Baulch with M. Hisarciklilar and D. Lawson (2004) How Many Chronically Poor People are There in the World? Some Preliminary Estimates, Chronic Poverty Research Centre, Working Paper No. 45.

Ministry of Agriculture (2003) Report of the Committee on Capital Formation in Agriculture, Directorate of Economics and Statistics, Ministry of Agriculture, Government of India: New Delhi.

Ministry of Finance (2014, and various years) Economic Survey, New Delhi: Ministry of Finance, Government of India.

Mishra, S.N. and R. Chand (1995) 'Public and Private Capital Formation in Indian Agriculture Comments on Complimentarity Hypothesis and Others', Economic and Political Weekly, 30 (25): A64-A79.

Mittal, R.B. (2011) 'Why Postpone Agricultural Reform?’ The Economic Times, July 2, 2011.

Mody, A. (2005) 'Quest for Inclusive Growth: Continuity and Constraints in Indian Economic Policies', Economic and Political Weekly, 40 (37): 4052-4061. 
Murgai, R. and S. Howes (2003) 'Karnataka: Incidence of Agricultural Power Subsidies', Economic and Political Weekly, 38 (16): 1533.

Namboodiripad, E.M.S. (1973) 'On Intermediate Regimes', Economic and Political Weekly, 8 (48): 2134.

NDC (2007) 54th Meeting of the National Development Council at the Vigyan Bhavan, New Delhi: Planning Commission, Government of India.

NFHS (2008) India National Family Health Survey 2005-06 (NFHS-3), New Delhi: International Institute for Population Sciences.

NRAA (2009) Rainfed Livelihoods - Progressive Paradigms, New Delhi: National Rainfed Areas Authority, Planning Commission.

Nehru, J. (1968) 'Agriculture - Basis of Economic Development', Jawaharlal Nehru's Speeches, Vol. 5. New Delhi: Delhi Publications Division, Ministry of Information and Broadcasting, Government of India.

Planning Commission (2008). Eleventh Five Year Plan (2007-2012), Agriculture, Rural Development, Industry, Services and Physical Infrastructure - Vol. III, Planning Commission, Government of India, New Delhi: Oxford University Press.

Planning Commission (2010) Mid Term Assessment of the Eleventh Five Year Plan, Planning Commission, Government of India, New Delhi: Oxford University Press.

Planning Commission (2011a) Report of the XII Plan Working Group on Natural Resources Management and Rainfed Farming, New Delhi: Planning Commission, Government of India.

Planning Commission (2011b) Approach paper to the XII Five Year Plan, Planning Commission, New Delhi: Government of India.

Planning Commission (2012) Twelfth Five Year Plan 2012-17(Vol. II), New Delhi: Planning Commission, Government of India.

Planning Commission (2014) Data Book, Government of India, available at http://planningcommission. nic.in/data/datatable/0306/Databook_June2014.pdf [accessed 17 April 2015]

PTI (2014) 'Income Inequality on the Rise in Countries like India: IMF', Times of India, 4 February 2014.

PMEAC (2012) Economic Outlook 2012-13, New Delhi: Prime Minister's Economic Advisory Council, Government of India.

Prasad, R. (2010) 'Zinc Biofortification of Food Grains in Relation to Food Security and Alleviation of Zinc Malnutrition', Current Science, 98 (10): 1300-1304.

Raina, R.S. (1999) 'Professionalisation and Evaluation: The Case of Indian Agricultural Research', Knowledge, Technology and Policy, 11 (4): 69-96.

Raina, R.S. (2011) 'Institutional Strangleholds: The Evolution of Agricultural Research in India', in D. Narayana and R. Mahadevan (eds), Shaping India, 99-123, New Delhi: Routledge.

Raina, R.S. (2013) 'Knowing and Administering Food: How Do We Explain Persistence?' Keynote address delivered at the National Seminar on Food Security and Food Production: Institutional Challenges in Governance Domain, organized by Indian Institute of Public Administration (IIPA), New Delhi, 31 October-1 November 2013.

Raina, R.S. (2014a) 'Beyond Supply Driven Science', Seminar, 654, February 2014: 69-74.

Raina, R.S. (2014b) What do Rainfed Farming Communities Want? The Hindu Survey of Indian Agriculture, Chennai: The Hindu.

Raina, R.S. and R.V. Sulaiman (2007) 'From Technology Development and Dissemination to Learning Approaches: Institutional Change for Rural Development', in V. Ballabh (ed.), Institutional Alternatives and Governance in Agriculture, New Delhi: Academic Foundation.

Raina R.S., S. Sangar, R.V. Sulaiman and A. J. Hall (2006) 'The Soil Sciences in India: Policy Lessons for Agricultural Innovation', Research Policy, 35 (5): 691-714.

Raj, K.N. (1964) 'Nehru, the Congress and Class Conflict', The Economic Weekly, Special Number: July 1964: 1231- 1234

Raj, K.N. (1973) 'The Politics and Economics of "Intermediate Regimes", Economic and Political Weekly, 8 (27): 1189, 1191-1198.

Ramasundaram, P. and Vennila, S. (2013) 'A Decade of Bt Cotton Experience in India: Pointers for Transgenics in Pipeline', Current Science, 104 (6): 697-698.

Rao, C.H. and A. Gulati (1994) 'Indian Agriculture: Emerging Perspective and Policy Issues', Economic and Political Weekly, 29 (55): A58-69.

Rao, V.K.R.V. (1982) Food, Nutrition and Poverty in India, Delhi: Vikas Publishing House Pvt Ltd.

Ray, S. (ed.) (2007) Handbook of Agriculture in India, New Delhi: Oxford University Press. 
Robinson, J. (1976). 'Introduction', in M. Kalecki, Essays on Developing Economies, Brighton: Harvester Press, and New Jersey: Humanities Press, 7-13.

Ruttan, V.W. (2005) 'Scientific and Technological Constraints on Agricultural Production: Prospects for the Future', Proceedings of the American Philosophical Society, 149 (4): 453-468.

Sawyer, M.C. (1985) 'The Economics of Michal Kalecki', Eastern European Economics, 23 (no. 3 and 4): $1-319$.

Shah, M. (2006) 'The Problem, in The Forsaken Drylands', Seminar, 564.

Singh, Sukhpal (2012) Modern Food Value Chains in India: Emerging Potential for the Poor, Delhi: Access Publication.

Sivaraman, B. (1991) Bitter-Sweet: Governance of India in Transition, New Delhi: Ashish Publishing House.

Sivasubramanian, S. (2000) The National Income of India in the Twentieth Century, New Delhi: Oxford University Press.

Srinivasarao, C. and Y.S. Rani (2013) 'Zinc Deficiency: A Productivity Constraint in Rainfed Crop Production Systems in India', SAT ejournal, 11, December 2013, 1-11.

Storm S. (1997) 'The Unfinished Agenda: Indian Agriculture under the Structural Reforms', The Journal of International Trade and Economic Development: An International and Comparative Review, 6 (2): 249-286.

Streeten, P. (1997) Review of Collected works of Michal Kalecki. Vol. 5. Developing Economies edited by J. Osiatynski, translated by C.A. Kisiel, in Economic Development and Cultural Change, 45 (2): 446-449.

Subramaniam, C. (1972) A New Strategy in Agriculture, New Delhi: ICAR.

Vaidyanathan, A. (2007) 'Discussing "Inclusive Growth" Ahead of its Time', Economic and Political Weekly, 42 (30): 3096-3099.

Vaidyanathan, A. (2010) Agricultural Growth in India: The Role of Technology, Incentives and Institutions, New Delhi: Oxford University Press.

Vasavi, A.R. (2012) Shadow Space - Suicides and the Predicament of Rural India, New Delhi: Three Essays Collective.

Vennila, S. (2006) 'Bt Cotton for Pest Management or Pest Management for Bt Cotton?' Current Science, 91 (12): 1596.

Vijayshankar, P.S. (2005) 'Four Decades of Agricultural Development in MP - An Agro-ecological Subregion Approach', Economic and Political Weekly, 40 (48): 5014-5024.

Vijayshankar, P.S. (2006) 'Unlocking the Hidden Potential of Dryland Agriculture', Seminar 564.

Vishwanath, T. and U. Serajuddin (2010) 'Welfare Impacts of Rising Food Prices in South Asian Countries', in S. Ahmed and H.G.P. Jansen (eds), Managing Food Price Inflation in South Asia, 45-84, Dhaka: The University Press.

Welthungerhilfe, IFPRI and Concern Worldwide (2013) Global Hunger Index - The Challenge of Hunuger, Building Resilience to Achieve Food and Nutrition Security, Bonn, Washington, DC, Dublin: Welthungerhilfe, IFPRI, Concern Worldwide.

WFP-MSSR (2009) Report on the State of Food Insecurity in India, Chennai: MSSRF and New Delhi: WFP. World Bank Team (2011) Perspectives on Poverty in India, New Delhi: World Bank and Oxford University Press. 

$\because$ Taylor \& Francis http://taylorandfrancis.com 


\section{PART II}

\section{India and the world}



$\because$ Taylor \& Francis http://taylorandfrancis.com 


\section{7 \\ POLITICS, SECURITY AND FOREIGN POLICY}

Rajat Ganguly

\section{Introduction}

India is fast emerging as a global power. Since the early-1990s, the country has made rapid economic progress, achieving high levels of economic growth, industrial development and a reduction in poverty levels. The middle-class has expanded, leading to a consumerist boom in the country. Industrial output has increased and agricultural production has remained steady. Although the Global Financial Crisis (GFC) did slow things down, India has fared far better when compared to other states. The Indian military is now the fourth largest in the world with a highly mechanised and mobile army, a strategic-strike capable air force and a blue water navy that is rapidly gaining in strength. Internationally, India's prestige and standing is at an all-time high and experts predict that India, along with China, will be the new entrants to the 'superpower club' in the twenty-first century. Politically, the various institutions of Indian democracy continue to function robustly, as attested to by the professional manner in which national elections were conducted in India in 2014 and a smooth transfer of power effected. The presence of a global diaspora and the spread of 'soft power' through movies, art, culture, dance, theatre, music and academia further augment India's global reach and standing.

Problems, however, remain and continue to create roadblocks in the way of further national progress and wellbeing. The Indian state has had to deal with ethnic violence in various forms on a regular basis in different parts of the country. Even rapid economic progress seems to have unleashed violent class warfare in the form of a Maoist insurgency, which has expanded spatially and is now considered by many to be the single biggest internal threat to national security. In foreign relations, the longstanding border dispute with China is nowhere close to being resolved while new tensions have emerged over the Indian Ocean and the South China Sea. Even though Pakistan returned to civilian rule in 2008, bilateral ties have continued to be vitriolic and fraught with tensions, particularly since the Mumbai terrorist attack and skirmishes along the Line of Control (LOC) in Jammu and Kashmir. Relations with United States and other major powers are also not always free of tensions. In an uncertain global political and strategic landscape, India has adopted a pragmatic and self-help oriented approach to security and foreign policy, which while augmenting India's military capacity may also open up new lines of conflict. 


\section{Rajat Ganguly}

In this chapter, I aim to do three things. First, I analyse domestic politics in India, focusing on various types of ethnic conflicts that have shaped the politics of the nation in recent times. Second, I discuss the Maoist insurgency, which has emerged as the major internal threat to national security. Finally, I look at the foreign policy posture of India since the early-1990s and analyse how the country is using foreign policy to bolster national security and transform its military into a modern fighting force.

\section{Politics in India}

India is an immensely diverse and complex nation. Its 1.3 billion (2014) population is divided into several religions: Hindus (80per cent), Muslims (11per cent), and Sikhs, Buddhists, Jains, Christians, Parsis and Jews (7per cent combined). Apart from Hindi (the national language) and English, which are spoken widely, there are at least 18 major languages (belonging to either Dravidian South India or Indo-European North India) that are recognised under the Constitution and over 780 minor languages and dialects (Hardgrave 1993: 54-55).

The majority Hindus are divided into a myriad of religious traditions and castes (jatis) that are hierarchically ranked, which vary according to region. The Hindus are also divided into different cultural groups or communities that are regionally concentrated and have their distinct language and cultural traits. The largest minority group, Muslims, are scattered across India although the main concentrations of Muslims are found in Uttar Pradesh, Bihar and West Bengal states. Fairly large numbers of Muslims can also be found in states like Assam, Gujarat, Maharashtra, Tamil Nadu and Kerala. In only one state, Jammu and Kashmir, and in one Union Territory, Lakshadweep, Muslims constitute a numerical majority of the population. Urdu is a popular language among north Indian Muslims; other Muslim communities may speak Bengali, Assamese, Gujarati, Tamil and Malayalam depending upon their location. While the majority of the Muslims belong to Sunni traditions, other religious traditions such as Shia, Aga Khani Khoja and Bohra are prominent as well (Khalidi 1995). The Sikhs are traditionally concentrated in the north Indian state of Punjab, although the relative prosperity of the Sikhs has resulted in outmigration and scattering of the community all over India. The Sikhs are particularly well represented in the Indian military and in the areas of business, commerce and agriculture. The Buddhist and Jain communities are very small in numbers. While Buddhist concentrations can be found in the Indian northeast (northern Bengal and Sikkim) and in states like Himachal Pradesh (Dharmasala) and Jammu and Kashmir (Ladakh), as well as concentrations in Maharashtra and Uttar Pradesh (Navayana Buddhists), concentrations of Jains can be found in the western states of Rajasthan, Gujarat and Maharashtra. Christians are scattered all over India, although concentrations can be found in the north-eastern states such as Mizoram and Nagaland, in south India such as in the state of Kerala and in the state of Goa in western India. Parsis and Jews are mostly concentrated in urban areas, particularly in and around the city of Mumbai.

India's tribal population (Scheduled Tribes) stands at around 84 million or 8.2 per cent of the total population of the country (Census of India 2011). An overwhelming majority of the tribal population lives in rural areas, particularly in the states of Madhya Pradesh, Maharashtra, Orissa, Gujarat, Rajasthan, Jharkhand, Chhatishgarh, Andhra Pradesh, West Bengal and Karnataka; these states together account for 83.2 per cent of the total Scheduled Tribes population of the country. Assam, Meghalaya, Nagaland, Jammu and Kashmir, Tripura, Mizoram, Bihar, Manipur, Arunachal Pradesh and Tamil Nadu account for another 15.3per cent of the total Scheduled Tribes population (Census of India 2011). The Union Territory 
of Lakshadweep has the highest proportion of Scheduled Tribes at 94.8per cent of its total population. India's 'Dalit' or 'Scheduled Caste' population is estimated to be around 170 million or 16.6per cent of the total population (Census of India 2011). ${ }^{1}$ Punjab (at 31.9per cent), followed by Uttar Pradesh, West Bengal and Bihar, has the largest Scheduled Caste population in India. These four states, along with Andhra Pradesh, Tamil Nadu, Maharastra, Rajasthan, Madhya Pradesh and Karnataka comprise the group of 'top ten' states in terms of large Scheduled Caste population in the country (Census of India 2011).

The framers of the Indian Constitution had realised that only a secular, democratic and federal state would have the capacity to effectively manage India's immense ethnic, religious, linguistic and regional diversity. Accordingly, the Indian Constitution, promulgated on 26 January 1950, laid down a set of fundamental rights and certain specific provisions to safeguard the interests of ethnic communities, especially the religious minorities. Key fundamental rights include the right to equality; the right to freedom; the right to freedom of religion; cultural and educational rights; the right not to be exploited; and the right to constitutional remedies. Under Article 14, the Constitution guarantees the equality of all persons before the law. Under Article 15, any discrimination between citizens on the grounds of religion, race, caste, sex or place of birth is strictly prohibited. The Constitution further abolished the practice of 'untouchability' under Article 17. Under Article 20, all minorities in India are given the right to preserve and promote their language, script and culture. Under Article 25, all persons are entitled to freedom of conscience and to freely practise and propagate their religion. For reasons of social justice and to create socio-economic opportunities, the Constitution also advocates affirmative action policies (through reservations or quotas) for the Scheduled Castes and Scheduled Tribes (Article 335 ) in college and university admission and in government employment. In proportion to their numerical strengths, the Constitution also allots reserved seats in the Lok Sabha (the lower house of the national parliament) and in the state legislative assemblies for Scheduled Castes and Scheduled Tribes (Hardgrave 1993: 54-55).

Along with constitutional safeguards, the administrative reorganisation of the Indian state sought to further strengthen ethnic and regional identities by accepting the demand for the creation of provinces based on broad ethno-linguistic criteria. In 1953 the States Reorganisation Commission was set up, which led to the enactment of the States Reorganisation Act of 1956. Under this Act, 14 states and five Union Territories were initially set up. Subsequent reorganisations and creation of more new states essentially followed the basic principle that major ethno-linguistic groups ought to have their separate states within the Indian Union (Phadke 1974; Brass 1994).

The Indian elites also realised the need to create a secular and federal polity in order to effectively manage India's ethnic diversity. Constitutional provisions and practices indicate that Indian secularism does not mean a strict separation between church and state; rather Indian secularism allows for state recognition and equal promotion of all religions (Hardgrave 1993: 54-68). The idea of a federal polity also allows the state to accommodate ethnic plurality and encourage cultural distinctiveness without letting any one ethnic group to dominate at the national or federal level. At the same time, however, the Indian Constitution, mindful of the dangers of federalism, denies states and ethnic groups the right to secede from the Federation (Dasgupta 2001: 54).

India's multi-party system is also a mechanism through which Indian elites have tried to manage ethnic differences and conflict by allowing ethnic communities to form distinct political platforms to voice their grievances and interests. Although after independence the Indian National Congress (INC) was a large 'umbrella' organisation that included various 


\section{Rajat Ganguly}

groups, interests and opinions and espoused socialist and welfarist ideology and policies, from the mid-1960s onwards there was a steady growth of regional parties that tapped into ethnolinguistic, religious and regional sentiments (Kothari 1964). These regional parties eventually challenged the Congress party, which under Indira Gandhi's leadership had increasingly started to resort to undemocratic, illegal and draconian measures to retain its monopoly over political power at the Centre and in the states. The creeping authoritarianism in Indian politics that emerged in the early-1970s eventually criminalised the polity, politicised the bureaucracy and security agencies and rode roughshod over opponents of the Congress party. In 1975 it led to the declaration of Emergency rule and the suspension of democracy. Forced by popular pressure to withdraw the Emergency and hold national elections in 1977, the Congress party was routed by an opposition consisting of a coalition of smaller national and regional parties. Over the next four decades, the phenomenal rise of regional parties and leaders, the gradual weakening of the Congress politically and organisationally, and the emergence and steady growth of the Hindu-nationalist Bharatiya Janata Party (BJP, Indian People's Party) contributed a great deal to the outbreak of ethnic violence and agitational politics across India.

A key form of ethnic conflict that emerged in India centred on the creation of new states. For instance, in 1960, mainly due to the agitations of Marathi and Gujarati speaking populations of the state of Bombay, the Bombay Reorganisation Act was passed and the ethno-linguistic states of Maharashtra and Gujarat were created. Then, in 1962, after the Indian government accepted the Naga tribes' demand for a separate state, three districts of the state of Assam were detached to create the new state of Nagaland. Thereafter, in 1966, the state of Punjab was divided to create the Hindi-speaking state of Haryana, and in 1971 Himachal Pradesh. In the early-1970s, three further new states - Meghalaya, Manipur and Tripura - were created in the northeast. The agitations and demands for new states, however, did not stop there. In the early-2000s, when the BJP-led National Democratic Alliance (NDA) government was in charge at the Centre, three new states were created by breaking up existing states: Jharkhand by breaking up the state of Bihar; Uttaranchal by breaking up the state of Uttar Pradesh; and Chhattisgarh by breaking up the state of Madhya Pradesh. Most recently, after years of vitriolic agitation and political deal making, on 3 June 2014, India's twenty-ninth state was born after the state of Andhra Pradesh was divided to create the new state of Telangana. Further agitations for statehood and state break-ups look inevitable in the future. In West Bengal, the Gorkhas of Darjeeling and the Rajbonshis of Cooch Behar have for long agitated for the creation of separate Gorkhaland and Kamtapur states respectively (Ganguly 2005: 467-502). In Assam, the tribal Bodo population has made a similar demand for a separate Bodoland and launched a violent campaign. Movements for a separate Vidarbha, Harit Pradesh and Jammu states have long histories of political agitation.

While the creation of linguistic states went some way to satisfy ethnic aspirations, expanded political participation and allowed people to access state and local governments more effectively, a key drawback of the process was that it encouraged parochialism based on language and religion (Hardgrave 1993: 54-68). In many states outside the Hindi heartland of central and northern India, such parochial sentiments gave rise to militant nativist movements that demanded preferential policies from state governments for the sons of the soil (especially in the areas of education and employment) at the expense of ethnic outsiders. Regional political parties sprang up to take advantage of such parochial sentiments and capture power in the state; once in office, these parties had little option but to promote and protect the interests of the indigenous communities. For instance, the Dravida Munnetra Kazhagam (DMK) party in Tamil Nadu emerged in the post-independence period 'as the harbinger of Tamil ethnicity and nationhood' (Phadnis and Ganguly 2001: 223). A key issue 
over which the DMK clashed with the Indian government was the imposition of Hindi as the sole official language. Portraying the Centre's language policy as cultural imperialism of the North over the rest of the country, the anti-Hindi agitation spearheaded by the DMK ultimately forced the Indian government to back down and allow major regional languages to co-exist with Hindi and English as national languages (Phadnis and Ganguly 2001: 218 232). Similarly, the ideology of the Shiv Sena party in Maharashtra, founded in 1966 by Bal Thackeray, is based on the concepts of the 'Bhumiputra' (sons of the soil) and 'Hindutva' (Hindu nationalism). Taking advantage of the socio-economic grievances and frustrations of the Hindu Maharashtrian community, the Shiv Sena rose into political prominence in Maharashtra under the banner of 'Maharashtra for Maharashtrians' and launched 'verbal and physical attacks at South Indian immigrants and Muslims' (Hardgrave 1993: 59). In the Indian northeast, too, the steady growth of parochial sentiments went hand in hand with the formation of regional political parties that championed the cause of the sons of the soil. In Assam, for instance, the All Assam Students Union (AASU) and the United Liberation Front of Assam (ULFA) steadfastly promoted the interests of the ethnic Assamese and launched attacks against Bengalis, Biharis and other outsiders (Ganguly 2007: 54-55; Ganguly 1997: 110-111). In Mizoram, violence broke out between the majority Mizo community and the minority Bru or Reang tribes after the Mizoram government led by the Mizo National Front (MNF) started adopting policies favouring the Mizo community (Bartwal 1998).

Even though the Indian Constitution denies the right of secession to ethnic groups within the Indian Federation, secessionist demands emerged at regular intervals. The initial challenge came in the form of the Naga and Mizo insurgencies in the Indian northeast, which were eventually neutralised through army action and political accommodation in the form of the creation of the new states of Nagaland and Mizoram (Ganguly 1997: 109-110). However, strong feelings of deprivation, neglect, economic and social marginalisation, and lack of empowerment continued to create resentment among many ethno-tribal groups in this region towards the Indian state. Such resentment often led to violent clashes between competing ethnic groups and between various ethnic groups and the Indian state. Of the various secessionist insurgent groups active in the Indian northeast today, the United Liberation Front of Assam (ULFA) is by far the most powerful and dangerous. Secessionist violence by Sikhs flared up in the state of Punjab in the early-1980s and eventually led to an invasion of the Harimandir Sahib (Golden Temple) in Amritsar, or more correctly Darbar Sahib which refers to the entire complex of shrines and building around the holiest Sikh religious shrine, by the Indian Army (codenamed Operation Blue Star) in June 1984 to flush out the militants who had taken shelter there (Kapur 1987). The Darbar Sahib complex was severely damaged in the fighting, which inflamed the anger felt by the Sikhs. In an act of retribution, two Sikh bodyguards assassinated Prime Minister Indira Gandhi in October 1984, which, in turn, led to anti-Sikh riots allegedly encouraged by some senior leaders of Indira Gandhi's Congress party in which several thousand Sikhs were killed. In May 1988, Indian security forces were once again forced to enter the Darbar Sahib complex (codenamed Operation Black Thunder) to evict militants who had moved back there and were using it as a shelter and a base of operations (Chadda 1997: 139). In the early-1990s the Punjab police force launched a harsh counter-insurgency operation against Sikh insurgent groups such as the Babbar Khalsa International, the Khalistan Zindabad Force, the Khalistan Commando Force and the Khalistan Liberation Army, which gradually weakened the potency of Sikh militancy in the Punjab. During the 1990s, India's attention shifted to the Kashmir Valley, where student demonstrations had rapidly escalated into a full-blown secessionist insurgency. Throughout the 1990s the violence in Indian Kashmir continued unabated 


\section{Rajat Ganguly}

and led to extremely tense relations between India and Pakistan. Although some positive developments have taken place in Indian Kashmir in recent years, Indo-Pakistani bilateral relations continue to be fraught with tensions, thus preventing the dispute from being resolved (Behera 2006). In 2010 there was a resurgence of pro-independence sentiments in the Kashmir Valley mainly due to the high-handed behaviour of the Indian security forces towards the local people, which led to street battles between stone-throwing protesters and the security forces. Over 50 people had been killed by mid-2010 in these violent clashes, and hundreds had been injured. Public support for the state government and the Indian state plummeted, leading to an almost complete paralysis of governance in the state. The Indian Prime Minister tried to quell the popular uprising in the Valley by promising the state a substantial degree of autonomy within the ambit of the Indian Constitution, but his offer received little support.

Communal and religious conflicts have also been a prominent feature of Indian politics after independence. The trauma of partition and the Hindu nationalist constituency's perception of 'Muslim appeasement' by ruling Congress leaders created tense communal relations from the beginning (Ganguly 1993: 102). The exigency of 'vote bank' politics further sharpened communal identities and feelings and often resulted in the outbreak and occurrence of communal riots. However, since the early-1990s, communal relations have hit rock bottom as both Hindu and Muslim fundamentalist forces have gained ground and Indian politics entered an era of weak central governments (Jaffrelot 1996; Hasan 1988). In December 1992 Hindu fanatics destroyed a sixteenth-century mosque called the Babri Masjid in the city of Ayodhya in Uttar Pradesh, disregarding orders against such an action from the Supreme Court and warnings from the Indian government. This incident sparked major communal rioting across the country. Muslim criminal gangs orchestrated a series of bomb blasts in Mumbai, India's commercial and financial capital, in March 1993 in which around 350 people were killed (Hansen 2001: 125). To avenge the bomb attacks, Hindu mobs in Mumbai, allegedly encouraged by the ruling Hindu nationalist Shiv Sena (Army of Shiv) party and segments of the state security forces, carried out a nine-day massacre of Muslims in the city. In February 2002 further communal carnage took place in Gujarat when several compartments of a train (the Sabarmati Express) carrying Hindu workers and pilgrims returning from Ayodhya caught fire just as it pulled out of Godhra station, killing 58 people. Rumours quickly spread that the train had been attacked by Muslim mobs (Godhra station was located in a predominantly Muslim area of the town), although no conclusive evidence regarding how the fire started and whether the incident was a pre-planned attack has as yet emerged. The Godhra fire led to one of the worst cases of anti-Muslim riots in Indian history in which some members of the BJP-led Gujarat state government and the state's police forces were alleged to be implicated.

The regular occurrence of various types of ethnic conflict raises serious questions regarding the security and wellbeing of the Indian state and its citizens and the quality and character of Indian secular democracy. Political parties in India have often paid only lip service to secularism and national integrity but actually behaved to politicise ethnic identities thereby sparking violent conflict. This has helped to empower and strengthen militant voices within communities leading to a sharp deterioration in interethnic relations. The politicisation of the democratic institutions of the state, a trend that started prominently in the 1970s, has further weakened the capacity of these institutions to deal effectively and fairly with ethnic political mobilisation and demands thereby causing widespread alienation of large segments of the population from the Indian state. This is particularly applicable in the case of the national and state criminal justice systems' ability to deliver justice to victims 
of ethnic and communal violence and to arrest and punish those guilty of instigating mass murder and crimes against humanity. Furthermore, harsh counter-insurgency operations launched by the Indian state in several parts of the country and the indiscriminate use of draconian legislation (such as the Armed Forces Special Powers Act-AFSPA; the Terrorist and Disruptive Activities (Prevention) Act-TADA; and the Prevention of Terrorism ActPOTA) that gives the security forces a carte blanche have resulted in serious allegations of human rights abuses against the state by leading international human rights bodies and nongovernmental organisations.

\section{The Maoist insurgency}

While the Maoist insurrection in Nepal officially ended in November 2006 with the signing of the Comprehensive Peace Agreement (CPA), the Maoist insurgency in India has actually grown spatially and strengthened over the last decade. Termed as the 'biggest threat to national security' by former Prime Minister Manmohan Singh, the Maoist insurgency is currently spread across nine states: Andhra Pradesh, Bihar, Chhattisgarh, Jharkhand, Karnataka, Maharashtra, Odisha, Uttar Pradesh and West Bengal. At least 12 different Maoist groups are known to be active across these nine states. Of these groups, the Peoples' War Group and Maoist Co-ordination Committee are the best organised and most active. These groups are known to be in possession of large quantities of weapons and ammunition (many of which have been forcibly seized from the police) and conduct periodic military training for their cadres that include jungle warfare and ambush skills. In July 2001, Maoists in India joined forces with the Maoist insurgents in Nepal, Bangladesh and Sri Lanka to form an umbrella organisation entitled the Co-ordination Committee of Maoist Parties and Organisations of South Asia. The Indian Maoists typically attack 'class enemies' such as the rural landed elite, police and security personnel, government officials, bureaucrats, politicians and suspected informers acting on behalf of the state. Maoists have also attacked public buildings, railway property, banks and police stations.

The Maoist insurgency traces its roots back to peasant struggles that have occurred in India historically. For centuries, abysmal levels of poverty, widespread hunger and abject caste and tribal identity-based exploitation and discrimination have been rampant in rural Indian society, feeding and provoking widespread discontent among poor farmers. Following independence, the Indian state's failure to implement radical agrarian reform - promises on which the hopes of millions of rural families were pinned - led many poor farmers to see the state as controlled by rich landlords, bureaucrats and capitalists (Banerjee 1984). The Indian government's poverty alleviation and rural development schemes further marginalised the small farmers, the landless peasantry and the tribal populations (Sharma 1999). Feeling betrayed and disillusioned, a number of peasant leaders started drawing inspiration from Mao Zedong's ideas of guerrilla warfare, protracted armed struggle by peasants and the forcible seizure of state power. A major peasant uprising took place in 1967 in Naxalbari in West Bengal; the aim of the uprising was to capture state power by encircling cities (Banerjee 1984). Although this uprising caused massive political turmoil in West Bengal in the 1960s and 1970s, eventually the state security forces ruthlessly crushed the movement. Still, some Maoist leaders and cadres were able to evade capture and from the early-1980s the movement began to slowly re-emerge and spread spatially especially in the densely forested and backward tribal areas of West Bengal, Bihar, Odisha, Uttar Pradesh, Madhya Pradesh, Maharashtra, Karnataka and Andhra Pradesh. When Bihar and Madhya Pradesh were broken up to create the predominantly tribal states of Jharkhand and Chhattisgarh, these states became a hotbed of Maoist activities. 


\section{Rajat Ganguly}

In the densely forested and remote tribal areas that have been 'liberated' from the state's control, the Maoists have tried to run a 'parallel state'. Cases of theft, robbery, rape, prostitution and the exploitation of lower castes by upper castes are decided promptly in people's courts; punishment can range from maiming to death sentences, with the decision of the 'kangaroo court' being final and binding (Mehra 2000). Besides enforcing law and order, the Maoists have been reported to take responsibility for providing basic education, maintaining irrigation reservoirs, running community kitchens and mobile medical units and enforcing a minimum wage for labourers. Furthermore, the Maoists have been reported to play the role of 'Robin Hood': collecting money from forest contractors, traders and landlords and distributing it to the poor and needy; halting the extortion of tolls by local goons from poor tribal people; forcing wealthy farmers to raise their employees' wages; and enforcing social reforms such as bans on alcohol and on extravagant expenditure at weddings, a custom that usually sends poor families deeper into debt (The Economist 1991).

As the Maoist insurgency gained in strength and spread spatially across the heartland of India, the Indian government reacted by allocating larger budgets for the security forces involved in anti-Maoist operations and deployed central forces to fight alongside state forces in affected areas. Very controversially, the Indian government turned a blind eye to the efforts of some states to arm civilians in affected areas and instruct them to fight the Maoists; this practice of creating a vigilante force (called Salwa Judum) was discontinued in 2011 by the order of the Indian Supreme Court after strident criticism from human rights and civil society groups and the media. While unconstitutional and illegal practices have been discontinued, the Indian state has deployed a massive paramilitary and police force in the so-called 'Red Zone' (comprising of areas in Chhattisgarh, Jharkhand, Bihar, Odisha, and West Bengal). The main aim of the crackdown on the Maoists seems to be to try and capture or kill the movement's top leaders and cadres, disrupt their planned activities, encourage defection and spread disarray within the insurgents. However, in spite of the state's best efforts, which did result in the capture and killing of several top Maoist leaders, the insurgency has remained potent (Chakrabarty 2014). The potency of the Maoists was demonstrated vividly in Chhattisgarh on 25 May 2013, when the insurgents ambushed a convoy of vehicles crammed with politicians from the Congress party who were returning from an election campaign rally. The insurgents overpowered the few security personnel present and rounded up several politicians for immediate execution. Their main target appeared to be a local politician called Mahendra Karma, who was considered to be the brain behind the creation of the now defunct Salwa Judum anti-Maoist vigilante force in 2005. Mr Karma was tortured and then shot dead along with 28 other people. The Chhattisgarh attack was followed by Maoist attacks in Bihar in June 2013 and Jharkhand in July 2013, which left many more security personnel and civilians dead.

The recent attacks on civilian targets by the Maoists perhaps signal a shift in their tactical thinking. In the past, the Maoists had concentrated their attacks on security forces and government officials; in the rare instance of an attack on any civilian, it was usually because they suspected the civilian to be an informant to the police and the government. But the recent indiscriminate attacks on civilians could be an effort to disrupt scheduled national and state elections in a major way. It could also be a signal to the Indian government and to the security agencies of the Maoists' potency as a fighting force. Some experts also believe that the attacks could reflect a generational change within the insurgency movement. Irrespective of the reasons for the attacks, it seems fairly certain that the attacks would lead to a hardening of stance by the Indian state. Local, state and national level politicians, irrespective of party affiliations, are likely to support extremely tough, perhaps even brutal, forms of response by the security forces (Chakrabarty 2014). 


\section{India's external security and foreign policy}

Since the end of the Cold War, India has spent a vast sum of money in modernising its military. In the space of 25 years, the Indian military has become the fourth largest in the world (Global Firepower 2013). It has a million plus volunteer army that is well trained, disciplined and equipped with modern weapons and technology. It has developed a robust air force with modern fighter jets capable of playing both offensive and defensive roles. It has also acquired a blue water capable navy whose strength is rapidly growing with the procurement and induction of aircraft carriers, diesel and nuclear powered submarines and a plethora of other naval assets and bases. In 1998, India broke its self-imposed moratorium on nuclear weapons testing by conducting a series of nuclear weapons tests and thereafter declaring itself to be a nuclear weapons state. Since the 1998 nuclear tests, India has rapidly developed a 'minimum credible deterrent' with ground and air-based nuclear weapons and is working towards acquiring the capability to launch nuclear weapons from nuclear powered submarines; once submarine launched ballistic missiles are inducted in the Indian Navy and become fully operational, it will complete India's strategic triad. Along with the development of nuclear weapons and their delivery systems, India has also come up with a nuclear doctrine anchored by the concept and pledge of 'no first use'.

The transformation of the Indian military into a modern fighting machine over the past 25 years has occurred due to changes occurring at the regional and global levels as well as a reappraisal of India's external security environment and needs by Indian political, military and bureaucratic elites. To Indian planners, a key development was the end of the Cold War and the break-up of the Soviet Union, which robbed India of a crucial ally that had stood by the country during its times of need. Political turmoil in Russia and the former Soviet space resulted in unreliable defence supplies, which adversely affected India's military whose weapons were predominantly Soviet-made. Indian leaders therefore understood and emphasised the need for India to build and consolidate its strategic autonomy in the face of a deteriorating international security and political milieu and the preoccupation of the major powers with their domestic problems. India's economic liberalisation, which unleashed the country's economic potential and produced growth rates of around 8.5 per cent on average since the early-1990s, made it possible to allocate more resources to the military even though military expenditure as a percentage of Gross Domestic Product (GDP) did not increase significantly.

In the twentieth century, India viewed the Chinese threat as largely coming across a 4,000 $\mathrm{km}$-long land border parts of which were in dispute. This threat became magnified after the Chinese invasion of India in 1962, the construction by China of an all-weather road linking Tibet with Xinjiang and a rail network linking Tibet with north-eastern China, the modernisation of the People's Liberation Army (PLA) and the establishment and consolidation of strategic ties between China and Pakistan. It was the fear of China that had prompted India to conduct a 'peaceful nuclear explosion' in 1974; thereafter, in 1998, India carried out a series of nuclear explosions and proclaimed its status as a nuclear weapons state primarily to establish a 'minimum credible deterrent' vis-à-vis China (The Hindu 10 November 2011). By the turn of the century, the PLA Navy's rapid development and Beijing's growing power projection capabilities and diplomatic clout in the Indo-Pacific basin began to ring alarm bells within the Indian government and the Indian military establishment. The PLA Navy had begun to invest massive resources on nuclear powered submarines, aircraft carriers, fixedwing fighter aircrafts for the aircraft carriers and other assorted naval hardware; it had also started conducting training for pilots who were to operate fighter aircrafts from the aircraft 


\section{Rajat Ganguly}

carriers and upgrading the equipment, training and communication gear of its personnel; furthermore, it had started installing sophisticated electronic and radar equipment, which was designed to improve the targeting capability of its ships, submarines and naval fighter aircrafts. American assessment of the PLA Navy's growth suggested that although China's power projection capabilities in the Indo-Pacific were somewhat limited in the immediate term, in the medium to long term Beijing would be capable of deploying substantial military power in far-flung areas well beyond China's regional waters (The New York Times 1 January 2014; Raja Mohan 2012a, 2012b, 2010; Holmes et al. 2009).

India's spending on defence and its military transformation was also influenced by the situation prevailing in Afghanistan. In Afghanistan, the Soviet military withdrawal in 1989 was followed by civil war until 1996 when the Pakistan-backed Taliban took over power. In this civil war, New Delhi supported the Northern Alliance, a largely Uzbek-Tajik-Hazara coalition fighting against the Pashtun warlords and the Pashtun dominated Taliban. During the 1996-2001 Taliban rule in Afghanistan, the group's hostility towards India became obvious. A large number of Afghan mujahideen, who had once fought against the Soviet occupying forces, were encouraged by the Taliban to infiltrate into Indian Kashmir where a separatist insurgency had started in 1989. In 1999, an Indian Airlines aircraft was hijacked by Islamic militants and flown to Kandahar in southern Afghanistan. Negotiations between the Indian authorities and the hijackers were complicated by India's lack of recognition of the Taliban regime and the Taliban's decision to surround the hijacked aircraft with its fighters in order to prevent Indian Special Forces from storming the aircraft and rescuing the passengers. The hijacking eventually ended after India released three militants serving time in Indian prisons. The Taliban's fall in 2001 and the subsequent US military occupation increased India's involvement in Afghanistan's development. As the US occupation gradually winds down, a resurgent Taliban could pose a serious threat to India's interests and assets in Afghanistan.

India's equation with Pakistan also took a nosedive in the post-Cold War era. In 1998, within a week of India's second nuclear tests, Pakistan carried out its own nuclear weapons tests, thereby confirming the suspicion that it had nuclear weapons hidden in the basement. Like India, Pakistan, too, proclaimed itself to be a nuclear weapons state but with one major difference: unlike India, which had pledged never to be the first in using nuclear weapons, Pakistan's nuclear doctrine advocated the first use of nuclear weapons in order to offset its conventional military inferiority against India (Chakma 2009). An accidental nuclear war in the event of a major crisis also could not be ruled out. Pakistan had actively supported the Sikh insurgency in the 1980s and the Kashmiri insurgency since the early-1990s. It had helped create and backed a plethora of Islamic groups, many of which were involved in insurgent activities in Indian Kashmir and other parts of India. In 1999, the Indian military even fought a brief border war with Islamic insurgents backed by Pakistani forces in the Kargil sector in Indian Kashmir, which further vitiated bilateral ties. The attacks on the Indian Parliament and the Akshardham Temple by Pakistan-based and -backed Islamic militants heightened tensions and the two countries came to the brink of war again in November 2008 when suicide terrorists belonging to the Lashkar-e-Taiba, an Islamic militant group based in Pakistan, carried out a daring attack on the Indian port city of Mumbai.

While still Prime Minister, Manmohan Singh and then Defence Minister A.K. Antony in 2011 publicly made the case for greater military spending to meet the threats posed by India's regional security environment. Singh cautioned the country that a serious threat of nuclear weapons proliferation was confronting the Indian subcontinent and that the security of nuclear materials was a matter of grave concern to the Indian government. He also cautioned 
that India was faced with multiple threats, including the threat of sub-conventional and cyber warfare. Singh argued that India's military forces must be equipped with all the necessary and most modern means in order to meet the multitude of threats - conventional, sub-conventional, cyber and nuclear - faced by the nation (The Indian Express 12 October 2011; Bhowmick 2012). Defence Minister A.K. Antony argued that even after the change in leadership in Beijing, China's stance towards the boundary dispute with India is unlikely to alter in the near future. The Indian military therefore must develop its capabilities to achieve and maintain a minimum credible deterrence against China (The Times of India 9 April 2013; Katoch 2013; Baweja 2013).

To speed up the Indian military's development and transformation, the Indian government paid attention to expanding defence relations with a large number of countries. According to Brian Hedrick of the Strategic Studies Institute (SSI) of the US Army War College, this was possible due to India's decision to move from a policy of 'non-alignment' to a policy of 'poly-alignment'. The 'poly-alignment' policy operated in a number of ways. First, the number of countries with which India established defence-specific agreements increased from seven in 2000 to 26 in 2008 as India diversified its defence procurements. Second, bilateral and multilateral military exercises became an enduring feature of India's defence relationships. Third, India articulated its aspiration to become a regional power across the Indian Ocean Region and actively built 'strategic partnerships' with key states and organisations that supported India's ambition (see chapter by Pardesi in this volume). Fourth, India built strategic partnerships with states that are established or emerging global leaders in order to acquire high international standing and to procure modern weapons systems and the technology and licence to produce these weapons systems eventually in India. Fifth, India forged and consolidated ties with smaller nations globally in order to obtain diplomatic support in international fora on a range of issues and to develop potential markets for India's own defence industry. Finally, India played an active leadership role in multilateral institutions such as the UN by committing itself strongly to peacekeeping operations and by paying lip service to the Non-Aligned Movement (NAM) (Hedrick 2009: 49-50).

One country with which India has dramatically improved its ties, particularly military and defence ties, is the United States. During the Cold War, India was often at loggerheads with the United States, which it blamed for supporting Pakistan and opposing India's position across a range of international issues (Chaudhuri 2014). The end of the Cold War and the onset of India's economic liberalisation started the thaw in bilateral relations, which was helped by the Indian Ministry of External Affairs adopting a more realist stance in international relations (Raja Mohan 2003). The United States began to see India as an 'anchor' around which stability in the Indian Ocean Region could be built and sustained and over the next two decades the two sides held a number of joint military exercises and strategic dialogues. American defence sales to India started to increase and in the period 2001-2013 US companies sold an estimated US $\$ 13$ billion worth of military hardware to India (Hardy 2013).

India also actively worked to strengthen its strategic relations with Russia, which continues to be the Indian military's principal supplier. The Indian Army plans to procure T-90 main battle tanks and the Indian Air Force the Sukhoi-30 MKI fighters from Russia; the Indian Navy has recently acquired the overhauled and refitted aircraft carrier, INS Vikramaditya, and several stealth frigates from Russia; it has also acquired on lease a nuclear powered submarine, INS Chakra, from the Russian Navy. Apart from the US and Russia, India has established strong defence collaboration with Israel, Australia, Japan, Singapore, Vietnam and several other European states. Prime Minister Manmohan Singh visited Japan 
in May 2013. A key outcome of the visit was a strategic convergence between the two countries that they need to work together to ensure the stability of the Asia-Pacific region in the face of a militarily aggressive China. To implement this, Japanese Prime Minister Shinzo Abe advocated that India and Japan should institutionalise and increase the frequency of joint naval exercises. Japan also agreed to sell to India the highly advanced amphibious aircraft ShinMaywa US-2, which has both civilian and military application (The Times of India 30 May 2013). In June 2013, Defence Minister A.K. Antony met with his Australian counterpart, Stephen Smith, in Perth and Canberra. The two sides acknowledged the need for deepening the India-Australia strategic partnership by stepping up military-to-military exchanges, holding regular bilateral dialogues on maritime security and planning for a joint naval combat exercise in 2015 to build confidence and familiarity between the two navies (The Times of India 6 June 2013).

\section{Concluding remarks}

India is an immensely diverse and unequal society where conflict between groups is to be expected. The framers of the Indian Constitution were mindful of this reality and tried to design a polity that would be able to contain conflicts as and when they emerged. To be sure, ethnic conflict in various forms has dotted the Indian political landscape since independence from British rule in 1947. While many such cases have been handled successfully by the state, in many others containing violence and finding a resolution acceptable to all parties has been a problem. Since the 1980 s, the intensity and ferociousness of ethnic violence has increased, putting the life and liberty of thousands at stake. Keeping pace with this development, the state's willingness and capability to respond to ethnic violence with repressive force has expanded exponentially.

Maintaining internal security and political stability is, therefore, a key national security challenge confronting India in the twenty-first century. It is also equally important for India to remain vigilant about threats to its security from external enemies. Some of India's external enemies, such as Pakistan and China, have been around for a long time and the Indian military must always remain prepared to deal with such traditional enemies if the need arose. However, key changes that have taken place in the South Asian region and globally since the end of the Cold War have brought with it not only an environment of uncertainty but also new sources of threat to India's national security from state, non-state and unconventional sources. India must therefore use its foreign policy skilfully to deal effectively with such myriad threats to national security in an uncertain, turbulent and rapidly changing world.

\section{Note}

1 The term 'Dalit' refers to ex-untouchables, people who traditionally were considered as 'untouchables' within the Hindu community and who fell outside the traditional four-fold Hindu varna system. Due to their untouchability status, Dalits have faced social exclusion, discrimination and violence, which often have prevented them from enjoying the basic human rights and dignity promised to all citizens of India.

\section{References}

Banerjee, S. (1984) India's Simmering Revolution: The Naxalite Uprising, London: Zed Books.

Bartwal, H. S. (1998) 'Fear of Militants, Mizo Reprisal Keep Reangs Away From Mizoram', Hindustan Times 27 May (Online Edition). 
Baweja, H. (2013) 'India Moves in More Troops, Stand-off With China Escalates', Hindustan Times 23 April http://www.hindustantimes.com/StoryPage/Print/1048784.aspx [accessed 28 December 2014].

Behera, N. C. (2006) Demystifying Kashmir, Washington, DC: Brookings Institution Press.

Bhowmick, N. (2012) 'Enter the Elephant: India Looks to Overhaul its Military', Time, 3 April http:// world.time.com/2012/04/03/indias-military-overhaul-through-export-and-import-defensespending-a-priority/print/ [accessed 28 December 2014].

Brass, P. (1994) The Politics of India Since Independence, Cambridge: Cambridge University Press.

Census of India (2011) Government of India, New Delhi.

Chadda, M. (1997) Ethnicity, Security and Separatism in India, New York: Columbia University Press.

Chakma, B. (2009) Pakistan's Nuclear Weapons, London: Routledge.

Chakrabarty, B. (2014) 'Maoism, A Recalcitrant Citizenry and Counter-insurgency Measures in India', Journal of Asian Security and International Affairs, 1 (3) (December): 289-317.

Chaudhuri, R. (2014) Forged in Crisis: India and the United States Since 1947, London: Hurst and Company.

Dasgupta, J. (2001) 'India's Federal Design and Multicultural National Construction', in A. Kohli (ed.), The Success of India's Democracy, Cambridge: Cambridge University Press, 49-77.

Ganguly, S. (1993) 'Ethno-religious Conflict in South Asia', Survival, 35 (2) (Summer): 88-109.

Ganguly, R. (1997) 'The Move towards Disintegration: Explaining Ethnosecessionist Mobilization in South Asia', Nationalism and Ethnic Politics, 3 (Summer): 101-130.

Ganguly, R. (2005) 'Poverty, Malgovernance, and Ethnopolitical Mobilization: Gorkha Nationalism and the Gorkhaland Agitation in India', Nationalism and Ethnic Politics, 11 (Winter): 467-502.

Ganguly, R. (2007) 'Democracy and Ethnic Conflict', in S. Ganguly, L. Diamond and M. F. Plattner (eds), The State of India's Democracy, Baltimore, MD: The Johns Hopkins University Press, 45-66.

Global Firepower (2013) 2013 World Military Strength Ranking, http://www.globalfirepower.com/ [accessed 28 December 2014].

Hansen, T. B. (2001) Wages of Violence: Naming and Identity in Postcolonial Bombay, Princeton, NJ: Princeton University Press.

Hardgrave, Jr, R. L. (1993) 'India: The Dilemmas of Diversity', Journal of Democracy, 4 (4) (October): $54-68$.

Hardy, J. (2013) 'India's Quiet, Big Naval Splash', The Diplomat, 3 June http://thediplomat. com/2013/06/indias-quiet-big-naval-splash/?allpages=yes\&print=yes [accessed 28 December 2014].

Hasan, M. (1988) 'Indian Muslims Since Independence: In Search of Integration and Identity', Third World Quarterly, 10 (April): 818-842.

Hedrick, B. K. (2009) 'India’s Strategic Defence Transformation: Expanding Global Relationships', Strategic Studies Institute, U.S. Army War College, vii + 60, http://www.strategicstudiesinstitute. army.mil/pdffiles/PUB950.pdf [accessed 28 December 2014].

Holmes, J. R., A. C. Winner and T. Yoshihara (2009) Indian Naval Strategy in the Twenty-first Century, London: Routledge.

Jaffrelot, C. (1996) The Hindu Nationalist Movement in India, New York: Columbia University Press.

Kapur, R. A. (1987) “'Khalistan”: India's Punjab Problem', Third World Quarterly, 9 (4) (October): 1206-1224.

Katoch, P. (2013) 'The Dilemma: Military Modernization in India', Fair Observer, 16 August http:// www.fairobserver.com/article/dilemma-military-modernization-India [accessed 28 December 2014].

Khalidi, O. (1995) Indian Muslims since Independence, New Delhi: Vikas Publishing.

Kothari, R. (1964) 'The Congress System in India', Asian Survey, 4 (December): 1161-1173.

Mehra, A. K. (2000) 'Naxalism in India: Revolution or Terror?', Terrorism and Political Violence, 12, (2): $37-66$.

Phadke, Y. D. (1974) Politics and Language, Bombay: Himalaya Publishing House.

Phadnis, U. and R. Ganguly (2001) Ethnicity and Nation-building in South Asia, revised edn, New Delhi; London; Thousand Oaks, CA: Sage Publications.

Raja Mohan, C. (2003) Crossing the Rubicon: The Shaping of India's New Foreign Policy. New Delhi: Viking.

Raja Mohan, C. (2010) 'PLA Power Projection Takes it Far From China to Indian Ocean', The Indian Express, 18 August, http://indianexpress.com/article/news-archive/web/pla-power-projectiontakes-it-far-from-china-to-indian-ocean/ [accessed 28 December 2014]. 
Raja Mohan, C. (2012a) Samudra Manthan: Sino-Indian Rivalry in the Indo-Pacific, Washington, DC: Carnegie Endowment for International Peace.

Raja Mohan, C. (2012b) 'India and China's First Aircraft Carrier', The Indian Express, 26 September, http://archive.indianexpress.com/news/india-and-china-s-first-aircraft-carrier/1008218/ [accessed 28 December 2014].

Sharma, S. D. (1999) Development and Democracy in India, Boulder, CO: Lynne Rienner.

The Economist (1991) 'The Robin Hood of Orissa', February 2.

The Hindu (2011) 'India's Military Modernization “To Contain China”: PLA Daily', 10 November, http://www.thehindu.com/news/international/indias-military-modernisation-to-contain-chinapla-daily/article2615757.ece?css=print [accessed 28 December 2014].

The Indian Express (2011) (12 October) 'Threat is Up, Both Global and Regional: PM', http://www. indianexpress.com/story-print/858638 [accessed 28 December 2014].

The New York Times (2014) (1 January) 'China's First Aircraft Carrier Completes South China Sea Drills', http://www.nytimes.com/reuters/2014/01/01/world/asia/01reuters-china-carrier. html? ref =world\&_r=0\&pagewanted = print [accessed 28 December 2014].

The Times of India (2013) (9 April) 'Antony Warns Army Against Threats from China, Pakistan', http:// timesofindia.indiatimes.com/india/Antony-warns-Army-against-threats-from-China-Pakistan/ articleshow/19450161.cms?prtpage $=1$ [accessed 28 December 2014].

The Times of India (2013) (30 May) 'India, Japan Join Hands to Break China's "String of Pearls"', http:// timesofindia.indiatimes.com/india/India-Japan-join-hands-to-break-Chinas-string-of-pearls/ articleshow/20341060.cms?prtpage $=1$ [accessed 28 December 2014].

The Times of India (2013) (6 June) 'India, Australia to Strengthen Defence Ties to Contain China', http:// timesofindia.indiatimes.com/india/India-Australia-to-strengthen-defence-ties-to-contain-China/ articleshow/20452688.cms?prtpage $=1$ [accessed 28 December 2014]. 


\title{
8 \\ IS INDIA A \\ SOUTH ASIAN OR AN ASIAN POWER?
}

\author{
Manjeet S. Pardesi
}

\section{Introduction}

India has aspired to play the role of a major power in Asia since its independence in 1947. However, the most widely accepted view of India in the extant literature is merely that of a 'limited hegemon' at the South Asian level (Basrur 2011: 181). In other words, India is regarded as a regional power as opposed to a major power. In fact, it is even believed that unless India is able to establish its primacy in its immediate neighbourhood in South Asia, it is unlikely to emerge as a major power (Mohan 2007). This chapter argues that these views notwithstanding, India has transcended the boundaries of South Asia and has emerged as a major power in Asia. While India is not a regional hegemon in South Asia as it has not been able to translate its overwhelming material preponderance in that region into primacy due to the challenge posed by Pakistan (and its partnerships with the United States and China), the gradual economic rise of India over the past two decades has given it the economic and military wherewithal to become a significant actor in the emerging balance of power politics in East Asia in general, and more specifically in Southeast Asia.

The remainder of this chapter is divided into three main sections. The next section provides a brief overview of India's foreign and security policy immediately after independence when it actually played the role of a major power in Asia. However, India's disastrous defeat in the 1962 Sino-Indian War reduced India's status to that of a regional power in South Asia. The subsequent section will focus on India's foreign and security policy in the aftermath of 1962 until the end of the Cold War in 1991. It will be shown that in spite of the successful vivisection of its subcontinental rival Pakistan in 1971, India was neither able to emerge as a regional hegemon in South Asia nor was it able to transcend its home region and play the role of a major power in Asia during this period. The systemic and domestic sources of India's inability to do so will be discussed here. Focusing on the post-Cold War period, the third section will demonstrate that India's gradual embrace of the market after its 1991 economic reforms and the simultaneous launch of its 'Look East' policy have now transformed India into a major power in Asia even as it has not been able to emerge as the undisputed regional hegemon in South Asia. It will be shown that even though India has not been able to establish its primacy in South Asia due to the challenge posed by Pakistan, India has emerged as a significant actor in the Asian balance of power. 


\section{India as an Asian great power, 1947-1962}

India accepted the security conception of the erstwhile British Raj after independence (while rejecting the security practices of the Raj as Jawaharlal Nehru, the first Prime Minister of India, did not aspire to play an imperial role in the subcontinent). By claiming itself to be the successor state of the Raj, ${ }^{1}$ independent India sought to refashion itself as the 'paramount power' in the subcontinent. Paramountcy implied the strategic subordination of the small states in the subcontinent to India while recognizing and accepting their independent status. This was most aptly demonstrated in India's relations with the Himalayan states of Nepal, Bhutan, and Sikkim. The treaties that India signed with these states in 1949 and 1950 made New Delhi in charge of their foreign and security policy. ${ }^{2}$ Notably, India became the only state in post-war (and post-colonial) Asia with its own protectorates with these treaties.

In spite of the 1947-1948 India-Pakistan War, the strategic implications of the partition of the subcontinent were not immediately apparent to India's post-independence leadership. In fact, immediately after independence, Nehru doubted the viability of the Pakistani state and believed that the partition of the subcontinent was temporary (Heimsath and Mansingh 1971: 121, 142). Furthermore, the division of Asia into distinct sub-regions like South Asia, Southeast Asia, and Northeast Asia was not yet apparent to the countries of this region or to the wider world. ${ }^{3}$ In October 1949, in a letter to India's chief ministers, Nehru asserted that 'the future of Asia will be powerfully determined by the future of India. India becomes more and more the pivot of Asia' (Gopal 1979: 59). Furthermore, Nehru felt that even as India was 'not directly a Pacific state, India will inevitably exercise an important influence there' (Nehru 1989: 536).

More importantly, Nehru's India played the role of a major power in Asia commensurate with this idea. Under Nehru's leadership, India organized the Asian Relations Conference a few months before the country's independence in March-April 1947. This was the first regional gathering of countries and colonial territories from all across Asia (Asian Relations 1948). In January 1949, India organized the Conference on Indonesia. This was the first conference organized by an Asian government to deal with a specific Asian issue - Indonesian independence. This conference ultimately influenced Indonesia's independence from the Dutch because of the impact that it had at the United Nations (Ton 1963: 98-102). A month later, India organized a conference of Commonwealth countries on Burma following which Burma became the first country to receive military aid from India (to help Burma with internal security issues). At the same time, New Delhi also cancelled the debts owed by the Burmese government to the Indian government incurred during its separation from British India in 1937 (Singh 1979: 56-59).

In 1951, India signed a treaty of friendship with Indonesia that had security-related undertones. This was Indonesia's first such treaty with a foreign country (Ton 1963: 109). A few months later, India signed a similar treaty with Burma. While India rejected Burma's call for an alliance of Southeast Asian countries to be led by New Delhi, the Indian and the Burmese leaderships maintained a very close relationship in their early post-colonial years and India even counselled Burma on that country's internal security issues (Ton 1963: 174 177). India also signed a treaty with the Philippines in 1952 which was tantamount to a nonaggression pact that took added significance in an environment in which China, postwar/ postcolonial Asia's other great power, appeared threatening as a result of the developments in Korea and Indo-China (Ton 1963: 267). In the mid-1950s, as a result of India's active diplomatic role in Indo-China, each of the three International Commissions of Supervision and Control for Vietnam, Cambodia, and Laos that were created in Geneva in 1954 was 
headed by an Indian chairman (SarDesai 1968: 4-5). In the coming years, India also signed security arrangements with the Indonesian air force (1956), navy (1958), and army (1960).

India's attempt to play the role of a major power was not limited to Southeast Asia only as New Delhi was also actively involved in Northeast Asian affairs. After the de facto division of the Korean peninsula in the aftermath of the Second World War, India's K. P. S. Menon (who eventually served as India's first foreign secretary) was appointed the chairman of the United Nations Temporary Commission on Korea (Pak 2000: 5). India also played an important role as the diplomatic interlocutor between China and the United States during the Korean War (1950-1953) in the absence of direct diplomatic relations between them. India had already recognized the People's Republic of China (PRC) by this time (despite American opposition) even as India was viewed as a communist sympathizer in Washington (Truman 1956: 362). This was unfortunate because India's support for the US-sponsored resolutions on Korea had annoyed the Soviet Union and China who had begun to suspect India's non-aligned credentials (Kim 2010). India also played a leading role in the post-war Korean settlement that was stuck on the question of the repatriation of prisoners of war (POWs). After Indian lobbying at the United Nations, India's Lieutenant General K. S. Thimayya was appointed as the chairman of the Neutral Nations Repatriation Commission, and Major General S. P. P. Thorat led some 6,000 Indian troops and administrative personnel in the Custodian Force that landed in Korea and actually implemented the exchange of some 23,000 POWs.

India also played an important role in bringing Japan back into the comity of nations in Asia in the aftermath of the Second World War. At the International Military Tribunal for the Far East in Tokyo, Judge Radhabinod Pal, the only Indian justice out of a total of eleven declared all twenty-five Japanese top leaders charged with Class A war crimes as not guilty (Kei 2007). Later, India felt that the San Francisco Peace Treaty was unfair to Japan and therefore signed a separate peace treaty that not only waived all wartime reparations, but was also post-war Japan's first treaty with an Asian state (the 'sham' Japanese treaty with Nationalist China ending the state of war with China notwithstanding) (Sato 2005). India also invited Japan to the first Asian Games in New Delhi in 1951 even though Japan had not been invited to the 1948 London Olympics. Similarly, under Nehru's leadership, Japan was invited to the 1955 Bandung Conference even though Japan became a member of the United Nations only in 1956.

Throughout the 1950s, India not only championed for the inclusion of the PRC in the United Nations Security Council, but also introduced Communist China and its Premier Zhou Enlai to the Afro-Asian countries at Bandung in 1955 (Mukherji 2008). While legitimizing China's military invasion and annexation of Tibet by signing the 1954 Panchsheel agreement, Nehru's India also tried to play the role of a diplomatic interlocutor between China and Tibet when New Delhi granted refuge to the Dalai Lama in the aftermath of the 1959 Lhasa Uprising (Pardesi 2011: 102-105). However, Sino-Indian relations rapidly deteriorated as a consequence and China launched a short but swift attack in late 1962 as Beijing (erroneously) feared that India wanted to convert Tibet into its pre-1950-1951 status as a buffer state between India and China (Garver 2006). India's disastrous defeat in 1962 removed India from the rank of a major power in Asia for the remainder of the Cold War.

\section{Reduced to a South Asian power, 1962-1991}

The 1962 Sino-Indian War proved to the world-at-large that India needed external support to meet the Chinese challenge. India sought and received military support from the 
United States (and other Western powers like the United Kingdom) during the war and in its immediate aftermath (Hoffmann 1990: 196-200, 206-210). As such, India was hardly capable of providing leadership in Southeast Asia that was in the midst of a rapidly changing geopolitical environment. India's vociferous opposition to the growing American involvement in Vietnam after 1964 further alienated many pro-Western states in Southeast Asia (Thakur 1979). Much to New Delhi's disappointment, India was not extended an invitation when the Association of Southeast Asian Nations (ASEAN), a regional grouping, was formed in $1967 .^{4}$ In the meantime, India's relations with Indonesia dramatically deteriorated when Indonesia threatened to open another front against India during the 1965 India-Pakistan War (Ayoob 1990: 41). While this was largely a result of the fact that India was critical of Indonesia's policy of Konfrontasi, it was becoming clear by the mid-1960s that the subcontinent would remain the primary area of concern for Indian foreign policy.

During the 1962 Sino-Indian War, more than half of the Indian army was facing Pakistan as New Delhi feared that Pakistan would open a second-front against India (Heimsath and Mansingh 1971: 171). China and Pakistan had dramatically transformed their relationship since 1962, and China issued an 'ultimatum' to India during the 1965 India-Pakistan War (Garver 2001: 194-204). Coming soon after China’s first nuclear test in 1964, this threat had an added significance for India. While India embarked upon its own nuclear programme in the aftermath of this threat (Pardesi, forthcoming), New Delhi realized that the ChinaPakistan nexus would mean that India would not be able to play any significant role outside of the subcontinent for the time being. For example, when Singapore's Lee Kuan Yew asked for India's assistance to train and equip the city-state's military after its independence in 1965, New Delhi chose not to respond (Huxley 2000: 11). Similarly, while the Indian navy announced its intention to assume the functions of the British navy after Britain's 1967 decision to withdraw from the 'east of Suez', India did not have the resources to play such a role (Thomas 1975-1976). This was despite the fact the Singapore's Lee had mentioned that he would welcome an Indian naval presence in Southeast Asia (Ghoshal 1996: 96).

By 1971, systemic factors had further circumscribed India's role beyond the confines of South Asia. After taking advantage of the Sino-Soviet split, the United States had formed a 'tacit' alliance with China by this time, an endeavour in which Pakistan had played a crucial role (Aijazuddin 2000). In the meanwhile, faced with the possibility of a US-ChinaPakistan entente, India signed a treaty with the former Soviet Union on the eve of the 1971 Bangladesh War (Mastny 2010). While India emerged as the predominant regional power in South Asia after the successful vivisection of Pakistan in 1971, it was unable to project its military power beyond its home region. In part, this was a result of the fact the pro-Western states of Southeast Asia became suspicious of India as they saw Soviet power lurking behind India's recent success. These perceptual factors apart, systemic and domestic-level factors continued to stymie India's efforts to play a larger role in Asia.

To begin with, Pakistan embarked on its own nuclear programme after 1971. China also began assisting Pakistan's nuclear efforts after India's first nuclear blast in 1974 (Garver 2001: 324-331). For China, Pakistan had emerged as a low-cost proxy to keep India focused on South Asian affairs instead of challenging China at a pan-Asian level, especially in East Asia (Paul 2003). In 1978, China and Pakistan formally announced the opening of the Karakoram Highway linking Pakistan's Gilgit-Baltistan region with China's Xinjiang. During the opening of the Karakoram Highway, China's deputy Prime Minister Li Xiannian noted that the highway allowed China 'to give military aid to Pakistan' (Topping 1979). In the meanwhile, China had also provided Pakistan with enough weapons-grade uranium for two atomic bombs by 1982 (Smith and Warrick 2009), and may also have provided Islamabad 
with a 'proven nuclear weapons design' by 1983 (Special National Intelligence Estimate 1983: 7).

In the aftermath of the Soviet invasion of Afghanistan in 1979, Pakistan re-emerged as an important partner for the United States to counter Soviet expansionism in South-Central Asia. 'The military importance of weapons transfers from the U.S.A. was historically crucial. Pakistan would not have become a serious military power without U.S. equipment' (Cohen 1980: 104). The external military support that Pakistan received from its extra-regional partners in Beijing and Washington prevented India from emerging as the undisputed regional hegemon in South Asia throughout the Cold War. However, systemic factors were not alone in conspiring against India's bid for regional paramountcy and its consequent inability to project power outside South Asia. India's domestic economic weakness was equally responsible for this outcome.

New Delhi's adoption of socialist and autarchic economic policies, especially from the mid-1960s onwards, meant that the Indian economy grew very slowly for the rest of the Cold War (especially when compared with Japan and the East and Southeast Asian 'tiger economies') (Panagariya 2008: 47-77). India's model of import-substitution industrialization also resulted in the lack of any meaningful economic interaction with East and Southeast Asia's export-oriented economies. The 'oil shocks' of the 1970s compounded India's problems as they used up India's scarce resources that might have been used to project India's power eastwards, especially after 1971 (Thomas 1982). India was also concerned about the efforts of Iran to play the role of a regional power in South Asia. In 1972, the Shah of Iran had declared that any attack on Pakistan would be tantamount to an attack on Iran and that Tehran was committed to the territorial integrity of Pakistan (Sen Gupta 1975: 178-180).

Consequently, New Delhi largely focused on subcontinental affairs during this period. In the aftermath of the 1971 Bangladesh War when the United States sent the USS Enterprise (that was believed to be nuclear-armed by strategists in New Delhi) into the Bay of Bengal, India adopted its own version of the Monroe Doctrine - the so-called Indira Doctrine (Cohen 2001: 137-138). According to the Indira Doctrine, South Asia was India's sphere of influence and India would not tolerate the intervention of any extra-regional power here unless it was on India's terms. At the same time, India would not intervene in the domestic affairs of the regional states unless requested to do so. While India had provided military assistance to Sri Lanka in 1971 (Manor and Segal 1985), the Indira Doctrine was more forcefully implemented in the 1980s when India intervened in the Sri Lankan civil war (1983-1990), ${ }^{5}$ prevented a coup in the Maldives (1988), and blockaded Nepal (1989-90) (Hagerty 1991). These developments and the rapid build-up of India's naval power in the Andaman and Nicobar Islands in the late 1980s emerged as a major cause of concern for several Southeast Asian states (many of which have sizeable populations of Indian-origin) (Gordon 1995: 293-295). Southeast Asian perceptions of India began to change only after the end of the Cold War.

\section{After 1991 - India re-emerges as a major power in Asia}

The end of the Cold War coincided with a major balance-of-payments crisis for India. This led the Indian government of Prime Minister Narasimha Rao and Finance Minister Manmohan Singh to launch a series of structural reforms as India began to embrace the market by launching a new industrial policy while reforming its financial sector as well. East Asia featured prominently at this critical juncture for New Delhi. Financial assistance from Japan (and its powerful position in international organizations such as the World Bank, 
the International Monetary Fund, and the Asian Development Bank) provided India with structural adjustment loans to implement these reforms (Sato 2012: 462). ${ }^{6}$ At the same time, India also drew inspiration from the East/Southeast Asian 'tigers' for its economic reforms (Singh 2006).

In tandem with these reforms, India also embarked upon a comprehensive 'Look East' strategy as it not only sought economic partners in East and Southeast Asia, a region that was emerging as one of the most dynamic centres of the world economy, but New Delhi also sought closer politico-military ties with the states of this region, especially in Southeast Asia. In addition to domestic economic changes, systemic factors also aligned to support India's 'Look East' strategy. The end of the Cold War and the disappearance of the Soviet Union meant that the Southeast Asian states began to view India favourably. This was especially true because India had no sources of bilateral disputes, especially territorial disputes (whether land or maritime), with any state in Southeast Asia. ${ }^{7}$ This was important simply because China was becoming militarily assertive in Southeast Asia in the late 1980s and early 1990s with its claims to the Spratly and Paracel Islands. At the same time, there were some concerns about America's continued military presence in Southeast Asia at this time as witnessed by its withdrawal from the Subic Bay naval base in the Philippines in 1992. In this era of strategic uncertainty, the Southeast Asian states also began to look towards India as a potential balancer of China's power in the region.

To be sure, the early 1990s was a particularly difficult time for India-Pakistan relations. Pakistan's support for the insurgencies in the Indian states of Punjab and Kashmir had continued to stifle any progress in their bilateral relations (Ganguly 1997). However, the success of India's nascent economic reforms called for a greater engagement with East and Southeast Asia, while the government of Prime Minister Rao also took advantage of the structural opportunity to build politico-military relationships with several Southeast Asian states on a bilateral basis (Pardesi 2010). India began conducting joint naval exercises with Indonesia, Malaysia, and Singapore in the vicinity of the Andaman and Nicobar Islands as early as 1991. India and Singapore also began conducting the Lion King annual bilateral antisubmarine warfare exercises in 1993. At the same time, India began a programme to train Malaysian pilots and ground supporting staff for the MiG-29 aircraft, while upgrading its defence cooperation with Vietnam.

Since then, India has continued to build on its politico-military relationships with the Southeast Asian states, most notably with Singapore and Vietnam. In 2007, India leased its air force base in Kalaikunda in West Bengal to Singapore for the space-constrained city-state to train its air force personnel in India. ${ }^{8}$ This was the first instance of a foreign military being granted training facilities in India on a long-term basis. In 2008, the two countries signed a similar agreement allowing the Singapore army to use the facilities of the Indian army in Deolali (Maharashtra) and in Babina (Uttar Pradesh). ${ }^{9}$ It has already been speculated in the Singaporean media that the city-state may grant India naval logistics facilities as a quid pro quo (Boey 2003). Similarly, while India has been helping Vietnam upgrade its defence industries since 2000 (while also providing training to Vietnamese scientists in civilian nuclear technology), Vietnam has granted docking rights to the Indian navy at its Nha Trang port (Dutta 2011).$^{10}$ India's only tri-service theatre command at Port Blair in the Andamans and the current (and anticipated access) to the ports in Southeast Asia gives India the ability to project its growing naval and air power in this region (DNA India 2010).

At the same time, India's budding relationship with the United States has provided an impetus to New Delhi's relationships with Japan and South Korea, both of which are amongst America's closest allies in East Asia. The rise of China is an important factor that 
has brought India closer to these Pacific democracies in recent years (Green 2011; Lee 2011). At the same time, the North Korean nuclear issue and the Islamabad-Pyongyang nuclear proliferation axis has further increased South Korea's and Japan's interest in building a meaningful strategic relationship with India (Squassoni 2006). Finally, the reliance of these Pacific powers on the Indian Ocean, especially for their energy needs, has led them to establish close maritime links with India, the pre-eminent resident regional power in the Indian Ocean. India and Japan are already conducting joint naval exercises in the Indian Ocean and in the waters around Japan (and have also participated in trilateral naval exercises with the United States). In fact, Japan has requested the Indian government to convert the annual US-India naval exercises into trilateral exercises involving Japan as well (Times of India 2014). Similarly, the South Korea-India partnership also 'has all the hallmarks of becoming a mini-Blue Ocean relationship' (Lee 2011: 162).

Notably, India is now a member of all ASEAN-centred regional security institutions such as the ASEAN Regional Forum (ARF), the East Asia Summit, and the ASEAN Defence Ministers Meeting Plus forum. Furthermore, India has ensconced itself in this larger Asian strategic theatre even as the India-Pakistan rivalry remains strong as ever and their Kashmir dispute remains unresolved. ${ }^{11}$ Moreover, Pakistan's close strategic relationship with China continues, while Pakistan has also been able to extract military concessions from the United States for over a decade in the aftermath of the 9/11 terrorist attacks (Siddique 2014; Shanker 2013; The Hindu 2014). It is largely believed that if the present trends continue (and if India's economy recovers) then India will be able to emerge as a great power in Asia even if the India-Pakistan dispute persists as a consequence of the growing economic (and therefore military) differential between these subcontinental rivals (Ganguly 2006). In other words, India is in the process of emerging as a great power in Asia even though India has not been able to emerge as the regional hegemon in South Asia.

\section{Conclusion}

India's quest for the status of a major power in Asia has remained constant in its worldview. According to Nehru, India was bound to play the role of 'leading and interpreting Asia, and specifically South East Asia to the wider world' (Brown 2003: 246). The centrality of Southeast Asia in India's worldview has not diminished more than sixty years after its independence. Explaining the rationale behind India's 'Look East' policy, India's former Prime Minister Manmohan Singh (who was also one of the architects of this policy) noted the following:

[India's Look East policy] was not merely an external economic policy, it was also a strategic shift in India's vision of the world and India's place in the evolving global economy. Most of all it was about reaching out to our [India's] civilizational neighbours in South East Asia and East Asia. I have always viewed India's destiny as being linked with that of Asia and moreso [sic] South East Asia.

Singh 2005

India does not want Southeast Asia to be dominated by any single great power, least of all by China. In 2005, Pranab Mukherjee, India's Minister of Defence noted that India's 'Look East' strategy was based on the principle of 'the maintenance of an equitable strategic balance' as it was 'vital for Indian security' (Mukherjee 2005: 24). These statements are important not only because India now sees itself as indispensable to the strategic balance of power in Asia, 
but also because Southeast Asian states view 'India as adding ballast - that is geostrategic weight - to relations with China' (Thayer 2011: 314).

While Southeast Asia remains central to India's 'Look East' strategy, India now views itself as a pan-Asian power. According to A. K. Antony, India's previous Defence Minister, India is 'an integral part of East Asia' (Press Information Bureau 2010). Notably, Japan and South Korea also seem to be reciprocating India's overtures. India and Japan have recently established the so-called ' $2+2$ dialogue' involving their respective foreign and defence secretaries to discuss regional security issues in Asia as well as the region's evolving strategic architecture (The Economic Times 2010). While this $2+2$ dialogue is Japan's third such relationship after the United States and Australia, it is India's first such engagement with an external power. Similarly, India, Japan, and the United States have also been holding regular trilateral dialogues since 2011 (Hindustan Times 2013). Likewise, India and South Korea established a strategic partnership in 2010 and have since been holding regular foreign policy and security dialogues (Times of India 2013).

Addressing the senior-most Indian military leadership in late 2013, former Prime Minister Singh noted that the Asia-Pacific region was fast becoming the 'arena for shaping the behaviour of major powers'. Given that economic power and consequent strategic focus was shifting from the West to the East, Singh told the country's top military brass that India must be able to 'institutionally' grapple with these dramatic transformations especially given the rising tensions in the 'seas to our [India's] east and the related "pivot" or "rebalancing" by the US in this area' (Singh 2013). This is the first time that the Indian government has asked the military to factor in America's 'pivot' to Asia in its planning.

India's quest to play the role of a major power in Asia is likely to receive a significant boost under the Hindu nationalist Bharatiya Janata Party government of Prime Minister Narendra Modi that came to power in May 2014. While all Indian governments have sought to promote India as a major power of some consequence, the Hindu right suffers from more status anxiety than the rest. To achieve this status, Modi's foreign policy is likely to be driven by a desire to bring about India's economic transformation. Modi is likely to 'Look East' in earnest to fuel India's economic growth. After being shunned in the West for his conduct in the 2002 Hindu-Muslim riots in Gujarat, Modi's foreign travels (before becoming the country's Prime Minister) took him to parts of East Asia, including Japan and China. Modi is a great admirer of Japan and is likely to seek closer economic and technological links with Tokyo. While economic links with China will also be enhanced, Modi will seek a balance to ensure India's national security. India now sees itself as an important part of the larger strategic theatre stretching from the Indian Ocean region into the western Pacific - the socalled Indo-Pacific region - that is emerging as Asia's new strategic theatre as a consequence of the simultaneous rise of China and India (Medcalf 2013). In fact, the term is also slowly entering the lexicon of the Indian leadership (Singh 2012).

\section{Notes}

1 Under the influence of India's nationalist elite, the departing British cast Pakistan in the role of a seceding state while arguing that the Indian Union would continue to exist.

2 Sikkim was absorbed into the Indian Union in 1975.

3 For example, the United States included Pakistan in the Southeast Asia Treaty Organization in 1954.

4 ASEAN's initial members included the following pro-Western regional states: Indonesia, Malaysia, Singapore, Thailand, and the Philippines.

5 This was the first phase of the Sri Lankan civil war that finally ended in 2009. 
6 In return for shipping its gold reserves to the Bank of England, India received financial assistance amounting to $\$ 210$ million from the Bank of England and \$195 million from the Bank of Japan.

7 India shares a land border with only one Southeast Asian state, Burma/Myanmar, which was established by their British rulers in 1937. India's maritime boundaries with Indonesia and Thailand were made permanent in 1978, while India's maritime border with Burma was finalized in 1987.

8 This agreement was renewed for another five years in 2012.

9 This agreement was also renewed for another five years in 2013.

10 In turn, India is helping Vietnam upgrade this port.

11 After openly going nuclear, India and Pakistan fought a brief but bitter limited conventional war in 1999 in Kargil and experienced a major militarized crisis in 2001-2002 in the aftermath of the December 2001 Pakistan-linked terrorist attacks on the Indian Parliament. The Pakistan-linked 2008 Mumbai terrorist attacks also caused a major crisis in their bilateral relationship.

\section{References}

Aijazuddin, F. S. (2000) From a Head, Through a Head, To a Head: The Secret Channel between the US and China through Pakistan, Karachi: Oxford University Press.

Asian Relations Organization (1948) Asian Relations: Being Report of the Proceedings and Documentation of the First Asian Relations Conference, New Delhi, March-April 1947, New Delhi: Asian Relations Organization.

Ayoob, M. (1990) India and Southeast Asia: Indian Perceptions and Policies, London: Routledge.

Basrur, R. (2011) 'India: A Major Power in the Making', in T. J. Volgy, R. Corbetta, K. A. Grant, and R. G. Baird (eds), Major Powers and the Quest for Status in International Politics: Global and Regional Perspectives, New York: Palgrave Macmillan.

Boey, D. (2003) 'Sky's the Limit with S'pore-India Defence Pact', Straits Times, 17 October.

Brown, J. M. (2003) Nehru: A Political Life, London: Yale University Press.

Cohen, S. P. (1980) 'South Asia and U.S. Military Policy', in L. I. Rudolph, S. H. Rudolph, and Others (eds), The Regional Imperative, New Delhi: Concept Publishing Company.

Cohen, S. P. (2001) India: Emerging Power, Washington, DC: Brookings.

DNA India (2010) 'Andaman and Nicobar to Become a Major Amphibious Warfare Base', 8 February.

Dutta, S. (2011) 'China in Mind, Salute and Port Plea to Vietnam', Telegraph, 17 September.

Ganguly, S. (1997) The Crisis in Kashmir: Portents of War, Hopes of Peace, New York: Cambridge University Press.

Ganguly, S. (2006) 'Will Kashmir Stop India's Rise', Foreign Affairs 85 (4): 45-56.

Garver, J. W. (2001) Protracted Contest: Sino-Indian Rivalry in the Twentieth Century, Seattle, WA: University of Washington Press.

Garver, J. W. (2006) 'China's Decision for War with India in 1962', in A. I. Johnston and R. S. Ross (eds), New Directions in the Study of China's Foreign Policy, Stanford, CA: Stanford University Press.

Ghoshal, B. (1996) 'India and Southeast Asia: Prospects and Problems', in B. Ghoshal (ed.), India and Southeast Asia: Challenges and Opportunities, New Delhi: Konark Publishers.

Gopal, S. (1979) Jawaharlal Nehru: A Biography Volume II: 1947-1956, London: Jonathan Cape.

Gordon, S. (1995) India's Rise to Power in the Twentieth Century and Beyond, London: St. Martin's Press.

Green, M. J. (2011) 'Japan, India, and the Strategic Triangle with China', in A. J. Tellis, T. Tanner, and J. Keough (eds), Strategic Asia 2011-12: Asia Responds to its Rising Powers, China and India, Seattle, WA: National Bureau of Asian Research.

Hagerty, D. T. (1991) 'India’s Regional Security Doctrine', Asian Survey 31 (4): 351-363.

Heimsath, C. H. and S. Mansingh (1971) A Diplomatic History of Modern India, Calcutta: Allied Publishers.

Hindustan Times (2013) 'India, Japan and US Hold Trilateral Dialogue', 2 May.

Hoffmann, S. A. (1990) India and the China Crisis, Delhi: Oxford University Press.

Huxley, T. (2000) Defending the Lion City: The Armed Forces of Singapore, St Leonards, N.S.W: Allen \& Unwin.

Kei, U. (2007) 'Pal's “Dissenting Judgment” Reconsidered: Some Notes on Postwar Japan's Responses to the Opinion', Japan Review 19: 215-224.

Kim, C. W. (2010) 'The Role of India in the Korean War', International Area Review 13 (2): 21-37.

Lee C. M. (2011) 'Coping With Giants: South Korea's Responses to China's and India's Rise', in A. J. Tellis, T. Tanner, and J. Keough (eds), Strategic Asia 2011-12: Asia Responds to its Rising Powers, China and India, Seattle, WA: National Bureau of Asian Research. 
Manor J. and G. Segal (1985) 'Causes of Conflict: Sri Lanka and Indian Ocean Strategy', Asian Survey, 25 (12): 1165-1185.

Mastny, V. (2010) 'The Soviet Union's Partnership with India', Journal of Cold War Studies 12 (3): 50-90.

Medcalf, M. (2013) 'The Indo-Pacific: What's in a Name?' The American Interest, 10 October.

Mohan C. R. (2007) 'India's Neighbourhood Policy: Four Dimensions', Indian Foreign Affairs Journal, $2(1)$.

Mukherjee, P. (2005) 'Valedictory Address' at the 7th Asian Security Conference, New Delhi, in N. S. Sisodia and G. V. C. Naidu (eds), Changing Security Dynamic in Eastern Asia: Focus on Japan, New Delhi: Institute of Defence Studies and Analyses.

Mukherji, R. (2008) 'Appraising the Legacy of Bandung: A View from India', in S. S. Tan and A. Acharya (eds), Bandung Revisited: The Legacy of the 1955 Asian-African Conference for International Order, Singapore: NUS Press.

Nehru, J. (1989) The Discovery of India, Centenary Edition, Delhi: Oxford University Press.

Pak, C. Y. (2000) Korea and the United Nations, The Hague: Kluwer Law International.

Panagariya, A. (2008) India: The Emerging Giant, New York: Oxford University Press.

Pardesi, M. S. (2010) 'Southeast Asia in Indian Foreign Policy: Positioning India as a Major Power in Asia', in S. Ganguly (ed.), India's Foreign Policy: Retrospect and Prospect, New Delhi: Oxford University Press.

Pardesi, M. S. (2011) 'Instability in Tibet and the Sino-Indian Strategic Rivalry: Do Domestic Politics Matter?', in S. Ganguly and W. R. Thompson (eds), Asian Rivalries: Conflict, Escalation, and Limitations on Two-Level Games, Stanford, CA: Stanford University Press.

Pardesi, M. S. (forthcoming) 'China's Nuclear Forces and their Significance to India', The Nonproliferation Review.

Paul, T. V. (2003) 'Chinese-Pakistani Nuclear/Missile Ties and the Balance of Power', The Nonproliferation Review, Summer.

Press Information Bureau (2010) 'India and South Korea Sign Two Landmark MoUs to Boost Defence Cooperation', Government of India, 3 September, http://pib.nic.in/newsite/erelease. aspx? relid $=65522$ [accessed 16 January 2014].

SarDesai, D. R. (1968) Indian Foreign Policy in Cambodia, Laos, and Vietnam, 1947-1964, Berkeley, CA: University of California Press.

Sato, H. (2005) 'India Japan Peace Treaty in Japan's Post-War Asian Diplomacy', Journal of the Japanese Association for South Asian Studies 17: 1-20.

Sato, T. (2012) 'Economic Relations Between India and Japan', Eurasian Geography and Economics 53 (4): 457-478.

Sen Gupta, B. (1975) 'Waiting for India: India’s Role as a Regional Power', Journal of International Affairs 29 (2): 171-184.

Shanker, T. (2013) 'Aid to Pakistan to Resume as Tensions with U.S. Eases', New York Times, 19 October.

Siddique, Q. (2014) 'Deeper than the Indian Ocean? An Analysis of Pakistan-China Relations', SISA Report No. 16, Center for International and Strategic Analysis, http://strategiskanalyse.no/ Publikasjoner\%202014/2014-02-27_SISA16_Sino-Pak_QS.pdf [accessed 6 April 2014].

Singh, M. (2005) 'Make 21st Century Truly an Asian Century: PM', Keynote Address by Prime Minister Singh at Special Leaders Dialogue of ASEAN Business Advisory Council, 12 December, http://pib.nic.in/newsite/erelease.aspx?relid=14102 [accessed 18 November 2013].

Singh, M. (2006) 'India Has Come to Terms with Globalisation: PM', Rediff, 18 March, http://www. rediff.com/money/2006/mar/18asoc.htm [accessed 10 January 2014].

Singh, M. (2012) 'PM's Opening Statement at Plenary Session of India-ASEAN Commemorative Summit', Prime Minister of India, 20 December, http://pmindia.nic.in/speech-details. php?nodeid $=1259$ [accessed 6 April 2014].

Singh, M. (2013) 'Excerpts of Address by the PM at the Combined Commanders' Conference', Prime Minister of India, 22 November, http://pmindia.nic.in/speech-details.php?nodeid=1396 [accessed 6 April 2014].

Singh, U. S. (1979) Burma and India, 1948-1962, New Delhi: Oxford and IBH Publishing.

Smith, R. J. and J. Warrick (2009) 'A Nuclear Power's Act of Proliferation', Washington Post, 13 November.

Special National Intelligence Estimate (1983), 'Chinese Policy and Practices Regarding Sensitive Nuclear Transfers', Director of Central Intelligence, 20 January. Released on 30 May 2012, http:// digitalarchive.wilsoncenter.org/document/116893 [accessed 10 February 2014].

Squassoni, S. A. (2006) 'Weapons of Mass Destruction: Trade Between North Korea and Pakistan', CRS Report for the Congress, 28 November. 
Thakur, R. (1979) 'India's Vietnam Policy', Asian Survey 19 (10): 957-976.

Thayer, C. A. (2011) 'The Rise of China and India: Challenging or Reinforcing Southeast Asia's Autonomy?', in A. J. Tellis, T. Tanner, and J. Keough (eds), Strategic Asia 2011-12: Asia Responds to its Rising Powers, China and India, Seattle, WA: National Bureau of Asian Research.

The Economic Times (2010) 'India, Japan Hold 2+2 Dialogue', 7 July.

The Hindu (2014) 'US Plans \$280mn Military Aid to Pakistan, Cuts Civilian Aid', 5 March.

Thomas, R. G. C. (1975-76) 'The Indian Navy in the Seventies', Pacific Affairs, 48 (4): 500-518.

Thomas, R. G. C. (1982) 'Energy Politics and Indian Security', Pacific Affairs, 55 (1): 32-53.

Times of India (2013) 'India, South Korea Hold Foreign Policy, Security Dialogue', 3 September.

Times of India (2014) 'Japan Wants to Join India-US Naval War Games', 12 January.

Ton, T. T. (1963) India and Southeast Asia, 1947-1960, Geneva: Librairie Droz.

Topping, S. (1979) 'Opening the High Road to China', New York Times, 2 December.

Truman, H. S. (1956) Memoirs: Years of Trial and Hope, Volume Two, New York: Doubleday \& Company. 


\title{
9 \\ INDIA'S ROLE AS AN INTERNATIONAL DEVELOPMENT ACTOR
}

\author{
Emma Mawdsley
}

India has been a provider of development assistance to other countries since the early 1950s, impressively soon after it achieved independence. This includes grants, loans, debt relief, scholarships, technical cooperation, food aid, peacekeeping and humanitarian assistance (Price 2005, Agrawal 2007, Chanana 2009, Meier and Murthy 2011, Chaturvedi 2012a, 2012b, Mullen 2013). Over the last decade India's visibility in and contributions to international development have significantly expanded, and together with other 'South-South' partners like Brazil and China, India is now successfully challenging the dominant, western-led norms, modalities and institutions of the 'international' development regime (Mawdsley 2012a). Development cooperation is rarely the explicit subject of foreign policy analyses, yet it has much to recommend it as a lens on the identities and interests that shape India's engagement with the South Asian region, the rest of the G77, other 'rising powers' and the West. In particular, the languages, performances, practices and agendas of development cooperation provide insight into a rich interplay between the realms of 'hard' and 'soft' power. As with all 'donor' or partner countries, development cooperation combines claims to a particular form of national virtue in combination with strategic geo-economic agendas, sometimes in complementary ways and sometimes in tension. India's development cooperation continues to be powerfully anchored in its colonial and post-colonial history, even as it is currently being re-tuned towards evolving foreign policy interests, capacities and contexts in the twenty-first century. Development cooperation is now a key element in the meetings and discussions of rising power initiatives and forums, notably IBSA (India, Brazil and South Africa), the BRICS Forum Summit (Brazil, Russia, India, China and South Africa), and the India-Africa Forum Summits; as well as in the global development governance architecture (UNDP 2013). It therefore provides a means of exploring India's re-positioning with G77 partner states, with other 'rising powers' such as China and Brazil, and with the 'established' powers.

The first part of this chapter gives a brief overview of the history, modalities and architecture of India's development cooperation. The second section changes tack to set out a critical analysis of India's discursive framing of its development cooperation relationships and initiatives within a construct of post-colonial and 'Third Worldist' solidarity. Here I focus on the projection of 'virtue' in the realm of foreign policy. Like other claims to virtue 
(such as those accompanying various forms of western foreign aid), I suggest that this reflects a real sense of doing and being 'good' that should not be dismissed as a simple veneer for more strategic interests. However, this frame can also work to obscure 'unenlightened' selfinterest, as well as the violence and contradictions of 'development' (or rather, economic growth strategies), both domestically and abroad. The chapter concludes with some thoughts on future directions for Indian development cooperation, with a focus on some of the emerging challenges that are likely to confront the Modi government and beyond.

\section{India's development cooperation: definitions, institutions, modalities}

India has been a provider of formal development assistance since the early 1950s (for detailed accounts, see Price 2005, 2011, Agrawal 2007, Chanana 2009, Meier and Murthy 2011, Chaturvedi 2012a, 2012b, Mullen 2013, Chaturvedi et al. 2014). This comprises various forms of concessional financing (e.g. grants, loans, Lines of Credit, debt relief), technical assistance (e.g. providing experts, training and educational scholarships) and humanitarian assistance (financing, personnel and in-kind, including food aid, medicines and so on). Cultural exchanges have also been enrolled in building good will and ties between India and its partner countries. As we will see, the last decade has marked a real acceleration and vitality in India's development cooperation flows, signifying growing capacity but also renewed recognition of its strategic value in supporting geo-economic and diplomatic interests.

Most of India's development cooperation flows and activities have traditionally focused on its South Asian neighbours. Piccio (2013) reports that in 2012-2013, Bhutan received 36 per cent (\$213 million) of India’s technical assistance budget, much of which is focused on generating hydropower, of which India buys back a substantial proportion; while Nepal received 8 per cent ( $\$ 49$ million). Afghanistan is an increasing priority for India, which is investing in roads, energy and social programmes, and has financed and built its new Parliament (Sachdeva 2014). India also has longstanding development partnership relations with many African countries, and it is notable that these are both expanding, notably through Lines of Credit (see below), but also flagship programmes, such as the pan-Africa e-network, and in terms of technical assistance (Cheru and Obi 2010, Mawdsley and McCann 2011). For example, in the second India-Africa Forum Summit held in Addis Ababa in 2011, Prime Minister Manmohan Singh pledged $\$ 700$ million to build educational institutions and training programmes across Africa, as well as a further $\$ 5$ billion in Lines of Credit (Piccio 2013). Demonstrating shifting domestic needs and changing external contexts, historic relations with Eastern African countries and South Africa are now being somewhat eclipsed by the new importance of central Africa and West Africa (Singh 2007, Vittorini and Harris 2011). The TEAM-9 initiative, for example, is now facilitating emerging relationships between India and eight oil-producing West African counties.

In reading and repeating figures like those cited above we must be aware that the complex nature and multi-institutional management of India's development cooperation mean that some caution needs to be exercised. Existing accounting systems are not necessarily set up to isolate and identify all of the flows that might come under this inherently diffuse category, which by their blurred and blended nature may in any case be evaded, double counted, or simply naturally subsumed in other transfers. Defining, calculating and monitoring SouthSouth flows are growing areas of pressure, as various donors and non-state development actors seek to enhance transparency across the whole sector (e.g. Tierney et al. 2011). While there are important rationales for these efforts, including domestic accountability and 
effective international cooperation, some Southern actors express concern that the real intent is to expose, manipulate and discipline the SSDC (South-South Development Cooperation) in ways that inhibit its autonomy and thus foreign policy value. Like other Southern development actors, India asserts its right to define development cooperation on its own terms rather than those of OECD-DAC (OECD Development Assistance Committee) or other international organisations. Bearing this in mind, the best available calculations suggest that Indian expenditure on foreign technical and economic cooperation constituted a historic high of 59.5 per cent of all MEA (Ministry of External Affairs) spending in 2012-2013, having generally hovered around 35-40 per cent since 1997-1998. As a percentage of GNP this comes to 0.074 per cent (Chaturvedi et al. 2014). Piccio (2013) reports that in 2013-2014 the Government of India put aside $\$ 1.3$ billion for foreign assistance, a figure that excludes Lines of Credit (see below). By Piccio's calculations this represents a fourfold increase since 2003-2004. It should also be noted that by adjusting these figures to Purchasing Power Parity, recipients may get a great deal more value for money from India than from western donors, depending on the type of flow.

A feature of India's development cooperation is the expertise it claims to derive from direct experience of many of the social, environmental and market conditions of partner countries. Examples include training in conducting elections in low literacy regions, developing ICT (information and communication technologies) systems and capacities in poorer contexts, and promoting agrarian technologies that suit dry and sub-tropical soils and climates. A second characteristic element of Indian development cooperation, again something it shares with other Southern donors and development partners, is the insistence that it responds to the needs and priorities of its partners, and that unlike western donors, India does not impose its own agendas or policy conditionalities. In a small number of countries, India's development cooperation accounts for a notable share of overall development assistance (such as Afghanistan and Nepal), and in the case of Bhutan, it comprises a significant proportion of the national budget. However, notwithstanding recent increases, in most countries India's development cooperation share tends to be relatively small. That said, as Bach (2013) rightly argues, calculations based on a 'traditional' reckoning of donor/partner influence through the quantum of 'aid' can underplay the geopolitical significance of South-South development cooperation.

Bach's observation points to a broader issue of profound importance, which is that South-South 'development cooperation' should not be mistaken for 'foreign aid'. It certainly has many shared practical and even conceptual elements with what the OECDDAC and multilateral development organisations would define as 'foreign aid' (or more properly Overseas Development Assistance: ODA). Like western foreign aid, Indian development cooperation is also partly located within a set of normative claims about 'moral' relations between states (but, as we shall see, very different from those framing NorthSouth flows); while clearly many of its material elements - technical assistance, grants and some types of loan - would comfortably fall under the definition of ODA. However, as well as its very different historical lineages and symbolic positioning (discussed in more detail below), SSDC is characteristically blurred and blended with trade, investment and diplomatic agendas. While informed comparisons can certainly be valid and productive up to a point, foreign aid and SSDC are not equivalent or synonymous, but arise from profoundly different historical structures and locations (although the direction of travel appears to be convergence in key regards: Mawdsley 2014b).

It is worth digressing here slightly to comment on some of the intellectual and political implications of this observation. Some commentators (more so in the West, but not 
exclusively so) tend to make a category error in simplistically treating 'aid' and 'South-South development cooperation' as equivalents, leading to distorted comparisons and conclusions. Deborah Bräutigam (2009) has been especially effective at demonstrating this in relation to Chinese 'aid', for example. However, other commentators (more so in the South, but again, not exclusively so) tend to overdraw the binary, refusing to see any shared conceptual or practical dimensions between aid and SSDC. This is often allied to a robust critique of 'imperialistic western aid', certainly justifiable to an extent - although not when 'western' aid is reductively treated as a single phenomenon. It can also be accompanied by the dismissal of any critical appraisal of SSDC as being motivated by ignorance and/or ulterior motives - again, sometimes a reasonable concern, but not universally so. This defensiveness, even if partly understandable, is not conducive to more critical or progressive analyses. The domain of policy-academic debate about SSDC is maturing and changing very rapidly, but it is an area that is prone to slippages and suspicions when it comes to assumptions about personal, national and institutional positionalities. We shall return to these observations in the conclusions.

To come back to the overview, India's institutional framework for development cooperation has historically been rather fragmented, and is currently in a period of adjustment. The Ministry of External Affairs (MEA) is nodal, but the Ministry of Finance, Ministry of Commerce and the EXIM Bank (Export Import Bank of India) are playing a growing role. A flagship programme, initiated in 1964 and which is in currently in a new phase of growth, is the Indian Technical and Economic Cooperation (ITEC) scheme. ITEC comprises projects and project-related work, deputations of experts and study tours, but its main focus is on providing training programmes in areas as diverse as small and medium enterprises, rural credit programmes, food processing, textiles and women's entrepreneurship. IT and computing skills represent an increasingly large share of the training available and in demand; and more recently it has expanded to include disaster relief aid. The scheme runs in over 150 countries, and through it the Indian government offers about 10,000 civilian and military placements a year (Chaturvedi et al. 2014). Some time ago, Agrawal (2007) estimated that there were some 40,000 ITEC alumni around the world, an expanding number of course. Partner governments are free to nominate their own candidates, usually bureaucrats and officials, who are then funded to travel to India and undertake the relevant training. In Africa, ITEC is bolstered by the Special Commonwealth African Assistance Programme (SCAAP), while a third programme, the Indian Council of Cultural Relations (ICCR), promotes an array of cultural interactions and tours. Chaturvedi et al. (2014) report that ITEC is now funded to the tune of $\$ 11$ million/year.

India's EXIM Bank now manages its official Lines of Credit (LoCs). Through LoCs, the Government of India helps lower risk by guaranteeing loans and providing interest subsidies, and different types are open to Indian firms, and overseas governments, firms and banks (Sinha 2010). Like other aspects of India's development cooperation, these LoCs are heavily tied to the purchase of Indian goods and services. India is criticised by the 'traditional' donors for blurring the lines between 'aid', geopolitics and commerce, but supporters of this blended approach argue that it provides a more effective bundling of financing and technical assistance (CII-WTO 2013). Indeed, if anything, it appears that 'traditional' donors may start to move more strongly in this direction (Mawdsley et al. 2014). These LoCs are one part of the growing choice of financial instruments and credit sources across the global South, offering both risks and rewards for lenders and borrowers. Like many other elements of Indian development cooperation they have a long history: Chaturvedi et al. (2014) document LoCs to Burma in 1950-1951, as well as other examples over the following decades. But 
like other elements too, the quantum, organisation and purposing of India's LoCs has been changing over the last decade. A much higher share is now going to African countries, while the shift to the EXIM Bank from the Ministry of Finance signals a firmer commercial agenda. Very clearly, the growing sums available through LoCs is indicative of India's strengthening economic clout: Chaturvedi et al. (2014) calculate total LoC commitments in 2012 as \$7.7 billion, comprising 153 LoCs in 94 countries. Projects financed include rice production in Senegal, power plants in Belarus and IT training centres in Mongolia (see also Mullen 2013).

Discussions have been underway since 2003 regarding stronger institutionalisation of Indian development cooperation. Somewhat halting progress followed, with various announcements and intentions not always finding a firm footing, but a breakthrough came in 2012 with establishment of a new Development Partnership Administration (DPA) within the MEA. The intention of the DPA is to enable a dedicated, more effective and streamlined set of development cooperation programmes. Different divisions deal with Lines of Credit, grant projects, civilian and defence training slots under ITEC and related programmes, and humanitarian/disaster responses in different regions/partner countries. Around 50 other Ministries, Departments and agencies are also involved through their involvement in technical cooperation programmes. However, differences within and between these institutions can lead to some policy incoherence; while development cooperation policymaking and programmes - like other parts of Indian foreign policy - may be hampered by the relatively small number of personnel in the MEA (and more specifically in the DPA), as well as by the rapidly growing field, some of which is bringing novel challenges in terms of expertise, scale, site and partner context (Chaturvedi 2012b). NGOs and other civil society groupings have, with very few exceptions, not been enrolled within India's development cooperation activities to date - although there are emerging forums of discussion and possible partnerships (Dubochet 2011, Roychoudhury 2013, PRIA-RIS 2013, Mawdsley and Roychoudhury 2015).

In respect of multilateral development organisations, India is a major provider of UN peacekeeping troops, and is now increasing its commitments - selectively - to a number of multilaterals, such as the World Food Programme. India is also becoming a larger and arguably more powerful creditor to a number of IMF and World Bank funds and institutions (the relationship is not straightforward: see Bryant 2008, Woods 2010, Vestergaard and Wade 2013). However, in terms of country-level collaboration, India tends not to sit on formal donor coordination bodies, with the exceptions of Afghanistan and Nepal. In some contexts this is because India's development cooperation flows are small and it does not have the capacity or will to join onerous coordination bodies. But it is also because the 'traditional donors' at the country level have not always fully woken up to the growing presence and importance of the non-DAC donors, other than China (Mawdsley 2010); while like a number of other Southern partners, India rejects the persistent colonial/post-colonial power relations embedded in these donor forums, and in dominant 'aid' ideologies, relationships and architectures more broadly (Nair 2013). Overall, while India is certainly engaging more closely with certain parts of the international development community, it is doing so on its own terms, and is presently showing little interest in being drawn into dialogue and emerging partnership initiatives, such as the Global Partnership for Development Effectiveness or the post-2015 development discussions. Where there is more activity is with rising power formations, such at IBSA (Vieira and Alden 2011) and the BRICS Forum Summit, although these are still coalescing and finding their identity and rationales (Price 2011).

This very short overview of India's development cooperation history, organisation and programmes can only scratch the surface, and readers are encouraged to turn to 
the more substantial works referenced. Taking a somewhat different approach, the next section turns to a critical appraisal of the discursive framework for Indian development cooperation.

\section{Framing Indian development cooperation}

India's foreign policy orientation and capacities in the twenty-first century show both continuity and change across a spectrum of issues and relationships (for different perspectives, see amongt others: Raja Mohan 2004, Malone 2011, Bajpai and Pant 2013, Chaudhuri 2013, Ogden 2014). It is striking then, that notwithstanding what has clearly been a very significant period of expansion and re-articulation of development cooperation since 2003, development cooperation, as a particular realm of foreign policy, has remained strongly discursively anchored to an earlier era, framed most notably by the Non-Aligned Movement and attempts to foster stronger 'Third World' diplomatic alliances and platforms within the UN, while promoting South-South economic integration. At official events, and in speeches, publications and communiqués, Indian development cooperation, like SSDC more broadly, is consistently framed around the following claims:

- The assertion of a shared experience of colonial exploitation, post-colonial inequality and present vulnerability to uneven neoliberal globalisation, and thus a shared identity of a 'developing' nation;

- Based on this shared experience, a specific expertise in appropriate development approaches and technologies;

- An explicit rejection of hierarchical relations, and a strong articulation of the principles of respect, sovereignty and non-interference; and

- An insistence on win-win outcomes and mutual opportunity provided by Indian development cooperation.

In relation to Africa, for example, Ministerial speeches will almost invariably start with the ancient trade ties of the Indian Ocean, move to shared colonial oppression, recall Gandhi's initiation into political and social activism in South Africa, and invoke Nehru's commitment to African independence and autonomy. In a visit to Mauritius in 2009, India's urbane UN representative, Shashi Tharoor, exemplified the content and tone of dozens of official speeches:

The India-Africa partnership has deep roots in history. Linked across the Indian Ocean, we have been neighbours and partners for thousands of years ... The advent of the Europeans and the colonial period disturbed these interactions but could not disrupt them. Later, both India and Africa shared the pain of subjugation and the joys of freedom and liberation. Satyagraha [truth force], nonviolence and active opposition to injustice and discrimination were first used by Mahatma Gandhi on the continent of Africa ... Nehru was also a firm believer and practitioner of the principle of Afro-Asian solidarity.

Parentheses added

The first observation here is that framing past relations and current interests in this way differs markedly from the recent mainstream constructions of foreign aid in the West (although see Lancaster 2007 as a reminder of the range/plurality within the 'West'). Even 
though OECD-DAC politicians and policy-makers publicly state that national self-interest is a motivation for their own aid (for example, in terms of national security), and indeed, are increasingly keen to make this case in the context of the financial crisis, the wider western public continue to overwhelmingly understand aid as 'charity' to the poor, whether or not they approve of such expenditure (van Heerde and Hudson 2010; see also Hulme and Fukuda-Parr 2009 on the emergence of the post-millennial normative aid regime). Dane Rowlands (2008: 8) observes that even amongst development professionals:

Despite the consistent evidence that [western] aid allocation tends to be dominated by ... political and strategic interests ... there remains within the development community as a whole a sense that the true objective and motivation of development is the moral one of assisting the less fortunate.

Although western development actors have, since the late 1990s, embraced the language of 'partnership', most commentators observe the continuities of paternalism and power that are structured around vertical hierarchies of those who give and those who receive (Baaz 2005; Hyden 2008). In contrast, India resists the terminology of 'donor-recipient' and 'foreign aid', tarnished as these terms are by dominant western/OECD-DAC associations. Mutual opportunity, win-win outcomes and post-colonial solidarity dominate the speeches, policy language and high-level 'conduct' of Indian development cooperation. Afghanistan, Bangladesh, Senegal and Sudan, for example, are not the objects of charity or compassion, but places that can (to use the language of gift theory) maintain their honour and status by providing resources, investment opportunities and markets in return; places that have been similarly unfairly suppressed by colonial powers and post-colonial inequalities. This rhetoric is given expression in the ritualised performances that surround events like the India-Africa Summit (launched in 2008), as well as bilateral high-level meetings and delegations. The red carpet is literally rolled out, and every effort made to enact and convey respect, while underlining the dignity and sovereign presence of the partner nations (Mawdsley 2012b). India is able to assert a claim to selfless good citizenship and solidarity, within and through a language of mutual benefit (rather than charity), by insisting on aligned experiences, interests and agendas between itself and its partners.

One outcome of the language of and commitment to mutual benefit and equality is the stated respect for sovereignty and position of non-interference. Indian development cooperation, as with SSDC more broadly, is characteristically not accompanied by policy conditionalities. Southern partners reject the practice of imposing changes on partner country governance structures, one of the most contentious aspects of mainstream international development. The Structural Adjustment Programmes of the 1980s and 1990s were a particularly explicit expression of this, but interference (direct and indirect) is in the founding DNA of post-war mainstream international development (Gould 2005): indeed, many would claim that efforts to 'reform' developing economies and societies is virtuous and necessary. Critics of this (official) stance of non-interference express concerns that it will undermine efforts to reduce corruption, achieve poverty reduction and promote human rights. In some cases it is taken as evidence that the rising powers in question have little or no commitment to 'inclusive development', but are overwhelmingly motivated by the pursuit of their own interests - securing investment opportunities, opening access to markets, capturing resource flows, and soaping diplomatic solidarities with political elites (Fuchs and Vadlamannati 2012). India's riposte, like that of other providers of SSDC, is located within its historic commitment to foreign policy principles that were enshrined in declarations at 
the Bandung Conference of 1955 . Western aid conditionalities have repeatedly breached that sovereignty, while for India non-interference is asserted to be a central and distinctive principle of its development cooperation politics and conduct. It is critical to observe also that western donors are also motivated by self-interest (defined in multiple and sometimes contradictory ways), and that foreign aid must always, first and foremost, be understood as a tool of foreign policy.

India's normative framing of its development cooperation activities and agendas can be seen as a continuance of what Philippe Nel (2010: 951) calls 'the unfinished struggle against disrespect and humiliation'. Drawing on constructivist international relations theory, Nel argues that the rising powers are presently seeking not just redistribution of global wealth and power (e.g. at the UN Security Council), but also recognition (see also Vieira 2012). The hierarchical languages and assumptions embedded in mainstream development over most of the post-1945 era are emblematic of decades of such humiliation - indeed, it is remarkable to what extent patronising and parochial languages and assumptions persist within everyday and official development discourse. While there have been previous attempts to build Third World platforms and joint demands, such as the New International Economic Order (NIEO) in the 1970s, what has changed is the economic and political muscle that the leading rising powers now command. There is no question that this South-South discourse projects a sanitised and highly selective account of interests, agendas and impacts: it certainly can, but will not necessarily or automatically, support the interests of poorer people or poorer countries (see below). But just like foreign aid for many westerners, India's development cooperation partnerships are constructed through a moral lens that has a real and deep purchase, in spite of contradictions and tensions in practice.

The key to both the legitimacy but also the problematic nature of these claims is that this framework tends to foreground an ethic of justice between states. Sovereign respect, (apparent) non-interference, and the claim to belong to and be working for the world's poorest, exploited and marginalised states is clearly appreciated by many within partner countries and beyond. It constitutes an entirely justifiable challenge to a manifestly unjust dispensation of global power that reflects unequal colonial and post-1945 power relations. However, this focus on justice between states risks serious inattention to justice within states, whether in terms of land rights, labour terms and conditions, civil and political freedoms, social discrimination, and so on (Prashad 2008). Assertions of win-win outcomes, let's say between India and Ethiopia or Nepal, are often founded on a simplistic construction of the 'national interest' of both partners, often equated with rapid and untrammelled industrial modernisation, whether in extraction, agriculture, infrastructure or manufacturing. This obscures and depoliticises the contested and dislocating nature of 'development', masking different sub-national interests of class, gender, region, sector, ethnicity and so on. Building roads, developing raw materials and 'modernising' agriculture will indeed bring benefits to many, but it also usually brings social and environmental costs, particularly to indigenous peoples, small farmers, herders, forest-reliant people and the poorest. How these are addressed, ameliorated and/or compensated, and whose voices are heard in the process, is the difference between growth and development.

The uneven social and economic consequences of India's international development agendas are often glossed over beneath a symbolic regime of striving nations seeking to contest inequalities and injustices within the international hierarchy of states. The domestic politics of development within partner nations are concealed in this account of mutual benefit and Third World solidarity. When Indian politicians and officials talks about 'respect for sovereignty', there is little acknowledgement that sovereign power may be contested 
from below, and that it by no means necessarily translates into a uncontested relationship between a nation-state and its citizens. An example of this can be found in state-supported Indian investment in agri-business in Ethiopia, which is officially framed on both sides as an example of win-win development cooperation (with Indian private sector investment being supported diplomatically, and through ITEC and Lines of Credit/official financing). However Ethiopian and Indian activists are attempting to raise issues of violent resettlement and dislocation, corrupt land deals, regressive tax and labour terms, and inattention to water and other sustainability issues (Rowden 2011). In doing so, they are drawing attention to the darker side of India's international and domestic 'development' path (see also Mawdsley and Roychoudhury 2015). Interestingly - and something that disconcerts simplistic accounts of India as opposite to the West, whether as hero or villain - the UK is also currently under fire for similarly damaging 'development' policies in Ethiopia (Smith 2014). To restate the point made earlier in this chapter, foreign aid and SSDC are certainly different in many regards, but this does not exclude some shared and/or similar components and characteristics.

To conclude this section, commentators across the political spectrum recognise a shift in Indian foreign policy since the new millennium. This is a diffuse, complex and partial shift, which shows both continuity and change, but India's détente with the United States, its pursuit of a permanent seat on the UN Security Council, and membership of the G20, the BRICS and IBSA, all point to a gear change in both its global power and its global positioning (Golub 2013, Mielniczuk 2013, Nel and Taylor 2013). The language of fraternity, solidarity and shared interests between poorer nations that was strongly characteristic of an earlier era persists to some extent across the foreign policy spectrum, but in the (diffuse) realm of 'development cooperation' this language appears notably unadulterated by more recent capacities, discourses and interests. While development cooperation practices and institutions are certainly changing, often in ways that are becoming more adept, agile and suited to changing strategic needs, the meta-narrative of South-South cooperation continues to definitively frame development partnerships within an earlier historical era. Over the coming decade(s) we are likely to see whether or not this framing can withstand the challenges of promoting inclusive or exploitative development, in the context of India's own development path, as well as the changing balance of power and alignment within and between the G77 and the G20.

\section{Conclusions}

Development cooperation both drives and reflects changing geographies of production and consumption, winners and losers, norm makers and takers, trade, investment and geopolitics. India is one of the oldest and largest providers of South-South development assistance, but like other (so-called) 'non-traditional' actors, its historic role as a development partner has, until the last decade or so, been largely overlooked by the international media, academia and policy analysts. This is an oversight that has been rapidly corrected, largely because of the broader BRICS phenomenon, and more specifically as the growing interest in China's development assistance started to prompt a wider evaluation of SSDC (Mawdsley 2012a). The last decade has witnessed growth across the spectrum of Indian concessional finance, technical assistance and humanitarianism, as well as trade, investment and diplomatic activity that falls under the somewhat amorphous category of 'development cooperation'. India is now a key player in the current re-making of global development norms, actors, modalities and institutions. 
While foreign policy analysts have tended to overlook this particular material and discursive domain, in this chapter I have suggested that development cooperation provides an interesting and important lens on changing capacities, interests and identities. A variety of disciplinary approaches are essential to understanding this complex, multi-sited and multi-scaled phenomenon, including Anthropology, Development Studies and Geography. Critical, reflective and progressive scholarship is essential in thinking through a field laden with normative values, conflicting interests and disputed or poorly understood definitions and categories (Eyben 2013).

A final thought on the future: at the time of writing, the Modi government has been in power for a few months, and there are no clear signs of how such a major regime change will play out in terms of foreign policy. Rather than the dangerous enterprise of speculating on future directions, I will raise briefly some (by no means all) of the issues that may have implications for the next decade of Indian development cooperation under Modi and beyond. The first is domestic scrutiny and perception. At present India's development cooperation is largely conducted by elite technocrats, insulated from both popular and party political consciousness. This is likely to change, with implications for how the government of the day justifies overseas expenditure. Although there is certainly likely to be criticism, perhaps counter-intuitively, there may also be considerable elite and middle class support (Mawdsley 2014a). A second issue concerns criticism and resistance by social movements and civil society organisations, domestically and abroad, as India contributes to economic growth in partner countries. The question of how winners and losers are created and treated within this context may become a pressing one where and when aggrieved groups are able to mobilise, nationally and transnationally. In particular, India will face growing reputational issues as its private sector companies - which are enrolled as vehicles of development cooperation - grow in activity and visibility (Rowden 2011, Mawdsley and Roychoudhury 2015). Third, India's development cooperation personnel and infrastructures will need to continue to strengthen given the growing workload of challenges and opportunities they face. Finally, the Government of India must decide on how best to pursue its interests within the rapidly changing realm of global development governance - what blend of nonengagement, dialogue and cooperation will work best with different actors and institutions - while balancing interests in the promotion of national interest and global public goods. As India's footprint grows in the South Asian region, Africa and beyond, so too will its exposure to risks and rewards, potentially opening up new strategic considerations in how it engages with international, regional and other platforms of development governance.

\section{References}

Agrawal, S. (2007) Emerging Donors in International Development Assistance: The India Case. International Development Research Centre (IDRC), Canada. http://www.idrc.ca/EN/Documents/Case-ofIndia.pdf [accessed 7 August 2014].

Baaz, M. (2005) The Paternalism of Partnership: A Postcolonial Reading of Identity in Development Aid, Zed Books: London.

Bach, D.C. (2013) 'Africa in international relations: "“frontier" as concept and metaphor', South African Journal of International Affairs, 20 (1): 1-22.

Bajpai, K. and H.V. Pant (2013) Indian Foreign Policy: A Reader, Delhi: Oxford University Press.

Bräutigam, D. (2009) The Dragon's Gift: The Real Story of China in Africa, Oxford: Oxford University Press.

Bryant, R.C. (2008) Reform of IMF Quota Shares and Voting Shares: A Missed Opportunity. Brookings Institute. http://www.brookings.edu/ /media/research/files/papers/2008/4/08\%20imf\%20bryant/ 0409_imf_bryant.pdf [accessed 7 August 2014]. 
Chanana, D. (2009) 'India as an emerging donor', Economic and Political Weekly, 44 (12): 11-14.

Chaturvedi, S. (2012a) 'India and development cooperation: expressing southern solidarity', in S. Chaturvedi, T. Fues and E. Sidiropoulos (eds), Development Cooperation and Emerging Powers: New Partners or Old Patterns?, 169-189, London: Zed Books.

Chaturvedi, S. (2012b) 'India's development partnership: key policy shifts and institutional evolution', Cambridge Review of International Affairs, 25 (4): 557-577.

Chaturvedi, S., A. Chenoy, D. Chopra, A. Joshi, and K-L. Lagdhyan (2014) Indian Development Cooperation: The State of the Debate, Sussex: IDS, Sussex University.

Chaudhuri, R. (2013) Forged in Crisis: India and the United States since 1947, London: Hurst and Co.

Cheru. F. and C. Obi (2010) The Rise of China and India in Africa, London and Uppsala: Zed Books and The Nordic Africa Institute.

CII-WTO (2013) India-Africa: South-South Trade and Investment for Development. The World Trade Organisation and Confederation of Indian Industry. http://irgamag.com/images/pdf/CII-WTO\%20 India\%20Africa\%20Report.pdf [accessed 7 August 2014].

'DN' (2003) 'Aid: old morality and new realities', Economic and Political Weekly, 38 (24): 2353.

Dubochet, L. (2011) The Changing Role of Civil Society in a Middle-Income Country. OxfamIndia, Working Paper XI. http://www.oxfamindia.org/sites/default/files/XI\%20The\%20Changing\%20Role\%20 of $\% 20$ Civil\%20Society\%20in\%20a\%20Middle-Income\%20Country.pdf [accessed 7 August 2014].

Eyben, R. (2013) 'Building relations in development cooperation: traditional donors and the rising powers'. IDS Policy Briefing 36, IDS, Sussex.

Fuchs, A. and K.C. Vadlamannati (2012) The Needy Donor: An Empirical Analysis of India's Aid Motives. University of Heidelberg Department of Economics Discussion Paper Series No. 532. http://ssrn. com/abstract $=2140949$ [accessed 6 August 2014].

Golub, P.S. (2013) 'From the new international economic order to the G20: how the "global South" is restructuring world capitalism from within', Third World Quarterly, 34 (6): 1000-1015.

Gould, J. (ed.) (2005) The New Conditionality: The Politics of Poverty Reduction Strategies, London: Zed Books.

Hulme, D. and S. Fukudu-Parr (2009) International Norm Dynamics and the 'End of Poverty': Understanding the Millennium Development Goals. Brooks World Poverty Institute Working Paper 96. http://www. eadi.org/fileadmin/MDG_2015_Publications/fukuda-parr_and_hulme_2009_international_norm_ dynamics.pdf [accessed 7 August 2014].

Hyden, G. (2008) 'After the Paris Declaration: taking on the issue of power', Development Policy Review, 26 (3): 259-274.

Lancaster, C. (2007) Foreign Aid: Diplomacy, Development, Domestic Politics, Chicago, IL: Chicago University Press.

Malone, C. (2011) Does the Elephant Dance? Contemporary Indian Foreign Policy, New York: Oxford University Press.

Mawdsley, E. (2010) 'The non-DAC donors and the changing landscape of foreign aid: the (in) significance of India's development cooperation with Kenya', Journal of Eastern African Studies, 4 (2): 361-379.

Mawdsley, E. (2012a) From Recipients to Donors: The Emerging Powers and the Changing Development Landscape, London: Zed Books.

Mawdsley, E. (2012b) 'The changing geographies of foreign aid and development cooperation: contributions from gift theory', Transactions of the Institute of British Geographers, 37 (2): 256-272.

Mawdsley, E. (2014a) 'Public perceptions of India"s role as a development cooperation partner: domestic responses to rising donor visibility', Third World Quarterly, 35 (6): 958-979.

Mawdsley, E. (2014b) 'International Development and "'Emerging Markets". Paper presented at a Workshop on 'Southern Futures', Copenhagen, 25th and 26th September 2014.

Mawdsley, E. and G. McCann (eds) (2011) India and Africa: Changing Geographies of Power and Development, Oxford: Fahamu Books.

Mawdsley, E. and S. Roychoudhury (2015) 'Civil society organisations and Indian development assistance: emerging roles for commentators, collaborators and critics', in S. Chaturvedi and A. Mulakala (eds), Indian Approach to Development Cooperation, Abingdon: Routledge.

Mawdsley, E., L. Savage and S-M. Kim (2014) 'A “"post-aid world"'? Paradigm shift in foreign aid and development cooperation at the 2011 Busan High Level Forum', Geographical Journal, 180 (1): 27-38.

Meier, C. and C. Murthy (2011) India's Growing Involvement in Humanitarian Assistance. Global Public Policy Institute Research Paper 13. http://www.gppi.net/fileadmin/media/pub/2011/meier-murthy_2011_ india-growing-involvement-humanitarian-assistance_gppi.pdf [accessed 7 August 2014]. 
Mielniczuk, F. (2013) 'BRICS in the contemporary world: changing identities, converging interests', Third World Quarterly, 34(6): 1075-1090.

Mullen, R. (2013) IDRC Report: The State of Indian Development Cooperation. Indian Development Cooperation Research: Centre for Policy Research, New Delhi. http://cprindia.org/idcr_report_ state_of_indian_development_cooperation.pdf

Nair, S. (2013) 'Governance, representation and international aid', Third World Quarterly, 34 (4): 630652.

Nel, P. (2010) 'Redistribution and recognition: what emerging regional powers want', Review of International Studies, 36: 951-974.

Nel, P. and I. Taylor (2013) 'Bugger thy neighbour? IBSA and South-south solidarity', Third World Quarterly, 34 (6): 1091-1100.

Ogden, C. (2014) Indian Foreign Policy: Ambition and Transition, Cambridge: Polity Press.

Piccio, L. (2013) 'India's foreign aid program catches up with its global ambitions', Devex [online], 10 May. Available at: https://www.devex.com/news/indias-foreign-aid-program-catches-up-with-itsglobal-ambitions-80919 [accessed 4 August 2014].

Prashad, V. (2008) The Darker Nations: A People's History of the Third World, New York: The New Press.

PRIA-RIS. (2013) 'India's global development presence and engagement of Indian civil society', workshop by Society for Participatory Research in Asia (PRIA) and Research and Information System for Developing Countries (RIS), Delhi.

Price, G. (2005) Diversity in Donorship: The Changing Landscape of Official Humanitarian Aid: India's Official Aid Programme. Overseas Development Institute HPG Background Paper. http://www.odi.org/sites/ odi.org.uk/files/odi-assets/publications-opinion-files/416.pdf [accessed 7 August 2014].

Price, G. (2011) For the Global Good: India's Developing International Role, Chatham House Report, London: Chatham House.

Raja Mohan, C. (2004) Crossing the Rubicon: The Shaping of India's New Foreign Policy, London: Palgrave Macmillan.

Rowden, R. (2011) India's Role in the New Global Farmland Grab, GRAIN and Economic Research Foundation: Delhi.

Rowlands, D. (2008) Emerging Donors in International Development Assistance: A Synthesis Report. PBDD Report. http://www.idrc.ca/EN/Documents/donors-international-development-synthesis-report. pdf [accessed 7 August 2014].

Roychoudhury, S. (2013) 'India's external aid: lessons and opportunities', Economic and Political Weekly, 7: 22-26.

Sachdeva, G. 'The India-Afghanistan partnership'. Paper presented at Research and Information Systems and The Asia Foundation, Author's Workshop on Indian Development Cooperation, Delhi, May 2014.

Singh, S. K. (2007) India and West Africa: A Burgeoning Relationship. Chatham House Africa Programme, Briefing Paper, April 2007. http://www.eldis.org/go/home\&id=63257\&type=Document\#.UJXloVb9HZ [accessed 7 August 2014].

Sinha, P. (2010) 'Indian development cooperation with Africa', in F. Cheru and C. Obi (eds), The Rise of China and India in Africa, London and Uppsala: Zed Books and The Nordic Africa Institute, 77-93.

Smith, D (2014) 'Britain is supporting a dictatorship in Ethiopiad'. The Guardian [online], 6 July. Available at: http://www.theguardian.com/world/2014/jul/06/britain-supporting-dictatorship-inethiopia [accessed 4 August 2014].

Tharoor, S. (2009) 'India-Africa; Partners in Development', [online], 3 November. Address by MOS (Minister of State) Dr Sashi Tharoor, University of Mauritius. Available at: http://indiahighcommauritius.org/pages.php?id=133 [accessed 17 March 2012].

Tierney, M. J., D. L. Nielson, D. G. Hawkins, J. Timmons Roberts, M. G. Findley, R. M. Powers, B. Parks, S. E. Wilson and R. L. Hicks (2011) 'More dollars than sense: refining our knowledge of development finance using AidData', World Development 39 (11): 1891-1906.

Timmons Roberts, J., M. G. Findley and D. G. Hawkins (eds) (2011) 'Expanding our understanding of aid with a new generation of development finance information', Special Issue of World Development, 39(11): 1891-2054.

United Nations Development Program (2013) The Rise of the South: Human Progress in a Diverse World. Human Progress Report: UNDP. http://hdr.undp.org/sites/default/files/reports/14/hdr2013_en complete.pdf [accessed 7 August 2014].

van Heerde, J. and D. Hudson (2010) "The righteous considereth the cause of the poor?" Public attitudes towards poverty in developing countries', Political Studies, 58 (3): 389-409. 
Vestergaard, J. and R. H. Wade (2013) 'Protecting power: how Western states retain the dominant voice in the World Bank's governance', World Development, 46: 153-164.

Vieira, M. (2012) 'Rising states and distributive justice: reforming international order in the 21st century', Global Society, 26 (3): 311-329.

Vieira, M. and C. Alden (2011) 'India, Brazil and South Africa: South-South Cooperation and the Paradox of Regional Leadership', Global Governance, 17 (3): 507-528.

Vittorini, S. and D. Harris (2011) 'India goes over to the other side: Indo-West African relations in the 21 st century', in E. Mawdsley and G. McCann (eds), India in Africa: Changing Geographies in Power and Development, Oxford: Fahamu Books, 203-217.

Woods, N. (2010) 'Global governance after the financial crisis: a new multilateralism or the last gasp of the great powers?' Global Policy, 1 (1): 51-63. 


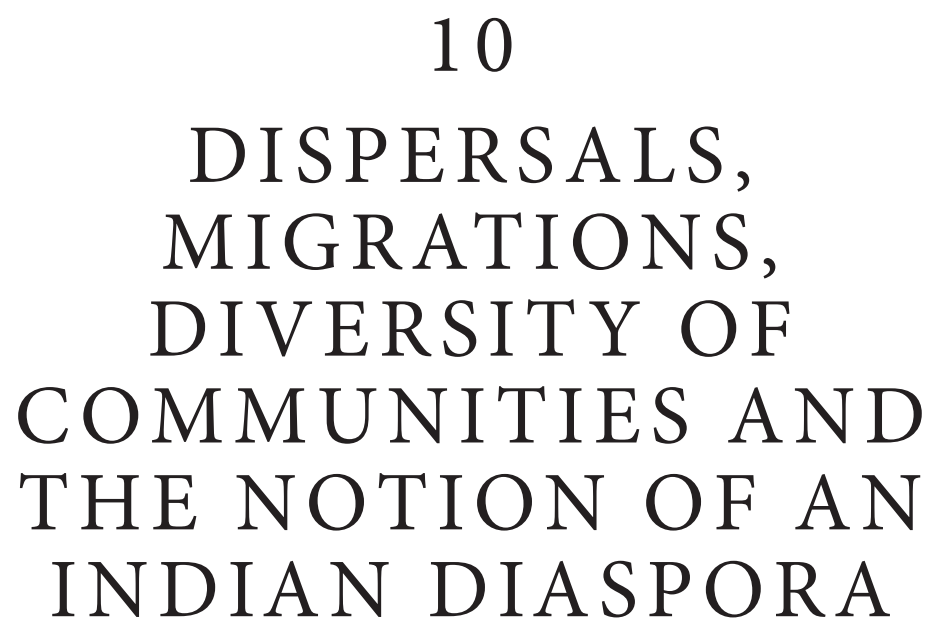

Brij V. Lal and Knut A. Jacobsen

'Like an overflowing container, Indians have spilled all over the world', said a Canberra-based humourist some years ago, adding that 'this spilling has been by and large to the benefit of the world'. He continued:

From Australia to Alaska and Britain to Bahrain, we are proudly carrying the flag of Indian culture and civilisation along with idlis, dosas and chicken curry. They say that when Hillary and Tenzing reached the peak of Mt Everest, they were served hot parathas and cold lassi at Bhappe da Dhaba. Hillary was so enthralled by these that he climbed Mt Everest twice. It is rumoured that the pathfinder on Mars found the thousand year relics of Patel the Motel among the rocks. You can find a Fiji Indian running an Indian grocery shop on the North Pole selling spices, rice, atta and dhal, along with copies of Hindi movies boldly labelled 'Pirated'.

Lal 2011: 136

It is true that the Indian diasporas, at more than 30 million strong, ${ }^{1}$ are visibly increasing in size, influence and importance, especially in western countries, though whether their presence there is beneficial or baleful for the host societies could be a matter of some jocular debate. But it is certainly debatable whether a Patel from East Africa, a Punjabi from Canada or a peasant from Fiji are all peas in the same pod. The Indian diasporas are the product of many causes and countless crossings, and it is divided and divergent in its aspirations and assumptions in so many crucial ways that would make the use of the word 'diaspora' in the 'singular' problematic. There are some points of convergence (in food, faith, festivals, fashion) which people of Indian origin share in common whatever their nationality, but there are many points of divergence as well where the particularities of class, nation, region, are accentuated. The enormous diversity of 'the Indian diaspora' should therefore be constantly borne in mind. 
The growth of, as well as the notion of, a large Indian diaspora is a phenomenon of the late twentieth century, and the very fact that it exists at all would be a source of bemused puzzlement to an observer from the previous century. The Hindu had little migratory instinct, wrote William Crooke in 1897, 'and all his prejudices tend to keep him at home'. He had his custom-bound routine and rituals and ceremonies to observe, deities to propitiate. There was no forgiveness for those who died in exile as they would then have no proper funeral oblations by the trusted family priest 'and would wander through the ages a starving, suffering, malignant ghost, because his obsequies have not been duly performed' (Crooke 1897: 326). There would similarly be no redemption for those who crossed the dreaded 'kala pani', the pollution-producing dark ocean. But the actual reality of the human experience in India is decidedly different. From time immemorial, people have moved about in search of adventure and opportunity. In medieval times, peasants left to escape the persecution and depredations of landlords. In other places, people left for foreign lands in search of trade and commerce, as historical relics in Southeast Asia show. Across the length and breadth of the Indian Ocean and the Bay of Bengal and around the Coromandel Coast, Indian traders plied their trade. Research is not clear about the movement of people across time and space in pre-European Asia. But whatever may have been the situation in the past, migration is now an accomplished fact of life in India, and a foreign passport or permanent residence a cherished symbol of success and achievement.

Indian migration and settlement in foreign lands is longstanding, but a developed consciousness of a diasporic community with a shared cultural heritage, variously connected and inter-connected, is a recent phenomenon. A generation ago, except for the passionate cricket-loving crowd in India who knew the exploits of Rohan Kanhai or Ron Ramdin, the islands in the Caribbean were places completely unknown, rumoured to be exotic but beyond comprehension. And most people even in those remote communities knew next to nothing about communities in other parts of the world who shared a history of servitude with them. No more. Travel and technology have revolutionised our notion of time and space. Breaking news of events in one part of the world reach another instantaneously. Organisations - Global Organisations of People of Indian Origin, for instance - facilitate exchange and communication in the broader diasporic community. V.S. Naipaul, Rohinton Mistry, M.G. Vassanji, Hanief Kuraishi, Salman Rushdie, to name just a few of the galaxy of Indian writers, are read right across the world. The diasporic experience is no longer on the margins of serious literary exploration. And the remotest villager in Suriname, or Guyana or Fiji or Uttar Pradesh has most probably seen 'Bend It Like Beckham' and 'Monsoon Wedding'.

Political boost to the notion of an India diaspora came from India itself. The impetus for this came in part from China's example of courting overseas Chinese funds, mostly those in Southeast Asia. Money was remitted to China along with investment in the development of infrastructure in places from where the original migrants had come. Large Southeast Asian Chinese companies, such as the Chorean Pokphand Group of Thailand, became significant investors in China (Skeldon 2010). If China could mobilise and harness the resources of the overseas Chinese for its development purposes, why could India not do the same, especially at a time when the Indian economy was opening up? There was deep realisation in the Indian policy circles 'that India needed to reinvent itself economically for it badly needed investment in infrastructure, which neither the Indian state nor private business had the capacity to mobilise' (Kudaisya 2006: 87).

An active engagement with the Non-Resident Indian (NRI) community would help. To that end, the Government of India set up a High Level Committee, chaired by the 
Hon. L.M. Singhvi, member of the Rajya Sabha, India's Upper House, and former Indian High Commissioner to the United Kingdom, to gain a deeper understanding of the aspirations, attitudes, strengths and weaknesses of the Indian diaspora and their expectations of India and to 'recommend a broad but flexible policy framework and country-specific plans for forging a mutually beneficial relationship with the PIOs and NRIs and for facilitating their interaction with India and their participation in India's economic development' (National Informatics Centre n.d.). The Indian diaspora it was said was 'well situated to play a pivotal role in energising and augmenting bilateral trade, investment, transfer of technology and tourism with more countries' (National Informatics Centre n.d.). Accordingly, a number of practical steps were recommended for greater engagement. Travel restrictions and impediments for PIOs were eased, and bureaucratic impediments around investment and repatriation of capital were reduced. The NRI could repatriate in foreign currency their earnings in India. Among the most symbolic celebrations of the diaspora was the convening of the Pravasi Bharatiya Divas on 9 January each year, the date commemorating Mahatma Gandhi's return to his native land after twenty-five years in South Africa. Luminaries from the Indian diaspora were invited to attend the event and were honoured for their distinguished and varied contributions to their respective countries. The word 'NRI' entered the Indian lexicon along with its partner 'diaspora' rendered in various pronunciations. The fanfare's initial appeal, its novelty value, has faded somewhat in recent years but not before creating an awareness of a larger community about which little was known in India before.

The celebrations in India gave concrete shape to a phenomenon already underway. Modern travel enabled people to transgress boundaries with unprecedented frequency. Technology (Skype, emails, Facebook, Twitter) facilitated regular communication through the mysteries and marvels of the cyberspace. The death of the ideology of assimilation in many western countries, the celebration of diversity and difference, encouraged multiple identifications. Identity was no longer a binary of either or. Fatima Meer, the distinguished South African writer and activist, could call herself a proud daughter of India without having her loyalty to her land of birth, South Africa, being called into question. Lord Dholakia embraced his cultural roots in Gujarat while being a member of the House of Lords. In far-flung former sugar colonies, descendants of indentured labourers sought to trace their roots in India, making regular pilgrimages to their ancestral villages. Dedicated internet sites promoted 'roots and routes' tourism. A broadening awareness of a large scattered community of people across the globe seized the imagination. The Nobel Prize for Literature awarded to V.S. Naipaul, the Trinidad-born writer, became a matter of intense pride to all Indians, at home and abroad, his earlier dark views about the subcontinent forgotten or forgiven.

There is now in the Indian diaspora itself a more realistic appreciation of difference and diversity among themselves. The PIOs and the NRIs differed from each other in their expectations, needs and aspirations. The NRIs generally maintained a keen and close link with India through regular visits and family networks while others, from further afar, with greater social and emotional distance from India, had a vicarious experience of a land from where their ancestors came. In the diaspora itself, the social circles of the different Indian diasporic communities intersected less and less; and sometimes there was muted antagonism between NRIs and PIOs born of mutual ignorance and prejudice. Within the overarching rubric of diaspora, then, are found many communities formed by different historical and social experiences with their own distinctive interests, assumptions and expectations. 


\section{Dispersals}

The creation of Indian communities across the globe has taken place across vast stretches of time and in distinct phases, and it is to these that we now turn. Southeast Asia was a known destination for Indian traders in spices, precious stones and textiles. Chettiers, or Indian moneylenders, were known to have plied their trade in Burma, Malaya, Thailand and Indonesia. Mappilas and Paravas also ventured across the borders of India. Across the Arabian Sea, Indian traders established their foothold on the east coast of Africa, in places such as Zanzibar, competing with Arab traders. Indian caravan trade reached the heart of central Asia (Bukhara, Samarkand and Tashkent) and Iran (Qazvin and Kashan) in the seventeenth century. Indian gypsies found their way to Europe in such places as Romania and Hungary. Testimony to the entrepreneurial spirit of the 'landlubbing' Indians, the accounts of the earliest journeys lie buried in the archives of deep time.

The spread of European capital across the globe in the late eighteenth and nineteenth centuries spurred the acquisition of cheap Indian labour through mostly foul means. Indian men and women were sold as slaves for employment in European factories and plantations by the Dutch in Ceylon and by the French in the Indian Ocean. They were accompanied by small streams of free migrants. The establishment of convict penal settlements in Bencoolen (1787-1825), the Andaman Islands (1793-1796 and 1858-1945), Penang (1790-1860), Melaka and Singapore (1825-1873), and in Burma and Mauritius saw further enforced migration of Indians. After the Mutiny of 1857, the Andaman Islands became a major destination, crossing the kala pani ('black waters') with the resulting loss of caste purity being thought as a particularly severe punishment (Anderson 2006: 44-45).

This practice of enforced migration paled before the advent of the indenture system in 1834 to meet the shortage of labour on the colonial plantations upon the abolition of African slavery in the British Empire in 1833 (Tinker 1974). What began as a tentative experiment became highly regulated by the latter half of the nineteenth century. Mauritius led the way, and by the time indentured emigration ended in 1916, over 1 million Indian indentured immigrants had been shipped to the principal 'King Sugar' colonies of Trinidad, Guyana, Suriname, Fiji and Natal. Their contracts provided for a return passage back to India at the end of their service, but fewer than 21 per cent returned. Enticed by new opportunities, dreading a long sea voyage back, fearful of the reception they might receive among their family and village friends, the majority stayed on. Their descendants constitute a large and visible part of the multicultural mosaic of their countries.

The largest numbers of Indian labourers, over 3 million, left under the kangani system ${ }^{2}$ to countries in Southeast Asia: Malaya, Ceylon and Burma. The kangani workers, recruited by middlemen, were principally from southern India just as the bulk of the indentured labourers (except to Natal since 1860) were from North India, until the 1870s mostly from the Bihar region and in the latter half of the nineteenth century from the eastern districts of the United Provinces (now Uttar Pradesh). The pattern of recruitment influenced the shape and content of Indian culture in the colonies. Where northerners predominated, north Indian cultural forms and practices gained ascendancy, and in places of southern dominance, as in Southeast Asia, south Indian cultural festivals and rituals shaped the overall pattern.

Everywhere, indentured emigration involved rupture and recuperation, but the pattern and the extent of disruption varied from place to place, depending upon the timing of the migration, the physical proximity to and frequency of contact with India, the size of the immigrant population and, importantly, the policy of the host society towards its immigrant population (Jayawardena 1968). Smaller numbers intensified the pressure to assimilate, as 
in some of the smaller West Indian islands (Mahabir 2009). The opportunity and facility for cultural reproduction was influential: the bigger the critical mass, the better the prospect for cultural reproduction. In some places, such as Guyana and other Caribbean islands, there was 'open market' for cultural exchange among the different communities, but in others, such as Fiji, the barriers to cultural interaction were reinforced by the state. In some places, the Christian missions made much headway, as in the Caribbean, whereas in some places, their influence was minimal, as in Fiji.

Overall, the societies that emerged in the former indentured colonies were essentially egalitarian and self-made, shorn of the hierarchies and protocols of their original homeland. Caste could not survive the crossing and the rigorous demands of plantation labour. The rupture was not abrupt as people continued to play at caste for a while, but it was effectively drained of life. What Hallup writes about Mauritius would apply equally to other places as well. 'Caste identity does not constitute a major constraint for upward social mobility among most Hindus: education, occupation, income, wealth and personal achievements are much more important status criteria' (1994: 315). Need and necessity rather than rituals and protocols governed matrimonial matters and social relationships. The disparity in sex ratio in the immigrant population forced cross-caste and even cross-religious marriages unimaginable in India. Enforced intermingling and freer social and sexual transaction was the order of the day within the regimented confines of the plantation regime. A semblance of normalcy returned a generation later as sex ratio in the community improved.

Women played an integral role in the formation and transformation of the broader social structures of the old Indian diaspora. They raised families in difficult circumstances, often without a helping hand, and facilitated the 'transmission and practice of folk religion and of tradition-based sanctions. In Guyana, writes Jeremy Poynting, women were the 'main preservers of Indian domestic culture' which was the 'principal means whereby Indians maintained their identity' (1987: 232). There is a debate whether the possibilities of emancipation offered by migration and indenture were thwarted by men who confined them back to patriarchal structures or whether women participated actively in the creation of a new society which restored some of the older values. Devarakshnam Govinden (2008) argues that in South Africa women were 'as much preservers of their race' as men, while for Fiji, Ahmed Ali suggests that many women 'preferred the security of a partnership with a male of another religion to the risks of physical and moral violence endemic in the girmit lines, and sometimes the cruel fate of a single unattached female' (2004: 99).

Religion survived the crossing in a simpler form around the Ramayana and to a less extent the Bhagvadagita. The indentured labourers were the carriers of Milton Singer's 'Little Tradition' of folk religion. Tulsidas' Ramayana became a religious, social and emotional anchor for the early indentured workers amidst an alien and often hostile environment, writes Sherry-Ann Singh of the situation in Trinidad (2012). The story of Lord Rama, exiled from the kingdom of Ayodhya for no fault of his own but who returned triumphant after fourteen years of exile, resonated in the experience of the indentured labourers. They saw in Rama's story a rendition of their own predicament. They, too, had been exiled from their homeland for no fault of their own, and their banishment would end one day. The text in the Awadhi language obviated the need for priestly intervention, was not recited individually or privately but collectively to the accompaniment of elementary music, so that its reading provided both enlightenment as well as entertainment in 'such a manner that despite and due to the lack of active sermonising, the philosophy hits home' (Singh 2012: 68): the philosophy of the importance of righteous conduct, duty to one's family and community, quest for truth and justice. Islam, too, survived the crossing. 'They held 
together more', wrote C.F. Andrew of the situation in Fiji, 'and even though they did not observe, to any great extent, the stated hours of prayer, they were Musulmans, and this gave them a dignity of their own' (quoted in Ali 2004: 105).

While the descendants of the indentured labourers made a success of themselves in the fields of agriculture, commerce and the professions, through sacrifice and frugality, their experience in politics was different. Everywhere, they encountered resistance to their demand for equality (Lal 2012). The colonial as well as the post-colonial angle of vision excluded or severely marginalised Indians from the national narrative. In Trinidad, writes Bridget Brereton, the Afro-Creole narrative was privileged 'as the core group in the national story', and their cultural forms as the origins of the new national culture. The message was that 'all other ethnic groups must suppress their unique cultures in the interest of nationbuilding' (Brereton 2013: 146). Forbes Burnham's Guyana followed a similar path. In Fiji, the indigenous Fijians claimed a pride of place in the nation's affairs and threatened retribution if their hold on power was challenged. In Mauritius, the creole plantocracy asserted its demands for a privileged position, while in South Africa, the apartheid regime ruled the roost. Much later, in Uganda and other countries, the Africanisation policies of independent governments forced Indians either to leave or fend for themselves. In recent years, things have improved, with the impact of globalisation and the acceptance of pluralism in national discourse, and several countries have Indian-supported parties in power. But the long history of marginalisation and exclusion has left deep scars on the lives of many Indian communities in different parts of the world.

The relationship of the indentured diaspora to India is a complex one, and there is some quiet dismay that India's current policy towards its diaspora seems to be underpinned by economic considerations. Brij Maharaj's observation that India was primarily interested in those with dollars, pounds and euros to invest will ring true to many along with the contention that there "was no interest in the descendants of indentured labourers in countries like Malaysia, Fiji, Trinidad, Suriname, Mauritius and South Africa' (Maharaj 2008: 33). In most places, remnants of Indian culture and traditions survive to varying degrees, and the interest in India of the Indian communities in the old diaspora is cultural and emotional rather than economic or political. There has been no rush to acquire dual Indian citizenship, for instance, and there is not likely to be one in the foreseeable future.

\section{Free migrants}

The same, though, cannot be said of Indian diasporic communities derived from free migration. There will be exceptions, of course, due to the time, nature and purpose of migration, but the free migrants from India maintain closer links with their homeland through marriage and social networks and frequent visits. Countless websites proliferate spreading information and misinformation about political developments in the subcontinent and cyberspace is replete with vigorous debates and discourses about culture, religion and politics. The bulk of these communities are found in Canada, the United States, the United Kingdom and, to a lesser extent, Europe.

The advent of the 'Dollar Diaspora' of the West as opposed to the 'Desperate Diaspora' of the developing world is of recent, post mid-twentieth century origin. Nonetheless, small groups of free migrants were finding their way to western countries from the late nineteenth century onwards. In Canada and the Pacific Northwest, for instance, Punjabis, mostly Sikhs, began arriving in small numbers from the late 1890s, finding employment in the timber industry (Takaki 2007, Lal 1980). They were joined by students and political 
activists. The Ghadr Movement, based in San Francisco and led by Lala Hardayal and Taranath Das, demanded independence for India, by force if necessary. The immigrants encountered widespread objection to Asian migration. 'White Canada Now, White Canada Forever', went one slogan. In 1907, there were riots against 'Orientals' in Vancouver. An attempt in 1914 by a group of determined Punjabis to test Canadian immigration laws failed. The Komagata Maru, with 376 East Indians aboard, the overwhelming majority of whom were Sikhs, was refused entry into Canadian ports and turned back. Soon afterwards, antiimmigration legislative barriers in both Canada and the United States reduced migration from India to a trickle. Between 1911 and 1920, only 1,460 Indians were allowed entry into Canada while in the United States 1,782 Indians were prevented entry in the same period. Canada and the United States were not exceptions but the rule: Asian, including Indian, immigration was discouraged across all the white dominions. And the barriers would not come down until the latter half of the twentieth century.

The same pattern is more or less true of the United Kingdom. The early migrants came either as appendages of returning imperial administrators or as seamen and demobilised soldiers. The United Kingdom was also the early foreign destination of choice for the wealthy and the well-connected Indian elite. A number of the subcontinent's future leaders, including Mahatma Gandhi, Jawaharlal Nehru and Muhammad Ali Jinnah were educated there. London became the hub for nationalist agitation. Numbers of migrants increased substantially after the Second World War as 'wartime labour shortages opened up all sorts of opportunities which had previously been closed to people of colour' (Ballard 2007: 590). Indian migrants to the UK came directly from the subcontinent (Punjab, Gujarat, Bengal and from districts in what are now Bangladesh and Pakistan) and from East Africa as decolonisation intensified and Asians began to feel the heat of African nationalism, numbering around 200,000 by 2001 (Castles 2009). They were joined by Indian migrants from other parts of the former British Empire, principally the Caribbean. It would be a mistake though to lump all the different categories of Indian migrants under a single rubric, for there are profound differences of values and orientation among them.

The dominant narrative of Indian experience in the United Kingdom and North America is constructed around visible success and achievements. These are advertised incessantly in local community magazines and internet sites. So, in the United States, most Indians are in the high income bracket, are college-educated, occupy prominent places in the professions and government service, not to mention the IT sector (Dwivedi 2011). Indians are increasingly taking to local and national politics. Bobby Jindall, the governor of Louisiana, is held up as a role model. In the United Kingdom, the Indian visibility in the media, public service and academia is clearly evident, as it is in the political arena. Compared to many immigrant communities, Indians have done well, the preferred professions for the young being Law, Pharmacy, Accountancy and Medicine. No less than 20 per cent of the places in British medical schools are now filled by British Asians, mostly British Indians (Ballard 2007: 593). The pattern is reflected in many other developed countries as well, such as Canada, Australia and New Zealand. But what is often overlooked is that the path to success has not been easy due in no small part to subtle institutional racism and discrimination. Acceptance in many quarters has met with resentment; and in depressed, de-industrialised towns and cities (Oldham, Bradford, Leeds, Blackburn), Indians, along with other Asian minorities, continue to bear the brunt of racial discrimination (Castles 2009: 29).

The Indian presence in North America and the United Kingdom is visible but its most interesting aspect is not the economic success of the Indian communities, important 
though that obviously is, but the creative ways in which its artists, writers and film makers are interpreting their multicultural experience in ways that go to the core of how they understand their complex identities and attachments. Indeed, some of the finest writings in the English language are coming from writers of Indian origin. It would be invidious to list names, but the works of M.G. Vassanji, Rohinton Mistry, Salman Rushdie, V.S. Naipaul, to name only a few of them, would rank among the great literary achievements of the twentieth century (Mishra 2007, Nelson 2010). And movies such as 'Bend it Like Beckham' have brought to audiences worldwide the pressures and expectations of growing up in the West, torn between the demands and obligations of two or more competing worlds and unable, in the end, to belong completely to any one of them.

The targeted labour migration of Indian workers to the Gulf region in the late twentieth century has led to the creation of a kind of society that cannot properly be called diasporic, for these are Indian citizens migrating temporarily for employment and returning to their home states after the expiry of their contracts, but their contribution to the Indian economy is substantial and underpins India's diasporic policy. The main recipient countries are Saudi Arabia, United Arab Emirates, Oman, Kuwait, Qatar and Bahrain. The total number of Indian migrants to the Gulf States in 2001 was estimated at 3,318,000, with Saudi Arabia $(1,500,000)$ and United Arab Emirates $(950,000)$ leading the way (Khadria 2009: 33). About 70 per cent of the migrants are semi-skilled or unskilled (masons, cooks, carpenters, drivers, electricians and the like). The money the migrants remit to India plays a significant part in many parts of the country. Indeed, in 2010 , India received $\$ 53.1$ billion in remittances while China received $\$ 51.3$ billion, though per capita, China edged India (Gupta and Choudhury 2012). Concern is sometimes expressed about the imbalances this causes in the local economy and society, and some foreign policy experts have expressed the fear of terrorists entering the country through the back door, by which they mean the indoctrination of migrant workers who upon returning to India joined terrorist networks in the country. This problem, if it is a problem, is in its embryonic stages, far outweighing the advantages conferred by the remittances.

There is another kind of Indian diasporic community which emerged in the late twentieth century about which little has been written. This is the community of the 'Twice Migrants' or the 'Twice Banished'. They are people from the old, plantation diaspora from the Caribbean, Fiji, Mauritius, Southeast Asia, Africa who have, for a variety of reasons migrated to Canada, the United States, the United Kingdom, Europe, Australia and New Zealand. Their numbers are small but increasing and in some places they form a significant part of the settled Indian communities. Their conception of homeland is multiple and multifaceted. India for them is largely 'an abstract, spiritual homeland', little more. They are detached from the political, cultural and economic developments and controversies of the Indian subcontinent though for no lack of trying on the part of organisations such as the Vishva Hindu Parishad, the Sangh Parivar and others like them which seek to elicit sympathy and support for their causes and values. They get a welcome reception among many members of the Indian diaspora, but not among the Twice Migrants. And finally, there is another as yet indefinable diasporic community emerging for whom questions of home and homeland are even more confusing. These are migrants who have moved at least twice in their lifetimes. They could be Fijian migrants in Australia or New Zealand who migrate to the United States of Canada for family or economic reasons, or migrants from India to the United Kingdom who leave for the United States for similar reasons. They do not feature much on the Indian radar. 


\section{The role of religion and the diversity of the Indian diasporas}

The Indian diaspora is an extremely diverse and plural phenomenon. It is divided not only into old and new, once and twice migrant diaspora communities, and a large number of regional and linguistic cultures, but also into a number of different religious traditions and identities as well. As Indians who have settled abroad assume new national identities worldwide, adopt new mother tongues and intermarry in their new countries, the diaspora will become further differentiated, also in terms of religion, as new ideas and practices blend with old ones.

Religion has been important for the preservation of personal dignity as well as identities and traditions in the diaspora, especially for the first generation. Religion has also been a main resource for transferring the diasporic project of the migrants to their children, to the 'second generation'. Temples were dominated by diaspora consciousness and the need to preserve Indian traditions in a foreign country and the transference of these traditions to the children. Temples were established as 'little Indias' (or 'little Punjabs', 'little Gujarats' and so on) with Indian languages, Indian dress and Indian food. Religion in India is a matter of socialisation as people have mostly inherited religious identities. The fear that the children would lose their Indian culture by not being provided with proper socialisation was an important motivation for establishing temples. To many countries, the free migrant males typically arrived first and wives and children a few years later when the men had established themselves with a secure income. Religious ritual life was often engaged in only after the wives and children had arrived and not to a small degree motivated by the wish to transfer the temple experience and ritual knowledge to the children.

While the first generation was eager to transfer their own diaspora consciousness to their children, the second generation, on the other hand, typically experienced a tension between their parents' diaspora consciousness and their own experience. They grew up in-between cultures and experienced not only the clash of values between generations but also the clash between the Indian (regional) culture and the culture of the new country. Those born in the new country were not Indian in the same way as their parents, but felt at home in the new country in which they were born. They were often treated as foreigners when visiting India, and to what degree they should be thought of as living in a diaspora depends on the discourse. From the point of view of the Indian diaspora discourse they are to be included in the Indian diaspora, but from the point of view of the new country they are British, Norwegian, Swedish and so on and at home in the new country.

Not only do the Indian diaspora populations belong to many different religions such as Hinduism, Sikhism, Jainism, Buddhism, Islam and Christianity, but none of these religions are monolithic traditions. Quite the reverse, each of them is divided into a number of schools, teachings and traditions. The Indian diaspora is sometimes mistakenly thought of as Hindu, but the diversity is immense. In fact, in many countries of Europe such as Italy, Spain, Greece, Norway and Denmark, the largest groups of Indians are, or were, for a long time, Sikhs. Many of the Sikhs, particularly in New Delhi, identify themselves primarily with a Punjabi diaspora and only secondary to an Indian diaspora, especially after the 1984 massacres of Sikhs, first under Operation Blue Star in Amritsar and then after the killing of Indira Gandhi by two of her Sikh bodyguards. Furthermore, the largest group of Hindus in many European countries such as Switzerland, Germany, Norway and Denmark, is the Tamils from Sri Lanka. The Sri Lankan Tamils are not Indian or part of the Indian diaspora, nor do many of them consider themselves to be part of the Sri Lankan diaspora. They constitute a separate Tamil Eelam diaspora. ${ }^{3}$ So, the Indian diaspora is not always mainly Hindu and nor is the Hindu diaspora only Indian. 
Establishment of temples and gurdwaras has been the most important act in the process of institutionalising religion in a new country of settlement. An enormous number of Hindu temples and Sikh gurdwaras in particular have been established worldwide, but also Jain temples. Indian Buddhists have established their own institutions, especially statues and paintings of their sacred symbol, Ambedkar, and organised annual Ambedkar events and celebrations. Indian Christians have mostly joined established churches, but may have often been given separate timeslots in the churches as well as South Asian priests in order to reproduce Indian Christian experiences and ritual patterns (see Jacobsen and Raj 2008). Establishment of new religious institutions often depends on significant economic support from the community and on individuals with particular organisational skills. These institutions have given opportunities for persons seeking leadership positions in the community and conflicts about leadership are not uncommon (see Singh and Tatla 2006). Ritual servants such as priests (Brahmans) for the temples and ragi jatha (a ragi group consists of three people: one playing the tabla, another playing the harmonium, and a third playing a stringed instrument, harmonium or cymbals) and granthis (readers of the Sri Guru Granth Sahib) for the gurdwaras have often continued to be recruited from India and this has strengthened the connection between the country of origin and country of settlement (Jacobsen 2012). Often, such ritual professionals from India are considered more authentic and authoritative than those raised in the diaspora. Religion in India is frequently the norm to which diaspora religions are measured against.

The first temples often try to be inclusive of large parts of the community, or they may be exclusive and represent family or local traditions, but when the Indian communities grow, new temples usually become established based on separate regional and linguistic traditions. Some temples may also be community or caste specific (Waghorne 2004). A recent phenomenon reveals an opposite trend, the building of large and prestigious 'display temples' and 'display gurdwaras' in Europe and North America that aim to be inclusive of large parts of the population. These temples and gurdwaras function to display the economic success and ambitions of the diaspora groups in the new country and their pride in the tradition. Good examples are the many Hindu display temples in the United States, the Swaminarayan temples and the Sikh gurdwaras in England. The Hindu 'display temples' may also be expressions of long-distance Hindu nationalism and the 'display gurdwaras' of long-distance Punjabi regionalism.

Preservation of religious identity and transfer of this identity to the children have been dominant motivations for the founding of religious institutions in the diaspora. However, for the second and third generations, religion raises a number of issues different from the concerns of the first generation. For the first generation, religion was about the preservation of Indian culture. For the second and third generations there is a tension between Indian culture and the culture of the country in which they live. They problematise concepts such as 'cultural' Sikh, Hindu and Jain and 'religious' Sikh, Hindu and Jain. They explore how being British Sikh or Norwegian Sikh is different from being Punjabi Sikh, and how being British Hindu or Norwegian Hindu is different from being Gujarati Hindu, Tamil Hindu and so on. Transformations are taking place rapidly. For the second and third generations the task has often been to try to differentiate Indian cultural identity from religious identity. Some of the second and third generation gravitate towards stronger religious identity in order to solve the problem of their in-between identities; others become secular. Autobiographies are good sources for investigating how those who have grown up outside of India try to solve the dilemmas and how they move away from Punjabi or Indian culture (see Jacobsen 2015). For some, moving away from culture means also moving away from religion, but for others 
an adoption of their religious tradition is instead a way to embed values in a universal system rather than in parochial culture.

An important part of the religious diversity in the Indian diaspora are the religious institutions of Dalits. Caste discrimination in the diaspora is an extension of Indian society and the prejudices held against them by Hindus, Sikhs, Christians and others. Some Dalits do not want to be part of the Indian diaspora but seek to escape from the Indian environment. Rachel McDermott (2008) has shown that Dalit Christians in the United States often prefer congregations where there are no other Indians because Dalits experience that the caste structure of India is reproduced in the diaspora in the United States. However, there is also an adoption of a common Indian Dalit identity. In the diaspora of the free migrants in particular, Dalits have established new religious institutions as a way to fight prejudices. Nevertheless, Dalits were part of the Indian diaspora from the beginning. They were part both of the indentured labour and the kangani system, and in 2006 Dalits in Canada celebrated a centennial ceremony for their arrival in Canada (Kumar 2011). In Canada, Ravidas temples have become the main meeting places of Dalits, while in the United States the Ambedkar International Mission has become an important institution as well. Two of the early Dalit leaders, Mangu Ram, the leader of the Ad Dharm movement among Dalits in Punjab, and Bhimrao Ambedkar, had both lived in the United States. Mangu Ram came to California as a farm worker in 1909 and returned to India in 1915. Ambedkar enrolled at Columbia University in New York for graduate studies in 1913 and returned to India in 1916. Mangu Ram and Ambedkar illustrate that diaspora experience has had a formative power on modern India by influencing significant persons. This formative influence of the diaspora is also exemplified with Mahatma Gandhi who lived in South Africa from 1893 to 1914, and who had also lived in England as a student from 1888 to 1891. From the 1950s, a large number of Dalits and especially Chamars migrated to England. A large part of the migrants came from Punjab, and among them many Dalits, since Punjab is the state in India with the highest percentage of Dalits. Around 100,000 Dalits now live in the UK (Kumar 2011: 23). With large-scale Dalit immigration came also more systematic caste-based discrimination (V. Kumar identifies schools, marriages, factories and pubs, religion, and songs as arenas of caste discrimination, and predicts it will get worse as Indian companies start operation in the UK; see Kumar 2011: 25-27). Dalits in the UK have organised themselves on the basis of religion and a large number of religious institutions have been established especially to honour the Buddha, Ambedkar and the medieval saint Raidas (Ravidas): Buddha Viharas, Ambedkar Bhawans, Ravidassia temples. As early as 1956, Ravi Das Sabhas were established in the UK. In 1961 the Bhaartiya Buddhist Cultural Association was established in order to organise the Buddhists, and in 1985 a number of organisations working in the name of the Buddha and Ambedkar for the betterment of Dalits formed the Federation of Ambedkarite and Buddhist Organisations, UK (Kumar 2011: 24). Thus religious organisations in the diaspora reflect similar efforts in India of Dalits organising themselves around religious symbols in order to attain justice. However, Dalits in the Indian diaspora have done as well economically and professionally as non-Dalits and their accomplishments likewise illustrate the success of the diaspora.

\section{Conclusion}

There is in India now a more informed awareness of the diasporas. Their achievements are celebrated with pride. In remote villages in Bihar and eastern Uttar Pradesh, for example, people meet Indians from distant lands in search of their roots. The reunions are often 
emotional. And in many parts of the Indian diaspora there is genuine pride in India's evolution as a global power through the usual chaotic processes of democracy (rather than military intervention or dictatorship). To see Manmohan Singh, a Sikh, whose party was headed by Italian-born Sonia Gandhi, being sworn into power as prime minister by a Muslim president, Abul Kalam, while the military remained in the barracks and the whole country applauded, is not a sight one often sees in many multi-ethnic societies of the world. As boundaries and binaries collapse and as technology revolutionises our notions of identity and citizenship, the Indian diasporas will continue to flourish.

\section{Notes}

1 The worldwide Indian diaspora is thought to number between 30 and 40 million people (Raj and Reeves 2008). V. Sinha (2011) suggests that 69 million Hindus live outside India.

2 The kangani recruitment system was primarily a personal or informal recruitment system and more flexible than the 'indentured labour' system. After 1910 kangani was the preferred system.

3 Many Sri Lankan Tamils do not identify with a Sri Lankan diaspora.

\section{References}

Ali, A. (2004) Girmit: Indian Indenture Experience in Fiji, Suva: Fiji Museum.

Anderson, C. (2006) 'Penal Settlement', in B. V. Lal, P. Reeves and R. Rai (eds), Encyclopedia of the Indian Diaspora, 44-46, Singapore: Editions Didier Millet.

Ballard, R. (2007) 'The South Asian Presence in Britain and its Transnational Connection', in A. K. Sahoo and B. Maharaj (eds), Sociology of Diaspora: A Reader, vol. 2, 587-617, New Delhi: Rawat Publications.

Brereton, B. (2013) 'Ethnic Histories: The Indocentric Narrative of Trinidad's History', in K. Mahabir (ed.), Caribbean Issues in the Indian Diaspora, 145-162, New Delhi: Serials Publication.

Castles, S. (2009) 'Indians in Britain', IMDS Working Paper, No. 11, New Delhi: International Migration and Diaspora Studies Project, ZHCES, JNU.

Crooke, W. (1897) The North-Western Provinces of India: Their History, Ethnology, and Administration, London: Methuen.

Dwivedi, M. (2011) 'Indian Diaspora in the United States: Issues and Perspectives', in IMDS Working Paper 40-421-12.

Govinden, D. (2008) 'The Indentured Experience: Indian Women in Colonial Natal', in J. C. Hawley (ed.), India in Africa, Africa in India. Indian Ocean Cosmopolitanism, 55-76, Indianapolis, IN: Indiana University Press.

Gupta, R. K. and R. N. Choudhury (2012) 'Migrant Communities and Remittances - Indian Experience', in S. K. Jain (ed.), Indian Diaspora in the Era of Globalisation, 45-56, New Delhi: Kalpaz.

Hallup, O. (1994) 'The Disintegration of Caste and Changing Concepts of Indian Ethnic Identity in Mauritius', Ethnology, 33 (4): 297-316.

Jacobsen, K. A. (2012) 'Tuning Identity in European "Houses of the Guru": The Importance of Gurdwaras and Kirtan among Sikhs in Europe', in K. A. Jacobsen and K. Myrvold (eds), Sikhs Across Borders: Transnational Practices of European Sikhs, 105-118, London: Bloomsbury.

Jacobsen, K. A. (2015) 'Young Sikhs and Literature: Identity Formations in Sikh Creative Writing in Norway', in K. A. Jacobsen and K. Myrvold (eds), Young Sikhs in a Global World: Negotiating Traditions, Identities and Authorities, 149-165, Farnham: Ashgate.

Jacobsen, K. A. and S. J. Raj (eds) (2008) South Asian Christian Diaspora: Invisible Diaspora in Europe and North America, Farnham: Ashgate.

Jacobsen, K. A. and K. Myrvold (eds) (2011) Sikhs in Europe: Migration, Identity and Transnational Practices, Farnham: Ashgate.

Jain, P. C. (ed.) (2007) Indian Diaspora in West Asia: A Reader, New Delhi: Manohar.

Jayawardena, C. (1968) 'Migration and Social Change: A Survey of Indian Communities Overseas', Geographical Review, 58 (3), 426-449.

Khadria, B. (2009) 'Bridging the Binaries of Skilled and Unskilled Migration from India', in IMDS Working Paper 13-15, 23-44. 
Kudaisya, G. (2006) 'Indian Leadership and the Diaspora', in B. V. Lal, P. Reeves and R. Rai (eds), Encyclopedia of the Indian Diaspora, 82-89, Singapore: Editions Didier Millet.

Kumar, V. (2011) 'The New Dalit Diaspora: A Sociological Analysis', MDS Working Paper, No.38, New Delhi: International Migration and Diaspora Studies Project, ZHCES, JNU.

Lal, B. V. (1980) 'Political Movement in the Early East Indian Community in Canada', Journal of Indian History, 58: 193-220.

Lal, B. V. (2011) Intersections: History, Memory, Discipline, Canberra: ANU Press.

Lal B. V. (2012) 'Trajectories of Transformation: Fiji Indians from Common Roll to Consociationalism', Diaspora Studies, 5 (2): 147-169.

Mahabir, K. (ed.) (2009) Indian Diaspora in the Caribbean, New Delhi: Serials Publications.

Maharaj, B. (2008) '(Step) Children of the Rainbow Nation? South African Indians in the PostApartheid Era', in A. K. Sahoo and K. L. Narayan (eds), Indian Diaspora: Trends and Issues, New Delhi: Serials Publications, 25-43.

McDermott, R. F. (2008) 'From Hinduism to Christianity, from India to New York: Bondage and Exodus Experiences in the Lives of Indian Dalit Christians in the American Diaspora', in K. A. Jacobsen and S. J. Raj (eds), South Asian Christian Diaspora: Invisible Diaspora in Europe and North America, 223-248, Farnham: Ashgate.

Mishra, V. (2007) The Literature of the Indian Diaspora: Theorizing the Diasporic Imaginary, London: Routledge.

National Informatics Centre (n.d.) 'The Indian Diaspora' http://indiandiaspora.nic.in/mandate.htm [accessed 2 July, 2015].

Nelson, E. S. (ed.) (2010) Writers of the Indian Diaspora: A Bio-Bibliographical Critical Sourcebook, New Delhi: Rawat Publications.

Poynting, J. (1987) 'East Indian Women in the Caribbean: Experience and Voice', in D. Dabydeen and B. Samaroo (eds), India in the Caribbean, 231-264, London: Hansib.

Rai, R. and P. Reeves (2008). The South Asian Diaspora: Transnational Networks and Changing Identities, London: Routledge.

Singh, G. and D. Singh Tatla (2006) Sikhs in Britain: The Making of a Community, London: Zed books.

Singh, S-A. (2012) The Ramayana Tradition and Socio-Economic Change in Trinidad, 1917-1990, Kingston, Jamaica: Ian Randle Publishers.

Sinha, V. (2011) Religion and Commodification: 'Merchandizing' Diasporic Hinduism, New York: Routledge.

Skeldon, R. (2010) 'Diaspora and Development: Lessons from the Chinese of Southeast Asia and Pointers towards a Research Agenda', in IMDS Working Paper, 22-24.

Takaki, R. (2007) 'The Tide of Turbans: Asian Indians in America', in A. K. Sahoo and B. Maharaj (eds), Sociology of Diaspora: A Reader, 863-876, New Delhi: Rawat Publications.

Tinker, H. (1974) A New System of Slavery: The Export of Indian Labour Overseas, 1834-1920, London: Oxford University Press.

Waghorne, J. P. (2004) Diaspora of the Gods: Modern Hindu Temples in an Urban Middle-Class World, New York: Oxford University Press. 


\section{1 \\ YOGA AND \\ PHYSICAL CULTURE \\ Transnational history and
blurred discursive contexts}

Mark Singleton

\section{Introduction}

We might consider yoga in contemporary India under three rubrics: 1) non-English speaking renouncer traditions, such as the Nāths, Rāmānandīs or Daśanāmi Saṃnyāsins, in which yoga sädhana plays a greater or lesser role and in which foreigners are rare; 2) modern, urban Indian schools of yoga open to householders and the general public in which Hindi or another Indian vernacular may be spoken, sometimes alongside English (e.g. Kaivalyadhama in Lonavla, or Swami Satyananda Saraswati's Bihar Yoga Bharati in Munghir, Bihar); and 3) schools and individual teachers catering almost exclusively for foreign students, who may adapt their teachings to the expectations of these students by teaching yoga forms popular in the West (perhaps most concentrated around Rishikesh in the state of Uttarakhand). In practice, there may be considerable overlap between these three groups. For example, foreigners may sometimes join a traditional sampradāya in which some yoga is practised; urban Indians increasingly partake in yoga classes aimed at foreign tourists; and some sampradāyas may adapt their teachings to reflect contemporary global trends (the Nāths, for example, appear to be foregrounding the practice of āsana in response to the global postural yoga boom and their perceived role as the inventors of hathayoga (Mallinson 2014: 174 n.38). The division nevertheless points to fairly distinct constituencies of yoga practitioners and teachers in India.

The emphasis in many contemporary Hindi yoga milieus remains on the health of the body, particularly in therapeutically-oriented institutions like Kuvalayananda's Kaivalyadhama, Yogendra's Yoga Institute, or the Vivekananda Yoga Kendra in Bangalore. ${ }^{1}$ Bihar Yoga Bharati also places a strong emphasis on the therapeutic applications of yoga (and publishes a series of books dedicated to the treatment of particular diseases), alongside a strong 'spiritual' orientation. In many cases, the discourses underlying the practices remain greatly influenced by Vivekananda, Aurobindo and other early modern pioneers of householder yoga in India. Within such yoga schools there may also be a markedly 
cultural-nationalist agenda, such as in the Vivekananda Kendra, or in the organization of the controversial Swami Baba Ramdev, perhaps today's most famous and widely followed public yogin (see Sarbacker 2013). Ramdev's practical yoga exercises are reminiscent of the 'subtle exercise' of Indira Gandhi's renowned yoga teacher Dhirendra Brahmachari (see Brahmachari 1965), and Ramdev's political orientation remains distinctly Hindutvainclined. ${ }^{2}$ In this context, it is also worth noting the prominent place given to yoga practice by the right-wing cultural-nationalist organization the Rashtriya Svayamsevak Sangh (RSS; see McDonald 1999 and Alter 2008).

However, in recent decades, yoga has become a thoroughly globalized practice, reaching well beyond South Asia to pervade urban societies across several continents. No reliable estimates for world-wide practitioner numbers are available, but a 2012 survey by the popular US magazine Yoga Journal reveals that 20.4 million Americans were practising yoga at that time, an increase of 29 per cent from 2008. More than 80 per cent of them were women. What is more, in spite of the global financial crisis that began in 2008, spending on yoga classes almost doubled during those four years, reaching $\$ 10.3$ billion (Yoga Journal 2012). Anecdotal reports gathered from yoga teachers and studio owners in Britain suggest a similar pattern there. These reports demonstrate the degree to which yoga has become a component part of social and personal life for millions of people outside of India. Perhaps the most prevalent and visible facet of yoga in the modern, globalized world is the practice of āsana, the physical postures of yoga. Today, āsana is sometimes popularly conceived and promoted as an alternative to 'conventional' exercise, a 'holistic' regime which contributes to the improvement of health, the reduction of stress and overall well-being. ${ }^{3}$ Significantly, in the same 2012 survey, the top five reasons stated for beginning yoga were flexibility, general conditioning, stress relief, improving overall health, and physical fitness (Yoga Journal 2012). While these may well not be quite the same motivations as for longer-term practitioners continuing yoga, they nevertheless indicate that in certain important global yoga constituencies (here, beginners in the United States), the health and fitness benefits associated with àsana practice are prioritized over and above other what may be more prominent concerns of yoga practitioners in pre-modern Indian traditions, namely meditational states, liberation (mokșa, kaivalya, etc.), or the accumulation of special powers (siddhi, vibhüti, see Jacobsen 2012).

There are of course seemingly similar mundane health concerns within, for example, pre-modern hathayoga (such as preventing constipation and gas, getting rid of excess fat and so on), and we need to be sensitive to similarities in modern and 'traditional' practice as well as to the differences. However, it is clear that as modern forms of yoga have developed and grown with such remarkable rapidity in a variety of distinct geographical and cultural spheres, the procedures, supporting narratives, end goals and applications have adapted and mutated accordingly. What results is in many respects new, by virtue of the very divergent contexts in which yoga is practised in the globalized world and the manifold techniques and ideas stemming from non-traditional sources, including the often complex, creative and recursive relationship that these techniques and ideas may have with the perceived 'tradition' itself. As Simona Sawhney puts it with regard to 'the modernity of Sanskrit', 'Cultural modernity itself becomes what it is by way of a confrontation with tradition - that is to say, with various contesting narratives about tradition' (Sawhney 2009: 14). Such is also most certainly the case with āsana, regardless of the relative age or particular genealogy of particular postures or sequences in contemporary practice. It is not necessary to assert a recent derivation for assanas in order to appreciate that āsana practice has taken on a life of its own in contemporary society, and that its role and function need to be considered in this light, as well as in the broader pre-modern context within South Asia. 


\section{Yoga and the global physical culture movement}

One context for understanding the particular development of āsana within contemporary, global contexts is as an outgrowth of yoga's creative dialogue with the global physical culture movement during the late nineteenth and twentieth centuries. During this time, new technologies of the body, mind and spirit, as well as the new or revisioned cultural or ideological frameworks that went along with them, were developed and disseminated across the globe, through photography, print media and travelling teachers. As these technologies and ideas circulated, they informed and were informed by the particular habitus ${ }^{4}$ in which they found themselves: adapting and causing adaptation, structuring and being structured through ongoing processes of dialectical exchange.

In India and elsewhere, physical culture enthusiasts experimented with the potential of yoga (in particular hathayoga). Yoga enthusiasts, inversely, experimented with the new, sophisticated resources of modern physical culture. In practice, however, it can be difficult to draw a bright line between these two 'camps', insofar as yoga and physical culture were regarded by many as allied, compatible sciences, with similar goals and interchangeable methods. One result of this synthetic bias was that core features of yoga traditions were reframed within the discourse of physical culture, resulting in historically unique modes of yoga practice. Such syntheses are perhaps characteristic of all revivalist movements, and are certainly a feature of the 'modern yoga renaissance' as a whole (De Michelis 2004). This period of creative exchange gave rise to a new perception of yoga as an Indian method of holistic fitness, which in some quarters displaced competing narratives of yoga's function and goal to become the predominant discourse. This endures today in the predominance of health and fitness-oriented äsana practice in many local and transnational varieties of global yoga culture.

The nineteenth century saw an explosion of interest in practices of health and fitness, often expressed in terms of the individual's duty to the nation and national militaristic prowess. Recapitulating and adapting Thomas Hobbes' influential vision of state and citizen, the body of the subject was perceived as a microcosmic instantiation of (a particular limb of) the state body. This vision became part and parcel of the patriotism and nationalist pride that accompanied the rise of the modern nation state. Alongside and within nation-specific rhetoric and praxis, there arose a common, international vocabulary of nationalist physical culture. As Patricia Uberoi (2006) puts it:

Somatic nationalist theories, along with the systems of knowledge that endorsed them and the related bodily disciplines, were part of the shared intellectual ambience of elite and reformist groups in the east and west alike, dialectically interrelated in a world system of nations.

Modern European somatic nationalist regimens can be traced to figures like J.F.C. Gutsmuth (1759-1839) and F.L. 'Turnvater' Jahn in Germany (1778-1852), whose hugely influential systems were designed to bring into being a new and improved German citizen (Mosse 1996: 42). In the century that followed, other European nations built on and adapted Germany's example, and national 'man-making' systems of gymnastics and exercise burgeoned, most notably in Britain, France, Prussia and Scandinavia (Hargreaves 1982, 1986; Singleton 2010 Chapter 4). In Britain, physical culture was underpinned by a cluster of values which came to be known as 'Muscular Christianity', and which promoted health and athleticism as a religious (and evangelical) imperative for British subjects at home and abroad. ${ }^{5}$ By the beginning of the twentieth century, European nationalist gymnastics systems 
had spread across the globe, with nationalist leaders advocating the adoption of physical culture as a solution to the generalized degeneration seen to be afflicting the nation, and as a means of assuring its military prowess. ${ }^{6}$ Physical training in line with European models was introduced into schools and military academies in China, Japan and India, albeit with significant regional variation (see Uberoi 2006 on the situation in China).

D.C. Mujumdar, in his English-language edition of the Encyclopedia of Indian Physical Culture (1950; originally published serially in Marathi between 1935 and 1950), echoing the values and the grammar of modern, European physical culture, writes: 'God cannot be pleased with the ugly, unhealthy, weak and flabby bodies. It is a sacrilege not to possess a fine, shapely, healthy body. It is a crime against oneself and against our country to be weak and ailing. Our own future and that of your Nation depend upon good health and enough strength' (ii). Much of the experimentation in Indian physical culture from the last quarter of the nineteenth century onwards was based on similar rhetorical exhortations, which recapitulated the religious-nationalist and eugenic concerns of 'physiological patriots' in Europe. ${ }^{7}$ To the end of improving the national 'stock', pioneers of Indian physical culture adapted technologies entering India from abroad - such as Ling-inspired gymnastics systems, Sandow bodybuilding and the physical culturism of the YMCA - and revived and adapted practices from the Indian traditions. The late nineteenth and early twentieth centuries were periods of intense creative activity, with innovators often drawing freely on whatever resources were at hand to construct (or revive) the Indian physical culture tradition. This included, of course, yoga, and in particular āsana, understood as a component part of physical culture itself, and subject to the same principles, rationales and ends. It was in this spirit of experimentation and revival that äsana came to form such an important part of the physical culture movement, not just in India but also abroad.

This said, it is important to understand that the spread of somatic nationalism throughout the world during this period rarely if ever represents a straightforward imposition of European knowledge systems upon non-European nations, even in the case of countries like British India, where certain gymnastics techniques were unambiguously introduced as part of the colonial state apparatus for controlling subject bodies. The dialectic of global physical culture in India not only left room for local variation, but also, crucially, encouraged resistance to unwelcome and antagonistic elements within the predominant discourse, through a return to indigenous forms and expressions of self-sufficiency, purity and strength - over and against racialist colonial narratives which served to demean the Indian body. Nor should one assume that, because such systems seemingly begin and flourish within the context of European modernity, comparable developments in other regions during the same period can also be satisfactorily viewed as modernities on the pattern of Europe. For one thing, this does not give proper consideration to the importance of parallel and alternative modernities which are not beholden to or derivative of the European model (see van der Veer 2014), nor to the kind of cultural exchange that is not linear, but is circular and dialectical.

To take but one intriguing early counter-example to the narrative of a unilateral flow of physical culture knowledge from Europe to Asia: perhaps the most influential of all pretwentieth-century European physical culture techniques, the 'Swedish gymnastics' systems stemming from the work of P. H. Ling (1776-1839) - whose work was to change the course of military training throughout Europe and, crucially, in India - drew inspiration from Chinese body exercises. ${ }^{8}$ These quintessentially European gymnastics systems, in other words, subsisted in a complex web of influence with Asiatic cultures of body discipline. This history, of course, becomes all the more tangled when adapted forms of Ling gymnastics make their way back to Asia as part of the pedagogical and military colonial apparatus in British India, 
which then exerts its own influence on modern conceptions of äsana as physical training and curative gymnastics. This example also illustrates that the colonial encounter is not sufficient to explain the cultural context of modern yoga, and exemplifies David Shulman's recent observation that our modernities 'ramify and exfoliate backwards', beyond the cultural and chronological boundaries that merely colonial history would impose (Shulman 2012).

Here, as in much of the history of transnational yoga in the modern age, it quickly becomes difficult to discern precise origins and clear genealogies for practices and belief, where borrowing, adaptation, mutation and rewriting are the rule. Like an open source computer code, modern yoga has been altered, adapted and rewritten by specialists and amateurs alike. So varied and divergent are its adaptations, indeed, that recourse to the original application(s) - namely ancient, traditional yoga(s) - is on its own insufficient to explain the complexities and innovations that characterize the particular version at hand. ${ }^{9}$

\section{Yoga physical culture in India}

De Michelis (2004) has identified the beginning of a fully-fledged 'modern yoga' with the publication of Swami Vivekananda's book Raja Yoga of 1896. While some have taken issue with this assertion, ${ }^{10}$ Vivekananda certainly created a modern vocabulary and grammar for yoga in 'the West' (Raja Yoga was written for an American audience), as well as in India, where Vivekananda's books, essays and lectures are still widely available today. His work was also instrumental in transforming the predominant perception of yoga from the disreputable practice of the exoticized or denigrated other into a discipline that could be undertaken by ordinary people everywhere. ${ }^{11}$ Significantly, Vivekananda was often outspoken in his dislike of $\bar{a}$ sana, and the renaissance of yoga that he inspired did not initially focus on the development of this aspect of practice. Although Vivekananda himself was an energetic proponent of nationalistic Indian physical culture, it was not until later that āsana began to be incorporated as a component part of the yoga renaissance that he himself had helped to initiate. Early renowned physical culture visionaries like Professor K. Ramamurthy, Rajaratna Manick Rao of Baroda and Pratinidi Pant (the Raja of Aund), experimented with combinations of modern western body development techniques and indigenous traditions, including yoga, and their teachings had a lasting effect on the development of yoga in succeeding generations.

The case of Pratinidhi Pant is worthy of note here. Süryanamaskār, today a component part of the global postural yoga class, was revived during the early twentieth century as a fitness regime aimed at improving the health of the citizen, and thereby of the nation. The person responsible for the popularization of süryanamaskār within the framework of modern physical culture was Pratinidhi Pant, the king of the Maharastrian state of Aundh, who was himself an avid bodybuilder, and a devotee of the teaching of the European muscle-man Eugen Sandow (1867-1925). The internationally renowned Sandow had a profound impact on global physical culture, and was perhaps especially influential in India, which he visited in 1905 as part of a Far East tour. Joseph Alter has suggested that it was Sandow, rather than Vivekananda or Aurobindo, who exerted the greatest influence on popular modern yoga (2004: 28), partly due perhaps to his method's reputation as a universal practice available to all, and not as inherently 'western' (Budd 1997: 85). Pratinidhi did not 'invent' sūryanamaskār. Mujumdar traces Pratinidhi's technique back to Rāmdās (seventeenth-century saint and guru of the Maratha king Śivāji), who he claims first popularized it, and to Balasaheb Mirajkar, the Raja of Miraj (Mujumdar 1950: 453). So while here as elsewhere it would be wrong to talk of invention (as if Pratinidhi had developed the practice out of whole cloth), it is clear that his revival represents a vital moment in our history - not least because the presentation 
of the subject, both in his 1938 book The Ten-Point Way to Health and in Pratinidhi's other writings, frames sūryanamaskār within discourses of modern physical culture such as those made prevalent by Sandow. Alongside this, Pratinidhi's nationalist and eugenic intentions can be clearly discerned. Eugenics is a markedly modern trope in modern yoga writing of the twentieth century (Singleton 2007). For example, writing in the preface to Mujumdar's Encyclopedia, he asserts that if girls and boys practise süryanamaskār, 'there will shortly be produced a type of humanity that shall excel in body, mind and soul any that the earth has yet brought forth and shall set a new standard for the race' (Mujumdar 1950: vii). Pratinidhi's cultural-nationalist intent is also in evidence, and he seems to have been directly inspired in his thinking by B.G. Tilak (1856-1920), extremist social reformer, physical culture advocate and 'Father of the Indian Unrest'. Although Pratinidhi does not himself appear to consider sūryanamaskār to be a part of yoga, its influence on modern transnational yoga systems is enormous. ${ }^{12}$ Pratinidhi himself recommended adding dandas (lit. 'stick') and other exercises to sūryanamaskār in order to make the body graceful (in Mujumdar 1950: vi), and in certain other modern variants of süryanamaskär such as those of K.V. Iyer and T. Krishnamacharya (see below) this seems to be precisely what occurred.

Rajaratna Manick Rao (1878-1954) is also worthy of note here, insofar as he was in some ways the epitome of the new, political and revolutionary renaissance of physical culture in India, and because he trained more than one key figure in the modern postural yoga renaissance. One noteworthy student is Sri Raghavendra Rao, pen-named 'Tiruka', who studied with Manick Rao and Pratinidhi Pant as well as other renowned teachers of yoga (notably Swami Sivananda of Rishikesh and Paramahamsa Yogananda) as part of a training in physical culture and martial combat techniques (see introduction to Tiruka 1977). However, Manick Rao's most influential student was undoubtedly Jagannath G. Gune (1883-1966) who would later become famous as Swami Kuvalayananda. Gune began as early as 1914 'to evolve a system of physical culture based on Yoga and to take steps to popularize that system' (Gharote and Gharote 1999: 14). He was ultimately very successful in this endeavour, establishing in 1921 what was to become perhaps the foremost institute of scientific yoga research and education in India - Kaivalyadhama in Lonavla, near Pune - and championing the cause of yogic physical culture throughout the country, in particular within the education system. His mass 'yogic' exercise schemes were subsequently employed in schools across the United Provinces (see Kuvalayananda 1936) ${ }^{13}$ Kuvalayananda's work was to have a profound effect on the perception of yoga as a regimen of physical culture and hygiene.

His yoga guru, Shri Madhvadasji (1789-1921) ${ }^{14}$ was also the guru of another pioneer of scientific research into yoga and yoga physical culture, Shri Yogendra (1897-1989), whose books, pamphlets and teachings were to contribute enormously to the development of yoga as a kind of public health and hygiene discipline, in explicit opposition to the secretive, mystical practice of 'sinister' hathayogins (Rodrigues 1997: 12). His yogic exercise is clearly influenced by non-Indian physical culture luminaries like Sandow, the Danish physical culturist J.P. Müller, American 'harmonial gymnasts' inspired by Delsarte (more below) and the pre-eminent American physical culturist Bernarr MacFadden, whom Yogendra knew personally from a sojourn in the United States between 1919 and 1924 (Rodrigues 1997: 105). Yogendra plays a key role in sanitizing the practices of hathayogins and making them available for an ordinary, householder public within the general frame of physical culture. Indeed, as an early emissary of yogāsana in the United States (giving perhaps the earliest āsana demonstrations in that country from 1921. Rodrigues 1997: 96), and later as an influential India-based proponent of the kind of alternative medicine, naturopathy and physical culture that he was exposed to in the US, Yogendra is in many ways an epitome of the trans-cultural 
flows and negotiations that have characterized the development of (postural) yoga ever since. In spite of misgivings later in life regarding yoga's by then established identification with physical culture and hygiene (see Singleton 2010: 119, n.3), and notwithstanding his deep engagement with the traditional texts of yoga, Yogendra was instrumental in establishing a new, modern form of hathayoga practice that was at least in part explicitly opposed to traditional modes of practice and life.

The 1920s and 1930s were a time of intense experimentation within Indian physical culture, and also a key moment in the refashioning of yoga as physical culture. Alongside Kuvalayananda and Yogendra we might briefly here consider B.C. Ghosh, whose impact on transnational networks of yoga practice continues to be felt in contemporary yoga practice, particularly in the United States. Ghosh was the brother of Paramahansa Yogananda, who was perhaps the most influential and well-known teacher of yoga in the United States after Vivekananda and before the arrival in the mid-to-late 1960s of a wave of Indian gurus like Swami Satchidananda and Swami Muktananda and, later in the 1980s, Osho. Yogananda's renown was in large part due to the success of his book Autobiography of a Yogi (1946). Ghosh was a physical culturist, and promoted a system of bodybuilding called 'muscle control'. In his 1930 book of the same name (co-authored with K.C. Sen Gupta), Ghosh states that he learned muscle control when he was very young from his brother Yogananda, as well as from one Chit Tun, a Burmese teacher who had settled in Calcutta in the 1920s (Ghosh and Sen Gupta 1930: 52). Yogananda himself states that he had 'discovered' a method of 'muscle recharging through will power' in 1916, and tested it on students at his school in Ranchi (Yogananda 1946: 374), and he seems to have continued to teach and demonstrate the method in the United States from at least 1923 (see Yogananda 1925: 44). Yogananda and Ghosh's muscle control system is reminiscent of popular European bodybuilding techniques of the time, and shows the influence of the popular offshoot of Transcendentalism known as 'New Thought'. It also seems evident that the name and the principles of the method derive from the world-famous bodybuilder Maxick, who authored two books in 1913 and 1914 entitled, respectively, Muscle Control; or Body Development by Will Power, and Great Strength by Muscle Control.

Ghosh became fascinated with the intersection of hathayoga and physical culture and developed a system which was a fusion of the two. Yogananda's biographer, Sananda Lal Ghosh, writes that B.C. Ghosh,

was the first Indian of contemporary times to introduce and make popular a system of Hatha Yoga that appealed greatly to the general public. He brought the ancient science of Hatha Yoga out of the hermitages and into the courtyards of homes and the fields of villages [... He was] a genius in the field of Hatha Yoga and physical culture. He was a pride of India, and will ever be remembered for introducing yoga exercises to the masses.

Ghosh 1980: xvii

It is difficult to assess the truth of the statement that Ghosh was the first Indian to make hathayoga exercises appealing to the masses (Yogendra and Kuvalayananda surely have a sizeable share of that honour), but it is clear that his influence within India was enormous. He was well known to India's most famous yoga teacher of the period, Swami Sivananda, and may have helped Sivananda develop a sequence of āsanas for health and fitness (Sanchez 2004). Ghosh's influence extended well beyond India, however. He had an international 
reputation as a bodybuilder, and throughout the 1930s regularly appeared in physical culture publications like the British magazine Health and Strength. His student, Bikram Choudhary, has become one of the most successful international yoga entrepreneurs of all time, teaching an intensely physical series of äsanas throughout the world. ${ }^{15}$ Another 'modern yoga lineage' stemming from Yogananda and Ghosh is that of Walt Baptiste (1918-2001), whose uncle was a close disciple of Yogananda. Baptiste began teaching yoga at the age of seventeen, and went on to develop a system of yogic physical culture that combined weight training, äsanas and meditation (Rosen 2001). Like Ghosh, Baptiste was a competitive bodybuilder (winning the Mr America title in 1949) and was also connected to Swami Sivananda, who bestowed on him the title 'Yogiräj' (ibid.). Baptiste's children - Baron, Sherri and Devi Ananda - are now also well-known yoga teachers in their own right.

\section{Harmonial gymnastics}

There are many other examples from the first half of the twentieth century of innovators who blurred the discursive and technological contexts of yoga on the one hand, and modern physical culture and its allied fields like naturopathy, 'alternative' medicine and curative gymnastics on the other. Given that the majority of the figures considered above have been male gurus - teaching predominantly, it seems, to male students - it may seem initially surprising that the practices of transnational yoga today are in fact dominated by women. Indeed, according to the 2012 Yoga Journal survey quoted at the beginning of this chapter, 82.2 per cent of yoga practitioners in the United States are women. There are many factors that contribute to this phenomenon, although it is not possible to go into the matter in any detail here. However, we can nonetheless note that one of the most important strands of yoga's transnational development is the tradition of women's gymnastics which grew up in Europe and America during the nineteenth century, and which I will refer to here as 'harmonial gymnastics', with reference to Sydney Ahlstrom's term 'harmonial religion' (Ahlstrom 1972). These gymnastics practices, often developed by and for women, emphasized the physical as the locus of access to the divine, variously conceived. Flourishing most usually in paraProtestant, 'unchurched' milieux which today might fall under the category 'spiritual but not religious', these movements were often in explicit reaction to the body denial that was seen to be a component part of Calvinist Protestantism (see Fuller 2001). The practices, which combined rhythmic breathing with postural stretching, exercise, concentration and prayer, were in many respects forerunners of the systems which abound in the modern metropolis (including urban centres in South and East Asia, of course) under the name of 'Hatha Yoga'. It may be, in fact, that the typical transnational Hatha Yoga class of today owes more to these traditions of women's gymnastics than it does to the hathayoga systems handed down in the history of India.

The American harmonial gymnastics tradition is exemplified in the person of Genevieve Stebbins (1857-c.1915), a dancer and gymnast who was inspired by the French drama and voice trainer François Delsarte (1811-1871), and who reworked his ideas into a new synthesis which drew inspiration from 'oriental' dance and yoga, as well as contemporary practical occultism (she was a member of the Church of Light, an occult order with close ties to the better known Hermetic Brotherhood of Luxor: see Godwin et al. 1995). Her 'American Delsartean training regimen' initiated a Delsarte craze in America. When, in his book Raja Yoga of 1896, Swami Vivekananda declares that the postures of hathayoga can be found in 'Delsarte and other teachers', he is very probably thinking of the harmonial gymnastics regimens popularized by Stebbins (Vivekananda 2001 [1896] 20). Stebbins's 
mélange of callisthenics, deep breathing, relaxation and creative energy, all aiming to develop the 'body, brain and soul' of the practitioner, contains many of the elements that one would expect to find in a modern Hatha Yoga class. Other influential figures in the merger of yoga and harmonial gymnastics include the Memphis-born, self-styled yogin̄ Cajzoran Ali (b. 1903), whose method, as set out in her Divine Posture Influence Upon Endocrine Glands of 1928, locates the key to the ultimate spiritual truth of yoga in the individual body, and draws deeply on the understandings of the body popularized by New Thought. Her course of posture training and 'breath culture' is designed to bring one into harmony with the God who is 'individualized within you', and her 'harmonial' yoga model is an important early precursor of New Age versions of (postural) yoga which emerged in the West from the 1970s onwards (Ali 1928: 15; see also De Michelis 2004: 184-186).

Similar experiments were going on at the same time in Britain, with the likes of Francis Archer and Mollie Bagot Stack, the founder of the most influential of women's gymnastics organizations in pre-World War II Britain, the Women's League of Health and Beauty. Stack had learned some yoga postures and relaxation techniques during a stay in India in 1912, and later incorporated them into her exercise regimes for modern British women (though never referred to as 'yoga'; Stack 1931). Like Stebbins and Ali, however, Stack's method presents a combined program of dynamic stretches, rhythmic breathing and relaxation within a 'harmonial' framework which closely mirrors the creative modulations of many of today's Hatha Yoga classes. One compelling hypothesis is that they developed in the context of modern traditions of quasi-mystic body conditioning, breathwork, concentration and callisthenics devised for women during the early part of the twentieth century. The fact that 'harmonial' forms of exercise were the accepted and dominant modes of practice for women in the West well prior to the yoga booms of the 1960s and the 1990s may also help to explain why contemporary Hatha Yoga classes are, demographically speaking, also dominated by women. Here, once again, I am speaking of contexts rather than origins, in which the recursive, densely synthetic growth of practices and discourses over time and across cultures makes it difficult to speak of unilateral sources or mere 'invention'. The gestation of yoga within the context of harmonial gymnastics traditions (itself, of course, just a theoretical term designating an internally varied cluster of practices and beliefs) represents a key moment in the religious cultural history of the nineteenth and twentieth centuries, and a significant habitus for the mutation and growth of yoga within transnational contexts.

\section{Conclusion}

Shigehisa Kuriyama (n.d.) proposes a thought experiment in which a late Ming-dynasty scholar discovers an illustrated sixteenth-century European gymnastics manual - De Arte Gymnastica by Mercuriale - in the archives of the Forbidden City: a gift from a foreign emissary. For centuries already in China, there has been an active 'gymnastics' tradition, known as yangshen, 'the cultivation of life'. In spite of this, the scholar is unable to make sense of the images of sinewy, straining physiques that are so different from the relaxed, unmuscular figures typically pictured in yangshen texts, and does not interpret the exercises depicted as disciplines for the cultivation of life. The conceptions of the body and its health contained within these images (and within the text that he cannot read) speak of different worlds, which require interpretative tools that the scholar does not possess. The same, mutatis mutandis, would of course apply to the foreign emissary were he to be granted a viewing of the yangshen texts. ${ }^{16}$ With reference to the possibility of 'a global history of medicine', Kuriyama notes that the most 'fundamental puzzle' 
is the astonishing diversity in conceptions of the body - a diversity not just in philosophical schemes and medical theories, in ideas about what makes up the body and how it works, but also in practices, in techniques of diagnosis and therapy, and in the disciplines that we broadly call exercise.

n.d.

The body may seem to be our fundamental, shared reality as human beings, and yet its structure and workings, as well as its function and purpose, can be worlds apart when considered through different cultural or chronological lenses, to the extent that they are almost mutually unintelligible. Such is the situation when we consider the body as it is conceptualized, tended and disciplined in the divergent ancient and modern somatic traditions known as 'yoga'. The body of modernity (and therefore the somatic technologies that surround it) is in many respects different from other bodies, from other eras and places.

Let us consider, for example, several interpretative transformations of the cakra system of the body as it traverses centuries and continents. In the eighth-century Kashmir tantric Kaula cult of Kubjikā known as the Paścimāmnāya (western transmission), there arose a system of six 'power-centres' (cakras), equivalent to six variant forms of the goddess Kubjikā and her consort, which are invested in the body of the yogin. As Alexis Sanderson points out, with the exception of the cult of the goddess Tripurasundarī, this conception of the body, which was later to become so predominant in models of yoga, 'is quite absent in all the [other] Tantric traditions' (1988: 687). Leaping forward to early twentieth-century century Bihar, Swāmī Haṃsasvarūpa published a book entitled Satcakranirupanacitram, which reinterprets the six cakra system, perhaps for the first time, along the lines of western anatomy, such that the Kubjikā 'powercentres' are transformed into empirical physical realities consonant with plexuses and nerve endings (Hamsasvarūpa c.1902). This anatomical interpretation of the cakras was subsequently to gain enormous popular currency within anglophone modern yoga and remains prevalent today. And finally, we leap from India to Europe, where, in Switzerland in 1932, C.G. Jung took the originally Paścimnāmnāya deity power-centres and re-envisaged them as universal psychosomatic realities corresponding to his own archetype theory (see Jung 1999), a vision which has endured within contemporary psychotherapeutic systems sympathetic to 'Eastern' thought (however creatively interpreted). Many more such key creative moments could be adduced here - and a cultural history of the cakras remains to be written - but let us stick with these three for the time being, merely on account of their strangeness to each other.

We can imagine the moment when, like Kuriyama's Ming-dynasty scholar poring over the renaissance gymnastics manual, exponents of each of these distinct phases in the global history of the cakras encounter the foreign or chronologically removed scheme. We can also imagine that after a period of initial confusion when faced with the strangeness of the remote other's model, our scholar sets to work to make it make sense within the frame of the reality which is proper to him, and is eventually able to find a satisfactory explanation in his own terms. In the history of yoga, particularly within the modern period and in its transnational instantiations, this is of course exactly what happened, what continues to happen, and perhaps what has always happened. Clearly, the process takes on increasing complexity and rapidity in the modern age as knowledge about yoga is disseminated across the globe by travelling teachers and print media, and as formerly alien forms of thought and practice are assimilated into the body and intention of the yoga practitioner. The history of yoga's interactions with the international physical culture movement is only one aspect of this complex process, wherein worlds interpenetrate but remain mutually intelligible only through interpretative work during which new significations, inevitably filtered by the naturalizing gaze of the practitioner 
or theorist, are brought to bear on the body. It is, nevertheless, an important history, insofar as many of today's contemporary expressions of yoga, both in India and abroad, bear the clear traces of this interpretative work. As well as furthering too our understanding of the modern history of yoga, such a cultural history of yoga as one somatic discipline among others may also serve as a contribution to a global history of therapeutic and religious sciences of the body through time.

\section{Notes}

1 On this latter, see Beckerlegge 2013: 327-350.

2 For a useful summary, see Christophe Jaffrelot's introduction in Jaffrelot 2007.

3 Indications are numerous and easy to find. As a single example, see http://medical-dictionary. thefreedictionary.com/Yoga + exercise (accessed 31 March 2013).

4 Pierre Bourdieu describes habitus as 'systems of durable, transposable dispositions, structured structures predisposed to function as structuring structures, that is, as principles which generate and organize practices and representations that can be objectively adapted to their outcomes without presupposing a conscious aiming at ends or an express mastery of the operations necessary in order to attain them' (1977: 72).

5 The term 'Muscular Christianity' was first used in a review of Charles Kingsley's 1857 novel Two Years Ago, and was taken up by Kingsley's friend Thomas Hughes in his Tom Brown at Oxford (1860), with reference to the training of the body for the advancement of God's work in the world.

6 On degeneracy narratives see Pick 1989; Rosselli 1980; Sen 2004.

7 The phrase is adapted from McDonald (1999). On eugenics in relation to physical culture and yoga, see Singleton (2007).

8 It is not clear to what extent Ling himself was influence by Chinese sources. N. Dally's work of 1857 offers a fairly extensive biography of Ling and a lengthy reflection on Ling's possible influences. Dally writes: 'comme ce corps de doctrine [de Ling] ne differe point de celui des Tao-Ssé, il faut bien admettre aussi que dans le même temps Ling avait entre les mains la Notice du P. Amiot ou quelqu'autre traité chinois original, rapporté soit par d'autres missionnaires, soit par des personnes attachées aux ambassades de l'Europe en Chine. La doctrine de Ling toute entière, théorique et pratique, n'est qu'une sorte de décalque daguéréotypique du Cong-Fou des Tao-Ssé; c'est le vase royal de Dresde, le splendide vase chinois, avec ses figures chinoises revêtues des teintes européennes' (1857: 155; see also Dudgeon 1895: 82 for a loose English translation of Dally's assertions regarding Ling). Dally is referring here to the work of Jean Joseph Marie Amiot (1718-1793), a Jesuit missionary to Peking (see Dudgeon 1895: 78). While Dally's assertions regarding Ling remain speculative, the influence of Kung-Fu (or 'Cong Fou' as it is usually spelled) is explicit in the work of influential Ling disciples G.H. Taylor (e.g. Taylor 1860: 33) and Hungarian exile M. Roth who was, according to Dudgeon, 'the most prominent exponent and successful practitioner of the [Ling] system in Great Britain' and who was also greatly interested in the application of Kung-Fu, as presented in Amiot's work, to curative gymnastics (Dudgeon 1895: 84).

9 Taking the analogy further, one might even say that in 'traditional' and 'modern' yoga alike there is a tension between corporate structures (traditional sampradāyas which practise yoga, or modern 'branded' yoga forms like Bikram ${ }^{\mathrm{TM}}$ or Iyengar Yoga ${ }^{\circledR}$ ) and non-corporate productions (freelance yogis developing practices in isolation from such corporate structures) reminiscent of the twentyfirst-century dynamic between I.T. firms like Microsoft and Apple, and open source platforms like Linux. Such a dichotomy, however, should not obscure the fact that both function in a relationship of influence, inspiration and antagonism with the other (Apple's iconic user interface is inspired by Linux; Linux's native LibreOffice suite is modelled on Microsoft's Office etc.).

10 For example, Killingley (2014: 33): 'The yoga Vivekananda taught was hardly "“fully fledged”; being more interested in doctrine than practice, he left it to later gurus to introduce more formal, and more recognizably yogic, practices'.

11 On the popular reputation of the yogi as rogue, see David White's Sinister Yogis (2009). For a summary of Vivekananda's statements on äsana, see Singleton 2010, Chapter 3.

12 There is a reference to sūryanamaskār in the Jyotsnā commentary on the Hathapradīpikā by Brahmānanda (d. 1842?), which recommends against 'activities that cause physical stress like excessive sūryanamaskārs or carrying heavy loads etc.' (kāyaklésavidhị̣ kāyakleśakaram vidhị̣ krịām bahusūryanamaskärādiprūpām 
bahubhārodvahanādirūpām ca, 1.61). Later, modern yoga pioneer Shri Yogendra would lament the 'indiscriminate mix[ing] up' of yoga and süryanamaskär by 'the ill-informed', asserting that such syntheses are 'definitely prohibited by the authorities' (Yogendra 1988 [1928]). Reading against the grain, however, we might speculate that such prohibitive declarations in fact point to a degree of popularity of süryanamaskär within yoga practice prior to the advent of modern teachers like Kuvalayananda and T. Krishnamacharya.

13 Joseph Alter's 2004 book Yoga in Modern India, between Science and Philosophy is in part an anthropological analysis of Kuvalayananda and the work of his institution.

14 For a short biography of Madhvadasji's very long life, see http:/www.yogadhama.com/ecoleyoga/?The-KAIVALYADHAMA-Centre\&lang=en. Accessed 2 July 2014.

15 See Fish (2006) and the non-academic study of Bikram Yoga by Benjamin Lorr (2013).

16 A situation perhaps not unlike P. H. Ling poring over diagrams of Chinese gymastics in Amiot's text (albeit mediated by the French priest's interpretations).

\section{References}

Ahlstrom, S. (1972) A Religious History of the American People, New Haven, CT: Yale University Press.

Ali, C. (1928) Divine Posture Influence Upon Endocrine Glands, New York: Cajzoran Ali.

Alter, J. (2004) Yoga in Modern India: The Body between Science and Philosophy. Princeton, NJ: Princeton University Press.

Alter, J. (2008) 'Yoga Shivir: Performativity and the Study of Modern Yoga', in Mark Singleton and Jean Byrne (eds), Yoga in the Modern World, Contemporary Perspectives, 36-48, London: Routledge.

Beckerlegge, G. (2013) 'Eknath Ranade, Gurus, and Jivvanvratīs: the Vivekananda Kendra's Promotion of the "Yoga Way of Life", in Mark Singleton and Ellen Goldberg (eds), Gurus of Modern Yoga, 327-350, New York: Oxford University Press.

Bourdieu, P. (1977) Outline of a Theory of Practice, Cambridge: Cambridge University Press.

Bourdieu, P. (1990) The Logic of Practice, Stanford, CA: Stanford University Press.

Brahmachari, D. (1965) Yogic Sūkșma Vyāyāma, New Delhi: Dhirendra Yoga Publications.

Budd, M. A. (1997) The Sculpture Machine: Physical Culture and Body Politics in the Age of Empire, Basingstoke: Macmillan.

Dally, N. (1857) Cinésiologie ou Science du Mouvement dans ses Rapports avec l'Éducation, l'Hygiène et la Thérapie Paris: Librairie Centrale des Sciences. Available at https://archive.org/stream/cinsiologieousci00unse/ cinsiologieousci00unse_djvu.txt [accessed 2 July 2014].

De Michelis, E. (2004) A History of Modern Yoga: Patanjali and Western Esotericism, London: Continuum.

Dudgeon, J. H. (1895) 'Kung-fu: or, Medical Gymnastics', Journal of the Peking Oriental Society 3, 341. Available at http://www.sacred-texts.com/tao/kfu/kfu001.htm"http://www.sacred-texts.com/tao/kfu/ kfu001.htm [accessed 2 July 2014].

Fish, A. (2006) 'The Commodification and Exchange of Knowledge in the Case of Transnational Commercial Yoga', International Journal of Cultural Property, 13: 189-206.

Fuller, R. (2001) Spiritual but Not Religious: Understanding Unchurched America, Oxford: Oxford University Press.

Gharote, M. L. and M. M. Gharote (1999) Swami Kuvalayananda - A Pioneer of Scientific Yoga and Indian Physical Education, Lonavla: Lonavla Yoga Institute.

Ghosh, B. C. and K. C. Sen Gupta (1930) Muscle Control and Barbell Exercise, Calcutta: College of Physical Education.

Ghosh, S. L. (1980) Mejda, the Family and Early Life of Paramahansa Yogananda, Los Angeles: Self- Realization Fellowship.

Godwin, J. (1994) The Theosophical Enlightenment, Albany, NY: State University of New York Press.

Godwin, J., C. Chanel and J. P. Deveney (eds) (1995) The Hermetic Brotherhood of Luxor: Initiatives and Historical Documents of an Order of Practical Occultism, New Beach, ME: S. Weiser.

Haṃsasvarūpa, S. (c.1902) Șațcakranirūpanacitram with Bhäsya containing the Pictures of the Different Nerves and Plexuses of the Human Body with their Full Description Showing the Easiest Method How to Practise Pranayam by the Mental Suspension of Breath through Meditation Only, Muzaffarpur, Bihar: Trikutivilas Press.

Hargreaves, J. (ed.) (1982) Sport, Culture and Ideology, London: Routledge and Kegan Paul.

Hargreaves, J. (1986) Sport, Power and Culture. A Social and Historical Analysis of Popular Sports in Britain, Cambridge: Polity.

Jacobsen, K. A. (ed.) (2012) Yoga Powers: Extraordinary Capacities Attained Through Meditation and Concentration, Leiden and Boston: Brill. 
Jaffrelot, C. (2007) Hindutva: A Reader, Princeton, NJ: Princeton University Press.

Jung, C. G. (ed. Sonu Shamdasani) (1999) The Psychology of Kundalini Yoga: Notes of a Seminar Given in 1932 by C. G. Jung, Princeton, NJ: Princeton University Press.

Killingley, D. (2014) 'Manufacturing Yogis: Swami Vivekananda as a Yoga Teacher', in Mark Singleton and Ellen Goldberg (eds), Gurus of Modern Yoga, 17-37, New York: Oxford University Press.

Kuriyama, S. (1999) The Expressiveness of the Body and the Divergence of Greek and Chinese Medicine, New York: Zone Books.

Kuriyama, S. (n.d.) 'Athens'. Unpublished draft paper.

Kuvalayananda, S. (1936) Yaugik Sangh Vyāyam, Lonavla: Kaivalyadhama.

Lorr, B. (2013) Hell Bent: Obsession, Pain and the Search for Something like Transcendence in Bikram Yoga, London: Bloomsbury.

Maheshananda, S. and B. R. Sharma (eds) (2012) A Critical Edition of Jyotsnā (Brahmānanda's Commentary on Hațhapradīpikā), Lovavla, Dist. Pune: Kaivalyadhama.

McDonald, I. (1999) “Physiological Patriots"? The Politics of Physical Culture and Hindu Nationalism in India', International Review for the Sociology of Sport, 34 (4): 343-357.

Mallinson, J. (2014) 'The Yogīs' Latest Trick', Journal of the Royal Asiatic Society, 24: 165-180.

Mosse, G. L. (1996) The Image of Man: The Creation of Modern Masculinity, New York: Oxford University Press.

Mujumdar, D. C. (1950) Encyclopedia of Indian Physical Culture, Baroda: Good Companions.

Pick, D. (1989) Faces of Degeneration, a European Disorder, c.1848-1918. Cambridge: Cambridge University Press.

Rodrigues, S. (1997) The Householder Yogi: The Life of Shri Yogendra, Bombay: Yogendra Publications Fund, the Yoga Institute.

Rosen, R. (2001) 'Walt Baptiste'. Available at http://www.yogajournal.com/wisdom/605_1.cfm [accessed 3 March 2013].

Rosselli, John (1980) 'The Self-Image of Effeteness: Physical Education and Nationalism in NineteenthCentury Bengal', Past and Present, 86: 121-148.

Sanchez, T. (2004) 'Origins of Yoga'. Available at http://www.usyoga.org/html/origins.htm [accessed 20 March 2005].

Sanderson, A. (1988) 'Saivism and the Tantric Traditions', in S. Sutherland, L. Houlden, P. Clarke and F. Hardy (eds) The World's Religions, 650-704, London: Routledge.

Sarbacker, S. (2013) 'Swami Ramdev: Modern Yoga Revolutionary', in Mark Singleton and Ellen Goldberg (eds), Gurus of Modern Yoga, 351-371, New York: Oxford University Press.

Sawhney, S. (2009) The Modernity of Sanskrit, London and Minneapolis: University of Minnesota Press.

Sen, S. (2004) 'Schools, Athletes and Confrontation: The Student Body in Colonial India', in J. H. Mills and S. Sen (eds), Confronting the Body, the Politics of Physicality in Colonial and Post-Colonial India, London: Anthem.

Shulman, D. (2012) ‘The Revenge of the East?’ New York Review of Books. October 11. Available at http:// www.nybooks.com/articles/archives/2012/oct/11/revenge-east/ [accessed December 2012].

Singleton, M. (2007) 'Yoga, Eugenics and Spiritual Darwinism in the Early Twentieth Century', International Journal of Hindu Studies, 11 (2): 125-146.

Singleton, M. (2010) Yoga Body, The Origins of Modern Posture Practice, New York: Oxford University Press.

Stack, M. B. (1931) Building the Body Beautiful, the Bagot Stack Stretch-and-Swing System, London: Chapman and Hall.

Taylor, G. H. (1860) An Exposition of the Swedish Movement Cure, New York: Fowler and Wells.

Tiruka (1977) Suryanamaskara, Malladhihalli: Sarvodaya Mudranalaya, Anathasevashrama Trust

Uberoi, P. (2006) 'Body, State and Cosmos: Mao Zedong's "Study of Physical Education" (1917)'. Available at http://ignca.nic.in/ks_41018.htm [accessed April 2014].

van der Veer, P. (2014) The Modern Spirit of Asia: The Spiritual and the Secular in China and India, Princeton, NJ: Princeton University Press.

Vivekananda, S. (2001 [1896]) 'Raja Yoga, or Conquering the Internal Nature', in The Complete Works of Swami Vivekananda, Calcutta: Advaita Ashrama.

White, D. G. (2009) Sinister Yogis, Chicago, IL and London: University of Chicago Press.

Yogananda, P. (1925) Psychological Chart, Los Angeles: Yogoda and Sat-Sanga Headquarters.

Yogananda, P. (1946) Autobiography of a Yogi, New York: Philosophical Library.

Yogendra, S.(1988 [1928]) Yoga Asanas Simplified, Santa Cruz: Yoga Institute.

Yoga Journal (2012) http://www.yogajournal.com/press/yoga_in_america [accessed 3 March 2013]. 


\title{
12 \\ MODERNISED \\ AYURVEDA IN INDIA AND THE WEST
}

\author{
Maya Warrier
}

Pre-modern Ayurveda is a health tradition based on Hindu and Buddhist cosmologies. Its earliest texts, compiled in Sanskrit, are at least 2,000 years old. These texts are concerned not just with curing disease but also with promoting a happy and fulfilled life. Beyond remedial medicine, Ayurveda is also traditionally concerned with caring for the self, and optimising health and well-being understood in the widest sense (Alter 1999; Cerulli 2012). Philosophical, spiritual, ethical, moral, dietary and lifestyle precepts and guidelines are all an inherent part of the Ayurvedic body of knowledge. ${ }^{1}$

In the traditional Ayurvedic perspective, the human body relates to the cosmos as microcosm to macrocosm. The understanding of human bodily processes is based on a theory of three humours, those of wind (vata), bile (pitta) and phlegm (kapha). Understandings of the body in pre-modern Ayurveda are very different from what we associate with biomedical and anatomical understandings today. Health here is understood in terms of humoral balance and harmony between the human microcosm and the macrocosm (Zimmerman 1979, 1980). Classical Ayurvedic texts recommend a range of procedures for treating illness, including alterations in diet and lifestyle, the ingestion of (mainly herbal) medicines, and procedures of elimination using such methods as purgation, emesis, enema oleation and sudation.

Ayurvedic practitioners have been receptive to insights provided by other health systems such as Unani (Greco-Arabic medicine) first brought to India around the eleventh century. From the late nineteenth century onwards they increasingly encountered the paradigms and practices of Western biomedicine, introduced to India by the British. This engagement resulted in sweeping changes to Ayurveda's representation, organisation and forms of practice in late colonial and post-colonial times. I use the terms 'modern/modernised Ayurveda' here to refer to the Ayurveda that developed as a result of this encounter. The history of modern Ayurveda can in fact be read as the history of this tradition's gradual biomedicalisation. Critics argue that the scale of this transformation is such that modern Ayurveda has very nearly lost its identity as a distinct health tradition. ${ }^{2}$

Alongside science and biomedicine, conceptions of spirituality and religion, as well as ideas of Indian nationhood, have all played a significant role in shaping modern forms of Ayurveda's self-representation and practice. The relative significance of the three strands 
has differed in different contexts, as have some of the meanings associated with each one. Spirituality, in particular, has assumed different meanings over time, and become particularly important in the course of Ayurveda's relatively recent popularisation within Western holistic health networks. In the following sections I will examine Ayurveda's modernisation in colonial India, its career in independent India, and recent developments resulting from Ayurveda's passage to the late-capitalist contexts of North America and Western Europe.

\section{Perceptions of Ayurveda in colonial India}

By the 1830s British colonisers in India had come to see science, technology and medicine as clear evidence of Britain's superiority over India. India was seen increasingly as superstitious and backward, and the colonisers saw it as part of their 'civilising mission' to transform India. In 1835 they closed down the 'Native Medical Institution' in Calcutta (set up 11 years previously) that had provided Indians with biomedical education alongside training in indigenous traditions. In its place a new Medical College was set up, which was to teach Western medicine exclusively, using English as the sole medium of instruction (Arnold 2000: 61-65).

This move was charged with symbolic meaning: Western medicine was clearly now the hallmark of a superior civilisation with a progressive agenda while indigenous practice was seen to be backward and to have outlived its use. The decision to close the Native Medical Institution was taken in the same year as Macaulay's Minute on Education, which was a decisive turning point in the history of the Raj. The Minute marked the victory of the Anglicists over the Orientalists in determining the pattern of higher education in India for the next hundred years (Arnold 2000: 61-65).

The setting up of the Medical College in 1835 ushered in a new era in Indian engagement with Western medicine. At first the Indian medical profession developed only gradually, partly because of the limited career prospects and financial rewards it offered. By the First World War, however, the number of Indian medical schools and colleges had grown, and enrolment in these was on the rise. A growing number of Indian men and women were now entering the profession in the cities, and finding employment with commercial and state enterprises as well as practising privately (Arnold 2000: 61-65).

Even as the biomedical institutional presence grew in the subcontinent, Ayurvedic practitioners began to feel increasingly marginalised - there was no state support for their tradition, and in comparison with biomedical practitioners, they commanded little authority in official circles and had access to few resources. In the 1890s, they came together to launch a move to revive Ayurveda - this initiative was closely aligned with the nationalist struggle against colonial rule that was now gaining increasing momentum (Leslie 1976). At the forefront of the Ayurvedic revivalist movement were Western educated elites who, on one hand, identified wholeheartedly with the project to modernise India, but who, on the other, sought to renegotiate the authority of science and translate it to fit the needs and idioms of Indian society, enabling India to forge a modernity appropriate to its own cultural legacies (Prakash 1999).

The revivalists emphasised the need to establish Ayurveda as India's national medicine, arguing that it was uniquely appropriate to Indian bodies and Indian environments. The revivalist discourse was characterised by a number of crucial features (Arnold 2000; Ganesan 2010). First, it borrowed heavily from Orientalist perspectives, arguing that following a period of early achievement, Indian civilisation, and traditions like Ayurveda, had fallen into decline, and now needed revival. Second, the early period of achievement was described 
in terms of a prevailing scientific spirit; thus if science was to serve as the yardstick for measuring medical knowledge and practice, then Ayurveda was the first and most ancient science. Third, this scientism of the early period was not seen as antithetical to the religious or spiritual realm. Instead, commentators on Ayurveda saw the early scientific and progressive spirit as supported by the divine insights and intuitions of spiritually enlightened sages who commanded extraordinary visionary powers of a kind as yet unknown to modern science. ${ }^{3}$ Ayurvedic knowledge was understood to be divinely revealed, scientific and true for all time.

The revivalist movement found institutional expression in the All India Ayurveda Mahasammelan or Ayurvedic Congress, established in 1907. This was the first professional interest group of indigenous practitioners to be set up in India. The Indian National Congress lent political support to the Ayurveda Mahasammelan and threw its weight behind the demand for government patronage for Ayurveda. In keeping with the Orientalist tradition, a number of intellectuals set out to document the scientific accomplishments of Ayurveda, and to re-establish its continuity with the modern world. They mined early Ayurvedic texts in order to try and showcase the scientific achievements of ancient India (Arnold 2000: 169176).

The renowned Bengali Ayurvedic physician, M. M. Gananath Sen, for instance, argued in his Hindu Medicine (1916) that the spirit of Ayurveda was the spirit of progress. '[... ] when the greater part of the world was submerged in the abyss of ignorance', he wrote, 'it is the Indian sages who first understood the necessity of dissection of the human body in the education of Physicians and Surgeons' (Ganesan 2010: 115). Nagendra Nath Sen Gupta, also a physician from Bengal, wrote: 'It would be no exaggeration to say that of all nations of the earth, the Hindus first turned their attention to the study of disease and the means of its alleviation' (Ganesan 2010: 112). It was a short step from arguing that the ancient Indians got there first, to arguing that other medical traditions were derived from Ayurveda. Shiv Sharma, who served as president of the All Indian Ayurvedic Congress for successive terms, could thus argue that Ayurveda's 'glowing embers had lighted the torch of Arabian medicine, and through it the fire of European medicine'. Extolling the 'high antiquity and originality' of Hindu medicine, he asserted that in the domain of medicine, the Greeks and Arabs were forever indebted to Hindus (Ganesan 2010: 113). The revivalists sought to forge a distinctively Indian kind of modernity, and a distinctively Indian kind of science, which would be continuous with, and borrow deeply from, both Indian (Hindu) traditions and Western science. Ayurveda in this view was at once part of an ancient Indian heritage and a symbol of Indian modernity; as such, it was also a source of Indian, and particularly Hindu, nationalistic pride.

Cooperation between indigenous systems of medicine and Western biomedicine was advocated both for ideological and pragmatic reasons. Western biomedicine appealed to most of these Indian elites as a modern, rational, research-oriented system, which had already demonstrated its usefulness in multiple areas of health and disease. They also recognised that Western biomedicine was here to stay, given the extent to which it was patronised by the colonial government. Despite the often acrimonious exchanges between advocates of Ayurveda and practitioners of Western biomedicine, the former tended by and large to seek some form of integration with the latter, in the spirit of what Gananath Sen described as 'open-hearted and liberal cooperation', which, in Sen's view, would serve well not just patients but also the larger medical profession in India as a whole (Ganesan 2010: 121).

Integration between Western biomedicine and Ayurveda was already being attempted in different Indian regional contexts. Dominik Wujastyk (2009: 211-217) has shown how from the late nineteenth century, illustrations of the Ayurvedic body were beginning to appear 
in print in ways that borrowed from Western anatomical drawings. The royal physician at the court of Farrukhabad, Muralidhar Sharma, produced in 1898 an edition of the ancient Ayurvedic text, the Sushruta Samhita, carrying a number of innovative medical images based on what Wujastyk (2009: 212) describes as a 'syncretic view of the human anatomy' combining Ayurvedic and Western elements. The Bengali physician Gananath Sen similarly used Western anatomical illustrations in his published work, providing Sanskrit explanations and terminology. P. S. Varier, a leading figure in the Ayurvedic movement in Kerala, authored publications on Ayurveda in Sanskrit using illustrations and explanations of human anatomy based on biomedical understandings. These authors seemed to make no real distinction between the Ayurvedic understanding of the body's constitution and the modern anatomical one; in their view both were valid, and could unproblematically be synthesised (2009: 213). These were hybrid texts, and they showed some epistemological dissonance between two completely different traditions. Wujastyk argues that perhaps precisely because of this dissonance, they made great strides in the illustration of Indian medical texts. These works, in Wujastyk's words, were 'earnest, ideologically informed, and the product of real learning' both in Sanskrit Ayurveda and in anatomy (2009: 217).

Throughout this period Ayurvedic texts were translated into English and a range of Indian languages, thus giving the revivalist movement the textual basis and authority it required, and making classical Ayurveda accessible to a wider audience. The printing press played a significant role in churning out articles, tracts, commentaries and medical journals on Ayurveda and supplying the literate public with information about Ayurveda and Ayurvedic remedies. Ayurvedic dispensaries came to be set up providing the public with treatments packaged in new forms more akin to biomedical treatment.

The revivalist movement made some headway when, on the basis of the MontaguChelmsford Report, the government in 1919 recommended reforms to increase Indian participation in the provincial governments (Arnold 2000: 183). The Indian National Congress passed resolutions asserting the usefulness of Ayurveda and Unani, and demanded the setting up of schools, colleges and hospitals based on the indigenous systems (Arnold 2000: 183). Members of the legislatures took up the cause and in a conciliatory move, the governments of Bengal and Madras set up committees of inquiry into the indigenous medical systems.

In Madras, the Minister of Health appointed a committee with Sir Muhammad Usman as chairman. The secretary and author of the committee report was Captain Srinivasa Murti. He was a doctor trained in biomedicine who had been an officer in the Indian Medical Service from 1917 to 1921. His report, the Usman Committee Report, published in 1923, was the first major government-backed study of indigenous medicine. It recommended that the state create bureaucratic structures for indigenous medicine parallel to those of modern medicine. It proposed that a Department of Indian Medicine be set up in the Ministry of Health. This would then be guided by a General Council of Indian Medicine composed of physicians and doctors sympathetic to the indigenous systems. All practitioners of indigenous medicine would be registered. After a period of time, once schools started producing 'qualified practitioners', those lacking the approved institutional training would no longer be admitted to the register. The report further proposed setting up a system of state hospitals and dispensaries linked to the schools of indigenous medicine (Arnold 2000: 184-185; Leslie 1973: 224-250).

Srinivasa Murti was an integrationist par excellence. In his view, given that all systems of medicine sought to preserve health and prevent or cure illness, there could in reality only be one system of medicine. The many existing systems, in his view, were but parts of 
this 'one system' - each a special 'school' rather than an independent system of medicine (Ganesan 2010: 119). He proposed setting up schools providing students with training in Indian systems of medicine while also inculcating a working knowledge of the Western system. Members of the Indian Medical Service expressed anger and dismay at the proposals of Murti's report; both professionally and politically, they found the syncretism it advocated unacceptable. However, 'for political reasons of its own' (Arnold 2000: 185), the Madras government chose not to heed the outcry and instead accepted the proposals. It sanctioned the setting up of a School of Indian Medicine in Madras along the lines recommended by Murti.

The School was opened in November 1924 by the Governor of Madras. Srinivasa Murti was appointed its Director. In a manner reminiscent of the Native Medical Institution of Calcutta in the 1820s, but with a different emphasis, once again indigenous medical knowledge was imparted alongside modern anatomy, physiology and surgery. Staff compiled textbooks and papers identifying 'correspondences' between the indigenous and Western systems. In 1932 the School was also entrusted with maintaining a register of all indigenous practitioners in the province (Arnold 2000: 185).

Over time, provincial governments began to grant assistance to institutions imparting instruction in Ayurveda. A few state governments set up boards to regulate indigenous practitioners. Most provinces had branches of the Ayurvedic Congress or independent professional organisations representing the interests of indigenous practitioners at regional level. On the eve of India's independence, there were more than sixty Ayurvedic colleges in the country. The Ayurvedic movement was on a fairly strong footing both at regional and national level.

\section{Ayurveda in independent India}

Most revivalists believed that Ayurveda would come into its own once India gained independence and Indians took over the governance of the country. Their expectations were belied however. The Indian government, sharing in the Nehruvian vision of the developmental state, sought to cast India in the mould of Western modernity. In the first two decades after independence, though central and state governments were sympathetic to the cause of Ayurveda, they supported modern biomedicine as the basis for the development of national health services, supporting training and research in Ayurveda only because they hoped that Ayurveda graduates would extend some form of medical relief to the countryside where biomedicine had not sufficiently made inroads (Leslie 1973; Brass 1972).

Spokespersons for Ayurveda who continued to lobby the Indian government for recognition and professionalisation of this tradition, did so on the strength of its Indianness. These interest groups argued that foreign rule (first Muslim, then British) had led to the suppression of indigenous medical knowledge and practice, and that the patronage and support of the newly formed government of independent India was indispensable for Ayurveda's revival. They argued that the political emancipation of the country was not enough - this needed to be backed by the emancipation of Ayurveda (Brass 1972: 350). They demanded that the government should declare Ayurveda as the national system of health care. Supporters of biomedicine who opposed this demand, they argued, should 'quit India' following the British example. Opposition to Ayurveda was seen as an insult to India's traditions, culture and people (Brass 1972: 350). Lobbyists couched their demands not on the strength of Ayurveda's intrinsic value as a health system, nor on the basis of a realistic assessment of its prospects and potential contribution to public health, but mainly on the 
basis of Ayurveda's value as an indigenous tradition, and therefore a symbol of nationalist aspirations.

The idea of Ayurveda's Indian provenance tapped into the idea, in circulation since the closing decades of the nineteenth century, of India as a land of spirituality. These ideas have retained their grip on the Indian imagination right up to the present. As Langford (2002: 17) notes, promoters and practitioners in late twentieth-century India have continued to 'employ potent neo-orientalisms, promoting Ayurveda as spiritually attuned, anti-materialist, and non-violent, in contrast to biomedicine'. These popular accounts of Ayurveda are in essence accounts of 'Indianness'; they are trenchantly nationalistic and often anti-Western in tone. They depict India as a land of 'traditional' wisdom, mystical and esoteric insight, and 'spiritual' prowess. India's so-called 'spirituality' in these popular discourses is contrasted with what is stereotypically portrayed as the 'shallowness' and 'fragility' of the 'materialistic' West (Langford 2002: 17).

In the face of the demands of the revivalists, the government's strategy over the years was to set up committee after committee to examine the key issues, sometimes making small concessions to the revivalists (Brass 1972; Langford 2002; Wujastyk 2008). Compared to biomedicine, Ayurveda remained drastically under-funded. In the states, the progress of Ayurveda varied considerably, with some states devoting significant proportions of the medical budget to Ayurveda, and others choosing to withhold financial support. Ayurveda students and graduates felt undervalued, since they could secure employment only in inferior positions in the health services earning salaries far below those granted to graduates of modern medical colleges. Throughout India, there were multiple strikes, demonstrations and agitations launched by students in Ayurvedic colleges demanding equality in status and pay with modern medical graduates (Brass 1972).

Even as late as the 1970s, there were no uniform educational standards binding on all Ayurvedic training institutions and no agreed professional standards for practitioners. Though all Ayurveda proponents agreed that national educational and professional standards would be desirable, they could not agree on the content of the curriculum and the qualifications necessary for professional status. Ayurveda interest groups seemed divided into two camps, that of the integrationists and that of the purists, but in fact the ideological differences between the two groups are far from clear (Brass 1972; Langford 2002: 108-116). Superficially, the integrationists favoured a modern curriculum that would incorporate both Western biomedical and Ayurvedic theory and practice. There were significant differences between these individuals, however, on the question of how much Ayurveda and how much biomedicine the curriculum should ideally incorporate. The dominant form of Ayurvedic education right up to the early 1970s was the integrated or concurrent version and most individuals recognised that this system was not working; it was producing practitioners qualified in neither system of medicine. The purists sought a return to the ancient Ayurvedic texts, and demanded that pure Ayurvedic theory should constitute the core of the curriculum. They too, however, were not averse to introducing aspects of Western anatomy and surgery into the curriculum - all such elements, however, were to be assimilated within an Ayurvedic framework.

The political antagonism between the two camps marked the history of Ayurveda throughout the 1950s and 1960s. Each group sought and secured the backing of powerful sections of the political system at central and state levels. The different governmentappointed committees looking into the matter of standardisation and professionalisation took sides with one or the other camp, with the result that the issue remained unresolved for nearly three decades. 
Finally, in 1970, the Ministry of Health established the Central Council for Indian Medicine (CCIM) and tasked it with drafting a standard Ayurveda curriculum, regulating practice, and designing research programmes for indigenous traditions.

In 1977, the curriculum prepared by the CCIM was finally adopted by Ayurvedic educational institutions (Langford 2002: 115-116). Following this curriculum meant that students would complete five years of study, divided into three parts of approximately a year and a half each. Successful candidates would be awarded the degree of 'Bachelor of Ayurvedic Medical Science' (BAMS). Whereas the new curriculum was seen as something of a victory for the purists, in fact it remained eclectic in its borrowing of both Ayurvedic and biomedical elements. Anatomy, for instance, was (and is currently) taught along biomedical lines while physiology followed (follows) Ayurvedic principles (Langford 2002: 115-116). The incompatibility between the two frameworks is seldom questioned or addressed, and students in effect get partial inputs from both, and a comprehensive understanding of neither. Most graduates go on to run private clinics or work for privately owned treatment centres. Some serve in less lucrative posts at government-run Ayurvedic colleges and hospitals.

In the 1990s there was a further crucial development in Ayurveda's post-colonial career in India. The central government instituted a new Department of Indian Systems of Medicine under its Ministry of Health in 1995. This has since been renamed the Department of AYUSH - Ayurveda, Yoga and Naturopathy, Unani, Siddha and Homeopathy. This development coincided with the sharp rise in international interest in indigenous systems of medicine across different cultural and regional contexts. Among the Indian government's stated aims were to improve primary, secondary and tertiary care utilising indigenous systems of medicine; invest in human resource development in this sector; preserve and promote cultivation of medicinal herbs and plants; encourage good manufacturing practices; and promote research and development.

The creation of the new Department has meant higher allocation of funds, better utilisation of resources and therefore more activity and higher visibility, as well as more autonomy to this sector. Part of the agenda behind this initiative was to tap into the emerging international market in indigenous medicinal plants and products. As Banerjee (2009) argues, these policy changes to a large extent reflect shifting patterns in global trade, and are prompted by the Indian government's desire to control the fast growing international market in herbs and herbal products since this market holds out the promise of significant commercial gain for the Indian economy.

Ayurveda retains a significant presence in the system of health provision in India today. Statistics compiled by AYUSH indicate that the total number of Ayurvedic hospitals in India in 2008 was just over 2,400, providing over 43,700 hospital beds for inpatients. ${ }^{4}$ The number of Ayurvedic dispensaries in the country that year was nearly 14,000, and there were roughly 8,000 manufacturing units producing Ayurvedic preparations. About 460,000 individuals were registered as Ayurveda practitioners in 2008 and there were 241 such Ayurveda training colleges in India jointly admitting over 10,000 students each year. There is considerable variation between different Indian states in terms of the scale of the Ayurvedic services provided in each. There is also considerable variation between urban and rural areas, and more generally between the rich and the poor.

As noted earlier, in the immediate aftermath of Indian independence, Ayurveda was promoted as a resource which could serve India's poor and rural populations who had no access to, or could not afford, biomedical facilities. Paradoxically, Ayurvedic branded products and services are now consumed mainly by urban middle-class Indians. At the same 
time, biomedical products now reach every corner of the Indian subcontinent and are readily available in rural areas. Bode (2008) argues that something of a market inversion has taken place, with poorer sections turning increasingly to biomedical drugs, and the middle classes becoming the main consumers of upmarket Ayurvedic products.

As far as qualified biomedical doctors and qualified Ayurvedic physicians are concerned, Prasad (2007) notes that many of these individuals, themselves from high-caste and upperclass backgrounds, prefer to serve the relatively affluent sections of the Indian population. The medical needs of villagers and the poorest sections of society are largely met by those with no recognised qualifications in any system, who practise different forms of medicine and therapy. Despite the government's rhetoric about providing primary health-care facilities in India's villages, in fact, Prasad argues, medical institutions, most of which tend to perpetuate an upper-class or elite culture, have been framed to suit the needs of the healthcare personnel, and not the needs of the masses. The result is a binary medical model with institutionalised forms of medicine (biomedicine as well as indigenous systems) catering to the needs of those who can afford them, and non-institutionalised forms serving the needs of those at the margins of society.

\section{Evaluating modernised Ayurveda in contemporary India}

On the face of it, it might appear that modern Ayurveda is thriving in the present Indian context. The reality, however, is more complex. For one thing, Ayurveda continues to occupy a status of inferiority in relation to biomedicine. This is reflected in the significantly lower allocation of government money to Ayurvedic projects and institutions relative to biomedicine. It is reflected also in the attitudes of students, most of whom aspire to a career in biomedicine, and end up studying Ayurveda only because they fail to make the necessary grades in the common entrance exam. Whereas the top scorers secure entry into biomedical colleges, others get relegated to one of the 'lesser' programmes including Ayurveda.

The students admitted to Ayurveda colleges are products of a Western system of schooling, which provides little background in critical aspects of Indian classical philosophy that underpin classical Ayurveda. Students also lack the necessary grounding in Sanskrit, the language in which the classical Ayurvedic texts were composed. In the few years of their training, they are unable to acquire enough knowledge of the classical modes of thought and of Sanskrit for them to engage with the full context and depth of the principles and methods undergirding Ayurveda. Their understanding of Ayurveda tends to remain relatively superficial. Additionally, barring significant exceptions, Ayurveda colleges tend to focus on Ayurvedic theory, providing little by way of expertise in practical application. Often clinical training is obtained not at Ayurvedic hospitals but at biomedical ones - thus theoretical and practical knowledge are sourced from completely different systems, and there is little attempt to provide a coherent account of the extent to which the two may be compatible.

In the move to systematise, modernise and standardise Ayurveda in independent India, this tradition has been depleted in more ways than one. Consultations at Ayurveda clinics are akin to those at biomedical ones - the physician examines the patient, studies any biomedical reports or test results that the patient may have obtained, writes prescriptions, and in some cases also dispenses medicines. Whereas traditionally the physician would prepare remedies according to the particular requirements of each patient, taking into account his/ her constitution, manifestation of symptoms, habits, dispositions, and relationship with the environment, now there is a reliance on standardised therapeutic remedies. Generalised medicines are targeted at diseases with little consideration of the particulars of individual 
contexts. The medicines, unlike the traditional concoctions made at home from fresh herbs, are mass-produced by pharmaceutical companies and have longer shelf-lives.

The flourishing Ayurvedic pharmaceutical industry in India has taken the preparation of Ayurvedic medicines out of the kitchens and workshops of local physicians, and has professionalised their manufacture, marketing and sales (Bode 2008). Some of the more capital-intensive manufacturing units are fully automated. Ayurvedic products are now presented in new forms such as sugar-coated pills and blister-packed capsules and tablets, and appear in well-designed glossy packages with catchy names. They are promoted by means of expensive advertising campaigns via modern mass media. Many are new products that do not follow classical formulae in terms of composition and methods of preparation; new branded products, including such things as Ayurvedic cosmetics, digestives and tonics, and shampoos and soaps, sell better, and at a higher price. They are therefore more profitable (Bode 2008).

This commoditisation of Ayurvedic medicine has been accompanied by efforts on the part of the industry to demonstrate the scientific basis of the formulations. Pharmaceutical companies claim that their research wings use tissue cultures, experimental animal studies and clinical trials to assess the toxicity and efficacy of products. Commercial interest drives much of this research, particularly given that Indian consumers lay considerable store by claims of scientific testing in product manufacture (Bode 2008). Critics argue that classical Ayurveda gets distorted when modern medical and scientific ideas and conceptions are read into them, and classical concepts are reinterpreted in terms of the principles of biochemistry and modern pharmacology. Yet, these problems are largely overlooked or denied.

In fact, according to Bode (2008) this kind of testing often lacks the rigour that is claimed. The research and review policies lack transparency, clinical trials are often inappropriate, uncontrolled and badly designed, and therefore their reliability is in doubt. Moreoever, these processes are not standardised. Though the Indian government has taken steps to regulate the production and sale of Ayurvedic remedies, these measures have been half-hearted and somewhat ineffective (Bode 2008: 48-56). These inadequate levels of standardisation and quality control present particular problems for the export of Ayurvedic preparations, especially to Western countries where the food and drug authorities impose much tighter controls on the identity and quality of herbal preparations.

Ayurvedic products in India are sold increasingly as 'authentic' indigenous commodities, and their wholesomeness and trustworthiness are emphasised (Bode 2008). They are contrasted with 'synthetic' biomedical products, and 'unnatural' modern cosmetics and toiletries. Manufacturers use religious symbols and myths to anchor their products in a Hindu and Indian cultural context. These products appear alongside other Hindu 'health' products such as yoga and meditation classes as fashionable, Indian, green, natural and safe alternatives to biomedical products and treatments.

Scholars like Leslie (1976), Brass (1972) and Bode (2008) have noted how the attitude of Ayurvedic revivalists and promoters is riddled with ambiguity and paradox. At the level of discourse they claim uniqueness and distinctiveness for Ayurveda, while in practice they borrow unquestioningly from the paradigms and methods of biomedicine. Others like Langford (2002) and Banerjee (2009) argue that the modernisation of Ayurveda is based on Indian mimicry of modern Western (particularly scientific and biomedical) institutions and practices. This mimicry, Langford argues, is only partial - it only partly reproduces the original, thereby making a mockery of it. The value of this hybrid tradition, Langford (2002) argues, lies not so much in its medical efficacy but in its symbolic cultural meaning and power for Indians. 
It is important to note that in addition to the institutions funded by government bodies and private industry, there also exists a small and declining number of traditional practitioners who still practise Ayurveda in a recognisably pre-modern form. Most scholars see these forms of practice as representing 'true' or 'authentic' Ayurveda as compared to the modernised variants. These traditional practitioners are mostly individuals who have learned Sanskrit and Ayurveda from an early age, usually as members of a family of traditional physicians, and who are apprenticed with experienced physicians in the family. Biomedicine and its paradigms and practices tend to be largely irrelevant to their practice. Anthropologists examining these traditional forms in India and Sri Lanka demonstrate that conceptions of person and illness here are very different from those in biomedicine. ${ }^{5}$ The body and the person are conceptualised as fluid and permeable, and as engaged in continuous interchange with society and the environment, in contrast with the biomedical model that understands body and person as discrete and bounded. Illness is understood as a disruption in processes and patterns of relationships such that body and mind, notions of selfhood, and relationships with others, are all affected to varying degrees; in attempting to effect a cure, the physician seeks to address these multiple issues. These forms of Ayurveda are fast disappearing; the traditional physicians have by and large given way to graduates from modern Ayurveda colleges, and their traditional ways of preparing remedies have been overtaken by the largescale production units run by the thriving pharmaceutical industry.

\section{Ayurveda as a 'global' health tradition}

Western audiences became increasingly aware of Ayurveda since the closing decades of the twentieth century. There have been a number of reasons for this. First, sections of the North American and West European public, growing increasingly disenchanted with various aspects of biomedicine, began to actively seek out alternative forms of treatment and therapy. Ayurveda held out the hope of 'natural' and 'safe' remedies, particularly for a number of chronic ailments. Second, Ayurvedic treatments and massages came to be included in holiday packages for tourists in parts of India (and Sri Lanka), and soon there was a mushrooming of Ayurvedic spas and retreats targeting well-heeled clients from India and abroad. The tourism ministries of some states have actively encouraged this; in Kerala in southern India, for instance, 'Kerala Ayurveda' is now promoted as a distinctive Ayurvedic tradition superior to other forms of Ayurveda. Third, Maharishi Mahesh Yogi's launching of his Maharishi Ayurveda in the 1980s, on the back of his popular Transcendental Meditation techniques, garnered considerable publicity for Ayurveda in the West (Humes 2008; Jeannotat 2008).

In the decades that followed, the number of promoters and practitioners of Ayurveda in Western Europe and North America grew; they included professionals trained in South Asia who migrated to the West to practise there, Europeans and Americans who trained at South Asian institutions and returned home to set up practice, as well as individuals trained at Ayurvedic training institutions in North America and Western Europe. Unlike the situation in contemporary India where students enter into Ayurvedic training programmes only when they fail to make the grades for entry into biomedical training courses, in North America and Western Europe individuals study Ayurveda mainly out of personal interest in alternative health systems. Many of these students describe themselves as spiritual seekers and their exploration of Ayurveda is often part of their spiritual questing (Welch 2008; Warrier 2009). There is the expectation that Ayurveda will provide them with spiritual insights which will enhance their self-knowledge and lead to self-empowerment. 
Among the more visible forms of Ayurveda in the West are clinics, retreats and spas offering a range of health and beauty treatments; popular literature on Ayurveda including, very significantly, self-help books; talks, seminars and workshops; Ayurvedic cosmetics, oils and health foods, and of course the ubiquitous Ayurvedic tea. Clinics and retreats are often located in secluded places of scenic beauty, where clients can get away, both physically and emotionally, from the stress of their everyday lives. There is a very vast body of popular literature on Ayurveda in circulation in the Western holistic health sector. Prominent authors include figures like Vasant Lad, David Frawley, Robert Svoboda, Deepak Chopra, Maya Tiwari (now Swamini Mayatitananda). These individuals emphasise the spiritual aspects of Ayurveda and many of them try and establish connections and correspondences between Ayurveda and other Indic traditions like jyotish (Indian astrology), gemology, postural and meditational yoga, vastu shastra (architecture based on ancient Sanskrit texts), and tantra. In some respects Maharishi Mahesh Yogi paved the way for this kind of interlinking. His Maharishi Ayurveda was a grand synthesising project in which he brought together a whole range of practices, each of which, he claimed, had 'Vedic' origins - they included such things as 'Gandharva Veda' or music therapy, 'Vedic Yagya' or sacrificial ritual, mantra chanting and meditation. The Maharishi also attempted a grand synthesis between Ayurveda and science and biomedicine; he presented his Maharishi Ayurveda as a part of 'Vedic science', the 'integral science of life' bringing together the 'latest discoveries of modern physics with the timeless wisdom of the Veda' (Jeannotat 2008: 290).

In keeping with the trend already established in India, most popular writers on Ayurveda in the West too follow an inclusive approach - combining biomedical and humoral frameworks in innovative ways. One of the most interesting figures in this regard is the vastly popular health guru Deepak Chopra, who started out as the Maharishi's protégé but then split away from the TM movement to set up his own health practice in the US. Chopra, a trained biomedic, brings his knowledge of biomedicine to bear on his discussion of Ayurveda. His Ayurveda is based on a radical mind-body paradigm of health and disease where disease is attributed to blockages in one's mental and emotional states. His psychologised version of Ayurveda thus treats all disease as the outward manifestation of deeper emotional and spiritual problems (Baer 2003; Aravamudan 2006: 257-261).

To set Anglophone Ayurveda in the West in context, we need to consider briefly the holistic health sector in Europe and America, which provides a home to this and other socalled 'complementary and alternative' health traditions. Scholars have noted important interconnections and overlaps between the holistic health network and networks of unchurched spirituality in Western contexts. Participants in these networks comprise in the main people who describe themselves as spiritual seekers, who reject organised religion, dogmatism and the authority of religious intermediaries, and who valorise, above all else, personal experience and personal authority in crafting meaningful spiritual lives for themselves. ${ }^{6}$ Shared meanings of health in this milieu carry references to optimising human potential (rather than simply curing disease), empowering the self through enhanced selfknowledge, and positive thinking. Health is understood here not just in somatic terms, but in terms of inter-linkages between mind, body and spirit. A very high value is placed on individual responsibility for health; health practitioners work with their clients more as counsellors and friends than as authority figures assuming responsibility for the client's health on the basis of their expert knowledge.

Ayurveda in this context becomes a means not merely to cure disease but to heal the self in its entirety through enhanced self-understanding and self-nurture. This is the most significant reinterpretation that Ayurveda has undergone in its modern transnational form. 
Whereas Ayurveda has developed into a medical system cum heritage product in mainstream post-colonial Indian contexts, in Western networks of health and spirituality, Ayurveda appears as, among other things, a crucial source of selfhood, and a means for enhancing health and well-being through self-knowledge. And this reinterpretation rests, crucially, on a new understanding of the doctrine of the three dosas or humours. Whereas traditionally the humours are understood as indices of states of health or disease, in the new understanding they become part of a typological system for classifying all persons into one of seven types; one may for instance be a pure kapha (phlegm), pitta (bile) or vata (wind) type, or a combination of two dosas, or a type where the three dosas are relatively balanced.

One's humoral constitution is understood to determine everything from one's personality, one's moods, likes and dislikes, to one's looks, and one's states of health or disease. Though this kind of categorisation and classification would seem oddly reductionistic in traditional Ayurvedic terms, it does enable adherence to a systematic programme of self-understanding and self-nurture. A number of self-help publications now available in print and online explain the different humoral types, inviting the reader to identify his/her constitution by means of a questionnaire, and offering dietary and lifestyle advice for each category. Ayurvedic food supplements, teas, oils and cosmetics are all often classified in dosa terms - so that there are pitta oils meant for 'pitta types' and vata teas intended for persons diagnosed with a vatapredominant constitution.

As Langford (2002: 248) perceptively points out for North American consumers of Ayurveda, prakrti or humoral constitution in these instances takes on connotations of a 'true inner self' seeking authentic forms of nurture and expression (see also Warrier 2009, 2011). Moreover as Zimmerman (1992) and others have noted, in its transnational Anglophone manifestation, Ayurveda's modalities are considerably toned down and softened to suit modern sensibilities. Some of the more violent and invasive practices involved in purgation, emesis and other forms of induced catharsis, still common in the Indian subcontinent, are rejected in favour of soothing, gentle treatments. Treatments cover a wide spectrum, ranging from those couched in the language of pampering and self-indulgence at one extreme to those focused on curing specific medical conditions at the other.

Ayurveda in Western contexts too is inevitably shaped and constrained by the institutions and frameworks of biomedicine. Ayurveda's description as a system of 'complementary' and/ or 'alternative' medicine itself indicates how biomedicine sets the terms for its enframing and how it operates at the fringes of the scientific and biomedical establishment (see Newcombe 2008). In most Western contexts too, practitioners are faced with professionalising dilemmas very similar to the ones faced by their counterparts in India (Reddy 2000, 2002; Warrier 2014). Regulation and standardisation are often deemed necessary by Western governments for domesticating traditions like Ayurveda and making them safe for clients. Ayurvedic medicines are required to meet the quality and safety standards imposed by government bodies. Most practitioners tend to welcome these measures since it gives their practice legitimacy and respectability, as well as greater visibility.

\section{Conclusion}

Ayurveda has inevitably undergone unprecedented transformation in the last two centuries. It has been reinterpreted to suit modern contexts; elements deemed least relevant have been discarded, and modern scientific paradigms have been adopted. This transformation has entangled it in larger debates about its place in the modern world. While transformation per se is inevitable, critics question the nature of this transformation - how far, they ask, 
can Ayurveda in post-colonial India claim identity as a distinct tradition if it borrows indiscriminately from biomedicine? How far are the different elements that make up this hybrid even compatible with each other?

The increasing interest in Ayurveda in the West, and the new emphasis on spirituality, has led to further changes in this tradition. Ayurveda's assimilation within a framework of Western spiritual seeking distances it somewhat from its biomedicalised and nationalistic manifestation in India. There are continuities between the two, yet new layers of meaning have been added as a result of Ayurveda's reframing as a tradition that enables the understanding, expression and nurture of one's true self. Could this new emphasis on a cosmopolitan and individualistic form of 'spirituality' serve as a corrective to Ayurveda's excessive preoccupation both with nationalistic chauvinism and with science and biomedicine in post-colonial India? The answer to this question is not yet clear; what is clear, however, is that promoters and practitioners in India, the Ayurvedic pharmaceutical industry, as well as the Indian government, are already responding enthusiastically to the new opportunities opening up as a result of Ayurveda's growing presence in the international market of herbs and holistic health.

\section{Notes}

1 For an overview of traditional Ayurveda as a health system, see Wujastyk (1993, 2003).

2 See, for instance, Leslie (1976); Shankar and Manohar (1995); Langford (2002); Bode (2008); Banerjee (2009).

3 It is noteworthy that indigenous folk traditions of healing, some of them highly efficacious for particular kinds of ailments, were largely excluded from this discourse because they were seen as 'primitive' and based on superstition; see Shankar and Unnikrishnan (2004).

4 'Ayush in India 2012' published by the Department of AYUSH, Ministry of Health and Family Welfare, Government of India. Available at: http://indianmedicine.nic.in/index3.asp?sslid=743\&s ubsublinkid=198\&lang=1 (accessed 30 July 14).

5 See, for instance, Kakar (1982); Nichter (1980, 1981, 1989); Nordstrom $(1988,1989)$; Obeyesekere (1976a and b, 1992); Trawick (1981, 1991, 1992). More recently, Sax and Nair (2014), in an examination of a traditional lineage of healers in Kerala who combine Ayurvedic remedies with ritual, problematise the sharp dividing lines often drawn between traditional and modern Ayurveda, and question the usefulness of such a distinction.

6 See, for instance, Heelas (1996, 2008); Fuller (2001).

\section{References}

Alter, J. S. (1999) 'Heaps of Health, Metaphysical Fitness', Current Anthropology, 40: S43-66.

Arnold, D. (2000) Science, Technology and Medicine in Colonial India, Cambridge: Cambridge University Press.

Aravamudan, S. (2006) Guru English: South Asian English in a Cosmopolitan Language, Princeton, NJ and Oxford: Princeton University Press.

Baer, H. A. (2003) 'The Work of Andrew Weil and Deepak Chopra: Two Holistic Health/New Age Gurus: A Critique of the Holistic Health/New Age Movements', Medical Anthropology Quarterly, New Series, 17 (2): 233-250.

Banerjee, M. (2009) Power, Knowledge, Medicine: Ayurvedic Pharmaceuticals at Home and Abroad, Hyderabad: Orient Blackswan.

Bode, M. (2008) Taking Traditional Knowledge to the Market: The Modern Image of the Ayurveda and Unani Industry 1980-2000, Hyderabad: Orient Longman.

Brass, P. R. (1972) 'The Politics of Ayurvedic Education: A Case Study of Revivalism and Modernization in India', in S. H. Rudolph and L. I. Rudolph (eds), Education and Politics in India: Studies in Organization, Society, and Policy, 342-371, Cambridge, MA: Harvard University Press.

Cerulli, A. (2012) Somatic Lessons: Narrating Patienthood and Illness in Indian Medical Literature, Albany, NY: State University of New York Press. 
Fuller, R. (2001) Spiritual but Not Religious: Understanding Unchurched America, Oxford: Oxford University Press.

Ganesan, U. (2010) ‘Medicine and Modernity: The Ayurvedic Revival Movement in India, 1885-1947’, Studies on Asia, Series IV, 1 (1): 108-131.

Heelas, P. (1996) The New Age Movement, Oxford: Blackwell.

Heelas, P. (2008) Spiritualities of Life: Romantic Themes and Consumptive Capitalism, Oxford: Blackwell.

Humes, C. A. (2008) 'Maharishi Ayur-Veda: Perfect Health through Enlightened Marketing in America', in D. Wujastyk and F. M. Smith (eds), Modern and Global Ayurveda: Pluralism and Paradigms, 309-331, Albany, NY: State University of New York Press.

Jeannotat, F. (2008) 'Maharishi Ayur-Ved: A Controversial Model of Global Ayurveda', in D. Wujastyk and F. M. Smith (eds), Modern and Global Ayurveda: Pluralism and Paradigms, 285-307, Albany, NY: State University of New York Press.

Kakar, S. (1982) Shamans, Mystics and Doctors: A Psychological Inquiry into India and its Healing Traditions, New York: Knopf.

Langford, J. M. (2002) Fluent Bodies: Ayurvedic Remedies for Postcolonial Imbalance, Durham, NC and London: Duke University Press.

Leslie, C. (1973) 'The Professionalizing Ideology of Medical Revivalism' in M. Singer (ed.), Modernization of Occupational Cultures in South Asia, 216-242, Durham, NC: Duke University Press.

Leslie, C. (1976) 'The Ambiguities of Medical Revivalism in Modern India', in C. Leslie (ed.), Asian Medical Systems: A Comparative Study, 356-367, Berkeley, CA, Los Angeles, CA and London: University of California Press.

Newcombe, S. (2008) 'Ayurvedic Medicine in Britain and the Epistemology of Practising Medicine in "Good Faith" in D. Wujastyk and F. M. Smith (eds), Modern and Global Ayurveda: Pluralism and Paradigms, 257-284. Albany, NY: State University of New York Press.

Nichter, M. (1980) 'The Layperson's Perception of Medicine as Perspective into the Utilization of Multiple Therapy Systems in the Indian Context', Social Science and Medicine, 14B (4): 225-233.

Nichter, M. (1981) 'Negotiation of Illness Experience: Ayurvedic Therapy and the Psychosocial Dimension of Illness', Culture, Medicine and Psychiatry, 5 (1): 5-24.

Nichter, M. and C. R. Nordstrom (1989) 'A Question of Medicine Answering: Health Commodification and the Social Relations of Healing in Sri Lanka', Culture, Medicine and Psychiatry, 13: 369-390.

Nordstrom, C. R. (1988) 'Exploring Pluralism: The Many Faces of Ayurveda', Social Science and Medicine, 27(5): 479-489.

Nordstrom, C. R. (1989) 'Ayurveda: A Multilectic Interpretation', Social Science and Medicine, 28 (9): 963-970.

Obeyesekere, G. (1976a) 'The Impact of Ayurvedic Ideas on the Culture and the Individual in Sri Lanka', in C. Leslie (ed.), Asian Medical Systems: A Comparative Study, 201-226, Berkeley, CA, Los Angeles, CA and London: University of California Press.

Obeyesekere, G. (1976b) 'The Theory and Practice of Psychological Medicine in the Ayurvedic Tradition', Culture, Medicine and Psychiatry, I: 155-181.

Obeyesekere, G. (1992) 'Science, Experimentation, and Clinical Practice in Ayurveda', in C. Leslie and A. Young (eds), Paths to Asian Medical Knowledge, 160-176, Berkeley, CA, Los Angeles, CA and London: University of California Press.

Prakash, G. (1999) Another Reason: Science and the Imagination in Modern India. Princeton, NJ: Princeton University Press.

Prasad, N. P. (2007) 'Medicine, Power and Social Legitimacy: A Socio-Historical Appraisal of Health Systems in Contemporary India', Economic and Political Weekly, 42 (34): 3491-3498.

Reddy, S. (2000) Reinventing Medical Traditions: The Professionalization of Ayurveda in Contemporary America, Unpublished PhD thesis, University of Pennsylvania, Philadelphia, PA.

Reddy, S. (2002) 'Asian Medicine in America: The Ayurvedic Case', Annals of the American Academy of Political and Social Science (Global Perspectives on Complementary and Alternative Medicine), 583: 97-121.

Sax, W. S. and H. K. B. Nair (2014) 'A Healing Practice in Kerala', in H. Naraindas, J. Quack and W. S. Sax (eds), Asymmetrical Conversations: Contestations, Circumventions, and the Blurring of Therapeutic Boundaries, 'Epistemologies of Healing' Series, Volume 14, 200-236, New York and Oxford: Berghahn.

Shankar, D. and R. Manohar (1995) 'Ayurveda Today: Ayurveda at the Crossroads', in J. V. Alphen and A. Aris (eds), Oriental Medicine: An Illustrated Guide to the Asian Arts of Healing, 99-105, London: Serindia. 
Shankar, D. and P. M. Unnikrishnan (eds) (2004) Challenging the Indian Medical Heritage, Foundation for Revitalisation of Local Health Traditions, Bangalore and Centre for Environment Education, Ahmadabad, Delhi: Foundation Books.

Trawick, M. (1981) 'The Ayurvedic Physician as Scientist', Social Science and Medicine, 24 (2): 1031-1050.

Trawick, M. (1991) 'An Ayurvedic Theory of Cancer', Medical Anthropology, 13: 121-136.

Trawick, M. (1992) 'Death and Nurturance in Indian Systems of Healing' in C. Leslie and A. Young (eds), Paths to Asian Medical Knowledge: Comparative Studies of Health Systems and Medical Care, 129-159, Berkeley, CA: University of California Press.

Warrier, M. (2009) 'Seekership, Spirituality and Self-Discovery: Ayurveda Trainees in Britain', Asian Medicine: Tradition and Modernity, 4 (2): 423-451.

Warrier, M. (2011) 'Revisiting the Easternisation Thesis: The Spiritualisation of Ayurveda in Modern Britain', in P. Heelas (ed.) Autonomous' Spiritualities beyond Religious Tradition (Volume III of Spiritualities in the Modern World: Within Religious Tradition and Beyond); 'Critical Concepts in Religious Studies' Series, 299-319, London and New York: Routledge.

Warrier, M. (2014) 'Ayurveda in Britain: The Twin Imperatives of Professionalization and Spiritual Seeking', in H. Naraindas, J. Quack and W. S. Sax (eds), Asymmetrical Conversations: Contestations, Circumventions, and the Blurring of Therapeutic Boundaries, 'Epistemologies of Healing' Series, Volume 14, 237-260. New York and Oxford: Berghahn.

Welch, C. (2008) 'An Overview of the Education and Practice of Global Ayurveda' in D. Wujastyk and F. M. Smith (eds), Modern and Global Ayurveda: Pluralism and Paradigms, 129-138, Albany, NY: State University of New York Press.

Wujastyk, D. (1993) 'Indian Medicine', in W. F. Bynum and R. Porter (eds), Companion Encyclopedia of the History of Medicine, vol. I, 755-778, London and New York: Routledge.

Wujastyk, D. (2003) 'The Science of Medicine' in G. Flood (ed.), The Blackwell Companion to Hinduism, 393-409, Oxford: Blackwell.

Wujastyk, D. (2008) 'The Evolution of Indian Government Policy on Ayurveda in the Twentieth Century', in D. Wujastyk and F. M. Smith (eds), Modern and Global Ayurveda: Pluralism and Paradigms, 43-76, Albany, NY: State University of New York Press.

Wujastyk, D. (2009) 'Interpreting the Image of the Human Body in Premodern India', International Journal of Hindu Studies, 13: 189-228.

Wujastyk, D. and F. M. Smith (eds) (2008) Modern and Global Ayurveda: Pluralism and Paradigms, Albany, NY: State University of New York Press.

Zimmerman, F. (1979) 'Remarks on the Conception of Body in Ayurvedic Medicine', South Asian Digest of Regional Writings, 18: 10-26.

Zimmerman, F. (1980 [1975]) 'Rtu-Satmya: The Seasonal Cycle and the Principle of Appropriateness', Social Science and Medicine, 14B, 99-106.

Zimmerman, F. (1992) 'Gentle Purge: The Flower Power of Ayurveda', in C. Leslie and A. Young (eds), Paths to Asian Medical Knowledge, 209-223, Berkeley, CA: University of California Press. 

$\because$ Taylor \& Francis http://taylorandfrancis.com 


\section{PART III}

Society, class, caste and gender 

$\because$ Taylor \& Francis http://taylorandfrancis.com 


\title{
13 \\ THE POLITICS \\ OF ECONOMIC \\ REFORMS IN INDIA
}

\author{
Diego Maiorano
}

\section{Introduction}

In July 1991, in the midst of a major balance-of-payments crisis, P. V. Narasimha Rao's government introduced a set of relatively radical policy changes in the economic sphere that came to be known as 'economic reforms' or 'liberalisation'. Trade barriers were significantly lowered; the policy of state regulation of industrial production (the so-called 'licence-Raj') ${ }^{1}$ was effectively dismantled; foreign investments were significantly liberalised. Overall, India abandoned a state-centric model of development to embrace a much more market-oriented one. Although reforms in other sectors (like labour laws and agricultural policy) were far less radical, and, as we shall see, India's economic reforms are in many ways only a half-hearted instance of economic liberalisation, the changes introduced by Rao's Finance Minister, Dr Manmohan Singh, did constitute a marked break with the past.

This is somewhat surprising and introduces us to the first question that this chapter addresses: how was the change possible? The literature on the relation between market reforms and democracy highlights how democracies often find it difficult to introduce and consolidate economic reforms (Przeworski 1991; Haggard and Kaufman 1994). Many argued, especially during the 1980s, that authoritarianism offered a more suitable environment for market-oriented economic reforms. Authoritarian regimes, this argument goes, are more insulated from the pressures coming from social groups that would lose from liberalisation. Even though this thesis has been seriously questioned (Geddes 1994; Giuliano et al. 2012), it remains that 'it is by no means certain that democracies will be able to deal satisfactorily with the inevitable tensions and costs that accompany reform' (Maravall 1994: 21). The Indian case, as we shall see in greater detail below, seemed to be particularly resilient to policy change (Bardhan 1998). What factors explain the introduction and then the consolidation of market-oriented economic reforms in India?

The second question that this chapter addresses concerns the consequences of the economic reforms, in particular the distributional effects of liberalisation. After almost twenty-five years of gradual liberalisation of the economy, who are the winners and who are the losers? Economic theory suggests that, at first, elite groups are more equipped to exploit the new opportunities unleashed by liberalisation. Therefore, economic reforms usually result in an increase of inequalities in the short term. The poor, theory suggests, 
will eventually benefit from the higher growth rates brought about by liberalisation when a process of income convergence should begin (Banerjee and Duflo 2003; Fosu 2009). Does this pattern apply to the Indian case as well?

The chapter is structured as follows. The next section answers the first question - how was liberalisation possible? I will present three arguments that can be found in the literature, showing how the combination of the severe financial pressures due to the balance-ofpayment crisis with the ability of the reform proponents to move carefully and strategically explain satisfactorily why India managed to abandon the state-led model to embrace a market-oriented one.

The following section deals with the second question, namely, who are the main beneficiaries of the economic reforms? I will show that a robust literature demonstrates that, unsurprisingly, elite groups are the undisputed winners of liberalisation and that the higher growth rates brought about by the economic reforms did not translate into a spectacular reduction of poverty. Politics and power relations within India's society explain these outcomes to a significant extent.

\section{How did it happen?}

Indian democracy was thought to be particularly change-resilient. Rajiv Gandhi's failed attempt to reform the economy in the late 1980 s, despite the huge parliamentary majority that he enjoyed (Manor 1987), seemed to confirm the view that the Indian state was in the hands of a coalition of 'dominant proprietary classes' (Bardhan 1998) that was powerful enough to impede any change in economic policy. The three classes were the big industrialists, the large farmers and the bureaucracy. All these three groups had benefited greatly from the state-led model of development that characterised India's political economy in the first decades after independence. The big business 'blocked industrial competition and innovation. The richer farmers in turn blocked agrarian reform, pushing the country instead to a Green Revolution that gathered pace in the 1970s, while many bureaucrats worked the planning and licenceRaj to their personal advantage and to the advantage of many of the politicians they served' (Ruparelia et al. 2011: 3). Given their dominance over India's politics, Pranab Bardhan (1998) (and many others) had argued that a radical reorientation of India's development model was, if not impossible, at least extremely unlikely.

The fact that the economic reforms did take place and were consolidated does not mean that these arguments were completely baseless. In many ways, India's economic reforms are only a half-hearted attempt, especially if we compare India's case with that of East Asian or Latin American countries. On the one hand, the constraints due to India's democratic regime imposed a certain degree of gradualism in implementing the reforms (Ahluwalia 2002). On the other hand, the 'dominant proprietary classes' were able to slow down or block a number of policy measures that would have negatively affected their interests.

In particular, Bardhan (2003) points out how the dominant coalition was able to prevent any significant reform in the agricultural sector; to keep a number of (regressive) explicit and implicit subsidies on items such as power, diesel, food and fertilisers; and to maintain a system of regulations that, although not matching that of the 'licence-raj', still allows bureaucrats (and politicians) to retain significant discretionary powers and avenues for amassing illicit wealth. Moreover, the business sector benefited enormously from the retreat of the state from the economic sphere, especially in terms of colonising (highly profitable) sectors hitherto reserved for the public sector like telecommunications or extractive activities. 
However, it is undeniable that the changes introduced by Dr Manmohan Singh in the summer of 1991 (and continued by successive governments) were quite revolutionary for India's standards. Three kinds of explanations can be found in the literature to explain the shift. The first one is what we could call the 'crisis' argument. The second is the 'elite' argument. The third is the 'stealth' argument. It is important to note that all these three explanations are not incompatible, but rather they reinforce one another.

The 'crisis' explanation is, somewhat paradoxically, proposed by both liberalisation champions (Bhagwati 2007) and opponents (Patnaik and Chandrasekhar 2007). Both highlight the fact that the economic reforms were possible essentially because, in the summer of 1991, India was on the edge of defaulting in the wake of a severe balance-of payment crisis. Where the two explanations differ is, on the one hand, on the causes that led to the crisis and, on the other, on the role that Bretton Woods institutions played in promoting the economic reforms.

According to Bhagwati (2007), the crisis was the result of the failure of the state-led model of development. The public debt-to-GNP ratio increased drastically through the 1980s due to the inability of the public sector to generate investments and to the growth of government spending that resulted in a quite sharp increase of the fiscal deficit. The 1990 oil shock aggravated the situation, but, Bhawati argues, the crisis was 'almost entirely "home-made" (p. 47).

Patnaik and Chandrasekhar (2007), among others, challenge this view. According to them the crisis was not structural, but was essentially due to financial speculation. Therefore, the government could have dealt with it without dismantling the dirigiste regime. However, the 'liberalization lobby, consisting of both the [International Monetary] Fund and the [World] Bank as well as elements within the Indian government and business class' (p. 55) succeeded in pushing India in the arms of the Bretton Woods institutions that, as a condition for conceding the much-needed loans, imposed the restructuring of India's economy. In this view the economic reforms appear as an external imposition by international capital on nearly bankrupted India.

Different interpretations of the causes of the 1991 crisis lead to different explanations of the origins of the economic reforms. Those who see the crisis as the (inevitable) failure of the dirigiste regime argue that the failure was so evident among policy-makers that, during the 1980s, a broad consensus emerged on what needed to be done (Panagariya 1994; Joshi and Little 1994). In particular, a small group of 'men with commitment and courage' (Das 2000: 240 quoted in Sengupta 2008) within key policy-making agencies were able to gradually persuade - also thanks to the example of China that had liberalised its economy at the end of the 1970s (Baru 2007) - supporters of the existing model that liberalisation was the only way forward. The critical economic situation in the summer of 1991 convinced also those who still opposed the economic reforms that the dismantling of the state-led model of development was inevitable (Dash 1999; Nayar 1998). Therefore, Bretton Woods institutions, rather than imposing the restructuring of the economy, pretty much knocked on 'an open door' (Nayar 2001 quoted in Sengupta 2008).

Sengupta (2008) challenges this view. She quite plausibly highlights how the process that led to the restructuring of the economy was less straightforward and that the reforms were the result 'of a prolonged political and ideological contestation over different explanations of past policy failures and different prescriptions for change' (p. 36). According to her the 'men with commitment and courage' remained isolated and in marginal positions until the economic crisis 'catapulted [them] to commanding positions' (p. 38) thanks to the insistence of Bretton Woods institutions that explicitly requested to negotiate the loans' conditionality 
with like-minded people. This acquired power (and the backing of the political authorities) shifted the balance of power in favour of the liberalisers that succeeded in marginalising the supporters of the dirigiste regime.

Sengupta's argument probably underestimates the extent to which the reforms were 'home-grown' (Chaudhry et al. 2004). Many protagonists of the reforms in the 1990s were already in powerful positions during the early 1980s. Indira Gandhi herself had changed her mind about economic policy. This does not mean that she wanted to dismantle the state-led model of development; but the changes introduced by her government in the early 1980s were a clear sign that liberalisers were acquiring more influence in economic policy-making (Maiorano 2015).

Sengupta also rightly emphasises the role of politics in bringing about the economic reforms. The view that a small group of technocrats (including Dr Manmohan Singh) managed to introduce and implement the reforms on their own is ludicrous. Rao strongly backed the policy change. James Manor (2011b: 206) reports a conversation that he had with the then Prime Minister in the early 1990s in which he explained his strategy. The economic reforms were part of a broader social-democratic agenda that Rao wanted to pursue. It was hoped that the liberalisation of the economy would bring higher rates of growth that in turn would generate higher revenues that in turn could be used for social programmes. Even though, at least until 2004, the 'social' component of this strategy was substantially ignored (as we shall see below), it remains that the political authorities were not acting simply under the pressure of the liberalisation lobby and of Bretton Woods institutions. The economic reforms were to a large extent domestic in their origins.

The 'elite' argument was proposed by Ashutosh Varshney (2007). His argument departs from the fact that, according to opinion surveys conducted in 1996, only about 19 per cent of the electorate had heard about the economic reforms. ${ }^{2}$ Not surprisingly, those who were aware of the changes in economic policy were mostly graduates: 66 per cent of them were aware of the reforms, whereas only 7 per cent of the poor had heard of them. The vigorous debate on liberalisation, Varshney concludes, was confined to 'the circle of India's elite politics' (p. 148).

Not only was the debate about economic liberalisation restricted to India's elites; but the content itself of the reforms, Varsheny argues, concerned those sectors of the economy that affected the interests of a tiny minority of the population, like the financial sector or trade policies. In fact, the reforms left largely untouched the agricultural sector, the labour legislation and, to a lesser extent, the public sector. In other words, the reformers concentrated their efforts on those areas that did not entail adverse (and immediately visible) consequences on the society at large.

Varshney adds another reason that allowed the economic reforms to be introduced. It is important not to forget that Rao's government did not enjoy a parliamentary majority. In order to have the budget laws passed, a political understanding with other political forces had to be reached. This was arguably not an easy task, but it was made easier by the broader political context of the early 1990s. This was a period when identity politics reached the centre stage in India. The campaign for the demolition of the Babri Masjid ${ }^{3}$ was at its height when the reforms were introduced. In December 1992 the mosque was eventually destroyed which caused prolonged communal tension throughout the country. Parallel to this, in 1990 V. P. Singh's government had implemented the recommendations of the Mandal Commission that envisaged reservations for the Other Backward Classes (OBCs) in public sector jobs. The 'mandalisation' of India's politics led to prolonged caste tension. 'The political logic induced by explosions of communal passions gave the reformers room 
to push reforms' (Varshney 2007: 149), thus facilitating the process of transformation of the economy. In other words, the realm of 'mass politics' was occupied by identity-based issues that effectively distracted the public opinion from the realm of 'elite politics' which is where the economic reforms were pushed through.

This explanation is convincing only to a certain extent. It is certainly true that the threat of Hindu nationalism pushed the parties of the left (the Communists and the Janata Dal) to unwittingly support (and vote for) the reforms. Having done otherwise would have caused the fall of the Congress government and opened the door for a BJP-led government. In short, the parties of the left 'disliked the reforms, but they disliked Hindu nationalism even more' (Varshney 2007: 156, emphasis in the text).

However, as Jenkins points out (1999), the link between identity politics and economic reforms is not so straightforward. For example, the government chose not to invest particular political energy on reducing the food subsidy in 1993-1994 because it felt it needed to dedicate its fullest attention to the extremely delicate political situation, in the wake of the destruction of the Babri Masjid. Therefore, identity politics can both help and constrain economic reforms. Moreover, Varshney's argument does not really explain why the 'elite' reforms were introduced and how the resistance of the small (but very powerful) business community was eventually overtaken.

The 'stealth argument', introduced by Rob Jenkins (1999), sheds much light on this point. The core of his argument is that the economic reforms could be introduced and consolidated because India's leaders were able to 'reform by stealth'. In the words of Narasimha Rao (quoted by Jenkins) 'what it really entails is a complete U-turn without seeming to be a U-turn' (p. 346). Three elements are central to Jenkins' explanation: first, the skills of India's political leaders; second, the fluid institutional environment in which they operated; and, third, the incentives provided by the first round of reforms introduced during the balanceof-payments crisis.

The core of Jenkins's argument is that the Indian government employed a series of tactics and subterfuges to conceal the revolutionary nature of the reforms and to break the front of opponents. 'These tactics include[d], in addition to pilfering: shifting unpleasant responsibilities and blame on to political opponents, surreptitiously compensating selected interests, concealing intentions, reassuring and then abusing the trust of long-time political allies, and obscuring policy change by emphasising essential continuity' (p. 7). In other words the fact that the economic reforms were introduced and then consolidated proves the 'very skilled nature of India's ruling political class' (Corbridge et al. 2013: 374).

Both formal and informal institutions helped the reformers. Federalism in particular proved to be crucial for easing opposition to the reforms. On the one hand, better off states had more incentives to embrace the process of liberalisation and were therefore less likely to constitute a united front with less economically developed (and hence less ready to embrace the reforms) states; on the other hand, since many of the reforms were to be implemented by the states, political resistance remained to a large extent confined within the boundaries of state-level political systems, leaving more space for manoeuvre at the centre. At the same time, the liberalisation of the economy ushered a process of 'provincial Darwinism' that forced the state leaders to compete with each other to make their states more business-friendly. The fact that even West Bengal, which was ruled by the Communist Party of India (Marxists) for more than thirty years, embraced economic reforms is revealing. ${ }^{4}$ This is also a key reason why the reforms gained a momentum of their own and became very difficult to reverse.

Jenkins's explanation is also an answer to the scepticism that can be found in the literature about the relation between economic reforms and democracy. He argues that 
India's democratic regime, far from hindering the process of liberalisation, actually helped reformers to introduce and consolidate economic reforms. In fact, it was precisely the openness and competitiveness of the democratic setting that made the kind of Machiavellian tactics employed by the reformers both necessary and possible. ${ }^{5}$

These tactics worked. The opposition to the reform process, especially by established businesses that feared competition from abroad, never coalesced enough to represent a threat for the liberalisation process. In fact, the business sector, after a few years of (not so effective) opposition, was quick to see the new opportunities that the economic reforms opened up, and became a strenuous supporter of liberalisation.

Let us now turn to the second question that this chapter addresses, that is, who benefited from India's economic reforms?

\section{Who benefited from liberalisation?}

Both theoretical considerations and empirical evidence suggest that, at least in the short term, the main beneficiaries of economic reforms are privileged groups (Banerjee and Duflo 2003). This is because they are more equipped to take advantage of the new opportunities unleashed by liberalisation. In a second phase, theory suggests, a process of income convergence should begin. There is reason to believe that this pattern might apply to India as well. However, while there is strong evidence that the economic reforms have so far disproportionately benefited the better off and that inequality has been increasing, the first signs of a reversal of this trend are very weak at best. ${ }^{6}$

A robust literature shows how elite groups are the real winners of the liberalisation process in India (e.g. Corbridge and Harriss 2000; Fernandes 2006; Kohli 2012). Since at least the last term in office of Indira Gandhi in the early 1980s, irrespective of the political party in power or the 'socialist' or 'neoliberal' policy regime, the central government has put at the centre of its developmental strategy the big business community and the urban middle class, ${ }^{7}$ whereas the poor and the peasantry were clearly relegated to a secondary position (Maiorano 2014). The economic reforms of the early 1990s accentuated this trend. Corbridge and Harriss (2000) characterise the process of liberalisation as an 'elite revolt' since 'the reforms of the 1990s have worked to the advantage of India's business and financial (and even agricultural) elites - those elites who have been in revolt against some aspects of the state-managed capitalism that served their interests previously' (p. 121).

The evidence is abundant. Banerjee and Piketty (2005) show how the shares of income of the top 0.01 and 0.1 per cent of the population shrunk sharply between the 1950s and the 1980s but then rose back to the levels of the 1950s by the mid-2000s. Similarly, Topalova (2008) calculates that the fruits of accelerated growth in the 1990s disproportionately benefited the top 15-20 per cent of the population in urban areas and the top 10 per cent in rural areas. Jayadev et al. (2011) also show that there are clear signs of 'growing interpersonal, inter-class and spatial divergences of wealth accumulation' during the post-reform period (p. 82).

This trend has much to do with the nature of the growth process in India. Unlike China, where the rapid economic expansion following liberalisation occurred first in agriculture and then in the manufacturing sectors, thus leading to a spectacular growth of real wages and hence to a very rapid reduction of poverty (along with rising inequalities), in India the economic boom was led by the service sector. In particular, much of the growth occurred in specific sub-sectors like software development and financial services that created (highlypaid) jobs for the educated elites. The great majority of the population remained stuck in the 
informal economy - where more than 90 per cent of the labour force is employed - with low (and stagnating) wages and low (or even declining) employment generation. ${ }^{8}$

That the economic reforms benefited the better offs, however, is not only due to the nature of the growth process, but also to precise political choices, reflecting the power that the 'proprietary classes' still exercise on India's politics. For instance, one of the consequences of the economic reforms should be the reduction of public expenditure. However, one area where the state has kept spending abundant resources is subsidies for its wealthy citizens. A number of items used primarily by the business sector, large farmers and wealthy urbanites like diesel, power, petrol and fertilisers constitute an enormous drain of resources for the public exchequer. What all these subsidies have in common is their regressive nature on the one hand, and the fact that they are politically impossible to withdraw on the other hand (Drèze and Sen 2013, Chapter 4).

It could be added that India's elite groups, and in particular the business sector, benefit from a number of implicit subsidies. On the one hand, corporations and the salaried taxpayers (who to a large extent coincide with the 'middle class') are the main beneficiaries of what the Finance Ministry calls 'revenue foregone', namely the amount of revenues that are not collected because of various exceptions and incentives. ${ }^{9}$ In 2013/14 the amount of revenue foregone was equivalent to about 5 per cent of the GDP that is, an amount sufficient to fund India's largest anti-poverty scheme (the Mahatma Gandhi National Rural Employment Guarantee Act, MGNREGA) for more than fifteen years. ${ }^{10}$ This policy, moreover, has been accompanied by substantial cuts in direct taxation (both on personal income and corporate profits) starting from 1980 (Maiorano 2014). On the other hand, the corporate sector benefit from another kind of implicit subsidy. This is the allocation of natural resources, land, telecommunication spectrum, and so on at give-away prices, usually in return for enormous kickbacks.

Let us now turn to public spending for the poor. It is difficult to find many countries in the world that spend fewer resources than India on health and education. According to the last available World Development Indicators, ${ }^{11}$ India spends 3.35 per cent of the GDP for education and 1.33 per cent of the GDP for health services. To put these figures into perspective, India spends 22 per cent less than sub-Saharan African countries for education and 50 per cent less for health. These figures remained more or less stable since 1991 and are only slightly lower than in the 1980s.

The agricultural sector has been similarly neglected. A combination of a steep decline of public investments in agriculture, decreasing availability of institutional credit to farmers and weak protection from global competition - along with deeper structural inequalities - led the agricultural sector into a state of deep crisis (Dev 2004; Vaidyanathan 2006; Radakrishna et al. 2007; Reddy and Mishra 2009; Vakulabharanam and Motiram 2011). Farm profitability decreased dramatically in the post-reform period, as witnessed by the tragedy of farmers' suicides - more than 270,000 between 1995 and 2011 (The Hindu, 3 July 2012) - and the steady diminution in the number of farmers - more than 14 million left cultivation between 1991 and 2011 (The Hindu, 2 May 2013).

That India's elite groups are the main winners of the process of economic reform is virtually undisputed. A much more debated issue is whether the development model embraced after 1991 has benefited the poor too - the 'Great Indian Poverty Debate' as two scholars called it (Deaton 2005). ${ }^{12}$

The emerging consensus is that the economic reforms have not been particularly propoor. This does not mean that poverty did not decline. Since the early 1970 s, poverty showed a clear downward trend that continued after liberalisation. It is particularly tricky 
to give estimates of poverty in India since the methodology used to calculate the poverty line changed several times in recent years and each time a new formula was released, the data were seriously questioned politically and statistically (Himanshu and Sen 2014). In any case, according to official data, poverty declined from 46.5 per cent in the early 1980 s to 29.8 per cent in 2009/10 (Corbridge et al. 2013, Chapter 3; Himanshu and Sen 2014). ${ }^{13}$ Different estimates produce different results, but what is clear is that poverty did decline sharply in the last three and a half decades.

The 1980s were particularly good years for poverty reduction. This was mainly due to the high rates of public investments in the agricultural sector following the introduction of the Green Revolution in the mid-1960s. During the 1980s, yields increased by about 30 per cent (as against about 10 per cent during the 1970s) and the primary sector grew by more than 3 per cent per year. Crucially, growth in the agricultural sector did trickle-down to the poor, as real agricultural wages increased by more than 5 per cent per year, an unprecedented rate (Drèze and Sen 2013: 84). Higher rates of growth in the industrial and service sectors - the 1980s were the years during which India's economy took off (Kohli 2006) - translated into a reduction of urban poverty too (Datt and Ravallion 2010).

In the 1990s, however, the pace of poverty reduction decreased. This is especially evident if we look at the rates of growth of real agricultural wages - the great majority of India's poor live in rural areas - which declined to about 2 per cent per year during the 1990s and to virtually zero per cent during the first half of the 2000s. It was only with the introduction of the MGNREGA in 2006, coupled with very high rates of economic growth since 2003, that real agricultural wages started increasing again (Drèze and Sen 2013: 89).

The situation of the poor engaged in non-agricultural activities was not much better. Real wages in manufacturing grew at about 2.5 per cent in the $2000 \mathrm{~s}$, which was much less than the growth of the GDP per capita and astonishingly less than the growth of real manufacturing wages in China, which grew at about 12 per cent per year during the same period (Drèze and Sen 2013: 90).

In general terms, as shown by Topalova (2008), during the 1990s economic growth became less effective at pulling people out of poverty than it had been during the 1970s and 1980s. India's performance is disappointing in comparative perspective too. Not only was poverty reduction per unit of growth between 1980 and 2010 much lower than that of other emerging economies like Brazil and China (Ravallion 2009); but India's elasticity of poverty - namely the amount of poverty reduction associated with the increase of per capita income - is lower than that of all the regions of the world, barring sub-Saharan Africa (Corbridge et al. 2013: 180).

Growing inequality explains to a large extent the declining effectiveness of India's growth to reduce poverty. Evidence of growing economic inequality (including between urban and rural areas) since the late 1980s is abundant (Deaton and Drèze 2002; Sarkar and Mehta 2010; ADB 2012; Jayadev et al. 2011; Banerjee and Piketty 2005; Himanshu 2007; Topalova 2008). There is also some strong evidence that shows that inequalities between Indian states are on the increase. This is again consistent with economic theory, as the historically more developed states were better equipped to benefit from the new opportunities unleashed by the economic reforms (Dasgupta et al. 2000; Kurian 2000; Ahluwalia 2000). Thus states like Maharashtra and Gujarat experienced very high GPD per capita growth rates throughout the 1990s (as they did throughout the 1980s), whereas India's poorest areas like Uttar Pradesh, Madhya Pradesh and Bihar lagged behind. Even though there are some faint signs of catching-up (particularly in Bihar and Madhya Pradesh), 'divergence remains the order of the day' (Corbridge et al. 2013: 157). 
This is particularly worrying in the Indian context for at least three reasons. First, current estimates of inequality might severely underestimate the problem. Drèze and Sen (2013) note that the calculation of the Gini coefficient ${ }^{14}$ for India is based on consumption expenditure, whereas in most other parts of the world it is based on income. The former underestimates the extent of inequality and recent research by the World Bank suggests that India's 'real' Gini coefficient might be comparable to that of some of the most unequal countries in the world like Brazil and South Africa (p. 503). Second, economic inequalities build on (and reinforce) appalling social inequalities, especially in terms of caste and gender relations. Third, India's human development indicators are abysmal. Drèze and Sen (2013, especially Chapter 3) provide a lucid (and rather depressing) picture of India's human development indicators many of which (including life expectancy, youth female literacy rates, child and infant mortality rates, access to improved sanitation, etc.) are considerably worse than those of much poorer neighbouring countries like Bangladesh and even Nepal (not to mention China or Brazil). Child malnutrition rates are worse - in many instances much worse than virtually all sub-Saharan African countries. ${ }^{15}$ This means that inequalities are likely to increase further in the future, since poor people's capabilities - and therefore their chances of escaping poverty - are not improving much or are improving at an excruciatingly slow pace.

Even leaving these considerations aside (and there is no reason why we should), growing inequality is not 'a lesser problem' (Panagariya 2008). Topalova (2008) shows that, had growth been neutral, poverty would have declined much more rapidly. This 'missing' poverty reduction amounts to 22 and 76 per cent for rural and urban India, respectively. Additionally, some recent studies argue that high levels of inequality hinder economic growth itself (Ostry et al. 2014), thus further reducing the pace of poverty reduction.

To sum up, the economic reforms benefited mainly elite groups in both urban and rural areas. Poverty did decline, but at a frustratingly slow pace, while non-income dimensions of poverty remain among the most severe in the world. In some states, multi-dimensional poverty is as extreme as in sub-Saharan Africa (Alkire and Santos 2010). It is also worth noting that the living conditions of the bottom decile of the population have hardly improved at all in recent decades (Corbridge et al. 2013, Chapter 3). This is not only due to the effects of globalisation and of the market-oriented economic reforms; it is also to a significant extent a reflection of power relations within India's society.

\section{Conclusions}

The story of India's economic reforms is the story of the enduring power of elite groups in India's politics. In short, the 'dominant proprietary classes' that had been able to substantially direct economic policies before 1991, are still in a position to influence economic policymaking to their advantage. The big business community, despite some initial opposition to liberalisation, rapidly became its stronger supporter. The community was able to colonise highly profitable areas hitherto reserved for the public sector, benefited from substantial tax incentives and received massive amounts of implicit and explicit subsidies. The bureaucracy still enjoys ample discretionary powers that allow it to significantly influence economic activity. ${ }^{16}$ The rich farmers were able to prevent painful reforms in the agriculture sector and, more significantly, were able to maintain a series of highly regressive subsidies on agricultural inputs.

However, one consequence of the economic reforms was that the internal composition of India's 'dominant coalition' changed. On the one hand, the weight of the urban world increased dramatically at the expenses of the agricultural sector. Since 1980, successive central 
governments put at the centre of their developmental strategies the urban middle class and the big business community. The corporate sector in particular has acquired tremendous influence in policy-making and has established a symbiotic relation with the government and with the entire political class, as the continuous emergence of scams involving businessmen and politicians belonging to every political party clearly shows.

On the other hand, the economic reforms changed the internal composition of each 'dominant proprietary class'. As Partha Chatterjee (2011) puts it, the dominance by a 'few "monopoly" houses drawn from traditional merchant backgrounds and protected by the licence and import substitution regime' ended (p. 24). Other, more dynamic firms acquired greater prominence. This is also evident from the relative importance of different business associations. During the heyday of the licence-Raj, the Federation of Indian Chambers of Commerce and Industry (FICCI) dominated the scene and enjoyed a special relationship with the (Congress) government. But since liberalisation, the Confederation of Indian Industry (CII), whose associates include some among the most dynamic and exportoriented firms in the country, acquired a more prominent role (Kochanek 1996). Montek Singh Ahluwalia (2002) 'quantifies' this process of internal recomposition of India's business community when he says that of the top 100 companies for market capitalisation in 1991, half of them are no longer in this group.

The middle class underwent a similar process of internal change. During the first decades after independence this social group was essentially made up of government officials and very few others. Starting at least from the early 1980s, this section of the population started growing exponentially. The economic reforms and the greater role played by the private sector contributed to expand further the middle class that is now the main protagonist of the 'new' India (Fernandes 2006). Its power is mostly evident when the government attempts to reduce subsidies on items like diesel or power. Huge protests usually erupt and the government in most cases has to reverse its decisions. Perhaps more importantly, the middle class matters 'because it dominates the media; because its opinions are the ones that politicians have to hear; and because every election in Indian history has been determined by issues that were first raised by the middle class' (Priya Sahgal, quoted in Fernandes 2006: 173).

The rural world changed significantly with liberalisation. A tiny elite among the farmers benefited from the greater opportunities unleashed by the opening of India's economy. However, the great majority of the peasants suffered from declining public investments, shrinking credit availability and rising cost of agricultural inputs. Medium-sized farmers who decided to turn to commercial crops suffered the most, as witnessed by the very high number of farmers' suicides in the last two decades.

Finally poverty declined, but at a very slow pace, a sign that the economic reforms have not been particularly pro-poor. Too many still live in abject conditions, as evident from India's depressing human development indicators. A few rays of hope emerged with the election of the United Progressive Alliance (UPA) in 2004 on the basis of a very progressive agenda. The UPA did give some substance to its socio-democratic promises and invested an unprecedented amount of resources and political energy to create an embryonic welfare state (Manor 2011a). There are some signs that these policy initiatives, coupled with robust economic growth, did result in a significant amelioration of poor people's lives and that economic growth finally became more inclusive. ${ }^{17}$ It remains to be seen if the new BJP-led government will continue on this path. 


\section{Notes}

1 Licence-Raj: the complex system of regulations, licences and accompanying red tape that was necessary to set up and run a business between 1974 and 1991.

2 In rural areas this percentage was 14 per cent, in cities, 32 per cent.

3 See (van der Veer 1987; Jaffrelot 1996).

4 Corbridge et al. (2013, Chapter 6) note how some states like Uttar Pradesh and Bihar did not enter such a competition mainly because their political systems got structured around identity and caste, rather than around issues of development. However, they note, it seems that at least Bihar has joined the competition after the election of Nitish Kumar as chief minister in 2005.

5 Jos Mooij (2005) reaches similar conclusions.

6 Some recent evidence suggests that, since 2004, growth might have become more inclusive. See James Manor's article in The Indian Express, 24 May 2014.

7 The concept of 'middle class' in India is problematic. What is usually meant by this term is not something in the middle of the social spectrum, but an elite that constitutes, at best, the top 20 per cent of the population. See (Sridharan 2004; Sheth 1999; Fernandes 2006). Corbridge et al. (2013, Chapter 3) note that, if we adopt the definition of 'middle class' for the developing world elaborated by Nancy Birdsall for the World Bank (according to which those with an income above $\$ 10$ a day, but excluding the top 5 per cent of that country are part of this social group), then India, 'even urban India alone, has no middle class' since everyone whose income is more than $\$ 10$ a day is in the top 5 per cent.

8 This is what a number of analysts called 'jobless growth' (e.g. Kotwal et al. 2011).

9 Obviously part of these exceptions and incentives are quite justifiable.

10 Ironically, before the launch of the scheme, the corporate-owned media repeatedly argued that the MGNREGA would bankrupt the country.

11 Accessed online 7 August 2014.

12 This debate has been usefully summarised by Himanshu and Sen (2014).

13 Please refer to Himanshu and Sen (2014), as the data from different years are not truly comparable.

14 The Gini coefficient measures the income distribution of a nation's residents. As such, it is the most common measure on economic inequality.

15 Joint Child Malnutrition Estimates (UNICEF/WHO/World Bank): http://data.worldbank.org/ child-malnutrition accessed on 28 August 2014.

16 Kanchan Chandra (2013) even argued that the number of (discretionary) permits that are needed to run a business is now higher than in the pre-reform period.

17 India Human Development Survey: http://www.ihds.umd.edu accessed on 28 August 2014.

\section{References}

ADB (2012) Outlook 2012: Confronting Rising Inequality in Asia, Manila: ADB.

Ahluwalia, M.S. (2000) 'Economic Performance of States in Post-Reforms Period', Economic and Political Weekly, 35(19): 1637-1648.

Ahluwalia, M.S. (2002) 'Economic Reforms in India Since 1991: Has Gradualism Worked?' Journal of Economic Perspectives, 16: 67-88.

Alkire, S. and Santos, M.E. (2010) Acute Multidimensional Poverty: A New Index for Developing Countries, Oxford: Oxford Poverty and Human Development Initiative Working Paper 38.

Banerjee, A.V. and Duflo, E. (2003) 'Inequality and Growth: What Can the Data Say?' Journal of Economic Growth, 8: 267-299.

Banerjee, A. and Piketty, T. (2005) ‘Top Indian Incomes, 1922-2000’, World Bank Economic Review, 19: 1-20.

Bardhan, P. (1998) The Political Economy of Development in India, New Delhi: Oxford University Press.

Bardhan, P. (2003) Poverty, Agrarian Structure, and Political Economy in India, New Delhi: Oxford University Press.

Baru, S. (2007) 'Strategic Consequences of India's Economic Performance', in B. Raj Nayar (ed.), Globalization and Politics in India, New Delhi: Oxford University Press.

Bhagwati, J. (2007) 'What Went Wrong?', in R. Mukherjee (ed.), India’s Economic Transition, 27-51, New Delhi: Oxford University Press.

Chandra, K. (2013) 'The New Indian State', paper presented at the International Workshop at the Forum for Asian Studies, University of Stockholm, 10 October 2013. 
Chatterjee, P. (2011) 'Democracy and Economic Transformation in India', in S. Ruparelia, S. Reddy, J. Harriss and S. Corbridge (eds), Understanding India's New Political Economy - A Great Transformation?, 17-34, Oxon: Routledge.

Chaudhry, P.K., Kelkar, V.L. and Yadav, V. (2004) 'The Evolution of "Homegrown Conditionality" in India: IMF Relations', Journal of Development Studies, 40 (6): 59-81.

Corbridge, S. and Harriss, J. (2000) Reinventing India: Liberalization, Hindu Nationalism and Popular Democracy, Cambridge: Polity Press.

Corbridge, S., Harriss, J. and Jeffrey, C. (2013) India Today: Economy, Politics and Society, Cambridge: Polity Press.

Das, G. (2000) India Unbound, New Delhi: Viking.

Dasgupta, D., Maiti, P., Mukherjee, R., Sarkar, S. and Chakrabarti, S. (2000) 'Growth and Interstate Disparities in India', Economic and Political Weekly, 35 (27): 2413-2422.

Dash, C.K. (1999) 'India’s International Monetary Fund Loans: Finessing Win-Set Negotiations within Domestic and International Politics', Asian Survey, 39 (6): 884-907.

Datt, G. and Ravallion, M. (2010) 'Shining for the Poor Too?', Economic and Political Weekly, 45 (7): $55-60$.

Deaton, A. (2005) 'Data and Dogma: The Great Indian Poverty Debate', The World Bank Research Observer, 20 (2): 177-199.

Deaton, A. and Drèze, J. (2002) 'Poverty and Inequality in India: A Re-examination', Economic and Political Weekly, 37 (36): 3729-3748.

Dev, S.M. (2004) 'How to Make Rural India Shine', Economic and Political Weekly, 39 (40): 4415-4422.

Drèze, J. and Sen, A. (2013) An Uncertain Glory: India and its Contradictions, New Delhi: Allen Lane.

Fernandes, L. (2006) India's New Middle Class: Democratic Politics in an Era of Economic Reform, Minneapolis, MN: University of Minnesota Press.

Fosu, A.K. (2009) 'Inequality and the Impact of Growth on Poverty: Comparative Evidence for SubSaharan Africa', Journal of Development Studies, 45 (5): 726-745.

Geddes, B. (1994) 'Challenging the Conventional Wisdom', Journal of Democracy, 5 (4): 104-118.

Giuliano, P., Mishra, P. and Spilimbergo, A. (2012) Democracy and Reforms: Evidence from a New Dataset, NBER Working Paper 18117, Cambridge, MA.

Haggard, S. and Kaufman, R.R. (1994) 'The Challenges of Consolidation', Journal of Democracy, 5 (4): 5-16.

Himanshu (2007) 'Recent Trends in Poverty and Inequality: Some Preliminary Results', Economic and Political Weekly, 42 (6): 497-508.

Himanshu and Sen, K. (2014) Revisiting the Great Indian Poverty Debate: Measurement, Patterns, and Determinants, Brooks World Poverty Institute Working Paper 203, Manchester.

Jaffrelot, C. (1996) The Hindu Nationalist Movement and Indian Politics: 1925 to the 1990s, London: Hurst $\& \mathrm{Co}$.

Jayadev, A., Motiram, S. and Vakulabharanam, V. (2011) 'Patterns of Wealth Disparities in India 19912002', in S. Ruparelia, S. Reddy, J. Harriss and S. Corbridge (eds), Understanding India's New Political Economy - A Great Transformation?, 81-100, Oxon: Routledge.

Jenkins, R. (1999) Democratic Politics and Economic Reform in India, Cambridge: Cambridge University Press.

Joshi, V. and Little, I.M.D. (1994) India: Macroeconomics and Political Economy, 1964-1991, Washington, DC: World Bank Publications.

Kochanek, S. (1996) 'Liberalisation and Business Lobbying in India', The Journal of Commonwealth and Comparative Politics, 34 (3): 155-173.

Kohli, A. (2006) 'Politics of Economic Growth in India, 1980-2005: Part I: The 1980s', Economic and Political Weekly, 41 (14): 1361-1370.

Kohli, A. (2012) Poverty Amid Plenty in the New India, Cambridge and New York: Cambridge University Press.

Kotwal, A., Ramaswami, B. and Wadhwa, W. (2011) 'Economic Liberalization and Indian Economic Growth: What's the Evidence?' Journal of Economic Literature, 49 (4): 1152-1199.

Kurian, N.J. (2000) 'Widening Regional Disparities in India: Some Indicators', Economic and Political Weekly, 35 (7): 538-550.

Maiorano, D. (2014) 'Continuity amid Change in India's Political Economy from 1980 to 2004', Economic and Political Weekly, 49 (9): 44-54.

Maiorano, D. (2015) Autumn of the Matriarch - Indira Gandhi's Final Term in Office, London and New York: Hurst \& Co./Oxford University Press. 
Manor, J. (1987) 'Tried, then Abandoned: Economic Liberalisation in India', IDS Bulletin, 18 (4): 39-44.

Manor, J. (2011a) 'Did the Central Government's Poverty Initiatives Help to Re-elect it?' in L. Saez and G. Singh (eds), New Dimensions of Politics in India - The United Progressive Alliance in Power, 13-25, Oxon: Routledge.

Manor, J. (2011b) 'The Congress Party and the "Great Transformation", in S. Ruparelia, S. Reddy, J. Harriss and S. Corbridge (eds), Understanding India's New Political Economy - A Great Transformation?, 201-220, Oxon: Routledge.

Maravall, J.M. (1994) 'The Myth of the Authoritarian Advantage', Journal of Democracy, 5 (4): 17-31.

Mooij, J. (ed.) (2005) The Politics of Economic Reforms in India, New Delhi: Sage Publications.

Nayar, B.R. (1998) 'Political Structure and India's Economic Reforms of the 1990s', Pacific Affairs, 71 (3): 335-358.

Nayar, B.R. (2001) Globalization and Nationalism: The Changing Balance of India's Economic Policy, 19502000, New Delhi: Sage Publications.

Ostry, J.D., Berg, A. and Tsangarides, C.G. (2014) Redistribution, Inequality and Growth, Washington, DC: International Monetary Fund.

Panagariya, A. (1994) 'India: A New Tiger on the Block?' Journal of International Affairs, 48 (1): 193-221.

Panagariya, A. (2008) India: The Emerging Giant, New York: Oxford University Press.

Patnaik, P. and Chandrasekhar, C.P. (2007) 'The Indian Economy under "Structural Adjustment”, in R. Mukherjee (ed.), India's Economic Transition, 52-86, New Delhi: Oxford University Press.

Przeworski, A. (1991) Democracy and the Market: Political and Economic Reforms in Eastern Europe and Latin America, Cambridge: Cambridge University Press.

Radakrishna, R., Shenoi, P.V. and Thorat, Y.S.P. (2007) Report of the Expert Group on Agricultural Indebtedness, Banking Division, Department of Economic Affairs, Ministry of Finance Government of India, New Delhi.

Ravallion, M. (2009) A Comparative Perspective on Poverty Reduction in Brazil, China and India, World Bank Policy Research Working Paper 5080, Washington, DC, 71-104.

Reddy, D.N. and Mishra, S. (eds) (2009) Agrarian Crisis in India, New Delhi: Oxford University Press.

Ruparelia, S. et al. (2011) 'Introduction: India's Transforming Political Economy', in S. Ruparelia, S. Reddy, J. Harriss and S. Corbridge. (eds), Understanding India's New Political Economy - A Great Transformation?, 1-16, Oxon: Routledge.

Sarkar, S. and Mehta, B.S. (2010) 'Income Inequality in India: Pre- and Post-Reform Periods', Economic and Political Weekly, 45 (37): 45-55.

Sengupta, M. (2008) 'How the State Changed Its Mind: Power, Politics and the Origins of India's Market Reforms', Economic and Political Weekly, 43 (21): 35-42.

Sheth, D.L. (1999) 'Secularisation of Caste and Making of New Middle Class', Economic and Political Weekly, 34 (34/35): 2502-2510.

Sridharan, E. (2004) 'The Growth and Sectoral Composition of India's Middle Class: Its Impact on the Politics of Economic Liberalization', India Review, 3 (4): 405-428.

Topalova, P. (2008) India: Is the Rising Tide Lifting All Boats? IMF Working Papers 08/54, Washington, DC.

Vaidyanathan, A. (2006) 'Farmers' Suicides and the Agrarian Crisis', Economic and Political Weekly, 41 (38): 4009-4013.

Vakulabharanam, V. and Motiram, S. (2011) 'Political Economy of Agrarian Distress in India since the 1990s', in S. Ruparelia, S. Reddy, J. Harriss and S. Corbridge (eds), Understanding India's New Political Economy - A Great Transformation?, 101-126, Oxon: Routledge.

Varshney, A. (2007) 'Mass Politics or Elite Politics? Understanding the Politics of India's Economic Reforms', in R. Mukherjee (ed.), India's Economic Transition, 146-169, New Delhi: Oxford University Press.

Van der Veer, P. (1987) “'God must be Liberated!” - A Hindu Liberation Movement in Ayodhya', Modern Asian Studies, 21 (2): 283-301. 


\title{
14 \\ DIVIDED WE STAND \\ The Indian city after economic liberalisation
}

\author{
Nandini Gooptu
}

Mahatma Gandhi's words that India lives in its villages are still a truism. But the accelerating pace of urbanisation suggests that, much before the close of this century, India will indeed live in its cities. ${ }^{1}$

In the wake of economic liberalisation in the early 1990s, the city has now displaced the village in public imagination as the quintessence of India as a rising, modern global power. Indeed, urban India is the microcosm of changes now sweeping through the country. Cities have witnessed the most rapid and thorough transformation, encompassing the built environment, governance, class relations, politics, work cultures, consumption patterns, lifestyles, and personal and social identities. Three hundred and seventy-seven million people, comprising of 31.2 per cent of the country's population, lived in Indian cities at the time of the 2011 Census, compared to 27.8 per cent in 2001 (Nijman 2012). The Twelfth Five Year Plan (2012-2017) of the Government of India estimates that urban population will rise to 600 million by 2031 (Planning Commission 2013: 318), amounting to an increase of over 200 million in twenty years. The international private consultancy firm, McKinsey Global Institute, projects that by 2030 over 70 per cent of Indian GDP will be produced in its cities, which could also generate 70 per cent of net new jobs (McKinsey Global Institute 2010: 13). In terms of this sheer anticipated scale of expansion, the city has captured the imagination of both the state and the private corporate sector as the most important engine of national growth and development and as the site of market expansion and investment. This spirit of urban optimism is reflected in the Jawaharlal Nehru National Urban Renewal Mission (JNNURM), India's largest ever urban development initiative, launched in 2005, driven by a shared government and private corporate imperative to transform the city. This buoyant perspective is, however, belied by growing evidence of urban class tensions and exclusionary forms of urbanisation, as evinced most glaringly in the mass displacement of the poor from urban land to give way to commercial development or in the activism of middle-classdominated neighbourhood Residents' Welfare Associations (RWAs) to consolidate private residential enclaves and secure better conditions of living for themselves by marginalising the poor. Indian city administration also demonstrates 'a firmly entrenched class-based dualism in the design of infrastructure and services' (Coelho and Maringanti 2012: 41), despite the introduction of myriad development interventions to cater to the basic needs of 
the poor to fulfil a stated official goal of inclusive development. The Indian city today, then, is a contested and divided terrain, riven by contradictions.

\section{Large and small towns in India's urbanisation}

The nature and rate of urbanisation and urban growth have elicited multiple interpretations, notwithstanding an emerging consensus about the importance of the city in India's future development and the indubitable fact that, in absolute terms, cities are the homes of hundreds of millions of Indians. The supposed steady growth of large cities, as a vindication of the direction of travel of economic policy since the 1990s, is celebrated in official urban policy, as well as by private consultancy firms, like McKinsey or Ernst and Young, that now increasingly advise the government, while they also shape market and investment strategies of the private sector. However, there is also an attendant, often exaggerated, fear of potential problems caused by unrelenting and unsustainable urban growth. The continued high incidence of urban poverty also elicits a moral panic about slum proliferation and the consequent decline in quality of life for all. These perceived threats to the vision of cityled economic development have contributed to an emphasis on infrastructure development (transport routes, housing, water supply, sanitation, solid waste management), local government reforms, financial capacity building and liberalised land markets. At the same time, market-driven urban economic growth is vigorously promoted, with its anticipated capacity to attract investment, generate employment and raise living standards, including that of the poor (Planning Commission 2013: Chapter 18; McKinsey Global Institute 2010).

Yet, to complicate and cast doubts on this policy narrative, urban growth has not, in fact, been on a steady upward trajectory from the 1990s, and urbanisation is much lower in India than in comparable developing countries and emerging economies. While 31 per cent of the population of India lives in cities, the comparative figures are 45 per cent in China, 54 per cent in Indonesia, 78 per cent in Mexico and 87 per cent in Brazil (Planning Commission 2013: 318). The overall national rate of urban population growth was 3.83 per cent, between 1971 and 1981, but declined to 2.73 per cent between 1991 and 2001, in the decade following economic liberalisation (Kundu, A. 2011: 8). This has been attributed to a slow pace of urban employment generation and rise in unemployment, thus discouraging inward migration into cities (Kundu 2003). Meanwhile, contrary to the official view of runaway city growth, India's megacities, with several million people, have been declining: Mumbai's growth rate dropped from 30.47 per cent during 1991-2001 to 12.05 per cent during 2001-2011, Delhi from 52.24 per cent to 26.69 per cent, and Kolkata from 19.60 per cent to 6.87 per cent (Nijman 2012: 11). During 2001 and 2011, a modest increase in urbanisation was registered over the previous decade. Urban population grew annually by 2.76 per cent between 2001 and 2011, as compared to 2.73 per cent between 1991 and 2001 (Kundu 2012: 225), and decadal urban growth increased from 31.2 per cent to 31.8 per cent in that period (Nijman 2012:10). While urban population growth might have been a consequence of distress migration caused by the decline of agriculture in this period and the crisis of rural livelihood, evidence suggests that population increase relating to poverty-induced migration from the countryside had a limited impact on urbanisation. Instead, Kundu shows an increase in migration among higher-income groups in search of economic mobility through employment, business or higher education in towns (Kundu 2012), which is reflected in significant regional variations and the concentration of urbanisation in economically advanced states and areas.

Urbanisation in India then has been much more modest than projections of hyperurbanisation of large cities would have us believe. However, a striking and novel feature of 
urbanisation in this period is the phenomenal increase in the number of urban centres, from 5,161 in 2001 to 7,935 in 2011, amounting to an increase of 54 per cent. This increase has been caused primarily by the addition of 2,532 new smaller settlements at the bottom of the urban system, called census towns, thus tripling their previous number (Nijman 2012:11). Census towns are those with a population of 5,000 or over, with less than a quarter of the male population engaged in agriculture, and a population density of at least 400 per square kilometre. Unlike 'statutory towns', they lack a designated urban local council, a corporation, a municipality or a town panchayat, but their population concentration and the sectoral weight of non-agricultural occupation earn them the status of 'town' in the census. Vital to India's recent urbanisation, then, are these census towns as well as other smaller urban settlements that point to a dispersed pattern of urbanisation. They testify to a process of autonomous urban growth from below, or 'subaltern urbanisation', without any deliberate planning or without being dependent on, or offshoots of, proximate larger urban centres (Denis et al. 2012). This suggests that urban development strategies of the JNNURM variety on a grand scale for large cities are largely irrelevant to much of the urban system in India.

Rather than relying on any large infrastructural projects or planned urban development strategies to attract investment, as promoted by government policy, these smaller towns have developed due to a variety of reasons. Their growth has been driven by local enterprises that have capitalised on, or adapted to, emerging economic conditions in a liberalised market with both local and global reach. Harda (population: 67,394) in Madhya Pradesh, for instance, has been transformed through an expansion of agro-commercial activities in the wake of market reforms and technological change in the local and regional wholesale grain business (cited in ibid; Krishnamurthy 2013). Tiruppur (population: 444,352) in Tamil Nadu, in contrast, is an example of provincial globalisation, having developed as a centre of textile manufacturing, linked with the export industry and integrated in the global value chain of garments, supplying to major retailers around the world. Kochi (population: 601,574) in Kerala has rapidly developed with the expansion of new housing, commercial activities and retail outlets in response to the inflow of remittances from workers in the Middle East. Tiruchengode in Tamil Nadu (population: 95,335) grew as a centre for education, drawing students from the local region as well as other parts of India and abroad, while also developing private healthcare services to cater to its rural hinterland. At the same time, it developed specialised production units for lorry engineering and bore-well rig assembly, with a regional, national and overseas market (Raman 2014). Denis et al. (2012) cite further drivers of such 'subaltern urbanisation', for instance, the lower cost of power, land and taxes as well as limited local regulations attracting entrepreneurs to these towns in preference to larger cities.

India's economic growth in general as well as urbanisation in particular are often considered to be 'jobless', especially due to low levels of industrialisation and the enclaved development of financial and IT and IT-enabled services in a handful of 'global' and large cities with a limited capacity to generate new jobs. Employment growth is believed to be mainly of an informal variety and concentrated in the expanding construction industry and service sectors of the consumer economy, offering low-skilled or unskilled, and low-paid work (Nijman 2012:11; Kundu, A. 2011, 2012). Yet the variety of small and medium-sized towns that have developed in recent decades may point to a greater diversity of livelihood and occupational opportunities relating to the specific configuration of the economy of each urban centre (Denis et al. 2012), although this does not necessarily imply upward economic mobility. Indeed, levels of urban poverty remain high with 26.4 per cent of the urban population below the poverty line, even according to the government's own current 
estimates, ${ }^{2}$ and smaller towns, in particular, suffer from a higher incidence of poverty than larger towns (Sharma 2012: 65).

While metropolitan megacities are declining at one end of the urban spectrum, and smaller towns have emerged as new centres of dynamism at the other end, medium-sized or larger provincial cities with populations over 1 million, numbering fifty-three according to the 2011 census (identified as Class I towns), have also assumed increasing importance in India's urban system and they account for 43 per cent of the urban population. Several of them are considered to be among the top hundred fastest growing cities in the world, according to the City Mayors Foundation, an international think tank on urban affairs. ${ }^{3}$ Rather than being focused on large metropolises, then, urbanisation in India is now occurring across the board (Mukhopadhyay and Maringanti 2014). Moreover, smaller towns and million-plus cities are together now seen as the sites of most extensive market expansion. These are believed to be the homes of India's growing, upwardly-mobile middle classes, committed to high levels of consumption and aspirational lifestyles. In 2008, Ernst and Young published a report entitled The Dhoni Effect: Rise of Small Town India, which calculated that while 40 per cent of urban disposable income was to be found in metropolitan centres in 2001, by the end of 2007, their share had reduced to about 30 per cent. The remaining 70 per cent came from twenty-two key urban towns (KUTs) and the rest of urban India (ROUI). Indeed, the report suggested that some 'non-metros' could boast higher levels of affluence than 'metros'. With reference to the small-town origin of India's highly enterprising and ambitious cricket captain, M.S. Dhoni, in its title, the report argued that non-metropolitan middle classes embody the new enterprising, aspiring, upwardly-mobile, consumer India.

Not all is, however, thriving in non-metropolitan India, especially in rapidly growing smaller towns with a population of less than 1 million. Kalpana Sharma recounts the disorganised state of urban local administration, the woeful inadequacy of infrastructure and essential services in these towns, and the significant skewing of these limited services in favour of the privileged, leaving the poor in appalling conditions (Sharma 2012). The municipal financial base of these towns and their administrative capacity are highly limited, and their infrastructure has failed to keep pace with population growth. Only megacities, million-plus cities and a handful of smaller towns of touristic or other significance had benefited from infrastructural investment through JNNURM, which was belatedly extended in the second extended phase under the Twelfth Plan to smaller towns, in recognition of their growing importance in the urban system, as compared to large urban centres that have hitherto been the targets of government policy.

\section{Urban development, reconfiguration of space, capital and class}

With cities, especially larger ones, being seen to propel economic growth in post-liberalisation India, they have come to be the focus of extensive, and arguably unprecedented, development policies. JNNURM, launched in 2005 for seven years and extended for a further two years until March 2014, epitomised the new approach to city development (Mahadevia 2006). According to the JNNURM Mission Statement, the realisation of the potential for high productivity of cities was 'contingent upon the availability and quality of infrastructure services', and this, in turn, required that 'private sector efficiencies ... be inducted in development, management, implementation and financing of projects, through Public Private Partnership (PPP) arrangements'. ${ }^{4}$ Two key elements of JNNURM, then, were infrastructure development and PPP, targeting megacities and million-plus urban centres, and seeking to turn many of them into 'world-class' cities. To achieve this, JNNURM was 
designed to help liberalise the urban land market, extend the commodification of land, and sweep away legal and institutional barriers to incentivise large-scale development of commercial projects under private initiative. Most notable in this respect is the removal of obstacles placed by the Urban Land Ceiling Act of 1976 that limits the extent of land ownership and thus impedes large-scale investment on land. Cities in receipt of JNNURM funds were under the condition that they needed to remove urban land ceiling obstacles.

If the projected vision of the state was to 'encourage reforms and fast track planned development of identified cities', ${ }^{5}$ JNNURM has been analytically identified as 'the official carrier of neoliberal urbanism' (Banerjee-Guha 2009). Drawing upon broader theories of urban institutional restructuring, spatial transformation, capital accumulation and gentrification, advanced variously by David Harvey, Neil Brenner and Nik Theodore, Roger Keil, Neil Smith and others, Banerjee-Guha (2009) has argued that the urban development strategy of JNNURM exemplified the redevelopment and revalorisation of urban land as the key instrument for capital accumulation. This process of land development displaced and dispossessed the poor from valuable space and prime real estate, often through force and coercion, and then reconfigured the built environment for upgraded and exclusive use by the privileged and the well-off, the gentry, thus closing the rent gap (Banerjee-Guha 2009; Whitehead and More 2007). In this process, private investors and the corporate sector have helped to design urban development plans and shape the course of local development policies. They capitalised on the new institutional arrangements for PPP under JNNURM and exerted direct influence over the parastatal agencies responsible for urban development, often in alliance with international consultancy firms such as McKinsey. By virtue of their privileged access to the institutional arenas of urban development policies, private developers have also cornered high value land at low cost, engaged in land grabbing and increased their control over urban space, be it for lucrative construction activities, land speculation or urban 'beautification' projects in tune with the preferences and predilections of the elite (ibid.; Mahadevia 2011).

In addition to enabling capital accumulation through real estate, assisted by new institutional arrangements, JNNURM and related urban development policies also have an obvious class dimension. It is now widely acknowledged that urban development policies, the morphological transformation of the built environment, the drives to 'beautify' and sanitise urban neighbourhoods, have been increasingly and significantly skewed in favour of the middle and upper classes, with an aim to making cities attractive for them, and to entice entrepreneurial, managerial and executive classes, not to mention investors - national and international. On this subject, Bhattacharya and Sanyal (2011) have drawn on the theoretical work of Saskia Sassen, and Michael Hardt and Antonio Negri to argue that urbanisation in India has also been characterised by the construction of modern, new townships and gated residential enclaves, designed in the image of global cities, away from the perceived filth and squalor of the poor and bypassing the congestion and over-crowding of older parts of the city. This privatised and 'by-pass model' of urban development, they argue, arises from the imperative to meet the needs of a new class that provides 'immaterial labour' through their intellectual work in the globalised financial and IT sectors in the new private corporate economy. They have gained hegemonic cultural status by virtue of their overwhelming importance in India's knowledge economy, which is reflected in the pattern of urban transformation. While being located at the heart of the modern corporate sector, this class relies on the labour of those in the informal sector of the 'need' or 'survival' economy, which remains excluded from modern capitalism and stays outside the circuit of capital, even while it is reproduced and constituted by the operation of capital. This form 
of urban economic dualism, along with gentrification and privatised 'by-pass urbanisation', have created an exclusionary and segregated process of urbanisation in India's large cities and sharpened urban class differences. While one strand of JNNURM is infrastructure development, the other is to ensure basic services for the poor, including housing and upgrading or improvement of slums. The latter has paradoxically provided an alibi in Delhi, Mumbai, Ahmedabad and other large cities to uproot vast numbers of the poor from their existing habitat on prime sites and relocate them in distant areas, often in urban outskirts. Although the stated rationale of such mass relocation is to improve the housing conditions of the poor, evidence suggests that their displacement reproduces the poverty of the affected groups (Coelho et al. 2012), thus reinforcing and augmenting inequality, polarisation and segregation in the city along class lines.

Slums and pavement dwellers as well as street vendors, who have been the targets of displacement in the above ways, have also been outlawed in dominant public discourse as law-breakers on grounds of their supposedly 'illegal' occupation of public land (Ghertner 2008; Eckert 2014). ${ }^{6}$ By extension, they are condemned, not only as encroachers on land, but as interlopers in the city itself. At the heart of this is a highly charged and emotive cleavage between the 'outsider' or 'alien' versus the 'insider' or 'citizen-resident' of the city. The 'outsider' is seen as being parasitic on the urban economy for not apparently contributing to the new entrepreneurial and ownership economy of liberalised India, in contrast to the home-owning, hard-working, wealth-generating urban middle and upper classes. Being engaged in a range of 'informal' economic activities, slum dwellers, and the poor more generally, are considered a burden and a drag on urban economies. This view harbours a notion of the obsolescence or redundancy of certain sectors of the urban economy and of urban residents. The poor are considered responsible for jeopardising urban regeneration and economic growth, and in particular, for preventing cities from achieving 'global' or 'world-class' status in today's globalised economy. To counter this in an inclusive mode of urban development, the poor have been sought to be integrated into the market and transformed into economic entrepreneurs through targeted policies of micro-credit and enterprise development, although the extent of the impact of this on poverty alleviation is limited.

Much anger is vented at these putative trespassers in the city, for draining urban resources and causing uncontrolled urban population growth, raising the spectre of a demographic menace that exerts intolerable and unsustainable pressure on public services and infrastructure. In turn, they are singled out for depriving 'legitimate' urban citizens from enjoying a decent quality of life, and forcing them to suffer from anything ranging from impregnable traffic congestion to disease contagion. An increasingly strident urban middle-class environmentalism has emerged (Baviskar 2006; Ghertner 2008, 2011c; Kumar 2012), building palimpsestically on an older trope of the poor as a threat to public health (Gooptu 2001, 2014), now emphasising their detrimental impact on sustainable urban development. Not surprisingly, government and municipal initiatives to remove slums have enjoyed widespread approval, if not outright support, for at long last enforcing the rights of middle-class citizens to a clean and aesthetically pleasing habitat and for finally ceasing to pamper the undeserving poor, who are electorally mobilised and can thus supposedly extract unreasonable and undue demands from politicians who rely on the poor as 'vote banks'. Middle-class wrath against the urban poor and an attitude akin to 'social Darwinism', according to Breman (2003), have come to underpin and confer public legitimacy on the force and coercion deployed in slum demolition initiatives. Court judgements, that manifestly undermine constitutional rights of citizens, have been hailed for sending a long overdue decisive message to the poor that they have no rights or entitlements 
in the city, and must face punitive consequences for their apparently lawless action (Ghertner 2008). The poor are also at the receiving end of policing and preventative laws that penalise their unwanted activities, including small-scale mobilisation or acts of resistance, even though these do not violate the law (Eckert 2014). 'The effect', as Eckert argues with her study of Mumbai, 'is to thwart the opportunities for marginalised segments of Indian society to struggle for their rights, resist exploitative relations, or simply become independent from their patrons' (ibid.: 291).

\section{Subaltern urbanisation, urban transformation and politics}

Accounts of neoliberal urbanism in India, as discussed above, tend to be metro-centric, and they emphasise the importance of land itself as the key source of accumulation. Studies of small-town growth suggest a different trajectory of non-metropolitan, 'subaltern urbanisation', as discussed above. In Tiruchengode in Tamil Nadu, for instance, Raman (2014) shows changing patterns of land use in spatial transformation and in the expansion of the built environment, but this does not conform to the neoliberal model of land development, accumulation by dispossession and gentrification of the metropolitan variety. Between 2001 and 2011, the built-up area of Tiruchengode increased dramatically by 66 per cent, from 6.39 to 10.63 square kilometres. Land here was used to locate various new firm clusters, such as that of lorry engineering and rig-making to drill bore-wells, supplying both to nearby states and to overseas markets in west Asia and South Africa. Land was also used to set up educational institutions that attracted students from the region, and also from north India and even Korea and Zimbabwe, around whom a rental market for housing and new housing complexes have also developed. Simultaneously, transport networks emerged to ferry teachers and students around the region. In all these, local entrepreneurs leveraged their long-standing political connections, dating back to the colonial period and the nationalist movement, to get favourable policies for taxation and interstate transport networks that were vital to the development of their businesses. This case highlights the importance of local, historical and contingent factors, both political and economic, while also showing the influence of market expansion and integration after economic liberalisation, linking the local to the regional, national and international. This is aligned with the pattern of 'subaltern urbanisation', discussed above, and suggests that theories of neoliberal urbanism do not travel well beyond metros.

Indeed, the analytical lens of neoliberalism, used in analogy with urban transformation in the West and relying on theories generated by such processes, is now increasingly seen as being of limited or partial explanatory value to understand urban change in India. The universal application of neoliberalism itself as an analytical tool is no longer considered efficacious in the face of myriad manifestations of 'actually existing neoliberalism' (Brenner and Theodore 2002), the expression of 'neoliberalism as exception' (Ong 2006), and neoliberalising projects unfolding in a variety of ways without conforming to a theoretical or ideological blueprint (Peck 2010). The shift in emphasis away from neoliberalism in studying Indian urbanisation does not merely constitute an analytical quest for local contextual variations and mutations of neoliberalism, but entails an expansion of the analytical repertoire to include other concerns, and indeed to recognise the contingent nature of urban transformation, that often does not follow a neoliberal logic. A move away from 'generalised theories of large-scale sociological processes' also focuses attention on diverse urban imaginaries and the everyday grounded realities, lived experiences and spatial politics of the city, as Anjaria and McFarlane (2011:2) point out. They advocate 'an approach 
to transformations in city space as a contingent set of arrangements produced by a diverse mix of historical and contemporary actors and processes' (ibid.: 6).

In this vein, Shatkin and Vidyarthi (2014: 3) emphasise what they call the 'chronic street level subversion' of policies, as well as the 'prevalence of forces within the state that militate against any rescaling of state power to empower municipal governments and the forces of capital'. They draw attention to 'new forms of political action over urban space' (ibid.: 7). As it is now well known, such politics surrounding land have emerged both from above and below. It is the interaction of, or confrontation between, the two that produces specific outcomes in urban spatial change. Elite mobilisation from above in the institutional arenas of urban development, in alliance with middle-class activists seeking to remove settlements of the poor, may be consistent with the terms of neoliberal urbanism and gentrification. However, these could be derailed by political strategies from below by the poor, who as 'vote banks' exert pressure on politicians to modify or abandon such projects. Big vision, corporate-inspired, word-class city branding projects need to be tempered in response to the exigencies of electoral and populist politics. Shatkin and Vidyarthi (2014) emphasise the rise of 'network politics' that relies on forging alliances among diverse actors to leverage particular outcomes in urban development. The range of such political actors now include dominant corporate groups and private consultancy organisations (Weinstein et al. 2014), alongside more familiar political and bureaucratic entities, as well as NGOs, associations of citizens and other private interests. If this wide range of elite and middle-class political actors is crucial in shaping urban development, Benjamin (2008) has highlighted the role of the poor through the concept of 'occupancy urbanism' to suggest that they use institutions and engage in a diverse range of actions to stake their claim to services and contested territories, and even 'pose multiple crises for global capital' (ibid.: 719). Similarly, going against an understanding of top-down urban change, in which the poor are cast either as victims or protestors, Ghertner (2011b) recounts how the idea of the world-class global city in Delhi is reinterpreted and recast by the poor as a new form of aesthetic imaginary that they too aspire to in the conception of their ideal home and their urban future. Although Roy (2009) has cautioned against over-reading the political capacity and agency of the poor as implied in the notion of 'occupancy urbanism', nevertheless these above instances demonstrate the importance of both politics and agency, as distinct from the structural logic of neoliberalism, in reshaping space and reimagining the city. Indeed, gentrification itself in the Indian context can be understood not merely as a neoliberal economic process, but as a political one. It articulates middle-class backlash and 'revanchism' against the increasing political assertion and democratic electoral participation of the poor and their heightened democratic aspirations (Gooptu 2011; Fernandes 2006), the reaction against which is manifested, for example, in strident elite attacks on 'vote bank' politics. Elite politics of this kind, in turn, confronts the forces of 'occupancy urbanism', 'street level subversion' and contested visions of the city. However, current evidence suggests that the ability of such politics from below to affect change remains largely confined to small-scale modifications, rather than achieving any substantial shift in either the over-arching agenda or the general direction of urban development policies.

\section{Governance, citizenship and the divided city}

If urban development policies have seen a sea of change in the post-liberalisation period, these have been matched with the introduction of new forms of urban governance. The 74th Amendment to the Indian Constitution in 1992 signalled political urges to improve 
governance through decentralisation and rescaling and reform of the state. This amendment devolved powers to urban local bodies to raise their own finances to manage their own service delivery with greater autonomy, and to engage citizens as active partners in a process of participatory governance through the institution of ward committees in city neighbourhoods (wards are the smallest units in local administration and form electoral constituencies in local councils). The participatory and democratic dimensions of governance reform and the aim of citizen engagement have, however, transpired to be largely the instruments to ensure more efficient urban management, so that cities may fulfil their role as the engines of the economy. This becomes apparent from the JNNURM Mission Statement with its emphasis 'on efficiency in urban infrastructure and service delivery mechanisms', alongside 'community participation, and accountability of ULBs (urban local bodies)/Parastatal agencies towards citizens'. ${ }^{7}$ Even more tellingly, the primacy of efficiency, as well as that of 'financialisation' and an overtly financial role of local governance, are revealed by the conditionalities set for urban local bodies (ULB) that received funds from JNNURM. The conditionalities included modernisation of municipal financial accounting systems, efficient and enhanced assessment and collection of taxes, notably property tax using GIS (Geographical Information Systems), and a move towards full cost recovery for delivering urban services to citizens (Shatkin and Vidyarthi 2014: 11), thus leading to a growing commodification and marketisation (e.g., through the levy of user charges) of what had hitherto been public goods, now redesignated as infrastructural services. Indian local bodies are now expected to function with a more entrepreneurial orientation in a businesslike and cost-efficient fashion, along the lines of profit-making private firms and corporate organisations, following market principles, and by developing a sustainable, independent financial base. This 'corporatisation' is, of course, in conjunction with a more entrepreneurial role that local institutions are expected to play in promoting urban capital accumulation, investment and growth, particularly through PPP, as seen in the previous section. This is reminiscent of David Harvey's (1989) analytical conception that entrepreneurial city governments in the neoliberal era have replaced erstwhile public service-oriented municipal administrations, and espoused 'governance', in place of 'government', to embrace private actors in city management.

Individual citizens, as well as other collective agents and organisations, purporting to represent citizens, are all invited to act as partners in local governance. These include local associations of urban residents, NGOs, community-based organisations (CBOs) and stakeholder groups, some of which are funded and sponsored by government schemes or by overseas aid donors. Moreover, parastatal bodies are given responsibility for local development policies, often by limiting or bypassing the power of elected ULBs, and forging alliances with the private corporate sector. Underlying this process of 'pluralisation' of the state and the parcelling out of state functions to a range of parallel bodies is a wider normative shift away from state-delivered welfarism and a responsibility to provide public goods and services. Instead there is a move towards citizen-led, inclusive practices of mobilisation and management of resources and services. Indeed, new institutional spaces for the direct exercise of citizenship in urban affairs are designed to be opened up by the rescaling and recalibration of the state. Citizens are urged to become involved in sharing the responsibility for purveying local services and bearing the costs. Thus, the citizen here is imagined as a responsibilised, selfgoverned agent, in a neoliberal mode, playing an active role in local affairs. At the same time, citizens in this form of governance are conceived primarily as customers and clients of local councils and consumers of services, who have a transactional relationship with local bodies. They are invited to engage in local municipal affairs to monitor service delivery in the form of social audit. Citizens' charters are introduced to enable active and vigilant citizens to hold local 
bodies accountable and enforce accountability. Systems of IT-based e-governance and a variety of customer-oriented innovations are also advocated for swift responses to citizens' needs and to render the interface between the citizen and the local body more efficient and consumerfocused. For instance, e-grievance redressal mechanisms have been set up in Karnataka to record and handle complaints, relating to local services, swiftly and efficiently (Ranganathan 2012). This is the largest e-governance project in the world and is intended to be scaled up nationally. However, Ranganathan shows that a legalistic, contractual relationship is forged through this form of interface between the individual citizen-customer and the local council, which not only erodes any other form of individual or collective negotiation or contestation, but also abjures any conception of rights, social citizenship or moral responsibility of the state towards citizens and replaces it with a consumer contract that can only be challenged on legal grounds. Not only is citizenship attenuated in this way, but also not everyone is cast as citizens on equal terms. Those unable to fulfil the above role of active consumer-citizen, usually poorer sections, are conceived as urban denizens and identified as population groups of the 'governed' and beneficiaries of local policy, to be targeted for the delivery of various kinds of services (Chatterjee 2004, 2008).

In all this, 'participation' is indeed the stated watchword or touchstone of urban governance today. Highlighting the fact that cities are projected as sites par excellence of participation, Coelho et al. (2013) use the term 'participolis', to describe contemporary Indian cities. However, as they explain, participation and consultation are being used by local bodies largely in instrumental or manipulative ways with the selective co-optation of particular sections of the population, often to push through policies by stealth. Those affected by particular policies are deliberately excluded, notably the poor, who find it hard to access events that Coelho et al. term 'chandelier consultations' (ibid.: 17), held at venues that are beyond the reach of all but the affluent. Moreover, participatory events have a performative or ritual character, carefully orchestrated and designed to generate consent around specific policies and projects. More broadly, they help to embed market discipline and the financialisation of municipal government through the veneer of consent (ibid.). Far from enabling citizens to play a constitutive role in urban policy, participation is ultimately an artifice that depoliticises urban development and manufactures consent.

Notwithstanding the circumscribed nature of participation, the frequently asserted aim of urban governance is to create inclusive cities. However, it is now widely accepted in the analytical literature that governance reforms have increasingly led to the empowerment of elite and affluent groups and the marginalisation of the poor in a number of different ways, notably relating to the role of parastatals, NGOs and RWAs. It is now well recognised that parastatals and nodal development agencies at the regional state level dominate the formulation and implementation of local development policies. These unelected institutions are more powerful than elected local bodies, and they represent a form of local development authority that bypasses elected councils (Benjamin and Bhuvaneswari 2006; Coelho et al. 2013). They are prone to the influence of private corporate interests and powerful groups of the wealthy with economic clout. In cities like Bangalore, dominant economic lobbies like the IT sector have exercised disproportionate influence in local development through the medium of parastatals. The poor have no access to these institutions, the policies of which have a significant impact on them. Instead, to represent their interests, unlike middle classes, who engage in NGO voluntarism and local activism, the poor rely on the patronage of local councillors, politicians and party politics (Harriss 2005). Yet these local politicians and local councils have little or no power to shape the policies of regional state level nodal agencies and parastatals (Benjamin and Bhuvaneswari 2006). These institutional arrangements, then, 
serve to disempower the poor by emasculating the very institutions to which they have access in determining local development.

If parastatals undermine the interests of the poor, civil society organisations (CSOs) and NGOs that work in partnership with local councils and other organisations, could be argued to offer a space to the poor to articulate their interests. Local institutions have developed extensive partnership with NGOs in service delivery and in poverty alleviation programmes, and they act as intermediaries and interlocutors between the poor and the state. NGOs and CSOs are, of course, argued to be the public voice of the poor. They are expected to act as institutions of people-centred development and represent a 'new localism' in governance and urban politics, and thus serve as the vehicles of participation and inclusion of the poor (Pinto 2006). NGOs working with slum dwellers, such as SPARC in Mumbai, have been celebrated for deepening democracy (ibid.; Appadurai 2002). However, other accounts have shown that SPARC failed to represent the interests of its constituents adequately and helped to shore up government policy that ill-serves the poor (Whitehead and More 2007; Roy 2009). Most importantly, as Ananya Roy (2009) has argued, NGOs like SPARC reinforce 'civic governmentality', by consolidating and legitimising the technologies, rationalities and mentalities of rule that underpin regimes of local governance. Thus, cities, as configured by institutions, practices and ideas of governance, relating to both private and state actors, remain exclusionary spaces from the perspective of the poor, despite the upsurge of 'inclusion' as a stated public commitment.

\section{The privatised city}

If the poor have been disempowered and politically marginalised in the above ways, the upper and middle classes have benefited from and gained in power through new institutional innovations. Many cities have seen the emergence of Residents' Welfare Associations (RWAs) as partners of the local council, while the statutory ward committees, as provided by the 74th amendment, to which the poor have access, are largely defunct or paper organisations, or only engaged in limited activities. Instead, RWAs have become highly organised and active institutions. The RWA system offers an institutionalised platform for the exercise of consumer-citizenship in practice. Their formation in urban neighbourhoods has been encouraged by local governments in order to transfer some key responsibilities and to act as allies in pushing through particular policies. These RWAs are disproportionately based in middle-class and affluent areas and they now perform a range of local functions. They are empowered to raise local resources and, with direct access to municipal councils, they have the capacity to corner existing resources at the cost of poorer neighbourhoods. The citizen-government partnerships scheme or bhagidari in Delhi, introduced in 2001, and the Mumbai Advanced Locality Management Programme, are key examples that have encouraged the creation of powerful RWAs. Debolina Kundu (2011) shows the involvement of RWAs in neighbourhood security arrangements, and in dealing with parastatals supplying key services, such as drinking water and sanitation. RWAs maintain roads, parks, community halls, street lights. In Delhi, they have also graduated to involvement in participatory local municipal budgeting, and have been empowered to select and prioritise local development or infrastructural projects and decide on resource allocation. In some cases, they raise funds for capital investment projects in their own locality. Away from the metros, RWAs are powerful in small towns too, such as in Tamil Nadu. In so far as these middle-class RWAs are concerned, they fit the bill of neoliberal responsibilised, enterprising consumer-citizenship in action. 
The power of RWAs should, however, not be over-estimated (Coelho et al 2013). They are not equally influential across India's urban centres. Their relationship with the local state is ambivalent where no formal partnership scheme is in place and they act as self-appointed lobby groups and local community mobilisers. Often RWAs play an important role in the property market and on issues surrounding property value and ownership, and thus compete with each other. RWAs in different localities of a city do not have shared aims and interests. As Srivastava (2014: 408) notes, RWAs of 'super-expensive south Delhi suburbs do not have much in common with the more modest locales in the east of the city - what their residents share is the claim to middle-classness' (emphasis in original). Most importantly though, it is by virtue of this 'claim to middleclass-ness' that RWAs play a significant role in configuring the relationship of the middle and upper classes vis-à-vis the poor.

While RWAs may like to see themselves in terms of activist citizenship and a vibrant civil society, they have evidently developed as key actors in class politics in the city. As the guardians of residential colonies and gated neighbourhoods of the middle and upper classes, they help to protect the distinctive class identity and the guarded and private nature of their neighbourhood communities. In addition to dealing with neighbourhood affairs, in Mumbai and Delhi, RWAs deal with encroachments and unauthorised settlements, and thus become central to a wider politics of control and contestation over urban land involving the poor. In this role, RWAs have launched strident campaigns to keep the poor at bay and turned to the courts to bring about the removal of these settlements of the poor, and to enforce their own rights to a high quality of life in the city, unencumbered by squatters or slum dwellers (Ghertner 2008). The RWA phenomenon points to an exclusionary and privatised process in urban governance, for it disproportionately empowers affluent and middle-class neighbourhoods, who have time and money as well as capacity to engage in local affairs. While the consumer-citizens of these neighbourhoods can rely on themselves and pay to meet their needs, local councils neglect the poor who are unable to do so, intensifying spatial inequality, overlaid with class difference. Furthermore, their approach to the mobilisation of local resources through paid services hastens financialisation and entrenches commodification, both in practice and principle. RWAs have been seen as the instruments of elite capture of local governance (Kundu, D. 2011). Ghertner (2011a, 2014) has argued, however, that RWAs do not represent middle-class capture of the state. Rather, the institutional incentives and arrangements provided by the state, in the form of bhagidari and other kinds of partnership, facilitated the empowerment of middle and upper classes in local politics. By virtue of bhagidari and property ownership, RWAs can access the state, thus 'gentrifying the state' and 'channels of political participation', while displacing the poor from informal linkages with local politicians, thus tilting policies towards the elites.

The politics of RWAs is, however, not merely a function of increasingly structurally skewed urban institutional re-engineering and redesign that serve to empower middle and upper classes. Importantly, they also represent deeper changes in culture and identity in the city, particularly relating to an emerging form of consumer modernity (Srivastava 2014). Srivastava argues that 'the privatised production of spaces of residence, leisure and shopping is a significant context of the making of middle-class activism and that it also gives rise to a broader set of ideas about bounded identities, interests, and rights of the consumercitizen' (ibid.: 409). Real estate development and the proliferation of private housing as well as privatised spaces of consumption and leisure have forged the identity of the consumercitizen as one who realises his or her citizenship within the private space, rather than the public domain, and through consumption and an emphasis on lifestyles that need to be protected. The language of nationalism, Srivastava suggests, has been repositioned and 
anchored within the sphere of the private neighbourhood and in the domestic arena of the family and private home, as aptly captured in his use of the phrase 'national domestic' (Srivastava 2012: 75). He attributes this to 'the consolidation of a relatively recent narrative of intimate and private spaces as the deus ex machina of personal transformation [which] is part of the wider renegotiations of the relationship between the state, the market, and citizens' (ibid.: 75). Not surprisingly, those who see themselves as the middle classes are aspiring to retreat into protected private spaces, with the poor banished from this vision. The city itself is being reimagined as a site of private fulfilment, rather than as a terrain of expression of public, civic culture. As Srivastava argues, the normative national community is now defined in terms of middle-class solidarity and the state is seen as the 'facilitator of individual choice' and 'a "friend" of the middle classes' (emphasis in original), rather than 'a benefactor of the poor' (Srivastava 2014: 414, 430). Srivastava's arguments pertain to large cities, specifically Delhi, and further research is needed to understand the nature of these privatising processes in smaller towns, relating to both entrenched claimants to middle-class status and the emerging, upwardly-mobile, yet precarious, sections, who have been identified to be at the heart of India's burgeoning market economy.

\section{Conclusion}

It is easy to see how in the past 20 years the idea of private ownership has had a huge debilitating impact on urban life. The city has changed from being a congenial space of shared amenities and relationships to a fearful nightmare of private strongholds and walled compounds - insecure, insular and isolated. ${ }^{8}$

Indian cities are often represented as a melting pot of people, spaces and cultures. Inequality is hardly a novel feature here, and urban class relations have, for long, been defined through the politics of space and differential consumption practices and economic experiences. Spatial restructuring has been an ongoing process for decades, if not centuries, in most towns and cities, although the scale and pace of change have been much augmented at certain conjunctures, such as in the later nineteenth- and early twentieth-century period of colonial rule or at the present time. What then are the distinctive features of urban transformation in this era of so-called 'India's urban awakening' (McKinsey Global Institute 2010)? New city imaginaries, with two contradictory visions, now frame urban transition. On the one hand, city development is understood in exclusionary terms as an opportunity for the fulfilment of private aspirations in privatised spaces by middle- and upper-class citizens as well as for private accumulation of capital by investors and corporate interests. On the other hand, the city is projected as a site of inclusion in top-down governance discourse and state rhetoric, though hardly achieving that goal in actual practice. Inclusive tendencies, of course, resonate with popular democratic urges and aspirations, but these are increasingly marginalised or muted by the exclusionary, privatising forces, and inclusion remains a conceit. As the contradiction between inclusion and exclusion plays itself out, Indian cities become increasingly politically contested, spatially unequal, economically stratified and socially divided.

\section{Notes}

1 'The urban century', by Puja Mehra, Business Today, 16 May 2010 http://businesstoday.intoday.in/ story/the-urban-century/1/5568.html [accessed 20 December 2014].

2 'New poverty line: Rs 32 in villages, Rs 47 in cities', Times of India, 7 July 2014. 
3 Website of City Mayors: the world's fastest growing cities and urban areas from 2006 to 2020: urban areas ranked 1 to 100, http://www.citymayors.com/statistics/urban_growth1.html [accessed 20 December 2014].

4 JNNURM, Overview: http://jnnurm.nic.in/wp-content/uploads/2011/01/PMSpeechOverviewE. pdf [accessed 26 December 2014].

5 Ibid.

6 This section is drawn from Gooptu (2014).

7 JNNURM, Overview: http://jnnurm.nic.in/wp-content/uploads/2011/01/PMSpeechOverviewE. pdf [accessed 26 December 2014].

8 'Insecure and insular in urban India' by Gautam Bhatia, The Hindu, 3 December 2014 http://www. thehindu.com/opinion/lead/insecure-and-insular-in-urban-india/article6655769.ece [accessed 20 December 2014].

\section{References}

Anjaria, J. S. and C. McFarlane (2011) Urban Navigations: Politics, Space and the City in South Asia, New Delhi and Abingdon, Oxon: Routledge.

Appadurai, A. (2002) 'Deep democracy: Urban governmentality and the horizon of politics', Public Culture, 14 (1): 21-47.

Banerjee-Guha, S. (2009) 'Neoliberalising the "urban": New geographies of power and injustice in Indian cities', Economic and Political Weekly, 44 (22): 95-107.

Baviskar, A. (2006) 'The politics of the city', Seminar, 516 (Special Issue: 'Shades of green: A symposium on changing contours of Indian environmentalism'): 40-42.

Benjamin, S. (2008) 'Occupancy urbanism: Radicalizing politics and economy beyond policy and programs', International Journal of Urban and Regional Research, 32 (3): 719-729.

Benjamin, S. and R. Bhuvaneswari (2006) 'Urban futures of poor groups in Chennai and Bangalore: How these are shaped by relationships between parastatals and local bodies', in N. G. Jayal, A. Prakash and P. K. Sharma (eds), Local Governance in India: Decentralization and Beyond, New Delhi: Oxford University Press.

Bhattacharya, R. and K. Sanyal (2011) 'Bypassing the squalor: New towns, immaterial labour and exclusion in post-colonial urbanisation', Economic and Political Weekly, 46 (31): 41-48.

Breman, J. (2003) The Labouring Poor in India: Patterns of Exploitation, Subordination, and Exclusion, New Delhi: Oxford University Press.

Brenner, N. and N. Theodore (2002) 'Cities and the geographies of "actually existing neoliberalism", in N. Brenner and N. Theodore (eds), Spaces of Neoliberalism: Urban Restructuring in North America and Western Europe, Oxford: Blackwell.

Chatterjee, P. (2004) The Politics of the Governed: Reflections on Popular Politics in Most of the World, New York: Columbia University Press.

Chatterjee, P. (2008) 'Democracy and economic transition in India', Economic and Political Weekly, 19 April: 53-62.

Coelho, K. and A. Maringanti (2012) 'Urban poverty in India: Tools, treatment and politics at the neoliberal turn', Economic and Political Weekly, 47 (47-48): 39-43.

Coelho, K., T. Venkat and R. Chandrika (2012) 'The spatial reproduction of urban poverty: Labour and livelioods in a slum resettlement colony', Economic and Political Weekly, 47 (47-48): 53-63.

Coelho, K., L. Kamath and M. Vijayabaskar (2013) 'Opening up or ushering in? Citizen participation as mandate and practice in urban governance', in K. Coelho, L. Kamath and M. Vijayabaskar (eds), Participolis: Consent and Contention in Neoliberal Urban India, New Delhi: Routledge.

Denis, E., P. Mukhopadhyay and M-H. Zerah (2012) 'Subaltern urbanisation in India', Economic and Political Weekly, 47 (30): 52-62.

Eckert, J. (2014) 'Preventative laws and the policing of the urban poor', in N. Gooptu and J. Parry (eds), Persistence of Poverty in India, Delhi: Social Science Press.

Fernandes, L. (2006) India's New Middle Class: Democratic Politics in an Era of Economic Reform, Minneapolis, $\mathrm{MN}$ and London: University of Minnesota Press.

Ghertner, D. A. (2008) 'Analysis of new legal discourses behind Delhi's slum demolitions', Economic and Political Weekly, 17 May: 57-66.

Ghertner, D. A. (2011a) 'Gentrifying the state, gentrifying participation: Elite governance programs in Delhi', International Journal of Urban and Regional Research, 35 (3): 504-532. 
Ghertner, D. A. (2011b) 'Rule by aesthetics: World-class city-making in Delhi', in A. Roy and A. Ong (eds), Worlding Cities: Asian Experiments and the Art of Being Global, Oxford: Blackwell.

Ghertner, D. A. (2011c) 'Green evictions: Environmental discourses of a slum free Delhi', in R. Peet, P. Robbins and M. Watts (eds), Global Political Ecology, London: Routledge.

Ghertner, D. A. (2014) 'Gentrifying the state: Governance, participation and the rise of middle class power in India', in G. Shatkin (ed.), Contesting the Indian City: Global Visions and the Politics of the Local, Chichester: John Wiley and Sons, Ltd.

Gooptu, N. (2001) The Politics of the Urban Poor in Early Twentieth-Century India, Cambridge: Cambridge University Press.

Gooptu, N. (2011) 'Economic liberalization, urban politics and the poor', in S. Ruparelia, S. Reddy, J. Harriss and S. Corbridge (eds), Understanding India's New Political Economy: A Great Transformation?, London, New York: Routledge.

Gooptu, N. (2014) 'The construction of poverty in colonial and post-colonial India: An overview', in N. Gooptu and J. Parry (eds), Persistence of Poverty in India, Delhi: Social Science Press.

Harriss, J. (2005) 'Political participation, representation and the urban poor: Findings from research in Delhi', Economic and Political Weekly, 12 March: 1041-1054.

Harvey, D. (1989) 'From managerialism to entrepreneurialism: The transformation in urban governance in late capitalism', Geografiska Annaler. Series B, Human Geography, 71 (1): 3-17.

Krishnamurthy, M. (2013) 'Margins and mindsets: Enterprise, opportunity and exclusion in a market town in Madhya Pradesh', in N. Gooptu (ed.), Enterprise Culture in Neoliberal India: Studies in Youth, Class, Work and Media, London: Routledge.

Kumar, S. (2012) 'Clean air, dirty logic? Environmental activism, citizenship and the public sphere in Delhi', in R. Desai and R. Sanyal (eds), Urbanizing Citizenship: Contested Spaces in Indian Cities, New Delhi: Sage.

Kundu, A. (2003) 'Urbanisation and urban governance: Search for a perspective beyond neo-liberalism', Economic and Political Weekly, 38 (29): 3079-3087.

Kundu, A. (2011) 'Trends and processes of urbanisation in India', Urbanisation and Emerging Population Issues 6: Human Settlement Group, International Institute for Environment and Development (IIED) and Population and Development Branch, United Nations Population Fund (UNFPA) http://pubs.iied.org/10597IIED.html (accessed 20 December 2014).

Kundu, A. (2012) 'Migration and exclusionary urbanisation in India', Economic and Political Weekly, 47 (26-27): 219-227.

Kundu, D. (2011) 'Elite capture in participatory urban governance', Economic and Political Weekly, 46 (10): 23-65.

Mahadevia, D. (2006) 'NURM and the poor in globalising mega cities', Economic and Political Weekly, 5 August: $3399-3403$.

Mahadevia, D. (2011) 'Branded and renewed? Policies, politics and processes of urban development in the reform era', Economic and Political Weekly, 46 (31): 56-64.

McKinsey Global Institute (2010) India's Urban Awakening: Building Inclusive Cities, Sustaining Economic Growth, http://www.mckinsey.com/insights/urbanization/urban_awakening_in_india (accessed 26 December 2015).

Mukhopadhyay, P. and A. Maringanti (2014) 'Articulating growth in the urban spectrum', Economic and Political Weekly, 49 (22): 44-45.

Nijman, J. (2012) 'India's urban challenge', Eurasian Geography and Economics, 53 (1): 7-20.

Ong, A. (2006) Neoliberalism as Exception: Mutations in Citizenship and Sovereignty, Durham, NC: Duke University Press.

Planning Commission, Government of India (2013) Twelfth Five Year Plan (2012-2017): Economic Sectors, Vol. II: New Delhi: Sage.

Peck, J. (2010) Constructions of Neoliberal Reason, Oxford: Oxford University Press.

Pinto, M. R. (2006) 'People-centred development and participatory urban governance: The Mumbai experience', in N. G. Jayal, A. Prakash and P. K. Sharma (eds), Local Governance in India: Decentralization and Beyond, New Delhi: Oxford University Press.

Raman, B. (2014) 'Patterns and practices of spatial transformation in non-metros: The case of Tiruchengode', Economic and Political Weekly, 49 (22): 46-54.

Ranganathan, M. (2012) 'Re-engineering citizenship: Municipal reforms and the politics of "e-grievance redressal” in Karnataka's cities', in R. Desai and R. Sanyal (eds), Urbanizing Citizenship: Contested Spaces in Indian Cities, New Delhi: Sage. 
Roy, A. (2009) 'Civic governmentality: The politics of inclusion in Beirut and Mumbai', Antipode, 4 (1): 159-179.

Sharma, K. (2012), 'Rejuvenating India's small towns', Economic and Political Weekly, 47 (30): 63-68.

Shatkin, G. and S. Vidyarthi (2014) 'Introduction: Contesting the Indian city: Global visions and the politics of the local', in G. Shatkin (ed.), Contesting the Indian City: Global Visions and the Politics of the Local, Chichester: John Wiley and Sons, Ltd.

Srivastava, S. (2012) 'National identity, kitchens and bedrooms: Gated communities and new narratives of space in India', in M. Liechty, C. Freeman and R. Heiman (eds), The Global Middle Classes: Theorizing through Ethnography, Santa Fe: School of Advanced Research Press.

Srivastava, S. (2014) 'Urban spaces, post-nationalism and the making of the consumer-citizen in India', in P. Chatterjee, T. G. Thakurta and B. Kar (eds), New Cultural Histories of India, New Delhi: Oxford University Press.

Weinstein, L., N. Sami and G. Shatkin (2014), 'Contested developments: Enduring legacies and emergent political actors in contemporary urban India', in G. Shatkin (ed.), Contesting the Indian City: Global Visions and the Politics of the Local, Chichester: John Wiley and Sons, Ltd.

Whitehead, J. and N. More (2007) 'Revanchism in Mumbai? Political economy of rent gaps and urban restructuring in a global city', Economic and Political Weekly, 23 June: 2428-2434. 


\title{
15 \\ INDIA'S MIDDLE CLASSES IN CONTEMPORARY INDIA
}

\author{
Leela Fernandes
}

\section{Introduction}

In recent years, India's middle classes have emerged as a central socio-economic and political force in contemporary India. In the wake of policies of economic liberalization that began in the 1980s and have accelerated since the 1990s, Indian and global public discourses have focused on the size and economic force of India's middle classes. Market research firms have touted the middle class as a lucrative consumer group while political leaders have portrayed India's middle classes as the public face of India's economic potential (McKinsey Global Institute 2007). Social and cultural critics have decried the elitism of the middle classes and the threat of rampant consumerism in a country still grappling with poverty and inequality (Gupta 2001). Political parties have increasingly sought to attract middle-class voters in ways that could potentially change future electoral calculations. Thus, in the 2014 elections, Narendra Modi was effectively able to appeal to what he called India's 'neo-middle class' (BJP 2014). In the midst of these layered trends, India's middle classes remain one of the most over-debated yet under-studied social groups in contemporary India. The realities of the lives, identities and politics of India's vast middle classes bear little resemblance to the heightened public rhetoric about this group.

This chapter will present an overview of some of the complexities and contradictions that shape India's middle classes. India's middle classes are characterized by considerable internal variations based on factors such as socio-economic standing, caste, religion and region. Such variation makes any attempt at generalizing about the nature and behaviour of India's middle classes at best a flawed enterprise. Yet this diversity coexists with a distinctive publicness to middle-class identity - where public and political discourses produce and make claims about a uniform middle-class identity with common interests. Such claims stem from the historical relationship between Indian nationalism and middle-class identity and have been accentuated and reworked in the post-liberalization period. The result is a paradoxical relationship between political claims regarding a singular middle class and a differentiated social group that ranges from very elite English urban upper-middle classes to lower-middle classes that struggle to maintain their socio-economic status. The chapter analyses this paradox and argues that the tensions produced by such fractures within the middle classes play an increasingly central role in shaping contemporary politics in India. The chapter is 
organized in four sections. The first section presents the historical context and theoretical problems that shape contemporary debates on India's middle class. The second section examines some of the key dimensions of the post-liberalization middle class. The third section examines the political implications of the fractures within India's post-liberalization middle class. Finally, the chapter concludes with a discussion of future directions for research on India's middle classes.

\section{Defining India's middle class: conceptual questions and historical factors}

Contemporary discussions of India's middle classes are fraught with conceptual ambiguities regarding the precise boundaries that mark this social group. Some of these ambiguities are not specific to India and stem from the relative absence of theoretical attention and depth that has been paid to the middle classes in comparative contexts. Marxian and neo-Marxian theoretical work on the category of class has tended to dismiss or neglect this social group in part because of the relative lack of attention that Marx paid to the middle class. In Marxian conceptions, the middle class is either conflated with the bourgeoisie or conceived of as a petty bourgeoisie that was without a social basis or a class that would ultimately become proletarianized (Marx and Engels 1848). Meanwhile, Weberian conceptions of class have resorted instead to conceptions of stratification based on income and status as measurements of middle-class location (Weber 1978). Contemporary studies of India's middle classes have tended to implicitly reflect these divergent conceptual streams. Social science scholarship has attempted to use income and consumption data to provide more precise and accurate measures of middle-class membership (Sridharan 2004). More anthropological scholarship has resorted to culturalist analyses of consumption and status as markers of middleclass distinction ${ }^{1}$ and status (Lukose 2009; Mazzarella 2003). Meanwhile, post-colonial approaches have sometimes reverted to conceptions that have absorbed the middle classes into homogeneous conceptions of a bourgeois or elite social group (Chatterjee 2004).

The conceptual difficulties of grasping India's middle classes are further complicated by the historical legacies of colonialism that have shaped the formation of this social group. In the first comprehensive attempt at providing a systematic analysis of the complexities of middle-class formation in India, B. B. Misra's classic study provides an entry point into the distinctive historical characteristics of India's middle classes (1961). As Misra's work indicates, British colonialism limited Indian industrialization and the corresponding expansion of an industrial middle class. Furthermore, a British system of using managing agencies to organize industrial development in India also restricted the growth of an Indian administrative core within the industrial sector (Misra 1961: 14). The result was that India's emerging middle classes relied primarily on education as a means of access to employment and economic power. This form of access, of course, was intertwined with existing forms of socio-economic power such as caste, religion and landownership. The colonial Indian middle class was thus marked by high degrees of uncertainty produced by its dependence on the colonial state for employment and the limits on its economic power in the context of the colonial political economy of India.

This sense of uncertainty was expressed and managed through various forms of public political and cultural expressions. As historians have shown, middle-class identity was expressed through public discourses of respectability, moral regeneration and social reform (Joshi 2001; Sarkar 2001). Such forms of expression were then reworked into the emerging nationalist politics of the Congress Party and Muslim League. Middle-class 


\section{Leela Fernandes}

claims of moral and cultural superiority were intertwined with emerging forms of politics in which the upper tiers of the middle classes claimed to serve as the ideal of representative citizenship. Thus, for instance in a range of local civic life, associational activities and municipal politics, the middle classes were able to use their resources of language and education to claim public civic power (Haynes 1991). These middle-class conceptions of 'public' interest were fundamentally based on a politics of difference and exclusion as they rested on socially segregated conceptions of urban civic order that viewed the poor as threats to hygiene and safety (Gooptu 2001). This tension between middle-class claims of representing the universal and public interests of the nation while reproducing a politics of differentiation and exclusion has been one of the critical factors that has shaped the nature of the Indian middle classes in contemporary India.

This brief historical sketch is not intended as an exhaustive or comprehensive picture of the historical formation of India's middle classes. Rather, it seeks to provide a sense of historical context that can highlight significant continuities between early dynamics of middle-class politics and contemporary debates on India's post-liberalization middle classes. Such continuities provide a useful caution against the tendency to assume that contemporary debates mark a self-evident break from the past. As the next section will demonstrate, the post-liberalization middle classes in contemporary India continue to grapple with the tensions between their claims of public representativeness on the one hand and the politics of difference (both in terms of differentiation within the middle classes and differences from subaltern social groups). The Janus-faced nature of the colonial middle class that sought to represent the Indian nation even as it produced exclusions of caste, gender and religion thus continues to shape this social group in the contemporary period.

\section{The post-liberalization middle class}

Contemporary political and public discourses are marked by highly inflated forms of rhetoric about the nature of India's middle classes. With the advent of policies of economic reforms in the 1990s, public discourses - from politicians, media outlets, businesses and marketing and advertising firms - centred on the change in the nature of India's middle classes. This depiction of change turned on questions of both substance and size. At a substantive level, the initial policies of reform in the 1990s were publicly associated with new forms of prosperity. Reforms were associated with an embrace of globalization that offered the middle classes a newfound prosperity. This prosperity was marked both by highly paid employment in new economy jobs such as information technology (Radhakrishnan 2011) as well as the ability to freely consume newly available consumer goods. In the early 1990s, media discourses were thus rife with rhetoric about a new middle class that was now free to break from the old restrictions and state dependency associated with Nehruvian state socialist ideologies and Gandhian moral norms of austerity (Fernandes 2006).

The purported change in the nature and character of the Indian middle classes has been accompanied by widespread public and academic debates on the size of this social group. In the early years of reforms in the 1990s, political and business leaders and mainstream media discourses presented sharply inflated figures of a large untapped middle-class consumer market comprised of between 100-300 million individuals. While some of the inflated rhetoric subsided when large segments of the middle classes did not in fact exhibit the kind of mass consumerism that had been anticipated in such discourse, rhetoric on the size of India's middle classes continues to shape contemporary conceptions of this group. Global and Indian market-oriented research firms such as the McKinsey Global Institute and the National 
Council of Applied Economic Research (NCAER) continue to create estimates of the size of India's middle class that are in the millions and continue to predict a rapid growth in this size in future years. Thus, in a recent estimate, the NCAER has estimated the current size of the middle classes as comprised of 160 million individuals and has predicted the size will increase to 267 million by 2015-2016 and to 547 million by 2025-2026 (Economic Times 2011).

Attempts to estimate the boundaries of India's middle classes based on household income and consumption patterns are an integral part of any endeavour at understanding the postliberalization middle class. The opening up of the Indian market and the availability of new consumer goods has produced a significant rise in consumption levels. This has been further intensified by a proliferation of media and public discourses that have constructed a 'new middle-class' identity that is associated with new consumption practices, lifestyles and status distinctions associated with new economy white-collar jobs. Indeed recent consumption data does show evidence of the ownership of new consumer items (see Table 15.1). Thus, for example, recent data show that 53.2 per cent of households own a mobile phone (with a higher level of 64.3 per cent of urban households owning a mobile phone) and 47.2 per cent of households own a television (with a much higher percentage of 76.7 per cent of urban households). However, such data must be contextualized with the nature of consumption practices in India. The purchase of consumer goods remains a significant household decision and middle-class families do not necessarily participate in patterns of western consumerism associated with the practices of repeat purchases of new brands or models of household items. Meanwhile the data indicates that only 4.7 per cent of households and a higher level of 9.7 per cent of urban households own a car (a more significant consumer purchase). This is an increase in 2001 estimates, which showed that 2.5 per cent of households owned a car and 5.6 per cent of urban households owned a car (Fernandes 2006: 81) but remains a relatively small percentage of households. This must be added to the fact that household income and asset ownership data does not provide sufficient contextual information of the nature of the household structure, level of indebtedness and factors of generational wealth or poverty. There are for example sharp differences between urban upper-middle class families that can engage in brand-related consumerism and middle or lower-middle class families that may strategically purchase consumer goods for an entire joint family household or for the purposes of using such a purchase as a marker of middle-class status.

The cautionary note necessary when interpreting changes in consumption patterns and asset ownership is underlined by the fact that data about middle-class consumption is shaped by the political and discursive strategies that shape the quantification projects of large market-oriented firms such as the NCAER and McKinsey Institute. Since the 1990s, the NCAER has for instance been both a leading source of data on consumption and household

Table 15.1 Households by possession of assets (\%)

\begin{tabular}{lccc}
\hline Asset & Total & Rural & Urban \\
\hline Television & 47.2 & 33.4 & 76.7 \\
Computer/laptop (with internet) & 3.1 & 0.7 & 8.3 \\
Computer/laptop (without internet) & 6.3 & 4.4 & 10.4 \\
Telephone (mobile only) & 53.2 & 47.9 & 64.3 \\
Car/Jeep/van & 4.7 & 2.3 & 9.7 \\
\hline
\end{tabular}

Source: Census of India, 2014 


\section{Leela Fernandes}

income and a political actor that has shaped the construction of middle-class identities. The NCAER for instance has used categories such as 'consuming class' and 'aspirants' that have built in normative assumptions that associate income-based social groups with middle-class aspirational identities (Fernandes 2006: 76). Such data may thus participate in the creation of a consumer-based middle-class identity as much as it reflects an objective measure of middle-class status defined by household income.

The complexities of attempting to 'measure' the middle class through quantitative data based on income and asset ownership reflects a deeper point regarding the way in which we understand the boundaries of the middle classes. Middle-class identity in many ways is defined by a kind of productive ambiguity. The nature of this social group rests on the fact that it is defined by two paradoxical characteristics. On the one hand, middle-class status is defined by the promise of access to membership - the aspirational promise of upward mobility for individuals within the middle classes (that for instance want to move from middle to upper-middle class status) and between classes (the promise of upward mobility for subaltern social groups seeking middle-class membership). On the other hand, middle-class status is fundamentally defined by an exclusionary politics of distinction. The 'middleness' of this class contains within it a sense of relationality in which its identity is defined by a demarcation both from the very rich as well as from the poor. Given that large sections of the middle classes are often more economically fragile and thus susceptible to anxieties of falling in social or economic status, middle-class identity is often built on carefully crafted distinctions based on lifestyle, status markers and claims of cultural and moral superiority. Such distinctions rest as much on internal differentiation within the middle classes as they do in relation to other socio-economic groups. The middle classes are thus the product of a politics of classification. Segments of this social group seek to police the boundaries of middle-class identity even as other segments contest and attempt to redraw these boundaries. It is this sense of uncertainty and fluidity that is missed by attempts to reduce the study of the middle classes to measurable questions of size based on household income or consumption.

This politics of classification has become particularly weighty in the post-liberalization context of contemporary India. In the initial phases of liberalization (both in Rajiv Gandhi's early appeals to a consuming urban middle-class identity and in the early period of liberalization in the 1990s), public and political rhetoric in India was saturated with euphoric claims of a new middle-class identity. This new middle-class identity was identified with the promise of an expanding consumer class that I have been analysing as well as with highly paid new economy jobs in the private sector (particularly in rapidly growing sectors such as Indian firms in the services and information technology sector as well as more broadly in multinational companies). The newness of this middle class, however, provided a misleading sense of access associated with India's liberalizing economy. In practice, the segments of India's middle classes that have benefited most from liberalization and from new economy jobs are the upper tiers of the English-educated urban middle classes. The newness of this middle class thus rested on a shift of this segment of the middle classes from well-paid and secure employment in the public sector to highly paid jobs in the new economy sector. Segments of this social group have in fact benefited significantly from jumps in private sector salaries and have been able to participate in the consumption of newly available consumer goods.

The implications of India's policies of economic liberalization for the broader middle classes in India have been more complex and varied. Members of the middle classes have sought to use individual strategies to try and gain benefits from the new economy sectors. Thus, individuals have sought to accumulate various forms of social and cultural capital ranging from smaller tactics of gaining computer skills, English training and knowledge 
about cultural styles (such as dress, speaking accents) to strategies of gaining credentials such as MBAs. Urban middle-class youth have been able to gain access to disposable income through employment in the services sectors and call centre jobs (Patel 2010). However, while such strategies have allowed individuals to gain some benefits particularly from service sector jobs, they have not necessarily produced structural access to broader segments of the middle classes (Fernandes 2006). Segments of the middle classes with access to toptier educational institutions continue to fill the high-end segments of new economy jobs. Access to new economy jobs continues to be structured by historical inequalities of caste and religion. Research on India's highly successful information technology industries has shown that access to new economy jobs in places such as Bangalore has been highly restricted to upper-caste Hindus (Radhakrishnan 2011; Upadhya 2007). While Muslims in India tend to represent a significant portion of India's urban population, both governmental reports and academic research have documented the growing political and economic marginalization of large segments of the Muslim community (Gayer and Jaffrelot 2011, Sachar Report 2006). Local ethnographic research has shown that while Dalits and Muslims use a variety of strategies such as education to gain access to middle-class status, members of these communities often experience long-term unemployment (Jeffrey et al. 2007). Education provides some forms of socio-cultural status but does not necessarily transform into economic access to employment.

India's middle classes in the post-liberalization period are thus characterized by a high degree of internal differentiation. The actual growth of asset ownership has often mistakenly led both public discourses and academic scholarship to conflate the middle classes with either elites or with the upper tiers of the English-speaking urban middle classes (Mazzarella 2003). In fact, large segments of India's middle classes live with high degrees of economic fragility or anxiety. New entrants to middle-class status such as Dalits who may have trouble gaining access to employment struggle both with the stability and meaning of middle-class status. Meanwhile, larger sections of rural and middle classes that may be more economically stable struggle with the anxieties of preserving their status in the face of socio-economic competition over jobs and education or in the face of basic economic pressures such as inflation. Thus, for instance, according to a survey by the Associated Chamber of Commerce and Industry (Business Standard, 2003), middle-income groups in major metropolitan cities hit by inflation in addition to rising costs in fuel, health and education, saw their household savings decline by 40 per cent in the three years between 2010 to 2013 . The survey showed a general decline in consumption for middle-class families in general and a decline in basic food consumption in lower-middle class families.

The discrepancies between the promise of middle-class wealth and status and the material inequalities that shape middle-class life have begun to shape the political behaviour of the middle classes in distinctive ways. The Indian middle classes have historically engaged in a politics aimed at differentiating their socio-cultural identity from subaltern social groups. This dynamic has continued in the contemporary period. Thus, in the context of the economic anxiety, the middle classes have mobilized in different ways in order to preserve their interests. New entrants to middle-class status have pressed the state for access to employment and education while the upper tiers of the middle classes have often engaged in a politics of backlash against state policies such as caste-based reservations. As contemporary scholarship has demonstrated, the rise of movements such as the Hindu nationalist movement and the Bharatiya Janata Party rested in part on an urban-middleclass backlash against a Congress government that they perceived as 'pandering' to Dalits and Muslims (Hansen 1999). Meanwhile, as Zoya Hasan has convincingly demonstrated, the rise of regional political parties and oppositional movements can also be understood in 


\section{Leela Fernandes}

part in relation to the socio-economic frustrations and political demands of the vernacular, rural middle classes (Hasan 1998). The politics of India's middle classes have thus played a central role in shaping some of the central trends in contemporary India. An analysis of the politicization of India's middle classes thus provides us both with a deeper understanding of this social group as well as an understanding of some of the central factors that are currently shaping contemporary political trends in India.

\section{The politics of India's middle classes in contemporary India}

In recent years, a number of well-publicized events have seemed to mark the emergence of a distinctive form of middle-class politics in contemporary India. This form of politics is intertwined with a growing sense of middle-class resentment against state governance and institutions that the middle classes perceive as failing to represent their interests. Several significant examples of this form of politics have emerged in recent years. Anna Hazare's high profile anti-corruption movement capitalized on middle-class frustrations with political corruption by invoking a much older historical middle-class self-identification as a social group that seeks to occupy a pure, apolitical realm. This sense of moral purity characterized historical conceptions of a middle-class sense of cultural superiority. More recently, in contemporary India the middle classes have viewed the expansion of democratic participation and political mobilization of subaltern groups as a threat to civic order (Hansen 1999). Hazare's anti-corruption rhetoric thus both captured a real sense of middle-class dissatisfaction and located his oppositional tactics on a longstanding middle-class antipathy towards democratic governmental institutions. A second example of this form of antiinstitutional politics is a longstanding middle-class resentment of a democratic state that this social group perceives as having been captured by subaltern social groups. For instance, significant segments of the middle classes embraced an 'anti-entitlement' sentiment in the run up to the 2014 national elections (Hasan 2013). ${ }^{2}$ Finally, a third significant example of middle-class resentment was illustrated in the mobilization against the brutal Delhi gang rape of a middle-class woman (Singh 2013). While women's organizations participated actively in the protests and focused on questions of violence against women, key themes that shaped the dominant public narratives of the protest were a sense of middle-class anger against state failure and strong demands for law and order including calls for the death penalty for rape. The rhetorical strategies of the protests thus intersected with the underlying pattern of a more generalized middle-class frustration with failures of governance.

Such political dynamics reflect an underlying paradox that has shaped the relationship between the middle classes and the Indian state. On the one hand, the Indian middle classes have in many ways been historically produced by and dependent on state policies. Thus, for instance, significant governmental investments in higher education directly contributed to the expansion and strength of India's middle classes and during the early decades of the post-colonial period India's middle classes were primarily dependent on state employment - whether in the public sector or in arenas such as civil service employment. Indeed, despite the growth of new economy jobs, sizeable sections of the middle classes continue to rely on state employment (Ganguly-Scrase and Scrase 2009) and middle-class competition over reservations in education reflect the continued role of the state in supporting the middle classes. On the other hand, large segments of India's middle classes have increasingly been driven by perceptions of a state that primarily caters to lower castes and classes. This middleclass sense of grievance at entitlements being provided to such marginalized social groups is at odds with this pattern of state entitlements being provided to the middle classes. This 
paradox is further heightened by the fact that, as I have argued earlier, the economic fragility of large segments of the middle classes means that such segments in fact demand more state support. The significant internal socio-economic differentiation within India's middle classes shapes and intersects with such political paradoxes.

The 2014 elections in India provide a central example of the political complexities of India's middle classes. In both his political platform and campaign rhetoric then candidate and now Prime Minister Narendra Modi displayed an astute ability to capitalize on the political and socio-economic contradictions that lie within the middle classes. The deployment of the category of 'neo-middle class' in both the BJP party manifesto and in campaign narratives invoked both this sense of differentiation and the general sense of middle-class economic anxiety. The manifesto for instance characterized this social group as

a large middle class with immense understanding, talent and purchasing power. In addition, a whole new class has emerged. Those who have risen from the category of poor and are yet to stabilize in the middle class, the 'neo-middle class'. This class needs proactive handholding. Having moved out of poverty, their aspirations have increased. They want amenities and services of a certain standard. They thus now feel that Government facilities and services are not up to the mark, and hence resort to the private sector for things like education, health and transport. This is obviously costly, putting the neo-middle class into a daily dilemma. As more and more people move into this category, their expectations for better public services have to be met.

BJP 2014: 17

The manifesto, and this newly constructed 'neo-middle class' identity effectively wove together the economic fragility of large sections of the middle classes with both a postliberalization aspirational identity as well as the historical reliance (and desire) of the middle classes for state supports. Thus, the manifesto turned to a call for strengthening the public sector and the government provision of 'educational scholarships and educational facilities, medical insurance and quality healthcare services, middle-income housing and efficient public transport systems' (ibid.). These promises coincided with clear signals that a Modiled government would forge ahead with accelerated policies of economic liberalization.

In this endeavour, the BJP and Modi in particular were able to weave together a political narrative that would appeal both to the upper tiers of the urban middle classes who have directly benefited from liberalization and the much larger segments of the middle classes who have struggled economically. Modi was further able to personally embody this narrative through his rhetorical style where he effectively stood for the aspirational new entrant to middle-class status (signalling both his caste identity and prior socio-economic disadvantages) even as he took on the role of the efficient CEO (chief executive officer) prime ministerial candidate that had once been projected onto Prime Minister Manmohan Singh. The significance of this political crafting of a middle-class identity lies in the fact that in contrast to earlier elections where middle-class voter turnout has been relatively low, the middle classes served as a swing group (shifting to support to the BJP) in ways that affected the outcome of the 2014 elections. The success of this identity as an electoral strategy does not, of course, mean that such an identity can automatically manage the very real economic inequalities within India's middle classes. The promise being made to India's 'neo-middle class' in many ways echoes the promise of the new middle class in the early euphoria of the 1990s. However, it does reinforce the growing socio-economic and political significance of India's middle classes and the need for ongoing and sustained research on this complex social group. 


\section{Future directions for the study of the middle classes in contemporary India}

In recent years, there has been a significant rise of both scholarly and public interest in understanding India's middle classes. Prior to this, academic research on the middle classes was largely limited to historical studies of middle-class public activities in the colonial and nationalist period. ${ }^{3}$ The growing political significance of the middle class and the complex differentiation that characterizes this group is such that there is a need for much closer and systematic study of India's middle classes. Significant gaps in current scholarship include a closer examination of regional variations in middle-class formation and practices particularly in under-studied regions of the country including those such as the northeastern region that are often left out of narratives of India's economic trajectories. Such research is already beginning to emerge in various institutions in India. ${ }^{4}$ However, an adequate understanding of India's middle classes and their impact in contemporary India will also require more than individual studies of particular segments and sections of this group. Given the diversity of the middle classes, it is an easy task to illustrate the uniqueness of particular social segments of this group as well as to contrast these segments with idealized images of the middle class that are shaped by the media and by political rhetoric.

An understanding of the impact of India's middle classes requires analyses that hold in tension both the contradiction and interrelationship between dominant narratives and internal differentiation. It is this dynamic that underlies the politicization of this social group, including the heightened political assertiveness and frustrations that have emerged since Indian independence and intensified in the post-liberalization period. India's middle classes, as this chapter has argued, cannot be reduced to a problem of measurement or to easy narratives about consumerism and elitism. The political force of the middle classes lies in a productive and messy ambiguity that shapes the boundaries of this group. This ambiguity is idealized through the promise of access and aspiration for new entrants even as it is mired in a politics of inequality and exclusion. In the midst of this uncertainty, individuals and social groups attempt to survive, adapt to and contest the unwieldy and weighty border that seeks to contain 'the Indian middle class'.

\section{Notes}

1 Such work has often drawn on Bourdieu's conception of social capital (1984). However, the culturalist reading of Bourdieu (that underplays Bourdieu's key understanding of class structuration and reproduction) places this work closer to Weberian conceptions of stratification.

2 This anti-entitlement sentiment comprised an attitude that the Congress government provided too many benefits to subaltern social groups and that such groups (such as the poor, Muslims and lower-caste groups) were dependent on a kind of entitlement culture.

3 Key exceptions to this include early work by Misra (1961) as well as work on caste and class by sociologists such as André Béteille. For recent work on the middle class see Béteille 2002.

4 For a range of such work see Lobo (2015).

\section{References}

Béteille, A. (2002) 'The Social Character of the Indian Middle Class', in Imtiaz Ahmad and Helmut Reifeld (eds), Middle Class Values in India and Western Europe, New Delhi: Social Science Press: 73-85.

BJP (Bharatiya Janata Party 2014) Election Manifesto, http://www.bjp.org/images/pdf_2014/full_ manifesto_english_07.04.2014.pdf [accessed 7 July 2014]. 
Bourdieu, P. (1984) Distinction: A Social Critique of the Judgment of Taste, trans. Richard Nice, Cambridge, MA: Harvard University Press.

Business Standard (2003) 'Inflation Eroding Savings of Indians Living in Metros: Assocham', 17 November, http://www.business-standard.com/article/economy-policy/inflation-eroding-savingsof-indians-living-in-metros-assocham-113111700436_1.html [accessed 24 July 2014].

Census of India (2014) Houses, Household Amenities and Assets 2011: Figures at a Glance, New Delhi: Government of India Publications, http://censusindia.gov.in/2011-Common/NSDI/Houses_ Household.pdf [Accessed 23 July 2014].

Chatterjee, P. (2004) The Politics of the Governed: Reflections on Popular Politics in Most of the World, New York: Columbia University Press.

Economic Times (2011) 'India's Middle Class Population to Touch 267 Million in 5 Years', February 6, http://articles.economictimes.indiatimes.com/2011-02-06/news/28424975_1_middle-classhouseholds-applied-economic-research [accessed 17 July 2014].

Fernandes, L. (2006) India's New Middle Class: Democratic Politics in an Era of Economic Reform, Minneapolis, MN: University of Minnesota Press.

Ganguly-Scrase, R. and T. Scrase (2009) Globalization and the Middle Classes in India: The Social and Cultural Impact of Neo-Liberal Reforms, London: Routledge.

Gayer, L. and C. Jaffrelot (2011) Muslims in India's Cities: Trajectories of Marginalisation, New York: Columbia University Press.

Gooptu, N. (2001) The Politics of the Urban Poor in Early Twentieth Century India, Cambridge: Cambridge University Press.

Gupta, D. (2001) Mistaken Modernity: India Between Worlds, Noida: Harper Collins.

Hansen, T. B. (1999) The Saffron Wave: Democracy and Hindu Nationalism in India, Princeton, NJ: Princeton University Press.

Hasan, Z. (1998) Quest for Power: Oppositional Movements and Post-Congress Politics in Uttar Pradesh, Delhi: Oxford University Press.

Hasan, Z. (2013) 'Middle Class Poised to Play Greater Role in 2014 Election', Hindustan Times, 28 September, http://www.hindustantimes.com/specials/coverage/ht-at-90/chunk-ht-ui-ht-at90-leadingstories/middle-class-poised-to-play-greater-role-in-2014-elections-zoya-hassan/sparticle10-1128305.aspx [accessed July 25, 2014].

Haynes, D. (1991) Rhetoric and Ritual in Colonial India: The Shaping of a Public Culture in Surat City, 1852-1928, Berkeley, CA: University of California Press.

Jeffrey, C., P. Jeffery and R. Jeffery (2007) Degrees Without Freedom? Education, Masculinities, and Unemployment in North India, Stanford, CA: Stanford University Press.

Joshi, S. (2001) Fractured Modernity: Making of a Middle Class in Colonial North India, New York: Oxford University Press.

Lobo, L. (2015) The Trajectory of India's Middle Class: Economy, Ethics and Etiquette, Cambridge: Cambridge Scholars Publishing.

Lukose, R. (2009) Liberalization's Children: Gender, Youth and Consumer Citizenship in Globalizing India, Durham, NC: Duke University Press.

Marx, K. and F. Engels (1848) The Communist Manifesto, trans. Samuel Moore, London: Merlin Press, 1998.

Mazzarella, W. (2003) Shovelling Smoke: Advertising and Globalization in Contemporary India, Durham, NC: Duke University Press.

McKinsey Global Institute (May 2007) The Bird of Gold: The Rise of India's Consumer Market, http:// www.mckinsey.com/insights/asia-pacific/the_bird_of_gold [accessed 23 June 2014].

Misra, B. B. (1961) The Indian Middle Classes: Their Growth in Modern Times, New Delhi: Oxford University Press.

National Council of Applied Economic Research (2005) The Great Indian Market, New Delhi: National Council of Applied Economic Research.

Patel, R. (2010) Working the Night Shift: Women in India's Call Center Industry, Stanford, CA: Stanford University Press.

Radhakrishnan, S. (2011) Appropriately Indian: Gender and Culture in a New Transnational Class, Durham, NC: Duke University Press.

Sachar Committee Report (2006) Ministry of Minority Affairs Government of India, http://www. minorityaffairs.gov.in/sites/upload_files/moma/files/pdfs/sachar_comm.pdf [accessed 23 July 2014]. 
Sarkar, T. (2001) Hindu Wife Hindu Nation: Community, Religion, and Cultural Nationalism, London: Hurst.

Singh, S. (2013) 'Delhi Gang Rape: Case Diary', Times of India, September 13, http://timesofindia. indiatimes.com/india/Delhi-gang-rape-Case-diary/articleshow/22455125.cms [accessed 25 July 2014].

Sridharan, E. (2004) 'The Growth and Sectoral Composition of India's Middle Classes: Its Impact on the Politics of Liberalization in India', India Review 1 (4): 405-428.

Upadhya, C. (2007) 'Employment, Exclusion and "Merit" in the Indian IT Industry', Economic and Political Weekly, 42: 1863-1868.

Weber, M. (1978) Economy and Society (2 vols) (edited by Guenther Roth and Claus Wittich), Berkeley, CA: University of California Press. 


\title{
16 \\ CASTE: WHY DOES IT STILL MATTER?
}

\author{
Surinder S. Jodhka
}

\section{Introduction}

Caste has come to be seen as a peculiar social institution of the traditional Indian/Hindu society. In this popular view, caste worked as a 'closed system' of social hierarchy where groups, often divided on the basis of their occupation, strictly followed codes of social interaction prescribed by tradition. According to this view, caste drew its ideological moorings from classical Hinduism. Caste groups were unequal, and were all ranked hierarchically based on their position in the Hindu religious ritual system, structured around notions of purity and pollution. The ritual 'status' of a group determined who they could interact with and who they could not. Thus, the ideas of untouchability, avoidance and discrimination in everyday social life were integral to caste. The typical social universe of its operation and reproduction was the Indian village.

Interestingly, despite its popular imagination as a uniquely Indian or South Asian reality, the term caste is not of native origin. Furthermore, there is no single local term to which it translates fully. It has its origin in the Portuguese word casta, meaning race, and was popularized to describe the social realities of India by the Portuguese seafarers, who arrived on the west coast of India for trade in the fifteenth century. There are a variety of terms that have been used locally to describe the ritual and social hierarchies of caste. The common Indian terms that have come to be popularly used to describe caste at a pan-Indian level are jatis and varna. However, they refer to different aspects of the system. While varna is invoked to describe the broad framework of hierarchy, a textual model, jatis corresponds to empirical groupings, the kinship communities. They are endogamous groups. Jatis are further divided into subgroups, with localized names and systems of classifications. Jatis and their sub-units are large in numbers and most of them have a regional concentration. Every region of India is believed to have more than 300 jatis. The nature and practice of caste divisions also varies across regions (Jodhka 2012).

The idea of varna is best articulated in Manusmriti, a classical Hindu text, presumably written by Manu. The text divides the Hindus into four mutually exclusive categories, the Brahman (priest), the Kshatriya (warrior), the Vaishya (trader) and the Shudra (peasant/ artisan/labourer). Beyond the four varnas is the achhhut (the untouchable). These four or five categories occupied different positions in the status hierarchy, with the Brahmans at the top, 
followed by the other three varnas in the same order as mentioned above, with the achhuts occupying a position at the very bottom.

Over the years, scholars have tried to identify the precise features of the caste system. For example, a well-known Indian sociologist G.S. Ghurye, identified six core features of the system: segmental division of society; hierarchy; restrictions on feeding and social intercourse; civil and religious disabilities and privileges of different sections; lack of unrestricted choice of occupation; and restrictions on marriage (Ghurye 1932). Similarly Declan Quigley points to the popular view of caste that identifies three core features of the system. First, 'the Hindu world is made up of a number of castes. Second, castes are closed social groups; and third, castes are hierarchically ranked on a purity-pollution scale according to their traditional occupations' (Quigley 1993: 1). However, Quigley also points out, and rightly so, that the empirical research on caste has repeatedly demonstrated that such generalized descriptive accounts are 'at best inadequate, at worst wholly misleading' (Quigley 1993: 2). In this chapter, I will try to show how even though the classical model remains influential and is invoked by a variety of actors for legitimacy or oppositional politics; the practice of caste on the ground has always been diverse and very different from this popular 'book-view' of caste. The chapter begins with an overview of the conceptual history of caste, followed by a brief discussion of the dynamics of its reproduction in contemporary times. I also discuss the nature and patterns of change being experienced in the institution in India today.

\section{Conceptualizing caste}

The origin of present day social science conceptualizations of caste could be traced to early writings on India by the Western travellers and colonizers. Though the source of their interest varied, they all tended to look at social and cultural life of the region as being very different from that of Europe. Over the years, India and rest of the 'eastern' world came to be viewed in the dominant Western discourses as the 'other' to the West European societies. Scholars like Edward Said (Said 1985) and Ronald Inden (1990) have described this orientalism, a discourse that tries to present oriental culture as being inferior to the West. Caste appeared as a good example of an institution of the 'peculiar orient'.

Given that these writings also became a source of knowing about India among the early social science scholarship in Western Europe, they tended to produce similar kinds of imaginations and arguments about the social and cultural life in the region. Examples of this could be found in writings of scholars like Marx and Weber. Marx, for example, wrote on the positive effects of colonial rule in India because it could break the traditional village community structured around caste (Marx 1853). The orientalist imagination had also presented caste as a rigid and static institution of Hindu religion, which had been around without any significant internal change in Indian society for centuries. Even though his theoretical orientation was very different from that of Marx and the orientalists, Max Weber too produced a static view of Hinduism, describing it as an otherworldly religious system based on the ideas of karma and re-birth. Caste, for Weber, was also a good example of what he described as 'status groups'. They were like ethnic communities, completely closed to outsiders. Recruitment to a caste group, like an ethnic group, was based exclusively on birth. However, unlike other ethnic communities, castes were also hierarchical and the order of hierarchy was acceptable to those lower down in the hierarchy (Weber 1946). While Weber accepted the 'orientalist' view about rigidity and unchanging nature of caste, he did not think that the presence of caste-like status groups was peculiar to India or the Hindus. 
Looking more closely on the subject in the same mould, Louis Dumont, a French scholar, reworked the orientalist view on caste in his well-known book Homo Hierarchicus: The Caste System and its Implications (first published in French 1966; the English edition appeared in 1970). Drawn mostly from the classical Hindu scriptures, he constructed a well-integrated theory of the caste system. As was the case with much of the classical orientalist writings, Dumont conceptualized caste as emanating from the Hindu religious system. According to him the structural logic of caste lay in the 'Hindu mind', as an ideological construct, which divided and hierarchized social groups on the basis of ritual purity or impurity of their occupations. Dumont's thesis on caste was, in many ways, an extension of the argument put forward by another French scholar, Celestin Bougle.

In an essay first published in 1908, Bougle had argued against those who looked at caste merely as a system of occupational specialization. He defined caste as a system consisting of hierarchically arranged hereditary groups, separated from each other in certain respects (caste endogamy, restrictions on eating together and on physical contact), but interdependent in other (traditional division of labour). The word 'caste', he emphasized, not only involved hereditary specialization of occupational groups but also differential rights. Different occupations were arranged in a hierarchical order that made their members socially unequal. Inequality was an essential feature of the caste system. Along with inequality, he also underlined the element of pollution as an important feature of caste. Different groups, in a caste society, tended to 'repel each other rather than attract, each retired within itself, isolated itself, and made every effort to prevent its members from contracting alliances or even from entering into relation with neighbouring groups' (Bougle 1971: 65). Thus Bougle identified three core features of the caste system, namely, hereditary occupation, hierarchy and mutual repulsion.

While Dumont agreed with Bougle's identification of core features of the system, he, however, argued that for a proper theoretical explanation of caste, it was important to identify one common element, 'a single true principle' to which the three features of the caste system suggested by Bougle could be reduced. Such a principle, Dumont argued, was 'the opposition of the pure and the impure'.

This opposition underlies hierarchy, which is the superiority of the pure to the impure, underlies separation because the pure and the impure must be kept separate, and underlies the division of labour because pure and impure occupations must likewise be kept separate. The whole is founded on the necessary and hierarchical coexistence of the two opposites.

Dumont 1998: 43

Another important and extremely contentious aspect of his theory was his assertion about the superiority of Brahman over the king. India was different from the West because in India status was not determined by the logic of political economy, as was the case with the West. In caste society, status as a principle of social organization was superior to power. Status encompassed power.

While Dumont's theory of caste has been very influential, it has also been widely criticized. He has been accused of presenting an ideologically biased view, an account that looked at it from upside down, as the Brahmans would wish to present it. Given that his sources were mostly textual, and that these texts were all written and retained by the uppercaste Brahmans, he constructed a theory that presented a Brahmanical perspective on the subject, an uncritical celebration of tradition. He has also been accused of ignoring the available empirical accounts of its functioning on ground, produced by professional social 
anthropologists in the form of village studies and monographs (Gupta 1991: 114). Some have accused him of also being selective in choice of textual sources (Das and Uberoi 1971).

In his defence Dumont would argue that he only tried to construct an ideal type of caste that theorized the underlying structure of the system and not the way caste was practised in everyday life. However, as Berreman pointed out, caste did not exist except empirically, in the lives of people as they interacted with each other. The lived experience of caste was very different from what Dumont seems to suggest. 'The human meaning of caste for those who lived it was power and vulnerability, privilege and oppression, honour and denigration, plenty and want, reward and deprivation, security and anxiety. As an anthropological document, a description of caste, which failed to convey this was a travesty in the world today' (Berreman 1971: 87-88; also see Gupta 1984). Similarly, Joan Mencher who conducted her fieldwork among the lower castes in a South India village reported that 'from the point of view of people at the lowest end of the scale, caste had functioned and continued to function as a very effective system of economic exploitation' (Mencher 1978). Fuller makes a related point in his criticism of Dumont's theory. It is not only the relations of power that his theory undervalues; such a notion of caste also undermines the obvious facts about the inequalities in material life and the role caste played in their reproduction. In his study of the redistributive system prevailing in the pre-colonial India Fuller shows how village level system of caste relations was integrated into a larger political authority, beyond the village (Fuller 1977).

Another point of contention in Dumont's theory has been his argument that constructs Indian and the Western societies as binaries where India is presented through categories of holism and hierarchy and the West with individualism and equality (Béteille 1986). Such a construct also tends to ignore the internal differences within societies and regions. The actually existing realities have never been so simple, in the West or in India. We can also find echoes of this argument in the historical scholarship on caste. As Bernard Cohn argues, the textual view of caste constructed through orientalist categories is fundamentally flawed because it constructs a picture of Indian society as

being static, timeless and space-less. Statements about customs, which derived from third century A.D. texts and observations from the late eighteenth century, were equally good evidence for determining the nature of society and culture in India. In this view of Indian society there was no regional variation and no questioning of the relationship between prescriptive normative statement derived from the texts and the actual behavior of individuals and groups. Indian society was seen as a set of rules, which every Hindu followed.

Cohn 1968:7-8

Following the works of Bernard Cohn, some other historians of modern India have also done important work on the subject. Perhaps the most important and influential of this scholarship has been the work of Nicholas Dirks. In his well-known book, Castes of Mind, Dirks convincingly shows how the colonial rulers through a process of enumeration and ethnographic surveys raised the consciousness about caste. They also produced social and intellectual conditions where 'caste became the single term capable of expressing, organizing, and above all "synthesizing” India's diverse forms of social identity, community and organization' (Dirks 2001: 5). Dumont's theory of caste is a restatement of the same colonial and orientalist formulation. 
Fallacy of this orientalist view of caste is also evident from the fieldwork-based writings on the Indian village. The field studies of the Indian village tend to present a much more diverse picture of caste. Many of these studies question the superiority of Brahmans and place the landowning caste at the centre of village social life. While some emphasized reciprocity and interdependence (Wiser 1936; Dube 1955; Srinivas 1955), some others point to the coercive nature of power in caste society. F.G. Bailey, for example, questioned even the idea of interdependence in caste society:

The system works the way it does because the coercive sanctions are all in the hands of a dominant caste. There is a tie of reciprocity, but it is not a sanction of which the dependent castes can make easy use.

Bailey, 1960: 258

Similarly Beidelman pointed to the exploitative nature of the relationship between the landowning and politically dominant jajmans, and those who provided them services of various kinds, those belonging to landless caste groups called kamins (Beidelman 1959). Some of these writings also raised wider theoretical questions regarding the relationship between status and power and validity of the claims made by Dumont on the encompassment of power by status. Gloria Goodwin Raheja, for example, argues that:

The relationship between a hierarchical order of castes, with its focus on the superior position of the Brahman, on the one hand, and a conception of sovereignty focused on the Hindu king or the royal functions of the dominant caste at the level of the village, on the other, has been a central reverberating issue in the anthropological and historical study of South Asian society ... Virtually all of the major contributions to the anthropological, indological and historical study of Hindu South Asia have been concerned in some fashion with this relationship, and have seen it to be constitutive of the fundamental aspects of social life, polity, and religion.

Raheja 1988: 497

Based on her study of a village in northern India, Raheja offered an alternative theory of caste and ritual practices, a theory that places 'dominant caste' at the centre of the caste system. She also questions the dominant 'Western view of Hindu society', which sees hierarchy as 'the sole ideology defining relations among castes' and reduces the role of the king and the dominant caste to a residual level. Instead, she argues that

there are several contextually shifting ideologies of inter-caste relationships apparent in everyday village social life. Meanings and values are foregrounded differently from context to context, and they implicate varying configurations of castes ... data on presentation patterns and language use from ... north Indian village ... indicate that aspects of inter-caste relations that ... I call 'centrality' and 'mutuality', are distinguishable from the ranked aspect that is usually called 'hierarchy' ... Among these configurations of caste, both the ritual centrality of the dominant caste ... and the mutuality among the castes of the village prove to be of more significance in social intercourse than the hierarchical pre-eminence of priestly Brahmans. 
These wide-ranging contestations of the popular Western view of caste point to the diversities that have been part of social and cultural life in the subcontinent. They also represent the diverse ways in which an institution like caste can be approached. The available theoretical formulations on the subject tend to vary depending upon whose experience of caste is being considered as the primary empirical reference point. A view from below is likely to be very different from the one from above or the middle. This diversity of perspectives and approaches to the subject continues to be an important aspect of the present discourse on caste in contemporary India, within social sciences and beyond (Jodhka 2012, 2015).

\section{Modern times and the changing realities of caste}

The British colonial rulers not only produced theories about Indian society and its social order of caste but also operationalized those categories in their administrative discourses. Perhaps the most important of these was the process of classification of caste communities into an all India schema. For example, they clubbed together the so-called untouchable communities into an administrative category, initially as 'depressed classes', and later listed them as Scheduled Caste (SC) in the Government of India Act of 1935. The postindependence Indian state continued with the same category but has over the years expanded the list of communities and scope of state action for their welfare and development. Though SC communities are identified at the state level, they are listed in the Constitution of the Indian Union with authorization of the President of India. This classification became an important medium for the post-colonial Indian state in its administrative strategies of transforming the institutionalized hierarchies of caste into an open social and economic order with a level-playing field.

The post-colonial state also legally abolished the practice of untouchability and initiated several other administrative measures for development and inclusion of the historically marginalized caste communities. First and the most important of these measures was the quota system, reservations of seats in government run educational institutions and for employment in government or state sector jobs. Second, the central and state governments also introduced various development schemes/programmes enabling the SCs to actively participate in the emerging economy and new avenues of employment. Third, the Indian Constitution also made provisions for reservations of seats for Scheduled Castes (along with Scheduled Tribes) in legislative bodies and other representational institutions as per their proportions in the total population.

Notwithstanding these proactive measures initiated by the Indian state, the middleclass that inherited power from the British colonial rulers shared the view that caste was essentially a mode of traditional life and would gradually decline and eventually disappear as India moves on the path of development and modernization. The engine of progress was to be the process of economic growth: industrialization, modern technology and urbanization.

\section{Changing caste}

As any other aspect of social life, the institution of caste would have always been undergoing change with changes in the larger social structure, economic life and political regimes. However, the nature and extent of change has perhaps been much more rapid over the past four or five decades. The changes in the traditional order of caste appear to be so significant that some scholars have even predicted its complete demise in the near future. The changes 
in the social order of caste have come about due to a variety of efforts and processes from 'below', from 'above' and from the 'side'.

Persistent mobilizations and organized movements of the traditionally marginalized who were at the receiving end in the 'traditional hierarchies' have been an important source of change in the caste system. It was during the colonial period that certain 'disadvantaged' communities, such as the non-Brahmans in South India and untouchables in western India mobilized against the prevailing structures of caste-based domination and exclusions (Pandian 2013; Omvedt 1976; O'Hanlon 1985). Since the early 1980s such mobilizations from the margins of Indian society have only grown and some have described them as a source of a 'silent revolution' (Jaffrelot 2003). Notwithstanding diversities and divergences, growing politicization of the 'backwards' and increasing Dalit assertions have fundamentally altered the grammar of Indian social and political life.

State policies and other initiatives from 'above' have also changed caste. The constitutional provisions in form of reservation policy have not only enabled a process of social and economic mobility among the ex-untouchable castes but have also been instrumental in producing a modern leadership from within these communities.

Caste has also changed with the social, economic and political transformations taking place on the 'side'. For example, the agrarian transformation ushered in by the success of the green revolution technology in some parts of the country and the development of industry in urban centres have made many of the traditional caste occupations redundant. At the same time, they have also provided new opportunities for employment outside the older economic order (Jodhka 2002).

James Manor, who has closely observed Indian politics and society for nearly five decades, has recently argued that among the most important changes to occur in India since Independence, two things stand out: the emergence of a democracy with deep roots in society; and the decline in the power of caste hierarchies across most of rural India. The latter change is not as widely recognized as it should be, but abundant evidence from diverse regions plainly indicates that it has been occurring - unevenly, but widely enough to be a national trend (Manor 2012: 14). Manor is only echoing what many other scholars doing field studies have been reporting from their regions for some time now. Historically, the process of disintegration of jajmani ties in some regions had begun during the colonial period.

Independence from colonial rule was an important turning point for the local agrarian economy and, its social organization, the institution of caste. State investments in rural development and agricultural growth provided positive impetus to the process of change on the ground. Social anthropologists studying rural social and economic life began to report about declining traditional hierarchies and old structures of dependency, including the traditional structures of caste hierarchy, sometime in the early 1970s (see Breman 1974; Béteille 1971; Thorner 1982). By the early 1980s and 1990s these changes became quite visible and started to reflect even in the democratic or electoral political processes.

For example, on the basis of his fieldwork in Rajasthan villages in the 1980s, Oliver Mendelsohn reported that the idea of the 'dominant caste', as proposed by M.N. Srinivas in the 1950s after his fieldwork in a South India village (Srinivas 1959), no longer made sense in rural Rajasthan. The 'low caste and even untouchable villagers were now less beholden to their economic and ritual superiors than was suggested in older accounts' (Mendelsohn 1993: 808). Interestingly, he also argued that 'land and authority had been de-linked in village India and this amounted to an historic, if non-revolutionary transformation' (Mendelsohn 1993: 807). By the turn of the century Srinivas himself argued in a paper, which he titled 'An Obituary on Caste as a System', that the 'systemic' features of caste were soon disappearing 
from the rural society in different parts of the country (Srinivas 2003). We can notice similar claims emerging from the writings of many other scholars who have been closely observing the dynamics of caste in contemporary India (Béteille 1997; Gupta 2000, 2004; Jodhka 2002; Karanth 1996; Charsley and Karanth 1998; Krishna 2001; Kapoor et al. 2010).

\section{Declining hierarchy, persisting inequality}

Perhaps the most surprising thing about caste in contemporary India is that when all social science evidence points towards a rapid decline of the old jajmani relations and erosion of its ideological hold over the minds of those located lower down in the traditional hierarchies, caste seems to be becoming politically more visible and socially more complex. The caste question today presents itself in newer and more complicated forms. Understandably, thus, the academic and popular interest in caste continues to grow.

\section{What makes caste persist?}

Social science scholarship has only just begun to engage with this question. One possible factor that makes the reality of caste continue to matter is the fact that even when socially and ideologically the traditional forms of relationships begin to disintegrate, material realities do not change much. For example, the economic inequalities across caste groups continue to persist or, in some cases, even witness a further escalation.

With its ideological decline, the social and political experience of caste becomes more intense for those at the lower end of traditional hierarchies. As the decline of their dependence on the agrarian economy and the locally dominant caste groups enables them to formally participate in the democratic political process as equal citizens, their entitlements over the local resources remain circumscribed by caste and the 'position' they have occupied in the old system of hierarchy, as the dominant groups view it. However, they no longer accept it as an inevitable reality or a part of their fate. They make claims over 'common' resources of the village, which had hitherto been under the exclusive control of the dominant caste communities. These assertions are not easily entertained by the dominant groups, and often result in different forms of violence against Dalits.

This is not simply a matter of perception. Resistance and caste related atrocities manifest a clear trend. A broad range of scholars concede to the fact that while the traditional ideological façade of caste or even its institutional hold has weakened, including the decline of untouchability, the violence committed on Dalits appears to be increasing, particularly over the past two or three decades (Béteille 2000; Shah 2000; Teltumbde 2010; Gorringe 2012; Mohanty 2007). However, some recent studies also point to the fact that these growing strains in caste relations, even when they manifest themselves in bloody violence, result in renegotiations of power relations across caste communities (see Pandian 2013).

The experience of mobility for those located at the lower end of the traditional caste hierarchy, namely their moving out of village and agrarian economy, is also not an easy process. Even those who are able to acquire technical and higher education (generally because of the quotas) find it hard to get into the higher echelons of power in the private sector.

Growing redundancy of old caste-based occupations and their dislike for traditional arrangements makes those from the ex-untouchable caste communities (the Dalits) try to move to urban areas for alternative sources of livelihood. However, they find it very hard to make headway beyond the margins of the emerging urban economy. Caste matters in the urban markets in many different ways for the Dalits trying to establish themselves in 
business. Urban markets have never been as open as they are made out to be in the textbooks of economics and sociology. In the Indian context, caste and kinship-based (and sometimes, religion-based) communities actively try to preserve their 'monopolies' in a given trade. Kinship networks play a very critical role in the urban business economy. Apart from working as gatekeepers, they matter in mobilizing capital, through banks and otherwise, the most critical requirement for businesses anywhere in the world. Given their past economic background, those from the historically deprived communities also do not own collaterals, such as agricultural lands or urban properties. The lack of 'social capital' and economic resources is further compounded by the presence of active 'prejudice' that manifests itself in many different ways in their everyday business life and aids in the reproduction of both, social/economic inequalities and caste identity among the Dalits, a sense of being different and unequal (see Jodhka 2010; Iyer et al. 2013; Hoff and Pandey 2004).

It is thus a widely recognized fact that caste matters in India's vast informal economy. Based on her study of a South Indian town Barbara Harriss-White concludes:

Caste ... provides networks necessary for contracts, for subcontracting and for labour recruitment within the informal economy ... liberalisation makes these caste-based relationships more important because it places a new premium on the advancement of interests ... caste is ultimately connected with all the other organizations of civil society that comprehensively regulate economic and social life.

2003: $178-179$

We see this script repeating itself even in the more advanced corporate sector and its hiring practices. My interviews (Jodhka and Newman 2007) with hiring managers in big private companies in Delhi clearly showed that even when they actively deny any consideration of caste and community in the process of recruitment, they openly showed preference for candidates with specific social and cultural skills. Given that the candidates they interview for these relatively high-end jobs are mostly screened, internally or by the hiring agencies, and they are all educated and qualified to be called for the interview, the interviews are meant to judge more than their technical skills and the quality of formal education. They look for 'suitability' of the candidate, the social and cultural aspects of their personality. Who is a suitable candidate and how do they judge the merit of those who are selected for the upperend jobs in the private sector?

Almost every respondent hiring manager interviewed agreed that one of the most important questions they ask the prospective candidates during the interviews is about their 'family background'. Family background, for them, is an important factor in determining the suitability of a candidate for the culture of the company. An equally important factor for hiring at the senior level is the linguistic skills of the candidate, their ability to speak and communicate in English fluently. In other words, the critical qualification for higherend corporate jobs are as much the 'soft skills', the nature and quality of 'cultural capital' (Bourdieu 1986) acquired through one's caste and class habitus which, even according to the hiring managers, was largely a determinant of one's social background and place of residence (rural-urban). The hiring manager we interviewed admitted to the fact that the response to the question about the family background also gave them an idea about their 'social origins'. Caste background of the candidates was not difficult to guess, most of them admitted. This knowledge of 'social background' of the candidate directly impacted their decisions on hiring.

When we followed them up with questions on 'quotas' and their opinions on reservations for the Scheduled Castes in the government jobs and educational institutions, nearly every 
one of them had a negative view on the subject. They all wanted 'merit' to be the sole criteria of judging candidates for recruitment, even when they all admitted that qualities other than merit tended to matter more in the selection process. This attitude also emanated from the fact that corporate houses in India are almost exclusively owned and managed by those from upper-caste backgrounds. A recent study based on a sample of 1,000 companies reported that as many as 92.6 per cent of the board members of Indian corporate houses were from the upper castes (44.6 per cent Brahmans and 46.0 per cent from various Vaishya castes; their proportion in the total population of India is around 10 to 15 per cent). In contrast, those belonging to the traditionally marginal communities (SCs, STs and OBCs) who make for more than 70 per cent of India's population were only 7.3 per cent of the sample (Daljit et al. 2012). It will be hard to view it as an outcome of a random process working on the basis of merit. The authors rightly conclude that the upper end of the Indian corporate sector 'is a small and closed world' where social networking plays an important role.

Still Indian corporate boards belong to the 'old boys club' based on caste affiliation rather than on other considerations (like merit or experience). It is difficult to fathom the argument that lack of merit is the cause for under representation. Caste is an important factor in networking. The small world of corporate India has interaction only within their caste kinship.

ibid: 42

Several other studies looking at social mobility in India reinforce the point that caste indeed works to block those located at the lower end of caste hierarchy (Kumar et al. 2002; Thorat and Attewal 2007; Thorat and Newman 2010; Vaid and Heath 2010). Even when the cultural or ideological hold of caste disappears; the real possibility of vertical social and economic mobility remains rather limited. Much of the mobility appears to be merely horizontal, from traditional caste occupations or agricultural labour in the village to insecure jobs at the lower end of India's vast informal economy. In the dynamic of change, 'the upper castes' are no longer 'cushioned from the forces of downward mobility', but more importantly, it is hard for those located at the lower end of 'traditional' hierarchy to move up (Vaid 2012: 420). In other words, the social mobility scenario in India presents a case of 'continuity rather than change' (Kumar et al. 2002: 2984).

\section{Concluding comments}

Notwithstanding its wide-ranging critiques, the orientalist view of caste, and its academic incarnations in a variety of modernization theories, has continued to be influential. We can see this not only in social science textbooks but also in popular middle-class discourses on the subject, and even in its articulations by popular social movements. However, the lived reality of caste has always been very diverse and complex. Caste persists even when it changes. It persists beyond the domain of religion, in economic life, in democratic politics and in media and other contemporary modes of cultural articulation. It has also had life beyond Hindu religion and beyond the boundaries of India. Caste and caste-like differences have been a common reality among a variety of religious groups in the subcontinent, the Muslims, the Christians or the Sikhs, even when they have had no Hindu ancestry.

As mentioned above, the classical view on caste also classified it as a kind of traditional institution, which was to gradually decline and eventually disappear with the evolutionary process of modernization. Indian society has indeed been undergoing a process of 'modernization' for 
more than a century now. Modern cities like Mumbai, Kolkata, Bangaluru, and many others, have been growing both in size and influence. Even though the proportion of urban population in India today is only around 30 per cent, the influence of modern urban life goes far beyond. The decline of the old agrarian economy is clearly evident from the fact that its contribution to the national income has come down from more than half in the early 1950s to merely 14 per cent now. A majority of Indians today are educated and mobile. The influence of urban middle classes and their styles of living have been growing across regions and communities of the subcontinent, particularly during the past two decades of neo-liberal growth.

Many in middle-class urban India would emphatically argue that indeed caste would and should have disappeared from public life by now had it not been kept alive by the wily actors in India's electoral politics. Its institutionalization through the reservation policy, quotas for Scheduled Castes and Other Backward Classes, is also cited as the other reason for its continued survival in India today. Even when its presence is recognized as a substantive reality in mainstream academic circles, it is generally viewed as a typical case of 'change and continuity'. The underlying assumption being that its continued presence is a result of incomplete modernization of India's economy and its cultural values. As the process of development matures under the neo-liberal market regime, caste is bound to disappear on its own, provided it is allowed to be forgotten by political entrepreneurs of Indian democracy.

However, as is evident from the discussion above and the large volume of empirical literature, caste continues to overlap and articulate with the newer forms of inequalities. While the older modes of social and economic life have changed, the change has not brought about an end to caste. Even when ritual order is de-sacralized, it survives as a system of social inequality and as a value that ranks people on a scale of honour and humiliation. Viewed from this perspective, caste may not appear to be a uniquely Indian or a Hindu social institution, and that is worth considering.

\section{Acknowledgements}

I am grateful to Sneha Komath and Anasua Chatterjee for their comments on an earlier draft of this chapter.

\section{References}

Bailey, F.G. (1960) Tribe, Caste and Nation, Bombay: Oxford University Press.

Beidelman, T.O. (1959) A Comparative Analysis of the Jajmani System (Association for Asian Studies, Monograph Series VIII), New York: J.J. Augustin.

Berreman, G. (1971) 'The Brahmanical View of Caste', in Dipankar Gupta (ed.), Social Stratification, 84-92, Delhi: Oxford University Press.

Béteille, A. (1971/1996) Caste Class and Power: Changing Patterns of Stratification in Tanjore Village, New Delhi: Oxford University Press.

Béteille, A. (1986) 'Individualism and Equality', Current Anthropology, 27 (2):121-134.

Béteille, A. (1997) 'Caste in Contemporary India', in C.J. Fuller (ed.) Caste Today, 150-179, Delhi: Oxford India Paperbacks.

Béteille, A. (2000) 'The Scheduled Castes: An Inter-regional Perspective', Journal of Indian School of Political Economy, 12 (3-4): 367-380.

Bougle, C. (1971) Essays on the Caste System, Cambridge: Cambridge University Press.

Bourdieu, P. (1986) 'The Forms of Capital', in John G. Richardson (ed.), Handbook of Theory and Research for the Sociology of Education, 241-258, New York: Greenwood Press.

Breman, J. (1974) Patronage and Exploitation: Changing Agrarian Relations in South Gujarat India, Berkeley, CA: University of California Press. 
Charsley, S.R. and G.K. Karanth (1998) Challenging Untouchability: Dalit Initiative and Experience from Karnataka, New Delhi: Sage Publications.

Cohn, B.S. (1968) 'Notes on the History of the Study of Indian Society and Culture', in Milton Singer and Bernard S. Cohn (eds), Structure and Change in Indian Society, New York: Aldine Publishing Company.

Cohn, B. (1996) Colonialism and its Forms of Knowledge: The British in India, Princeton, NJ: Princeton University Press.

Daljit, Han Donker and Ravi Saxena (2012) 'Corporate Boards in India: Blocked By Caste', Economic and Political Weekly, 47 (31): 39-43.

Das, Veena and J.P.S. Uberoi (1971) 'The Elementary Structures of Caste', Contributions to Indian Sociology (n.s.) 5: 33-43.

Davis, Kingsley and Wilbert E. Moore (1945) 'Some Principles of Stratification', American Sociological Review, 10 (April): 242-249.

Dirks, N.B. (2001) Castes of Mind: Colonialism and the Making of Modern India, Princeton, NJ: Princeton University Press.

Dube, S.C. (1955) Indian Village, London: Routledge and Kegan Paul.

Dumont, L. (1998) Homo Hierarchicus: The Caste System and its Implications, Delhi: Oxford India Paperbacks (first published in 1970).

Fuller, C.J. (1977) 'British India or Traditional India?: An Anthropological Problem', Ethnos 3-4: 95121.

Ghurye, G.S. (1932) Caste and Race in India, London: Kegan Paul.

Gorringe, Hugo (2012) 'Caste and Politics in Tamil Nadu', Seminar 633, May: 38-42.

Gupta, Dipankar (1984) 'Continuous Hierarchies and Discrete Castes', Economic and Political Weekly, 19 (46): 1955-2053.

Gupta, Dipankar (1991) Social Stratification, Delhi: Oxford University Press.

Gupta, Dipankar (2000) Interrogating Caste: Understanding Hierarchy and Difference in Indian Society, Delhi: Penguin.

Gupta, Dipankar (ed.) (2004) Caste in Question: Identity or Hierarchy, New Delhi: Sage Publications.

Harriss-White, B. (2003) India Working: Essays on Society and Economy, Cambridge: Cambridge University Press.

Hoff, K. and P. Pandey (2004) 'Belief Systems and Durable Inequalities: An Experimental Investigation of Indian Caste', Policy Research Working Paper 3351, Washington, DC: World Bank.

Inden, Ronald (1990) Imagining India, Oxford: Blackwell.

Iyer, Lakshmi, Tarun Khanna, and Ashutosh Varshney (2013) 'Caste and Entrepreneurship in India', Economic and Political Weekly, 48 (6): 52-60.

Jaffrelot, C. (2003) India's Silent Revolution: The Rise of Low Castes in North Indian Politics, Delhi: Permanent Black.

Jodhka, S.S. (2002) 'Caste and Untouchability in Rural Punjab', Economic and Political Weekly, 37 (19): $1813-1823$.

Jodhka S.S. (2010) 'Dalits in Business: Self-Employed Scheduled Castes in North-West India', Economic and Political Weekly, 45 (11): 41-48.

Jodhka S.S. (2012) Caste. Oxford India Short Introductions, Delhi: Oxford University Press.

Jodhka S.S. (2015) Caste in Contemporary India, New Delhi: Routledge.

Jodhka S.S. and Katherine Newman (2007) 'In the Name of Globalisation: Meritocracy, Productivity and the Hidden Language of Caste', Economic and Political Weekly, 42 (41): 4125-4132.

Kapoor, D., C.B. Prasad, L. Pritchett, and D. Shyam Babu (2010) 'Rethinking Inequality: Dalits in Uttar Pradesh in the Market Reform Era', Economic and Political Weekly, 45 (35): 39-49.

Karanth, G.K. (1996) 'Caste in Contemporary Rural India', in M.N. Srinivas (ed.), Caste: Its Twentieth Century Avatar, 87-109, New Delhi: Penguin.

Krishna, Anirudh (2001) 'What is Happening to Caste? A View from some North Indian Villages', Working Paper SAN01-04, Durham, NC: Duke University, Terry Sanford Institute of Public Policy.

Kumar, S., Anthony Heath and Oliver Heath (2002) 'Determinants of "Social Mobility in India", Economic and Political Weekly, 37 (29): 2983-2987.

Manor, J. (2012) 'Accommodation and Conflict', Seminar, 633, May: 14-18.

Marx, Karl (1853) 'The British Rule in India', New York Daily Tribune, 25 June, http://www.marxists.org/ archive/marx/works/1853/06/25.htm [accessed 12 February 2013].

Mencher, J.P. (1978) Agriculture and Social Structure in Tamil Nadu: Past Origins, Present Transformations and Future Prospects, Delhi: Allied. 
Mendelsohn, O. (1993) 'The Transformation of Authority in Rural India', Modern Asian Studies, 15 (4): 805-842.

Mohanty, M. (2007) 'Kilvenmani, Karamchedu to Khairlanji: Why Atrocities on Dalits Persist?', www. Boell-India.Org/Download_En/ Mohanty_Amrita_Corrected.Pdf [accessed 9 November 2009].

O'Hanlon, Rosalind (1985) Caste, Conflict and Ideology: Mahatma Jotirao Phule and Low-Caste Protest in 19th Century Maharashtra, Cambridge: Cambridge University Press.

Omvedt, G. (1976) Cultural Revolt in a Colonial Society: The Non-Brahman Movement in Western India: 1873 to 1930, Bombay: Scientific Socialist Education Trust.

Pandian, M.S.S. (2013) 'Caste in Tamil Nadu (II): Slipping Hegemony of Intermediate Castes', Economic and Political Weekly, 48 (4): 13-15.

Quigley, D. (1993) The Interpretations of Caste, Delhi: Oxford University Press.

Raheja, G.G. (1988) 'Caste, Kingship, and Dominance Reconsidered', Annual Review of Anthropology, 17: 497-522.

Raheja, G.G. (1989) 'Centrality, Mutuality and Hierarchy: Shifting Aspects of Inter-Caste Relationships in North India', Contributions to Indian Sociology (n.s.) 23 (1): 79-101.

Said, E. (1985) Orientalism, Harmondsworth: Penguin.

Shah, G. (2000) 'Hope and Despair: A Study of Untouchability and Atrocities in Gujarat', Journal of Indian School of Political Economy, 12 (3 and 4): 459-472.

Srinivas, M.N. (ed.) (1955) India's Villages, London: Asia Publishing House.

Srinivas, M.N. (1959) 'The Dominant Caste in Rampura', American Anthropologist, 61: 1-16.

Srinivas, M.N. (2003) 'An Obituary on Caste as a System', Economic and Political Weekly, 38, (5): 455-459.

Teltumbde, A. (2010) The Persistence of Caste, New Delhi: Navayana.

Thorat, S. and P. Attewell (2007) 'The Legacy of Social Exclusion: A Correspondence Study of Job Discrimination in India', Economic and Political Weekly, 31: 4141-4145.

Thorat, S. and K.S. Newman (ed.) (2010) Blocked by Caste: Economic Discrimination and Social Exclusion in Modern India, New Delhi: Oxford University Press.

Thorner, A. (1982) 'Semi-Feudalism or Capitalism? Contemporary Debate on Classes and Modes of Production in India', Economic and Political Weekly, 17 (49-51): 993-999, 2061-2086.

Vaid, Divya (2012) 'Caste-Class Association in India: An Empirical Analysis', Asian Survey 52 (2): 395 422.

Vaid, Divya and Anthony Heath (2010) 'Unequal Opportunities: Class, Caste, and Social Mobility', in Anthony Heath and Roger Jeffery (eds), Diversity and Change in Contemporary India, 129-164, Oxford: Oxford University Press.

Weber, Max (1946) From Max Weber: Essays in Sociology (Introduction, edited and translated by H.H. Gerth and C. Wright Mills), Oxford: Oxford University Press.

Wiser, W.H. (1936) The Hindu Jajmani System, Lucknow: Lucknow Publishing House. 


\title{
17 \\ CORRUPTION AND ANTI-CORRUPTION IN MODERN INDIA \\ History, patronage and the moral politics of anti-colonialism
}

\author{
William Gould
}

More than any other general election before it, India's 2014 contest was characterised by a politics of anti-corruption. The rising popular appeal of the Aam Aadmi Party (AAP), the anti-corruption party under the leadership of Arvind Kejriwal partly reflected, and partly created, this trend. And the appeal of AAP has, in turn, built upon an apparently increasing sense in public life in India, that both the scale and importance of 'corruption' scandals relate back to a fundamental problem in the conduct of politics. The contemporary anti-corruption movement could therefore signal a change in the structure and practice of politics in India. Some observers have explored the agendas of both AAP and Narendra Modi, for example, in terms of a critique of 'patronage politics' (Jenkins 2014). Arguably too, these changes represent a new kind of politicisation of a hitherto apathetic urban middle class, for whom both the AAP and Bharatiya Janata Party (BJP) have both traditionally had a strong appeal. These urban professional, small trader and white-collar constituents have formed the basis of the larger anti-corruption movement (from which AAP emerged in late 2012). For some, this even represents a new manifestation of Indian democracy, which is alternative to, and largely divorced from what Chatterjee has described as the 'paralegal' confrontations with the state by poor and marginalised communities (Chatterjee 2004: 60-78).

The rise of large-scale anti-corruption movements in India therefore reveals more than simply public dissatisfaction and vocal opposition to the rumour of apparently ever increasing corruption scandals. This chapter will argue that their reception in public debate is related to two long-term features of Indian political debate since the 1940s: first a longstanding popular critique of the (post)-colonial state which contains within it the idea of a lost moral politics of anti-colonialism; and second the survival of a practical politics of anticorruption in the forms of patronage politics in Indian parties. Both features illustrate how corruption and anti-corruption in Indian politics has not been static. Changing conventions and languages of politics have moulded both phenomena in phases in which India's political economy was 'planned', as well as since the early 1990s in the environment of liberalisation 
and deregulation (Harriss-White 1996: 31-39). As Steven Pierce (2014) has argued, in his work on Nigeria, we might rather think of the morally complex fields of 'corruption' as a 'complex' that is contingent on situation, place, context and changing forms of jurisdiction. In this phenomenon, in any one particular place, there are a range of different kinds of linguistic dynamics, intellectual traditions encoded within the vocabulary that produce the idea of corruption. This is, at one level, spatially scaled. Local concerns interact with the national, with perceptions of what is happening in politics at the centre, affecting how Indians feel they can approach the state (Gupta 2012). Because this is also about shifting political perception, international considerations also have a role, as evidenced in the effects of Transparency International's perception indexes, and the role of international sporting corruption (Majumdar and Mehta 2009).

But if the changing political complex of corruption and anti-corruption relate to how Indians engage with the state, then it is the specific experience and history of the colonial state that is here perhaps key to the particular characteristics of the role of corruption in Indian politics. Colonialism has brought specific temporalities to the politics of corruption and anticorruption, which allow us to view it along two different scales. In terms of a long durée, it is ultimately a history of critiques of the colonialism system, whether from a position of larger critiques of western modernity, or from a direct reflection of the outcomes of autocracy. In this sense, corruption only becomes such in India, in relation to a larger sense of political integrity arising at certain temporal moments when forms of popular sovereignty and concepts of liberty were articulated such as the period surrounding independence in 1947 and the first democratic elections. The modern anti-colonial critique of corruption sets up the notion of the 'ordinary' citizen's struggle against autocracy and the state, which has become a key feature of post-colonial anti-corruption movements. At another scale, anti-corruption movements appear to have arisen at moments when the political system is unable to contain the working of certain kinds of capital or resource accumulation. If we view corruption as an alternative political economy which maintains its own forms of social and administrative stability, once that stability is threatened, social and political competition produces anti-corruption protest. We will explore that briefly especially for the period from the mid-1980s to the mid-1990s and the period since 2006.

This is not to argue that India is entirely unique in terms of the forms of corruption that have arisen within the state. But here we need to distinguish between large-scale scandals on the one hand and routine practices and perceptions of corruption on the other, although the two can and have been inter-related. The former are common to any and every political system. Non-routine scandals have been an important part of national and regional debate, and especially for the period from the 1980s. In general they involve large-scale (often international) bungs, kick-backs or rake-offs from contracts, and/or, misappropriation of public funds, sometimes at a systematic and totalising scale. The large-scale Bofors scandal of 1987 represented the quintessential example of international procurement corruption in India. In this, Rajiv Gandhi, India's Prime Minister at the time, was implicated along with Swedish government ministers in the receipt of kick-backs from the deal between Swedish arms manufacturer Bofors and the Government of India (Sen Gupta 1989: 1615). Bofors effectively became a by-word for corruption in general - a signal to the population as a whole that the rot could, and often did, travel right to the top. More recently, we might include the huge scandal involving the mis-selling of telecommunications licences between 2008 and 2012, which according to The Economist allegedly led to the misappropriation of the equivalent of $\$ 40$ billion dollars in revenue (Economist 2012). For the most part, such scandals are one off events, or relate to specific kinds of unique industrial rent-seeking opportunities. 
The second, routine forms of corruption (sometimes linked to specific scandals) connect more clearly to internal structures of state expenditure and developmental finance and they appear and occur at a range of levels in the polity. Their routine nature is often derived from the ways in which they are hierarchically systematic. It is in this second group that some of the most clear links to longer term histories of corruption and anti-corruption are most pertinent. Many, for example, have reflected the opportunities presented by forms of public control of the supply and sale of goods, common to a range of command economies. In this sense they are linked, in various ways, to the phenomenon of 'Licence Permit Raj': We could trace this back, too, to the 1950s as we will see below, but more recently, it could be explored from the 1981 cement scam involving A.R. Antulay (SCI 1984), but more intensely to the mid-1990s Bihar food relief scam and fodder scam involving Laloo Prasad Yadav via the animal husbandry in which around 950 crore rupees were embezzled (Jenkins 2007: 55-69). Other cases can be found for different regions, for example, the Jharkand medical equipment scam (2008) (Prasad and Chauhan 2009), the Gujarat VDSGCU ${ }^{1}$ sugarcane scam, as reported in The Indian Express (2009), and the Orissa mining scam (2009) (Mishra 2010: 49-68). In the 2000s, perhaps the largest of all was the UP (Uttar Pradesh) Foodgrain scam that ran between 2002 and 2010, which involved misappropriation of the PDS (public distribution system) scheme to the estimated amount amount of Rs 35,000 crore (Madhavi 2013: 42-50). At another level, the stakes involved in the protection of such vast resources help to explain the connections between politicians and organised crime, which in some areas has connected to large-scale public works projects. In 2006 in UP, Mulayam Singh Yadav attempted to crack down on the road construction mafia in Rae Bareli, along the lines that 'nobody should be spared, even if they are from the Samajwadi party' (i.e. his party). At that time, it was estimated that there were 280 mafia groupings in UP, 120 land mafia, 44 contract mafia, 36 criminal and 31 liquor mafia. With huge financial resources and power, they entered politics to protect their interests (Mishra 2006). This involved what came to be known as the Satyendra Dubey case - a person who attempted to expose contract mafia involved in the gold quadrilateral project linking Delhi, Calcutta, Mumbai and Chennai and who was murdered in 2003. However, the largest numbers affected by this situation are ordinary road users, particularly those using cheap or badly maintained vehicles.

Contained within these large-scale systematic scams are smaller, more localised versions of the same process, that in some cases feed into the larger-scale misappropriation, but in other cases are based on what had become a routine form of administration. One of the best documented examples of this is in the work of Robert Wade in the Irrigation department in Andhra Pradesh. Wade showed how Irrigation Executive engineers might pay up to ten times their annual salary for operating a canal system, which they will pay off by selling, in their turn, posts, getting payments from subordinates who get rake-offs from maintenance contracts. If the lower level officers fail to live up to this system, they too were subject to transfer. For Wade, similar patterns could be seen in any department that had regulatory functions, subsidised goods or public works contracts to allocate. In these departments, some posts are more valuable than others, and so open to price competition (Wade 1982: 287-328).

However, these events fully become part of the politics of corruption only at the moments at which they are public scandals and have an effect on the function of politics, or public political debate. In other words, their representation as 'scandal' or within another aspect of the terminology of corruption, relates to public and political tolerance - the moment at which the normal acquiescence in the functioning of their forms can no longer be sustained, and creates political instability and conflict. These moments also, fundamentally link to public notions of the state and how its agents 'ought' to operate or behave according to certain 
yardsticks of moral governance. In this sense, as I will argue throughout, they link strongly to debates about the nature of the Indian state, many of which relate back, fundamentally, to a critique of colonial power. Key in these historical transformations were three historical phases, the late 1930s to mid-1950s, the mid-1980s to mid-1990s and the period from 2006 to the present. Rob Jenkins (2007) identifies similar phases in charting specific grassroots/ popular forms of anti-corruption movements. This chapter, however, attempts to link those moments, too, specifically to forms of political critique and social mobilisation that pre-date the movements themselves. The first phase was one in which a 'modern' notion of corruption and anti-corruption became particularly important - the phase of India's decolonisation between the 1930s and 1950s. The appearance of anti-corruption as a form of political discourse in this period linked to various means of critiquing the colonial state and/ or promoting a particular vision of the 'modern' state. In the form of corruption allegation, on the other hand, it sustained political competition around networks of patronage. These themes continued to be of importance through the changes of the 1980s-1990s but this time in the context of a changing political-administrative nexus, as the Congress declined in authority, and with the effects of economic liberalisation. Finally, from 2006, citizens' movements, some of which were built on the Right to Information Movement, strengthened or proliferated as political-business links and crime in politics was exposed anew.

\section{Corruption, anti-corruption mobilisation and critiques of the colonial state}

In the last three years, possibly even since the passage of India's Right to Information Act of 2005, anti-corruption has had an unrivalled appeal across the political spectrum, and nearly everyone has wanted a piece of it. AAP's agenda on anti-corruption is multi-faceted, including the Jan Lokpal (Ombudsman) Bill itself, a citizen's charter, women's security, police reform, and a range of proposals associated with the catchy attack on the three 'c's of 'corruption, communalism and crony capitalism' (AAP 2014). AAP candidates have been selected, in many cases, with an eye to their association with grassroots anti-corruption movements and commitment to these specific agendas, or the absence of a criminal record (Times of India 2014a). The rise of the party has even been associated, some argue, with larger shifts in Indian political mobilisation, from older concerns of identity politics to those of everyday social entrepreneurialism (jugaad) and the ubiquitous use of electronic social media (Chopra 2014). It is also strongly linked to the projection of a politics of 'ordinariness' and the concerns of the basic citizen.

Other parties have also attempted to ride the wave of anti-corruption: Narendra Modi has adopted a markedly Thatcherite appeal of small government, efficiency, public spending cuts, deregulation and privatisation (Economic Times 2014), as a means of showing how he might rein in older forms of briefcase politics (Kochanek 1987: 1278-1301). These poses have often defined the lines of electoral debate too: Kejriwal has directly attacked Modi's supposed 'Gujarat development model' by suggesting that it is a smokescreen to obscure economic and financial benefits for big business in Gujarat, in long standing connections between the BJP and larger business houses. These accusations of corporate cronyism, printed in The Times of India have involved, for example, exposure of the Ambanis' KrishnaGodavari (KG) gas deal, and questions about how the industrialist Gautam Adani could have increased his wealth 12-fold during Mr Modi's tenure, bypassing environmental and industrial regulations (Times of India 2014c). He accused Mr Modi of transferring a free public hospital built after the 2001 earthquake to the Adani group, which has become a for-profit 
business (Bidwai 2014). Finally, the Congress-led regime, accused as it is for having failed to root out corruption, has attempted to shore up its anti-corruption credentials. In early 2014, Rahul Gandhi attempted to push through a Judicial Standards and Accountability Bill, the Whistleblowers Protection Bill, the Right of Citizens for the Time Bound Delivery of Goods and Services, the Prevention of Bribery of Foreign Public Officials Bill and the Prevention of Corruption (Amendment) Bill. All were shelved for fear that the president might question their announcement as a clutch of Ordinances, creating embarrassment in the lead up to the elections (Times of India 2014b).

Although novel in scale and context in 2014, the politics of anti-corruption has a long political tradition, and all of its movements in that year link back to some of the abiding themes of a much earlier phase of anti-colonialism. India's very first elections under universal suffrage in 1951-1952 were marked by an extensive and well-developed politics of anti-corruption mobilisation, not least within the Congress's own processes of candidate selection. In the distribution of tickets for each constituency, eliminated candidates were able to send complaints to the Congress centre, many of which contained prolix accounts of links between the successful candidate, licence-permit control and local businesses. In these complaints, the term 'corruption' took on a new set of political meanings, noticed not least by the Prime Minister who commented in the lead up to the elections that 'merely shouting from the rooftops that everyone is corrupt creates an atmosphere of corruption' (Gould 2011: 77). As we will see in the second section, this process of corruption publicity underpinned forms of political competition within different constituencies.

However, the significance of this publicity lay in its connection of high-level bureaucratic misdemeanours with a notion of popular civic rights, and the claims of ordinary people against an outdated and essentially foreign administration. In the lead up to the 1951-1952 elections, newspapers were replete with reports about the relationship between the thriving politics of 'blackmarketeers' in the aftermath of war-time controls and the political market in licences and permits. These forms of corruption publicity had developed as a result of popular (urban) reactions to food and civil supply administration, a bureaucracy put in place as a means of administering war-time controls since $1942 .{ }^{2}$ It was therefore directly linked to ideas of failed liberation from the structures of colonial control, put in place in a phase of high political repression. As well as those seeking licences, urban workers were also affected by the controls via systems of rationing; this could also be represented as a 'people's' struggle against colonial bureaucracy. As a result, both the vernacular and English language presses were replete with discussions about scandals involving the control of licences and permits by the powerful, including those in government. ${ }^{3}$ Moreover, these forms of publicity represented struggles against forms of business cronyism, since the system of licences and permits which underpinned the system of controlling sale and distribution of goods, had been used to favour certain commercial interests in some of the big cities.

The popular call to break the 'nexus' between business, administration and politics, as publicised by Kejriwal then, is derived from a much earlier phase of Indian electoral politics, and was well discussed in the 1940s and 1950s. It is worth considering the implications of this for how we might view 2014's electoral race and the role of political corruption therein, in the longer term. First is the point that in the lead up to 1952, 'corruption' was viewed as a problem of political inheritance and specifically of the colonial bureaucracy. In this sense, anti-corruption since then has been based in a history of a particular popular view or critique of the Indian post-colonial state. This critique had some of its antecedents in the late 1930s Congress ministries that offered Indian political parties the first real opportunity to put their critique of 'colonial corruption' into effect. In UP and Bihar for example, formally appointed 
anti-corruption committees exposed, perhaps for the first time from a position of power, the colonial conceit that India was 'inherently corrupt'. Instead, they argued, the state itself directly promoted traditional patron-client relationships, turned a blind-eye to low-level forms of commission or customary payment, or even allowed the working of systematic forms of rent seeking as a means of assuaging local conflicts (Gould 2011: 106-109). ${ }^{4}$

These Congress-led anti-corruption reports argued that the colonial bureaucracy therefore had mapped onto a range of traditional relationships that failed to embrace the 'modern' principles of governance being espoused by the ruling regime. In other words, corruption was a symptom of anti-modernity. In the immediate post-colonial period, this had its effects on ideas of bureaucratic reform, despite, as David Potter argues, the strong continuities in administrative culture (Potter 1997). G.B. Pant's main anti-corruption measure in UP in the late 1940s-1950s was the transferring/replacing of 'inefficient' colonial officers. The implication here was that the administration had not undergone sufficient change and needed to move away from older colonial cultures into a new atmosphere of public accountability. ${ }^{5}$ This idea was to continue to mark official views of corruption and the state well into the 1960s. The state as an active modernising force, which broke down or ameliorated the norms of traditional and medieval societies, also characterised the Santhanam Committee report on corruption in India in 1964 (Santhanam 1964: 101).

Alongside these ideas of the modernising state and failing political integrity, was another discourse of popular responsibility and oversight. In ideological terms, this strongly related to the institutional development of Indian political parties within the colonial system, which while rendered powerless by a restricted franchise and constitution, nevertheless formed civic institutions that both critiqued, but also mirrored the state. As a result, for many such organisations, change had to come from non-official bodies, since internal reform within the colonial system had proved impossible. It had to come from the political community itself. Responsibility for change therefore lay in the development of bodies and organisations of civic action, which would reflect public opinion, and expose public abuses. Subsequently, 'citizens' organisations sprung up across north India from 1948-1951, particularly in cities, with a view to exposing the illegitimate activities of individual officers. The precursor then, to the contemporary grassroots right to information (RTI) movements, particularly emerging from the 1980s,${ }^{6}$ and even anti-globalisation lobbies such as the National Alliance of People's Movements, are older movements of civic engagement. In their early phases of the late 1940s and 1950s, these involved self-styled 'citizens' organisations, many of which campaigned against specific 'corrupt' officers linked to food and civil supply controls (Gould 2011: 127).

These processes and principles have affected what anthropologists and political scientists were to find from the early to mid-1990s in India. Work on late twentieth-century ideas about 'discourses' of corruption in India have discussed a grand dichotomy between common acceptance of everyday and local means of 'getting things done' on the one hand, and loftier critiques of that same state, as larger political visions of 'citizenship' on the other. Jonathan Parry and Akhil Gupta have, in different ways, described this as acquiescence in day-to-day corruption, alongside a parallel internalisation of citizenship values, especially for the period of the early 1990s as India went through the changes of economic liberalisation. Parry, in his study of recruitment to the Bilai Steel Plant shows how the 'idea' of corruption has tended to inflate the notion of the phenomenon of corruption, thereby leading to forms of acquiescence in its day-to-day operation, as a kind of optical illusion. However, he concludes that the popular view of corruption as a 'moral wrong' is testimony to the increasing internalisation of citizenship values in the particular phase of his research from the 1980s-1990s (Parry 2000: 27-55). Gupta has shown, again for the mid-1990s, how the 
popular politics of corruption throws up many visions of the state, sometimes mediated through experience, and sometimes through the media. In this way, the state has spatially interacting levels, representations and practices and as a result of corruption discourses, is constituted in multiple mediated ways (Gupta 1995: 375-402). This vision of what the state 'ought' to be doing at different levels, despite its older 'colonial' structures being intact, relates right back to the mid-century debates about state modernisation, since it is inherently moulded by older experiences of a colonial system.

This gulf between the experience of everyday corruption and the rights of citizens in a larger vision of the state is central to the politics of anti-corruption too in the last decade or so, and most recently in the politics of the AAP. Kejriwal and a number of institutions like the AAP represent corruption as systematic failure of governance, which for some has quasifeudalistic causes. Their remedies are based in an appeal to larger frameworks of civic values, outside the purview of the state itself, devolving power to 'aam log', via institutions such as Mohalla Sabhas. Their appeal is to the lofty ideal of 'swaraj', transparency in government, social justice for minorities in relation to the police, decentralisation via the empowerment of 'gram sabhas'. Here again too then, is an implicit critique of the state, whose corruption can be best combated via a civic critique rather than either complete overhaul or internal reform of its structures. But this is articulated by highlighting the everyday-ness of the effects of corruption. More than any other party, the success of the AAP (the acronym of which means 'you' in Hindi), has been the performance of 'ordinariness'. The party logo is a sweeper's broom, Kejriwal, its leader, is commonly seen with a scarf over his head (a common worker's mode of dress) and direct appeals to the electorate have been couched in terms of leaders being 'the same' ordinary people as the audience. This association of anti-corruption with a notion of the 'everyday' is significant too in the ways in which anti-corruption has directly entered both political mobilisation and inter-party competition, as we will see in the section below.

\section{The concept of 'integrity' and the politics of patronage}

In the early 1950s, often inherent in the critique of an incomplete 'modernisation' of the state and its colonial antecedents as a basis of corruption, was a second tendency connecting to it the idea of a failing tradition of political integrity or morality. At the end of Jawaharlal Nehru's life, W.H. Morris-Jones noticed this phenomenon as a process in which 'corruption is at once what one political language calls the other and what happens when one is displacing the other' (Morris-Jones 1964). This was often articulated in the rhetoric of a lost tradition of 'national service', exemplified by some of the key figures of the 'freedom struggle' or cognate leaders of sectional/regional political groups. This political rhetoric has commonly appeared in electoral competitions through to the present, although it has shifted in context from its roots in India's earliest democratic mobilisations. In the lead up to the first general elections in India, contemporary political scientists observed this as a phenomenon of a new generation of political publicists who had begun to displace or replace older leaders who were associated with a Gandhian moral politics (Brass 1965: 45). In competitions between this new breed of career politicians following independence, a series of provincial competitions commonly revolved around mutual accusations of corruption. For example, in UP scandals involving mud-slinging between the likes of P.D. Tandon and Rafi Ahmed Kidwai (around accusations that the latter had embezzled money from the Provincial Congress Committee), ${ }^{7}$ led Nehru to mourn the loss of an older idea of anti-colonial integrity (Hindustan Times 1949). Conflicts between the Congress Party and the Congress Socialist Party in the 1930s-1940s were based 
around ideas and interpretations of 'corruption', in which the Congress mainstream was viewed as a preserve of bourgeois high caste professionals. This sentiment also had its own hierarchical and popular element to it, which connected to the ideas of everyday visions of the state. It was essentially part of a public outcry which had a wide social appeal: in the 1950s and 1960s, the assumed illicit profits of politicians in distributing licences and permits for trade, in the civil supply bureaucracy outlined above, was also portrayed in the press as a betrayal of an older moral politics championed by Mahatma and his followers (National Herald 1948: 9).

Such movements were not confined to the immediate aftermath of independence, or to the ruling party. As in the 1950s calls to populism, the JP or Total Revolution movement of Jayaprakash Narayan against the government of Bihar and Indira Gandhi at the centre in 1974, was based in the dream of rebuilding a Gandhian utopia against contemporary corruption (Wood 1975: 320-322). In the late 1980s and 1990s, this discourse of lost integrity was even more squarely directed against the Congress Party as 'regime', but from a very different direction. The increasingly successful (in the 1980s) Hindu right parties used a range of authoritarian critiques of the 'appeasement' of sectional interests as a 'corruption' of the national interest specifically in reactions to the implementation of the Mandal Commission, which created further categories of caste reservations for 'Other Backward Castes'.

The notion of corruption as a decline in political morality then, also appeals to parties who have sought to revive the moral impulses of 'national' unity. When in October 2013, Narendra Modi launched plans for a 182 metre statue of the iron man of India in Gujarat, Vallabhai Patel, he made a clear bid to appropriate one of the main 'heroes' of the freedom movement, representing again a rejuvenated politics of integrity (BBC News South Asia 2013). The gigantic Patel, which would be the largest in the world, is at once a challenge to the Nehru dynasty (the alternative right-wing first PM), lip-service to Hindu nationalism that grew out of the Congress, a celebration of a tough stance on separatism (Patel was the great integrationist of Princely states) and on group concepts of citizenship rights (Patel famously challenged Muslims to 'prove' their loyalty to India) (in Chopra 2004: 58). Although Modi's proposed necropolis is comparable to that of the Dalit leader, Mayawati, who has constructed monuments to Ambedkar all over the state (Jaoul 2006: 175-207), the BJP has traditionally been dominated by an anti-reservation ideology. In 2014, Modi himself has shifted more towards a pro-Mandal stance. But his party and its affiliates (as well as his largely urban supporters) have been quick in the past to juxtapose their supposed tough stance on 'corruption' against a perceived growth in political corruption and criminalisation attending, as they see it, the rise of caste based parties since the 1990s.

Since the mid-2000s, alongside these party political challenges, have been a range of NGO and citizens' organisations which often campaigned against large capital projects with an environmental impact, or highlighted the high levels of criminalisation in India's formal political institutions (Minch 2013). ${ }^{8}$ This politics of integrity has been promoted by more radical sections of those espousing a politics of anti-colonialism in a context of market liberalisation, but this time from two related but quite different directions. On the one side, the Right to Information Act of 2005 (which followed state acts implemented since 1997), helped to galvanise a range of existing 'peoples' pressure groups (Webb 2010), NGOs and grassroots movements engaged in campaigns opposing large-scale industrial, commercial and capital projects affecting traditional environments. Movements such as the National Alliance of People's Movements (and its sub-organisations), the Narmada Bachao Andolan, Mazdoor Kisan Shakti Sangathan, and Rural Litigation and Entitlement Kendra were now able to uncover forms of political-business corruption in their campaigns more effectively. On the other side, from 2011, a concerted political protest movement under the 
leadership of the Maharastrian leader Anna Hazare promoted the implementation of a Jan Lokpal (Ombudsman) Bill to specifically target political parties, leaders and government ministers. Hazare outwardly projects himself as a Gandhian. His Ralegaon Siddhi based movement in Maharashtra is evidently based on Gandhi's Phoenix farm. He promotes many similar campaigns to Gandhi (on social reform and alcoholism) and he has taken on similar religious idioms (Sengupta 2012: 593-601). Arrayed behind Hazare were a range of interests, including groups who had been involved in 'legal activism' such as the People's Union for Civil Liberties. However, the political meanings attributed to Hazare have been quite different from those associated with anti-corruption movements of most grassroots citizens' organisations. In response to Anna Hazare's 2011 movement, the Independent Left critiqued the Jan Lokpal Bill as a movement of the urban middle classes and legal activists with an interest in a strong state, with potentially authoritarian undertones (Sitapati 2011: 39-45).

Given the largely ubiquitous and appealing nature of these discourses of declining political integrity, not to mention their cross-sectional popular appeal, they have always played a role in the everyday conduct of party politics across India. Indeed, it might further be argued that since the profits of political corruption, especially those traditionally involving links with local/regional business interests described generally as 'licence-permit quota raj' have always been publicly (if not explicitly) acknowledged in India as a necessary feature of political success, an anti-corruption stance is also a key strategic dynamic of the politics of patronage. In Paul Brass's recent study of the anti-corruption crusading politician of 1940s-1980s UP, Chaudhuri Charan Singh, this relationship between corruption and anti-corruption, is essentially a political game in the cut and thrust of political funding and vote banks, especially at the time of elections. For Brass, networks of political corruption link to administrative action, and are based on a dialectic between corruption and anti-corruption lobbying against rivals. The latter is never about rooting out corruption. It is about either irritation about not having successfully gained access to resources for your own party - not having successfully corrupted, or it is about schadenfreude as your political opponents experience miseries and accusations. Or finally, it is about the promotion of ethnic or caste particularism - the need to corrupt, to promote the interests of your community (Brass 2012).

In this context, appeals to a lost (often Gandhian) political morality were a very useful, if risky strategy, in which accusations of corruption could be connected to all manner of sectional abuses, including the cronyism that grew from both casteism and communalism. This game of political recrimination quickly found its natural home in the politics of local electoral politics, particularly at the state level, and thrived on what Kochanek and Brass traditionally described as forms of clientelism. In this sense, a rooted politics of anticorruption has always existed alongside or even within the very political structures that have arguably allowed what Kejriwal described as a political-business 'nexus' to survive - the old factories of 'briefcase' or pork-barrel politics which kept Congress's (and other parties') electoral options alive, factions tentatively united and alliances usefully fluid (Brass 1965). Although these forms of corruption allegation are difficult to uncover and connect to specific scandals for contemporary India, it is possible to find their early forms in detailed historical records surrounding the nomination of candidates for India's first general elections.

Here it is worth remembering that although the internal factions of the Congress worked rather like opposition parties in many respects, the clear difference was the degree of 'insider' information rival candidates for selection to a particular seat might have about each other. This was a dynamic for creating a fluidity of alliances that could change over time (Kothari 1964), and which necessitated the control of financial resources and incentives to build networks of followers. But this system could not have been exposed and direct corruption allegations 
made, without the internal political structures allowing a form of reporting to the central party machinery, as well as a sense of dissatisfaction or conflict between particular leaders. In the 1951 state elections, candidate selection was worked out in a process by which District Congress Committees (DCC) sent recommendations to the State Parliamentary Board. Members of the DCC would therefore need to mobilise networks of supporters to get their men or women selected. However, the All-India Congress Committee (AICC) allowed those unsuccessful in their selection to send in an appeal or representation against a rival candidate. ${ }^{9}$ These representations contained, in a large number of cases, accusations of corruption. In the normal everyday conduct of politics, the sorts of relationships between business interests and politicians, or nexuses between leaders and bureaucrats that these accusations exposed would have been tolerated, unworthy of comment. But in a context of lost electoral selection, specific competitors had a reason to expose them. In other words, the very production of information about corruption was linked to the process of political competition at an everyday level.

These internal corruption allegations, in turn, generated a larger publicity of corruption which could in some instances grow into the scale of a scandal, connecting internal information to newspaper coverage. This was particularly the case for the most prominent provincial leaders, against whom the most involved, complex and widespread accusations were generated by numerous rivals. But equally, the fact that such accusations were based on political competition made them difficult to verify, and made it relatively easy for the leaders themselves to be shielded by the involvement of subordinates, particularly those within the administration. Three such leaders in the state of UP, who were subject to widespread corruption allegations during the 1951 state elections were Chaudhuri Charan Singh, C.B. Gupta and Ram Ratan Gupta. Charan Singh was accused specifically of packing various Congress organisations with members of his own caste and of getting control, unfairly, of the Meerut DCC. ${ }^{10}$ Importantly though, he responded to such allegations with the claim that he was bound to be the subject of nefarious corruption allegations, precisely because he himself had gone out of his way to root it out in others (Brass 2012: 156). C.B. Gupta who was one of UP's first Food and Civil Supply Ministers and who went on to be Chief Minister, was accused in a lengthy and detailed set of allegations penned by a rival, Balkrishna Sharma, of freezing the supply of sugar for large bribes and for systematically distributing licences and permits (in 21 separate instances) to specific followers. ${ }^{11}$ Linked to Gupta's followers and therefore also within the sphere of these accusations against the minister, was the industrialist from Kanpur, Ram Ratan Gupta. He was represented as a key figure in the promotion of blackmarketing activity in the election files, and one of the central 'business' contacts to the Gupta group. ${ }^{12}$ Perhaps most importantly, the extent of 'mud-slinging' between political rivals was particularly intense in the city of Kanpur which meant that the allegations against Ram Ratan Gupta featured in the press. ${ }^{13}$ This was also connected to the sense in which popular protests against corruption regularly identified a political-business network, and such stories circulated well and sold copy.

Highly significant in these factional political corruption allegations then, was the position of the bureaucracy, and its erstwhile connection to an older 'corrupt' colonial administration. On the one hand, because the colonial administration was expected to have been 'naturally' corrupt, it was equally expected that political leaders would control it for their clients. When the AICC received the complaints a common response was that investigation/action was not necessary, not least because the disgruntled appellant would not in any case have had the 'influence' to win the election. Implicit in this kind of response was the point that patronage and perhaps even forms of illicit profit associated with it, were a necessary condition of electoral success. Oh the other hand, such connections both shielded the leader from direct popular accusations of corruption and added to the discourse of corruption being derived 
from older colonial structures. In the allegations of S.K.D. Paliwal and Balkrishna Sharma against C.B. Gupta, the latter had maintained his networks of influence via the distribution of licences and permits. The key administrative figure in this process was the Town or District Rationing Officer - the highest level bureaucrat in the food and civil supply machinery. It was more often than not this figure who became the direct victim of popular protests, unravelling scandals and the like, when in most cases they were acting on behalf of Members of Legislative Assemblies (Gould in Sherman et al. 2014: 34-63).

These patterns of administrative-political interaction formed the basis for more developed networks of administration-derived rent seeking and political patronage later in the century. Just as changes around independence made their role the subject of renewed public scrutiny, so later in the century specific changes in the nature of political consensus and the working of the economy (especially between the mid-1980s and mid-1990s) brought renewed interest in, and exposure of these routine forms of malfeasance. In the 1960s and 1970s, political use of bureaucratic transfer (ostensibly set up to prevent corruption, but ultimately encouraging it) (de Zwart 1999), was of course routinely continued. One retired Central Bank of India (CBI) officer told us,

I remember when I was DIG ... Mr Bahuguna, ${ }^{14}$ who is now dead, he spoke to me once. He said to me, such and such person, you have Yadav, you have transferred him... I said, he has done 6 years in the district and under the rules he has got to go. He said, administratively, you are perfectly right, but my problem is that the President of the UP Congress is a Yadav and this man is a Yadav... and it is important to me now to keep the president of the Congress on my side for political reasons. ${ }^{15}$

As the work of Akhil Gupta, Craig Jeffrey and Barbara Harriss-White suggests in different ways, changes in the economy, and weakening of the Congress consensus from the mid- to late 1980s, began to expose these nexuses between politician and bureaucrat more clearly as an unacceptable state of affairs in popular critiques of corruption. At one level, this came about via government initiatives. In 1986 a government commission was set up in UP to explore the working of district administration. In its interviews with members of 'the public', it found that increasingly in the last few years, people had looked up 'to muscle power, political patronage and money power for protection and their well being, rather than to the observance of law and the normal administrative apparatus' (CDLA 1986: 67). For the ordinary citizen, the report noted that '... government employees at all levels, and specially at the local levels do not assist an ordinary citizen even in routine matters unless he uses political influence or lobbying or jumps the queue through improper action.' (CDLA 1986). At another level it was clear in everyday discussion of corruption. Akhil Gupta's ethnographic work for the period of the late 1980s and early 1990s demonstrated an increasing popular awareness of the need to 'perform' certain kinds of approaches to state officials, and how a sense of this performance related to larger-scale notions of corruption as a whole in India. This, he argued, was related to changes in the media in which large-scale scandals and the idea of corruption at the national level came to inform citizens' views of themselves via the prism of corruption. This in turn reflected back on everyday practices of approaching the state (Gupta 1995: 390-400). Since the passage of the Right to Information Act in 2005, this sense of performance with the state, has been increasingly carried out by activists working on behalf of the poor and marginalised, in seeking out information about a range of government welfare projects and public works. And once again, as the work of Sandeep Pandey in UP has shown, this activity has been based on a renewed effort to expose older forms of political-bureaucratic patronage and systematic failures (Pandey 2011). 


\section{Conclusion}

Where does this leave anti-corruption as a project in modern India, beyond that of political mobilisation or strategy? If twentieth-century forms of anti-corruption have only traditionally arisen at certain moments of political instability, change or opportunity as seems evident in our comparison between early post-independent and contemporary India, then for the rest of the time, populations would appear to acquiesce in its existence as a 'normal' function of the economy and politics. As far as modern parties are concerned, candidates are expected to have 'local influence' - this has remained a constant throughout India's democratic existence - and as with bureaucratic recruitment, influence is outwardly connected to the distribution of state resources (RBCC 1955: 125-145). Certainly, the highly systematic forms of rent seeking described by the likes of Robert Wade (1982), Craig Jeffrey (2001) and Barbara Harriss-White would appear to show that processes of accumulation take place both in normal phases of bureaucrat control/planned economic development (Wade), and in phases of economic deregulation (Harriss-White 1996). In this sense, we might view corruption as an alternative political economy, which is more explicitly 'exposed' when the political and social interests that it serves are radically disturbed. Anti-corruption movements and public discussion about corruption, for example, are naturally more common around times of electoral contest. But on a longer historical scale they have also seemed to appear at moments of state transition, for example, as colonialism declined in the 1940s-1950s, as the old network of Congress power disintegrated and the economy liberalised in the early 1990s, and as coalition politics became the norm, electronic media exploded and RTI gave grassroots access to protests in the 2010s.

This begs the question, for whom does corruption (and anti-corruption) ultimately matter in modern India? Being represented mainly as a concern of the urban and erstwhile high caste voter, movements such as those of Anna Hazare (and to some extent even AAP), perhaps become relatively empty domains of the (hitherto apathetic) middle classes' complaints about a state that no longer adequately serves its interests. Arguably, today, this is a constituency brought up on the promises of development and prosperity in the wake of 'liberalisation' and 'deregulation' - the consumers of, for example, the BJP's 'India Shining' campaign of 2004, who target their occupational frustrations on an older Nehruvian bureaucracy and planned economy (Sitapati 2011: 43-44). Equally, corruption is represented as being everywhere, permeating nearly all forms of government and even represented as a social as well as a bureaucratic plague. As a result, it can be extended to cover all manner of agencies and potential abuses. Appealing to every party, anyone, or anything can essentially turn out to be 'corrupt' and its tentacles reach everywhere. At another level, the notion of a lost Gandhian political integrity, particularly in the work of Hazare and the Hindu right, in different ways, represents a specifically middle-class notion of political conduct. This is a morality that presupposes a social connection to political-administrative interaction and the 'rule of law', within which such classes have a specific stake, as the holders of office and wielders of legal citizenship rights. This, in turn leads us into relativist arguments from the position of privilege. Ashis Nandy's remarks at the Jaipur literary festival in January 2013 were interpreted as a commentary on the natural propensity for corruption of low castes (Iqbal 2014). Partha Chatterjee's concept of paralegal mobilisation within 'political society' for those living on the margins also presupposes that anti-corruption is a largely urban middle-class privilege, and perhaps renders the very notion of corruption/anti-corruption relatively meaningless to the poor (Chatterjee 2004).

However, despite the largely urban middle-class support for Anna Hazare in 2011, and the currently recorded urban support for AAP, it is dangerous to assume that in the longer term 
anti-corruption has had little or no purchase for the poor, either in urban or rural constituencies. Equally, associating 'absence' of anti-corruption mobilisation among lower castes in India as lack of interest, sets up a false opposition between a politics of 'community' and another of citizenship, suggesting that the former experience a different moral universe. Yet all inhabitants of the land seek to get their work done, protect their families, find a livelihood and make sense of state rules. Bearing in mind the means by which cultures of anti-corruption can be located in an array of critiques of the (colonial/neo-colonial) state, we might better explore the many ways in which notions of 'corruption' for the poor are potentially alternative rather than absent. As a number of popular movements have suggested too, they are perfectly capable of mobilising comparable discourses of integrity in governance and a politics of civic rights. Since 1998, the Denotified and Nomadic Tribes (DNT) movement in India, for example, has repeatedly evoked the idea of a 'loss' of potential citizenship rights that needs to be recovered. This has taken place via forms of civic engagement and protest that specifically target and expose police corruption, and mobilise around a specific form of critique of colonial inheritance. ${ }^{16}$ Another relatively large movement promoting RTI in rural UP for example, Asha Parivar, under the leadership of Sandeep Pandey, has had extensive success in mobilising the rural poor of Lucknow, Hardoi and surrounding districts in anti-corruption movements. ${ }^{17}$

Ultimately, just as collecting data on the nature and extent of corruption is inherently difficult, so too is the project of uncovering the reasons for anti-corruption. Whatever the historian or political scientist can ascertain about political behaviour, even at times of elections in India, is based on data that is inherently urban-skewed. It is probably the case that the electoral polls for 2014 for example, as in previous elections, are not a particularly accurate measure of how the vast majority of the electorate will vote. This is not just because of the myriad of regional parties, whose forms of voter mobilisation complicate these predictions. It is also the fact that these polls largely fail to accurately capture the voting habits of rural populations. Therefore relatively little is known either about the views of rural constituencies or the politics of anti-corruption. Equally, we might ask what will become of the agendas of anti-corruption, once the real business of forming a coalition government across a range of regional parties begins to take effect. Whether or not it radically changes the practice of politics in India, given its historical trajectories, the appeal of anti-corruption is unlikely to diminish for the foreseeable future.

\section{Notes}

1 Vadodara District Sugarcane Grower's Cooperative Union.

2 For example, see the humorous complaints about rationing and supply corruption in Pioneer, 22 June 1949.

3 For example, a series of such scandals were reported in the Citizen Weekly, 12 February 1949, and reported in Bombay 3 March 1949.

4 See 'Report of the Anti-Corruption Committee', General Administration Department (hereafter GAD), Box 594, File 70/1938.

5 Interview with R.K. Trivedi, 30 October 2005, Lucknow.

6 See, for example, Rural Litigation and Entitlement Kendra v. State of UP, WP 8209, 8821 of 1983 (1985.03.12) (Dehra Dun Quarries Case), accessible at https://www.elaw.org/node/2671.

7 Jawaharlal Nehru to Purushottam Das Tandon, 18 February 1949, Sardar Patel's Correspondence 1945-50, Vol. 8, pp. 289-289.

8 In August 1997, the Election Commissioner G.V.G. Krishnamurti revealed that 1,500 candidates contesting elections in the 1996 General Election to the Lok Sabha had criminal records for murder, dacoity, rape, theft or extortion. Nearly 700 members of the 4,722 members of the State Legislative Assemblies were involved in criminal trials and cases were pending against them. 
9 These complaints can be found in the AICC election files in the Nehru Memorial Museum \& Library (hereafter NMML).

10 'Allegation against the proposed candidature of C. Charan Singh from Bhagpat (West) of Meerut District', AICC Papers, Election Files, File No. 4602, NMML.

11 'Appeal of Balkrishna Sharma', in 'Representations against Shri Chandra Bhan Gupta for selection to the State Assembly Elections', AICC Papers, File no. 4709 1951, NMML.

12 'Representations against Ram Ratan Gupta for Hardoi District (North) in the State Assembly Elections', AICC Papers, File No. 4674 1951, NMML.

13 Hindustan Times, 12 November 1951; Pioneer, 12 November 1951; Aaj, 13 November 1951.

14 Hemvati Vandan Bahuguna was Chief Minister of Uttar Pradesh between 1973 and 1975.

15 Interview with J.N. Chaturvedi, 25 October 2005, Dehra Dun.

16 See, for example, the DNT Rights Action Group publications under the editorship of Ganesh Devy from 1998.

17 Some of the RTI work of Asha Parivar can be found at http://ashaparivar.org/projects/jsk/ (accessed on 1 May 2014).

\section{References}

Aam Aadmi Party (AAP) (2014) 'Manifesto', available at http://www.aamaadmiparty.org/manifesto-2014 [accessed 25 April 2014].

BBC News South Asia (2013) 'India's Narendra Modi Lays Foundation Stone for "World's Tallest Statue", 31 October, http://www.bbc.co.uk/news/world-south-asia-24753802 [accessed on 27 April 2014].

Bidwai, P. (2014) 'Kejriwal Takes on Demagogue Modi', Daily Star, 25 April.

Brass, P. (1965) Factional Politics in an Indian State: The Congress Party in Uttar Pradesh, Berkeley, CA: University of California Press.

Brass, P. (2012) An Indian Political Life: Charan Singh and Congress Politics 1937-1961, Delhi: Sage.

Chatterjee, P. (2004) The Politics of the Governed: Reflections on Popular Politics in Most of the World, New York: Columbia University Press.

Chopra, P. (2004) (ed.), Thematic Volumes on Sardar Vallabhbhai Patel: Muslims and Refugees, Delhi: Konark Pub.

Chopra, S. (2014) The Big Connect: Politics in the Age of Social Media, Delhi: Random House India.

Commission on District Level Administration (CDLA) (1986) Report, Vol. 1, August, Lucknow: Indira Bhavan.

Economic Times (2014) 'Narendra Modi’s Supporters Expect a Thatcherite Revolution', 6 April, http:// articles.economictimes.indiatimes.com/2014-04-06/news/48908426_1_narendra-modi-modicabinet-air-india [accessed 25 April 2014].

Economist (2012) 'Megahurts: What a Scandal says about Government and Corruption in India', 11 February.

Gould, W. (2011) Bureaucracy, Community and Influence in India: Society and the State, 1930s-1960s, London: Routledge.

Gould, W. (2014) 'From Subjects to Citizens? Rationing, Refugees and the Publicity of Corruption over Independence in UP', in Taylor C. Sherman, William Gould and Sarah Ansari (eds), From Subjects to Citizens: Society and the Everyday State in India and Pakistan, 1947-1970, 34-63, Delhi: Cambridge University Press.

Gupta, A. (1995) 'Blurred Boundaries: The Discourse of Corruption, The Culture of Politics, and the Imagined State', American Ethnologist, 22 (2): 375-402.

Gupta, A. (2012) Red Tape: Bureaucracy, Structural Violence and Poverty in India, Durham, NC: Duke University Press.

Harriss-White, B. (1996) 'Liberalisation and Corruption: Resolving the Paradox (A Discussion Based on South Indian Material', IDS Bulletin, 27 (2): 31-39.

Hindustan Times (1949) 'Address to Congress Members of the Assembly and Workers at Lucknow', 4 April.

Indian Express (2009) 'Sugarcane Scam: Accused Held from Maharashtra', 17 November.

Iqbal, M. (2013) 'Jaipur Festival Ends but Controversy Lingers', The Hindu, 29 January 2013, http:// www.thehindu.com/news/national/other-states/jaipur-literature-festival-ends-but-controversylingers/article4354622.ece [accessed 1 May 2014].

Jaoul, N. (2006) 'Learning the Use of Symbolic Means: Dalits, Ambedkar Statues and the State in Uttar Pradesh', Contributions to Indian Sociology, 40 (2): 175-207. 


\section{William Gould}

Jeffrey, C. (2001) “'A Fist is Stronger than Five Fingers": Caste and Dominance in Rural North India', Transactions of the Institute of British Geographers, 25 (2): 1-30.

Jenkins, R. (2007) ‘Civil Society versus Corruption', Journal of Democracy, 18 (2): 55-69.

Jenkins, R. (2014) 'Is "Programmatic Politics" Possible in the Absence of Party Programmes? Assessing the Alleged Demise of Patronage Politics in India', Ballots and Bullets, http://nottspolitics. org/2014/04/02/is-programmatic-politics-possible-in-the-absence-of-party-programmes-assessingthe-alleged-demise-of-patronage-politics-in-india/ [accessed 17 April 2015].

Kochanek, S. (1987) 'Briefcase Politics in India: The Congress Party and the Business Elite', Asian Survey, 27 (12): 1278-1301.

Kothari, R. (1964) 'The Congress System in India', Asian Survey, 4 (12): 1161-1173.

Madhavi, R. (2013) 'Economic Crime and Punishment: A Legal Perspective', IUP Law Review, 13 (3): 42-50.

Majumdar, B. and N. Mehta (2009) India and the Olympics, London: Routledge.

Minch, M. (2013) 'Criminalisation of Politics and Indian Administration', Spectrum: A Journal of Multidisciplinary Research, 2 (10): 34-38.

Mishra, B. (2010) 'Agriculture, Industry and Mining in Orissa in the Post-Liberalisation Era', Economic and Political Weekly, 45 (20) 15 May: 49-68.

Mishra, S. (2006) 'Mulayam Hit Mafia Hard: Uttar Pradesh CM Mulayam Singh Orders Massive Crackdown On Mafia', India Today, 16 October.

Morris-Jones, W.H. (1964) The Government and Politics of India, London: Hutchinson University Library.

National Herald (1948) 'Control Blesses the Rich and Curses the Poor: Gandhiji Says Monopolies Must Go at Once', 7 January, 9.

Pandey, S. (2011) 'Again It's a Fakir Folks', Tehelka, 23 June, http://archive.tehelka.com/story_main50.as p?filename $=$ Ws23062011LokpalBill.asp

Parry, J. (2000) “"The Crisis of Corruption” and “The Idea of India”: A Worm's Eye View', in I. Pardo (ed.), The Morals of Legitimacy, 27-55, New York and Oxford: Berghahn Books.

Pierce, S. (2014) A Moral Economy of Corruption: State Formation and Political Culture in Northern Nigeria, Durham, NC: Duke University Press.

Potter, D. (1997) India's Political Administrators: From ICS to IAS, Delhi: Oxford University Press.

Prasad M. and Chauhan, N. (2009) 'Healthcare Scam: CBI Raids 14 Premises in Jharkhand', The Indian Express, 1 September.

Report of the Backward Classes Commission (RBCC) (1955) Vol. 1, 125-145, Simla: Government of India Press.

Sen Gupta, B. (1989) 'From Bofors to Boforitis', Economic and Political Weekly, 24 (2) (22 July): 1615.

Sengupta, M. (2012) 'Anna Hazare and the Idea of Gandhi', The Journal of Asian Studies, 71, 03 (August): 593-601.

Sitapati, V. (2011) 'What Anna Hazare's Movement and India's New Middle Classes Say about Each Other', Economic and Political Weekly, 66 (30): 39-45.

Supreme Court of India (SCI) (1984) R.S. Nayak v. A.R. Antulay, 16 February 1984, AIR 6841984 SCR (2) 495, 1984 SCC (2) 1831984 SCALE (1)198.

Times of India (2014a) 'AAP Snubs 2013 Protocol for Candidate Selection', 17 February, available at http://timesofindia.indiatimes.com/india/AAP-snubs-2013-protocol-for-candidate-selection/ articleshow/30541436.cms [accessed 30 April 2014].

Times of India (2014b) 'Cabinet Develops Cold Feet on Rahul Gandhi's anti-graft Ordinances', 1 March.

Times of India (2014c) 'Modi a "Property Dealer" for Ambani, Adani and Tatas, Kejriwal says', 9 March.

Wade, R. (1982) 'The System of Administrative and Political Corruption: Canal Irrigation in South India', Journal of Development Studies, 18 (3): 287-328.

Webb, M. (2010) 'Success Stories: Rhetoric, Authenticity and the Right to Information Movement in North India', Contemporary South Asia, 18 (3): 293-304.

Wood, J.R. (1975) 'Extra-Parliamentary Opposition in India: An Analysis of Populist Agitations in Gujarat and Bihar', Pacific Affairs, 48 (3): 320-322.

Zwart, F. de (1999) The Bureaucratic Merry-Go-Round: Manipulating the Transfer of Indian Civil Servants, Amsterdam: Amsterdam University Press. 


\title{
18 \\ REGIONAL \\ PERSPECTIVE
}

\section{Gujarat and the contradictory co-existence of economic enterprise and political illiberalism}

\author{
Harald Tambs-Lyche and Nikita Sud
}

\section{Introduction}

The state of Gujarat, at the western extreme of the Indian subcontinent, has been in the news throughout the young twenty-first century. Since 2014, the former Chief Minister of the state has been Prime Minister of India, and the election which brought him this victory was the first ever to give an absolute majority to the Bharatiya Janata Party (BJP), often called the 'Hindu fundamentalist' or 'Hindu Nationalist' party. Ever since that party gained power in Gujarat in 1995, the state has been seen as the 'showcase' of the Hindu right. Then, early in 2002, a violent clash between the Hindu and Muslim communities resulted in the death of some 1,500 to 2,000 people, with a majority of Muslims among the killed. Modi's overwhelming election victory in December of that year was seen as partly a result of this violence, to which the government he led had been at best indifferent.

Another aspect of this recent history of the state has been striking economic growth, apparently the result of the Gujarat government's 'business-friendly' liberalisation policies, with active support for Indian and international investors. This growth, however, is also seen as having brought increasing social inequality as well as pollution, and the situation of religious minorities such as Muslims has worsened under the BJP regime. After the 2014 national elections, when Modi became Prime Minister, the promises of the BJP, as well as the fears of the opposition, turned around the question: would India's development and policies follow the Gujarat model?

As this is written, it may yet be too early to answer this question. In this chapter we shall look more closely at the constellation of forces that have produced, and are producing, the present situation in Gujarat. 


\section{Geographical factors in Gujarat's history}

The first element here is the location of the state, on the west coast of India, bordering on Pakistan to the north, and on the Indian states of Rajasthan to the northeast, Madhya Pradesh to the east, and Maharashtra to the southeast. The state covers 184,035 square kilometres, and had a population of 60,439,692 in the 2011 Census. The state is mainly situated north of the Western Ghats, and is linked by several overland routes to the heartland of Northern India. Thus it provides the heartland's most direct access to the sea, and from Gujarat ships have sailed to the Gulf and the Red Sea, to East Africa, and to Peninsular South Asia throughout history as we know it. Commerce, then, and towns that were centres of trade have profoundly influenced Gujarat society. It has often been said that here, the merchant castes (Vaishya) are second in rank only to the Brahmans, and superior to the Kshatriya varna from which kings come. Members of the trading communities were important in the Vallabhi kingdom, an offshoot of the Gupta empire, which fell in 784 AD. Merchants occupied important political posts, such as dewans (ministers) at the time of the Solanki (Northern Chalukya) kingdom of the eleventh to thirteenth century (Majumdar 1956). They continued to be a strong lobby under the Gujarat sultanate, from the late thirteenth century onwards. The strong position of the merchants means that Gujarat may have been the first Indian region to develop a veritable bourgeoisie.

Under the Muslim Sultans Gujarat proved an important adversary as the Portuguese, in the sixteenth century, extended their control over Indian Ocean trade to this region. But gradually Gujarat and its merchants reached a modus vivendi with the Portuguese, and Gujarati merchants came to dominate the international trade of Portuguese India, while the two states - Gujarat had been annexed to the Mughal empire under Akbar in 1573 generally maintained peaceful relations (Chaube 1975; Sheikh 2010).

Both the Solanki kingdom and the sultanate were based in the plains of mainland Gujarat, and the 'peninsular' parts of the state - Saurashtra and Kacch - were not always controlled from the centre. The vassal states situated here were at times conquered and controlled, at other times effectively independent. The ebb and flow of central power meant, however, that the area of the present state formed a common political arena, characterised by a clear centre-periphery axis.

The importance of trade and merchants was not evenly distributed along this axis. The centre of merchant strength was the mainland of Gujarat: ports like Vallabhi (near presentday Bhavnagar), Bharuch (Broach), Khambhat (Cambay) and Surat were, at different times, the main gateways to Upper India. Of these only Vallabhi was (correspondence with latter part of phrase) in peninsular Gujarat, presently called Saurashtra, but it was close to the mainland. Saurashtra and the island of Kacch were close to the main trade routes, but still stood apart. Throughout the middle ages, and, effectively, until their incorporation into the modern state of Gujarat in 1961, these regions retained a 'feudal' structure, where merchants were at the mercy of the princes (Tambs-Lyche 2010, 2011). The northernmost part of the mainland - North Gujarat - was traversed by the trade routes, but this area, where the Solanki capital Patan had been located, also came to occupy a peripheral position from around 1411, when the Sultan Ahmedshah founded the region's principal city of Ahmadabad. The town continued as the seat of the Mughal governors after the conquest of Gujarat by Akbar in 1573 (Gillion 1968). 


\section{Political dimensions in the history of the region}

The centre-periphery dimension is, therefore, central to an understanding of the region. Central Gujarat has, since at least the eleventh century, been controlled by strong states. Villages were generally not walled, and peasants in the central villages were not armed: they were defended by the armed forces of the state. In between these villages, however, we find stretches of less fertile land, where the peasants gained part of their living from raiding the bigger villages. In the periphery, Saurashtra, Kacch and parts of North Gujarat, villages were protected by walls, and armed peasants furnished much of the military strength of the rulers. This opposition has consequences even today, notably in the contrasting interests of peasants, with the Kolis representing the descendants of the armed peasants of the periphery, while the Kanbi/Patidar caste complex stems from the central, state-controlled area (TambsLyche 2010).

Some of the princes of the periphery - like those of Kacch, Junagadh, Jamnagar and Bhavnagar, as well as the centrally located state of Baroda - grew important enough, from the sixteenth century onwards, to constitute veritable states with an army and a state bureaucracy. But most of the princely states, especially in Saurashtra, were extremely small, consisting of one or a few villages. The British recognised most of the ruling princes of Gujarat, and the political opposition between centre and periphery lasted till well after independence. In Saurashtra, the princely states disappeared only in 1952, when they were merged into the United State of Saurashtra. The British annexed only a small territory directly: Ahmedabad and its surroundings were thus taken over in 1820. Even in the Gujarat heartland, the important princely state of Baroda persisted till 1949. The political map of Gujarat, in British times, was thus particularly complex: more than 200 princely states existed in Saurashtra alone. Even after their merger into Gujarat state, the larger princely capitals retained strong local patriotism linked to their specific histories. The languages of the periphery - Kathiawadi in Saurashtra, and Kacchi - are close enough to Gujarati to be considered 'dialects', but different enough for some to see them as separate, regional languages.

In Saurashtra, independence and the dissolution of the princely states implied an important shift in power: the princely and landholding Rajputs lost control, and the bourgeoisie consisting mainly of merchants, Brahmans and to some extent Patidars took over. One of their first moves was a land reform, weakening the Rajputs and strengthening, above all, the Patidars. The formation of a united Gujarat state, including Saurashtra and Kacch, implied that a bourgeois power constellation, centred on Ahmadabad, now dominated the state, reducing former elites in the peripheral regions to a subordinate position (Tambs-Lyche 1997).

\section{Hindu-Muslim relations}

Most of these states had Hindu rulers, but there were also Muslim states, of which Junagadh was the most important. The ruler of this state, in southwestern Saurashtra, actually tried to join Pakistan after the partition of British India, but on the initiative of Sardar Vallabhai Patel, then minister of the interior, the Indian army occupied the state in 1948. The ruler, who had fled to Pakistan, was deposed.

This leads us to a third particularity of Gujarat: the importance of Hindu-Muslim relations. Though the Muslim minority is not particularly large in Gujarat (9.1 per cent of the population in recent counts), the long period of the Muslim sultanate and Mughal rule - effective until the Mahratta incursions of the eighteenth century - had produced an important Muslim 
elite, whose culture is still symbolised by exquisite architectural monuments - particularly in Ahmadabad. Other groups converted to Islam during this period. In many cases, these groups were examples of syncretism: Muslim religious practices co-existed with 'Hindu' customs, in terms of marriage and other traits of social behavior. Muslim occupational groups were considered the equals of their Hindu counterparts in terms of caste, or - the more common term in Gujarat until recent decades - 'kom' (from Persian qoum, with the same etymological origin as English 'community'). Indeed, as late as the 1970, the Hindu-Muslim controversy was often seen, in the villages, as peculiar to urban politics.

The British and post-independence period has seen a decline of the Muslim elites in favour of Hindu and Jain groups, and though Hindu-Muslim relations have not always been conflictual in Gujarat - indeed, historically speaking, co-existence and mutual influence has been more typical - the changing relationships between Muslims and Hindus still form a recurrent theme in the region's history. In recent years, the influence of Hindu nationalism as well as Muslim militancy influenced by the Gulf has considerably sharpened the potential conflict between Hindu and Muslim groups.

\section{Particularities of caste in Gujarat}

A fourth particularity is found in certain characteristics of the caste system of Gujarat. One feature was the division into two blocks, one led by the Rajput land owners and princes and dominating the agricultural sector, particularly in the periphery. The other block was led by the merchant castes, and in the central areas - where peasants had been unarmed - certain castes like the Patidars tended to affiliate themselves with this block from the nineteenth century onwards. Two blocks of peasants, differently situated in relation to those in power, thus opposed each other: for short, we may identify them with the peripheral Koli caste, historically allied to the Rajputs, and the Patidars of the centre. This feature underscores the centre-periphery dimension. Another feature, partly linked to this division, was the importance of hypergamy, with women marrying into a higher caste. Thus women from the Koli caste might marry Rajput men, while the topmost level of the Patidar farming caste gave their daughters in marriage to Brahmans. These marriages did not weaken the hierarchy but they did create vertical solidarities which were important on the social, cultural and political level. These vertical solidarities are still important, influencing political alliances (TambsLyche 2010).

\section{Gujarat in the colonial period}

When the British took control of Central Gujarat in 1820, they found the country ravaged by the wars of the preceding period. In this particular area, Pax Britannica did favour reconstruction, and Ahmedabad soon recovered its position as a centre of trade and manufacture. In Bengal and other places, imported English textiles destroyed the market for local produce, but much less in Ahmedabad, since the coarse cotton produced in the city continued to find buyers among the Indian popular classes. Thus the Ahmadabad capitalists did not suffer greatly from colonialism: indeed, the coming of the railway favoured the growth of the city's trade. The leading merchant families of the city strengthened both their political and their financial position under colonial rule. This, to a considerable extent, was taking place at the cost of the older Muslim elite.

The Hindu and Jain merchants founded new industries, textile factories which, unlike others in the subcontinent, were entirely controlled by Indians. With the introduction of 
municipalities, they came to dominate politics, too (Gillion 1968: 40-98). Part of their strength stemmed from the older 'guild assemblies' (Mahajan) and the institution of Nagarsheth (head of the guild assembly), which were important in Ahmadabad and other cities well before municipal politics were introduced - the institution of Nagarsheth is attested in Ahmedabad from the eighteenth century (Gillion 1968: 20-23). I.P. Desai (1964), investigating municipal politics in the small Saurashtra town of Mahuva in the late 1950s, felt that both the authority and the functioning of the town council represented a direct continuation of the earlier guild assembly.

Second only to Bombay as a centre of the textile industry, Ahmedabad was often called 'the Manchester of India'. As Bombay expanded in the nineteenth century, it was mainly Gujarati merchant communities which constituted the Indian sector of its trade. These included the Parsis, who originally came to Gujarat as 'refugees' from Islamisation in the ninth century. They played an important role in Bombay's trade, but perhaps even more in the production of regional identity, in that they wrote and published books in the Gujarati language and contributed to a cultural and literary awakening in the province.

Gujarat had always had important commercial links overseas, but these, too, expanded strongly in the British period, when British territories in Africa, South East Asia and the Gulf were open to Indian traders. Indeed, the main presence of Indian traders throughout much of Britain's overseas empire was constituted by Gujarati and Sindhis: Sindh, now in Pakistan, shows considerable cultural continuity with, and has strong historical links to, Gujarat.

The migration of indentured Indian labour to the sugar colonies, such as Mauritius, Fiji, Trinidad and Guyana, were mainly of people from Central, Eastern and Southern India. But they were followed by smaller numbers of Gujarati traders exploiting the market provided by the expatriate Indians. East Africa was, however, particularly important. The traditional merchant communities already had a presence here, and when the British had the railway built to Lake Victoria, they used Indian labour and technicians. These were mainly Sikhs from Punjab, and few of them stayed on in Africa when the work was finished, but in the meantime, a famine in 1899-1902 had led a new social group to migrate: these were Patidar farmers from Charottar, south of Ahmedabad, and they established themselves as traders and intermediaries between Africans and the British in East Africa (Morris 1968). The Patidars, through migration and social mobility - they entered trade and manufacture in Gujarat itself - became a significant addition to the Gujarati bourgeoisie of merchants and Brahmans.

The relative absence of colonial influence meant that the Ahmedabad bourgeoisie had a particular character. It is typical that few of the important merchants spoke English. They remained vegetarians and teetotallers, and very few adopted European dress. While its industries made Ahmedabad one of the most modern cities of the subcontinent, it was equally one of the most Indian. This particular character, merging Indianness with modernity, and owing little to a properly colonial experience, is still typical of the Gujarat scene.

\section{Towards independence and after}

When Gandhi returned from South Africa in 1915, he joined an independence movement and a Congress Party which was well established in Ahmedabad's bourgeoisie. The town now became Gandhi's base for many years as he worked to extend the appeal of the independence movement to much larger sections of the population.

Gandhi himself was from a Gujarati merchant caste, and his father had been the minister (dewan) of several states in Saurashtra. His vegetarianism and much of his ideology of 'non-violence' can be traced to this source. In spite of his unconventional ideas on matters 
such as untouchability and unionism he went down well with the powerful Ahmedabad families, and they gave him considerable support (Spodek 2011). One move which was to shape Ahmedabad's economic climate was the trade union he helped to found. This was a union bent on compromise with the factory owners, stressing their moral duty towards their workers as well as the duties of the workers to them. It made for peaceful conditions in Ahmedabad's textile industry until the owners started to close down their factories in the 1980s. Jan Breman (2004) and others have documented the pauperisation of the textile workers that resulted.

Until independence, mainland Gujarat was seen as one of the most highly developed regions of India, with a flourishing industry and a strong agricultural sector which had long been well integrated into the market economy. The peripheries, such as Saurashtra and Kacch, were in contrast seen as backward. Still, when these regions joined the new state of Gujarat in 1961, they formed part of one of the country's richest and most 'advanced' states.

There followed years of frustration, as other regions were catching up. Gujarat had few natural resources for industrialisation, such as coal or iron, and the shortage of energy was limiting growth. The Narmada project, constructing enormous dams and electric power stations (at the cost of displacing very large numbers of people, mainly in other states) became a central point in Gujarat politics. Part of Modi's strength comes from championing this project, and his insistence that a very large portion of the electricity produced should come to Gujarat. The strong position of his party also stems from a long tradition of bourgeois hegemony, where the local capitalists are seen as the champions of progress and development for the state. This is supported by a considerable literature on the great businessmen of Gujarat as architects of present and future prosperity.

Recurrent themes in Gujarat's modern history include the centrality of geography, the role of merchants and entrepreneurs in economic and political life, and the politics of identity that underlies the distribution of power. The post-independence, post-unification state of Gujarat demonstrates a continuity of these key characteristics.

\section{Shifting economic geography}

Having lost Bombay to Maharashtra in 1961, Gujaratis and their government were determined to make a success of the economic belt along the railway linking Ahmedabad, Baroda and Surat to Bombay. Business propelled by the entrepreneurial Gujarati continued to flourish in many other parts of Gujarat, such as tile manufacture in Morbi (see Das 1998) and salt manufacture in Kachchh. Yet, the government of the new state channelled disproportionate resources into the industrial belt in the mainland. The Gujarat Industrial Development Act 1962, led to the establishment of the Gujarat Industrial Development Corporation (GIDC). Its main purpose was to 'assist in the rapid and orderly establishment, growth and development of Industries in the State of Gujarat' (Government of Gujarat 1962). The idea was for entrepreneurs to lease plots developed by GIDC, with electricity, sewerage, roads and other infrastructure, in order to focus on manufacturing. The initial GIDC estates were set up in the mainland, especially in South Gujarat. Even today, the mainland has 115 GIDC estates, and Saurashtra and Kachchh combined have 71.

To an extent, Gujarat's so-called 'golden corridor' has lost its sheen over time. While it is still prosperous and home to some of the state's best known industries such as Zydus Cadila pharmaceuticals, Torrent Pharma and Reliance Textiles, this region is reaching saturation in terms of land, and is also highly polluted. Further, in the current phase of economic reform, India's economy is generating new business demands, which look beyond the metro cities 
and national economy serviced by the golden corridor. With trade liberalisation, privatisation of most industries, encouragement of infrastructure development through Public Private Partnerships, and altogether more outward looking business enterprise models, there is renewed focus on the coastline. Gujarat is being projected as a 'global business hub' (Government of Gujarat 2014), with a 'silver corridor' powered by ports, export-oriented Special Economic Zones (SEZ), power plants, oil refineries and a range of manufacturing units. Port-based industry at Hazira, the Reliance petroleum refinery at Jamnagar, exportoriented cement manufacturing in Abdasa, Kachchh, and a vast SEZ in Mundra with an airstrip, port, private rail line, power plant and a range of manufacturing and packaging facilities, are products of this shifting economic geography.

In the case of Kachchh, for long ignored in the economic map of Gujarat, the economic geography of globalisation has coincided with the political economy of natural disasters. In 2001, Kachchh witnessed a devastating earthquake. Since then, in an attempt to rejuvenate the region, the government has announced several packages for enterprise generation. The seemingly untapped desert land, proximate to the border with Pakistan, is being developed to have prosperity coincide with peace. In a skewed development model, which prioritises economic growth over human development or environmental sustainability (Shah et al. 2002), the mangroves, fragile desert ecosystems, pastures and coastline of Kachchh have become (un)fair game in the economic progress scripted by the likes of Sanghi Cement, Adani Ports, Jindal Pipes, and so on. In this story, Kachchh is painted as a vast, unproductive territory that is only now being tapped. This is to the detriment of the livelihoods of the largely lower caste and Muslim salt pan workers, pastoralists, fish workers and forest produce pickers whose common lands are being appropriated under new development models in tune with global economic geographies (Sud 2009).

But as the old adage goes, the only constant seems to be change. After the global financial crisis of 2008, there is increasing realisation that while integration with the global economy is desirable, Gujarat or indeed the country cannot be over-dependent on global markets. Instead, local and global manufacturers have sought to tap India's demographic dividend and 'Make in India', for the Indian market. Unsurprisingly, Modi's old playing ground of Gujarat will be one of the test cases for his Make in India campaign. One result of this new and ongoing shift, which had already started under the previous Congress-led UPA government, is the move from export-oriented SEZs to internal manufacturing-oriented National Industrial and Manufacturing Zones, Special Investment Regions, Industrial Corridors and the like. Gujarat and enterprising Gujaratis are once again at the forefront of this new move. The Adanis, who own India's largest SEZ at Kachchh, are now the key investors in the Dholera Special Investment Region, which will be part of the upcoming Delhi Mumbai Industrial Corridor, being built with Japanese collaboration. The thrust of Gujarat's economic geography is shifting towards the mainland, once again.

\section{Merchants and entrepreneurs in economic and political life: growth over redistribution}

Merchants and entrepreneurs have shaped not just the economy, but also politics in Gujarat over time. This is apparent in the discussion of Gujarat's history above, and is also visible postindependence. The state has had a symbiotic relationship with traders and manufacturers. Its policies have supported them, been responsive to them, and they have buttressed ruling dispensations in return. On the few occasions that a ruling party has gone against the perceived interests of these groups, it has faced a backlash, and even a shift in power. 
From the start, growth rather than redistribution headlined the development agenda of the government. The beneficiaries were entrepreneurs who had access to capital, and to a range of schemes for business generation. These included the 'Technicians' Scheme' of 1969, under which technically qualified persons with a viable project were offered loan finance up to 100 per cent of the fixed assets costs, working capital and pre-operative expenses, on liberal terms. From 1973, persons without a technical background but with experience of sales, management or trade were also able to access business finance under the 'New Entrepreneurs' Scheme'.

In addition to involving Brahmans and Vaniyas, from the late-nineteenth century, textile and related industries had been able to absorb artisanal middle castes such as Suthars (carpenters), Lohars (ironsmiths), Kansaras (coppersmiths) as well as Patidars. In the first half of the twentieth century, individuals from these groups had set up small-scale enterprises servicing modern industries, say through the manufacture of wooden bobbins and machine parts (Streefkerk 1997). Thus, in addition to traditional business groups, these emerging entrepreneurs benefited from the policies of the new state government.

It is clear that entrepreneurship, particularly in manufacturing, flourished in the 1960s and 1970s. Gujarat had 749 large factories in 1960, 1,129 in 1969 and 1,837 in 1978. Further, there were 1,948 small-scale units in 1960, 12,000 in 1969 and 34,000 in 1978 (Pathak 1982). Apart from direct government intervention, merchants and entrepreneurs have benefited from their dominance over Gujarat's very successful cooperative movement, especially cooperative credit. Interviews with directors of cooperative banks show that leadership positions in these institutions tend to be dominated by particular upper castes, with credit flowing along caste lines (Sud 2012). In a reminder of the synergetic relationship between private capital, government and politics, it is not surprising that many prominent political leaders have had their initial administrative experience, and seed electoral campaign finance, through the cooperative system. This mutuality has also guaranteed that the government has looked the other way in a series of cooperative scandals in Gujarat, where dubious loans have resulted in banks defaulting and even shutting down. This, of course, has been to the detriment of ordinary depositors (Bhatt 2002).

At times, entrepreneurial groups have risen due to the unintended consequences of government action. Redistributive land reforms were unsuccessful in Gujarat (Shah and Sah 2002). The only notable success was in Kachchh and Saurashtra where estates owned by former princes and large landlords passed into the ownership of tenant tillers (not landless labour). While the losers of this land reform, or redistribution of privilege (Herring 1983) were mostly Rajputs, allied to the British, against the nationalist movement, the gainers were largely Patidars. The latter were a core constituency of the Congress Party, and best represented by their tallest leader: Vallabhbhai Patel. This social distribution of political allegiance had something to do with the failure of even marginal land reform in the mainland, where ownership was often with upper and middle castes, including Patidars. The Patidars have been at the forefront of the green revolution in Gujarat, taking advantage of scientific advances in seeds, irrigation and cropping techniques. Their resultant wealth has been ploughed back into cash crops like cotton and groundnut, but also into a diversification towards agro-industry and entrepreneurship, especially among the younger generations (Rutten 1995). It is these powerful political groups that have straddled agriculture and industry, and benefited from government largesse, that have demanded selective market liberalisation from the 1990s. In the case of land, agrarian and agro-industrial entrepreneurs have lobbied for the opening up of land markets, such as through the easy convertibility of agricultural land for industrial purposes. These same groups have opposed the entry of 
foreign capital into the state, unless in partnership with local business or when ancillary benefits to local business are apparent (Sud 2012). The entrepreneurial and practical Gujarati has moved with the times, partaking of land reform and government largesse in the dirigiste era and demanding specific types of liberalisation during market reform.

The cosy relationship of traders, entrepreneurs and the powers-that-be has been unsettled in two notable periods of Gujarat's recent history. Led by students and the political opposition, the Navnirman movement of 1974 protested against corruption and price rise. It resulted in the resignation of the Chief Minister. Significant finance for dissidents came from the unlikely source of Saurashtra's traders and millers of edible oil, and their counterparts in the rice business. Following inflation after the world crude oil price shocks of 1973, these traders had been making huge profits through hoarding and speculation. In response, the national government, led by the Indira faction of the Congress, had instructed its Gujarat counterpart to impose levies on rice and groundnut. Forced to sell at fixed purchase price, Gujarat's powerful traders rebelled, with much success.

A few years after the traders' revolt, it was the turn of consolidated elite interests to flex their political muscle. In 1980-1985, under the leadership of Jinabhai Darji and Madhavsinh Solanki, the Congress Party engineered a massive electoral coalition of Kshatriyas-HarijansAdivasis-Muslims (KHAM). These groups, which had been on the peripheries of power politics in the post-independence period, then received significant representation in the legislature and government ministries. One of the early tasks of this government was to reopen about 25,000 cases of land ceiling avoidance. The potential beneficiaries were from the KHAM groups, and the potential losers were Patidars and other upper-caste land owners. Immediately, a conglomerate of 13 organisations representing the dominant castes and classes petitioned the High Court to halt the government's new land initiative. Among them were the Gujarat Chamber of Commerce and Industry, the Gujarat Chamber of Agriculture and the Khedut Samaj (Farmers' Society). After this action, local government administrators filed a report suggesting that if the land redistribution cases were not given up, 'class war' would break out in Gujarat. Under tremendous strain from various sides, by 1983, the government withdrew all cases against the evaders of land ceiling (Sud 2012).

After stamping their authority over politics, Gujarat's traders and entrepreneurs have mostly gone along with governments that by and large represent their interests. A more recent iteration of the government-business relationship was seen after the 2002 communal violence. When the Modi government's handling of the violence was criticised in the national press and even in the national Confederation of Indian Industry (CII), a group of prominent Gujarati businessmen stood by Modi. Gautam Adani, owner of India's largest private port and SEZ in Mundra, Indravadan Modi of Cadila Pharma, and Karsanbhai Patel of the Nirma Group established the rival Resurgent Group of Gujarat. They and many other Gujarati businessmen then offered monetary and moral credence to Modi's Vibrant Gujarat business summits. The latter aimed to attract investment back to Gujarat after the economic and political disturbance of the riots, and the earthquake of 2001. The Vibrant Gujarat summits have become one of Modi's most talked about initiatives in building a business-friendly image for himself, and for Gujarat. The sustained backing of Gujarat's entrepreneurs is the foundation of this image and investment building exercise. One of the first prominent public calls for Modi as Prime Minister was made at Vibrant Gujarat 2012 by these same business people. It is no coincidence that in the year since the declaration of Narendra Modi as the BJP's prime ministerial candidate in November 2013, the stock market value of the Adani Group rose by a stupendous 94 per cent. 


\section{The politics of identity}

To contemporary observers, Gujarat is associated with the politics of regional and religious identity. In regional terms, Gujarati pride or asmita, the will of 'five crore Gujaratis' (50 million), and аарпи Gujarat aagvu Gujarat (our Gujarat, unique Gujarat) are just some of the Pan-Gujarat constructs being peddled today. Gujarati asmita, for instance, has been invoked in the wake of criticism of the 2002 violence. Gujarati pride also headlined Narendra Modi's bid for prime ministership. It has been suggested that Modi is Gujarat's retribution for Sardar Patel apparently being denied a shot at power in New Delhi in 1947. Of course regional pride, which easily slips into chauvinism, is built on 'imagined communities' (Anderson 1983) and selective interpretations of history. The link drawn between Patel and Modi misses another Prime Minister from Gujarat: Morarji Desai, who served in the Janata government from 1977-1979. Modi's prime ministerial campaign, in which all parliamentary seats from Gujarat went to his BJP in 2014, was centred on sending 'Gujarat's son' to Delhi. The projection of a business-friendly model of economic reform as the specifically 'Gujarat model of development' is part of the state's regional brand building exercise.

Yet Gujarat as we know it today is a very recent creation. For centuries, scholars and intellectuals have interrogated 'the idea of Gujarat' (see Simpson and Kapadia 2010) and asked koni koni chhe Gujarat, or to whom does Gujarat belong? (Poet Narmadashankar Lalshankar Dave (b. 1833), known popularly as Narmad, cited in Yagnik and Sheth 2005: 201). Even more recently, the unified state of Gujarat has struggled to shake off the sub-regional Kathiawadi, Kacchi and (mainland) Gujarati identities that are enhanced by the varied histories, cultures, languages and access to resources for these areas. Post-independence politics has been a fertile ground for the playing out of contests over regional and sub-regional identity.

Around the time of Gujarat's formation as a united state, there was a deep schism between Congressmen from the mainland versus those from other regions. When Jivraj Mehta from Saurashtra became Chief Minister in 1957, much of his cabinet was from Saurashtra and he refused to take orders from the mainland dominated Gujarat Pradesh Congress Committee. Even now, the replacement of the BJP Chief Minister Keshubhai Patel by Narendra Modi in 2001 was seen by Patel's supporters as a great affront to Rajkot city, and Saurashtra more broadly, to which he belongs. When Modi stood for a by-election from Rajkot in 2001, local BJP workers refused to campaign for him. Schisms in regional and sub-regional identity are not played out in high politics alone. On an everyday basis, one feels the tension between local and sub-regional identification, versus a rather top-down regional Gujarati identitybuilding project. Kachchh, for instance, has significant fault-lines in its meshing with greater Gujarat (Simpson 2010).

As in the case of regional identity, Gujarat's politics of religious identity construction is also ongoing, and often reveals fragile foundations. For some, Gujarat has been a Hindu rashtra or Hindu nation-state from the mid-1990s, which coincides with the BJP's ascent to power. This is the impression one would get by reading the signboards that dot the state's cities and towns, and now increasingly villages. Put up by organisations such as the Vishva Hindu Parishad (World Hindu Council), an affiliate of the BJP, these boards welcome visitors to the 'Ambaji Pradesh [province] of Hindu rashtra', and the like. Daily life carries on around these cartographic artefacts. Village and town councils, even when these have representation from non-Hindu nationalist parties, do not seem to feel the need to remove the Hindu rashtra boards in an ostensibly secular country.

The quotidian acceptance of a majoritarian Hindu idiom is repeated across space. Private transport services into Gujarat tend not to serve non-vegetarian food as this will apparently 
antagonise 'Gujaratis'. The latter is usually a reference to Gujarat's Hindu upper-caste ruling groups, as vegetarianism is not common among lower castes, indigenous tribes and the minority Muslim and Christian communities. Similarly, government offices regularly sport posters and even micro-shrines of Hindu deities. These are presumably erected by Hindu employees, some with BJP affiliations. Again, that this is acceptable in what are constitutionally mandated secular public spaces speaks volumes about the attempted Hindutva-isation of Gujarat.

By Hindutva, we refer to the ideology of Hindu nationalism, centred on the idea of India as one nation, one culture, one people. But even in the artificial, clear-cut boundaries demanded by political identity construction, Hindutva faces dissonance from caste. Till the mid-1980s, caste and sub-regional politics, not Hindutva, dominated Gujarati electoral contests. This is clear in the preceding discussion of KHAM, and the Saurashtra-Kachchh-mainland divide. While the BJP has sought to override these contests to build a pan-Hindu identity with Muslims and Christians as the 'other', on an everyday basis the Hindutva movement faces the challenges from alternative identity divisions. Thus, decisions about political representation and voice often have to take into account caste and sub-caste claims. Lower castes and indigenous groups, while incorporated in Hindutva movements to some extent, continue to be marginalised when it comes to experiencing any substantial power. Upper castes dominate government, politics and business. Hindutva then, despite its current success in Gujarat, is built on a fragile foundation. This foundation needs the constant fertiliser of minority bashing, regional Gujarati-Hindu chauvinism, violence, and invoking the threat of terrorism from within and from neighbouring Pakistan.

To conclude, Gujarat is built on many historic particularities, and certain recurring themes around geography, entrepreneurship and identity. Over the decades, progressive and outward looking Gujarat has faced the test of economic competition, the demands of globalisation, and the schisms of identity and fierce contests over electoral and social power. As enterprising Gujaratis have faced economic challenges, they have also been susceptible to the entrenching of narrow political identities. This explains the contradictory co-existence of economic enterprise with political illiberalism in the state. It remains to be seen how long this pattern will last. Gujarat has been the theatre of constant innovation, and it is hard to believe that the current impasse will remain unchallenged.

\section{References}

Anderson, B. (1983) Imagined Communities, London: Verso.

Bhatt, S. (2002) 'Gujarat's Rotting Co-op Banking Sector and the Conspiracy of Silence,' Rediff.com, November 21. http://www.rediff.com/election/2002/nov/21guj3.htm [accessed 17 April 2015].

Breman, J. (2004) The Making and Unmaking of an Industrial Working Class: Sliding down the Labour Hierarchy in Ahmedabad, New Delhi: Oxford University Press.

Chaube, J. (1975) History of the Gujarat Kingdom, 1458-1537, Delhi: Munshiram Manoharlal.

Das, K. (1998) 'Collective Dynamism and Firm Strategy: Study of an Indian Industrial Cluster,' Entrepreneurship and Regional Development, 10: 33-49.

Desai, I. P. (1964) Some Aspects of Family in Mahuva, London: Asia.

Gillion, K. L. (1968) Ahmedabad: A Study in Indian Urban History, Berkeley, CA: University of California Press.

Government of Gujarat (1962) Gujarat Industrial Development Act (1962), 1962: GUJ: XXIII, Ahmedabad: Government of Gujarat.

Government of Gujarat (2014) Vibrant Gujarat 2015: Overview, Ahmedabad: iNDEXTb, http://www. vibrantgujarat.com/vg-2015.htm, accessed 27 October 2014.

Herring, R. J. (1983) Land to the Tiller: The Political Economy of Agrarian Reform in South Asia, Delhi: Oxford University Press. 
Majumdar, A. K. (1956) Chaulukyas of Gujarat, Bombay: Bharatiya Vidya Bhavan.

Morris, S. (1968) Indians in Uganda: Caste and Sect in a Plural Society, London: Weidenfeld and Nicholson.

Pathak, P. G. (1982) 'Industrial Structure in Gujarat - A Study in Spatial Dimension' in D.T. Lakdawala (ed.), Gujarat Economy: Problems and Prospects, Ahmedabad: Sardar Patel Institute of Economic and Social Research, 441-475.

Rutten, M. F. (1995) Farms and Factories: Social Profile of Large Farmers and Rural Industrialists in West India, Delhi: Oxford University Press.

Shah, G. and D. C. Sah (eds) (2002) Land Reforms in India. Performances and Challenges in Gujarat and Maharashtra, Volume 8, New Delhi: Sage.

Shah, G., M. Rutten and H. Streefkerk (eds) (2002) Development and Deprivation in Gujarat, Delhi: Sage.

Sheikh, S. (2010) Forging a Region. Sultans, Traders and Pilgrims in Gujarat, 1200-1500, Delhi: Oxford University Press.

Simpson, E. (2010) 'Making Sense of the History of Kutch', in E. Simpson and A. Kapadia (eds), The Idea of Gujarat: History, Ethnography and Text, New Delhi: Orient Blackswan, 66-83.

Simpson, E. and A. Kapadia (eds) (2010) The Idea of Gujarat: History, Ethnography and Text, New Delhi: Orient Blackswan

Spodek, H. (2011) Ahmedabad: Shock City of Twentieth-century India, Bloomington, IN: Indiana University Press.

Streefkerk, H. (1997) 'Gujarati Entrepreneurship: Historical Continuity against Changing Perspectives', Economic and Political Weekly, 32 (8): M2-M10.

Sud, N. (2009) 'The Indian State in a Liberalizing Landscape', Development and Change, 40 (4), 645-665.

Sud, N. (2012) Liberalization, Hindu Nationalism and The State: A Biography of Gujarat, New Delhi: Oxford University Press.

Tambs-Lyche, H. (1997) Power, Profit and Poetry: Traditional Society in Kathiawar, Western India, Delhi: Manohar.

Tambs-Lyche, H. (2010) 'Reflections on Caste in Gujarat', in E. Simpson and A. Kaadia (eds), The Idea of Gujarat. History, Ethnography and Text, New Delhi: Orient Blackswan: 100-119.

Tambs-Lyche, H. (2011) 'The Quest for Purity in Gujarat Hinduism: A Bird's-eye View,' South Asia, XXIV (3): 333-353. (Special Number 'Religion in the Making of a Region: Perspectives from Gujarat', edited by N. Sud and H. Tambs-Lyche).

Tripathi, D. and M. Mehta (1990) Business Houses in Western India, London: Jaya Books.

Yagnik, A. and S. Sheth (2005) The Shaping of Modern Gujarat: Plurality, Hindutva and Beyond, New Delhi: Penguin Books. 


\title{
19
}

\section{INTIMATE SPACES OF STRUGGLE}

\section{Rethinking family and marriage in contemporary India}

\author{
Mallarika Sinha Roy
}

\author{
Introduction
}

Justice Bhakthavatsala observed during a hearing in a domestic violence case that it was alright for a husband to beat up his wife as long he was taking good care of her. The woman had complained to the bench of Justice K Bhaktavatsala and Justice BS Indrakala that her husband beat her up regularly and had once thrown her out of their house.

Justice Bhaktavatsala told the 28-year-old woman that she has to adjust with the husband and that all women suffer in marriages.

'Why are you still talking about his beatings? I know you have undergone pain. But that is nothing in front of what you undergo as a woman. I have not undergone such pain. But madam (Justice BS Indrakala) has,' he observed.

But the woman told the court that she was unwilling to return to her husband.

Justice Bhaktavatsala asked the husband to take his wife and son out for a lunch and have a davanagere benne dose (a popular dish) and hoped it will be alright.

Hindustan Times (September 8, 2012)

Justice Bhaktavatsala's remarks did not go unnoticed by women lawyers and feminist activists. ${ }^{1}$ The more pressing issue is, perhaps, not the eventual removal of all family court matters to another judge but, as Srimati Basu has argued, the popular belief (especially among the urban middle class) that law has weaponized marriage to break family units. ${ }^{2}$ Basu's work puts the Indian women's movement in front of the troubling question of the gap between the proverbial cup and the lip: the effective impact of reforms in family and marriage laws on everyday lives of Indian women. ${ }^{3}$ It is important to revisit the intimate spaces of struggle - familial and marital 
- to rethink the parameters of measuring success. Such an attempt, however, does not evade the impasse confronted by the women's movement, but rather seeks to underline the 'move' in women's movement. Instead of becoming confined within mutually exclusive spheres of triumph and failure, it may be more rewarding to examine and appreciate the excess of legal reforms: in terms of new scholarship on family studies (Arunima 2003; Basu 1999, 2012; Chatterjee 2004; Dube 1997; Ghosh 2006; Nair 1996; Sarkar 2003, 2009; Sen 1999; Sunder Rajan 1993, 2003; Uberoi 1994, 1996). The fascinatingly diverse sources of family studies, ranging from religious tracts (usually the basis of customary family laws), printed domestic manuals from the nineteenth century, ethnography of kinship systems, literary texts, pamphlets, autobiographies, to archival records of legislations and adjudications, unveil the complexity in discourses of family and marriage. Drawing from Rajeswari Sunder Rajan's observation that feminist interventions in exploring questions of conjugality, widowhood, sexual labour and nationalism have expanded the horizon of women's movement, I argue that it is necessary to understand the social and cultural anxieties that motivate historical moments of encoding legal reforms rather than any simplistic resolution of legal debates (2010). A brief historiography of family studies can be a suitable point of beginning to elaborate this argument.

The study of family in India has travelled a chequered path since the 1950s. From the study of kinship systems and household patterns in Anthropology and later in Sociology (which often presumed the Hindu family as its principal protagonist), the modes of inquiry have gradually incorporated the issues of division of labour and structure of authority, networks of consumption and the political economy of marriage alliances, the position of women and patterns of intimacy, and the regulation of sexuality. ${ }^{4}$ The ideological deployment of an essentialized set of family values in the politics of nation building, in collective mobilizations, and in cultural representations have also come under academic scrutiny (Chatterjee 1995; Dwyer and Pinney 2002; Forbes 1996; John and Nair 1998; Liddle and Joshi 1986; Sarkar 2003; Stree Shakti Sangathana 1989). The shift in family studies since the 1980s marks a transformation from 'rather sterile debates on the prevalence of joint versus nuclear families', to a politicized field of raising questions regarding violence, discrimination, and resistance based on the unavoidable variables of class, caste, and religion (Sen et al. 2011: 4). Instead of focusing on the impact of modernity in challenging the traditional moral universe of 'Indian family', the discursive formation of such a dichotomy between tradition and modernity has become the centre of academic attention. The production of studies on family by the statist institutions and formulation of social policies affecting family are not so much interesting in terms of information, argues Patricia Uberoi, but rather 'as an insight into official thinking on family' (Uberoi 1996: 135). Uberoi refers to diverse sources like the policy documents produced after the International Year of Family in 1994 (following the United Nations declaration), and the cinematic text of Hum Apke Hain Kaun ...! [Who Am I to You...] (1994), one of the most successful Hindi films to celebrate the 'traditional' Indian family, to articulate the connections between shrinking social welfare responsibilities of the state in post-liberalization India and an upsurge in iconizing family values. Uberoi's claim substantiates the glamorizing of family and heterosexual marriage in the cultural rhetoric of globalization (exemplified in popular films, television series, and printed magazines) in the last two decades.

It does not come as a surprise that this shift coincides largely with the rise of the autonomous women's movement in India. This chapter argues that reforms and backlashes, often in cyclical regularity, exist in the longer life of every movement and the women's movement is no exception; and yet, newer thoughts and writings on these intimate spaces of struggle have helped the women's movement to address the legal gridlock from new angles. Following Kalpana Kannabiran's call for an interdisciplinary approach involving social sciences, humanities, and 
legal studies to study the 'three dimensional' family, this chapter points at three interconnected intellectual trajectories of exploring family and marriage (2006).

\section{Women's history and the history of Indian family}

An important aspect of this shift in family studies concerns the fluidity between the boundaries of private and public spheres, whereby family is destabilized from its location in the private domain. Following the Foucauldian concept of governmentality, Sarah Hodges shows how the 'modern' reproductive family is central to the techniques of governance in India. Hodges urges historians to 'intervene in these debates and point out the conceptual ruptures and rough edges which characterize the history of population as an object of knowledge in India' (2004: 1157). Women's history, however, had already begun such interventions: research on the intertwining relations of power between discourses of nationalism and family fashioned a new history of the Indian family. Tanika Sarkar's insights into the world of domestic relations towards the end of the nineteenth century revisits Foucault's analysis of the continuity of governmentality between family and state in eighteenth-century Europe through the lens of colonial modernity. Sarkar explains how 'the household was likened to an enterprise to be administered, an army to be led, a state to be governed - all metaphors rather poignantly derived from activities that excluded colonized Bengalis' (2003: 197), and confirms that 'unlike Victorian middle-class situations, then, the family was not a refuge after work for the man. It was their real place of work' (2003: 197).

If the family space turned into the first realm of 'modern' governance for the colonized Indians in the nineteenth century, situating the family in the early modern period concerns covering a more meandering track cross-cutting public and private domains. Through the 'snapshot' method this section freezes two frames of the history of family, and the cumulative effects of such details are expected to provide the comparable contexts for the postcolonial situation. It is, consequently, important to remember that this recounting of history is not merely a backdrop for contemporary family studies, but rather, a more nuanced genealogy.

The beguiling strength of kinship terms, which are much detailed and broader in Persian, Arabic, or vernacular languages than English, in constructing a 'family' in the early modern period is perhaps most effectively demonstrated in the life of Begum Sombre of Sardhana (1741/53-1836). Michael H. Fisher gives us a snapshot of her life and her family and with this single instance a range of kinship terms - their official status and the informal privileges, obligations and authority, their limitations, their unconventional deployment - are unfolded into a captivating story of survival. Fisher (2004) alerts us in the beginning that the Begum led an atypical life where the power dynamics varied considerably over time. Let me quote from Fisher's essay to give a glimpse of the Begum's 'familial' relations,

A woman evidently sold as a slave in her youth, she built an elaborate and complex court and households around herself, attaining near sovereignty over a substantial territory during highly unstable political and military conditions. After leaving her apparently patriarchic and patrilineal natal family, this woman, later known as Begum Sombre, seems to have lived sequentially as a Muslim (or at least Islamicised) courtesan or a domestic slave, as the purchased mistress/consort of a Catholic Christian European mercenary, as a virtually independent female ruler of a princely state, as a Catholic convert, as the wife of a European mercenary in her service, and as the adoptive mother of several generations of relatives of her first master/consort. 
It is important to note that her sexual relations with her master/consort/husband at different periods of her life enhanced her ability to gain a family even though she never bore a child (as far as historical records ascertain). Her religious conversion, political allegiance, or, economic support consolidated this constructed family, and her gender was crucial for the success of establishing these relations - as a 'daughter' in the Mughal imperial family and in the Catholic Church; as a 'sister' or 'daughter' of leading officials of the East India Company; as a 'mother' in her adopted family and among the larger number of her dependants. Begum Sombre's ingenuity lies in rising from a state of complete dependency and sustaining her status as an independent woman through forming familial relations on her own terms and enjoying the deference of her adopted son and several godchildren in exchange of appropriate gifts as long as she lived. The political economy of affect in the Begum's family functioned around her. With deft use of kinship terms, language in her court, her personal attire and bearing, and lavish hospitality Begum Sombre made Sardhana one of the most prosperous areas of north India. Her achievements set her as an exemplar of survival during one of the most volatile periods modern Indian history.

In contrast to Begum Sombre, Maharani Sunity Devee presents a different kind of connection between the politics of private and public domains. In 1878 Nripendra Narayan Bhup Bahadur (1863-1911), king of the princely state of Coochbihar married Sunity Devee (1864-1932), daughter of Keshab Chandra Sen, a renowned leader of Brahmo-Samaj - the reformist religious sect founded by Rammohun Roy. In the annals of the Brahmo movement, the 1878 marriage is usually referred as 'the embarrassing Coochbihar marriage' since Sunity Devi was an under-age bride according to the Native Marriage Act III of $1872 .{ }^{5}$ It is especially perplexing because Keshab Chandra Sen had been instrumental in passing the 1872 Act. David Kopf's history of the Brahmo movement analyses the Coochbihar marriage as a manifestation of the ambivalence inherent in Keshab Chandra Sen's charismatic personality (1979). This marriage alliance, however, was more than a reflection of the conflicts and uneasy negotiations between religious and social reform movements. Major Dalton, the British Resident in Coochbihar in 1878, was the principal architect of the marriage alliance. Keshab Chandra Sen, a well-known loyalist to the British crown, accepted Dalton's proposal of marriage. He stated in a letter to his friend Miss Cobb on 29 April 1878,

The British Government sought me and my daughter; a Christian Government that knew me thoroughly to be a Brahmo leader, proposed the alliance and the weighty interests of a State were pressed on me with a view to induce me to accept the proposal and make the needful concessions. I found such arguments as these placed before me: 'Here is the Cooch Behar State, a den of ignorance and superstition, with a corrupt court given to dissipation, polygamy, intrigue and oppression. The young Rajah has been saved by the British Government acting as his guardian. The women of the Raj family have been mostly removed to Benares, and others will follow. The administration of the affairs of the State has greatly improved in all departments, education, police, revenue, health etc. Under the management of the competent officers appointed by the British Government ... Not a vestige of the old regime will remain, and the ground will have been thoroughly cleared for political and social improvements when the young Rajah will be formally installed and begins to govern his immense territory. It is desirable, it is of utmost importance, that he should have an accomplished wife ... A good and enlightened wife, capable of exercising a healthy influence on the Rajah is the one thing needful in Cooch Behar State.' The Government, in presenting these views before me, seemed to ask 
me whether I would give my daughter in marriage to the Maharajah and thus help forward the good work so gloriously begun in the State by our benevolent rulers in the interests of the millions of the subject population ... I have acted as a public man under the imperative call of public duty.

Devee 1921: 71-73

Women in the royal households of princely states presented a rather enigmatic problem for the British administration. Wives, mothers, sisters, daughters, and concubines enjoyed a direct access to the ruler, which could be translated into various privileges, beyond the surveillance of resident British officials (Ramusack 2004). If the indirect rule of the Empire over princely states was to be a success it was imperative to conquer the hostile zenana exerting an inexplicable power through their sexuality and to recast the queen (and her household) into a recognizable mould of 'enlightened' docile elegance. The Coochbihar marriage alliance was, as per Sen's (1999) own admission, part of the British policy to install modern governance in Coochbihar and it began from installing a particular art of governance within the royal family. In a curious subversion of the gender hierarchy, the British imperial administration could rest assured only when the male body politic of the native princely state was securely placed under the nurturing benevolent guidance of a reformed and recast woman.

These snapshots from history signal the transformation of the ideology of family from early modern to the imperial modern period, especially the cultural production of an ideal family through an ideal monogamous union. Such ideological production, however, has had its local variants and was largely dependent on the demand of women's productive and reproductive labour. Prem Chowdhry's research on women in colonial Haryana reveals a peculiar contradiction in the gender hierarchy which valued women's labour in the field but considered the customary practices of bride-price and widow-remarriage (karewa) - generally regarded as indices of greater freedom for women - as disgraceful (1989). Chowdhry shows a tacit complicity of the British in sustaining this contradiction since the colonial government paid a lip service to encourage 'liberal' norms but did precious little to ensure women's access to property or legal claims of inheritance. ${ }^{6}$

Samita Sen's research on female factory labour in the jute mills of Calcutta in the early twentieth century shows that regulation of female sexuality among the 'single' women migrant labour was not part of the industrial management policy in the initial stages of industrialization (Sen 1999). However, the imposition of family values on workers' families began when the labour lines came to be viewed as source of future labour and women's reproductive labour became valuable for the management.

The gradual delegitimation of Nair matriliny in the Malabar region through a series of legislations from the mid-nineteenth century to early twentieth century exemplifies the extent of this ideological production of 'modern' family. G. Arunima writes that 'more than legal infringements, it was the cultural production of a new morality that made matriliny appear as an "uncivilized" and "unnatural" way of life by the twentieth century' and locates the critical relationship between land-ownership, property rights, customary laws of inheritance, and caste status in the legal debates on matriliny (1995: 159; 2003). The polyandrous customary marriage - sambandham - and the matrilineal family - taravadu - came to signify an older form of kinship system which needed to be replaced by modern civilizational values of monogamy and patrilineal descent. Following her research it is possible to argue that before the legislations Nair matriliny was rarely a space of pure agency for women, but the moral discourse of the new laws by the end of nineteenth century was premised on regulating female sexuality and institutionalizing patri-virilocal notions of family. Arunima's observation that well-known 
Malayali artist Raja Ravi Varma's painting There Comes Papa (1893) becomes akin to a clarion call for the end of matriliny is worth noting, as the painting celebrates domesticity, nuclear family, and conjugal love (possibly also the virtuous monogamous union). It is important to track this social coding of love, especially within the domain of marriage, to explore the social sanctions which govern family through relations of caste, class, religion, and region.

\section{Transformation of intimacy: love and marriage in contemporary India}

Like the matrimonial column ${ }^{7}$, [I am] searching everywhere

Like the matrimonial column, [I am] staring at everyone

for my brother's bride -

...

Never lazy in her profession,

Swifter than gadget, she must function.

Elegant must be her person, tinged with sophistication.

Without an ego of recognition

She must understand relation.

'Good luck' - she must bring in ton.

Responsibility, she must understand -

But should also be fun. ${ }^{8}$

The above paragraphs are translation from a song in a Bollywood romantic comedy - Mere Brother ki Dulhan (2011) [My Brother's Bride]. The young hero sings, imitating signature dance moves of more established Bollywood romantic heroes, to sundry women he meets during his journey from Delhi to Shimla - looking for a suitable bride for his London-based elder brother. The lyric produces the image of the perfect bride/wife sought by the postliberalization urban middle-class male, while the rather staggering list of qualities demanded of the bride/wife reflect the anxieties of the patrilineal, patrilocal family in an age of globalized modernity. Following Patricia Uberoi's observations on the representations of the 'crisis' in family precipitated by the post-liberalization affective individualism in popular films, it is possible to argue that the popular discourse has also increasingly begun to represent 'Indian family values' as a portable asset and constructed the notion of 'love-cum-arranged' marriages as the ideal for the new global Indian (2006: 180-216). ${ }^{9}$

In Mere Brother ki Dulhan, the bridegroom loses confidence in his own choice after a nasty break-up with his long-standing girlfriend in London, and bestows the task of finding a suitable girl for him to his family in India. Such a move by diasporic single Indian men, without the event of break-up, is not exceptional. Fuller and Narasimhan's ethnographic study of Eighteen-Village Vattimas in Tamil Nadu narrates two cases in which US-based young men had left the task of selecting the bride to their parents in India, and have had successful marriages (2008: 748) ${ }^{10}$ While 'fair-skinned beautiful girls are most likely to impress potential husbands' in these marriage alliances, the senior kin-group tries to make sure that conditions like educational qualifications, employment or employability, and set cultural practices that define 'middle class' in India are compatible long before the actual bride and groom meet in person (Fuller and Narasimhan 2008: 748). ${ }^{11}$ Premarital romantic love, consequently, is antithetical to marriage in an idealized Indian family - both Hindu and Muslim (Mody 2002). It is interesting to note that Perveez Mody revisits the Native Marriage Act III of 1872 to historically situate the legality of marriages outside all religious practices in her ethnography 
of 'love marriages' in Delhi in the 1990s. She points out that marriages registered under this Act (revised in 1954 as the Special Marriage Act) came to be known as civil marriage or court marriage. Civil/court marriages are socially looked down upon, even by the court functionaries in Tis Hazari whom Mody interviewed, because such marriages are born out of individual choice defying kin-group's consent. Companionate marriage, in this Indian incarnation, rests partially on the ideal of affective individualism as decision-making powers of the family and elder kin-group are invested in constructing a compatible match. ${ }^{12}$

The significance of caste and religion, however, cannot be wished away (Chakravarti 2003). ${ }^{13}$ In many parts of India meting out gruesome and fatal punishments to inter-caste lovers by their communities is not uncommon. The prevalence of caste panchayats or khap in Haryana, Punjab, and western Uttar Pradesh in sanctioning punitive actions against errant inter-caste couples, often also against family members of the lower-caste partner, indicate how 'criminalization of love' occurs, to borrow a phrase from Pratiksha Baxi (2014: 237). ${ }^{14}$ Prem Chowdhry has extensively discussed a host of court cases regarding 'runaway marriages' or elopements in Haryana and Punjab where families forcibly parted the consenting couples because of their inter-caste unions and then lodged criminal cases of abduction and rape against the man (2004). Inter-religious marriages are also frequently dealt with such severity. Samita Sen, Ranjita Biswas, and Nandita Dhawan discuss the 'Rizwanur case' ${ }^{15}$ in West Bengal to unveil how laws made to protect women against violence are deployed to deny agency of an adult woman in her own marriage (2011: 18-21). The collusion of state, family, and law in punishing the rebel couple underlines the reproduction of caste/religious endogamy.

Feminist lawyers and commentators on legal theory have discussed the crucial role of the state in supervising laws regarding marriage, especially child marriage (women under 18 years of age and men under 21 years of age), divorce and, more recently, domestic violence (Agnes 2011; Baxi 2014; Kapur and Cossman 1996). One of the chief conundrums in investigating procedures of family courts relates to the confused traffic between civil and criminal law at various levels of mediation, legal representation, and adjudication. Srimati Basu notes how regularly domestic violence is invoked in cases of divorce in her ethnography of family courts principally in and around the city of Kolkata (Basu 2012). The other significant challenge concerns, as Basu and Pratiksha Baxi argue, the perilous situation that heterosexual women face while 'exercising their positive right to choose when, if, and whom to marry', especially when laws of marriage refuse to consider women as independent decision-makers notwithstanding the legal definition of adulthood (Basu 2012; Baxi 2014: 237). Along with riddles of legal reforms, the affective qualities of love, pain, and violence have never ceased to haunt feminist explorations of marriage and domestic violence. V. Geetha, in a penetrating examination, 'On Bodily Love and Hurt', points at the curious import of 'jealousy' in the masculinist idea of romantic love between couples (1998). Shalini Grover's reflections on the love-marriages in a lower-income area of southern Delhi expands Geetha's argument by analysing the insecurities of women in 'love marriage' couples while facing domestic violence (2009).

Jonathan Parry's remarkable account of 'Ankalu's Errant Wife' and what he calls the 'labour aristocracy' around the Bhilai steel-plant in Chhattishgarh provides insights into the changing nature of conjugal intimacy and meanings of marriage in lower-caste non-metropolitan urban India (2001). Parry's anecdotes on the custom of having multiple partners in an older 'coldbrained' marriage system among the Satnamis of Chhattisgarh, however, reflect a sense of detached amusement at the lack of emotional expectation in such marriages. The tone of defining 'old' and 'new' meanings of conjugal love seem uncomfortably close to an ahistorical framing of the ethnographer-informant relationship. It is also deeply problematic when Parry 
arrives at the conclusion that the inter-generational transformation in conjugal intimacy from casual cohabiting sexual partners to intensely involved monogamous couples - is being shaped by the post-liberalization competitive market forces, without any reference to histories of labour and gender in colonial India. Samita Sen's (1999) account of the deployment of family as an ideology among the working-class households in early twentieth-century Calcutta has already given us a more nuanced analysis of the connection between state, market, and family values. Parry's conclusion fails to situate the recursivity of mobilizing family values by the colonial/postcolonial state, consequently leaving his ethnographic characters more cartoonish than realistic.

It is the least polemical to argue, given the rich scholarship on multiple roots of gender hierarchy, that for the majority of women marriage remains possibly the most defining moment of life and love-marriages have rarely meant freedom to choose the marital partner. And yet, it would certainly be unfair to don the blanket of victimhood over all women in contemporary India. Though the admirable ingenuity of Begum Sombre in utilizing kinship relations remains a historical exemplar, the genealogy of women's agency can be traced through Rajasthani women's oral traditions of articulating suffering and sacrifices; through strategies adopted by rural women of various castes in Lahoorpur (Uttar Pradesh) for intergenerational gender mobility; through the direct political speech of peasant women in Singur (West Bengal) defending their livelihood (Raheja and Gould 1994; Kalpagam 2008; Sinha Roy 2012). Such challenges produce splinters within the ubiquity of patrilineal, patrilocal family and marriage practices, politicize the space of intimacy through heterogeneous registers of activism, and acknowledge population groups that rupture the ideology of family.

\section{Radical desires: sexuality and love outside normality}

With the release of Deepa Mehta's film Fire in December 1998, same-sex love, especially lesbianism, became the centre of a public debate. The film contained scenes of physical love between two married sisters-in-law living in a joint family, both of whom are trapped in loveless heterosexual marriages. The film became front-page news when activists of 'Shiv Sena' - a right-wing political organization - vandalized cinema-halls showing Fire in metropolitan cities like Bombay and Delhi. Shiv Sena, supported by the Bharatiya Janata Party, declared that the film was polluting Indian culture by showing corrupt Western practices like lesbianism in an Indian family. ${ }^{16}$ As the uproar against the screening of Fire spread to the provinces of Tamil Nadu, Karnataka, and Assam, protests against such vandalization also began to attract public attention. ${ }^{17}$ Some lesbian activists in various cities decided to be visible in anti-vandalization protests as lesbians. By carrying placards like 'Indian and Lesbian' they protested against homophobia within the discourse of Hindu nationalism as well as the more general unease concerning non-normative sexual practices (Bacchetta 1999, Sharma 2006: 10-21). 'For once', writes Sibaji Bandyopadhyay, 'the depiction of bare flesh and carnal dealings on cinematic screen became an occasion to talk about sexuality, not purely in sexual terms' (2012: 246).

Several discursive threads were intertwined in the Fire controversy. While unravelling these complex knots, Sibaji Bandyopadhyay argues, 'the researcher learns to her/his surprise that unravelling in this case is the same as weaving ... the context itself begins to behave like a text-in-the-making' and his sprawling essay on the controversy covers an astonishing range of issues in which to weave in references to same-sex love - in Sanskrit and Persian texts from pre-modern India, Greek philosophy and epics, the Old Testament, poems from seventeenthcentury England along with writings of Frederick Engels, Kraft-Ebbing, and Freud to situate 
the mysterious 'origin' of same-sex love (Bandyopadhyay 2012: 245). Though Bandyopadhyay arrives at the conclusion that the so-called East and West have always locked horns in blaming the 'other', the search for the Indian-origin of same-sex love has yielded an interdisciplinary scholarship to build a new critical vantage point for studying family and marriage in the Indian context (Bose and Bhattacharya 2007; Narrain and Bhan 2005; Dave 2012; Gopinath 2005; Kapur 2005; Vanita and Kidwai 2000; Vanita 2002, 2005).

The insights provided by this growing literature offer us two important arguments. One, same-sex love was a minor social and legal offence in pre-colonial India, which took a dominant form of homophobia as the British colonial rule criminalized any sexual act 'against the order of nature' (Section 377 in the Indian Penal Code, first compiled in 1860) (Vanita and Kidwai 2000). Two, same-sex love in contemporary India is not an exclusively urban middle-class experience but rather remains part of everyday life among different classes, communities, and regions (Sharma 2006, Vanita 2009). However, an overwhelming presence of power regimes within family structures which promote compulsory heterosexuality is quite irrefutable. The existing scholarship on same-sex love suggests a more nuanced position in understanding the negotiations internal to a family or a community to accommodate sexual alterity. Such an argument cancels the diametrically opposite positions of heterosexuality and same-sex love by keeping open the possibility of simultaneous existence for both kinds of desire. This is not to dismiss the political necessity of oppositional positions to contest compulsory heterosexuality, but rather to account for the persistence of same-sex desire in spite of the pall of silence cast over it in a heteronormative society (Boyce 2008).

Ruth Vanita has tracked several cases of lesbian relationships to give us, on the one hand glimpses of family and community consent to lesbian marriage, and on the other hand the severity of social pressure faced by lesbian couples (2009: 47-60). Instances of successful lesbian marriage are, expectedly, few. The case of Bateka Palang, 30, and Maleka Nilsa, 25, two Kondh tribal women from Orissa, who got married in the presence of family, according to traditional practices in November 2006 is one such marriage. The acceptance of the two families by following the custom of 'bride-price' problematizes the role of custom in forming a tradition. One example of a happy ending, however, is outweighed by the tragic conclusion of many love stories in joint suicide of both lovers. Vanita writes that suicide notes of lesbian lovers are often the only public declaration of their everlasting love. This final act of resistance reminds us of Spivak's acclaimed essay 'Can the Subaltern Speak?' (1988). Given the reinforced criminalization of same-sex love in contemporary India one cannot but agree that the sexual subaltern remains as mute as Spivak's gendered subaltern. ${ }^{18}$ The only available means to keep the challenge against compulsory heterosexuality alive is to consider lesbian suicides as vantage points to reflect on lives that resisted and not their deaths as closure to the struggle, to remain ever-attentive to the unconventional utterances, to be able to undecipher the language of resistance spoken through bodies of the sexual subaltern. ${ }^{19}$ If same-sex love has been stigmatized as a 'disease' by hetero-patriarchy, the diseased gendered body, in the form of a person with disability, presents a different angle towards politics of difference. Scholars in disability studies, many of whom are also activists in the nascent disability movement in contemporary India, have argued that struggle for equality in a largely apathetic society must coincide with critical reflections on the social experience of disability - in addition to, and at times beyond, the medicalization of physical and mental impairments (Addlakha 2007; Das and Addlakha 2001; Ghai 2002; Kumar and Anuradha 2009; Mehrotra 2004) ${ }^{20}$ Increasingly sexuality of persons with disabilities has emerged as an apt entry-point to understand the enmeshed character of social and corporeal (including mental illness) discrimination. Following Judith Butler's pithy reflections on 
the critique of sexuality as 'merely cultural' by the materialist school of Marxism (1997), it is possible to argue that the sexual division of labour (especially the political economy of care), normative sexuality (reproductive heteronormativity), and legal 'personhood' to claim rights are integral parts of the discourses of disability. Rethinking the continuum of governmentality between family and state must take account of the ways in which sexuality - in relation to class, race/caste, place and space (in terms of urban/semi-urban/rural), gender

- becomes the principal governing principle of disability.

Indian state's idea of social responsibility towards its disabled population can be gauged through a widely reported case of mass hysterectomies performed on women inmates of a state-run home for the mentally challenged in Pune, Maharashtra in February 1994. In Rajeswari Sunder Rajan's reflections, this 'scandal' of the state becomes more than an exposé, and lays bare the extent of biological determinism in the statist interpretation of care for the disabled (Sunder Rajan 2003: 72-112). Sunder Rajan also brings to the fore the role of family in 'managing' disabled members, which is crucial for understanding the statist twist in an ideological deployment of family to justify the shrinking space of welfare and concentrating the political economy of care within the family. Renu Addlakha has stated in clear terms how women with disability become less than women in the family as they often fail to perform their ostensibly 'natural' role of care-giving (Addlakha 2007). The fear of reproducing a diseased generation (or a generation dependent on state welfare) on the one hand, and inversion of naturalized femininity on the other, make sexuality a central axis of governing disabled women.

If mental illness of women is marked on their bodies through forced hysterectomies, limb deformity (or visual impairment) inscribe a woman as a burden and push her into, ironically, a life of hard physical labour. Nilika Mehrotra narrates the data gathered from 49 case studies of disabled women in rural Haryana and Mehrotra's matter of fact tone uncovers with a chilling precision how women with limb deformities are often married off to the same family as her sister, or to the same man, so that she can be 'cared for' by her sister, how she is allowed to take longer in performing all household chores, and how she is more vulnerable to domestic violence (Mehrotra 2004). Disabled men also are subjected to stereotyping and suffer from low self-esteem, and yet they usually receive better care inside the family: their physical impairments are discovered earlier than women as a male child's health is more closely monitored than a girl child's (Addlakha 2007). Taking the gendered body and emotions as a composite, rather than a binary, it can be fruitful to map the history and sociology of activism, policy measures, and legal reforms to re-frame the milestones in the women's movement.

\section{Conclusion}

Beginning with the conceptual premise that deeper structures of gender discrimination can be challenged and eventually remedied with legal reforms, the contemporary women's movement is undergoing a churning within itself. These three trends in family studies are indicators of new directions that Indian feminist scholarship is forging ahead in and certainly places no claim in listing all intellectual developments. Education, health, demography, and violence constitute some of the major fields not covered in this chapter, in which the institutions of family and marriage are now being re-examined.

This chapter has been an effort in outlining how the orders and borders of family studies have been challenged. The enormous significance accorded to family and marriage in contemporary India contains subversion. This chapter revisits the contested fields of intimacy from subversive locations by exploring the margins of family studies. Engagement with margins problematizes the position of the speaking subject. For example, if one 
were arguing from the point of view of a disabled woman should she speak as a woman with disability, as a 'deviant' body, or, as a gendered subaltern? These questions are not merely rhetorical. 'What is required', argues Anita Ghai, 'is a consideration of multiple constraints that inhibit the articulation of difference' and feminism needs to go beyond mere recognition of difference (Ghai 2002: 64). Integrating articulations of difference will require the Indian women's movement to redraw the intimate spaces of struggle and the process may be messy; but fighting against the multi-pronged structure of prejudice was never supposed to be easy.

\section{Notes}

1 The Karnataka State Commission for Women severely criticized his comments, and women advocates gave a representation to the chief justice expressing serious objection to his statements. For detailed reports see The Hindu and The Hindustan Times, 8 September 2012; and 'Petition to Chief Justice of India - Remove Justice Bhaktavatsala of Karnataka High Court' in www.kafila. org (http://kafila.org/2012/09/05/petition-to-chief-justice-of-india-remove-justice-bhaktavatsalaof-karnataka-high-court/).

2 Seminar presented by Srimati Basu titled 'The Trouble with Marriage: Law, Violence and Feminist Jurisprudence' at the Centre for Women's Studies, Jawaharlal Nehru University (18 March 2014).

3 An important critique of the legal reforms comes from Flavia Agnes, feminist author and lawyer, regarding the failure of Indian women's movement to secure a broader base for laws to protect women from violence (Agnes 1992).

4 Some of the early works of note on family and kinship in India are - Gough (1956); Karve (1953); Béteille (1965); Madan (1965); Shah (1968).

5 Sibnath Shastri, a leading Brahmo personality of late nineteenth century, has given a detailed account of the crisis in the Brahmo movement precipitated by the Coochbihar marriage. Those who protested against Keshab Chandra Sen's acceptance of this marriage formed Sadharan Brahmo Samaj on 15 May 1878, and with his followers Keshab Chandra Sen formed Nababidhan - New Dispensation (Shastri 1911: 274-294).

6 Flavia Agnes argues that the highly acclaimed and widely publicized colonial law reforms on 'women's question' - Sati Regulation Act (1829), Widow Remarriage Act (1856), Age of Consent Acts (1860 and 1891), and the Child Marriage Restraint Act (1929) - ironically 'provided a forum for the collusion of local patriarchal interests with the anti-women biases of British jurists and laid firm legal ground for the diminution of women's rights in India' and civil law reforms carved out a space for men's individual property rights, strengthened caste affiliations, and weakened women's rights of inheritance by making land alienable and transferable (Agnes 2000: 120).

7 Matrimonial column refers to advertisements in newspapers seeking suitable brides and grooms. Recently the acceptability of matrimonial websites, where candidates can self-register, is increasing. 'Love, arranged by Shaadi.com', tagline of one of the most popular matrimonial websites, captures quite comprehensively the popular mode of arranged-love marriages in middle-class urban India.

8 Words in italics refer to the exact English words used in the Hindi song.

9 Ethnographers of kinship and marriage in contemporary India have scrupulously avoided putting love-marriage and arranged-marriage in opposition to each other, and have focused on the heterogeneous practices of 'love-cum-arranged' companionate marriages (Donner 2002; Fuller and Narasimhan 2008; Kolenda 1978; Mody 2002; Vatuk 1982).

10 Match-making depends on the elaborate network of caste and kin-group. In addition, newspapers and websites for seeking suitable alliances are also much in use. Rochona Majumdar gives an interesting history of professional matchmakers - ghataks - in nineteenth-century Bengal (Majumdar 2009: 25-32).

11 For Eighteen-Village Vattimas sub-caste endogamy forms an important part of match-making because partners sharing the same sub-caste culture are believed to have enduring nuclear family units.

12 Louis Dumont has made the distinction between 'primary marriage' and 'secondary marriage'. The primary marriage is more strictly regulated, more expensive, and prestigious than the secondary marriage, and often also remarriage, which is less elaborately ritualized (1988: 83). 
13 It is worth remembering that Dr Bhimrao Ambedkar stated specifically, while drafting the Hindu Code Bill, that inter-caste marriages are necessary for eroding the caste system. In the Bill he also went on to make provisions for women's equal right to inherit father's property, to divorce, to demand maintenance, to adopt, to bequeath property and countered the attacks from the more conservative sections of the legislators that such legal provisions would break the family as an institution.

14 Khap refers to all male village panchayats or assemblies where women cannot enter even when the discussion concerns their marital status, sexual purity, or livelihood.

15 In September 2007 a Muslim lower-middle class man Rizwanur Rehman, and Priyanka Todi daughter of a wealthy Hindu industrialist - both consenting adults - got married in Kolkata, in spite of serious opposition from Priyanka Todi's family. It became a public issue when Rizwanur Rehman's body was found a few weeks later by a railway track, and his death was dismissed as suicide. Protests by Rizwanur's family and kin led to further investigation and there was a public outcry against the alleged involvement of top-ranking police officials with Priyanka Todi's natal family.

16 For a comprehensive report on the Fire controversy, see (http://cscs.res.in/courses_folder/othercourses/papers.2008-03-17.1729485494/glimpses-of-the-fire-documenting-the-debates-aroundthe-film-fire).

17 Several feminist authors and activists registered their protest against the cultural policing of Shiv Sainiks by responding to the controversy. For example, John and Niranjana 1999; Kapur 2000; Upadhya 1998.

18 In December 2013 the Supreme Court of India has revoked the judgment passed by the Delhi High Court in 2009 decriminalizing same-sex love, and has reasserted Section 377.

19 Seminar presented by Navaneetha Mokkil titled 'Living Together, Dying Together: The Lesbian as a Political Subject' at the Centre for Women's Studies, Jawaharlal Nehru University (28 October 2014).

20 Disability studies is now opening up to explorations of the notions of deviant bodies in literature and travelogues, the relations between science, technology, and biological determinism, and is addressing issues like ageing.

\section{References}

Addlakha, R. (2007) 'How Young People with Disabilities Conceptualize The Body, Sex and Marriage in Urban India: Four Case Studies', Sexuality and Disability, 25(3): 111-123.

Agnes, F. (1992) 'Protecting Women Against Violence? Review of a Decade of Legislation, 1980-89', Economic and Political Weekly, 27 (17): WS19-WS33.

Agnes, F. (2000) 'Women, Marriage, and the Subordination of Rights', in P. Chatterjee and P. Jeganathan (eds), Subaltern Studies XI, 106-137, Delhi: Oxford University Press.

Agnes, F. (2011) Family Law: Marriage, Divorce, and Matrimonial Litigation, Delhi: Oxford University Press.

Arunima, G. (1995) 'Matriliny and its Discontents', India International Centre Quarterly, 22 (2/3): 157167.

Arunima, G. (2003) There Comes Papa: Colonialism and the Transformation of Matriliny in Kerala, Malabar, c. 1850-1940, Hyderabad: Orient Blackswan.

Bacchetta, P. (1999) 'When the (Hindu) Nation Exiles its Queers', Social Text, 61:141-166.

Bandyopadhyay, S. (2012) Sibaji Bandyopadhyay Reader, Delhi: Worldview.

Basu, S. (1999) She Comes to Take Her Rights: Indian Women, Property, and Propriety, Albany, NY: State University of New York Press.

Basu, S. (2012) 'Judges of Normality: Mediating Marriage in the Family Courts of Kolkata, India', Signs, 37 (2): 469-492.

Baxi, P. (2014) Public Secrets of Law: Rape Trials in India, Delhi: Oxford University Press.

Béteille, A. (1965) Caste, Class, and Power, Berkeley, CA: University of California Press.

Bose, B. and S. Bhattacharya (eds) (2007) The Phobic and the Erotic: The Politics of Sexualities in Contemporary India, Calcutta: Seagull Books.

Boyce, P. (2008) 'Truths and (Mis) representations: Adrienne Rich, Michel Foucault and Sexual Subjectivities in India', Sexualities, 11 (1-2): 110-119.

Butler, J. (1997) 'Merely Cultural', Social Text, 52/53: 265-277. 
Chakravarti, U. (2003) Gendering Caste: Through a Feminist Lens, Calcutta: Stree.

Chatterjee, P. (1995) The Nation and its Fragments: Colonial and Postcolonial Histories, Delhi: Oxford University Press.

Chatterjee, I. (ed.) (2004) Unfamiliar Relations: Family and History in South Asia, Delhi: Oxford University Press.

Chowdhry, P. (1989) 'Customs in a Peasant Economy: Women in Colonial Haryana', in K. Sangari and S. Vaid (eds), Recasting Women: Essays in Colonial History, 302-360, Delhi: Kali for Women.

Chowdhry, P (2004) 'Private Lives, State Intervention: Cases of Runaway Marriage in Rural North India', Modern Asian Studies, 38 (1): 55-84.

Das, V. and R. Addlakha (2001) 'Disability and Domestic Citizenship: Voice, Gender, and the Making of the Subject', Public Culture, 13 (3): 511-531.

Dave, N. N. (2012) Queer Activism in India: A Story in the Anthropology of Ethics, Durham, NC: Duke University Press.

Devee, S. (1921) The Autobiography of an Indian Princess, London: John Murray.

Donner, H. (2002) “'One's Own Marriage”: Love Marriages in a Calcutta Neighbourhood', South Asia Research, 22 (1): 79-94.

Dube, L. (1997) Women and Kinship: Comparative Perspectives on Gender in South and South-East Asia, New Delhi: Vistaar Publications.

Dumont, L. (1966) Homo Hierarchicus: The Caste System and its Implications, Chicago, IL: Chicago University Press.

Dwyer, R. and C. Pinney (eds) (2002) Pleasure and the Nation: The History, Politics and Consumption of Public Culture in India, Delhi: Oxford University Press.

Fisher, M. (2004) 'Becoming and Making "Family" in Hindustan",' in I. Chatterjee (ed.), Unfamiliar Relations: Family and History in South Asia, 95-121. Delhi: Oxford University Press.

Forbes, G. (1996) Women in Modern India, Cambridge: Cambridge University Press.

Fuller, C. J. and H. Narasimhan (2008) 'Companionate Marriage in India: The Changing Marriage System in a Middle-class Brahman Subcaste', Journal of the Royal Anthropological Institute, 14(4): 736-754.

Geetha, V. (1998) 'On Bodily Love and Hurt', in M. E. John and J. Nair (eds), A Question of Silence: The Sexual Economies of Modern India, 304-331, Delhi: Kali for Women.

Ghai, A. (2002) 'Disabled Women: An Excluded Agenda of Indian Feminism', Hypatia, 17 (3): 49-66.

Ghosh, D. (2006) Sex and the Family in Colonial India: The Making of Empire, Cambridge: Cambridge University Press.

Gopinath, G. (2005) Impossible Desires: Queer Diasporas and South Asian Public Cultures, Durham NC: Duke University Press.

Gough, K. (1956) 'Brahmin Kinship in a Tamil Village', American Anthropologist, 58: 826-853.

Grover, S. (2009) 'Lived Experiences: Marriage, Notions of Love, and Kinship Support Amongst Poor Women in Delhi', Contributions to Indian Sociology, 43 (1): 1-33.

Hindustan Times (2012) 'Controversial Judge Taken Off Family Cases', September 8, http:// www.hindustantimes.com/india-news/newdelhi/controversial-judge-taken-off-family-cases/ article1-926399.aspx (last accessed 10 June 2015).

Hodges, S. (2004) 'Governmentality, Population and Reproductive Family in Modern India', Economic and Political Weekly, 39 (11): 1157-1163.

John, M. E. and J. Nair (eds) (1998) A Question of Silence: The Sexual Economies of Modern India, Delhi: Kali for Women.

John, M. E. and T. Niranjana (1999) 'Mirror Politics: "Fire", Hindutva and Indian Culture', Economic and Political Weekly, 34 (10-11): 581-584.

Kalpagam, U. (2008) 'Marriage Norms, Choice and Aspirations of Rural Women', Economic and Political Weekly, 43 (21): 53-63.

Kannabiran, K. (2006) 'Three-Dimensional Family: Remapping a Multidisciplinary Approach to Family Studies', Economic and Political Weekly, 41(2): 4427-4433.

Kapur, R. (2000) 'Too Hot to Handle: The Cultural Politics of "Fire”, Feminist Review, 64: 53-64.

Kapur, R. 2005. Erotic Justice: Law and the New Politics of Postcolonialism, New Delhi: Permanent Black.

Kapur, R. and B. Cossman (1996) Subversive Sites: Feminist Engagements with Law in India, New Delhi: Sage.

Karve, I. (1953) Kinship Organisation in India, Bombay: Asia Publishing House.

Kolenda, P. (1978) Caste in Contemporary India: Beyond Organic Solidarity, Menlo Park, CA: Benjamin/ Cummings.

Kopf, D. (1979) The Brahmo Samaj and the Shaping of the Modern Indian Mind, Princeton, NJ: Princeton University Press. 
Kumar, M. P. and S. E. Anuradha (2009) "Nonconformity Incarnate": Women with Disabilities, Gendered Law and the Problem of Recognition', Economic and Political Weekly, 44 (44): 37-43.

Liddle, J. and R. Joshi (1986) Daughters of Independence: Gender, Caste, and Class in India, Delhi: Kali for Women.

Madan, T. N. (1965) Family and Kinship: A Study of the Pandits of Rural Kashmir, Delhi: Oxford University Press.

Majumdar, R. (2009) Marriage and Modernity: Family Values in Colonial Bengal, Durham, NC: Duke University Press.

Mehrotra, N. (2004) 'Women, Disability and Social Support in Rural Haryana', Economic and Political Weekly, 39 (52): 5640-5644.

Mody, P. (2002) 'Love and the Law: Love-marriage in Delhi', Modern Asian Studies, 36 (1): 223-256.

Nair, J. (1996) Women and Law in Colonial India: A Social History, Delhi: Kali for Women.

Narrain, A. and G. Bhan (eds) (2005) Because I have a Voice: Queer Politics in India, Delhi: Yoda Press.

Parry, J. P. (2001) 'Ankalu's Errant Wife: Sex, Marriage and Industry in Contemporary Chhattisgarh', Modern Asian Studies, 35 (4): 783-820.

Raheja, G. G. and A. G. Gold (1994) Listen to the Heron's Words: Reimagining Gender and Kinship in North India, Berkeley, CA: University of California Press.

Ramusack, B. (2004) Indian Princes and Their States, Cambridge: Cambridge University Press.

Sarkar, T. (2003) Hindu Wife, Hindu Nation: Community, Religion, and Cultural Nationalism, Delhi: Permanent Black.

Sarkar, T. (2009) Rebels, Wives, and Saints: Designing Selves and Nations in Colonial Times, Delhi: Permanent Black.

Sen, S. (1999) Women and Labour in Late Colonial India: The Bengal Jute Industry, Cambridge: Cambridge University Press.

Sen, S., R. Biswas and N. Dhawan (2011) Intimate Others: Marriage and Sexualities in India, Calcutta: Jadavpur University, School of Women's Studies.

Shah, A. M. (1968) 'Changes in the Indian Family: An Examination of Some Assumptions', Economic and Political Weekly, 3 (1-2): 127-134.

Sharma, M. (2006) Loving Women: Being Lesbian in Unprivileged India, Delhi: Yoda Press.

Shastri, S. (1911) History of the Brahmo Samaj, Calcutta: R. Chatterji.

Sinha Roy, M. (2012) 'Rethinking Female Militancy in Postcolonial Bengal', Feminist Review, 101: 124 131.

Spivak, G. C. (1988) 'Can the Subaltern Speak?' in C. Nelson and L. Grossberg (eds), Marxism and the Interpretation of Culture, 271-313, Basingstoke: Macmillan.

Stree Shakti Sangathana (1989) 'We were Making History ...': Life stories of Women in Telengana People's Struggle, Delhi: Kali for Women.

Sunder Rajan, R. (1993) Real and Imagined Women: Gender, Culture and Postcolonialism, London: Routledge.

Sunder Rajan, R. (2003) The Scandal of the State: Women, Law, Citizenship in Postcolonial India, Durham, NC: Duke University Press.

Sunder Rajan, R. (2010) 'Death and the Subaltern', in R. C. Morris (ed.), Can the Subaltern Speak? Reflections on the History of an Idea, 117-139, New York: Columbia University Press

Uberoi, P. (ed.) (1994) Family, Kinship and Marriage in India, Delhi: Oxford University Press.

Uberoi, P. (1996) 'The Family in Official Discourse', India International Centre Quarterly, 23(3/4): 134-155.

Uberoi, P. (2006) Freedom and Destiny: Gender, Family, and Popular Culture in India, Delhi: Oxford University Press.

Upadhya, C. (1998) 'Set This House on Fire', Economic and Political Weekly, 33 (50): 3176-3177.

Vanita, R. (ed.). (2002) Queering India: Same-sex Love and Eroticism in Indian Culture and Society, New York: Routledge.

Vanita, R. (2005) Love's Rite: Same-sex Marriage in India and the West, New York: Palgrave Macmillan.

Vanita, R. (2009) 'Same-sex Weddings, Hindu Traditions and Modern India', Feminist Review, 91 (1): 47-60.

Vanita, R. and S. Kidwai (2000) Same-Sex Love in India and the West: Readings from Literature and History, New York: Palgrave Macmillan

Vatuk, S. (1982) 'Changing Patterns of Marriage and the Family in an Urbanized Village in Delhi, India', in Helen I. Safa (ed.), Towards a Political Economy of Urbanization in Third World Countries, 119-150, Delhi: Oxford University Press. 


\title{
20 \\ ADIVASIS AND \\ CONTEMPORARY INDIA \\ Engagements with the state, non-state actors and the capitalist economy
}

\author{
Uday Chandra
}

\section{Introduction}

Any consideration of contemporary adivasi politics must confront the prior question of who is an adivasi (and who is not). The answer is, alas, far from obvious even to those, or perhaps especially to those, who claim to study adivasi politics. We know that the neologism 'adivasi', which was coined in the early twentieth century in what is now Jharkhand (Hardiman 1987: 15), literally means something akin to 'ancient inhabitant'. The term represented an attempt by the leaders of social movements in late colonial Jharkhand and its adjoining areas to articulate a political vocabulary beyond the English word 'tribe' with its colonialera associations of backwardness and savagery. To this extent, 'adivasi' has always been less a social-scientific label to describe existing social groups than a category imbued with a political aspiration, namely, to unite groups that are characterized as 'tribes' or 'scheduled tribes' in colonial and postcolonial India. The implication is that one is no longer only a Munda, Kondh or Bhil, but a member of an emergent all-India collective.

Yet not every 'tribe' found in colonial censuses can be straightforwardly called adivasi in contemporary India. By convention, the term 'adivasi' is limited in its usage to scheduled areas defined under Schedule V of the postcolonial Indian constitution. In other words, those living in Schedule VI areas in north-eastern India are neither described as adivasis nor do they call themselves as such. The distinction between these two types of scheduled areas on the mainland and the north-eastern frontier of India corresponds to an older divide between what the Government of India Act, 1935 defined as 'partially excluded areas' and 'wholly excluded areas' and what the earlier Government of India Act, 1919 defined as 'typically backward tracts' and 'really backward tracts' (Chandra 2013a: 149). Schedule V areas have, following colonial precedent, been understood by the postcolonial Indian state to be more integrated with 'mainstream' or caste society than Schedule VI areas on the north-eastern frontier. To the extent that an adivasi identity is located exclusively in the Schedule $\mathrm{V}$ areas, it is important to recognize the intimate relations between the notion of 'adivasi' and mainstream caste society in modern India. The same cannot be said for 'tribes' or 'indigenous peoples' residing in Scheduled VI areas today, whose notions of belonging 
transcend national boundaries via church, activist and NGO networks as well as culturalhistorical ties with Southeast Asia and Inner Asia. Adivasis, in sum, exist only in the Schedule $\mathrm{V}$ areas on the Indian mainland where, despite the existence of internal frontiers, the nationstate is inescapable.

Yet we must also recognize that the term 'adivasi' is far from uniformly used within Schedule V areas. First, there are individuals and groups within these scheduled areas who simply do not aspire to be 'adivasis' in the all-India sense. They prefer instead to be Oraons or Todas with the distinctive historical meanings that these communities have come to embody locally and trans-locally. Second, there are individuals and groups whose aspirations take shape within the contours defined by right-wing Hindu organizations, which see 'adivasi' as a politically divisive, even pernicious, term. They prefer to call themselves 'vanvasis' (literally, 'forest dwellers'), and would like to extend this neologism to others they deem to be similar to themselves. Third, there are groups in these scheduled areas that do not claim to be 'adivasis' because they seek to be recognized by the postcolonial state as 'scheduled tribes'. Far from abandoning colonial stereotypes of backwardness and savagery, they seek to enact these tropes of what I have elsewhere termed 'primitivism' (Chandra 2013a) in order to force their way into the official schedule or list of 'tribes' recognized by the Indian state. In the strict sense, therefore, very few groups defined by the contemporary Indian state as 'scheduled tribes' in Schedule V areas call themselves 'adivasi', though it remains a matter of lively debate among activists and academics whether self-ascription should be the sole basis of defining an adivasi identity.

It may be fair to say that the empirical connotations of the term 'adivasi' are considerably narrower than the political aspirations represented by the term, and this is arguably why social scientists are far from unanimous in adopting it. Over the past two decades, politically-engaged scholars seeking to express solidarity with particular adivasi movements have tended to prefer 'adivasi' to describe all state-defined 'scheduled tribes' in Schedule V areas (see, e.g. Baviskar 1995; Sundar 1997; Damodaran 2002; Rycroft and Dasgupta 2011). This is, of course, as much a political choice on the part of these scholars as it is an intellectual one. Such a choice may, however, be accompanied by a willingness to speak for 'adivasis' in a quasi-activist tone at the risk of ventriloquizing and disregarding inconvenient realities. On this count, a significant strand of scholarship on modern India has questioned and criticized the notion of 'adivasi' as a useful empirical category (see, e.g. Béteille 1986; S. Guha 1999; Prasad 2003). These critics contend that the politics surrounding the term 'adivasi' are hardly any different from the colonial notion of 'tribe' that has been discredited globally over the past half century (Fried 1975; Fabian 1983; Mamdani 1996; Kuper 2003; Rolph-Trouillot 2003). Moreover, following the writings of the sociologist G.S. Ghurye (1943, 1963), these scholars question the analytical utility of the term 'adivasi' as a marker of irreducible cultural and political difference in Indian society. From an altogether different perspective, an emerging body of scholarship has also questioned the intellectual and political value of the term 'adivasi' insofar as it is tied inextricably to the postcolonial Indian nation-state. These scholars argue for the need to connect the local with the global without the mediation of the national, and hence, call for erstwhile 'tribes' in India to rally under the global banner of 'indigeneity' today (see, e.g. Munda and Bosu Mullick 2003; Karlsson 2003; Karlsson and Subba 2006). The political aspirations of 'indigenous' populations, according to these advocates, transcend the nationstate, and the politics of indigeneity thus paves the way for emancipating marginalized groups from their imprisonment in specific national contexts. Without adjudicating between these divergent scholarly perspectives, it may be wise to conclude that it is neither 
easy to ascertain who is an adivasi (and who is not), nor is it obvious that the term itself is particularly helpful.

It is worth clarifying here that none of the preceding discussion is meant to go so far as to suggest that the term 'adivasi' is an empty signifier. But it is equally important to clarify that the term is far more contested and narrower in empirical scope than its proponents acknowledge. With these clarifications in mind, we may proceed to the core of this chapter, which is divided into three sections: (1) adivasis and the state; (2) adivasis and non-state actors; (3) adivasis and the capitalist economy. In each section, I shall explore the fuzziness of the term 'adivasi', and urge the reader to compare and contrast different instances of adivasi politics in contemporary India. What makes adivasi politics distinctive is, arguably, worth noting as much as what challenges pre-existing ideas of adivasi alterity.

\section{Adivasis and the state in contemporary India}

A dominant strand of scholarly and popular common sense has tended to characterize adivasis as inherently at odds with the modern state in India. Recent claims that adivasi communities are deeply invested in 'obstructing the state' (Gell 1997) or 'keeping the state away' (Shah 2007) have an older pedigree that dates back to colonial anthropologist-administrators such as Edward Dalton (1872), Herbert Risley (1891), William Crooke (1896), and W.H.R. Rivers (1900). Later ethnographers, most notably Verrier Elwin (1943) and Christoph von Fürer-Haimendorf (Mayer 1981), kept alive the apocryphal image of the noble savage as the antithesis of modern civilization and added that the former's existence was being increasingly threatened by the latter. Early subaltern studies and their fascination with nineteenth-century rebellions also ensured, in their own way, that 'tribe' and 'state' continued to be represented as antonyms (Arnold 1982; R. Guha 1983; Dasgupta 1985; Bhadra 1985; Sarkar 1985). As a consequence, the adivasi as an exemplar of Otherness, untouched in absolute or relative terms by processes of modern state formation, has resonated nicely with a more general social-scientific understanding of 'tribes' as state-repelling agents (see, e.g. Lévi-Strauss 1969; Clastres 1987; Scott 2009; Hobart and Kapferer 2012).

By contrast, a diverse range of scholars have now shown that adivasi communities across India are deeply entangled within the logics of modern state power. We know that the social and economic histories of the Bhils in western India, for example, were closely intertwined with Mughal, Maratha, British colonial, and Indian postcolonial states over the past four centuries (Guha 1999; Skaria 1999). Similar longue durée histories of adivasi-state relations for northern, central, eastern, and southern India have revealed how foraging and hunting groups in forest niches were 'professional primitives' (Fox 1969) embedded in complex hierarchies of caste, land, ritual, and privilege (Hockings 1980; Sinha 1982; Singh 1988; Sundar 1997; Schnepel 2002). A nuanced historical understanding of the pre-modern pasts of those groups we identify as 'adivasi' today paves the way for a deeper knowledge of how these groups are enmeshed within modern states in colonial and postcolonial India (Chandra 2013b). If forests and hills are deemed marginal spaces by modern states, we need not assume that the state is somehow weak, absent, or at odds with those inhabiting these spaces. Indeed, as a widely read volume on modern statemaking in the margins argues, margins are suffused with the languages and logics of stateness (Das and Poole 2004). We must thus not only locate adivasi communities within processes of modern state formation, but also appreciate how the notions of 'tribe' and 'adivasi' have taken their historical forms in close conversation with colonial and postcolonial states in India. To put it bluntly, there are no 'tribes' or 'adivasis' outside the domain of the modern Indian state. 
This is not to suggest, of course, that adivasi-state relations in contemporary India are amicable. Adivasi politics vis-à-vis the postcolonial Indian state are characterized, above all, by negotiating claims that seek to ameliorate socioeconomic conditions as well as to alter state-society relations in legally-demarcated Schedule V areas. Social movements are the principal mechanism through which negotiations with the state take place. These social movements may be mediated by external activists from urban middle-class society in India or abroad as, for instance, in the well-known Narmada anti-dam movement (Baviskar 1995; Nilsen 2010; Whitehead 2010; Thakur 2014) or the ongoing anti-mining protests in Orissa and Jharkhand today (Padel and Das 2010; Damodaran 2012). But it is also possible that movements may be organized and led by adivasis themselves as, for instance, in the KoelKaro movement in Jharkhand (Ghosh 2006; Chandra 2013c) or when groups such as the Gaddis and Gujars seek recognition as 'scheduled tribes' (Kapila 2008; Mayaram 2014). Both types of movements put forth a set of claims to governmental officials and use the available cultural and material resources to negotiate smartly. Whereas some claims such as those of the Narmada Bachao Andolan (NBA) tackle the risk of dispossession and displacement, others such as the Gujars' seek to enhance one group's position relative to others' in the region. Political parties such as the Jharkhand Mukti Morcha (JMM) and the Communist Party of India (Marxist) have also participated in adivasi negotiations with postcolonial state structures over regional autonomy in Jharkhand and the recognition of Santali as an official language in West Bengal. Negotiations with the state are also negotiations of state power from below, and to this extent, adivasi movements are characterized by a blend of conflict and conformity as they seek to attain their goals.

Students of adivasi politics have often assumed coherence on the part of claim-making communities vis-à-vis the state, but this is rarely ever the case in practice. Adivasi communities in contemporary India are fissured along the lines of class, gender, and generation, and their claims on the state differ accordingly. Movements such as the NBA have, for instance, emerged as key mechanisms of social mobility for low-status Bhils who have not enjoyed the traditional privileges of dominant lineages (Thakur 2014). Similarly, Munda women have featured prominently in protest politics in rural Jharkhand because these are well-trod avenues for exiting the drudgery of domestic work and the burden of traditional expectations at home. At the same time, young adivasi men tend to be at the forefront of social movements, which offer greater freedom and opportunities for leadership than in their gerontocratic communities in which village elders reign supreme (Chandra forthcoming). In each case, what it means to be 'adivasi' is itself open to questioning from within and without. If village elders from dominant lineages oppose a dam project on the grounds that they will lose their ancestral lands, the claims put forth will differ substantially from those by younger men and women who seek to sell their lands to the highest bidder and move to a big city. In fact, in the case of forest rights, recent scholarship on Gujarat, Orissa, and Uttar Pradesh suggests that, even where the language of 'custom' prevails, individual and household calculations trump collective interests in adivasi negotiations with the postcolonial state (Kashwan 2011; Shutzer 2013; Vaidya 2014). We must acknowledge, therefore, that the aspiration to speak for all adivasis invariably conceals the particular interests at stake, but these interests need not always be so opaque to researchers that coherence can be assumed.

To sum up, adivasi-state relations in contemporary India follow pre-existing patterns of negotiation and accommodation. Far from keeping the state at arm's length, adivasi communities everywhere make their presence felt in the domain on postcolonial governmentality. In doing so, they invoke a notion of 'community' that is as much an aspiration of social movements as it is a strategic essentialism. Non-adivasi activists and politicians also 
take up adivasi political causes, thereby opening up a new terrain of negotiation within social movements in addition to those within the 'community' and in the governmental domain. The interaction between these diverse terrains of negotiation with their accompanying conflicts and compromises, ultimately, determines the success of particular movements. Although the modern state penetrates adivasi communities and suffuses their languages and logics of protest, the state itself is made and remade from below by adivasi claim-making in particular regions and localities.

\section{Adivasis and non-state actors in contemporary India}

Non-state actors have until recently been neglected in the study of adivasis, though Christian missionaries, extreme right-wing and left-wing organizations, and indigeneity activists dot the landscape throughout the Schedule V areas. Each of these actors differs from each other as well as the postcolonial state, but these differences do not necessarily imply antagonisms. As far as adivasis are concerned, these non-state actors can be valuable allies in negotiations with the state as well as in achieving social mobility for particular individuals and groups. Yet, at the same time, these supra-local actors come armed with their own agendas, which may sit uneasily with the ambitions of adivasis themselves. A balanced assessment of the relationship between adivasis and various non-state actors in the Schedule V areas must thus avoid the twin evils of partisanship and demonization.

Christian missionaries were vital catalysts of adivasi politics in the colonial period, but Gandhian politics, the passage of anti-conversion laws, and the infamous Niyogi Commission report dealt a severe blow to missions in the early years of the Indian republic (Roberts forthcoming). Missionaries could no longer proselytize under Indian law, and this meant that the 'encounter of peripheries' (Carrin and Tambs-Lyche 2008) from Europe and India came to an abrupt halt in Schedule V areas. Missionaries continued to have an impact on the education as well as living standards among adivasis, especially the Christians among them (Sahay 1976; Corbridge 2000: 70). As a former bishop of the Lutheran church in Ranchi put it, even those adivasis who were hostile to their Christian peers and the Gospel recognized the educational and medical benefits provided by missions (Minz 1998: 36-37). But the superior socioeconomic status enjoyed by Christian adivasis did not encourage further waves of conversion in the postcolonial period. Nor did the official reservations policy for scheduled tribes replicate the success of missions (Higham and Shah 2013). Instead, indigenous revivalism centred on the sarna (literally, 'sacred grove') gave a fresh lease of life to what the early colonial censuses, following the anthropological wisdom of the day, termed 'animism' (Munda 2000).

Sarna activism has been, however, upstaged by the proselytizing work done by right-wing Hindu organizations in the heart of contemporary India. The Hindu Right in India prefers the term 'vanvasis' (forest dwellers) to 'adivasis', and since the 1950s, it has run a sustained campaign in western, central, and eastern India to make good Hindus of these vanvasis. The Hindu Right argue that vanvasis are 'default Hindus' (Baviskar 2007: 282), some of whom have been misled by Christian missionaries since the mid-nineteenth century. In arguing thus, right-wing Hindu activists follow the postcolonial constitution, which treats the scheduled tribes as Hindus unless they declare themselves Christian, Muslim, and so on. Shuddhi or purificatory rituals of re-conversion to Hinduism have typically accompanied medical and educational benefits to bring adivasis into the Hindu nationalist fold in Gujarat, Maharashtra, Madhya Pradesh, Chhattisgarh, and Orissa (Xaxa 2000; Desai 2007; Froerer 2007; Kanungo 2008), and the rewards have been reaped not only in electoral contests (Thachil 2009), but 
also during anti-Muslim pogroms such as the notorious one in Gujarat in 2002 (Lobo 2002; Devy 2002). It would be easy to dismiss right-wing Hindu proselytization as a top-down process with limited reach within rural adivasi communities, but as the rich ethnographic studies by Amit Desai and Peggy Froerer in Maharashtra and Madhya Pradesh show, a sizeable section of adivasis have received right-wing proselytizers rather enthusiastically and sought to 'mainstream' themselves as modern vanvasi votaries of the Hindu rashtra. Much of this success owes to the translation of Hindu myths and legends into adivasi folk idioms, on the one hand, and the accommodation of adivasis within the right-wing Hindu vision of national development, on the other (Kanungo and Joshi 2010). With the rise of the Hindu Right to national power in 2014, it remains to be seen whether those calling themselves vanvasis stand to gain materially from the new political dispensation.

In contrast to the Hindu Right, militant left-wing outfits have achieved relatively little among adivasis. 'Naxalites', as Indian Maoists are popularly called, invariably hail from upper to middle caste backgrounds in rural and urban India, and their entry into the forests and hills of the Schedule V areas has been occasioned by military-strategic considerations more than any eclectic affinities with adivasi politics (Chandra 2014a). There has been a lively, albeit pointless, debate in metropolitan India between those who believe Maoism is an imposition on hapless adivasis abandoned by the postcolonial Indian state (Guha 2007; Simeon 2010; Sundar 2014) and those who believe Maoism is the most forceful articulation of longstanding adivasi grievances against the state (Navlakha 2010; Satnam 2010; Roy 2011). This intra-elite debate is pointless because the neat either/or choice it poses makes little sense on the ground, least of all to adivasis themselves. What we do know is that class, religious, generational, and gender divides within adivasi communities are crucial to understand who participates in the Maoist movement, how, and why. Despite their elders' disapproval, young adivasi men and women entered the Maoist movement through real or fictive kinship (Shah 2013a). Thereafter, they sought to assert themselves within local webs of rural politics as political agents, even leaders (Chandra 2013c). The same ambitions, however, also led adivasi youth away from the Maoists towards counterinsurgency (Sundar 2010) and the developmental state apparatus (Shah 2013b). Adivasi agency is slippery, and, as the Maoists have now realized, its revolutionary potential can dissipate rather quickly. The numerous Maoist splinter groups in eastern-central India and the active participation of adivasis in counterinsurgency testify to the limited opportunities afforded by the Maoist movement to adivasis. If the Maoist movement has failed to leave any lasting imprint on adivasi communities, it is not for want of effort but due to the shifting political calculations of adivasi youth seeking social mobility and power in and outside the movement.

The sprinkling of indigeneity activists found throughout India has an even more limited impact on adivasi life than the Maoists do. These activists represent adivasi predicaments today as local manifestations of the worldwide problems faced by ex-tribal 'indigenous' populations (see, e.g. Munda and Bosu Mullick 2003). By connecting the local with the global, indigeneity activism in India seeks to bypass the overbearing presence of the nationstate in adivasi life (Karlsson 2003). But, as Kaushik Ghosh (2010) has pointed out, reading indigeneity into adivasi politics amounts to a subtle epistemic violence that effaces the critical differences that exist between settler colonies in the Americas and Australia and the postcolonial world. Furthermore, the activists' desire to bypass the postcolonial nation-state sits oddly with ongoing adivasi negotiations with the state in the Schedule V areas. For the most part, indigeneity activists are well-meaning middle-class Indians from clean-caste backgrounds, but their tendency to ventriloquize for adivasis is invariably linked more to the construction of their own radical selves than with the articulation of genuine adivasi 
aspirations in the public sphere (Chandra 2013d). Indeed, as a recent monograph by Alpa Shah (2010) explains, indigeneity discourses fundamentally misrepresent adivasis by casting them as noble 'eco-savages' living in harmony with nature and their millennia-old traditions in the scheduled areas. It remains to be seen how indigeneity activists respond to these criticisms, including those from adivasis themselves, and whether they can recalibrate their politics to better fit everyday realities in the scheduled areas.

In sum, non-state actors such as missionaries, extreme right- and left-wing organizations, and indigeneity activists structure adivasi lifeworlds today in both complementary and contradictory ways. On the surface, right- and left-wing organizations seem to be at loggerheads with each other, yet skirmishes between them are rare despite their coexistence in central and eastern India. Conflicts do exist, however, between missionaries and the Hindu Right in the scheduled areas, especially where state governments are more sympathetic to the latter. But, at a different scale of politics, missionaries and indigeneity activists may have a common interest in transnational advocacy on behalf of their adivasi wards. Adivasis have little choice today but to navigate this complex web of complementarities and contradictions, minimizing threats to their well-being and enhancing prospects for social mobility simultaneously. When seen alongside their negotiations with state structures, it is possible to appreciate the fraught terrain in which adivasi aspirations take shape in contemporary India.

\section{Adivasis and the capitalist economy in contemporary India}

Just as scholars have conventionally located the state outside adivasi life, so, too, has the modern capitalist economy. It has thus been argued that market processes are destroying the social fabric and confidence of rural adivasi communities, and rendering them homeless, landless, and destitute (Elwin 1943; Padel and Das 2010; Damodaran 2012). This argument, which undoubtedly has its origins in colonial anthropology (see, e.g. Dalton 1872), treats both adivasis and forest environments as precariously placed within a global capitalist economy (Suykens 2009), and calls for a kind of salvage anthropology to rescue both from extinction (Damodaran 2002; Padel 2010; Padel et al. 2013). But these arguments by scholaractivists, much like those of indigeneity activists discussed in the previous section, practise a politics of ventriloquism that, unwittingly, silences adivasi voices (Shah 2010). It is not that the subaltern cannot or does not speak, but that she is not heard by those who insist on speaking for her (Spivak 1988). As such, it is necessary to pay heed to adivasi voices and agency in order to rethink how capitalist economic processes play out in the Schedule $\mathrm{V}$ areas today: Our focus here will be on scholarship concerning three closely related aspects of contemporary capitalism in these areas: land and forests, rural livelihoods, and migration to cities.

As far as land and forests are concerned, there is no doubt that, over the past century and a half, processes of sedentarization and peasantization have accompanied widespread deforestation and an expansion of the arable frontier in Schedule V areas (Gadgil and Guha 1995; Rangarajan 1996). There is also little doubt that these socioeconomic processes are linked to the 'primitive accumulation of capital' (Marx 1967: 713-774), which has been integral to colonial and postcolonial state formation in India (Sivaramakrishnan 1996). But, far from being simply a top-down imposition, the management of land and forests has placed adivasis in a 'double bind' (Banerjee 2006). On the one hand, the expansion of the arable frontier has provided adivasi peasants the opportunity to create private landed property that is recognized by the state and protected through tenancy legislation such as the Chotanagpur Tenancy Act (1908) and the Central Provinces Land Alienation Act (1916) (Upadhya 2010; 
Thakur forthcoming). As such, a number of early adivasi movements such as those of the Munda Sardars and the Tana Bhagats sought either the recognition or the protection of private property in land (Dasgupta 1999; Chandra 2014b). Even recent adivasi politics has prioritized land rights for individuals, including women, and households following progressive legislation such as the Forest Rights Act (2006) (Rao 2008; Kashwan 2011; Shutzer 2013; Thakur 2014). On the other hand, modern regimes of forest conservation since the 1870s have tended to partner with adivasi communities, especially dominant lineages within them, to protect endangered species of trees and wildlife in protected forests as well as to profit from commercially valuable trees, most notably sal (Shorea robusta), and from vermin eradication (Sivaramakrishnan 1999). Accordingly, recent attempts at joint forest management' draw on a longer history of adivasi-state relations, in which a balance is sought between conservation and profit and, equally, between participatory and technocratic modes of governance (Sundar 2000; Sundar et al. 2001). The adivasis' double bind today stems from their contradictory role as holders of private land rights in forest tracts and as state-appointed conservators of the same tracts. It is not surprising, therefore, that governmental bids for land acquisition today on behalf of public or private corporations are met with a mix of approval and consternation within rural adivasi communities, deepening existing conflicts along class, gender, and generational lines and, indeed, interrogating the notion of being 'adivasi'.

Rural adivasi livelihoods and the politics of work in Schedule V areas are no less contentious today. On the one hand, adivasi youth, like their counterparts elsewhere in contemporary India, are steadily moving away from farm labour to take up non-farm livelihoods and work in cities (Shah and Harriss-White 2011). On the other hand, a plethora of non-governmental organizations or NGOs now routinely intervene in adivasi livelihood activities, ostensibly to ensure food security and economic stability for rural households within local and regional agrarian markets (Chandra 2013b: 304-313; Shutzer 2013). From my fieldwork in rural Jharkhand, I found that those adivasis who own more and better land are more likely to benefit from NGO interventions, especially via governmental schemes such as the Swarnajayanti Gram Swarojgar Yojna (SGSY) and the National Rural Employment Guarantee Act (NREGA). At the same time, those from outside these better off households are more likely to stop farming and shake off any ties of patronage or bondage that may have previously existed. In other words, existing power differentials arising from the ownership of land within adivasi villages may be widening in a sense, but non-farm work, including in NGOs and insurgent groups, also threatens to overturn existing village hierarchies abruptly. In a similar vein, conflicts over livelihoods within adivasi villages may be seen, for example, in fierce debates over the 'traditional' production of rice beer and other kinds of female work defined by 'custom' (Shah 2011; Chandra 2013c). These brewing intra-community conflicts in relation to land and livelihoods are, of course, anything but uncommon in adivasi villages in contemporary India (see, e.g. Sivaramakrishnan 1998). These conflicts between the young and the old, women and men, peasant and landlord are, to say the least, symptomatic of modern capitalism in the countryside, and it would be fair to say that rural adivasi communities are certainly not exempt from them.

Migration to cities is another classic feature of modernization worldwide, and young adivasi men and women have not been shy to migrate to major Indian cities in search of work and leisure. There is an active debate over whether adivasi migration to cities can be regarded as simply an economic phenomenon by which adivasis are being incorporated into a 'precariat' at the bottom of the expanding capitalist economy in contemporary India (see, e.g. Breman 1996; Mosse et al. 2002; Breman et al. 2009) or if such migration is better viewed as a cultural phenomenon that permits adivasi youth to break free from the 
shackles of 'tradition' and 'custom' in order to experience the seductions and freedoms of urban life alongside its dangers (Shah 2006; Hansen and Verkaaik 2009). What this debate misses, however, is that adivasi migration to cities is rarely permanent, and exploitation and freedom are false alternatives from the migrants' perspectives. It may be better to view migration as a livelihood strategy embedded within a household's multiple livelihoods, especially for the land-poor, youth, and women, namely those who are at the receiving end of village hierarchies in rural adivasi communities. When, for example, adivasi women migrate to Delhi or Mumbai as maids, they find themselves as breadwinners for the first time with all the risks attendant upon this role as they seek to supplement their rural household incomes (Wadhawan 2013). To judge these women a priori as 'free' or 'exploited' within a wider capitalist economy is to necessarily ignore questions over multiple livelihood strategies pursued by adivasi households today, the stretching of kinship networks between the country and the city, and the prospects of social mobility in urban spaces. The challenges and opportunities of migrant work thus present themselves in their myriad hues to adivasi men and women in the Schedule V areas today. There is little reason to believe that they will wish away these challenges and opportunities, and confine themselves simply to playing 'traditional' roles in their rural homes.

In short, we are to take adivasi voices and aspirations seriously, our understanding of capitalist economic processes in the Schedule $\mathrm{V}$ areas ought to depart sharply from the received view on the matter. While human poverty and degradation remain vital issues in these areas, they cannot be said to exist exclusively there; nor can it be said reasonably that they are all that exist in these areas. The politics of land and forests, work and livelihoods, and migration to cities throw up opportunities and challenges for adivasis, especially those at the receiving end of rural hierarchies, and moreover, raise important questions about what it means to be 'adivasi' today. There are, after all, very real differences, material as well as symbolic, between adivasi elders and youth, dominant and subordinate lineages, and men and women in adivasi villages. The workings of capitalist economic processes sharpen these differences and call the notion of an adivasi 'community' into question. This state of affairs may trouble those who prefer to live with simplified visions of adivasi life, but it ought not to trouble those who recognize that it is part and parcel of modern life and there can be no return to some Edenic state of innocence in which all were equal and nature's abundance ensured plenty for all.

\section{Conclusion}

In this chapter, I have sketched a broad overview of adivasi engagements with the state, non-state actors, and the capitalist economy in contemporary India. For each of these engagements, I have sought to demystify the conventional wisdom on adivasis by invoking the best available scholarship on the subject to help us understand different aspects of contemporary adivasi life. Far from being hapless victims of modern political and economic processes, adivasis are subject-citizens of the Indian republic with their own distinctive set of anxieties and achievements as well as constraints and opportunities. Moreover, adivasis are political agents with their own wills and voices that often fly in the face of those who dare to speak for them. But when we ask ourselves what is most distinctive about adivasi politics in contemporary India, it may be most appropriate to say that it is the struggle to define who is an 'adivasi' and who is not in rapidly changing times. 


\section{References}

Arnold, D. (1982) 'Rebellious hillmen: The Gudem-Rampa risings, 1839-1924', in R. Guha (ed.), Subaltern Studies I: Writings on South Asian History and Society, New Delhi: Oxford University Press.

Banerjee, P. (2006) 'Culture/politics: The irresoluble double-bind of the Indian adivasi', Indian Historical Review, 33 (1): 99-126.

Baviskar, A. (1995) In the Belly of the River: Tribal Conflicts over Development in the Narmada Valley, New Delhi: Oxford University Press.

Baviskar, A. (2007) 'Indian indigeneities: Adivasi engagements with Hindu nationalism in India', in M. de la Cadena and O. Starn (eds), Indigenous Experience Today, New York: Berg Publishers.

Béteille, A. (1986) 'The concept of tribe with special reference to India', European Journal of Sociology, 27 (2): 296-318.

Bhadra, G. (1985) 'Four rebels of eighteen fifty-seven', in R. Guha (ed.), Subaltern Studies IV, New Delhi: Oxford University Press.

Breman, J. (1996). Footloose Labour: Working in India's Informal Economy, Cambridge: Cambridge University Press.

Breman, J., Guérin I., and Prakash A. (eds) (2009) India's Unfree Workforce: Of Bondage Old and New, New Delhi: Oxford University Press.

Carrin, M. and Tambs-Lyche, H. (2008) Encounter of Peripheries: Santals Missionaries and Their Changing Worlds 1867-1900, New Delhi: Manohar.

Chandra, U. (2013a) 'Liberalism and its other: The politics of primitivism in colonial and postcolonial Indian law', Law \& Society Review, 47 (1): 135-168.

Chandra, U. (2013b) Negotiating Leviathan: Statemaking and Resistance in the Margins of Modern India, $\mathrm{PhD}$ dissertation, Yale University.

Chandra, U. (2013c) 'Beyond subalternity: Land, community, and the state in contemporary Jharkhand', Contemporary South Asia, 21 (1): 52-61.

Chandra, U. (2013d) 'Going primitive: The ethics of indigenous rights activism in contemporary Jharkhand', South Asia Multidisciplinary Academic Journal 7, http://samaj.revues.org/3600 [accessed 17 April 2015].

Chandra, U. (2014a) 'The Maoist movement in contemporary India', Social Movement Studies 13 (3): 414-419.

Chandra, U. (2014b) 'Millenarian dreams, modern aspirations: Tribal community-making and contentious politics in colonial Chotanagpur', Max Planck Institute Working Paper 14-01, http://www. mmg.mpg.de/fileadmin/user_upload/documents/wp/WP_14-01_Chandra\%20Millenarian\%20 Dreams,\%20Modern\%20Aspirations.pdf [accessed 17 April 2015].

Chandra, U. (forthcoming) 'Intimate antagonisms: Adivasis and the state in contemporary India', in R. Nasir Uddin and E. Gerhartz (eds), Futures of Indigeneity: Spatiality, Identity Politics and Belonging, New York: Berghahn Books.

Clastres, P. (1987) Society against the State: Essays in Political Anthropology, New York: Zone Books.

Corbridge, S. (2000) 'Competing inequalities: The Scheduled Tribes and the reservations system in India's Jharkhand', The Journal of Asian Studies, 59 (1): 62-85.

Crooke, W. (1896) The Tribes and Castes of the North-western Provinces and Oudh, Calcutta: Office of the Superintendent of Government Printing.

Dalton, E.T. (1872) Descriptive Ethnology of Bengal, Calcutta: Office of the Superintendent of Government Printing.

Damodaran, V. (2002) 'History, landscape, and indigeneity in Chotanagpur, 1850-1980', South Asia, 25 (2): $77-110$.

Damodaran, V. (2012) 'Globalisation and sacred adivasi landscapes of eastern India', in P. Daly and T. Winter (eds), Routledge Handbook of Heritage in Asia, Abingdon and New York: Routledge.

Das, V. and Poole, D. (eds) (2004) Anthropology in the Margins of the State, Santa Fe, NM: School of American Research.

Dasgupta, S. (1985) 'Adivasi politics in Midnapur, c.1760-1924', in R. Guha (ed.), Subaltern Studies IV, New Delhi: Oxford University Press.

Dasgupta, S. (1999) 'Reordering a world: The Tana Bhagat movement, 1914-1919', Studies in History, 15 (1): $1-41$.

Desai, A.A. (2007) Witchcraft, Religious Transformation, and Hindu Nationalism in Rural Central India, PhD dissertation, The London School of Economics and Political Science.

Devy, G.N. (2002) 'Tribal voice and violence', Seminar, 513: 39-48. 
Elwin, V. (1943) Loss of Nerve: A Comparative Study of the Result of the Contact of Peoples in the Aboriginal Areas of Bastar State and the Central Provinces of India, Bombay: Wagle Press.

Fabian, J. (1983) Time and the Other: How Anthropology Makes its Object, New York: Columbia University Press.

Fox, R.G. (1969) “Professional primitives”: Hunters and gatherers of nuclear South Asia', Man in India, 49 (1): 139-160.

Fried, M.H. (1975) The Notion of Tribe, Menlo Park, CA: Cummings Publishing Company.

Froerer, P. (2007) Religious Division and Social Conflict: The Emergence of Hindu Nationalism in Rural India, New Delhi: Social Science Press.

Gadgil, M. and Guha, R. (1995) Ecology and Equity: The Use and Abuse of Nature in Contemporary India, New Delhi: Penguin Books.

Gell, A. (1997) 'Exalting the king and obstructing the state: A political interpretation of royal ritual in central India', Journal of the Royal Anthropological Institute, 3 (3): 433-450.

Ghosh, K. (2006) The Modernity of Primitive India: Adivasi Ethnicity in Jharkhand and the Formation of a National Modern, $\mathrm{PhD}$ dissertation, Princeton University.

Ghosh, K. (2010) 'Indigenous incitements', in D. Kapoor and E. Shizha (eds), Indigenous Knowledge and Learning in Asia and Africa: Essentialism, Continuity and Change, New York: Palgrave Macmillan.

Ghurye, G.S. (1943) The Aborigines - 'So-called' - and their Future, Poona: Gokhale Institute of Politics and Economics.

Ghurye, G.S. (1963) The Scheduled Tribes, Bombay: Popular Prakashan.

Guha, R. (1983) Elementary Aspects of Peasant Insurgency in Colonial India, New Delhi: Oxford University Press.

Guha, R. (2007) 'Adivasis, Naxalites and Indian democracy', Economic \& Political Weekly, 42 (32): 33053312 .

Guha, S. (1999) Environment and Ethnicity in India, 1200-1991, New York: Cambridge University Press.

Hansen, T.B. and Verkaaik, O. (2009) 'Introduction - urban charisma: On everyday mythologies of the city', Critique of Anthropology, 29 (1): 5-26.

Hardiman, D. (1987) The Coming of the Devi: Adivasi Assertion in Western India, New Delhi: Oxford University Press.

Higham, R. and Shah, A. (2013) 'Conservative force or contradictory resource? Education and affirmative action in Jharkhand, India', COMPARE, 43 (6): 718-739.

Hobart, A. and Kapferer, B. (eds) (2012) Contesting the State: The Dynamics of Resistance and Control, Wantage: Sean Kingston Publishing.

Hockings, P. (1980) Ancient Hindu Refugees: Badaga Social History, 1550-1975, The Hague and New York: Mouton.

Kanungo, P. (2008) 'Hindutva's fury against Christians in Orissa', Economic \& Political Weekly, 43 (37): 16-19.

Kanungo, P. and Joshi, S. (2010) 'Carving out a white marble deity from a rugged black stone?: Hindutva rehabilitates Ramayan's Shabari in a temple', International Journal of Hindu Studies,13 (3): 279-299.

Kapila, K. (2008) 'The measure of a tribe: The cultural politics of constitutional reclassification in North India', Journal of the Royal Anthropological Institute, 14 (1): 117-134.

Karlsson, B.G. (2003) 'Anthropology and the "indigenous slot": Claims to and debates about indigenous peoples' status in India', Critique of Anthropology, 23(4): 403-423.

Karlsson, B.G. and Subba, T.B. (eds) (2006) Indigeneity in India, London: Kegan Paul.

Kashwan, P. (2011) Democracy in the Woods: The Politics of Institutional Change in India's Forest Areas, PhD dissertation, Indiana University.

Kuper, A. (2003) 'The return of the native', Current Anthropology, 44 (3): 389-402.

Lévi-Strauss, C. (1969) The Raw and the Cooked, New York: Harper \& Row.

Lobo, L. (2002) 'Adivasis, Hindutva and post-Godhra riots in Gujarat', Economic \& Political Weekly, 37 (48): 4844-4849.

Mamdani, M. (1996) Citizen and Subject: Contemporary Africa and the Legacy of Late Colonialism, Princeton, NJ: Princeton University Press.

Mayaram, S. (2014) 'Pastoral predicaments: The Gujars in history', Contributions to Indian Sociology, 48 (2): 191-222.

Marx, K. (1967) Capital: A Critique of Political Economy, Volume I, New York: International Publishers.

Mayer, W.V. (ed.) (1981) Culture and Morality: Essays in Honour of Christoph von Fürer-Haimendorf, New Delhi: Oxford University Press. 
Minz, N. (1998) 'Christianity among the Mundas, Oraons, and Kharias of Chotanagpur', in F. Hrangkhuma (ed.), Christianity in India: Search for Liberation and Identity, New Delhi: CMS/ISPCK.

Mosse, D., Gupta, S., Mehta, M., Shah, V., Rees, J. and KRIBP Project Team (eds) (2002) 'Brokered livelihoods: Debt, labour migration and development in tribal western India', Journal of Development Studies, 38 (5): 59-88.

Munda, R.D. (2000) Adi-dharam, Religious Beliefs of the Adivasis of India: An Outline of Religious Reconstruction with Special Reference to the Jharkhand Region, Chaibasa: BIRSA.

Munda, R.D. and Bosu Mullick, S. (eds) (2003) The Jharkhand Movement: Indigenous Peoples' Struggle for Autonomy in India, Copenhagen: International Work Group for Indigenous Affairs.

Navlakha, G. (2010) 'Days and nights in the Maoist heartland', Economic \& Political Weekly, 45 (16): 38-47.

Nilsen, A.G. (2010) Dispossession and Resistance in India: The River and the Rage, Abingdon and New York: Routledge.

Padel, F. (2010) Sacrificing People: Invasions of a Tribal Landscape, New Delhi: Orient Blackswan.

Padel, F. and Das, S. (2010) Out of this Earth: East India Adivasis and the Aluminium Cartel, New Delhi: Orient Blackswan.

Padel, F., Dandekar, A., and Unni, J. (2013) Ecology, Economy: Quest for a Socially Informed Connection, New Delhi: Orient Blackswan.

Prasad, A. (2003) Against Ecological Romanticism: Verrier Elwin and the Making of an Anti-Modern Tribal Identity, New Delhi: Three Essays Collective.

Rangarajan, M. (1996) Fencing the Forest: Conservation and Ecological Change in India's Central Provinces, 1860-1914, New Delhi: Oxford University Press.

Rao, N. (2008) 'Good Women do not Inherit Land': Politics of Land and Gender in India, New Delhi: Social Science Press.

Risley, H.H. (1891) The Tribes and Castes of Bengal, 4 vols., Calcutta: Bengal Secretariat Press.

Rivers, W.H.R. (1900) The Todas, London and New York: Macmillan.

Roberts, N. (forthcoming) The Power of Conversion and the Foreignness of Belonging, Berkeley, CA: University of California Press.

Rolph-Trouillot, M. (2003) 'Anthropology and the savage slot: The poetics and politics of Otherness', in Global Transformations: Anthropology and the Modern World, New York: Palgrave Macmillan.

Roy, A. (2011) Walking with the Comrades, New Delhi: Penguin Books.

Rycroft, D. and Dasgupta, S. (eds) (2011) The Politics of Belonging in India: Becoming Adivasi, Abingdon and New York: Routledge.

Sahay, K.N. (1976) Under the Shadow of the Cross: A Study of the Nature and Processes of Christianization among the Uraon of Central India, Calcutta: Institute of Social Research and Applied Anthropology.

Sarkar, T. (1985) 'Jitu Santal's movement in Malda, 1924-1932: A study in tribal protest', in R. Guha (ed.), Subaltern Studies IV, New Delhi: Oxford University Press.

Satnam (2010) Jangalnama: Travels in a Maoist Guerrilla Zone, translated by Vishav Bharti, New Delhi: Penguin Books.

Schnepel, B. (2002) The Jungle Kings: Ethnohistorical Aspects of Politics and Ritual in Orissa, New Delhi: Manohar.

Scott, J.C. (2009) The Art of Not Being Governed: An Anarchist History of Upland Southeast Asia, New Haven, CT: Yale University Press.

Shah, A. (2006) 'The labour of love: Seasonal migration from Jharkhand to the brick kilns of other states in India', Contributions to Indian Sociology, 40 (1): 91-118.

Shah, A. (2007) "Keeping the state away": Democracy, politics, and the state in India's Jharkhand', Journal of the Royal Anthropological Institute, 13: 129-145.

Shah, A. (2010) In the Shadows of the State: Indigenous Politics, Environmentalism, and Insurgency in Jharkhand, India, Durham, NC: Duke University Press.

Shah, A. (2011) 'Alcoholics Anonymous: The Maoist movement in Jharkhand, India', Modern Asian Studies, 45 (5): 1095-1117.

Shah, A. (2013a) 'The intimacy of insurgency: Beyond coercion, greed, or grievance in Maoist India', Economy and Society 42 (3): 480-506.

Shah, A. (2013b) 'The tensions over liberal citizenship in a Marxist revolutionary situation: The Maoists in India', Critique of Anthropology, 33 (1) 91-109.

Shah, A. and Harriss-White, B. (2011) 'Resurrecting scholarship on agrarian transformations', Economic E Political Weekly, 46 (39): 13-18. 
Shutzer, M.B. (2013) 'The practice of custom in India's recognition of Forest Right's Act: Case studies from Kalahandi, Odisha', South Asia Multidisciplinary Academic Journal 7, http://samaj.revues.org/3623 [accessed 17 April 2015].

Simeon, D. (2010) 'Permanent Spring', Seminar 607, URL: http://www.india-seminar. com/2010/607/607_dilip_simeon.htm [accessed 17 April 2015].

Singh, C. (1988) 'Conformity and conflict: Tribes and the "agrarian system" of Mughal India', Indian Economic and Social History Review, 23 (3): 319-340.

Sinha, S. (1982) Tribes and Indian Civilization: Structures and Transformation, Varanasi: N.K. Bose Memorial Foundation.

Sivaramakrishnan, K. (1996) Forests, Politics and Governance in Bengal, 1794-1994, PhD dissertation, Yale University.

Sivaramakrishnan, K. (1998) 'Work, identity, and statemaking in the forests of southern West Bengal', PoLAR, 21 (2): 26-40.

Sivaramakrishnan, K. (1999) Modern Forests: Statemaking and Environmental Change in Colonial Eastern India, Stanford, CA: Stanford University Press.

Skaria, A. (1999) Hybrid Histories: Forests, Frontiers, and Wildness in Western India, New Delhi: Oxford University Press.

Spivak, G.C. (1988) 'Can the subaltern speak?', in C. Nelson and L. Grossberg (eds), Marxism and the Interpretation of Culture, Urbana, IL: University of Illinois Press.

Sundar, N. (1997) Subalterns and Sovereigns: An Anthropological History of Bastar, 1854-1996, New Delhi: Oxford University Press.

Sundar, N. (2000) 'Unpacking the "Joint" in Joint Forest Management', Development and Change, 31: 255-279.

Sundar, N. (2010) 'Vigilantism, culpability and moral dilemmas', Critique of Anthropology, 30 (1): 113 121.

Sundar, N. (2014) 'Mimetic sovereignties, precarious citizenship: State effects in a looking glass world', The Journal of Peasant Studies, 41 (4): 469-490.

Sundar, N., Jeffrey, R., and Thin, N. (eds) (2001) Branching Out: Joint Forest Management in India, New Delhi: Oxford University Press.

Suykens, B. (2009) 'The tribal-forest nexus in law and society in India: Conflicting narratives', Critical Asian Studies, 41 (3): 381-402.

Thachil, T. (2009) The Saffron Wave Meets the Silent Revolution: Why the Poor Vote for Hindu Nationalism in India, $\mathrm{PhD}$ dissertation, Cornell University.

Thakur, V. (2014) Unsettling Modernity: Resistance and Forced Resettlement Due to Dam in Western India, PhD dissertation, Yale University.

Thakur, V. (forthcoming) “Logjam": Peasantisation-caused deforestation in Narmada valley', in M. Rangarajan and K.Sivaramakrishnan (eds), Shifting Ground: People, Animals and Mobility in India's Environmental History, New Delhi: Oxford University Press.

Upadhya, C. (2010) 'Law, custom, and adivasi identity: Politics of land rights in Chotanagpur', in N. Sundar (ed.), Legal Grounds: Natural Resources, Identity, and the Law of Jhakhand, New Delhi: Oxford University Press.

Vaidya, A.P. (2014) The Origin of the Forest, Private Property, and the State: The Political Life of India's Forest Rights Act, $\mathrm{PhD}$ dissertation, Harvard University.

von Fürer-Haimendorf, C. (1981) Tribes of India: The Struggle for Survival, Berkeley, CA: University of California Press.

Wadhawan, N. (2013) 'Living in Domesti-City: Women and migration for domestic work from Jharkhand', Economic \& Political Weekly, 48 (43): 47-54.

Whitehead, J. (2010) Development and Dispossession in the Narmada Valley, New York and New Delhi: Pearson International.

Xaxa, V. (2000) 'Tribes, conversion and the Sangh Parivar', Jnanadeepa, 3 (1): 23-35. 

$\because$ Taylor \& Francis http://taylorandfrancis.com 


\section{PART IV}

\section{Religion and diversity}



$\because$ Taylor \& Francis http://taylorandfrancis.com 


\title{
21 \\ MYTH AS HISTORY AND HISTORY AS MYTH \\ The instructive case of India
}

\author{
Gerald James Larson
}

\section{Introduction}

Few modern nation states are as diagnostically interesting as India in exhibiting the wellknown paradoxical comment of William Faulkner: 'The past is never dead. It's not even past' (Faulkner 1951: 92). As I have argued elsewhere (Larson 1995: 52-141), layers of cultural development in the South Asian region going all the way back to the second millennium BCE have left significant cultural residues and valuations even in twenty-first century India, for example, from the Indus Valley Civilization in the third and second millennia BCE $(c$. 3000-1500 BCE), the Indo-Brahmanical (Vedic and Upanișadic traditions) (c. 1500-600 BCE), the Indo-Śramanical (Buddhist, Jain and other non-Vedic traditions) $(600 \mathrm{BCE}-300 \mathrm{CE})$, the classical Indic (Hindu epic and Purānic traditions) (c. 300-1200) the Indo-Islamic (c. 12001757), the Indo-British (c. 1757-1947), and, of course, the new Indian nation state itself since partition and independence (1947-present) (Larson 2012: 121-135) .

I am not suggesting that these cultural layers and options are significant in some essentialist or reified Procrustean sense, but, rather, I see them in the sense of ever-present forces of contentious interaction, much like geological tectonic plates constantly moving and pushing one another over long periods of time, to use the well-known metaphor of the Allchins (Allchin, B. and R. 1982: 13). Or, if one prefers a biological metaphor, these cultural layers are much like the unfolding secondary trunks of a single banyan tree that can spread over an acre with odd and conflicting twists that continually reshape the emerging tree, which was W. Norman Brown's favourite metaphor for describing modern India (Brown 1961: 433-434).

Social scientists often miss the 'la longue durée' of Indian cultural history because of their orientation to modern social science methods (Braudel 1972). There are, of course, important exceptions in this regard, for example, McKim Marriott, T. N. Madan, Gananath Obeyesekere, who truly grasp the profound meaning of ancient Indian social reality. Humanists, of course, with their focus on classical texts and philology often have the opposite problem. They sometimes become tone deaf to the manner in which the classical insights of Indic ritual, philosophy, religion, poetry, sculpture, and painting from pre-modern periods in Sanskritic and Arabic South Asian traditions are in significant ways present as living options in terms of behaviour, aesthetic taste, beliefs, and commitments in twenty-first-century cultural life 
in modern India. Here again, of course, there are important exceptions, for example, W. Norman Brown, Franklin Edgerton, Wilfred Cantwell Smith, et al., who fully grasp the value of ancient humanistic insights that continue to be relevant in the present. In other words, the past is alive and well in modern India, pace those who gloss over India's ancient past because the modern notion of 'social science' seems to be absent or those so caught up in obscure textual and philological details that they lose touch with the contemporary relevance of what they study.

What is intriguing, indeed, astonishing, about India's assimilation and retention over time of vast cultural differences is that many of our usual notions for interpreting social reality begin to appear strangely inappropriate, challenging us intellectually to re-think the notions themselves. In this regard, two commonly understood notions especially call out for reinterpretation in any attempt to understand Indian civilization whether in terms of its traditional heritage or its current contemporary social reality, namely, our notions of 'myth' and 'history'.

I wish to argue that what is crucial to understand in order to appreciate Indic notions of 'history' and 'myth' is that Indic traditions themselves appear to exhibit as 'myth' what modern scholars attempt to construe as 'history'. This in turn makes possible an interesting mirror reversal, namely, that what modern scholars appear to construe as 'history' is what Indic traditions themselves would for the most part consider to be 'myth'. This somewhat odd juxtaposition is what I am trying to suggest by my title to this chapter, namely, 'Myth as history and history as myth: the instructive case of India'.

\section{The notion of 'myth'}

Before proceeding further, however, let me make clear what my own understanding of 'myth' is, followed by my understanding of the notion of 'history'. The notions of 'myth' and 'history' have been discussed in all sorts of ways, and there is a vast bibliography of such discussions. I only wish to show here, however, how I am using the notions, so that I can present my basic argument in what I hope is a clear and consistent manner in the sequel. For my purposes,

a myth or mythology means a narrative or a collection of narratives about the gods or supernatural beings used by a people - clan, tribe, or ethnic community - for purposes of interpreting the meaning of their experience and their world, both individually and corporately. Such narratives may describe the creation of the world, ... the destruction of demonic forces, the origin of death, ... and so on. What is fundamental in the definition of 'myth', however, ... is that myth articulates the basic self-understanding of a people and thereby operates as a kind of charter for the total cultural life.

Larson 1974: 1

Such a definition is clearly Dumézilian (Dumézil 1958), but it is also compatible with Malinowski's functionalist observation that myth,

enhances and codifies belief; it safeguards and enforces morality; it vouches for the efficiency of ritual and contains practical rules for ... guidance ... Myth is thus a vital ingredient of human civilization; it is not an idle tale, but a hard-worked active force. 
My understanding of the notion of 'myth' also includes the insight of my former colleague in history of religions, Raimundo Panikkar.

A living myth does not allow for interpretation because it needs no intermediary. ... Myth is precisely the horizon over against which any hermeneutic is possible. Myth is that which we take for granted, that which we do not question; and it is unquestioned because, de facto, it is not seen as questionable.

Panikkar 1979: 4-5

The myth or mythical narrative exhibits the unquestioned presuppositions with which and through which a community understands itself. Sometimes myth is understood literally or dogmatically, but sometimes, perhaps more often, many ancient peoples fully appreciate myth as a symbolic portrayal or an imaginative projection of the way the world is for them.

\section{The notion of 'history'}

As for the notion of 'history' or 'historical traditions', Romila Thapar's characterization is broadly inclusive and especially useful with respect to India.

Historical traditions emanate from a sense of the past and include three aspects: first, a consciousness of past events relevant to or thought of as significant by a particular society, the reasons for the choice of such events being implicit; second, the placing of these events in an approximately chronological framework, which would tend to reflect elements of the idea of causality; and third, the recording of these events in a form which meets the requirements of that society.

If the above definition is acceptable, then it can in fact be said that every society has a concept of the past and that no society is a-historical.

Thapar 2013: 4

Furthermore, a distinction is usually made between 'history' itself as the events and actions that make up the past in contrast to what is usually called 'historiography', the study of the accounts given of that past and the modes of investigation for constructing interpretations of those events and actions (Little 2012: 1-22).

In this regard, there have been at least two prominent lines of argument in discussions of historiography about the nature and validity of historical knowledge (Weingartner 1967: 7-12). The first line is sometimes called an 'explanatory dualist' or 'hermeneutic' line of argument, which distinguishes between the Naturwissenschaften (the hard sciences) and the Geisteswissenschaften (the 'spiritual' or humanistic sciences), arguing that historical understanding is uniquely different from scientific understanding in that 'historical awareness' focuses on human 'understanding' (verstehen) and the actions of persons in specific contexts in the past - a line of argument that can be traced primarily in European continental philosophy from Hegel through Rickert, Dilthey, Troeltsch, Mannheim, Vico, Croce and R. G. Collingwood (Little 2012: 4-11). A second prominent line of argument sometimes called a 'deductive-nomological' or 'covering-law model' argues that the NaturwissenschaftenGeisteswissenschaften dichotomy is confusing and unnecessary, arguing that the historian is as much subject to the universal principles of verifiability and/or falsification as the natural scientist. This line of thinking about historical knowledge largely grows out of British and American analytic philosophy. For the most part, it is fair to say that the former or 'explanatory 
dualist' line of argument has been followed by most historians in recent theoretical work. There are, of course, numerous nuances and variants to the various theoretical discussions, and there are many historians, probably most, who quietly pursue their historical research without unduly taxing themselves over the theoretical issues.

In any case, it is no exaggeration to say that an historical perspective is a completely taken-for-granted presupposition of what it means to be human, or, as Ortega y Gasset has put it: 'man ... has no nature; what he has is - history' (Kaufmann 1975: 157), or as R. G. Collingwood has put it, in a somewhat more imperial manner: 'the chief business of twentieth-century philosophy is to reckon with twentieth-century history' (Collingwood 1944: 56). We all, I think, more or less, accept this view of the importance of history - indeed, find it hardly controversial. The human condition is an historical condition.

In contemporary social life we have often become sceptical about traditional metaphysics and normative philosophy generally. We have realized that a two-valued logic is only one kind of logic. We have frequently abandoned normative ethics and engage, rather, in metaethics. We have often ceased taking religions seriously as cogent belief systems about which we care very much. We have even questioned the procedures and validity of our scientific theorizing together with its operational applications. But no one of us seriously doubts that such subject-areas as metaphysics, logic, ethics, religion, science and cultures in general have a 'history'. To the contrary, all of these subject-areas for many of us are only meaningful or interesting precisely because they have a 'history'.

Our unquestioning assumption that there is such a thing as 'history' provides a basic coherence for most of what we do and what the world is 'really' like for most of us. Whether what we do and think has any ultimate significance may be an open question, but that what we do and think has a 'history' is seldom seriously doubted.

\section{'Myth' as 'history' and 'history' as 'myth'}

Here I return to my earlier reference to Raimundo Panikkar and his comment: 'Myth is that which we take for granted, that which we do not question; and it is unquestioned because, de facto, it is not seen as questionable' (Panikkar 1979: 4-5). Panikkar has focused on this taken-for-granted sense of history to make a somewhat startling claim, namely, that our contemporary notion of 'history' itself is in important respects our modern 'myth'. That is to say, what is the most taken-for-granted presupposition in a community, what is completely unquestioned and assumed by everyone is the 'myth' of that community, and a prime candidate for the primordial 'myth' of our contemporary intellectual life is, according to Panikkar, the 'myth' of 'history'. This does not mean that the symbolic and imaginative narratives of modern 'history' are, thus, not true in some sense. Quite the contrary, they are completely true in the sense that the 'myth' of 'history' is the unquestioned presupposition in all of our attempts to 'understand' 'history', whether we use an explanatory dualist version of the 'myth' or a 'covering-law' model version of the 'myth', and perhaps most of all, if we make use of a theological or biblical version of the 'myth' of 'history'.

Perhaps needless to say, Panikkar's assertion that 'history' is little more than our modern 'myth' is something of an equivocation, or, at best, an exaggeration, but Panikkar's suggestion makes a telling point in our attempts to understand contemporary India and the manner in which pre-modern layers of cultural development continue to be present. The telling point is that our assumption about the reality of 'history' may itself in some sense be best understood in terms of 'myth', and, if that is the case, we might well learn something important about our own notion of 'history' from examining some foundational 'myths' from pre-modern 
India. Put another way, it perhaps can be argued that the boundary line between 'myth' and 'history' in our modern sensibility is simply not present in an Indic context, that is, in Hindu, Buddhist and Jain contexts. Along the same lines, the boundary between what is human and what is divine in an Indic environment is much more porous than our usual contemporary understanding of the human and divine, again, at least in Hindu, Buddhist and Jain traditions.

\section{Historical, pre-historical, un-historical}

In this regard, the conventional distinction all too often drawn between cultures that are 'historical' vis-à-vis those that are supposedly 'non-historical' or 'pre-historical' is clearly wrongly formulated. The distinction resembles the distinction criticized by Plato in the Statesman between 'Greeks' and 'barbarians' (Hamilton and Cairns 1961: 1026). What appears to be a dichotomy of two well-formed classes is in reality one well-formed class, that is, the Greeks, and some sort of formless entity, that is, 'barbarians' or everybody else! In a similar fashion the distinction between 'historical' cultures and 'non-historical' cultures is wrongly framed. The 'historical' is any culture that accepts a certain conceptualization of 'history', and 'non-historical' or 'pre-historical' is simply a formless group of everybody else. In fact, of course, every culture has some sense of the meaning of the events and actions that together make up the past, and the task is one of formulating what the well-formed classes might be. When we recognize that our modern notions of 'history' may in some important sense be our modern 'myth' of 'history', this opens up a vast range of 'historical' ('mythical') classifications that need to be formulated.

\section{Cyclical and linear}

Yet another wrongly formulated dichotomy that has been conventionally employed is the distinction between 'cyclical' and 'linear' views of 'history', with linear being progressive development from the past into the future that is characteristic of 'historical' cultures in contrast to 'cyclical' repetitive or recursive views of time typical of 'un-historical' or 'prehistorical' static societies. The distinction is faulty mainly because it cuts across almost any conceptualization of time, whether ancient or modern, eastern or western. It is a distinction based on a metaphor and can be used in all sorts of ambiguous ways. It can be argued, for example, that Hegel's notion of 'history' is clearly cyclical as well as linear. Likewise, one can argue that the Hindu and Buddhist notions of time and history are cyclical but also linear in important respects. Romila Thapar comments as follows about 'cyclical' and 'linear' in Indian conceptualizations.

Some scholars maintain that cyclic notions of time are characteristic of India and the recurring cycle is a refusal of history. ... But a different reading can be given of cyclic time. Cyclic or cosmological time becomes the circumference of social activity, seen sequentially as units within which a society is created, lives out its history and is extinguished. Change therefore is evident. ... Cyclic cosmology therefore marks a growing concern with the relationship between past and present. ...

There is also in the epic the initial notion of linear time. This is evident in the recording of descent through genealogies. These are not elaborate, but they record a sense of the chronology of person and event. 
This is not to suggest that the metaphors 'cyclical' and 'linear' have no descriptive or heuristic utility. It is only to suggest that they are not necessarily helpful metaphors in determining well-formed classes of what can and cannot be considered 'historical'.

\section{Four recent books on India's 'history'}

Four recent books are especially interesting by way of illustrating the theoretical problem I have been attempting to identify in this chapter, namely, the manner in which we conceptualize and apply our modern notions of 'history' (and 'myth') in ways that may well lead us to overlook certain foundational notions of 'history' that go all the way back to Vedic and possibly pre-Vedic times and that continue to be the 'historical' worldview of many people in contemporary India. The four books I have in mind are Wendy Doniger's The Hindus: An Alternative History (Doniger 2009); Sheldon Pollock's The Language of the Gods in the World of Men: Sanskrit, Culture, and Power in Premodern India (Pollock 2006); Romila Thapar's The Past Before Us: Historical Traditions of Early North India (Thapar 2013); and Ramachandra Guha's India After Gandhi: The History of the World's Largest Democracy (Guha 2007). All four books are important scholarly achievements, and let me make it clear at the outset that what I shall be suggesting in the sequel in no way is meant to denigrate what these four books accomplish, that is to say, thoughtful, critical, and comprehensive treatments of certain aspects of the modern 'historiography' of India.

\section{Wendy Doniger}

Wendy Doniger's book, The Hindus: An Alternative History, is an attempt to get beyond what she calls the 'Brahmin imaginary', that is, the conventional elitist brahmanical interpretation of Hindu culture.

Different Hindus not only lived different Hinduisms but privileged different aspects of Hinduism, different qualities among the (non)-defining clusters ... In addition to including women's as well as men's voices and Other Ranks as well as Brahmins, Hinduism is composed of local as well as pan-Indian traditions, oral as well as written traditions, vernacular as well as Sanskrit traditions, and non-textual as well as textual sources.

Doniger 2009: 32

Doniger's narrative overall focuses on the rich mythologies, legends, and tales, so typical of Hindu religious traditions, and she also offers brief comparative discussions of how Hindus fared vis-à-vis the encounter with Islamic traditions from the Delhi Sultanate (1210-1526) through the Mughal period to the first contacts with the British in the mideighteenth century. Doniger throughout is not especially interested in theorizing and takes a tongue-in-cheek perspective on much of what she writes. She concludes her 'alternative history' with the following wry comment:

India is a country where not only the future but even the past is unpredictable. If you have read this far, dear reader, and have plowed through these many pages, and have paid any attention at all, you will have learned at least one important thing. You could easily use history to argue for almost any position in contemporary India. 


\section{Sheldon Pollock}

Sheldon Pollock's The Language of the Gods in the World of Men, in contrast to Doniger's mythological story-telling, focuses less on religion and more on the development of literature, looking first at Vedic Sanskrit as a largely unchanging ritual or liturgical medium (through much of the first millennium BCE, a language medium that begins to change or be modified in the last century or two BCE and the first centuries CE into a general literate (written) and literary medium with the emergence of kāvya (classical Sanskrit poetry) and praśasti (inscriptional panegyric). It is in the first centuries CE (and to some degree in the last few centuries BCE) that the great epics (Rāmāyaṇa, Mahäbhārata) take definitive shape, lawbooks emerge (Dharmaśāstras), 'historical' texts (Itihāsa-purāna) begin to be composed, and learned Sāstra literature generally is created in all sorts of intellectual subject-areas. This is also the period, of course, in which the literate medium of Sanskrit becomes increasingly prevalent in Buddhist (both Theravāda and Mahāyāna) and Jaina texts. Moreover, the emergence of Sanskrit as a cosmopolitan medium coalesces with the discourses of political power in the South Asian region, and what Pollock calls a 'Sanskrit cosmopolis' (analogous in some respects to the Latinate world of pre-modern Europe) that spreads widely throughout South and Southeast Asia. According to Pollock, this Sanskrit cosmopolis begins to fade in significance towards the end of the first millennium $\mathrm{CE}$, transmuting into numerous local vernacular languages (again an analogy with the development of European vernacular languages in the Latinate world up to the end of the pre-modern period). The dichotomy of 'cosmopolitanism'/'verna-cularism' or 'cosmopolitanization'/'vernacularlization' is fundamental, according to Pollock, in order to understand pre-modern South Asia.

\section{Romila Thapar}

Romila Thapar directly addresses the issue of historiography in India and the claims from the early colonial period along the lines of A. A. Macdonell's comment, 'early India wrote no history because it never made any' (Thapar 2013:19), or Rapson's comment, from his, The Cambridge History of India: 'In all the large and varied literatures of the Brahmans, Jains and Buddhists there is not to be found a single work which can be compared to the Histories in which Herodotus recounts the struggle between the Greeks and the Persians' (Thapar 2013: 19). Thapar also, however, quotes a further comment of Rapson: 'But this is not because of the people of India had no history ... We know from other sources that the ages were filled with stirring events; but these events found no systematic record' (Thapar 2013: 19). Thapar then proceeds to show how historical awareness slowly emerges, first, through what she calls 'embedded history', that is, bits and pieces of historical events and actions that can be found in primarily ritual texts (Thapar 2013: 49-143). Second, she looks at what she calls the emergence of 'externalized' history when attempts to describe past events are able to stand alone apart from ritual or religious intentions in such texts as the epics (Rāmāyana and Mahābhārata), lawbooks, early philosophical writings, kāvya (classical Sanskrit poetry), praśasti (inscriptions) and so forth, that become prevalent in the post-Gupta period (Thapar 2013: 144-262). She also distinguishes between three distinct kinds of historical traditions. There are the Itihāsa-purānic texts ['itihāsa' meaning, 'thus indeed it was', and 'purāna' meaning, 'old stories or tales/myths'] that are largely sectarian but also trace the various lineages of rulers and dynasties, composed by Brahman authors (Thapar 2013: 265-318). She contrasts this, second, to the extensive story literature and lineage literature composed by bardic authors (sometimes over-written by later Brahman writers) that provide slightly more realistic accounts of families and dynasties (vamisāualīs, vamisánucaritas, and so forth) (Thapar 2013: 
319-377). Third, Thapar focuses on the extensive Śramanical literature (Buddhist and Jain) that offers alternative accounts of the past in various kinds of historical writing (biographies, chronicles, temple histories, and so forth) (Thapar 2013: 442-596). Thapar concludes her excellent survey with the following diagnostically interesting comment.

But somewhere a beginning has to be made towards thinking about the idea of history in early India, and that is what this book has attempted. I have tried to argue that there is what might be called a historiographical trajectory, although not altogether smooth, in the texts to which I have referred. This points to a concern with a historical past, even if this past is constructed in ways different from what we conventionally regard as historical. I have argued that a sense of history and historical consciousness existed, that there were historical traditions emerging from diverse historiographies, and that these occasionally took the form of historical writing.

Thapar 2013: 701

Thapar's comment is diagnostically interesting because it expresses a remarkable scepticism. There is, to be sure, a 'historiographical trajectory', but it is not 'altogether smooth', and, more than that, there is an historical past, 'even if this past is constructed in ways different from what we conventionally regard as historical'.

\section{Ramachandra Guha}

Ramachandra Guha's India After Gandhi: The History of the World's Largest Democracy undertakes a task that few have attempted, namely, to write a history of democracy in India since partition and independence. He sets forth his basic purpose in the Prologue to his book.

In the academy, the discipline of history deals with the past, while the disciplines of political science and sociology deal with the present. This is a conventional and in many ways logical division. The difficulty is that in the Indian academy the past is defined as a single, immovable date: 15 August 1947.

In the decades since 1947, the present has moved on ... The past, however, has stayed fixed. By training and temperament, historians have restricted themselves to the period before independence.

Guha 2007:12

He concludes his comments in the Prologue with the following.

This book is ... simply an attempt to tell the modern history of one-sixth of humankind ... However, the manner of the telling has been driven by two fundamental ambitions: to pay proper respect to the social and political diversity of India, and to unravel the puzzle that has for so long confronted scholar and citizen, foreigner as well as native - why is there an India at all?

Guha 2007: 15

Through some thirty detailed chapters, Guha then traces the history of 'the world's largest democracy' through the Nehru era, the Indira Gandhi and Rajiv Gandhi periods, the problems over Kashmir, Punjab, and the Sikh community, Islamic terrorism, the 'pogroms' 
that occurred against the Sikhs after Indira Gandhi's assassination in Delhi in 1984, and the burning of the train carrying Hindu pilgrims and the resulting violence, primarily among Muslims, in Gujarat in 2002. In an Epilogue to his study, he offers the following two comments:

As a modern nation, India is simply sui generis. It stands on its own, different and distinct from alternative political models such as Anglo-Saxon liberalism, French Republicanism, atheistic communism, and Islamic theocracy...

So long as the constitution is not amended beyond recognition, so long as elections are held regularly and fairly and the ethos of secularism broadly prevails, so long as citizens can speak and write in the language of their choosing, so long as there is an integrated market and a moderately efficient civil service and army, and - lest I forget - so long as Hindi films are watched and their songs sung, India will survive.

Guha 2007: 758-759

\section{Exogenous versus endogenous historiography}

What becomes clear, in my view, in a careful reading of these recent 'histories' or 'historiographies' of India is that they are all what I am inclined to call 'exogenous' historical studies. They are all addressing the Indic material from the 'outside' in terms of the interpretations of the meaning of the past. The methodologies employed are almost entirely derived from European models of historiography. One is reminded of Sir Isaiah Berlin's comment.

It seems to me that the thought of the nineteenth and early twentieth century was astonishingly Europocentric. When even the most imaginative and the most radical political thinkers of those times speak of the inhabitants of Africa or Asia, there is, as a rule, something curiously remote and abstract about their ideas ...

... the peoples of Africa and Asia are discussed ... seldom, if ever, in their own right, as peoples with histories and cultures of their own; with a past and present and future which must be understood in terms of their own actual character and circumstances.

Berlin 1979: 354

Much has changed, of course, in more recent historical research, but much continues along the same lines as Berlin observed to be the case in earlier years. I am inclined to think in this regard that Wendy Doniger's 'alternative history', Sheldon Pollock's 'Sanskrit cosmopolis', Romila Thapar's 'embedded history', and Ramachandra Guha's 'history of the world's largest democracy' are all twenty-first-century retrofits or reconstructions of what India's 'history' ought to be in order to bring it up to compliance with 'code', to use a metaphor from the building trades. This is especially apparent in Romila Thapar's work and the work of Sheldon Pollock. In the case of Thapar, she concludes her massive study of Indian historiography with the phrase, 'even if this past is constructed in ways different from what we conventionally regard as historical'. In the case of Sheldon Pollock, it is diagnostically interesting that he finds evidence for his reconstruction of the history of Sanskrit literature in the Latinate world of pre-modern Europe, without hardly a mention of what might have been obviously argued as a more apt comparison, nearer at hand, namely, the 'Arabic cosmopolis' 
throughout South and Southeast Asia, a 'cosmopolis' that operates in precisely the same time-frame as his so-called 'Sanskrit cosmopolis'. One is tempted to argue for what might be called a 'Neo-Orientalist' bias in all four of these recent historical discussions, 'Neo' not in the sense of colonialist control but, rather, 'Neo' in the sense of historiographical control. Ramachandra Guha recognizes this to some degree when he asserts at the end of his study: 'As a modern nation, India is simply sui generis' (Guha 2007: 758). In my view, he could well have extended his assertion to the entire panorama of the subcontinent's development.

\section{Towards an endogenous historiography}

I argued in an article many years ago the conventional view that modern notions of history are absent in South Asian thought. I commented: 'to put it directly, historical interpretation is ours, not theirs! ... In a South Asian environment ... historical interpretation ... is a zerocategory' (Larson 1993: 381).

Now, however, I recognize that I was mistaken. It is not the case that historical interpretation is a 'zero category'. It is, rather, the case that there is a different view of historiography appropriate to the Indic intellectual environment, based largely on the philosophical insights of Sāṃkhya (Larson and Bhattacharya 1987) and Pātañjala Yoga (Larson and Bhattacharya 2008) philosophy together with the Itihāsa and Purānic textual traditions, a worldview that mixes 'history' with 'myth' with alacrity but nevertheless represents a coherent 'historiography', albeit a puzzling and complex one.

I have in mind the common worldview of karma (karman) and rebirth (punarjanman) that is presupposed among the various dharma-traditions (Hindu, Buddhist and Jaina) in South Asia, or what Gananath Obeyesekere has characterized as the 'karmic eschatologies ... found only in Indic religions' (Obeyesekere 2002: 17, Lipner 2010a, 2010b, Malinar 2010). In his important study entitled, Imagining Karma, Obeyesekere documents a fundamental distinction between 'rebirth eschatologies' and 'karmic eschatologies'. The former, rebirth eschatologies, are found throughout the world, often in small-scale tribal contexts, or in more complex social contexts (for example, the Pythagoreans in Hellenic and Hellenistic traditions, and so forth), linked with ancestor-rituals, and with or without 'ethicization'. Karmic eschatologies, however, are unique to Indic traditions and have highly developed accounts of 'ethicization' in terms of good and evil deeds, moral behaviour, moral retribution, and so forth (Obeyesekere 2002: 17-18).

There are many texts that could be cited by way of describing the 'karmic eschatologies' of the Indic worldview, but, in my view, there are two that are not only typical but also analytically interesting in terms of exhibiting the common framework of world periods (yugas) and world geography (loka, dvīpa), namely, (1) the Viṣnupurāna, Book I, Chapter III and Book II, Chapter II; and (2) 'knowledge about the world' (bhuvana-jñāna) as set forth in the commentary attributed to a certain Vyāsa on Yogasūtra III.26 (Wilson 1972: 19-24 and 134-141, Larson-Bhattacharya 2008: 91-99). The account in the Viṣnupurạna is a well-known mythological characterization, whereas the account in the Yogasütra is a more systematic theoretical interpretation (Larson 2014: 113-123). Both accounts are typical of the sorts of discussions one finds in most of the other Purạnas, the great epics, the Hindu law books, and in most Buddhist and Jaina accounts as well (Jacobi 1961a: Volume 1: 200-202 and Jacobi 1961b: Volume 4: 129-138 and La Vallée Poussin 1961a: Volume 1: 187-190 and La Vallée Poussin 1961b: Volume 4: 129-138).

Descriptions of cosmological time in terms of yugas and the details of the description of cosmological geography in terms of the 'world egg' (brahmānda) need not detain us. 
Suffice it to say, that the former has to do with the well-known theory of declining yugas or 'world periods' from the perfect Krta (abiding for 1,728,000 human years), through the Treta (1,296,000 years), to the Dvappara (864,000 years) and, finally, to the Kali (432,000 years), together with the various correlations of these numbers in a declining progression through seventy-two Manvantaras that is without beginning (anädi). The latter, namely, the "world egg' has to do with the threefold division of the cosmos in terms of the seven heavenly sattva-worlds (lokas) of extraordinary sentient beings such as gods and yogins, the terrestrial rajas-worlds of our earth with its seven continents, the seven 'nether' (pätälas) tamas-worlds together with the seven 'hells' (narakas) or tamas-worlds ending with the lowest 'hell' (Avīci).

Throughout these worlds are all sorts of sentient beings working out their karmic trajectories through on-going cycles of manifestation or coming forth and withdrawal (pralaya and mahapralaya). This is the case with Brahmā and the world egg or universe as well. The so-called 'creative-force', Brahmā, sometimes called Hiranyagarbha, the 'golden germ or womb' and the world egg itself both under-go periodic manifestation and withdrawal as well. The worlds, whether in manifestation or in withdrawal, are subject to a beginningless process (parināma) of time or becoming (bhava). How the cycles unfold is determined by the trajectories of the various species of beings that have been self-constructed by the afflictions (kleśas), actions (karman), ripenings (vipāka), and resulting residues (vāsanās, āsayas, samnskāras) of their own behaviour or functioning.

Leaving aside the mythological descriptive framework, what is of greater interest are three fundamental principles that appear to provide a basis for this common Indic worldview that is taking shape in the first centuries of the Common Era in many areas of South Asian cultural life, namely, what I would identify as a principle of synchronic phylogeny (varnāśrama-dharma, or the rough equivalents in Buddhist and Jaina texts), a principle of diachronic ontogeny (punarjanman), and a principle of precessional transformation (samsāara). By the term 'phylogeny' I mean the Indic account of the development of the material world and its sentient species, based on the old Sāmpkhya philosophy. By the term 'ontogeny' I mean the Indic account of the development of the individual sentient being (whether human, animal, divine, and so forth) over many rebirths. By the term 'precessional' I mean the manner in which Indic transformation unfolds in keeping with the notion that the universe is overall running down or declining. I am using the term 'principle' in the general sense of an established presupposition accepted commonly in a cultural environment. ${ }^{1}$

\section{The principle of synchronic phylogeny}

Our modern notions of history, deriving largely from the Mediterranean of Late Antiquity and from modern theorizing about historiography, are for the most part absent in Indic thought in the early centuries CE. There is, however, an odd notion of 'history' operating, but it is certainly not our modern western notion. What, then, is the Indic notion? What is striking about the Indic worldview (as exemplified in the Yuga periods and the 'world-egg' geography) is that everything is perfect, properly formed, and excellent at the outset of the world process with the accompanying paradoxical claim that the process is beginningless. In other words, nothing new can emerge that is not already presupposed and fully formed at the outset, but that which is fully formed was or is, as it were, without beginning! According to Madhav Deshpande, there is a deep conservatism in classical Indic thought. He comments:

All forms existed, and it is a matter of pure accident that certain forms are or are not found in a particular text, a particular time or a particular region. Thus, the problem 
of 'existence' was separated from the problem of 'attestation'. Non-attestation did not imply non-existence. While eternal existence was the fact, the attestation and non-attestation of forms was a matter of historical accident.

Deshpande 1979: 9-10

Whatever changes occur either in language or in society are treated as 'options', hence, the system of varnăsarama-dharma (the ideal synchronic order of caste and stage of life). Language, society, and cosmos were dealt with largely in a deductive fashion. The human community is not to be viewed as developing over time diachronically. It is to be viewed, rather, in terms of 'synchronic phylogeny'.

History as viewed from this deductive perspective is not a matter of new creation of events or new inventions, but simply an unfolding of implicit aspects and values of the eternally self-existing reality.

Deshpande 1979: 18-19

To do 'history' in this sort of synchronic perspective is continuously to look back and remember the eternal first principles that are truly authoritative and make possible the options with which we must continually live.

\section{The principle of diachronic ontogeny}

Yet in a problematic manner, the synchronic phylogeny wherein everything is fully formed at the outset links up with a second principle, which in a puzzling way appears to undercut the first principle. The second principle might be expressed in the following manner. Everything is fully formed at the outset, beginninglessly, then so likewise are all sentient creatures throughout the extended universe. There never was a time, in other words, when I or any other sentient creature was not, since all were there potentially at the outset. Hence, through all the unfolding periods of becoming, I, along with all other sentient creatures, must also have been becoming, or, in other words, the principle of karma and rebirth (punarjanman). My identity in this particular rebirth is shaped by a linear series of preceding lifetimes stretching back to a beginningless beginning! In any particular lifetime, the sentient being is part of an unfolding synchronic whole, but the particular identity of a given rebirth has been shaped by an incredibly complex series of linear actions (karman) which have determined my synchronic place in this particular rebirth. Moreover, if the process is beginningless and, hence, infinitely so, then my actions as a sentient being have undoubtedly brought me into almost every possible life-form that has been formed from the outset, beginninglessly!

There are, therefore, two continually intersecting processes. On the one hand, there is the synchronic phylogeny of everything having been fully and perfectly formed at the outset. On the other hand, there is a continuously operating linear (diachronic) ontogeny of individual sentient beings whose trajectories in rebirth after rebirth are determined both by the synchronic presuppositions coming from the past being projected into the future, and by my continuing actions as a 'dividual' sentient being, to use McKim Marriott's well-known neologism (Marriott 1990: 1-39).

From one point of view, the system appears to be completely determined (synchronically) along the lines of varnäsrama-dharma. From another point of view, however, the system is completely open and free, in the sense that at any given point-instant, I, along with all sentient beings, must engage in action (karman) that will shape my future becoming (ontogenetically). 
There is a profound 'fluidarity' or 'plasticity' in the understanding of selfhood or identity, not only for human sentient beings, but for all forms of life, including animals, gods, demons, spirits, and so forth, in their respective levels (lokas) of becoming. There is a simultaneous synchronic-cum-diachronic inter-subjectivity in all forms of sentient life whereby sentient beings are regressively and progressively 'creating' a common life-world.

\section{The principle of precessional transformation}

There is still another principle in Indic thinking, however, that always accompanies the intersecting processes of synchronic phylogeny and linear ontogeny. Not only is everything present in its perfect and well-formed nature at the outset beginninglessly (synchronic phylogeny), and not only are all sentient beings nevertheless undergoing recurring linear identities based upon their karma in rebirth after rebirth, the entire cosmic drama is continually declining. The world is continually running down, falling backwards, or regressing from an original excellence. The Indic worldview, of course, is not unique in this regard. The notion of the world running down is frequently accepted in the ancient world. It is widely accepted in the ancient Near East, in ancient Greece, and elsewhere. What makes the notion of decline especially poignant in the Indic worldview is the strong linkage of decline with karma and rebirth.

The reasons for decline are problematic in most discussions of decline in the ancient world. Typical is Madhav Deshpande's comment:

It is not very clear why such a doctrine of decline developed in ancient India. It is conceivable that the invasion of the Greeks and the emergence and dominant political and social position of the non-Vedic religions like Buddhism and Jainism were viewed to be 'darker times' in comparison with previous ages, and this might have led to the theory of four ages.

Deshpande 1979: 6

Such an explanation may not at all be necessary. More likely, in my view, is that the notion of declining ages has a great deal to do with ancient traditions of 'astronomy'/astrology that were widespread throughout the ancient world.

Since the plane of the earth's equator is at a slight angle (twenty-three and one-half degrees) to the ecliptic, the vernal equinox of the beginning of spring 'precesses' or moves backwards through the ecliptic one degree of arc about every seventy-two years. It takes approximately 26,000 years (or more precisely just under 26,000 years) for this precession or falling backwards to make a full circle so that the vernal equinox can occur again at its starting-point. According to one calculation, the oldest zodiacs were constructed by using the fixed star Aldebaran in the exact middle of Taurus, thereby making the vernal equinox at one degree of Aries around 4139 BCE (Gleadow 1969: 55ff.). Other calculations have also been used for determining the 'Ages' of the world. Generally, however, it was understood that a time-frame of approximately 26,000 years was needed for a complete 'precession' (or falling backwards). It is known as the 'Great Year', and it may well have an analogue in the Yuga theory. All of the numbers mentioned in the Yuga theory discussed earlier, namely, 1,728,000, 1,296,000, 864,000 and 432,000 years together with some seventy-two 'humanintervals' (Manvantaras), appear to reflect a comparable understanding of the 'Great Year'.

The large numbers used are probably due to the desire to express mathematical ratios and relations in term of whole numbers. Since so much ancient knowledge relating to astronomy/ 
astrology is traceable to the ancient Near Eastern cultures of Babylonia and Sumeria, it is credible to think that in the first centuries CE (that is, the period of the Itihāsa and Purānic textual environment) calculations reflecting continual decline become part of framing the Indic conceptual account of karma and rebirth. A. L. Basham comments,

Western [that is, Greek, Near Eastern and Mediterranean] astronomy brought to India the signs of the zodiac, the seven-day week, the hour, and several other ideas ... Like all ancient astronomy, that of India was restricted owing to ignorance of the telescope ... For purposes of calculation the planetary system was taken as geocentric, though Aryabhata in the 5th century suggested that the earth revolved round the sun and rotated on its axis ... The precession of the equinoxes was known ... as were the lengths of the year, the lunar month, and other astronomical constants.

Basham 1981: 492-493

In using the expression 'precessional transformation', however, it is not my intention to enter into the problem of origin, or diffusion, or scientific explanation. My point, rather, is to highlight a dominant mind-set regarding the unfolding of time. The mind-set is one of falling backwards, of 'precessing', and, hence, at least in the classic Indic formulation, of the present and future always becoming the past (or, in other words, karma and rebirth).

To be sure, we are free to act in what appears to be the 'present' moment, but we are not changing only the present. We are also re-covering and/or re-membering the past. Given such a mind-set of 'precessional transformation', there are only two possible options: either acquiescing or adjusting or harmonizing with what is (was), that is to say, the option of varnāśrama-dharma (synchronic phylogeny), or somehow renouncing in terms of the quest for mokṣa or nirvāna or some other renunciatory technique (linear ontogeny in an environment of precessional transformation). Clearly these principles that are presupposed, mutatis mutandis, throughout the dharma-traditions (Hindu, Buddhist and Jaina) of the Indic worldview of karmic eschatologies can be described as 'cyclical' so long as it is remembered that the critical intuition is a cycling neither into the present nor the future but, rather, a linear cycling into the past, a 'falling backwards', a 're-covering', or 're-membering', or 'precessing' for which my own karma is fully accountable, because what was is what is, and what was, in fact, is nothing less than what will be!

\section{Note}

1 I have written about these matters in several other publications and express my thanks especially to Philosophy East and West for permission to use some material from my article, 'The Trimürti of Smrti in Classical Indian Thought', Philosophy East and West, Volume 43, No. 3, July 1993, 373 and 381-385. It was in this article that I first discussed the three principles in a systematic manner. I have also discussed this basic conceptual scheme in other articles. See Gerald J. Larson, 'Karma as a "Sociology of Knowledge" or "Social Psychology" of Process/Praxis', in Karma and Rebirth in Classical Indian Traditions, ed., Wendy Doniger O'Flaherty (Berkeley, CA: University of California Press, 1980), 303-316; also, Gerald J. Larson, 'The Structure of Ancient Wisdom, Part II', Journal of Social and Biological Structures, Volume 6, 161-167; also Gerald James Larson, 'Hindu Cosmogony/ cosmology', in J. W. Haag, G. R. Peterson, M. L. Spezio (eds), The Routledge Companion to Religion and Science, London: Routledge, 113-122; Larson-Bhattacharya (eds), Yoga: India's Philosophy of Meditation, Volume XII, Encyclopedia of Indian Philosophies (New Delhi: Motilal Banarsidass, 2008), 91-100. 


\section{References}

Allchin, B. and R. Allchin (1982) The Rise of Civilization in India and Pakistan, Cambridge: Cambridge University Press.

Basham, A. L. (1981) The Wonder That Was India, Calcutta: Rupa Reprint.

Berlin, Sir Isaiah (1979) 'Nationalism: Past Neglect and Present Power', in Partisan Review 46, cited in Henry Hardy (ed.), Isaiah Berlin: Against the Current: Essays in the History of Ideas (2001), Princeton, NJ: Princeton University Press.

Braudel, F. (1972) The Mediterranean and the Mediterranean World in the Age of Philip II, trans. S. Reynolds, New York: Basic Books.

Brown, W. N. (1961) 'The Content of Cultural Continuity in India', Journal of Asian Studies 20 (August): 427-434.

Collingwood, R. G. (1944) An Autobiography, London: Penguin Books.

Deshpande, M. (1979) 'History, Change and Permanence: A Classical Indian Perspective', in G. Krishna (ed.), Contributions to South Asian Studies, Delhi: Oxford University Press.

Doniger, W. (2009) The Hindus: An Alternative History, New York: Penguin Press.

Dumézil, G. (1958) L'idéologie Tripartite des Indo-Européens, Brussels: Collection Latomus, Volume 31.

Edgerton, F. (1965) The Beginnings of Indian Philosophy, Cambridge, MA: Harvard University Press.

Faulkner, W. (1951) Requiem for a Nun, New York: Random House.

Gleadow, R (1969) The Origin of the Zodiac, New York: Atheneum.

González-Reiman, L. (2009) 'Cosmic Cycles, Cosmology, and Cosmography', in K. A. Jacobsen (ed.), Brill Encyclopedia of Hinduism, Volume 1, 411-428, Leiden: Brill.

Guha, R. (2007) India After Gandhi: The History of the World's Largest Democracy, New York: Harper Collins.

Hamilton, E. and H. Cairns (eds) (1961) The Collected Dialogues of Plato, The Statesman (pp. 1018-1085), New York: Random House, Pantheon Bollingen Series LXXI.

Jacobi, H. (1961a) 'Ages of the World (Indian)', in James Hastings (ed.), Encyclopedia of Religion and Ethics, Volume 1, New York: Charles Scribner's Sons.

Jacobi, H. (1961b) 'Cosmogony and Cosmology (Indian)', in James Hastings (ed.), Encyclopedia of Religion and Ethics, Volume 4, New York: Charles Scribner's Sons.

Kaufmann, W. (ed.) (1975) Existentialism from Dostoyeuski to Sartre, New York: Penguin Press.

Larson, G. J. (ed.) (1974) Myth in Indo-European Antiquity, Berkeley, CA: University of California Press.

Larson, G. J. (1980) 'Karma as a "Sociology of Knowledge" or "Social Psychology" of Process/Praxis', in Wendy Doniger O'Flaherty (ed.), Karma and Rebirth in Classical Indian Traditions, Berkeley, CA: University of California Press.

Larson, G. J. (1983) 'The Structure of Ancient Wisdom, Part II', Journal of Social and Biological Structures 6: 161-167.

Larson, G. J. (1993) 'The Trimūrti of Smrti in Classical Indian Thought', Philosophy East and West 43 (3), 373-388.

Larson, G. J. (1995) India's Agony Over Religion, Albany, NY: State University of New York Press.

Larson, G. J. (2012) 'Independent India (1947-)', in K. A. Jacobsen (ed.), Brill Encyclopedia of Hinduism, Volume 4, 121-135, Leiden: Brill.

Larson, G. J. (2014) 'Hindu Cosmogony/Cosmology', in J. W. Haag, G. R. Peterson, M. L. Spezio (eds), The Routledge Companion to Religion and Science, London and New York: Routledge.

Larson, G. J. and R. S. Bhattacharya (eds) (1987) Sämkhya: A Dualist Tradition in Indian Philosophy, Volume IV, Encyclopedia of Indian Philosophies, Karl H. Potter (General Editor), Princeton, NJ: Princeton University Press.

Larson, G. J. and R. S. Bhattacharya (eds) (2008) Yoga: India's Philosophy of Meditation, Volume XII, Encyclopedia of Indian Philosophies, K. H. Potter (General Editor), Delhi: Motilal Banarsidass.

La Vallée Poussin, L. (1961a) 'Ages of the World (Buddhist)', in James Hastings (ed.), Encyclopedia of Religion and Ethics, Volume 1, New York: Charles Scribner's Sons.

La Vallée Poussin, L. (1961b) 'Cosmogony and Cosmology (Buddhist)', in James Hastings (ed.), Volume 4, Encyclopedia of Religion and Ethics, New York: Charles Scribner's Sons.

Lipner, J. (2010a) 'Karman', in K. A. Jacobsen (ed.), Brill Encyclopedia of Hinduism, Volume 2, 778-788, Leiden: Brill.

Lipner, J. (2010b) 'Saṃsāra', in K. A. Jacobsen (ed.), Brill Encyclopedia of Hinduism, Volume 2, 848-854, Leiden: Brill. 
Little, D. (2012) 'Philosophy of History', in E. N. Zalta (ed.), Stanford Encyclopedia of Philosophy, (Winter 2012 edition), http://plato.stanford.edu/archives/win2012/entries/history/ [accessed 17 April 2015].

Madan, T. N. (2006) Images of the World: Essays on Religion, Secularism and Culture, Delhi: Oxford University Press.

Malinar, A. (2010) 'Time and Destiny', in K. A. Jacobsen (ed.), Brill Encyclopedia of Hinduism, Volume 2, 870-876, Leiden: Brill.

Malinowski, B. (1948) Magic, Science and Religion and Other Essays, New York: Free Press.

Marriott, M. (ed.) (1990) India Through Hindu Categories, New Delhi: Sage Publications.

Obeyesekere, G. (2002) Imagining Karma: Ethical Transformation in Amerindian, Buddhist, and Greek Rebirth, Berkeley, CA: University of California Press.

Panikkar, R. (1979) Myth, Faith and Hermeneutics, New York: Paulist Press.

Pollock, S. (2006) The Language of the Gods in the World of Men: Sanskrit, Culture, and Power in Premodern India, Berkeley, CA: University of California Press.

Smith, W. C. (1957) Islam in Modern History, New York: Harper and Row.

Thapar, R. (2013) The Past Before Us: Historical Traditions of Early North India, Cambridge, MA: Harvard University Press.

Weingartner, R. H. (1967) 'Historical Explanation', in Edwards, P. (ed.), The Encyclopedia of Philosophy, Volume 3, New York: Macmillan Publishing.

Wilson, H. H. (ed. and trans.) (1972) The Viṣnu Purāna, Calcutta: Punthi Pustak. 


\title{
22 \\ MATTERS THAT MATTER \\ Material religion in contemporary Hinduism
}

\author{
Vasudha Narayanan
}

\section{Sarasvatī in Embassy Row, Washington DC}

An unusual National Public Radio (NPR) story aired in the United States in June 2013. Entitled, 'A Hindu Goddess Arrives To Bless Embassy Row', it was certainly exceptional on many levels. The report said:

Winston Churchill graces the grounds of the British Embassy. Outside the Indian Embassy, Mahatma Gandhi looks as though he's in full stride, clad in loincloth and sandals. And now, there's a Hindu goddess. Sarasvatī just arrived. She stands in a garden in front of Indonesia's embassy, glowing white and gold, with her four arms upraised.

NPR 2013 (see Figure 22.1)

Noteworthy, too, is the fact that this sixteen-foot Hindu goddess of knowledge and performing arts is outside the embassy of Indonesia, a predominantly Muslim country, where only 3 per cent of the population is Hindu. Under this statue is a short description of the goddess from the perspective of the Indonesian embassy:

Dewi-Saraswati (Saraswati Goddess) ... is portrayed standing straight, facing forward, looking to the right direction, depicting positive thinking based on values of the truth. Universally, Saraswati is known as the Goddess of knowledge and art, embodied as a beautiful woman, as a symbol that science is something beautiful and attractive, in her hands she bring (sic):

- Book-lontar leaf [palm leaf used for book manuscripts in pre-modern India] symbolizing knowledge

- Mandolin symbolizing art and culture

- Aksamala/ rosary/tasbih beads symbolizing unlimited knowledge

- Lotus flower symbolizing holiness

- Swan symbolizing wisdom. ${ }^{1}$ 


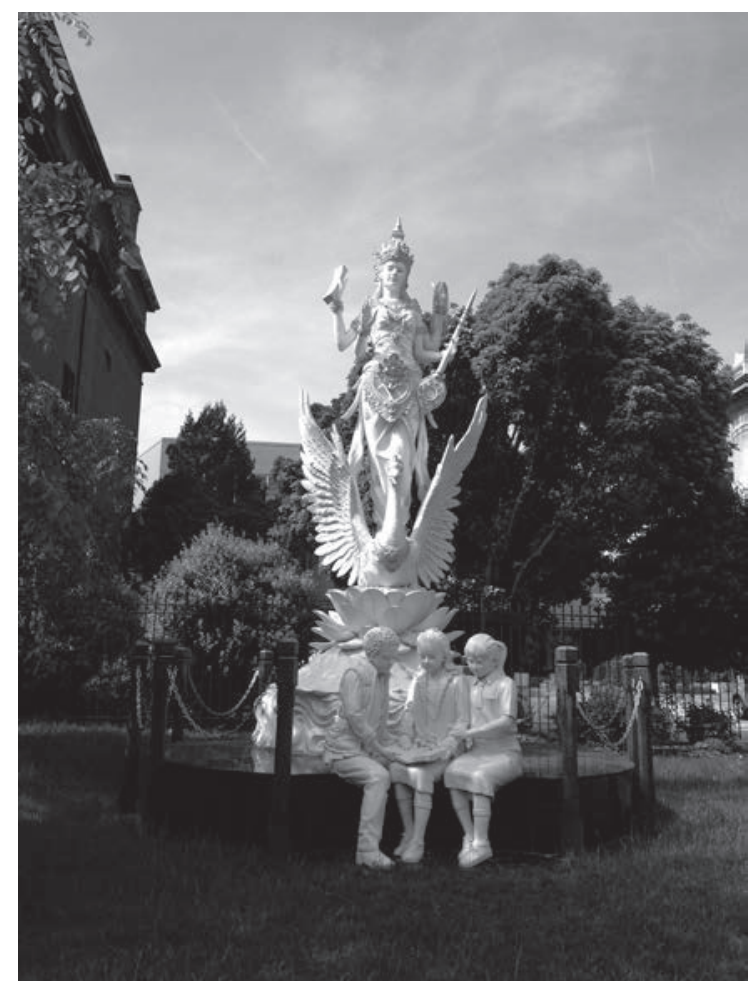

Figure 22.1 Sarasvatī image in Embassy Row in front of Indonesia's embassy

Source: Courtesy of Vasu Mohan

Hindus all over the world worship the goddess Sarasvatī; and while most Hindus (more than 800 million) live in India, there are large numbers in many parts of the world. Sarasvatī, in fact, is the main deity enshrined in the Hindu Temple and Cultural Center of Champaign, Illinois, USA and one of the primary deities at the Manav Mandir Temple, Merritt Island, Florida. Hinduism has to be studied as a global religion and all people from the sub-continent have been inextricably connected with other countries for millennia. Hindu philosophies and practices have been in Southeast Asia for about 2,000 years and it should not surprise us that Sarasvatī, a very tangible expression of the tradition, is outside the Indonesian, and not the Indian embassy. And thus, while this chapter focuses on material culture primarily in contemporary India, many themes and discussions will be drawn from and also be relevant in understanding contemporary global Hindu traditions.

Using the Sarasvatī image in Embassy Row as a segue into a discussion on material religion, we can develop several themes suggested by the statue and the sign under it, and explore their importance in the Hindu traditions in contemporary India. We can also raise questions on the connections between 'material' substances, 'spirit', and liberation from the cycle of life and death. Does 'matter' obstruct the path of the spirit or soul to liberation? Is it fundamentally opposed to the category/categories of 'spirit/ soul/ God?' What do the themes suggested by the explanatory plaque under the Embassy Row Sarasvatī tell us about the role of material culture in contemporary Hindu practice in India and in other parts of the world? In answering these questions, our discussions will include the following themes: 
1 The importance of 'images' in the Hindu traditions and their 'on-your-face' materiality. What is the ultimate status of 'matter' in Indian philosophies?

2 The manuscript and the book in Sarasvatî's hand, which invite us to think both about knowledge and the publishing industry.

3 Performing arts - as suggested by the vinna ('Mandolin') in her hand.

4 The image laden festival of navarattri, the nine-night, autumnal festival presided over by the three goddesses, Sarasvatī, Lakșmī, and Durgā, in South India, with special adoration of Sarasvatī on the penultimate day which, in fact, bears the eponymous name, 'Sarasvatī Pūjāà'.

5 The tasbih/rosary beads and the swan: what is the difference between the knowledge symbolized by the book and the 'unlimited knowledge' and wisdom symbolized by the bird and the beads?

A discussion of these themes will lead us to understand the network of affordances connected with these material objects, which point to a more complex connection between 'matter' and 'spirit' than a simple polarity. It is certainly true that many Hindu texts recognize a fundamental distinction between 'spirit' or souls and primordial matter; the Viṣnupurāna (1.9), a text composed in the first few centuries CE, for instance, hails Viṣnu ('the all-pervasive one') as the supreme soul and as 'the cause of matter (pradhāna) and spirit (pumān)'. There are, however, many kinds of materialities, many perspectives on, and even many gradations of these materialities, and at least two categories of 'spirit' (a soul that is in the cycle of life and death, and 'personal God'/Supreme Being/brahman) in the six 'orthodox' schools of Hindu philosophy. These 'orthodox' schools of Hindu philosophy, in contra-distinction to those that they classify as being 'heterodox' (forms of Buddhist and Jain thought, as well as Cārvāka or materialism) acknowledge the Vedas as the highest authority and source of knowledge.

In our discussions in this chapter, we will work with two large categories (cetana or 'that with consciousness' and acetana or 'that without consciousness') which are internal categories in Indian philosophy, and which subsume the sub-categories of 'spirit' and matter. These discussions are closely tied to ideas of brahman, or the Supreme Being which, according to some schools, resides in 'matter', both inherently, and in special ways through consecration rituals, and also to concepts of what is 'sacred' and what is not. A thread that we will valorize in this chapter is that, starting with the 'orthodox' schools of Hindu philosophy, almost all forms of matter point to and are even encompassed in the understanding and experience of the supreme deity or brahman; and the affordances (if one uses this term in a Gibsonian sense) of matter ultimately lie in the path to liberation or mokșa, variously defined. The denial of anything 'spiritual' is seen as the characteristic of the Cārvākas, the only 'materialist' school of philosophy. While considering potential functions of matter, which are said to lead one away happily from the snares of this material world and on the path of liberation, we will also pay attention to some political and socio-cultural contexts in which specific manifestations of material objects are created or used in veneration.

It is only through the multifarious deployment of 'materiality' that we have constructed, conserved, transmitted, encountered, and experienced the many features of religious and cultural traditions, including Hinduism. Temples, icons, paintings, art, music, texts, performance of recitation, ritual, festivals, are part of the networks of materiality. In discussing these themes, we get multiple perspectives (including some political, philosophical, and sociological contexts) on the materiality and religious culture in contemporary India.

Although the presence of material religious culture in Hindu traditions is palpable, it has to be seen in the context of the many texts that speak about brahman, the Supreme 
Being, which the Upanișads (c. sixth century BCE) say is ineffable. The initial paradox is that brahman both is and pervades through the universe. Alexander Duff (1806-1878), a Church of Scotland missionary, a pioneer of education in India was the author of India and India Missions: Including Sketches of the Gigantic System of Hinduism Both in Theory and in Practice. This treatise, published in 1839, was one of the first summaries of Hinduism, and in it, he explains this complex religion to his church colleagues, and to the English-speaking world. Missionaries, 'Orientalists' who studied the classical and sacred texts of India, and government administrators, were the major British players in colonial India in the nineteenth century, brokering the knowledge of and interpreting Indian religions to Europe, and also to America. The missionaries had been horrified by their perception of the Hindu worship of 'idols'; and yet, the 'Orientalists' who had been translating the many Hindu texts spoke about the 'spirituality' inherent in these works. Duff writes of this paradox thus:

Strange as it may sound in the ears of those who may never have heard of the Hindus but as a nation of polytheists and idolaters, it is, nevertheless, true, that the very foundation of their system is laid in the belief and assertion of the existence of one great universal self-existing Spirit.

Duff 1839: 74

The paradox of the 'materiality' in practice, and the perception of an underlying 'spirit' in the entire universe as gleaned from the Hindu compositions (notwithstanding the materiality of the text itself) is still a conundrum which many schools of Hindu philosophy try to explain.

There is considerable diversity in the understanding of 'matter'. The Sāṃkhya philosophy perceives the universe as being populated by many spirits and one primordial 'material' which then evolves and diversifies into many kinds of material 'evolutes'. Sāṃkhya greatly influenced the many Vedānta systems of theology and philosophy, such as the Advaita Vedānta and communities such as the Śrī Vaiṣnavas. The non-dualist Advaita school of thought considers the experiential awareness of the ultimate being as transcending all distinction between spirit and matter. Some traditions think of matter as feminine and as an obstacle to the realization of the spirit. Others think that it is only through matter that one realizes or attains the spirit.

While I will be casting the net wide and draw examples from many Hindu traditions to make my points, I will focus more closely on the Śrī Vaiṣnavas - a historically important Hindu community which has built hundreds of temples in India and, now, in many places in the world, and which also has a significant corpus of devotional and philosophical texts composed over more than a millennium. Many important Viṣnu temples in India (including the two richest Hindu temples in the world - the famous 'Balajī' or Venkațeśvara temple at Tirumala - Tirupati, and the Padmanabha Swami temple in Tiruvananthapuram), as well as several in Canada, the United States, and Australia, have a Śrī Vaiṣnava provenance, or follow forms of Śrī Vaiṣnava rituals. As we will see soon, Rāmānuja (traditional dates 1017-1137 CE), the most important teacher in this tradition, argues that prakrti which is one form of acetana ('without consciousness'), and cetana ('with consciousness', 'spirit'), both have ultimate reality because they form the body of brahman, the Supreme Being that pervades and yet transcends the universe. And the Śrī Vaiṣnava tradition also has a unique understanding of images and icons, the most 'material' form of the deities. But are the 'images' that we see in temples all over India and in many parts of the world considered to be 'matter?' An understanding of one Hindu perspective gives us an idea of the plural understanding of matter. 


\section{Material, non-material, hyper-material: gigantic images and different 'matters'}

Although an elegant sixteen-feet tall, the Embassy Row Sarasvatī in Washington DC is quite small in comparison to the mega-statues of deities that have risen all over India. One may argue that the Indian images pale in comparison to the gigantic Buddhas in East Asia; ${ }^{2}$ nevertheless, enormous images of many Hindu deities, especially Hanumān, have become extraordinarily popular in many parts of India. In this section we will consider the rising popularity of gigantic images in contemporary India, the prevalence of the iconic presence of deities in Hindu temples all over the world, and the philosophical question of different kinds of 'materiality' in at least some threads of Hindu philosophy.

Hindu, Buddhist, and Jain images compete for the dubious record of being among the tallest ones in India. Whereas objects of devotion set in pilgrimage complexes, such as the tenth century CE Jain teacher Gomațeśvara (fifty-seven feet) in Sravana Belgola, Karnataka, and the Hindu deity/devotee Hanumān (eighteen feet) in Nammakkal, Tamilnadu, were once considered to be very tall, they are now relatively small in comparison to the newly built figures. There is an eighty-four feet high statue of the Jain teacher, Ādināth, in Barwani, Madhya Pradesh; and the Vīra Abhaya Añjaneya Hanumān Svāmī ('Lord Hanumān, heroic son of Añjana, who makes [his devotees] fearless') made up primarily of concrete, rises to 41 m (135 feet) in Vijayawada, Andhra Pradesh. These are just a few of the dozens of tall statues of India; so popular is this genre of representation that there are dedicated websites to list the 'statues over 80 feet tall' and those just short of 80 feet. $^{3}$

While large images were certainly part of prestige-temples in the past in India, the supergigantic images seem to be a modern phenomenon. Lutgendorf, in writing in 1994 about the advent of large Hanumāns in the Indian scene underscores the political context of these images:

Given the fluidity and potency of this god, having the biggest Hanuman on the subcontinental block is clearly a goal worth pursuing - but the meanings that can be read into this pursuit are multiple. The rhetoric of late twentieth-century Hindu revivalism appeals to pervasive fears of loss of power; it warns of Hindus 'becoming a minority' in their own country and stridently calls for 'protection' (rakșā) - of dharma, cows, and women.

Lutgendorf 1994: 244-245

The political rhetoric embedded in these material depictions of deities is undeniable, but advances in super-materials and technology (many of these statues have steel reinforcements), as well as the increasing bandwidth of an affluent middle-class population, have also contributed to an inordinate number of such gigantic images in India and in some diasporic communities, such as Trinidad. There is no doubt that at least on one level such large statues are made for the same reasons why large 'prestige' temples were created in India and in Southeast Asia for millennia: on the one hand, they exude social power and cultural capital, and on the other, they make strong political statements.

Is this Sarasvatī in Embassy Row - or are any of the gigantic images that have been raised in India, or even the smaller icons enshrined in the temples - 'God'?, what form of reality do they embody or represent? Arguably, one of the most striking features of the Hindu traditions is the full-fledged depiction of deities in human, animal, plant, and fossil 'forms;' and this was probably one of the most important parts of the tradition that the Muslim and colonial/Christian rulers in India could not quite understand. 
As has been discussed in several forums, Hindus apprehend the material forms of deities in multiple ways. The Vìraśaiva community and the Brahmo Samaj, for instance, do not venerate the deity in the form of an image in a temple, even though the Virraśaivas do worship Śiva in the form of a linga. On the other hand, the Śrī Vaiṣnava community believes that Viṣnu and Śrī are present on this earth in a temple in the same manner as they are in heaven; and between the eighth and thirteenth centuries CE, this tradition also developed a theology that articulated a seamless relationship between the manifestation of the universe, the external manifestation of the deity in the temple, and the inner embodiment of God within the devotee's own heart. Rāmānuja, the most important theologian of the Śrī Vaiṣnava community, builds his philosophy on texts that many Hindus accept as authoritative (such as the Vedas, the Upanișads, Bhagavadgittā, and the Brahmasūtra) and argues that all souls (sentient beings) as well as insentient material form the body of brahman, the Supreme Being (Carman 1974; Lipner 1986: 85-86; Srinivasa Chari 1994: 60-62; Thibaut 1890: 419-424; 457-463 etc.). In fact, the very meaning of 'Vișnu' is 'all pervasive', and his immanence through space and time, matter and spirit, is an important part of the Śrī Vaiṣnava community's world view.

Later Śrī Vaișnava theologians also write that Viṣnu has two kinds of bodies: on the one hand, the entire universe is his body, and on the other, he also takes specific physical forms, as in his descents (avatāras) as Rāma and Kṛṣna, and in his incarnations in the worshipable form (arcāvatāra) enshrined in temples (Srinivasa Chari 1994: 207-232; Narayanan 1985). Although the image in the temple may be made of earthly material, it is a real body of Viṣnu, just as the entire universe is also a body of Vișnu. Far from regarding the temple image as a body made of stone or hewn out of rock, the Śri Vaișnava understands the image to be made of a non-earthly transcendental substance, a kind of hyper-material which is unique to the deity and is made perceivable on earth only by virtue of Vișnu's desire to be accessible to his devotees. This manifestation of Vișnu, however, does not exist in contradistinction to, nor is it lesser than his manifestation in the heart of the devotee. Further, some Śrī Vaiṣnava theologians like Pilḷai Lokācārya (thirteenth-century CE) ultimately understand the external manifestations in temples to be superior to all other forms of God (Narayanan 1985: 62-64).

Pilḷai Lokācārya's younger contemporary, Vedānta Deśika (1268-1368), clearly articulates this philosophical description of the various gradations of matter and spirit, giving us one distinctive Hindu perspective of how they fit in the grand scheme of things. There are other systems of Indian thought which have also addressed this issue. Sankara (c. eighth century CE) expounded a philosophical system, Advaita ('non-dualism') which is better known outside the Indian sub-continent in many registers. According to this philosophical school, which is further expanded on by Śankara's followers, the manifest universe (including all its material components) is, from the higher perspective of liberation, without ultimate 'reality'; that is, it is something which is part of a wondrous illusion. Other philosophical world views on spirit-matter which are well known emanate from the Sāṃkhya and Sāṃkhya-Yoga schools. These darśanas hold that the universe is comprised of innumerable puruṣas (spirit/souls) which are enmeshed in the non-conscious prakrti or primordial matter. The two are forever distinct but real, and the purusas only get liberation when they extricate themselves from prakrti. As Jacobsen explains:

The purpose of the Sāmkhya system of thought is to show by rational arguments the possibility of realizing the truth that consciousness is and has been separate from matter. The material manifestations of the world are a real transformation of matter, 
but the association of consciousness and matter, which leads to the manifestation of the world, is ultimately not real, but is based on ignorance. When purușa has been known, the manifestations of prakrti dissolve in prakrti. Sāmphya does not deny the reality of matter, but claims that every individual has a consciousness part and a material part, and that the consciousness part is eternal and unchanging while the material part is eternal and changing. Change is associated with pain, duhkha, and absence of change with freedom.

Jacobsen 2015: 52

Rāmānuja and his followers differ from Śankara in holding the universe as real because it - including matter - is brahman/Vișṇu's body. Rāmānuja's position is also different from the Sāmkhya-Yoga variations in that he insists on the ultimate connectedness and unity between brahman/Vișnuu, souls or conscious beings (cetana) and non-conscious (acetana) materials, and does not subscribe to the fundamental purușa-prakrti dichotomy of the Sāṃkhya-Yoga tradition. Rāmānuja's followers also expand upon these categories and introduce gradations in the 'non-conscious' substances present in the universe. Deśika, like Rāmānuja, says that the supreme brahman or Viṣnu is the soul, the ätman of the entire universe. He further says that Viṣnu is eternally and continually united with Śrī or Lakṣmī, the goddess, and together, they pervade the universe, just as our souls pervade our human bodies. The universe - the divine body of Vișnu - is divided into cetana and acetana. Here, we do not see the term 'living' or 'spirit' as different from 'matter'; brahman encompasses both, resolving the paradox in this philosophical system. In turn, cetana and acetana are further sub-divided into more categories. Conscious beings (cetana) include three kinds of souls - the eternally and always liberated celestial devotees of Viṣnu; those beings who were originally bound by karma and who have now reached liberation; and finally, those - like most of us human and animal forms now alive - which are still bound to the cycle of life and death.

But what is the philosophical status of 'matter' or 'material substance'? Vedānta Deśika divides acetana into jaḍa ('inanimate') and ajaḍa ('not-inanimate'). All jaḍa is divided into 'matter' (prakrti) and 'time' (käla). There is only one example of ajadia - that which is 'notinanimate' (but which is not 'animate' either). This, according to Deśika, is a form of 'hypermaterial', or stuff that transcends all matter; Deśika calls it śuddhasattva or exclusive, 'pure' purity. This larger philosophical picture of where 'matter' and spirit fit in the larger scheme of things can be put schematically thus (see Figure 22.2).

As seen here, there are many gradations of material substances and it is not a simple paradox or distinction between spirit and matter - indeed, even in philosophical schools like Sāṃkhya and Sāṃkhya-Yoga where the distinction between spirit and matter may be the overt position, there are many fine nuances. Deśika talks about a new category which he calls suddhasattva, a kind of hyper-matter. In many Hindu traditions, and most importantly articulated by the Bhagavadgitāa, (particularly Chapter 14), prakrti, the primordial matter from which the universe is made manifest, has three intertwined strands of qualities (guna) inherent in it; these are sattva (purity); rajas (energy, passion, motion); and tamas (darkness, slothfulness, dullness). All three qualities are present always in various proportions in prakrti - but Deśika's śuddhasattva is pure, complete sattva, not mixed with and not blemished by the other two qualities, and therefore very different from prakrti. Śuddhasattva is pure, unadulterated sattva, luminous, a super substance, transcending anything found on earth.

According to Deśika and Piḷai Lokācārya, the 'physical' bodies of the various incarnations of Viṣnu such as Rāma or Kṛ̣ṇa, indeed, the forms of the very worshipable incarnations (arcāvātara) in temples - the forms through which the inexplicable, ineffable brahman, which 


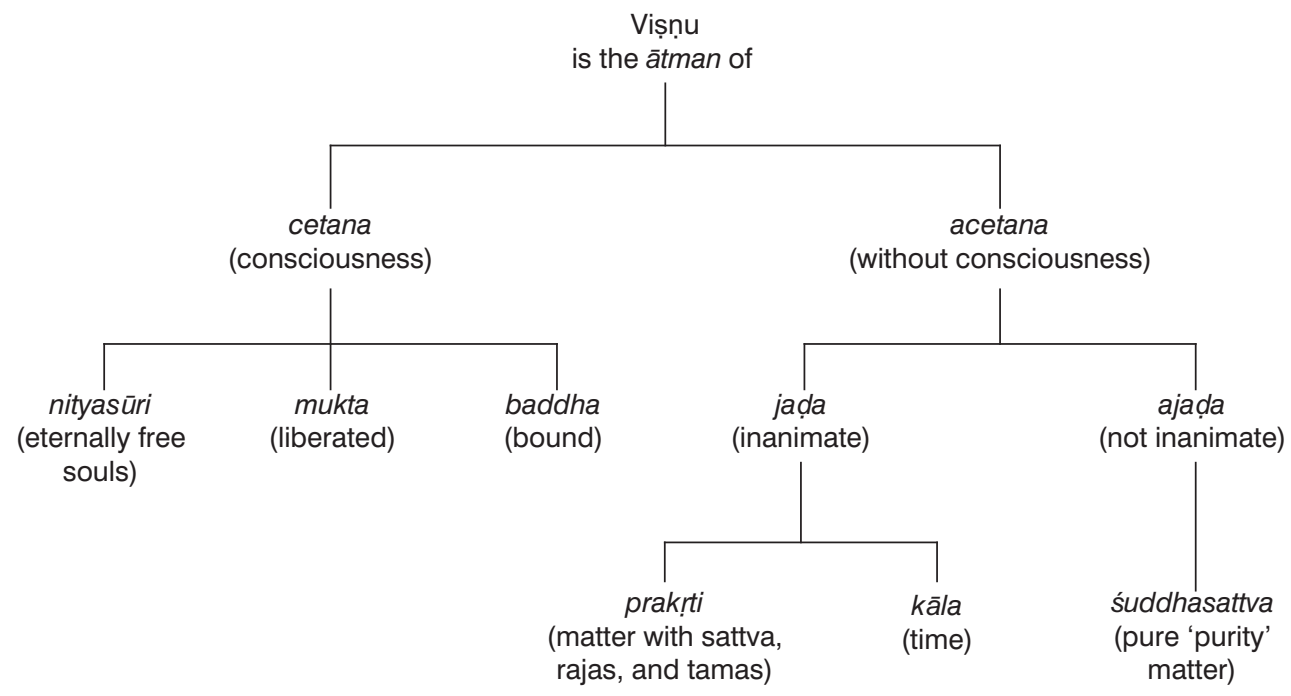

Figure 22.2 'Matter' and spirit in the larger scheme of things

pervades the entire universe manifests itself to human beings, is said to be made of this suddhasattva, this hyper-matter, which is different from all matter as we know it. This sattva or 'purity' is, as we saw, is hierarchically higher than the three qualities (guna) driven matter which constitute all living creatures and material things. The raw, regular material from which an image is hewn almost transubstantiates into this super sattva during the rituals of consecration. And yet, this super śuddhasattva is not 'spirit', in the sense of it being the ätman, or 'consciousness', or cetana either.

The paradox of the worshipable image in the Śrī Vaișnava tradition is that while this manifestation of the deity is so obviously made of stone or metal, it is believed to be aprakrta or non-material. We are confronted with a paradox: what appears to non-Hindu eyes as the most gross and material representation of the deity is understood by the Śri Vaișnava to be a divine, auspicious form, composed of a non-material substance that exists only in heaven and in the temple on earth. In Deśika's articulation, the image must not be regarded as a material object. It is a personal god, luminous, and complete with all auspicious qualities; it is transcendent and supreme, yet easily accessible - a bit of heaven on earth. Thus, Deśika's - and the Śrī Vaișnava's - answer to the paradox of spirit and matter is to posit (or recognize, depending on one's perspective) - a new category which is neither cetana nor prakrti.

Arguably, the Embassy Row Sarasvatī and some of the tall images in India are not consecrated and thus different from the worshipable, 'living' images. And some consecrations are temporary; icons may be infused with divine life during rituals like Gaṇeśa pūjā or Durgā $p \bar{u} j \bar{a}$ but this 'life' - that is, the presence of the Supreme Being - is said to leave after the worship is over, and the icons become clay or papier mâché again; material which can be immersed in water with due respect. But the lines between consecrated images in temples and images kept in family altars, or even paper pictures of deities, are very fuzzy. Most Hindus today tend to respect all depictions of deities; and all have the potential to be venerated.

Like these deities and printed versions of them, books and paper slide and glide through the seamless spectrum of sacrality in Hindu practices. 


\section{'Book-lontar leaf symbolizing knowledge': respect for books and the print culture}

Sarasvatī carries a manuscript in her hand; the Indonesian embassy refers to this as 'Booklontar leaf [palm leaf used for book manuscripts in pre-modern India] symbolizing knowledge'. Paper and books have the affordance of knowledge in multiple senses - both in the initial sense of having an easily discoverable sense of knowledge - specifically of a transformative wisdom, as well as 'suggesting' or 'inviting' one to a perceived higher path. While very few things are common for all Hindus, one can say that possibly most would think of even printed pictures of deities as worthy of respect and would hesitate, say, if they were asked to put a good picture of Lakșmī in a shredder. At a much simpler level, even something as starkly material as paper is to be respected in some contexts, because it has the possibility of offering knowledge. Even though in everyday life, Hindus may not think twice about tearing paper or using it for packing, they would avoid touching it with their feet; and if they do so accidentally, they may make a quick gesture of respect. This sentiment is so well recognized that even facile, tongue-in-cheek lists which stereotype Indians in popular culture, consider 'stepping on a book or paper' second in lists of prioritized issues that are said to be offensive. ${ }^{4}$

Writing was not considered favourably in India until possibly well into the Common Era (Staal 1979, Brown 1986), and yet, Sarasvatī is seen with a manuscript in hand, a manuscript that conveys to the devotee her knowledge and mastery over letters and the books. In fact, the Guruparamparāprabhāvam by Pinpalakiya Perumāl Jīyar, a thirteenth-century biography of many of the Śī Vaiṣnava poets and teachers refers to a library as Sarasvatì bhanḍaram ("the storehouse of Sarasvati'; Jìyar 1975: 225). The Indonesian Sarasvatī holding a manuscript in her hand also pushes us to think of the palpable print culture in India; for, although paper and printed books were introduced late, and literacy is not very high in India (64.8 per cent),${ }^{5}$ the field of publication is said to be booming and some of the largest book-fairs in the world are held in Kolkota, New Delhi, and Chennai. But even then, the books displayed even in these fairs are said to be only a fraction of the large numbers that are thought to be produced and statistics are certainly hard to come by (Darnton 2002: 239-240; Pathak 2011). What we do know is that the earliest publications in India, at least in Bengal, the region where a fairly thorough study was undertaken in the mid-nineteenth century, 'the total output of works in Bengali before 1820 came to only thirty titles, most of them on Hindu religion and mythology' (Darnton 2002: 241). It is notable that the earliest print publications were in the field of Hinduism; new innovations seem to get blessed, validated, and accepted faster if they popularize religious themes. This was clear when film making was introduced to India in the early twentieth century, and we turn to this plasticity of the performing arts now.

\section{'Mandolin symbolizing art and culture': performing arts in the Hindu traditions}

Like the earliest publications in Bengal, many of the earliest movies in India were based on religious narratives. Early titles included Shree Pundalik (Marathi, 1912); Raja Harischandra (Marathi, 1913); Keechaka Vadham ('The slaying of Keechaka', Tamil, 1918), and so on. Although movies with secular themes quickly became popular, even now, religious themes are explicitly and implicitly woven through Indian movies. Although cinema, the ultimate medium for performing arts became a carrier for the Hindu traditions only in the twentieth century, one can say that the Hindu traditions have been transmitted through the performing 
arts for millennia. Thus, when the Indonesian embassy describes the vin $\bar{a}$ in the hand of the Embassy Row Sarasvatī as 'Mandolin symbolizing art and culture', we can keep two things in mind; it is not just the content of the performing arts that is frequently suffused with religious culture, but the arts themselves are considered by many Hindus as a path leading one to liberation. The performing arts have embodied the Hindu traditions in multiple ways; cinema and television continued and changed the traditions of music and dance, religiosity, and culture. In text and practice, many Hindus perceive music and dance - the most embodied forms of recreation, sensuality, and religiosity, as palpably offering a network of affordances leading one to mokșa.

The materiality of the performing arts can be approached in multiple ways from the viewpoints of the performer, the audience, and the observer. The human body carries aspects of Hindu cosmologies and is used as a vehicle for learning about and depicting the Hindu traditions, on the one hand, and as experiencing what is perceived as divine in this life itself. Lutgendorf, discussing the centrality and physicality of the 'gaze' and 'seeing' in India, emphasizes the substantial nature of these acts:

When Hindu images are crafted, their painted or inlaid eyes are customarily added last and then ritually 'opened', establishing the deity within the icon and making him or her available for the primary act of worship, which is 'seeing/looking' (darśana; Hindi darśan). In Indian English, people go to temples 'to take darśan'; Hindi favors 'to do darśan' (darśan karnāa - both idioms imply a willful and tangible act. 'Darśanic' contact invites the exchange of substance through the eyes, which are not simply 'windows of the soul', but portals to a self that is conceived as relatively less autonomous and bounded and more psychically permeable than in Western understandings.

Lutgendorf 2006: 232

This seeing can be used as a lens to understand performance and cinema. Second, the aesthetic theories emanating from the Natyaśāstra (c. first and second centuries CE), the classical text on dance and drama, speak about the unique 'taste' and 'flavour' or enjoyment that rises from the performing, the viewing and what happens in between. Here, the

primary and individualized human emotions (bhāva) generated by the multifarious experiences of life are transmuted, through their representation by actors in a dramatic spectacle, into universalized emotional 'flavors' (rasa) that may be savored by audience members at the safe remove that theater provides.

Lutgendorf 2006: 237

Referring to Richard Schechner, Lutgendorf argues that 'Indian theatre is more typically 'rasa-driven', and that 'a familiarity with "rasaesthetics" - a more somatically based understanding of the effect of performed emotions on the spectator - could enlarge the conceptual vocabulary of Western critical theory' (Lutgendorf 2006: 238).

As a related note, we should note that while Western scholars have long accepted the importance of 'seeing', an equally important way in which (what is beheld to be) 'divine' is apprehended is through touch. Touch is powerful; so by touching the object of veneration (for example, the threshold of a temple, the feet of holy people, the arati flame which is used in rituals of adoration) one becomes a receptacle for this power (Glushkova 2015: 118-123). At the same time, the object of veneration - as in the consecrated icons in South Indian 
temples - may be considered to be so powerful that lay people are prohibited from touching them; only initiated priests are said to have the strength to bear the power of the 'live deity'.

Music and dance performances are staples in contemporary Indian television and cinema. Looking further, one can easily see that in the Hindu tradition, music and dance are closely allied with temples; temple walls in India, Cambodia, Bali, and Atlanta portray hundreds of dancers. Dances and architectures depict embodied cosmologies; architecture connects the dance and dancer to the cosmos.

In 'narrative' India that is both imagined and perceived, deities and devotees dance the cosmos, dance their relationship to each other, and to the powers of the universe. Krṣna danced through many moonlit nights with Rādhā and the other cowherd girls; he connects the dancers through devotion and through passion in a cosmic mandala. He danced on the serpent Kāliya, subduing its ego. Siva and Pārvatī, the archetypal dancers, paradoxically portray cosmic energy as well as tranquillity. Sarasvatĩ is, of course, the patron goddess of music and many performing arts.

One of the primary ways in which the transmission of Hindu/Indian culture takes place in temples and in private studios and homes in many parts of the world where Hindus live is through the performing arts, especially a classical form known today as bharata nattya. The term 'bharata nātya' is popularly translated as the 'drama according to Bharata' or the 'dance of India' and is a name given in the twentieth century to a dance form that existed in South India for several hundred years. To learn classical Indian dances like bharata nātya, Odissi, Kuchipudi, or even folk dances like garba $\bar{a}$ is to learn stories about Hindu gods and goddesses; it is to learn ways of body languages seen in the sub-continent; it is to learn the emotions that are intricately tied into the depiction of the human-divine relationships.

Balasarasvati ('little Sarasvatî'; 1918-1984), arguably one of the best-known Indian classical dancers of the twentieth century, once compared her dance to the structure of a great temple; perhaps this, above all, illustrates liberation or mokșa as one possible affordance of performing arts, and one that is most valorized by some Hindus. She compared the alärippu, the first item in the repertoire, to the grand entrance, the majestic tower (gopuram) of a temple. The traditional items that follow - the jatisvaram and sabdam are, she said, like the vestibule, the corridor that leads one to the grand hall in this place of worship. The varnam, which is the central piece of the recital (it is here that the artist depicts the soul's passion for the Supreme Being), is the piece that gets one close to the inner shrine. 'This is the space', she said,

which gives the dancer expansive scope to revel in the music, rhythm and moods of the dance. The varnam is the continuum which gives ever expanding room to the dancer to delight in her self-fulfillment, by providing the fullest scope to her own creativity as well as to the tradition of the art.

When one dances the padam [the next item in a traditional performance],

one experiences the containment, cool and quiet of entering the sanctum from the external precincts. The expanse and brilliance of the outer corridors disappear in the dark inner sanctum; and the rhythmic virtuosities of the varnam yield to the soulstirring music and abhinaya [expression] of the padam. Dancing to the padam is akin to the juncture when the cascading lights of worship are withdrawn and the drum beats die down to the simple and solemn chanting of sacred verses in the closeness of god. Then, the tillana [this is the pure abstract dance where the 
sparkling footwork dominates] breaks into movement like the final burning of camphor accompanied by a measure of din and bustle.

Pattabhi Raman 2001

By now, she says, the devotee internalizes the deity she has worshipped outside and completes the traditional order by dancing to a simple devotional verse (Pattabhi Raman 2001).

The dancer dances her worship in the temple, creates the temple within her body, and dances the temple in her performance. Further, dances teach one about the pantheon of gods in the Hindu traditions. To learn these dances is to know their physical appearances, their insignia, the colour of their clothes, and their demeanour. Many of the classical Indian dances depict the heroic deeds of these deities. For a child or teenager to learn classical Indian dances is to know stories of these deities that their parents are familiar with, the Hindu traditions that they grew up with in India or Trinidad or South Africa. Knowledge of Hinduism is not just of lofty philosophies for the large part; it is largely knowing stories from the epics Rāmāyaṇa and the Mahābhārata (c. $400 \mathrm{BCE}-400 \mathrm{CE}$ ) and texts called Purānas (c. first millennium $\mathrm{CE}$ ). Knowledge of these stories, along with local narratives, is known and transmitted in many communities, in most parts of India. While there are hundreds of stories and some are better known in certain areas, there is a certain corpus of tales that almost all Hindus in the diaspora have either heard or seen performed in their childhood. The dances also inform us about the social structures of the Hindu traditions. To learn dance is to enter the world of chaste wives, filial sons, committed students, chivalrous warriors, and righteous kings; it is to know the way in which the perfect couple, Rāma and Sìtā related to each other; it is to know the filial piety of Ganeśa, the relationships between a human being and a personal deity. It is to know the received traditions of power structures; it is to know the relationships between kings and ministers, teachers, and students.

Some Hindus and scholars see this heritage as directly influencing Indian cinema today. Lutgendorf says that the cultural-historical approach of some scholars traces

the distinctive 'Indianness' of Indian popular cinema ... to older styles of oral and theatrical performance, some of which survive into modern times ...

On the one hand, one encounters grandiose claims that the classical tradition - and especially the two Sanskrit epics - constitute 'the great code' of popular filmmaking and that 'any theoretical critique of Bombay Cinema must begin with a systematic analysis of the grand Indian metatext and "founder of (Indian) discursivity," namely the ... [Mahäbhärata/Rāmāyaṇa] ...' (Mishra 1985:14). This is a claim that is sometimes made by filmmakers themselves, as when Mumbai director Dharmesh Darshan tells an interviewer, 'In India, our stories depend on the Ramayan - all our stories are somewhere connected to this holy book' (Kabir 2001: 93).

Lutgendorf 2008: 43

Although he acknowledges the overwhelming significance of the epics and the Puranas on modern cinema, Lutgendorf cautions against the essentialism and fastforwarding techniques this approach may involve. We cannot, he says hold that there is 'an unchanging "essence" of Indian performance, or ... imply that some genetic inheritance predisposes South Asians to relish three-hour spectacles of music, dance, and high emotion' (Lutgendorf 2008: 43).

But cinema does not have to depend on Purānic or epic content for it to be religious. Plate argues that cinema is connected to religion and materiality in a number of ways. The material production of cinema and its very creation involves labour done by large contingents of 
people who 'aim to represent' and 're-create' a particular world and make it accessible to an audience, triggering mythological and symbolic dimensions across those worlds. Further, the act of watching itself is a 'sensual experience done by actual bodies in actual space ... an activity that becomes religious in its form' (Plate forthcoming). One can add that the emotions experienced then would also be similar to notions of rasa discussed earlier in this chapter. Plate also shows how the material effects of cinema linger for a long time and people 'religiously reproduce the world of the film' in their lives. In short, as he elegantly says, 'Cinema is a material media practice that is constantly embodied and re-embodied in and through bodies, time, and space' (Plate forthcoming).

Cinema, like all performances, is dynamic and innovative. Each time a musician plays a rāga on the vinna - the very one that Sarasvatī holds in her hand - it sounds different. And while connections of modern performing arts with the natya sástra, the epics, and the Purānas are abundantly evident, so too are the mutual exchanges and enrichments with other cultures; classical Carnatic music songs on Rāma have been composed in rāgas called Husseini and Paras ('Persian'). Music, dance, and cinema are part of the larger cultural traditions marked by mutual transmission and transformation, whether it is India or Indonesia.

\section{Worshipping Sarasvatī during the nine nights and ten days of the Navarātri festival}

Music and dance are valorized and Sarasvatī is worshipped in the states of Tamil Nadu, Karnataka, and Andhra Pradesh, South India, during the festival of Navarātri ('nine nights;' also known as daśharā or 'ten days'). Perhaps nowhere is 'material' culture as evident as it is during this festival. During these nine nights and ten days, women from some communities and castes in South India set up large tableaux of steps in their homes. These steps are covered with cloth, and populated with clay, papier-mâché, and wooden dolls, colourfully painted. On the ninth day (mahānavamī), a day which South Indians call 'sarasvatīpūjā', our goddess who graces Embassy Row, is venerated as the patron of music and learning.

Navarātri in certain communities in Tamilnadu and Karnataka is a domestic festival, primarily directed by women, and marked with a festival of dolls. A room is set apart and filled with exquisite dolls for the play of the goddesses Lakșmī, Sarasvatī, and Durgā. This display is called kolu, a Tamil word borrowed from the Telugu koluvu or 'sitting in state'. This is a word used like darbār, or 'holding court', a term more recognizable in many parts of India. Women take leadership roles in worshipping the goddesses on these days. The tableaux they set up depict scenes from Hindu stories and are similar to the nativity scenes that one sees around Christmas. The focal point in the living or family room at home is the set of seven or nine tiers or steps filled with dolls, with prominence given to dolls representing the goddesses. Parks, schools, stores, and scenes from everyday life may also be arranged on the floor and, in recent years, themes that raise our consciousness of social issues are popular.

The tiered Navarātri steps may possibly simulate courtly darbār of King Krishna Deva Raya (reigned 1509-1529) of the Vijayanagara empire. Yet others would say that the steps denote the various parts of the universe, with animals, human beings, and celestial beings on the lower tiers and representations of the Supreme Being on the highest step, creating a pyramid of devotion. While there is no textual basis for this - or even for this specific celebration of Navarātri - like many Indian ideas, this rationale too takes a life of its own. Thus, it is a microcosm of the universe with the deity presiding on top. Others say that this is the time sacred for the goddess and that by arranging the dolls, the whole area becomes the play, the $\bar{\imath} l \bar{a}$, of the deities. 
Historical narratives, including accounts by Western travellers during the time of the Vijayanagara empire in South India (c. fifteenth to sixteenth centuries CE), give us details of the celebrations in the royal courts. Foreign visitors report that during Navarātri, the king, in his capital city of Hampi, watched a royal procession from the Navarātri pavilion or mandapam. The king and courtiers sat on various levels watching the festivities. The festival culminated in a grand celebration, with the king holding court. It is possible that this act of a royal court or (koluvu or darbär) is what is re-created today in the domestic celebration of Navarātri kolu, with the tiered tableau of dolls representing the king and his courtiers.

The fluid and elastic boundaries between concepts of the 'sacred' and the 'secular' that is characteristic of many perspectives in the Hindu traditions is particularly visible in the Navarātri festival. The entire kolu display is considered to be sacred even though 'secular' dolls may be set up on the tiers. For these nine days, the area is treated as the family shrine, and the dolls are considered to be consecrated. This sense of considering material images as alive and sacred is also seen in other parts of India; for instance, Hindus in the neighbourhoods and large family homes in West Bengal create large images of Durgā during this time and she is said to be infused with life for the few days of Navarātri. In West Bengal, Durgā is set up in the context of various backgrounds connected with popular culture. Scenes of Durgā against the Titanic or in Jurassic Park, or accompanied by Rambo, have been popular in the past; more recently, in 2007, attorneys representing J.K. Rowling sued a local neighbourhood in Kolkota for infringement of copyright when they re-created scenes from Harry Potter, complete with a replica of the Hogwarts school for wizards. (The Delhi High Court ruled in favour of the local neighbourhood and Harry Potter got to spend Navarātri with the goddess.)

As in Kolkota, since the second half of the twentieth century, the displays in the cities of Chennai (Madras) and Bangalore in India portray events of social importance, or even serve to be educational. Social themes have gained in prominence in post-colonial India and serve to raise people's consciousness on issues such as India's independence movement, organ donation and family planning. The displays are put up by the entire family, with women deciding the main themes. More recently, since the 1980s, free neighbourhood newspapers in Chennai, such as the Adyar Times and Mylapore Times have contests with visiting judges and sponsor prizes for the best displays.

Every evening during Navarātri, women and children in Tamil Nadu dressed in bright silks visit friends, admire the display of dolls, play musical instruments, and sing songs from the repertoire of classical music, usually in praise of one or another of the goddesses. Chickpeas and various other kinds of peas and beans, symbolic of fertility and prosperity are said to be sacred to the goddesses, and snacks made with these ingredients are frequently given in little packets to the visitors. It is a joyous time of festivity, music, elegance, and beauty, and the festival is a celebration of the embodiment of the divine in a 'female' form. The last two days of the festival are countrywide holidays in India and for people of South Indian origin, dedicated to the goddesses Sarasvatī and Lakṣmī. Large pictures of Lakṣmī and Sarasvatī, draped with garlands of fresh flowers, are kept in front of the display of dolls and worshipped.

Over and above these domestic and community celebrations, there is also a martial flavour to this festival. Some people believe that on the ninth day, Arjuna, one of the heroes of the epic Mahäbhärata, found his weapons that he had hidden a year before. It is said that he paid respects to his weapons, acknowledging their importance, before he started battle with his cousins. Because of this story, in Tamil Nadu, Karnataka, and Andhra Pradesh, the last two days dedicated to Lakșmī and Sarasvatī are called ayudhapūjā ("veneration of weapons and machines'). 
As a legacy of the Vijayanagara empire which covered parts of the modern state of Karnataka, we find some of the best-known and majestic Navarātri/Daśharā celebrations in this area. In the city of Mysore, the Mahārāja would worship the goddess Cāmuṇụi (a form of Durgā), ritually venerate the royal throne, weapons, and other symbols of royal power, as well as the multiple forms of the goddess Lakșmī. On the tenth day, he would ride on a gold seat on top of the royal elephant in a long and colourful procession to the northeast boundary of the city. After ritually hunting animals and worshipping the śam $\bar{\imath}$ tree, the torchlit procession came back to town for a royal darbār. Indeed, in an opulent display of military prowess, many kings and warriors in pre-colonial India frequently led ceremonial forays to the borders of their kingdoms and ritually crossed boundaries to simulate attacks against enemies - possibly a few miles away from the place where neighbouring monarchs were making those very ritual crossings into their own land.

In post-independent India, the grandeur and pageantry of the royal tournaments and processions associated with ayudhapījā have been replaced with more pervasive community celebrations. On the ninth day, the day of sarasvatīp $\bar{u} j \bar{a}$, Sarasvatī is worshipped in domestic and public forums. In Tamil Nadu, the day is marked by keeping all the musical instruments in the house, some writing devices, selected textbooks, computers, and so on, in front of Sarasvatī, and the display of dolls, to be blessed by her for the rest of the year. Weapons, tools, vehicles, modes of transportation, including public buses and trains, cars and bikes, and in recent years, even sporting gear, are shown respect. These are decorated with garlands and coloured kumkum powder and dedicated to the goddesses with locally constructed neighbourhood rituals, generally without the assistance of Brahman ritual specialists or other priestly personnel. It is a time when one recognizes with respect what one owes to the tools of trade, recreation, and entertainment.

The last day, the 'victorious tenth' day of Navarātri ('Vijayādaśamī' or 'Daśharā' in South India; 'Bijoya' in Bengal), when kings formerly made their symbolic conquests of other land, is dedicated to Lakșmī, the goddess of good fortune. People start new ventures, new account books, and learn new things on that auspicious day. Students in performing arts frequently meet and honour their traditional teachers - a practice very much encouraged among Hindus in the diaspora - and learn new pieces of music or the first steps of a new dance, and acquire new knowledge. On the last days of the Navarātri festival, the fortune of learning, the wealth of wisdom, and the joy of music are said to be given by the grace of the goddesses.

\section{The 'rosary', the swan, and the lotus}

The rituals connected with sarasvatīpūja explicitly articulate the respect shown to learning and performing arts and we noted that books, laptops, musical instruments, all that have a network of affordances connected with knowledge, and with continuing culture and tradition, are revered this day. But the Embassy Row Sarasvatī also comes with other symbols; she carries the 'akșamālā /rosary/tasbīh beads', stands on a lotus, and is accompanied by a swan. ${ }^{6}$ The beads are said, according to the sign below, to symbolize 'unlimited knowledge'; the swan is said to indicate 'wisdom'. Even this brief blurb below the statue seems to make a distinction between the 'knowledge' symbolized by the book on the one hand, and the 'unlimited knowledge' and 'wisdom' symbolized by the rosary and the swan, on the other. This distinction is inherent in some dominant strands of thought in the Hindu tradition, starting with the Upanișads. The Mundaka Upanișad states that there are two levels of knowledge: 
Two types of knowledge a man should learn ... the higher and the lower. The lower of the two consists of the Rgveda, the Yajurveda, Sāmaveda, the Atharvaveda, phonetics, the ritual science, grammar, etymology, metrics, and astronomy; whereas the higher is the one by which one grasps the imperishable.

Mundaka Upaniṣad 4-5; Olivelle 1996: 268

It is striking that the Upanișads, which the Hindus consider to be the last part of the Vedas, place themselves - and the specific, named Vedas in the category of 'lower' knowledge that is, part of learned, cognitive knowledge, whereas the higher knowledge is said to be the experiential wisdom, the experience of brahman itself. The higher knowledge cannot be grasped by words or the mind, and cannot be expressed. The manuscript points one in the direction of knowledge learned from books; on the other hand, the beads, which one uses for countless repetition of mantras or divine names, is seen here as symbolic of the higher knowledge. The swan (technically, goose), in popular culture, is indicative of the soul's connection with brahman, and also said to be symbolic of a soul which is only focused on getting the knowledge through which it gets the higher liberating wisdom. In much of Sanskrit literature, the hamssa is said to have discerning wisdom, separating 'milk from water'; and the Indian way of saying that it separates what is real from what is irrelevant, like separating the wheat from the chaff (Vogel 1962:7).

The Embassy Row Sarasvatī, therefore, provides us with a way of understanding the significance of material culture in contemporary Hinduism in India, and even Indonesia. But the location of this goddess is outside the Indonesian embassy which represents a country where less than 3 per cent of the population is Hindu. India, in line with its identity of being a sovereign, socialist, secular democratic republic (as stated in the preamble to the Indian constitution), is generally very careful about officially having religious symbols on public view. The Indonesian embassy, on the other hand, makes a political statement by having a Hindu goddess in its premises. Linda Wertheimer, the host of the NPR talk show introduced at the beginning of this chapter, asked Indonesian Ambassador Dino Djalal about the reasons for having Sarasvati. 'Indonesia is home to the largest population of Muslims in the world', she asked the ambassador; 'Why did you decide on a Hindu goddess?' Wertheimer noted in the broadcast that ' $[\mathrm{O}] \mathrm{f}$ all the statues on Massachusetts Avenue, that all of the embassies have put in front of their embassy, most of them are elderly gentleman with beards'. Ambassador Djalal, laughed, said that was a million dollar question and said:

One of the most famous - if not the most famous - islands in Indonesia is Bali. And Bali is a Hindu enclave in Muslim-majority Indonesia. And I think it says a lot about our respect for religious freedom that the statue in front of the country with the largest Muslim population is a Hindu statue. And, you know, we feel good about it. ${ }^{7}$

To have Sarasvatī, a Hindu goddess here, in front of the embassy whose country has the largest Muslim population in the world, is clearly not just a whimsical or aesthetic statement; it is a political one, just as it is to have gigantic Hanumāns, Buddhas, and Jain teachers in other parts of Asia.

\section{Concluding material}

Goddesses like Lakșmī are addressed as prakrti - the original nature or substance - and as vikrti, the modified and evolved state of prakrti, from which the material world arises and 
which is in essence non-different from prakrti (see Jacobsen 1999: 49-52). ${ }^{8}$ So too, as we have discussed, materialities and meanings are essentialized and evolve. Matter, in Hindu schools of thought and practice, as we have been discussing in this chapter, is heterogeneous. There are different kinds of 'matter-s' and different meanings attached to them. Meanings may be simultaneous and successive, or at any given time people may hold only one as important. Paper, however late its entrance into Indian culture, and however lowly, still has the potential to teach; and should not be shown disrespect. Matter, paradoxically is fluid; sometimes concrete, sometimes hyper-material, a tall statue may be a symbol of political clout, cultural capital, a deity who grants desires, a manifestation of ultimate reality, and move between the states. The significance of the materialities arises in part from their affordances to give, on the one hand, learning, happiness, and prosperity on this earth, and on the other, detachment and liberation from the cycle of life and death. It is through multiple matters that reality is continually created, manifested, and re-created; our bodies are matter and we think with physical brains composed of material grey cells. However, our bodies that are matter are also pervaded, at least in the material eyes of some Hindu schools, with souls. And both the nonconscious matter and souls are pervaded, as we saw, by brahman, or a super-soul and form its body; so that which has 'consciousness' or 'spirit' is also heterogeneous.

Despite her very material body and material accessories, despite her political and aesthetic presence, the explanatory statements about Sarasvatī (which are congruent with interpretations of the attributes given in oral traditions and popular culture) push one to explore the connections between materiality, consciousness, and deities with and without form. Her attributes suggest networks of affordances connected with materiality and performativity; and paths to liberation through them and transcending them. Like the embassy which is the piece of sovereign territory, a tangible presence of the country it represents, the goddess on Embassy Row is also - depending on one's perspective - fully divine or fully material, and as some could hold philosophically, a presence on earth as she is in heaven.

\section{Notes}

1 Transcribed from photographs of the statue and sign kindly supplied by Vasu Mohan, Washington DC, 24 May and 10 June 2014.

2 For instance, see the top three amongst the tallest statues in '7 Largest Statues in the World' at http://www.touropia.com/largest-statues-in-the-world/, accessed 30 May 2014

3 See 'Top 12 Incredibly Tallest Statues in India', accessed 5 June 2014. http://www.walkthroughindia. com/walkthroughs/top-12-incredibly-tallest-statues-in-india/

Of the top ten statues under eighty feet in height, five are of the divine-monkey deity, Hanumān; see ‘Top Ten Large Statues of India Below 80 Feet', http://www.walkthroughindia.com/ walkthroughs/top-ten-large-statues-of-india-below-80-feet/, accessed 5 June 2014.

4 http://www.storypick.com/12-simple-ways-piss-indian/, accessed 2 April 2014.

5 http://censusindia.gov.in/Census_And_You/literacy_and_level_of_education.aspx, accessed 10 June 2014. The figures are for the $200 \overline{1}$ census.

6 The hamsā is literally a goose but frequently translated as 'swan'.

7 Transcript of 'A Hindu Goddess Arrives To Bless Embassy Row'. http://www.npr.org/templates/ transcript/transcript.php?storyId=197146433, accessed 5 June 2015.

8 The Lakșmi Astotram is a prayer popular in Tamil Nadu in both domestic and temple spaces, and is used in ritual worship in Srī Vaișnava temples. It is of unknown date and origin which records one hundred and eight names of the goddess Lakșmī. It was probably canonical by the thirteenth century at least because Vedānta Deśika alludes to it. In this prayer, Lakșmī is addressed as prakrti and as vikrti. Although this prayer is transmitted and learned by way of oral tradition, it is now printed in prayer manuals and also available in the internet. 


\section{Bibliography}

Brown, C. M. (1986) 'Purāna as Scripture: From Sound to Image of the Holy Word in the Hindu Tradition', History of Religions, 26 (1): 68-86.

Carman, J. B. (1974) The Theology of Rāmānuja: An Essay in Interreligious Understanding, New Haven, CT: Yale University Press.

Darnton, R. (2002) 'Book Production in British India, 1850-1900', Book History, 5: 239-262.

Duff, A. (1839) India and India Missions: Including Sketches of the Gigantic System of Hinduism Both in Theory and in Practice, Edinburgh: J. Johnstone.

Glushkova, I. (2015) 'Objects of Worship as a Free Choice: Vițhobā (god), Dñyāneśvar (saint), Dñyāneśvarī (book), or samāalhī (grave)?', in K. A. Jacobsen, M. Aktor and K. Myrvold (eds), Objects of Worship in South Asian Religions: Forms, Practices and Meanings, 109-128, Abingdon: Routledge.

Jacobsen, K. A. (1999) Prakṛti in Sāṃkhya-Yoga: Material Principle, Religious Experience, Ethical Implications, New York: Peter Lang.

Jacobsen, K. A. (2015) 'The Material Culture of Sāṃkhya: Kapila as Object of Worship', in K. A. Jacobsen, M. Aktor and K. Myrvold (eds), Objects of Worship in South Asian Religions: Forms, Practices and Meanings, 51-66, Abingdon, Routledge.

Jīyar, P. P. (1975) Arayirappati Guruparamparāprabhāvam, S. Kirusnasvami Ayyankar (ed.), Tirucci: Puttur Agraharam.

Kabir, N. M. (2001) Bollywood: The Indian Cinema, London: Channel 4 Books.

Lipner, J. (1986) The Face of Truth: A Study of Meaning and Metaphysics in the Vedāntic Theology of Rāmānuja, Albany, NY: State University of New York Press.

Lutgendorf, P. (1994) ‘My Hanuman Is Bigger Than Yours', History of Religions, 33 (3): 211-245.

Lutgendorf, P. (2006) 'Is There an Indian Way of Filmmaking?', International Journal of Hindu Studies, 10 (3): $227-256$.

Lutgendorf, P. (2008) 'Cinema', in S. Mittal and G. R. Thursby (eds), Studying Hinduism: Key Concepts and Methods, 41-58, London, Routledge.

Mishra, V. (1985) 'Towards a Theoretical Critique of Bombay Cinema', Screen, 26 (3-4): 133-146.

Narayanan, V. (1985) 'Arcāvatāra: On earth as He Is in Heaven', in J. P. Waghorne, N. Cutler, and V. Narayanan (eds), Gods of Flesh/Gods of Stone: The Embodiment of Divinity in India, 53-68, Chambersburg, PA: Anima.

NPR (National Public Radio) (2013) 'A Hindu Goddess Arrives To Bless Embassy Row', http://www. npr.org/2013/06/30/197146433/hindu-goddess-blesses-embassy-row June 30, 2013 [accessed 5 June 2014]

Olivelle, P. (1996) Upanișads, Oxford: Oxford University Press.

Pathak, A. July 6, 2011. 'Publishing in India Today: 19,000 Publishers, 90,000 Titles, Many Opportunities', http://publishingperspectives.com/2011/07/publishing-in-india-today-19000publishers-90000-titles/ [accessed 5 June 2014].

Pattabhi Raman, N. (2001) 'What is Bharata Natyam?' http://www.narthaki.com/info/articles/article35. html [accessed 8 June 2014].

Plate, S. B. (ed.) (2003) Representing Religion in World Cinema: Mythmaking, Culture Making, Filmmaking, New York: Palgrave/St Martins, 19-42.

Plate, S. B (forthcoming) 'Cinema', in Manuel Vásquez and Vasudha Narayanan (eds), The Companion to Material Religion, Oxford: Wiley-Blackwell.

Srinivasa Chari, S. M. (1994) Vaișnavism: Its Philosophy, Theology, and Religious Discipline, Delhi: Motilal Banarsidass Publishers.

Staal, F. (1979) 'The Concept of Scripture in the Indian Tradition', in Mark Juergensmeyer and N. Gerald Barrier (eds), Sikh Studies: Comparative Perspectives on a Changing Tradition, Berkeley, CA: Graduate Theological Union.

Thibaut, G. (1890) The Vedânta Sûtras: With the Commentary by Sankarâkârya [and the Commentary of Râmânuga], Oxford: Clarendon Press.

Viṣnupurāna, see H. H. Wilson.

Vogel, J. P. (1962) The Goose in Indian Literature and Art, Leiden: E. J. Brill.

Wilson, H. H. (1840) The Vishńu Purána: A System of Hindu Mythology and Tradition, London: J. Murray. 


\title{
23
}

\section{HINDU PILGRIMAGE SITES AND TRAVEL}

\section{Infrastructure, economy, identity and conflicts}

\author{
Knut A. Jacobsen
}

Religions are grounded in geography, so too the religions of India. Their ritual life takes place in homes, temples and on the streets, in cities and villages, and in a variety of landscapes. Their key mythological and historical events are often thought to have occurred in these landscapes and their sacred figures are believed to have travelled in them. A large number of places in India are associated with such figures and mythological and historical events, and many of these sites attract visitors from beyond the location itself and they have thus become centres for religious travel and pilgrimage rituals. Religious traditions in India have at least since the time of the growth of Buddhism in the centuries around the beginning of the Common Era, propagated the great importance of 'salvific space"1 and the ability of these types of spaces to remove different kinds of suffering and to offer rewards to those who visit them. Travel to these places has been associated with the granting of religious rewards such as the attainment of salvation, mokșa, but also other rewards such as health, riches and rebirth in a wealthy family or in a heavenly world. Being present at the sites where the mythological or historical events according to the religious traditions have taken place may fulfil the religious longings of the pilgrims as well as confirm religious teachings and identities. Religious traditions of Hindus, Buddhists, Jains, Sikhs, Muslims and Christians possess pilgrimage sites in India, and travel to them remains one of the main expressions of religion in contemporary India. One aspect of religion in contemporary India is that more people travel on pilgrimage probably than ever before. ${ }^{2}$

One of the religions in India, Hinduism, is known to have a particular strong locative dimension (Bharati 1963, 1970, Eck 2012, Jacobsen 2013). One reason for the extensive sacred geography of Hinduism is that according to the Hindu traditions the divinities are present in the world and their powers are most strongly available, many Hindus believe, at particular sites, often marked by temples housing statues or icons (mürtis) of gods and goddesses. These statues in the temples are not symbols, but the divine powers themselves are present in the material objects of worship (see Jacobsen et al. 2015). The objects of worship are thought of as living icons and the temples are the homes of the gods and goddesses with the priests as their servants. These places may become pilgrimage sites to which people from 
outside of the locality travel to avail themselves of the salvific power. Other religions in India may have different views of the presence of the divine in statues, but those who identify with these religions may nevertheless also believe in the salvific power of pilgrimage places and they have strong pilgrimage traditions. Jainism and Buddhism have traditions of pilgrimage travel to places associated with their founding teachers of salvific liberation, the tivthankaras, buddhas and bodhisattvas, and other powers. Sikhism has pilgrimage traditions to the historical gurdwaras associated with their ten gurus from Guru Nanak to Guru Gobind Singh. Indian Roman Catholics perform religious journeys to places in India associated with their saints and places famous for visions of the Virgin Mary. Muslims travel not only on the Hajj to Mecca, but within India to visit dargāhs and other graves of holy persons. Contemporary India is a sacred landscape for several religions and these religions have separate imaginary religious maps with their own sacred sites. Some places are shared, and in India it is not uncommon for people to visit pilgrimage places devoted to sacred figures from different religious traditions from their own. I have frequently observed Muslims visiting the Catholic pilgrimage place of Velankanni in Tamil Nadu, and Hindus visiting the Muslim Dargāh of Nagore. The healing powers of these places attract large numbers of people regardless of their religious identity, and some also visit out of curiosity and for entertainment. That places are shared may in other instances mean contested (Sikand 2003). Claiming a place as sacred for one's own religion can also be an attempt at land grabbing as exemplified by the Ayodhya dispute and may represent expansion of one religion or reflect changing relations of power in society (Jacobsen 2013, Nandi 1986, Nath 2001, Sharma 1965). The immense importance of pilgrimage places in India may historically have its origin in the competition between Brahman priests and Buddhist institutions for the economic resources of ritual clients. Pilgrimage was absent in the ancient Vedic tradition (Bharati 1963, 1970, Hazra 1940, Jacobsen 2013, Nandi 1979/1980, 1986, Vassilkov 2002), but played an important role in early Buddhism. Religious travel to the places that were considered significant in the life of the historical Buddha and to stüpas with his earthly remains were, according to Buddhism, instituted by the Buddha himself. Some of the salvific power of the Buddha was thought to have remained in his relics and also at the places where the most important events of his life occurred, and they became sites of pilgrimage. They were often marked by stüpas, monuments containing his relics and symbolizing his presence, with the promise to those performing pilgrimage to these places of benefiting from their salvific power. The number of stūpas was expanded under the emperor Aśoka who used stūpas as well as pillars and inscriptions to mark areas under the political control of his empire. The marking of space as belonging to Buddhist institutions probably caused some Brahmans to start placing statues of gods at some locations and make them available for worship. The worship at these sites by giving gifts to the Brahmans was important also for the development of the Hindu temple traditions. Pilgrimage is not mentioned in the Vedas, and the earliest text to promote pilgrimage as a Hindu practice is found in the great Hindu epic the Mahäbhārata, probably only in its later parts, possibly written in the third, fourth and fifth centuries CE. This insertion of pilgrimage texts into the Mahäbhärata and the transformation of the text probably reflected the economic interests of the professional narrators (Vassilkov 2002) as well as of pilgrimage priests (Jacobsen 2013). Pilgrims usually would stay for a few days at the pilgrimage places and perhaps the bards adapted the narratives to the length required by the pilgrims. The Vedic gods were placeless (Angot 2009), but the narratives of the Hindu gods and goddesses connected them to the geography of India. The most important genre of text of these narratives, however, is not the Mahābhārata but the Purānas, a genre which was used by the pilgrimage priests to promote sacred sites and the new Hindu gods (who 
unlike the Vedic gods belonged to localities), and the promise of religious rewards to those who would visit and perform religious rituals at the places (see Nath 2001, 2007, 2009). Hindu pilgrimage is based on the belief that divine powers are present at particular sites, at some moments of time more intensely than others, and that by visiting these places when the powers are most strongly present, the pilgrims may fulfil vows and offer thanks for the fulfilment of wishes, gain or protect purity, overcome disease, obtain promises of riches, health, rebirth in Heaven and other salvific goals. For Hindus, travel to sacred sites is not a religious duty but a popular religious practice. In contemporary India, it is a favourite leisure time activity and has high entertainment value. It is likely that as many as 70 million pilgrims participated in the Mahākumbhamelā pilgrimage festival in Allahabad (Prayāg) in 2013, both to avail themselves of the opportunity offered by the combination of auspicious space and time and for entertainment and curiosity. But the large number of people participating in the Mahākumbhamelā is also an expression of contemporary changes in pilgrimage traditions in India. Current developments such as improvements in transportation and other infrastructures, economic growth and increased popularity of holiday travel, as well as the strengthening of religious identities and the use of religion in the competition for ideological hegemony have produced a peak in pilgrimage in India.

\section{Infrastructure and technology}

Travel is a normal activity in the modern world, and so is pilgrimage travel. The number of people travelling to India's pilgrimage places has increased enormously over the last 150 years. The building and expansion of the railway system altered the patterns of pilgrimage throughout India (see Kerr 2002, 2006). Its continuous expansion and the development of the road system and improved quality of car and bus travel have provided easier access and safer travel, and resulted in not only an increase in the annual flow of pilgrims but also new patterns of pilgrimage. Easy access has created larger crowds. Crowds and easy access have further increased the magnetism ${ }^{3}$ of sites and the larger the crowds, the more people want to visit a place.

There are countless examples in India of the transformation of pilgrimage travel and patterns due to railway connections and improved roads. Places that before were accessible only after long walks can now be reached by bus. Good examples are the North Indian pilgrimage places of Hardwar, Rishikesh and Badrinath, which used to be reached by foot, but to which pilgrims now arrive by train (to Hardwar) and by bus. This has led to a large increase in the number of pilgrims and a change in their expectations. Even to those places which are not yet completely accessible by road, the distances that have to be walked have become shorter and more easily accessible. Services along the route and accommodation have improved, and the number of pilgrims has soared from a few thousand a year to millions in many places (good examples, also from North India, are Amarnath and Vaishno Devi in Jammu and Kashmir). Travel to Amarnath used to involve several days of trekking, but now one can walk from a comfortable hotel to the cave with the sacred linga and back in one day. Helicopter pilgrimage to Amarnath is also available, to avoid walking completely. The meaning of pilgrimage is then simply to have darsan at the sacred site. Travel agencies specializing in pilgrimages organize multi-site pilgrimage tours on which pilgrims may have darśan at a number of places on one trip (for a description see Gold 1988).

In South India as well, a number of pilgrimage places have been transformed by railway and road construction, and one such place is the pilgrimage centre of Shri Sailam in Andhra Pradesh. Before construction of the road, Shri Sailam was accessible only by difficult treks 
and had very limited services for the pilgrims who are reported to have suffered greatly from the lack of water and shelter. The contrast between the before-and-after infrastructure improvements is striking. In 1927 P. V. Hanumantha Rao wrote an account, 'Report of the Pilgrimage to Sreesailam', which gave a description of the difficult situation for the pilgrims. He started his report by stating:

The journey to Srisailam is most tiresome and difficult ... No water is available for many miles to come, and in places where it is available, is only rainwater stored in small pools. ... the [sanitary] arrangements are most unsatisfactory. They are not sufficient to meet the demand of so many thousands of pilgrims.

Rao 1927: 1

Rao emphasizes the great suffering of the pilgrims:

One who had occasion to visit that holy place will not forget the sufferings he had undergone throughout his life. The place is devoid of shade or shelter and the authorities have not made any arrangements for the stay of pilgrims. Each pilgrim gets a small shelter of twigs and cooks his food underneath it. The demand for water was so great that many pilgrims flocked to river Krishna a day previous to Sivaratri. The suffering of others that remained in Sreisailam (sic.) was indeed very great. The outer Koneru water was so dirty and yet people flocked to it. ... Starting from Nagaluty no water is available as far as Pecheruvu and from Pecheruvu to Srisailam, a distance of 26 miles. ... The way is hopelessly bad, slippery and narrow in many places. ... If only pilgrims are aware of the great hardships and difficulties that are experienced, I am sure many would not venture to such a place.

Rao 1927: 7-8

The law and order situation was also a problem for pilgrims: 'In addition to pilfering, decoities also took place. Men were beaten and their all was stolen. One cannot be sure of reaching home safe and sound after his pilgrimage to Srisailam' (Rao 1927: 9). Rao concludes that unless something is done to improve the situation for the pilgrims, the officials should 'emphatically prevent the pilgrims from going to Srisailam' (Rao 1927: 9), and that 'If such state of affairs continues for some years more the pilgrimage to Srisailam must be forgotten' (Rao 1927: 8). The contrast between this description of an actual pilgrimage and the Māhātmyas (texts that tell stories about sacred sites and promote their salvific power) and Purānic propaganda texts promoting pilgrimage places is noticeable. After visiting the place, Rao changed his mind, from feeling a sense of pride that the pilgrimage place was in his district to shame. Rao asked the government to take responsibility 'to do the needful to relieve the distress of pilgrims' (Rao 1927: 2). He reports that 25,000 pilgrims came to Shri Shailam that year (1926), which he thinks was a record high (Rao 1927: 7). In contrast, three quarters of a century later, in 2002, the number of pilgrims for the Sivarātri festival alone was 600,000 (Reddy 2014: 189), the annual flow in the millions. It was after the building of roads in 1956-1957 that the situation changed. Reddy writes in her study of Shri Shailam:

The construction project marked a major transformation for Shri Shailam town as bus transportation services started immediately and eventually led to an exponential increase in the number of pilgrims visiting Shri Shailam throughout the year, particularly during annual festivals. This has in turn greatly stimulated the economy 
of the pilgrimage center. ... The road construction was the turning point for the temple ... and it facilitated a link between Shri Shailam and major cities in the north, the south and the east by making travel for pilgrims much more feasible and safer than before.

Reddy 2014: 164

More pilgrims led to further economic investments:

Private developers are able to purchase land from the SD [Shrīshaila Devasthānam] and are allowed to build large-scale residential buildings equipped with amenities to accommodate a year-round pilgrim population.

Reddy 2014: 165

Reddy also mentions how Shri Shailam further developed into a centre of learning both with traditional schools as well as a branch of Telegu University, and a heritage museum and a tribal museum. Old sites of religious significance have been restored which gives the pilgrims a quite different experience. The places are grouped together as part of an established pilgrimage route, but now special bus tours are organized to transport the pilgrims between the places. Tour guides now guide pilgrims and the Andhra Tourist Department arranges boat trips, and a ropeway has been built and 'sites that were previously ignored have become popular sightseeing places that any pilgrims enjoy during their visit to Shri Shailam' (Reddy, 2014: 166). Prabhavati Reddy sums up the transformation in the following way:

Prior to the road construction, the sites ... served as resting places, since pilgrimages were conducted mostly on foot. Older pilgrims had a deep emotional attachment to these places since they stayed there for a significant amount of time during their journeys. ... For modern pilgrims these places are merely a set of tourist sites which can be seen and experienced in a matter of hours.

Reddy 2014: 166

The state (Endowments Department of Andhra Pradesh [EDAP]) has both administered the centre and been agent of the religious programme and implemented the changes in the physical geography and the temple complex. It also played a significant role in the revival of the religious culture with the establishment of temple traditions and daily practices, and special religious programmes and annual festivals.

The history of the transformation of Shri Shailam due to improved infrastructure has been documented in detail (Reddy 2014), but a large number of Indian pilgrimage centres have experienced or are experiencing similar or even greater expansions; notable examples are Vrindavan and Hardwar. As pilgrimage tourism, now often called 'heritage tourism', has become an important area of investment, and many pilgrimage places are being selected as 'mega tourist destinations', pilgrimage sites are being transformed into 'tourist friendly places'.

The Internet and mobile phones also play a role in the contemporary transformation of pilgrimage rituals, creating new ways of organization. An example is found in Siddhpur in Gujarat, the place for śräddha for mothers, and a place of cremation, and an important place for worship of the Kapil muni avatära (see Jacobsen, 2008a). When I did fieldwork in Siddhpur in 1999, the priests performed śräddha rituals individually for each family. Each priest sat with a few persons in a circle around him or just opposite. When I revisited Siddhpur in 2012, not 


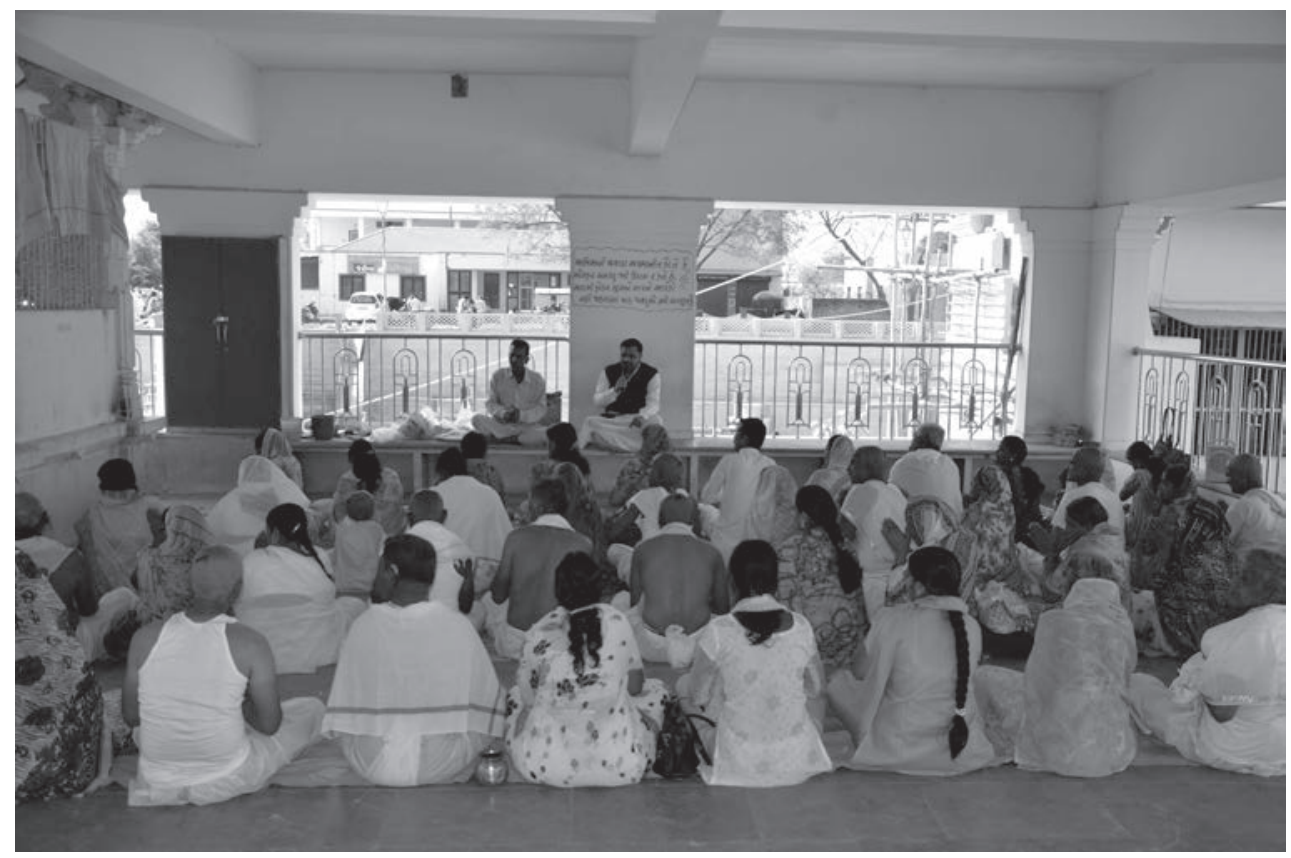

Figure 23.1 Srāddha ritual as a collective ritual for a large group in contemporary Siddhpur

Source: Knut A. Jacobsen

only was the Kapil Mandir being renovated and expanded because of a government grant to increase its attraction for pilgrims, but the priests had started to utilize mobile phones as well as the Internet to organize the clients of their śäddha rituals in a different manner. The priests were using email to organize people so that they arrived on the same day and performed the śräddha together at the same time in one common ritual event. Between fifty and one hundred pilgrims were now sitting in rows like in a classroom and the priest led the ritual from an elevated platform (see Figure 23.1) and had them all perform the details of the ritual with the material items in front of them and repeat the mantras together at the same time (see Figure 23.2). While the sequence of the śräddha ritual was the same, the experience had become different, as it now had become a collective ritual for a group of more than fifty participants and was no longer an individual family ritual. In 2012 Siddhpur had become part of a Gujarat state project of infrastructure development to promote 'heritage tourism', leading to further changes. The railway station at Siddhpur was also rebuilt to attract pilgrims. In the Tourism Corporation of Gujarat document seeking developers for the project, cultural heritage, as well as the connection between the economy and preservation of cultural heritage, were emphasized. ${ }^{4}$ Here the concept of pilgrimage was replaced by the secular concepts of 'tourism and cultural heritage', and preservation of the cultural heritage was seen as urgent due to economic growth and urbanization threatening this heritage.

\section{Economy}

In the above descriptions it becomes apparent that there is a close relationship between pilgrimage and the economy. Pilgrimage in India has probably always had a strong economic dimension. Economy has influenced the growth, development and decay of pilgrimage places. 


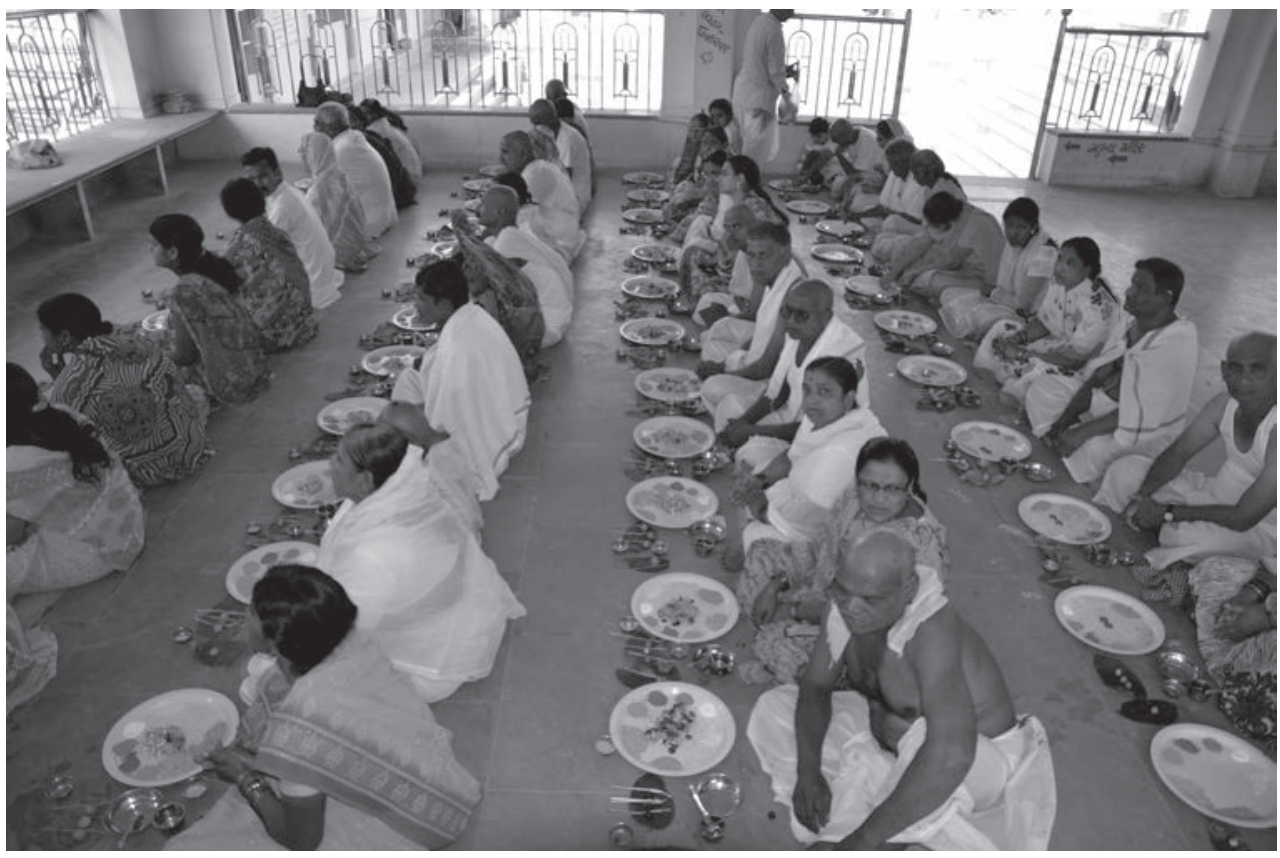

Figure 23.2 The pilgrims sitting in rows with the material items of the śräddha ritual in front of them

Source: Knut A. Jacobsen

Competition for ritual clients and their economic resources lies at the foundation of the dynamics of pilgrimage and has been important for the rise and fall of pilgrimage places. The exaggerated claims of salvific rewards said to be granted to those who visit the places, which are a feature of the texts and persons propagating the pilgrimage places, have to be explained in the context of this competition for clients and their economic resources. Pilgrimage places are economic institutions that often depend almost totally on the economic resources of the pilgrims and they compete with other pilgrimage places for these economic resources. Pilgrims are most often aware of the exaggerated nature of the claims of the pilgrimage places and the greed of the pilgrimage priests, but they nevertheless do perform the journey and participate in the rituals. However, the pilgrimage priests, the pandās, have the lowest status among Brahmans in India and are considered greedy and rapacious (Lochtefeld 2010: 131). Pandās, writes Lochtefeld in his study of Hardwar as a place of pilgrimage, 'have clear incentives to seek the largest possible gift, whereas clients have clear incentives to offer less' (2010: 131). Gifts transfer inauspiciousness from the clients to the priests, and this inauspiciousness/impurity adds to the pandās' low status. Today pandīas can have other jobs and act as pand̄ās in their spare time. They have adapted to the growth of tourism to the pilgrimage places and expanded their business to include hotels and shops and so on, which is not that different from their previous work.

After the urban decay in ancient India from the third century CE (Sharma 1987), caused by economic changes, some cities survived or recovered as urban centres by redefining themselves as salvific cities claiming to possess inherent salvific power and thus securing an income from pilgrims. The idea of salvific space and the practice of pilgrimage were of great importance for the Hinduization of India. The promotion texts of many Hindu pilgrimage places are found in the Māhātmyas that typically exaggerate the salvific rewards, and the texts 
are in reality advertisements. The Māhātmyas were often written by pilgrimage priests, who harvested the economic benefits of the pilgrims and made a living from offering services to them. An important aspect of the texts is the promotion of gifts to the Brahmans and a variety of rituals were invented to increase income. One example from Hardwar tells how

every pilgrim was obliged to throw a small piece of gold into the Ganges, without which the bathing would not be efficacious. As one might expect, this gold did not simply fall to the riverbed, but provided a rich harvest for the functionaries there, who would either retrieve it before it hit the bottom or use small flat baskets to sort through the debris. Timur mentions this in his brief description of Hindu practices, and it continues to this day.

Lochtefeld 2010: 66

As this example illustrates, the economy is at the core of the institution of pilgrimage and probably was so from early on. The texts promote the view that the sites have salvific power and grant that pilgrims will get rewards, and encourage them to buy the ritual services of the Brahmans. Hindu pilgrimage texts focus most typically on the sites, and much less on the travel to the sites (Jacobsen 2013). The transport to the sites does not seem to have been an important part of the economy and could, it seems, be more or less eliminated without the sacred power of the place becoming eliminated. An exception is the loss of merit from travelling by ox cart to Prayāg, asserted in the Māhātmyas about this place, but which may also be economically motivated due to an unwillingness of the pandīs to share any of the economic resources of the pilgrims with ox-cart drivers.

The origin of pilgrimage as part of the Brahmanical tradition was probably an imitation of Buddhist pilgrimage rituals in order to compete with Buddhist institutions for the economic resources of the pilgrims. The Māhātmyas were incorporated into Purānas, and this Purānization of pilgrimage traditions 'was a successful ancient Indian marketing device that contributed to the transmission of sacred geography' (Reddy 2014: 105). As Ian Reader has noted:

Pilgrimage is located in and operates through the marketplace, and it is through the mechanisms of the marketplace that constructs such as the sacred are materialised and successful pilgrimage sites emerge. ... If pilgrimage is about faith, miracles and worship, it is also about marketing, promotion, invention, entertainment, material consumption, the buying of goods and sightseeing.

Reader 2014: 195

Reader suggests that marketing is the central issue of pilgrimage that needs to be addressed to understand how and why pilgrimage comes about and attracts clientele. Hindu pilgrimage succeeded not least because of successful marketing. The social system of pre-modern, and to some degree modern Hindu India, was based on caste, a hierarchy legitimized by an ideology that claimed that most people were inherently impure. Caste ideology was obsessed with impurity, and so was the ideology of Hindu pilgrimage. The priests at the pilgrimage places promised removal of impurity (päpa) but at the same time they promoted an ideology of its omnipresence. The idea of impurity secured their own social status as well as their economic well being. In recent years more emphasis has been placed on pilgrimage as heritage tourism and celebration of identity, but the idea that by visiting pilgrimage places one washes away impurity persists. 
One reason for the current peak in pilgrimage travel is that the religious and economic institutions have a shared interest in the growth of pilgrims and both participate in marketing the places. Buddhadeb Chaudhuri researched how the idea of sacredness of the pilgrimage site Bakreshwar (a śakti pițha) in West Bengal was transmitted in order to attract pilgrims in the 1970s (Chaudhuri 1981). The main temple in Bakreshwar is a Siva temple devoted to Śiva as Bakranāth. Another important attraction is its hot springs that were believed to have healing powers. Chaudhuri investigated the increase in the number of pilgrims. How was it that the number of pilgrims continued to grow despite secularization of society? Bakreshwar gives several reasons. The Sanskrit school attracted students from a wider area and they 'played an important role in propagating the cult of Siva of Bakreshwar' (Chaudhuri 1981: 49). The Brahman priests have usually had a jajmānī relationship to pilgrim families, and members of these families have moved to a wide area for education, marriage and work, and have propagated the sacredness of the place. The priests have also used modern ways of communication associated with tourism to attract pilgrims, such as distribution of pamphlets and postcards describing the sacredness of the region and the powers of the hot springs in the area to cure diseases. While sādhus (ascetics) wander and spread the word about sacredness as well as the food and gifts offered to them at the places of pilgrimage, other persons who also have material benefits from the pilgrims, such as shop owners, also propagate the place's sacredness 'out of their own economic interests' (Chaudhuri 1981: 50). The annual fair attracts shop owners as far away as Kolkata and also beyond the state of West Bengal to set up shops. Even the beggars, noted Chaudhuri, 'have abiding interest in the perpetuation of the sacred myth of Bakreshwar which would attract more and more visitors to the sacred area and fetch them more money' (Chaudhuri 1981: 52). Chaudhuri counted 606 shop owners in the annual fair of 1974 with around 20,000-25,000 pilgrims. Chaudhuri also noted that modern media such as newspapers and radio, improved transport systems and tourism have contributed to spreading the religion of Siva at Bakreshwar. The Brahmans distributed pamphlets at the site about the sacred stories of the place. It was also notable that the sacredness of the place was advertised in newspapers in Kolkata by the Tourist Department of West Bengal thus encouraging pilgrimage tourism.

Chaudhuri concluded that the most distinctive feature of Bakreshwar was not the dominance of Siva worship, but 'the presence of numerous ritual styles, sects, faiths, temples and shrines' (Chaudhuri 1981: 86). This plurality is a function of the marketplace. The economic incentive is to offer as varied products as possible and to include everyone. The more varied the religious traditions, the more people will come and contribute to the economy. Chaudhuri notes that the commercially oriented attitude of the Brahman families is quite conspicuous: 'The economic implications are often more emphasized, sacred contents are becoming less meaningful' (Chaudhuri 1981: 91). However, the phenomenon of Hindu salvific space at pilgrimage places has throughout history aimed to attract as many devotees as possible and to promote the belief that all the goals of religion are easily attainable for everybody. Hindu salvific space at pilgrimage places includes everyone. No one is excluded and even the worst criminal can easily attain mokșa just by taking advantage of the salvific power of the pilgrimage place, according to the Māhātmyas. An important reason for this attitude is economic, as a means to attract as many pilgrims as possible. Pilgrimage in India therefore tends to promote inclusiveness and a welcoming attitude towards all. The web pages that advertised the 2013 Mahākumbhamelā in Prayāg read like a commercial: 'This is the only time and place in the world where you can unburden your sins and achieve "Nirvana" from the vicious cycle of birth and rebirth. ${ }^{5}$ The same web page states: 'Kumbh 
Mela is not just a mere festivity like Diwali and Holi', but 'this event gives them [the participants] a golden opportunity to liberate themselves from the miseries and sufferings of life. It enables them to take a holy dip in the sacred water and wash away all the sins they have committed in the past'. It is easy and nothing other than contact with the water is needed: 'taking a holy dip in water paves the way for attainment of Moksha'. ${ }^{6}$ The increasing number of pilgrims at the Prayāg Mahākumbhamelās indicates to what degree the idea of salvific space and pilgrimage is thriving in contemporary Hinduism and of its economic importance for the groups who profit from it.

\section{Identity and conflicts}

Pilgrimage in India is to a large degree a local and regional phenomenon, an expression of local and regional patriotism and identity. The promotional literature of pilgrimage places can be understood also as a form of local patriotism. Among Hindus there is no agreement on a single pilgrimage site being more important than all others, but in the regions some pilgrimage places have been important for the development of its religious identity (Bhardwaj 1973, Jacobsen 2013). Examples of such regional sites are Pandharpur in Maharashtra, Sabarimala in Kerala, Tirumala and Shrisailam in Andhra Pradesh, Amarnath and Vaishno Devi in Jammu and Kashmir, Varanasi and Allahabad in eastern Uttar Pradesh. One reason the Mahākumbhamelā in Allahabad is attended by the largest number of people is that it is situated in the middle of the Ganges Valley, which is densely populated; the population in Uttar Pradesh alone is more than 200 million. In other words, the large majority of the pilgrims of the Mahākumbhamelās come from the region itself. Uttar Pradesh is often thought of not as a region but as the centre, however, the state is in fact culturally and linguistically divided into several regions. This is not denying that many visitors come from other states as well as from abroad for the Mahākumbhamelā. The blending of the pilgrimage industry and tourism is typical of contemporary pilgrimage, and some sites have been able to attract international tourists. Varanasi, often promoted as the pilgrimage centre of Hinduism, is also just a regional centre, enthusiastically promoted by its own pilgrimage industry, and the promotional texts about Varanasi, several of which have been written by Western scholars (for a good example see Eck 1982), contrast greatly with the views of those Indians who do not share the belief in the city's sacredness or participate in its ideology of local patriotism. ${ }^{7}$ Writes the Indian sociologist Dipankar Gupta:

For most Indians who don't live in Varanasi, though many local residents would disagree, it is a stinking, dirty pile of earth and bricks, with temples at every street corner that are equally filthy.

Gupta 2009: 22

The quote, which contrasts totally with the promotional texts about Varanasi, not least those written by Western scholars, illustrates the importance of local patriotism in the admiration of pilgrimage places. And Gupta notes the role of Westerners in the transformation of the image of Varanasi:

Yet, as foreigners are crowding this place many Indians have begun to find virtues in Varanasi. They too come to this city as tourists and not as they used to earlier, just to die by the Ganges and go straight up without further mediation.

Gupta 2009: 22 
Followers of religions may claim places as theirs by arguing that mythological events supposedly took place there. Human-built structures such as stüpas, temples and statues on these sites can be markers of ownership and expressions of power. The erection of giant statues of the Buddha and of the Hindu gods Hanumān (Lutgendorf 1994) and Siva (the world's largest is apparently in Kathmandu, Nepal and is 43.5m high, completed in 2010) that can be observed at many places in contemporary India is a way of claiming space as belonging to one's own religion. Giant Buddha statues have been built and more are being planned in Sarnath and Bodhgaya (Jacobsen, 2010). A new Hindu temple, Chandrodaya Mandir, to be built in Vrindavan will be the tallest temple structure in India. It will have a height of about 210 metres, and be perhaps the world's tallest temple. ${ }^{8}$ President Pranab Mukherjee laid the foundation stone for the temple on 16 November 2014. Statues of Ambedkar are found in a large number of villages and cities in India, and Ambedkar is often claimed to be the person of whom there are the most public statues. Currently the Indian government is making a statue of Sardar Vallabhai Patel, one of the founding fathers of India, which will be 182 metres high, making this the largest statue in the world according to the website that promotes the project, ${ }^{9}$ reflecting the current power of the Bharatiya Janata Party, and larger than the Buddha statues promoted by the Bahujan Samaj Party when it was in power in Uttar Pradesh (Jacobsen 2010).

The conflict of sacred space in India that has received most attention is the place considered by many Hindus to be the birthplace of Rāma: the city of Ayodhya (but see Sikand 2003 for a number of other disputed places). The Bharatiya Janata Party (BJP) rallied support around the supposed birthplace of Rāma as a strategy to mobilize a political constituency in order to win national elections in the late 1980s and 1990s. The strategy was to rally Hindu voters by focusing on identity issues. The difficulties experienced by Hindus wishing to worship at the birthplace of Rāma was used as a symbol to propagate the view that religious pluralism in India had a negative impact on the Hindus. The mosque Babri Masjid in Ayodhya was used to symbolize a postulated neglect of the religious interests of the Hindus by the Indian government. Hindu nationalists argued that the Babri Masjid was built on an earlier temple that marked the birthplace of Rāma. Hindu nationalism here used traditions of pilgrimage and salvific space to mobilize Hindus politically. Procession pilgrimage that conquers space as it moves onwards (Davis 2005, Jacobsen 2008b, 2009), the idea of the divine as weak and threatened by contemporary human impact on the pilgrimage sites, the identification of the materiality of the salvific site with the salvific power as such were used for political purposes. The political movement managed to mobilize religious organizations and individuals and led to the forceful destruction of the mosque on 6 December 1992. This was followed by communal riots in which several thousand people were killed, the majority of them Muslims. The High Court of Allahabad ruled on 30 September 2010 to divide the property in three equal parts - one part to Hinduism, one to Muslims and one part to the Hindu organization Nirmohi Akhāṛā. ${ }^{10}$ The lawyers appealed against the judgment and the issue has not been resolved. The conflict demonstrates that both religious and political powers are concerned with places of pilgrimage and illustrates the way expansion of pilgrimage space can be a way to secure land for one's own religion.

The ideology of a homogeneous Hindu nation used geography and Hindu sacred spaces to affirm a Hindu essence, its Hinduness, hindutva. The use of processions to claim land was combined with the issue of Ayodhya, claiming that the ground under the Babri Masjid was Hindu sacred ground; that it was the space on which the god Rāma had manifested. The court verdict of 30 September 2010 confirmed this interpretation, the peculiar Hindu view of connecting geography and mythology, that spaces are divinities, as absolutes that even the 
gods must obey. The case of Ayodhya shows that the postulated timelessness of sacredness is an efficient promotion device, and indicates the connection of pilgrimage space to the desire of political dominance. Sites can be contested and thus gain increased importance as they become symbols of power. Political conflicts over pilgrimage places highlight the paradox that the material pilgrimage site is not only the immanent form but also a transcendent salvific power, and emphasizes the question of to what degree are contemporary geographical places to be identified with the salvific sites of the sacred narratives (Jacobsen 2013). Hindu sacred narratives are often presented as describing events of previous yugas involving ideas that are removed from contemporary conceptions of history.

Shared sacred space is not an unusual phenomenon in south Asia and it can be a source not only of conflict but also of the development of a composite culture (Sikand 2003, Jacobsen 2009). The composite culture of India has meant that many Hindus worship at Muslim sacred places, especially Sufi shrines. A famous case of a tirtha that is shared by several religions is the Ayyāppan pilgrimage to Sabarimalai which combines the worship of the Muslim Vāvar at the foot of the Sabari Hill and the Hindu god Ayyāppan at the top. The shrines of Vāvar and Ayyāppan provide, according to one observer, 'a place where all distinctions, including religious ones, are broken down' (Daniel 1984: 252). Sikand has observed that in the Muslim dargāhs Hindus revere the Muslim saints 'in a purely functional sense - powerful beings endowed with considerable śakti or power, capable of granting their wishes, of providing sons to barren women or a cure to a deadly disease' (2003: 18). The composite culture is a practice supported by traditions, but not by doctrines. Sikand argues nevertheless that shared religious traditions defy the preconception that religious communities are sharply divided from one another, homogeneous and neatly defined. They point instead to ways people can come to terms with multiple religious identities and suggest the possibility of finding truth in a multiplicity of religious contexts and represent a critique of religious hierarchies and orthodoxies, and perhaps also ways to share places of pilgrimage. But the Ayodhya conflict illustrates that the shared religious traditions of the Hindu-Muslim composite culture, which was a dominant phenomenon in Indian religious culture, have lost much of their strength during the last hundred years. Sikand has argued that the quest for social ascension translated into assertions of a more orthodox 'Hindu' and 'Muslim' identity and 'upwardly mobile sections within these communities fiercely attacked the shared religious traditions that had once characterized them' (2003: 14). This led to the transformation of sacred space and pilgrimage places were used to confirm religious identities.

The growth of pilgrimage travel in contemporary India is influenced by the mobilization around regional and religious identities but probably even more by the rapid improvements of infrastructure and the growing market economy. Economic interests and power are often found expressed in sacred geography. However, the focus of Hindu pilgrimage in contemporary India seems to a certain extent to be on happiness and auspiciousness and leisure time entertainment, similar to the idea of travel promoted by the tourist industry, and less on the discomfort of travel and the reward of mokșa. Improved infrastructure and improved economy are transforming Hindu pilgrimage.

\section{Notes}

1 For the concept of 'salvific space', see Jacobsen 2013.

2 Mass pilgrimage to many places started only with the economic, political and technological changes of the British. The neutrality of British colonial power with regard to religious issues favoured the consolidation of Hinduism. The pilgrim tax was abolished in 1833, but even before 


\section{Hindu pilgrimage sites and travel}

this abolition the number of pilgrims had grown. Pilgrimage had become a status ritual that spread from aristocratic families to the recently ennobled zamindars and to the emerging business and service class (Entwistle 1987). From the late eighteenth century, aristocrats and merchants began to restore the old ghäts in cities such as Mathura, Vrindavan, Ayodhya and Varanasi, and many new ones were built throughout the nineteenth and twentieth centuries (Entwistle 1987).

3 For the concept of 'magnetism' in relation to pilgrimage, see Preston 1992.

4 See http://www.gujarattourism.com/file-manager/tenders/118/siddhpur_pmc.pdf [accessed 28 December 2014].

5 http://kumbhmela.co.in/kumbhmela1.html [accessed 1 January 2012].

6 http://kumbhmela.co.in/kumbhmela1.html [accessed 18 January 2012].

7 The idea of Varanasi as a sacred city and a site welcoming and rewarding pilgrims was important for the re-establishment of Varanasi as an urban centre after the period of urban decay and the disappearance in the first centuries of the Common Era of Varanasi's ancient settlement of Rajghat near the confluence of Ganga and Varana, today on the northern outskirts of the city. The increasing number of Indian and international tourists visiting Varanasi has led to the establishment of new rituals and festivals in order to satisfy the tourists who expect to experience religion as part of their visit.

8 See 'Vrindavan -spiritual capital of India to get a 700 feet high temple', https://www.iskconbangalore. org/vrindavan-spiritual-capital [accessed 28 December 2014] and 'President Pranab Mukherjee to lay foundation stone of tallest Krishna temple in Vrindavan', DNA, Saturday, 15 November 2014, http://www.dnaindia.com/india/report-president-pranab-mukherjee-to-lay-foundation-stone-oftallest-krishna-temple-in-vrindavan-2035410 [accessed 28 December 2014].

9 See 'Sardar Vallabhbhai Patel', http://www.statueofunity.in/statue-of-unity-sardar-vallabhbhaipatel.html [accessed 28 December 2014]. It is called a statue of unity, according to the website, because Patel 'was determined to unite 562 princely states with the mainstream India after the British Raj came to an end'.

10 See http://www.allahabadhighcourt.in/ayodhyabench4.html and http://rjbm.nic.in/ [accessed 2 January 2012].

\section{References}

Angot, M. (2009) 'Land and Location: errant gods, erring Asuras and the land of men: place and space in Vedic literature', in D. Berta and G. Tarabout (eds), Territory, Soil and Society in South Asia, 41-97, New Delhi: Manohar.

Bharati, A. (1963) 'Pilgrimage in the Indian Tradition', History of Religions, 3 (1): 135-167.

Bharati, A. (1970) 'Pilgrimage Sites and Indian Civilization', in J.W. Elder (ed.), Chapters in Indian Civilization, 85-126, Dubuque, IA: Kendall-Hunt.

Bhardwaj, S.M. (1973) Hindu Places of Pilgrimage in India, Berkeley, CA, University of California Press. Chaudhuri, B. (1981) The Bakreshwar Temple: a study on continuity and change, Delhi: Inter-India.

Daniel, V.E. (1984) Fluid Signs: being a person the Tamil way, Berkeley, CA: University of California Press.

Davis, R.H. (2005) 'The Iconography of Rama's Chariot', in D. Ludden (ed.), Making India Hindu: religion, community and the politics of democracy in India, 2nd ed., 27-55, New Delhi: Oxford University Press.

Dubey, D.P. (ed.) (2001a) Kumbha Mela: pilgrimage to the greatest cosmic fair, Allahabad: Society of Pilgrimage Studies.

Dubey, D.P. (2001b) Prayaga: the site of Kumbha Mela: in temporal and traditional space, New Delhi: Aryan Books International.

Eck, D.L. (1982) Benares: city of light, Princeton, NJ: Princeton University Press.

Eck, Diana (2012) India: a sacred geography, New York: Harmony Books.

Entwistle, A. (1987) Braj: center of Krishna pilgrimage, Groningen: Egbert Forsten.

Gold, A.G. (1988) Fruitful Journeys: the ways of Rajasthani pilgrims, Berkeley, CA: University of California Press.

Gupta, D. (2009) The Caged Phoenix: can India fly? New Delhi: Penguin.

Hazra, R.C. (1940) Studies in Purānic Records on Hindu Rites and Customs, Dacca: University of Dacca.

Jacobsen, K.A. (2008a) Kapila: founder of Sāmkhya and Avatāra of Viṣnu, New Delhi: Munshiram Manoharlal.

Jacobsen, K.A. (ed.) (2008b) South Asian Religions on Display: religious processions in South Asia and the diaspora, London: Routledge. 
Jacobsen, K.A. (2009) 'Processions', in K. A. Jacobsen (ed.), Brill's Encyclopedia of Hinduism, Volume One: regions, pilgrimage, deities, 445-455, Leiden: Brill.

Jacobsen, K.A. (2010) 'Establishment of Buddhist Sacred Space in Contemporary India: the Ambedkarite Buddhism, Dalit civil religion and the struggle against social exclusion', in Eliezer Ben-Rafael and Yitzhak Sternberg (eds), World Religions and Multiculturalism: a dialectic relation, 219-236, Leiden: Brill.

Jacobsen, K.A. (2013) Pilgrimage in the Hindu Traditions: salvific space, London: Routledge.

Jacobsen, K.A., Mikael Aktor and Kristina Myrvold (eds) (2015) Objects of Worship in South Asian Religions: forms, practices and meanings, London: Routledge.

Kerr, I.J. (2002) 'Reworking a Popular Religious Practice: the effects of railways on pilgrimage in 19th and 20th century South Asia', in Ian J. Kerr (ed.), Railways in Modern India, 304-327. Delhi: Oxford University Press.

Kerr, I.J. (2006) Engines of Change: the railroads that made India, Westport, CT: Praeger.

Lochtefeld, J.G. (2010) God's Gateway: identity and meaning in a Hindu pilgrimage place, New York: Oxford University Press.

Lutgendorf, P. (1994) 'My Hanuman is bigger than yours', History of Religions, 33 (3): 211-245.

Nandi, R.N. (1979/80) 'Client, Ritual and Conflict in early Brāhmaṇical Order', Indian Historical Review, 6: 64-118.

Nandi, R.N. (1986) Social Roots of Religion in Ancient India, Calcutta: University of Calcutta.

Nath, V. (2001) Purānas and Acculturation: a historico-anthropological perspective, New Delhi: Munshiram Manoharlal.

Nath, V. (2007) 'Purānic Tīrthas: a study of their indigenous origins and the transformation (based mainly on the Skanda Purāna)', Indian Historical Review, 34: 1-46.

Nath, V. (2009) The Purānic World: environment, gender, ritual and myth, New Delhi: Manohar.

Preston, J.J. (1992) 'Spiritual Magnetism: an organizing principle for the study of pilgrimage', in A. Morinis (ed.), Sacred Journeys, 31-46, Westport, CT: Greenwood Press.

Rao, P.V.H. (1927) Report of the Pilgrimage to Sreesailam, Nandyal: The Sree Kanyakaparameswari Press.

Reader, I. (2014) Pilgrimage in the Marketplace, New York: Routledge.

Reddy, P.C. (2014) Hindu Pilgrimage: shifting patterns of worldview of Shri Shailam in South India, London: Routledge.

Sharma, R.S. (1965) Indian Feudalism c. A.D. 300-1200, Calcutta: University of Calcutta.

Sharma, R.S. (1987) Urban Decay in India (c. 300-c. 1000), Delhi: Munshiram Manoharlal.

Sharma, R.S. (2001) Early Medieval Indian Society: a study in feudalization, Calcutta: Orient Longman.

Sikand, Y. (2003) Sacred Spaces: exploring traditions of shared faith in India, Delhi: Penguin.

Vassilkov, Y. (2002) 'Indian Practice of Pilgrimage and the Growth of the Mahābhārata in the Light of New Epigraphical Sources', in M. Brockington (ed.), Stages and Transitions: temporal and historical frameworks in epic and purānic literature, 133-156, Zagreb: Croatian Academy of Sciences and Arts. 


\title{
24 \\ AMBEDKAR'S LIFE AND HIS NAVAYANA BUDDHISM
}

\author{
Eleanor Zelliot
}

Dr B. R. Ambedkar is probably more famous in India now than during his lifetime (18911956). He is known for two roles; as dynamic leader of the Untouchables and architect of the Indian Constitution. Shortly before his death he converted to Buddhism and this may be the most influential of all his leadership roles. He was not able to create any permanent organization in the two months between conversion and his death but his writing and the work of his followers has begun to produce change in a country in which Buddhism had disappeared before the modern period (see Figure 24.1).

Two movements in the late nineteenth century indicate a revival of Buddhism in South Asia. A Sri Lankan Bhikshu, Anagarika Dharmapala (1864-1933), established the Maha Bodhi Society in India in 1891, the year of B. R. Ambedkar's birth. The chief task of the Maha Bodhi Society was to restore the Buddhist temple at Bodhgaya to Buddhist hands. Conversion was not on the agenda and most of those involved in the society were practising Hindus, usually of high caste. However, the Maha Bodhi journal served as a priceless mode of information for anyone interested in Buddhism.

In south India, in the same period, there was a flourishing of publications on Buddhism. The Essence of Buddhism (1907), by Lakshmi Narasu, was so meaningful to Ambedkar that he arranged for a reprint in 1948. Narasu and Pandit Iyothee Trass, his associate, represent a strong, high intellectual revival in the south (see Aloysius 1998; Perumal 1992). But this had weakened by the time Ambedkar was looking for information and support 30 years later.

Ambedkar's first encounter with Buddhism has assumed almost a mythic quality. When Ambedkar passed the fourth Standard English exam, his community celebrated. A teacher at Wilson High School in Bombay presented him with his Marathi book on the life of the Buddha. Dada (K. A.) Keluskar knew Ambedkar's father, Ramji Subedar, also a teacher and principal of an army school. He also knew the Gaikwad of Baroda, who was to become Ambedkar's benefactor. He is representative of Maharashtrian intellectuals drawn to Buddhism.

Ambedkar went on to become one of the most highly educated men in the Marathi speaking area. He had a PhD from Columbia University, the equivalent from London's School of Economics and also passed the English Bar examinations. He came back to his home area and began his work on the problems of the Untouchables. 


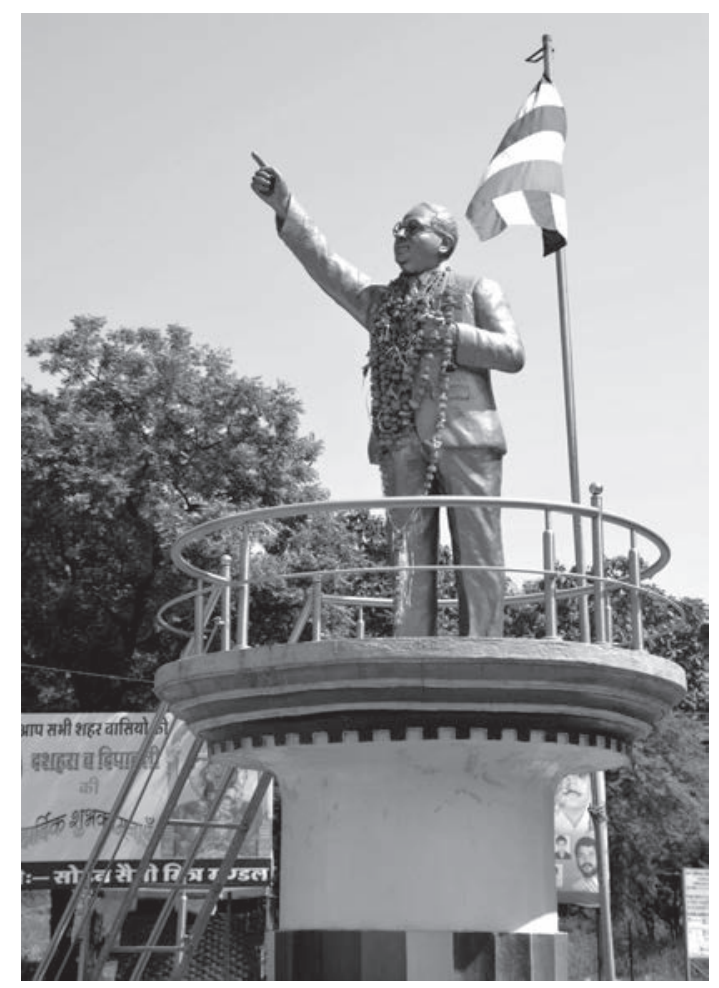

Figure 24.1 Statue of Ambedkar with the Buddhist flag (Nepanagar, Madhya Pradesh)

Source: Knut A. Jacobsen

Ambedkar was able to build on previous leadership. In the Marathi speaking area, two extraordinary Mahars made a real difference in preparing their people for change. In the Nagpur area, Kisan Fagoji Bansode (1879-1946) started schools, unions, newspapers, and called conferences. He was matched in the west by Shivram Janba Kamble (1875-1942). There were also reform efforts from higher castes. Vital Ramji Shinde (1873-1944), a Maratha, was extraordinarily able to build schools and curiously enough was interested in Buddhism. A nineteenth-century Mali, now known as Mahatma Phule, was an inspiration to Ambedkar and actually Ambedkar's thought is sometimes called Phule-Ambedkar. Jyotirao Phule (1827-1890) was anti-caste, pro-education, a writer, an organizer, a creator of institutions that left their mark on Maharashtra. He was a high caste, as was Shinde, but that did not keep his thought from being very influential in the Ambedkar movement. Ambedkar would say that his three gurus are the Buddha, Mahatma Phule and Kabir, a Hindi Bhakti poet-saint his father was devoted to.

Ambedkar's caste, the Mahar, was the largest Untouchable caste in the Marathi speaking area, composing about a tenth of the population. They were village servants with a number of responsibilities and duties. They did not do sanitation work like the Bhangis. Castes came from Gujarat and Uttar Pradesh to fill that function. Chamars worked with leather and Mangs made baskets and functioned as entertainers for the village. Basic to all Untouchables was agricultural labour. Dragging dead cattle out of the villages was the only clearly polluting work Mahars did; nevertheless they were not allowed in the temple or generally in the homes or streets of caste Hindus. In the modern period, many of their village servant functions were 
performed by modern means such as the post office, leaving Mahars free and encouraged to enter new occupations, working in the mills and the docks. Most important, they also served in the British army; Ambedkar came from such a Mahar army family (see also Ahir 1964, 1982, 1995).

\section{Satyagrahas}

One of the most interesting aspects of the Ambedkar movement is his relationship to Mahatma Gandhi. In brief, Gandhi believed change of heart in caste Hindus was the necessary element in progress while Ambedkar held political and legal rights were essential. His reaction to the Vaikam Satyagraha illustrates the complexity of the situation.

One Gandhian Satyagraha important to the Ambedkar movement was at Vaikam in Kerala (1924-1925). It involved chiefly the Irava caste of Untouchables and it was an effort to secure the use of a road going around the temple at Vaikam. Ambedkar wrote about this Satyagraha:

For us, the most important event in the country today is the Satyagraha at Vaikam ... Most of you know what sort of debate is going on at Vaikam. The Untouchables of Vaikam insist that they should all be allowed to use a road which is used by all people and by animals as well. We are not much concerned with all the vacillation and compromise this protest has brought about. The fact to remember is this that even after a whole year of protest, there is no result. It is true, of course, that some political leaders have changed their attitudes regarding the Satyagraha for it has been conclusively proved now that the argument of political before social is a worthless one ...

Before Mahatma Gandhi, no politician in this country maintained that it is necessary to remove social injustice here in order to do away with the tension and conflict, and that every Indian should consider it his sacred duty to do so. According to Mahatma Gandhi, social and political causes are not separate but are one and the same, and therefore he goes around telling people that independence cannot be achieved without Hindu-Muslim unity and the removal of untouchability.

However, if one looks more closely one finds that there is a slight disharmony between Mahatma Gandhi and untouchability, just as there is between Kasturba Gandhi and Lakshmi! For he does not insist on the removal of untouchability as much as he insists on the propagation of Khaddar or Hindu-Muslim unity. If he had he would have made the removal of untouchability a precondition for membership of the Congress as he made yarn spinning a precondition for voting in the party. Well, be that as it may, when one is spurned by everyone, even the sympathy shown by Mahatma Gandhi is of no little importance.

Zelliot 2013: 77-78

The Satyagraha seems to have ended with the moving of the road a little further from the temple.

After Ambedkar's return in 1923 from his American and English study, he devoted his life to the movement of Untouchables. This included three Satyagrahas, the Gandhian term, even though all three were foreign to Gandhi and completely out of his compass. The first was in 1927 after the Government of Bombay decreed that all public places should be open to all castes. Ambedkar called a conference at Mahad, a small town south of Bombay, in the Ratnagari area. A tank (pond) was used by all caste Hindus in the little town. The mayor of 
the town was very sympathetic to Ambedkar and had encouraged him to come. Ambedkar's conference was held on Muslim land outside the city. A group of Ambedkar's followers left the conference and drank water at the tank. They were chased away by Brahmans. Ambedkar called off the Satyagraha and fought in the courts for the right to use the water. The event was so meaningful to his caste that the saying 'make a mahad' indicated brave attempts at equality. There is now a college in Mahad. At a second conference, the Manusmriti, India's classic law book with harsh penalties for Untouchables and women for overstepping their boundaries, was burned publicly. A Brahman associate of Ambedkar actually put the Manusmriti in the fire I am told.

The second Satyagraha Ambedkar participated in, although at a distance, was a 1929 effort to enter the Parvati temple which dominated Pune from a hill above the city. Privately owned, the law allowing public places being open to Untouchables did not apply. For several months groups of Untouchables from several castes would climb the hill at Parvati until blocked. There was some violence and the important Chambhar leader Rajbhoj was injured.

The Kalaram temple in Nasik was the site of a very important Satyagraha from 1930 to 1935. This time period included the Round Table Conferences in London that determined the future of India. Ambedkar was very much involved and there he fought for separate electorates for the Untouchables. The Satyagraha's failure added strength to Ambedkar's claim that Untouchables were separate from caste Hindus and should be so treated. Efforts to join in temple activities were constantly met with violence. Toward the end of 1935 a determination to leave Hinduism caused Ambedkar to announce that publicly. The announcement that he was leaving Hinduism was made in Yeola in Nasik District. The reaction of India's various religions was both positive and negative. Most positive was that of the Sikhs who were not only welcoming but also went so far as to build Khalsa College in Bombay as a token of their commitment and to encourage Ambedkar to design and staff it. Some Christian leaders welcomed the idea of mass conversion; others were hesitant to involve such numbers. A Christian friend consulted Gandhi before coming to Ambedkar, which irritated him greatly. Most unusual was an Italian Buddhist monk, Lokanatha, who encouraged the idea of conversion. Lokanatha explained to Ambedkar that the Untouchables had been Buddhist before the Hindu revival of the Gupta period. He also presented Ambedkar with his writing on Buddhism.

Ambedkar's call to change religion was often very strong, even bitter. This is understandable because for Ambedkar a combination of any religion with Hinduism was impossible. This made him a very harsh critic of Hinduism. Buddhism seemed to have become combined with most of the South Asian countries' religions; in Tibet, the Bo; in Japan, Shinto and Buddhism share the field. In much of southeast Asia, ancestor worship is an important part of Buddhism. Ambedkar could not find any way in which Buddhism could be merged with Hinduism. A section of the speech on change of religion is so passionate it takes a poetic form.

Religion is for man; man is not for religion.

If you want to gain self-respect, change your religion.

If you want to create a cooperating society, change your religion.

If you want power, change your religion.

If you want independence, change your religion.

If you want to make the world in which you live happy, change your religion.

Why should you remain in a religion that does not respect your manhood? 
Why should you remain in a religion that does not let you enter its temples? Why should you remain in a religion that does not give you water to drink? Why should you remain in a religion that does not let you become educated? Why should you remain in a religion that bars you from good jobs?

Why should you remain in a religion that dishonors you at every step?

That religion which forbids humanitarian behavior between man and man is not religion but a reckless penalty.

That religion which regards the recognition of man's self-respect as $\sin$ is not religion but a sickness.

That religion which allows one to touch a foul animal but not a man is not a religion but a madness.

That religion which says that one class may not gain knowledge, may not acquire wealth, may not take up arms, is not a religion but a mockery of man's life.

That religion which teaches that the unlearned should remain unlearned, that the poor should remain poor, is not a religion but a punishment.

Do not say: men who treat animals with more respect than humans and who respect all Brahmans as gods are religious.

Do not say: men who feed ants with sugar and let men go without water are religious.

Do not say: men who embrace another religion and push their own far from them hate society.

Zelliot 2013: 154-155

Ambedkar said:

Because we have the misfortune of calling ourselves Hindus, we are treated thus. If we were members of another Faith, none would dare treat us so. Choose any religion which gives you equality of status and treatment. We shall repair our mistake now. I had the misfortune of being born with the stigma of an Untouchable. However, it is not my fault; but I will not die a Hindu, for this is in my power.

Zelliot 2013: 147

In May 1936 Ambedkar called an all Bombay district Mahar conference. This is the only time the caste identity was used. Meetings were held in the Naigao area of Dadar in Bombay. B. S. Venkatrao, the 'Hyderabadi Ambedkar', was president of the conference. B. K. Gaikwad, the leader of the Nasik Satyagraha, was also prominent. The conference endorsed the idea of conversion.

\section{Intellectuals and Buddhism}

Meanwhile there was increasing interest in Buddhism, chiefly among intellectuals. A. R. Kulkarni left his law practice in Nagpur to study Buddhism and Ambedkar had many questions for him. Among the most important intellectuals were Dharmanand Kosambi and his son D. D. Kosambi. Kosambi, from a Brahman family, wrote 'Bhagwan Buddha', published in 1940, which greatly influenced Ambedkar's approach to Buddhism. He not only built a vihara in Bombay for the use of Ambedkar's people, but became a bhikkhu for a time. His son, D. D. Kosambi, was a widely acknowledged scholar and did much to ensure the translation and use of the Pali scriptures. 
Among the most interesting intellectuals was a trio of high caste north Indian Hindus. The close friends who often talked of what they could do to revive Buddhism were especially important in the day-to-day formation of Ambedkar Buddhism. Rahul Sankrityayan was a brilliant and charismatic lecturer, very interested in Tibet. He brought Tibetan manuscripts to India and had a special concern for Buddhists as he travelled widely. Anand Kausalyayan was especially interested in the study of Hindi and not only established a college in Nagpur but translated Ambedkar's 'The Buddha and His Dhamma' into Hindi. Jagdish Kashyap was primarily interested in education. He taught at Banares Hindu University and he worked to try to restore the ancient university at Nalanda to its former glory.

An English convert to Buddhism, the Ven. Sangharakshita, met Ambedkar before the conversion and discussed Buddhist conversion with him. His organization created the TBMSG (Trailokya Bauddha Mahasangha Sahayaka Gana), which was the Indian branch of the Friends of the Western Buddhist Order. TBMSG established an institution near Pune which did economic and social work as well as meditation and teaching and later a very elaborate institution in Nagpur. A new leader, Lokamitra, also English, has continued to expand its influence and programme.

\section{Ambedkar's all India service}

In the 1940s, Ambedkar was able to work in fields that affected all of India, not just the Dalits. He became Minister of Labour in the Viceroy Council. In 1947 the constituent assembly was created to work on the constitution of India. Ambedkar had become law minister in Nehru's first cabinet. And as such he was chairman of the drafting committee for the constitution. With considerable brilliance he managed the discussion that created the constitution, and he came to be called the architect of the Indian Constitution. He then was assigned to work on the Hindu Code Bill where he got much less support and in 1951 he resigned. It is widely supposed that Gandhi was responsible for Ambedkar's initial appointment to the Viceroy's council.

\section{6 - the conversion}

The current most acceptable name for Ambedkar's Buddhism is Navayana, a 'new vehicle'. The prevalent name after the conversion was Neo Buddhist, but this was then discarded as indicating an inferior Buddhism. The term Dalit (oppressed) came into use when the Mahars named the Dalit Panthers after the Black Panthers in the United States. Black and Dalit are similar terms in that they are self-chosen and do not indicate any fault of the group itself. Dalit replaces the term used by Gandhi, Harijans, meaning people of God, which was never acceptable to Ambedkar who felt it was patronizing. Dalit encompasses all the marginalized: Scheduled Castes, Scheduled Tribes, nomads and other backward castes.

\section{Conversion}

The actual conversion took place on 14 October 1956, 20 years after the initial decision to leave Hinduism and convert to Buddhism. The traditional oaths at the conversion ceremony were administered in Pali by the oldest Bhikshu in India, Mahastavir Chandramani. At the age of 83, the Ven. Chandramani was head of an ashram at Kushinagar, in northern India. He was a Burmese Buddhist who had studied in Sri Lanka. Also present at the conversion ceremony was the general secretary of the Maha Bodhi society, Devipriya Valisinha. Both 
Ambedkar and his wife, Dr Ambedkar, were converted. Also at the ceremony was Waman Godbhole, an employee of the Indian railways who had basically organized the 14 October ceremony.

The conversion ceremony was held in Nagpur, home of the Nags, people Ambedkar felt had been Buddhist in pre-Hindu days. Interestingly enough, Buddhist remains were found near Nagpur within 30 years of the conversion. Ambedkar recited his own version of Buddhist oaths and then as a Buddhist offered conversion to a massive audience. There were according to estimates, over a half a million people coming from all over the Maharashtrian area, dressed in white (see also Kadam 1997).

The twenty-two oaths taken at the time of conversion offer another rejection of Hinduism. The first five reject the worship of specific gods and goddesses, referring to the actual worship Untouchables would perform before the conversion.

\section{Buddhist's Oaths}

1 I will not regard Brahma, Vishnu and Mahesh as Gods nor will I worship them.

2 I will not regard Rama and Krishna as Gods nor will I worship them.

3 I will not accept Hindu Deities like Gauri, Ganapati etc. nor will I worship them.

4 I do not believe that God has taken birth or incarnation in any form.

5 I do not believe that Lord Buddha was the incarnation of Vishnu. I believe this propaganda is mischievous and false.

6 I will never perform any Shraaddha nor will I offer any Pinda.

7 I will never act against the tenets of Buddhism.

8 I will never get any Samskaar performed by Brahmins.

9 I believe in the principle that all are equal.

10 I will try to establish equality.

11 I will follow the Eight Fold Path of Lord Buddha.

12 I will follow all the ten Paramitas of the Dhamma.

13 I will have compassion on all living beings and will try to look after them.

14 I will not lie.

15 I will not commit theft.

16 I will not indulge in lust or sexual transgression.

17 I will not take any liquor or drink that cause intoxication.

18 I will try to mould my life in accordance with the Buddhist preachings, based on Enlightenment, Precept and Compassion.

19 I embrace today the Bauddha Dhamma discarding the Hindu Religion which is detrimental to the emancipation of human beings and which believes in inequality and regards human beings other than Brahmins as low born.

20 This is my firm belief that Bauddha Dhamma is the best religion.

21 I believe that today I am taking new-birth.

22 I solemnly take oath that from today onwards I will act according to the Bauddha Dhamma. ${ }^{1}$

Ambedkar died within two months of the conversion and the conversion campaigns were continued by the Ven. Kausalyayan and others who had become Buddhist. The conversions continue and only recently a conversion of a group of nomads and people who would have been Scheduled Tribes but had no permanent address was conducted in Bombay at the race track. 


\section{The Buddha and his Dhamma}

Ambedkar finished his major project called The Buddha and His Dhamma (Ambedkar 1997; Rathore and Verma 2011) before his death. The book is an extremely personal creation of Ambedkar. It is clear that he took every detail of the manuscript under his direction. The Buddha and his Dhamma was not published until after Ambedkar's memorial service, but was as he planned it. Ambedkar arranged most of the format of the book and decreed that on every page there should be an outline of the mudra of teaching, viktara mudra. Each verse was numbered somewhat in the way of a Christian Bible. Most of the earlier scholars wrote their own versions of The Buddha and His Dhamma. The ones by Lakshimi Narasu and Dharmanand Kosambi were of special importance for Ambedkar's essay.

Ambedkar noted in his introduction there were four problems for him in the teaching of Buddhism that were quite puzzling; one was the answer to the question of Parivaja namely leaving home as a wanderer. The traditional answer is the Buddha took Parivaja because he saw a sick person, an old person and a dead person. The answer is absurd on the face of it, wrote Ambedkar, who then involved the Buddha in peace making among tribes. The second problem was created by the four Aryan truths: if life is sorrow, death is sorrow and rebirth is sorrow, if this is true there is an end to everything! The four truths deny hope to man. Does this mean this gospel of the Buddha is a gospel of pessimism? Do the Aryan truths form part of the original or are they later accretions by the monks? The third problem relates to the doctrines of soul, to karma and rebirth. The Buddha denied the existence of the soul but he is also to have said to confirm the doctrine of karma and rebirth. This contradiction needs to be resolved. The fourth problem relates to the Bhikshu: was this to create a perfect man or to create a social servant? This is a very real question; on it depends the future of Buddhism; so Ambedkar thought (see also Omvedt 2003; Pandyan 1996).

The life of the Buddha was told in a very traditional way; every insight is attached to some phase of the Buddha's life. There is no expounding of doctrine other than directly by the Buddha. The conclusion of the book includes tributes to the Buddha's greatness by western scholars.

\section{Elements of Navayana Buddhism}

In the current Buddhist community there are Bhikshus from the community itself and from England, Sri Lanka, Thailand and Burma. The most effective Buddhist Bhikshu in Nagpur is from Japan. He has led pilgrimages to Bodhgaya, built a number of new viharas and won a highly respected place as an interpreter of Buddhism.

Ambedkar's great wish was to create a sangha of Bhikshus that would be socially aware that would then be of great help to the community. He even secured land in Bangalore for the establishment but the plans never worked out.

There is no direct replacement for the colourful Hindu ceremonies of Ganapati or Durga. There is, however, a new tradition, which unites the community and offers colour and education (see also Beltz 2004: Jondhale and Beltz 2004). The largest by far of the pilgrimages is the one in Nagpur in October. It is estimated that half a million people came to Nagpur for the 14-15 October 1956 conversion ceremony. The fiftieth anniversary of the conversion probably brought twice that number to the city. The conversion was held in a large field near the Vaccine Institute on the outskirts of Nagpur. (The field is now fully inside the growing city.) The Nagpur field of conversion (diksha bhumi) is now the site of an enormous stupa, modelled after the main classic stupa at Sanchi. The stupa was inaugurated in 2001 by the late Dr K. R. Narayanan, then President of India. 


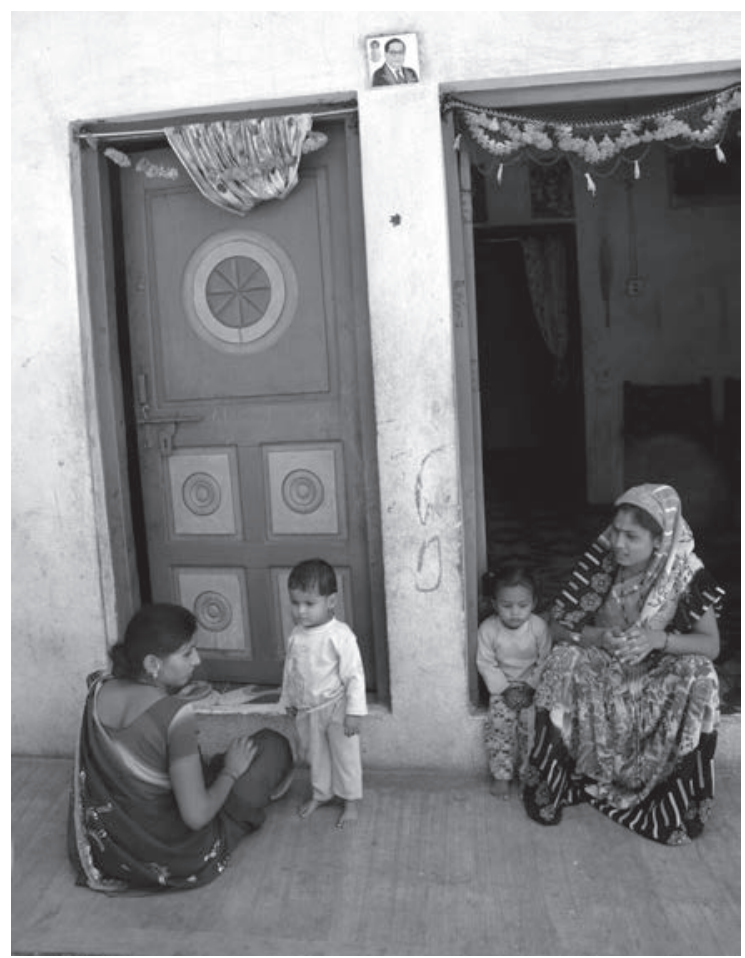

Figure 24.2 Buddhists with picture of Ambedkar above the front door as a mark of their identity as follower of Ambedkar's tradition of Buddhism (Nepanagar, Madhya Pradesh)

Source: Knut A. Jacobsen

Pilgrimages on every 6 December Ambedkar's death day, are observed. A pilgrimage to the chaitabumi in Bombay draws ever increasing numbers also from distant places. The stupa there is representative of the whole religion. It does not hold relics but holds an image of the Buddha. Outside there are numerous areas where people buy books and cassettes and music and hear speeches and they often stay with people in Bombay, creating a network of interested Ambedkarites.

There is now an organization of women for rights and responsibilities. The first effort was for women associated with a political figure. This reached new heights of power when Mayawati became the associate of Kanshi Ram and the Bahujan Samaj Party. She most recently served a full five-year term as chief minister in Uttar Pradesh. Buddhist women have also been active and several go to each of the conferences of Sakyamuni (daughters of the Buddha, an international group). Lokamitra has introduced marriage among Bhikshus. His wife, Professor Goody, is head of Ambedkar college in Pune. There is commitment to scholarship and to the study of Buddhist society in India mostly among higher educated young Dalits. There is an all India acceptance of Ambedkar as one of three makers of modern India (with Gandhi and Nehru). All over India there is a recognition of the importance of the Buddhist path. There is, however, a need for recognition of the conversion meaning in the larger Buddhist world (see Figure 24.2). There is a need for the Buddhist conversion in India to be recognized outside of India.

Since 1956 there has been growth in two new fields, Dalit art and Dalit literature (an excellent Dalit autobiography is Moon 2000). Beginning with Marathi in the early 1970s, 
Dalit literature has appeared in almost all Indian languages. The literature is not usually about Buddhism, but the writers will tell you that Buddhism freed their minds, Dalit literature deals with Buddhism at times and a poem by the late Daya Pawar attempts to give sorrow a new meaning:

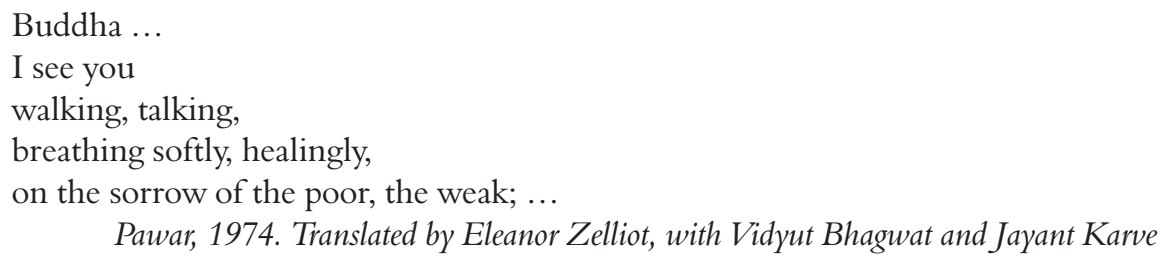

Navayana will grow and change with its rich heritage, its highly educated members and its international connections. We can count on some sort of creativity. The cultural identity of the Untouchables is just now being explored. The art of drumming is an example of its complexity. Pariah is a word derived from drum. Drumming was an important part of some Untouchable relationships with the larger community. Consequently some Untouchables find it tainted by its function for higher castes and refuse any connection. Others find it a glorious talent.

\section{Note}

1 From a pamphlet distributed at conversion ceremonies.

\section{References}

Ahir, D. C. (1964) India's Debt to Buddhism, New Delhi: Maha Bodhi Society of India.

Ahir, D. C. (1982) Dr. Ambedkar on Buddhism, Bombay: Siddharth Publications.

Ahir, D. C. (1995) A Panorama of Indian Buddhism, Delhi: Sri Satguru Publications.

Aloysius, G. (1998) Religion as Emancipatory Identity, A Buddhist Movement among the Tamils under Colonialism, New Delhi: The Christian Institute for the study of Religion and Society, New Age International Limited Publisher.

Ambedkar, B. R. (1997) The Buddha and His Dhamma, Nagpur: Buddha Bhoomi Publication.

Beltz, J. (2004) Mahar, Buddhist and Dalit, Religious Conversion and Socio-Political Emancipation, New Delhi: Manohar.

Jondhale, S. and J. Beltz (eds) (2004) Reconstructing the World, B.R. Ambedkar and Buddhism in India, New Delhi: Oxford University Press.

Kadam, K. N. (1997) The Meaning of the Ambedkarite Conversion to Buddhism and Other Essays, Mumbai: Popular Prakashan PVT, Ltd.

Moon, Vasant. (2000) Growing Up Untouchable in India, A Dalit Autobiography, G. Omvedt (trans), Lanham, MD: Rowman \& Littlefield Publishers.

Narasu, L. (2002) Religion of the Modern Buddhist, G. Aloysius (ed.), Delhi: Wordsmiths.

Omvedt, G. (2003) Buddhism in India, Challenging Brahmanism and Caste, New Delhi: Sage Publications.

Pandyan, D. K. (1996) Dr. B.R. Ambedkar and the Dynamics of Neo-Buddhism, New Delhi: Gyan Publishing House.

Pawar, D. (1974) Kondwada, Pune: Magova Prakashan.

Perumal, S. (1992) Revival of Tamil Buddhism, A Historical Survey, Vellore: Forum for New Society.

Queen, C. S. and S. B. King (eds) (1996) Engaged Buddhism, Buddhist Liberation Movements in Asia, Albany, NY: State University of New York Press.

Rathore, A. S. and A. Verma (eds) (2011) B.R. Ambedkar the Buddha and His Dhamma, A Critical Edition, New Delhi: Oxford University Press.

Zelliot, E. (2004) Dr. Babasaheb Ambedkar and the Untouchable Movement, New Delhi: Blumoon Books.

Zelliot, E. (2013) Ambedkar's World: The Making of Babasaheb and the Dalit Movement, New Delhi: Navayana. 


\title{
25
}

\section{RELIGION, IDENTITY AND EMPOWERMENT The making of Ravidassia Dharm (Dalit religion) in contemporary Punjab}

\author{
Ronki Ram
}

\section{Introduction}

The present-day Indian state of Punjab has a unique pattern of caste hierarchy that differentiates it from the rest of the country. In the country at large, Brahmans (the priestly class, knowledge people) are placed at the top of the Hindu caste hierarchy ${ }^{1}$ whereby they continue to enjoy special social privileges, such as being the custodians of the sacred and spiritual realms in the religious traditions now popularly called Hinduism or Hindu Dharma. However, in Punjab, they did not enjoy such a privileged status at all. On the contrary, they were treated rather derogatorily ${ }^{2}$ and contemptuously called a mang khani jat (a community/caste simply living on alms). The marginalization of Brahmans, however, does not eliminate the possibility of the presence of caste-based social exclusion in the state. Curiously enough, caste and social exclusion continue to persist even today, though with a difference (Ram 2004a). It replaced Brahmans with Jat Sikhs. ${ }^{3}$ While replacing Brahmans, Jat Sikhs, however, did not inherit the complex patterns of ritual and ceremonial practices of the former. They came to acquire a dominant social position perhaps because of their material strength, which also extends their hold over the resource-rich management committees of Sikh shrines popularly known as gurdwaras. ${ }^{4}$ In other words, Jat Sikhs, unlike Brahmans, came to acquire the status of a dominant caste not by virtue of their being closer to sacredness and the ceremonial paraphernalia of spirituality, but for their hegemony over the agricultural land as well as gurdwaras and other panthic (Sikh organizational) institutions. There is hardly a village/town/city in the state of Punjab that does not retain a gurdwara or several gurdwaras. Many Dalits ${ }^{5}$ embraced Sikhism in the hope of escaping social exclusion but they ${ }^{6}$ failed to find a place in the management committees of the gurdwaras. Such committees are invariably monopolized by Jat Sikhs who constitute around 30-33 per cent (one-third) of the total population of the state and occupy the biggest chunk of the agricultural land (more than 80 per cent). ${ }^{7}$ It is the material and the numerical predominance of Jat Sikhs, formerly a Shudra (lower/menial) caste, coupled with their monopoly over the control of the management committees of the gurdwaras that has helped them in acquiring the status of a dominant caste in the state. Gurdwaras, over the years, have emerged as centres of Sikh identity (Takhar 2005: 21). 
Thus contrary to the purity-pollution principle of the caste system, the mechanism of social exclusion in Punjab is historically tied to the asymmetrical structures of the rural economy that privileged the hegemonic interests of the land owning 'agricultural castes' over the landless Dalits. Dalits along with all other non-agricultural castes were historically deprived of land ownership rights in Punjab (The Land Alienation Act of 1900). In addition, under the informal local customary scheme of patron-client relationships (popularly known as razat-namas) they were also denied ownership rights even to the plots of land on which their houses were built in the segregated colonies in the vicinity of the mainstream villages. The land on which Dalits were allowed to build houses in the segregated residential areas was legally recorded in the name of the local dominant peasant caste. The customary social separatism and land deprivation of Dalits continued even during the colonial rule of the British administration. It was only after India's independence that such laws were declared null and void through the concerted efforts of Dr B. R. Ambedkar, the chief architect of the constitution of Independent India and the 'messiah of the downtrodden'.

The annulment of the above-mentioned draconian laws, however, could not empower the Dalits and they remained landless. Though they are the second largest community in the state, ${ }^{8}$ and their numerical strength is almost equal to that of the Jat Sikhs, their share in the total number of operational holdings in the state is just 4.82 per cent and they occupy only 2.34 per cent of the total area under cultivation. Notwithstanding their being highest in numbers in Punjab in comparison to their counterparts in the rest of the country, less than 5 per cent of them are cultivators (the lowest in India). Since they are deprived of land and accordingly pushed to the lowest rank in the caste hierarchy, they were/are also deprived of any share in the management committees of Sikh shrines.

Confronted with deprivation of land ownership and absolute marginality in the realm of ecclesiastical authority, it is commonly believed that Dalits often took a fancy to borrowing the sub-caste titles of the dominant local castes and felt proud in imitating their cultural patterns and religious iconography, what Srinivas aptly called sanskritization (Srinivas 1956). Dalits in Punjab have also tried to seek upward social mobility at times through religious conversion. Since the superiority of the dominant caste is less rooted in the cultural sphere and more in its hold on the land, it does not matter much if the Dalits decorate their names with sub-caste titles of the dominant castes or embrace the mainstream religion. In the agrarian economy of the present-day Indian state of Punjab, what really matters the most is not the cultural dimension of social mobility but the material domain of social existence. In other words, Dalit social mobility in Punjab needs to be seen more in the mode of assertion, demanding an equal share in the local structures of power than in meekly following in the cultural footsteps of the upper/dominant castes. Since the possibility of acquiring land through redistribution or radical land reforms seems quite bleak and the mode of conversion has already failed to improve the social status of the Dalits, many began to realize that their genuine salvation might lie in establishing their own distinct religion as well as religious spaces.

It seems that Dalits are now no longer seeking equality in the otherwise unequal social space by asking for an equal share in the existing social structures in the society. On the contrary, they are asserting equal status and dignity by establishing their own religious and cultural space in the society. The move towards instituting a separate Dalit religious space seems to be parallel to the magnificent presence of gurdwaras in the state and the gurdwaras' contribution in allocating dominant social status to Jat Sikhs. There is a local adage that whosoever holds a dominant position in the organizational settings of the gurdwaras also holds a dominant social status and controls the levers of power at the grassroots. Thus in 
the religiously dominated and segmented social space in the contemporary Indian state of Punjab, it seems appropriate to seek upward social mobility by invoking a religious trajectory.

This chapter aims to explore the rise of the Ravidassia Dharm in Punjab as a way to Dalit empowerment as well as a distinct Dalit identity. It is based on the premise that Ravidassia Dharm is a response to the caste-based social exclusion that is faced by Dalits in the state. They ventured into this highly ambitious mode of upward social mobility after having had their fingers burnt in conversion and cultural emulation strategies of upward social mobility. The only way left to them, it seems, was to construct their own separate Dalit identity thoroughly rooted in the fertile land of religions in the region. Moreover, Dalits of present-day Punjab have a rich legacy of Guru Ravidass, their own low-caste-fellow and a well-known Santpoet of the medieval north Indian bhakti movement, who unleashed a frontal attack on the dominant structures of the Brahmanical social order while deploying the unique strategy of bhakti-based religion as a vehicle of peaceful social protest.

\section{Lineage of Ravidassia Dharm}

Though the Ravidassia Dharm came into formal existence on 30 January 2010 in the form of a declaration ${ }^{9}$ made by the Sants ${ }^{10}$ of Dera ${ }^{11}$ Sachkhand Ballan ${ }^{12}$ (henceforth Dera Ballan), its genesis can be traced to the formation of the Ad Dharm movement ${ }^{13}$ in pre-partition larger Punjab in the 1920s. Ad Dharm was the only movement of its kind in the northwestern region of India that aimed at securing a respectable place for Dalits through religious reformation, cultural transformation and political assertion rather than seeking emancipation through conversion or sanskritization. It was during the evolution and expansion of this movement that the idea of a separate Dalit religion was envisioned and formed to a large extent. Although this movement ceased to exist in its vehement form after the provincial elections of 1946, its emphasis on social transformation and religious reformation continues to reverberate the rank and file of the various sections of the Dalit communities in Punjab even today. One of its major contributions towards the formation of a Dalit religion is the articulation of a popular counter Dalit narrative emphasizing the existence of a rich imaginary universe of Dalit cultural heritage.

The popular counter Dalit narrative was, however, originally developed by Jyotirao Phule of Maharashtra and later on Babu Mangu Ram Mugowalia (hereafter Babu Mangu Ram), the founder of the Ad Dharm movement, made it popular in the region. The central thesis of this narrative depicts the natives of the region as the rulers of the land who were stripped of their rich cultural heritage by the alien Aryans. The Aryans, tells the narrative, forcibly snatched from the natives almost everything worth possessing and reduced them to slaves (untouchables). They erased their geographies while wiping out the tangible cultural heritage of the natives, deprived them of their history, and consequently pushed them into oblivion, thus, ultimately detaching them from their native religion, culture, heroes, gurus (preceptors) and glory. In the absence of a tangible Dalit cultural heritage, such a Dalit counter narrative facilitated to a great extent in retrieving the lost and hitherto scattered social worldview of the Dalit natives of Punjab, who take pride in considering themselves as indigenous people or the sons of the soil. The Dalit natives often claim to have their own rich cultural heritage - ethos, ceremonies, prayers, kathas (stories), heroes, gurus, rules, traditions, culture, auspicious dates, festivals, symbols, folklores and religion - formed over centuries that they wanted to bring forth in their struggle for self-respect and social uplift. The popular Dalit narrative became the most appropriate way for viable Dalit empowerment. 
Once the owners of the land and the rulers of their own destiny, the natives were allegedly devalued into several detestable social categories known by varied nomenclatures such as atishudras, chandalas, antyajas, pariahs, dheds, panchamas, avarnas, namashudras, aspristhas, achhuts, dasus, dasas and anairyas. Legal categories of Depressed Classes/Scheduled Castes (SCs) and the patronage category of harijans (children of god) are yet another set of nomenclatures attached to them. The legal categories of Depressed Classes and Scheduled Castes were coined by the British administration, whereas the patronage category of harijans was the outcome of M. K. Gandhi's approach to the question of untouchability in India. The legal category of SCs became the standard term for the general depiction of ex-untouchables in public discourse since India's independence. However, none of the above-mentioned categories of varied nomenclatures were devised by ex-untouchables themselves. The only category that they coined themselves is the political category of Dalit, which was developed by the Dalit Panthers, a radical group founded by some ex-untouchables in Bombay in 1972, who were inspired by the Black Panther Party of the United States. ${ }^{14}$ It is, perhaps, for the first time in the history of Dalit struggle that the ex-untouchables might have thought to designate themselves as such, which "was not only to be interpreted as "the oppressed", but also as the "the proud, the defiant"', who are eager to become rulers rather than be ruled by the upper/dominant castes (Zelliot 2001: v).

The narrative further reiterates that Dalits should not be repressed by their forced low caste social status; rather they should deploy their so-called low-caste identity to contest the upper/dominant castes' hegemony and to retrieve their lost glory. It boldly underlines that if the subjugated Dalits seek to shed their subordination and retrieve their lost glory, they need to establish their distinct Dalit identity fortified within the structures of a separate Dalit religion that will eventually help them shape a new society free from the oppressive binaries of high/low and pure/polluted (Juergensmeyer 1988: 276, 279 and 281; Mendelsohn and Vicziany 2000: 10). This popular counter Dalit narrative received a tremendous response from the Dalits who were deeply initiated into the organizational and ideological anchors for self-respect and social justice during the famous Ad Dharm movement in the pre-partition Punjab, which stirred many of them with the novel idea of a lost rich Dalit cultural heritage and its reclamation through the establishment of a separate Dalit religion popularly known as Ravidassia Dharm.

Ravidassia Dharm is thus the manifestation of the unique process of relocation of Dalit cultural heritage by building on the indigenous and pre-Aryan socio-cultural heritage of the natives. ${ }^{15}$ It designates the natives as Ravidassia/Ad Dharmi (original inhabitants/natives) and their society as Ravidassia Samaj. It also claims to include those ex-untouchable people who have been initiated into the Nirankari, Radhasoami, Sarsa Vale, Ak Jot, Divya Jyoti Jagriti Sansthan and similar other such popular faiths of sant mat (Sant tradition). In fact, many of the ex-untouchable followers of different orders of the Sant tradition in contemporary Punjab take pride in considering Guru Ravidass their saviour, whose teachings embolden them to stand up for themselves, and many of them admit to belong to Ravidassia Dharm.

\section{From Ad Dharm to Ravidassia Dharm}

The philosophy behind the emergence of Ravidassia Dharm began to evolve in Punjab during the $1920 \mathrm{~s} .{ }^{16}$ It was precisely during this period that the above-mentioned famous Ad Dharm Dalit movement was born in Punjab. In fact, it was this movement that had sown the seeds of the alternative Dalit discourse and separate Dalit religion in the state. It was also during this movement that the radical image of Guru Ravidass, a Dalit nirguna sant- 
poet of the medieval north Indian bhakti movement, was meticulously projected to carve the trajectory of recently emerged Ravidassia Dharm in the contemporary Indian state of Punjab. The fact that the Dalits of Punjab, especially those who belonged to the Chamar (leather working) caste, consider Sant-poet Ravidass their Guru, made the Ad Dharm movement instantly popular among them and later on it was these Dalits who became the devotees of the Ravidassia Dharm.

Guru Ravidass was already well known among the lower castes in Punjab. The fact that forty poems and one couplet of the sacred bani (poetry) of Guru Ravidass are included in the Adi Granth (Sri Guru Granth Sahib) speaks volumes for his popularity in the region. He is believed to have visited Punjab during his journeys towards Rajasthan. Stories about his meetings with Guru Nanak, the founder of the Sikh traditions, are also very popular among the Dalits of the state. His struggle against the system of untouchability, based on an enlightened vision of an egalitarian social order (begumpura) at a time when no one was ready to lend a supporting hand to the oppressed untouchables, won him a special place in the minds of the Dalit masses. Strategically, the Ad Dharm movement exploited the mass popularity of Guru Ravidass in the region by displaying his pictures as its emblem, reading his poetry as a revolutionary text and deploying legends about him as illustrations of lowercaste pride and power (Juergensmeyer 1988: 33). In a nutshell, Guru Ravidass, who had already set the ball of alternative Dalit religion rolling, "was brought to the centre-stage in Punjab by the Ad Dharm movement' (Ahir 1992: 105). It was the Ad Dharm movement that initially ignited a desire among the ex-untouchables of the region to strive for a separate Dalit religion for the emancipation and empowerment of their community. The Ad Dharm movement came forward to portray Dalits as a separate qaum (an Urdu word derived from Persian and loosely translated as 'nation', 'people' or 'community') with a distinct social identity and rich religious heritage. Under the leadership of Babu Mangu Ram (Manak 1985: 6; Sain 1985: 37), the movement decided to stop Dalits from falling prey to the strategic designs of the various upper-caste social reform organizations by providing them with an alternative social and political platform to compete independently for their genuine civic rights. The Ad Dharm movement had come to realize that the only way to liberate the Dalits of Punjab from the shackles of social exclusion was to relocate and to institutionalize their native but lost religion rather than to make the Dalits an appendage to the so-called upper/ dominant caste social reform organizations or to allow them to dabble in the promised but false space of so-called egalitarian religions.

One of the foremost tasks facing the Ad Dharm movement was to put in place the essential ingredients of the proposed Dalit religion. Among them the compilation of a holy scripture of Dalit religion was given top priority. Babu Mangu Ram worked meticulously towards that end. The leaders of Ad Dharm decided to compile a separate Dalit sacred text comprising the bani (spiritual poetry) of Guru Ravidass and various other Dalit Sants on the pattern of already existing mainstream sacred scriptures (Guru Granth Sahib) in the region (Takhar 2005: 10). For this purpose, Babu Mangu Ram approached two famous Ravidassia religious centres of his time - Dera Chak Hakim near Phagwara city and Dera Ballan near Jalandhar city (Juergensmeyer 1988: 85). Sant Pipal Dass of Dera Ballan and Sant Hiran Dass of Dera Chak Hakim

were charged to fashion a body of scripture for the Ad Dharm under the title "Sri Guru Ad Prakash Asankh Deep Granth" (The Lord's Original Scriptures of Infinite Light), but for most of the movement's history this document remained only a name. 
However, in the meantime, Rae Das Ki Bani, a collection of the poetry of Ravidass and the verses of Sant Haran Dass, published in 1908 (Allahabad: Belvedere press) by the latter, came to be considered as the religious text of the Ad Dharm (Juergensmeyer 1988: 85 and 87). Later on, Sant Isher Dass from the village Nandgarh in Hoshiarpur District in Punjab compiled the holy book of the Ad Dharm titled as Ad Prakash (The Original Light). ${ }^{17}$ Manorama electronic press published the first 500 copies in 1983. It is important to note that the title Ad Prakash was chosen by the leaders of the Ad Dharm movement (Juergensmeyer 1988: 52). In the aftermath of the Vienna attack, Ad Prakash is once again in the limelight, resulting in the printing of around 2,000 copies of its Punjabi and Hindi editions. ${ }^{18}$

The compilation of the sacred scripture of Ad Dharm was, in fact, an important step towards the systematization of the Ravidassia Dharm. Babu Mangu Ram expressed his will to his close associates that in his death ceremony couplets from the sacred Ad Prakash should be chanted so that his death rituals could not be usurped by any mainstream religion to the disadvantage of the emerging alternative Dalit theology and philosophy carefully groomed under his leadership. ${ }^{19}$ His wish was honoured. ${ }^{20}$ Since then Ad Prakash has been referred to, at least among the Ad Dharmis, as the religious text of the Ravidassia community and has also emerged as a pictogram of distinct Dalit identity. Ad Prakash has provided the Dalits of Punjab with a symbol of a separate religious identity, which they consider as a viable mechanism for their upward social mobility and empowerment. ${ }^{21}$

The project of forming a distinct Dalit identity and its consolidation is clearly reflected in the pages of the historic Ad Dharm Report (Juergensmeyer 1988:290-308), which emphasized devotional reading of sacred scriptures of the then newly compiled Ad Prakash and expected that the precepts should become the foremost duty for all Ad Dharmi/Ravidassias. The report urged every Ad Dharmi/Ravidassia to be a missionary for the Ad Dharm faith and to remember Guru Dev (the sacred name) for half an hour each morning or evening. It is expected that every Ad Dharmi boy and girl should perform such duties after the age of five. To strengthen a separate Dalit identity, every Ad Dharmi was asked to celebrate the festivals of Adigurus and to follow the teachings strictly. They were also expected to conduct the marriage ceremonies according to a distinct ritual, as was already done in the case of Sikhism, by the passing of the Anand Marriage Act in October 1909 (Takhar 2005: 16). The report exhorted that Ad Dharmis should marry only Ad Dharmis, but if someone does marry an outsider, he or she should be brought into the fold of the Ad Dharm religion. Ad Dharmis should follow Ad Dharm rules and should call themselves Ad Dharmis. They should also register in the census as 'Ad Dharmi'. In order to clearly distinguish themselves from Hindus and other communities, the followers of the movement were asked to use the colour red (the colour their ancestors preferred) as a marker of their distinct identity. The Ad Dharm Report further emphasized that anyone who violates the laws of the Ad Dharm or of the guru, or insults these laws in one way or another, will be liable for punishment. In some cases the violator could even be excommunicated. The report further mentioned in unambiguous terms that the essential teachings of the Ad Dharm will always remain the same and no one should dare to challenge or change them. The Ad Dharmis were asked to boycott and abandon books such as the Manusmriti and other granths and shastras (sacred books), which were alleged to have created the problem of untouchability and led to discrimination against the ex-untouchables. All such commandments seem to be intended for the construction of Ad Dharm as a separate religion of the Dalits of Punjab, which has ultimately flourished in the form of Ravidassia Dharm.

Ravidassia Dharm thus draws heavily on the persona and philosophical teachings of Guru Ravidass. What made him the most popular Sant in northern India, apart from the factors 
mentioned above, was probably his fight against untouchability and his frequent standoffs with the pandits and priests of Varanasi, one of the important sacred centres of the Hindu traditions and a seat of Brahman learning (Prasad and Dahiwale 2005: 250). Yet another important aspect of Guru Ravidass' life that made him a role model of the downtrodden is the deep importance that he attributed to the dignity of manual labour, the mainstay of a vast majority of Dalits. Consequently, this in turn has inspired many Dalits who take pride in highlighting their so-called low-caste titles publicly. One often finds in the Doaba region of Punjab motorcycles and cars with stickers proudly proclaiming: putt chamaran de (Sons of Chamars) and SC boys. Thus Dalits, while following the path shown by Guru Ravidass, have not only refused to conceal their so-called inferior social status, they have also started questioning rather vehemently the entire Hindu social hierarchy that has forced them to live on the socio-cultural margins for centuries. The preaching of Guru Ravidass, in fact, has taken the shape of a political strategy based on his 'dissident socio-religious philosophy and ideology' (Schaller 1996: 94). The 'dissident socio-religious philosophy and ideology' of Guru Ravidass has eventually become the cradle of the recently emerged Ravidassia Dharm in the present-day Punjab.

\section{Ravidass Deras: harbingers of Ravidassia Dharm}

Ravidass Deras may be considered as the precursors of Ravidassia Dharm. Interchangeably known as gurughars (abodes of the Guru), temples, gurdwaras, and simply Deras, they began emerging in Punjab in the early twentieth century. A vernacular field study completed in 2003 puts their number as around 100 (Qadian 2003). Since then many more such Deras have come into existence in Punjab (Ram 2008: 1343). Ravidass Deras devised their own separate rituals, ceremonies, slogans, symbols, auspicious dates, customs, ardas (prayer), kirtan (musical rendering of sacred hymns), religious festivals and iconography. Since the entire array of religious and cultural activities in Ravidass Deras revolves around the teachings and life of Guru Ravidass, the latter emerges as the central figure in the premises of these sacred and socio-cultural Dalit sites. Guru Ravidass idols are installed and worshipped in the sanctum sanctorum of almost all such Deras. Guruship is also bestowed on the head priests of the Ravidass Deras, popularly known as gaddi nashins (Heads of Deras). Calendar posters printed in the image of Guru Ravidass decorate the walls of the premises of these Deras. Quite interestingly, the portrait of other untouchable Sants and of Dr B. R. Ambedkar can also be seen hanging on the walls of Ravidass Deras.

Many Ravidass Deras have erected state-of-the-art buildings equipped with all modern utilities. In order to look different from both the Hindu temples and Sikh gurdwaras, Ravidass Deras based their architecture on a combination of them. Like the Sikh gurdwaras, almost all of the Ravidass Deras have langar halls (verandas where food is served) with free communal kitchen facilities. Partaking in seva (voluntary service) and food in the langar halls is a common practice. The head priests of Ravidass Deras are revered as gurus and their advice is candidly sought in almost all affairs, sacred as well as mundane, by their large number of followers all over Punjab. Non-stop recitation of sacred scriptures is another regular feature of these Deras, which offer their followers well-protected sacred and social space where they feel at home. Regular visits to these Deras, not only on specially marked auspicious and sacred dates and days, but also on a daily basis clearly attest to their massive popularly among the lower castes.

The emergence of Ravidass Deras amidst the gurdwara-dominated culture of Punjab and the arising of a separate Ravidassia identity has led to bitterness, provocations, confrontation 
and even violent clashes between Dalits and dominant castes in the state. The Ravidass Deras not only symbolize the assertion of a distinct Ravidassia identity, but also the emergence of a 'counter-public' (Hardtmann 2009; Narayan 2011) of Ravidassia Dharm. The phenomenon of Ravidass Deras has taken the form of a new socio-cultural Dalit movement. It is popularly known as the 'Ravidassia movement' or the 'Ravidass Deras Dalit movement'. Led by the Sants of Dera Ballan, this new Dalit socio-cultural movement 'is silently sweeping the Punjab countryside offering a new hope to the untouchables, particularly the Chamars', argues V. T. Rajshekar, editor of the famous weekly Dalit Voice (Rajshekar 2004: 3). It has generated a sense of confidence among the socially excluded sections of the periphery of Punjab and provided them with an opportunity to exhibit their hitherto eclipsed Dalit identity. The movement of Ravidass Deras, argues Rajshekar, 'reflects the fast changing socio-cultural scene of Punjab where the once powerful and revolutionary Sikh religion is failing to meet the needs of the oppressed who discovered the right remedy to cure their wounded psyche in the Ballan experiment' (Rajshekar 2004: 3). The secret of the success of this movement, perhaps, lies in an excellent strategy based on close interaction between the two rich subaltern traditions: the north Indian radical bhakti movement and neo-Buddhism. The Sants of Ravidass Deras, particularly of Dera Ballan, have been quite successful in blending together the poetry of Guru Ravidass and the philosophy of neo-Buddhism as propounded by Dr Ambedkar (Ambedkari 2005: 5). In Ravidass Deras the ecstasy and reason of the song of the utopia of Begumpura (free from all sorts of fears), as envisaged by Guru Ravidass in the early modern period, fits perfectly well with the analytical resonances of the Prabuddha Bharat of Dr Ambedkar, one of the most popular and reason-based utopias envisioned by dalit-bahujan (Scheduled Castes and Other Backward Classes) intellectuals and leaders of the anti-caste movement during the colonial period. Dera Ballan has become a paragon of the Ravidass movement in northwest India. It has also been regulating the affairs of various Ravidass Deras overseas through its international trusts ${ }^{22}$ and has been making strenuous efforts for the consolidation of Ravidassia identity and the construction of a separate Dalit religion - Ravidassia Dharm.

Ravidass Deras are not merely a religious space. They in fact symbolize a meticulous on-going process of the concretization of a separate Dalit identity. Their central concern has been to present themselves as different from the Hindu temples and Sikh gurdwaras, and to provide an alternative religious domain where their followers need not hide their identity and meekly suffer the onslaught of social exclusion. Their distinctiveness also lies in the fact that they neither take refuge in any of the established theologies nor do they present themselves as emulating the dominant socio-cultural ethos of upper-caste society. On the contrary, they proudly differentiate themselves from the mainstream religious systems and also contest the long imposed supremacy of those systems over the Dalits.

The figure of Sant-poet Ravidass is worshipped as a Guru in Ravidass Deras, and the prefix of Guru before Ravidass and the heads of Ravidass Deras separate the Ravidass Deras from Sikh gurdwaras, where the phenomenon of human guruship ceased to exist after the proclamation of Adi Granth as Guru Granth Sahib by the tenth Guru, Guru Gobind Singh. Thus in Sikh gurdwaras, Guru Ravidass is addressed as bhagat and not guru. The issue of bhagat versus guru has not only pitted the Ravidassia community and Jat Sikhs against each other in Punjab and elsewhere, but has also led to communal polarization in the Sikh and Dalit diasporas as well.

Another key factor that underlines the assertion of a separate identity by the Ravidass Deras is the distinct nomenclature preferred by its priests, distinguishing them from their counterparts in Sikh gurdwaras. The titles of the last names of the Sants of Ravidass Deras 
are Dass (humble). It seems that they have inherited the tradition of suffixing Dass from Guru Ravidass, whose first name is also suffixed with Dass. Singh invariably follows the first names of male Sikhs initiated in the Khalsa. ${ }^{23}$ Though Sants of Ravidass Deras keep unshorn hair, a flowing beard and don a turban, like that of the Khalsa Sikhs, they still do not consider themselves as Sikhs. Some of the heads of Ravidass Deras were also clean-shaven.

Har (Supreme Being), the insignia of Ravidass Deras, known as koumi nishan (community symbol) of the Ravidassia Samaj, is yet another distinct identity marker that endows them with a separate identity. The religious symbol of the Sikh gurdwaras is khanda (a two-edged sword over a quoit with two crossed sabres below the quoit) and the symbols of Hindu temples are a trident, the written mantra Om or names of gods and goddesses. The insignia har is composed of a sun-like circle with an image of forty rays on its circular edge. The forty rays round the circle of the insignia signify the forty hymns of Guru Ravidass. Within the circle, there is another smaller circle within which har is inscribed in Gurmukhi script with the sign of a flame on the top of it. The flame represents the nam (word) that illuminates the entire world. The sign of the flame crosses over into the bigger circle. In between the larger and smaller circles is written a couplet: Nam tere ki joti lagayi, bhaio ujiaro bhavan saglare (Your name is the flame I light; it has illuminated the entire world). This inner circle couplet is taken from one of the forty hymns of Guru Ravidass. The insignia har represents the very being of Guru Ravidass and his teachings. The insignia har is chosen after the name of their Guru (ravi (sun) dass (servant), servant of the sun). The Dalits, especially the Chamars of Punjab, proudly hoist flags with the image of har over their religious centres, atop vehicles during processions on the occasions of Guru Ravidass' birth anniversaries and other festivities, and raise slogans such as guru ravidass shakti amar rahe (Long live the grace of Guru Ravidass). The insignia har has become a distinct marker of a separate Dalit identity. It is also being circulated in the form of souvenirs, stickers and wall calendars printed in the image of Guru Ravidass.

The format of the ardas (a formal prayer recited at most Sikh rituals) performed in the Ravidass Deras also differentiates the Ravidassias from the Sikhs. It is comprised of a shloka (couplet) and one of the forty hymns of Guru Ravidass. ${ }^{24}$ The ardas closes with the utterance bole so nirbhay, sri guru ravidass maharaj ki jai (Fearless is the one who utters: Victory to Shri Guru Ravidass), whereas in the Sikh religion the ardas concludes with bole so nihal, sat sri akal (Blessed is the one who utters: True is the Immortal One). The reference to nirbhay (fearless) in the conclusion of the ardas of the Ravidass Deras has become a central motif of the Dalit consciousness. The inclusion of the word nirbhay in the ardas of Ravidass Deras is thus not only symptomatic of the historical oppression of the Dalits at the hands of the upper castes, but is also indicative of their determined willingness to confront it head-on.

Like ardas, arti (a Hindu ritual which consists of waving burning wicks before the sacred images) that is offered at the altar of the sanctum sanctorum of Ravidass Deras differentiates them from that of Hindu temples. ${ }^{25}$ The Sants of Ravidass Deras do not wave burning wicks. They blow a conch shell and rattle a gong, which is followed by the recitation of a hymn from the bani of Ravidass. ${ }^{26}$ The salutations in the Ravidass Deras have also been formulated selectively in order to project their separate identity. Different religious communities have their own way of greeting. Sat shri akal (True is the Immortal One) is the greeting of the Sikhs. Namaste, jai ram ji ki (victory to Ram) and jai sita-ram (victory to Sita-Ram) are examples of some of the many greetings of Hindus. Ravidass Deras adopted the greeting jai gurudev (victory to the divine Guru) or jai guru ravidass (victory to Guru Ravidass) to which they reply dhan guru dev (blessed the divine Guru). The short version of the greetings is jai santan di (victory to the Sants). ${ }^{27}$ 
The forms of ardas, arti, insignia and salutations adopted by the Sants of Ravidass Deras have thus become distinct markers of a separate Dalit identity that not only differentiate them from other religious communities in Punjab but also present them as prominent Dalit social and religious sites. The Ravidassia movement, argues Kathryn Lum, 'uses religion as a tool to push for greater social equality ... while discouraging any affiliation to other religions' (Lum 2009). Ravidass Deras, in fact, have become a testing ground for the cultivation of a separate Dalit identity in the form of a 'separate religion based on the bani (sacred scriptures) of Guru Ravidass Ji' (Lum 2009). In other words, Ravidass Deras have evolved into a nursery of symbols, icons, signifiers and narratives of a separate Dalit identity that have helped greatly in shaping the contours of a separate Ravidassia Dharm. Almost all the principles of the newly established Ravidassia Dharm as mentioned in the Amritbani Satguru Ravidass Maharaj $(\text { Arsh 2012) })^{28}$ are adopted from the sacred repertory of Ravidass Deras.

\section{Conclusion}

Ravidassia Dharm is a response to social exclusion emanating from discriminatory and oppressive social structures coupled with the persistence of acute landlessness among Dalits in Punjab. It has provided Dalits with a distinct social identity deeply rooted in the 'sons-of-the-soil' thesis which proclaims that they are the descendants of the natives of this land who were deprived of their past glory by alien marauders. Dalits' failure to overcome their historic subjugation through the tested models of upward social mobility, conversion and sanskritization, forced them to look for an alternative way of social emancipation and empowerment. It was in this critical context that the newly established Ravidassia Dharm has attempted to come to their rescue with the aim of providing them with a distinct Dalit identity anchored in a separate Dalit religion. It empowers Dalits to peacefully contest their historically entrenched social exclusion and enables them to press for their rightful share in the local structures of power while upholding their distinct Dalit identity.

The chapter has further illustrated that although the Ad Dharm movement was the originator of the idea of a separate Dalit religion, it came to acquire its current shape in the form of Ravidassia Dharm through the versatile agency of numerous Ravidass Deras. These Deras provide distinct socio-religious space to its followers, mostly Dalits, who seem to feel empowered to exhibit their separate Dalit identity as a channel of upward social mobility. Thriving on distinct Dalit identity markers such as separate Dalit religious shrines, centres of pilgrimage (Shri Guru Ravidass Janam Asthan Temple, Seer Goverdhanpur), slogans (bole so nirbhay, sri guru ravidass maharaj ki jai), salutations (jai guru dev, dhan guru dev), arti and prayers (nam taro arti majan muraray ... and har so hira chhadh kai ...), insignia (har), traditions, rituals, Dalit gurus and heroes, festivals and sacred texts (Amritbani Satguru Ravidass Maharaj), Ravidass Deras are fast emerging as potent centres of Dalit empowerment in the state of Punjab. It also encourages its followers to highlight rather proudly their distinct identity as a way of Dalit empowerment conscientiously invigorated by the newly established Ravidassia Dharm.

\section{Clarification}

Caste names are used in the paper for academic purposes. Any inconvenience caused by such an exercise is deeply regretted. 


\section{Acknowledgement}

I am grateful to K. C. Sulekh, Lahori Ram Balley, C. L. Chumber, Mohan Lal Pheloria, the late I. D. Pawar, the late K. C. Shenmar, the late Chanan Lal Manak, the late D. C. Ahir, the late Advocate Bhagwan Dass and many more who helped me generously during the fieldwork. I am indebted to my wife and children who kept me free from the home front. Last but not least, thank you to Knut A. Jacobsen, who persuaded me to prepare this piece. For all the views articulated in this paper, however, I alone am responsible.

\section{Notes}

1 For the caste system, see Chapter 16 in this volume.

2 There is a common saying in Punjab that if the first person you meet in the early morning by chance happens to be a Brahman then your whole day gets spoiled.

3 A local peasant caste, which was otherwise assigned the lower status in the predominant Hindu social order. Jat Sikhs claim to occupy the top position in the distinct caste hierarchy in Punjab. For details see Singh (1977:70).

4 The annual budget of the Shiromani Gurdwara Prabandhak Committee (SGPC), the apex religious organizational body of Sikhs that controls their shrines, for the financial year 2013-2014 was Rs. 800 crore ( 8 billion rupees).

5 Dalit (ex-untouchables) is a sociological category that became a buzzword during the Dalit Panther movement in Maharashtra in the 1970s. In its wider usage, it includes Scheduled Castes (SCs), Scheduled Tribes (STs), Other Backward Castes (OBC), minorities and women. However, in the present study, I have confined it to SCs only, which is the politically correct use of the term.

6 Dalits who converted to Sikhism can be divided into two segments. One consists of Mazhabis and Rangretas, who were members of Chuhra caste (sweepers). The other consists of Ramdasias, who were Julahas (weavers) before their conversion to the Sikh religion. For details see Ram (2009: 6-8); Ram (2004b: 5-6).

7 Punjab is a Sikh (59.9 per cent) majority state. However, around 60 per cent of the Sikh population consists of Jat Sikhs who comprise about 30-33 per cent of the total population of the state.

8 They constitute as many as 29 per cent of the total population of Punjab, highest in comparison to all other states in India and much higher than the national average of 16 per cent. The proportion of the SC population is further going to increase rather significantly, as Mahatam/Rai Sikh - another downtrodden community - has recently been included in the SC list of the Indian constitution-wide ( $(\mathrm{f})$ in part XIV) Constitution (Scheduled Castes) Order (Amendment) Act, 2007, No. 31 dated 29 August 2007 (Punjab Government Gazette, Regd. No. CHD/0092/20062008, No. 45, 9 November 2007).

9 The declaration was made in Shri Guru Ravidass Janam Asthan Temple, Seer Goverdhanpur, a suburb of Varanasi, Uttar Pradesh eight months after the attack on the life of two topmost Sants of the Dera Sach Khand Ballan at a Guru Ravidass Temple in Vienna on 24 May 2009. In the attack around sixteen people were reportedly injured. Sant Ramanand, the second-in-command of Dera Ballan later succumbed to his injuries leading to a massive backlash in India, which caused huge losses to public and private properties worth thousands of millions of Indian rupees and a curfew for four days (for details see: Ram 2012: 696-700).

10 The term Sants refers to holy persons throughout the Hindi and Punjabi speaking territories in India and the diasporas. Many of the Sants remain nomadic, while a few of them lead a sort of settled celibate life in shrines, devoted to prayers and recitations of the sacred names received from their respective Gurus.

11 Dera literally implies a holy abode free from the structural bindings of institutionalized religious orders and is the headquarters of a group of devotees vowing allegiance to a particular spiritual person who is reverently addressed as Sant/Guru/Baba/Mahraj Ji. A Dera thrives on a distinct philosophy, rituals and symbols that are inspired by the teachings of a particular holy person, living or historical, after whom it has been established.

12 Dera Sachkhand Ballan, also known as Dera Shri 108 Sant Sarwan Dass Ji or simply Dera Ballan, is situated about twelve kilometres away from Jalandhar city. 
13 The Ad Dharm movement came into existence along with several similar movements in a number of regions (Adi Andhra, Adi Karnataka and Adi Dravida movements in south India and the Adi Hindu in Uttar Pradesh) in India in the 1920s. What made this movement the most popular were its low-caste character and the vehemence of its struggle against the structures of social domination. It laid special emphasis on distinct Dalit identity. For details see: Juergensmeyer (1988); Ram (2004c: 323-349).

14 'Dalit Panthers' Manifesto' in Satyanarayana and Tharu (2013: 55 and 64).

15 In fact, this argument somehow resembles that of Ambedkar where he articulated his choice for conversion to Buddhism on account of Buddhism being the ancient religion of the Mahars of Maharashtra. In a similar vein, Ravidassia Dharm is considered to be the ancient religion of the Dalits of Punjab.

16 For a detailed account of the various political developments in the 1920s see Juergensmeyer (1988: 20-32); Omvedt (1994: 105-107); Mendelsohn and Vizciany (2000: 99); Piplanwala (1986: 1015); Ahir (1992: 9-11); Hardtmann (2009: 54-56).

17 Ad Prakash Granth contains 1,248 pages, which include hymns of Guru Ravidass, Maharishi Valmiki and Kabir, apart from many other Adi Gurus. For details see Ram and Bains (1985: 1920). Also based on a personal interview with Chanan Lal Manak, Jalandhar, 1 May 2001.

18 Punjabi Tribune (Chandigarh), 7 July 2009.

19 Interview with Chanan Lal Manik, 1 May 2001.

20 Interview with Chatter Sain, son of Babu Mangu Ram Mugowalia, Garshankar (District Hoshiarpur), 27 April 2001.

21 Interview with Chatter Sain, son of Babu Mangu Ram Mugowalia, Garshankar (District Hoshiarpur), 27 April 2001.

22 Dera Sach Khand Ballan has established the following international charitable trusts abroad for the dissemination of the bani of Ravidass amongst the Dalit Diaspora: Shri 108 Sant Sarwan Dass Charitable Trust (UK); Shri 108 Sant Sarwan Dass Charitable Trust (Vancouver) Canada; and Shri 108 Sant Sarwan Dass Charitable Trust (USA). These trusts are managed mostly by Non-Resident Indian (NRI) Dalits from the Doaba region of Punjab who constitute a large diasporic community (Ravidassia Samaj) of the devotees of Guru Ravidass and the followers of the Dera Sach khand Ballan.

23 The title 'Singh' became popular among the Sikhs after the formation of the Khalsa in 1699.

24 The shalok is Harso hira chhadh kai karih an ki as, te nar dojak jahige sat bhakhai Ravidass (Those who renounce a diamond like Hari [God] and pin their hopes on others, shall go to hell - this is the truth, says Ravidass). The hymn is namu tero arti majanu murare, hari ke nam binu jhuthe sagal pasare. For details see: Callewaert and Friedlander (1992: 163-164, 230).

25 In Sikh gurdwaras, however, arti is not performed. Guru Nanak referred to arti in the hymn Dhanasari 3 (Adi Granth: 13). The entire cosmos, said he, is performing the arti of a single God. The whole sky is the platter and all the stars are its burning wicks. For details see: See Deep 2001: 44-46.

26 Based on participant observation by the author.

27 Based on participant observation by the author.

28 Holy book of the sacred scriptures of the Ravidassia Dharm. It contains the hymns of Guru Ravidass. It was compiled after the Vienna attack as an important component of the quick process towards the establishment of distinct Ravidassia Dharm.

\section{References}

Ahir, D. C. (1992) Dr. Ambedkar and Punjab, Delhi: B.R. Publications.

Ambedkari, N. (2005) 'Dera Sach Khand Ballan Dae Manjil Whal Vadde Kadam' (The Surging Step of Dera Sach Khand Ballan towards its Destination), Begumpura Shaher (weekly, Jalandhar), Vol. 2: 5.

Arsh, S. R. (English transl.) (2012) Amritbani Satguru Ravidass Maharaj, Seer Goverdhanpur, Varanasi (UP): Shri Guru Ravidass Janam Asthan Public Charitable Trust.

Callewaert, W. M. and P. G. Friedlander (1992) The Life and Works of Raidas, New Delhi: Manohar.

Deep, D. S. (2001) Sadhan Main Ravidasa Sant: Jiwan Ate Vichar (Sant Ravidass among the Saints: Life and Thought), Patiala: Punjabi University.

Hardtmann, E-M. (2009) The Dalit Movement in India: Local Practices, Global Connections, New Delhi: Oxford University Press. 
Juergensmeyer, M. (1988) Religious Rebels in the Punjab: The Social Vision of Untouchables, Delhi: Ajanta Publications.

Lum, K. (2009) 'Face to Faith'. http://www.theguardian.com/commentisfree/belief/2009/may/08/ kathryn-lum-face-to-faith [accessed on 21/08/2014].

Manak, C. L. (1985) 'Krantikari Aagoo: Babu Mangu Ram Mugowalia Atey Ad Dharm Lehar' (Revolutionary Leader: Babu Mangu Ram Mugowalia and Ad Dharm Movement), 3-8, Souvenir: Babu Mangu Ram Mugowalia 99th Birth Anniversary, New Delhi: 41, Kundan Nagar.

Mendelsohn, O. and M. Vicziany (2000) The Untouchables: Subordination, Poverty, and the State in Modern India, Cambridge: Cambridge University Press.

Narayan, B. (2011) The Making of the Dalit Public in North India: Uttar Pradesh, 1950-Present, New Delhi: Oxford University Press.

Omvedt, G. (1994) Dalits and the Democratic Revolution, New Delhi: Sage Publications.

Piplanwala, B. H. R. (1986) 'Lothian Committee and Ad Dharm Mandal', Kaumi Udarian 1 (2): 10-15.

Prasad, C. and M. Dahiwale (2005) 'Ravidass in the Contemporary World', in E. Zelliot and R. Mokashi-Punekar (eds), Untouchable Saints: An Indian Phenomenon, 249-256, New Delhi: Manohar.

Qadian, S. N. B, (2003) Jagat Guru Ravidass Sampradaya Sant Te Sadhna Sthal (Saints and Deras of World Guru Ravidass Panth), Jalandhar: Dera Sant Sarwan Dass Ji Sachkhand Ballan.

Rajshekar, V. T. (2004) 'A Silent Socio-Cultural Revolution Sweeps Punjab: Ravidass Saints Gain Millions of Followers', Dalit Voice 23: 3-5.

Ram, R. (2004a) 'Untouchability in India with a Difference: Ad Dharm, Dalit Assertion, and Caste Conflicts in Punjab', Asian Survey 46 (6): 895-912.

Ram, R. (2004b) 'The Dalit Sikhs', Dalit International Newsletter 9 (3): 5-7.

Ram, R. (2004c) 'Untouchability, Dalit Consciousness, and the Ad Dharm Movement in Punjab', Contributions to Indian Sociology (N.S.) 38 (3): 323-349.

Ram, R. (2008) 'Ravidass Deras and Social Protest: Making Sense of Dalit Consciousness in Punjab (India)', Journal of Asian Studies 67 (4): 1341-1364.

Ram, R. (2009) 'Ravidass, Dera Sachkhand Ballan and the Question of Dalit Identity in Punjab', Journal of Punjab Studies 16 (2): 1-34.

Ram, R. (2012) 'Beyond Conversion and Sanskritisation: Articulating an Alternative Dalit Agenda in East Punjab', Modern Asian Studies 46 (3): 639-702.

Ram, B. and J. Bains (1985) 'Ad Dharm, Ad Prakash Granth, Ad Dharmi Qaum', 19-20, Souvenir: Babu Mangu Ram Mugowalia 99th Birth Anniversary, New Delhi: 41, Kundan Nagar.

Sain, C. (1985) 'Ghadri Taun Ad Dharmi: Babu Mangu Ram Ji Mugowalia' (From Revolutionary to Ad Dharmi: Babu Mangu Ram Ji Mugowalia), 35-37, Souvenir: Babu Mangu Ram Mugowalia 99th Birth Anniversary, New Delhi: 41, Kundan Nagar.

Satyanarayana, K. and S. Tharu (eds) (2013) The Exercise of Freedom: An Introduction to Dalit Writing, New Delhi: Navayana.

Schaller, J. (1996) 'Sanskritization, Caste Uplift, and Social Dissidence in Sant Ravidas Panth', in David N. Lorenzen (ed.), Bhakti Religion in North India: Community, Identity and Political Action, 94-119, New Delhi: Manohar.

Singh, I. P. (1977) 'Caste in a Sikh Village', in Harjinder Singh (ed.), Caste among Non-Hindus in India, 66-83, New Delhi: National Publishing House.

Srinivas, M. N. (1956) 'A Note on Sanskritisation and Westernization', The Far Eastern Quarterly 15 (4): 481-496.

Takhar, O. K. (2005) Sikh Identity: An Exploration of Groups Among Sikhs, Aldershot: Ashgate.

Zelliot, E. (2001) From Untouchable to Dalit: Essays on the Ambedkar Movement, New Delhi: Manohar. 


\title{
26 \\ MUSLIMS IN \\ CONTEMPORARY INDIA \\ Socio-religious diversity and the questions of citizenship
}

\author{
R. Santhosh
}

\section{Introduction}

India is the third largest Muslim populated country in the world with an estimated number of over 160 million, constituting roughly 15 per cent of its population. Apart from its substantial size, Muslims in India present a fascinating picture in terms of their historicity, sociocultural diversity, religious composition, theological orientations, and above all, as the largest minority in a Hindu majoritarian secular country. All of these areas have been subjected to intense empirical as well as theoretical debates within academic circles; producing some of the fascinating scholarly works on Muslim society in India. The fundamental theoretical question that underlines most of these inquiries is the distinct character of Muslim encounter with modernity in the specific geopolitical landscape of India during colonial as well as post-colonial contexts. These studies have substantially enriched the debates on Islamic encounter with modernity by theorising the context-specific negotiations of Muslims with the ideological and institutional dimensions of Indian modernity, thus complicating metanarratives of this engagement at the global level.

Several of the contemporary Muslim situations in India reflect the complexities of this encounter; including the nature of political mobilisation of Muslims and their engagement with Indian democracy, their uneasy relationship with the Indian secularism and the fragmented sub-identities within Islam in India owing to diverse theological interpretations and mobilisations. These complexities reveal the extraordinary diversity within Muslim societies in dealing with the challenges posed by modernity and late modernity. They also challenge the stereotypical images about Muslims as a homogeneous and monolithic community bound together by a rigid religious identity, as the bewildering diversity within Indian Muslims in terms of theology, caste, class, ethnicity and geographic differences have played pivotal roles in defining the contours of these encounters.

The status of Muslims in India as the largest religious minority stands out as the most significant factor that influences the varied dimensions of their everyday existence. The 
Muslim religious identity becomes seminal in areas such as citizenship questions, political articulations and socio-economic development as it has tremendous implications on historical as well as contemporary narratives of these dimensions. It is also central to the historical narratives such as the spread of Islam across the subcontinent and the rise of the Mughal Empire, colonial encounter with the British, partition of India and the genesis of Pakistan and the situation of Muslim minorities in the post-colonial India. The unique political scenario in India characterised by the growth of Hindutva ideological and political forces further complicates and problematises the question of religious identity of Muslims, as according to these discourses, Muslims constitute the 'other' of Hindu cultural nationalism. These discourses and political mobilisation are also interspersed with the legacy of frequent religious violence between Hindus and Muslims, where the latter suffered heavily compared to their Hindu counterparts. In that sense, the story of Muslims in contemporary India demands a comprehensive analysis through the lens of security, equity and identity as the citizenship questions, the nature of their political participation and development scenario are highly contingent on their Islamic religious identity.

This chapter makes an attempt in that direction by focusing more on the scenario of citizenship and political articulations of Muslims in contemporary India. It provides an account of the emergence of religious diversity in terms of reformist/revivalist movements within Indian Islam that led to the fragmentation of religious identities and resulted in the emergence of a vibrant public sphere among them. The nature of social stratification, especially the prevalence of caste and the recent caste-based mobilisation is discussed in the next section. A broad overview of the socio-economic profile of the community and the recently published Sachar Committee Report is discussed in the following section. The final part of the chapter looks into the political dimension of the community, and analyses especially their citizenship questions in the background of a surging Hindutva discourse in India.

\section{Religious diversity and theological contestations within Islam in India}

The dominant historiographical accounts on the spread of Islam in India tend to see it not as an expansion, which implies imposition, and which in turn implies use of force, an old European stereotype; but rather to view it as an assimilation (Eaton 2000: 35). This process was quiet and slow, shaped by diverse actors, in particular localities, pursued a variety of agendas and responded to what others did resulting in the establishment of substantial Muslim populations in different parts of India over several centuries (Saberwal 2010). Eaton also highlights the processes of culture as accommodation, appropriation, and assimilation, which had the effect of transforming what had begun as an Arab tradition into what we call a world religion (Eaton 2003:6). The complex historical processes characteristic of the spread of Islam also ensured the multiplicity of its religious articulations and identities, much contrary to the impression of Islam being a monolithic religion. During the course of its development, different theological schools and their institutionalisation have resulted in the fragmentation of Muslim identity across the subcontinent. Concerted efforts of religious reformism have played a vital role in this process, and characteristically, these efforts and the counter efforts shared uncompromising, yet, divergent understanding of what constitutes 'true Islam'.

Throughout the Islamic history, the question of sources of authority from where specific guidelines can be drawn to govern personal as well as public affairs has been a highly contested one. Reformist and revivalist attempts are a reflection of concerted attempts to arrive at definitive conclusions regarding the question of authority in Islam, especially when 
the community experience a sense of degeneration and downfall of its fortunes. A pattern of rethinking tradition, as a means of adapting to change was set well before Muslims felt the direct impact of western modernity but these processes got impetus in the context of colonial advent that reinforced the notion of a perceived downfall of its fortunes (Brown 1996; Dallal 1993). The reformist discourse exhorted to go back to the originals, and to find out the truth about Islamic teachings from the Quran and Hadith directly so that the dangerous innovation (bid'a) mostly influenced by Hinduism and blind adherence (taqlid) to the teachings of the classical law books can be avoided. Scholars have pointed out that though these movements claim a going back to the originals and the tradition; in reality all these movements were specifically modern (Asad 1986; Madan 1997; Nandy 1990; Reetz 2006; Robinson 2008; Sanyal 1996; Turner 2001).

Shah Wali-Ullah (1702-1762) is widely considered as the forerunner of such reform and regarded as the one who inspired a number of reformist organisations in nineteenth- and twentieth-century India. He exhorted different Sufi orders to put their trust in a rational and broad-minded interpretation of the fundamentals of the Islamic belief system by focusing on Hadith as the authentic source of Islam and emphasised the exercise of independent judgment on an individual basis (Dallal 1993; Madan 1997; Sanyal 1996). Deriving inspiration from Wali-Ullah and declaring themselves as his successors, scholars like Nazir Husayn Dilhlawi (d. 1902) established Ahl-e-hadith, which adopted an extreme form of literalism in the matters of Hadith along with the rejection of taqlid. They disagreed with Wali-Ullah's moderate approach and adopted and bound themselves to a single, literal meaning of texts of the Quran and Hadith and denied the efficacy of qiyas (the use of logical reasoning to decide a legal question) (Brown 1996; Sanyal 1996).

One of the most significant and systematic traditionalist attempts to reject the visibly western ideas of Sir Sayyid Ahmad Khan (1817-1898) and his modernist Islam was the establishment of Dar ul-Ulum founded by Muhammad Qasim Nanotwi in 1867 at Deoband near Delhi. The basic aim of the Deobandi School was to return to the tradition of 'the two main streams of Islamic tradition, that of intellectual learning and spiritual experience' (Metcalf 1982:139). The Deobandi School advocated return to the Quran and the prophetic tradition and though they vehemently opposed the worship of local saints and their graves, they did not relinquish their connections with the mystical Sufi orders of Islam (Madan 1997; Metcalf 1982, 2004; Reetz 2004). Jamaat-e-Islami is significant in this analysis because it has raised political issues associated with Islam in the most forceful way. Abul ala Maududi (1903-1979), the founder of the organisation was convinced that a modern nation-state that functions on the basis of democracy, secularism and nationalism is against the basic tenets of Islam and argued that establishment of an Islamic state based on sharia is the paramount obligation of every true believer. Maududi's ideas have had a long-lasting influence on the articulations of political Islam in the Indian subcontinent (Ahmad 2008, 2010b; Metcalf 2004). Tablighi Jamaat, established by M. Mohammad Illyas (1855-1944), which is currently the largest Islamic organisation in the world, on the contrary, eschew visible ideological positions and abstain from public debates and instead focus on individual transformation through preaching tours (Mayaram 1997; Metcalf 1993, 2004; Sikand 1999; Reetz 2006, 2008).

While these movements criticised the orthodoxy for corrupting Islam and deviating from its actual path, Maulana Ahmad Raza Khan Barelwi (1856-1921) established Ahl-e-Sunnat as a resistance movement from the traditional Sunni sections against the reformist attempts. The theological position propagated by Ahmad Raza was Sufi-oriented, shrine-based folk Islam of mainly rural north India. He accorded priority to the principles of adherence (taqlid) where Muslims were called upon to stick to established traditions and more particularly to 
their law schools (mahdab) and to their religious guide (pir), a function closely associated with Sufi heritage (Reetz 2006:65 Metcalf 1982; Sanyal 1996).

These attempts aimed at reforming the Islamic community on various theological grounds and are important in the analysis on the formation of Islamic identity. Other than agreements in some basic aspects, there are considerable differences of opinion among these various movements. While a perceived notion of the degradation and decline of religion was widely shared by all these movements, the question of dealing with it gave rise to a number of diverse positions and debates. These movements and theological debates hardly remained at the exclusive realm of the Muslim elites and exerted tremendous impact on the everyday life of ordinary Muslims across these countries. The very foundation of religious identification and perception of religiosity has been fragmented among the masses due to these centurieslong attempts at reforming the community. Claims as the practitioners of 'true Islam' are always made by defining 'true Islam' as a highly exclusionary term professed and practised only by the respective claimants. Other than disseminating their own theological position through the vast network of madrasas and religious institutions, these movements engaged in considerable public activities to refute others' claim on the 'true Islam'. These varied forms of interventions included debates and public meetings, religious tracts and fatwas, legal proceedings, preaching and so on. The public debates between various groups on a number of contentious issues were the most significant ways of reaching out to the public on several theological issues (Metcalf 1982; Sanyal 1996). Even while these debates failed to attain conclusive positions on theological controversies, they played a significant role in re-affirming the participant's identification with their own group and this process was also creating an Islamic public sphere (or rather competing Islamic public spheres) (Reetz 2006:114). In other words, these debates produced one of the profound consequences of Islamic encounter with modernity: the objectification of religious knowledge and the democratisation of Islamic theology with long-lasting implications on the internal dynamics of the community (Eikelman and Piscatori 1996).

\section{Social stratification and emerging caste consciousness among Indian Muslims}

Though sectarian diversity among Indian Muslims such as Ahmadiyyas, Bohras, Sunnis and Shias is evident, the question of caste assumes significance on several grounds. ${ }^{1}$ The prevalence of the caste system among Indian Muslims is a testimony to the historical process of how a religion preaching equality gets transformed during its expansion and gets entrenched within existing hierarchical social structures of the host society. Upon the establishment of Muslim rule in India, a clear social stratification came to be established between the foreign and immigrant Muslims constituting the ashraf and the local Muslims who were converted to Islam in due course mostly from the lower castes becoming ajlaf. The lowest among the ajlaf was designated arzal, indicating their most depressed status (Jain 2005; Sikand 2005; Zainuddin 2003). One of the pioneering sociologists of Muslims in India, Imtiaz Ahmad, has recorded the elaborate caste system and forms of social stratification through his studies (Ahmad 1973, 2010a). ${ }^{2}$ While the ashraf are divided into four major subgroups, called the Saiyed, Shaik, Moghal and Pathan, the ajlaf are further divided into numerous sub-castes in different linguistic areas of the country. ${ }^{3}$ Ahmad points out that caste structures found among Muslims are analogous to those of Hindus as the major attributes such as endogamy, occupational specialization, hierarchical gradation of status groups and ritual considerations in commensal restrictions are found among Muslims as well (ibid.). The persistence of 
caste stratification among Indian Muslims has resulted in far-reaching consequences on their socio-economic mobility. Since the majority of Muslim converts were Súdras and from Hindu ex-untouchable castes whose traditional occupations have been service and menial jobs, extreme social and economic backwardness prevented them from making use of the opportunities of education and other forms of social mobility that was available in independent India. They have been given the 'Other Backward Class (OBC)' tag along with socio-economic weaker sections from other religions and are hence eligible for the benefits of reservation in education and government jobs.

The reinvigoration of backward caste movements among Hindus since the 1990s has influenced the caste equations within Indian Muslims as well. ${ }^{4}$ There is increasing discontent among the large sections of lower-caste Muslims against Muslim upper-caste religious elites and this is evident from the emergence of lower-caste Muslim mobilisation in different parts of the country and increasing clamour for change from these activists (Ahmad 2003; Alam 2010; Hansen 2000; Sikand 2002; Zainuddin 2003). Though the religious elites try to suppress these movements either by denying the existence of the caste system in India or by raising the bogey of fragmenting an already beleaguered community on caste lines, these movements are attaining momentum (Ahmad 2003). Indicating deeper tendencies of lower-caste solidarity among Muslims, mobilisation of Dalit Muslims has also began attaining momentum and the champions of these initiatives argue that the socio-economic conditions of the lowest sections of Muslims are worse than that of the Hindu Dalits and hence call for urgent attention and intervention from the state. All India Pasmanda Muslim $M a h a z^{5}$ represents such an initiative originated in Bihar during the early 1990s and now spreading to different parts of the country (Alam 2010). The increasing caste consciousness and fragmentation of a monolithic Muslim religious identity has significant implications for the political mobilisation of Muslims in the country and will be discussed in a later section.

\section{The scenario of socio-economic development}

The question of socio-economic development of Muslims in India needs to be located within the specific historic contexts of their mass migration to Pakistan following the partition and bloodshed in 1947 as well as their status as the largest religious minority in the post-colonial India. This foregrounding is important because, the question of socio-economic development of a minority community needs to be analysed in the wider context of three interrelated components, namely security, identity and equity. While their interrelation is extremely crucial, this section looks exclusively at the question of equity, and the following section will examine the implications of identity and security of the Muslim community in India.

The large-scale out-migration of Muslims into Pakistan immediately after partition resulted in the exodus of Muslims who occupied higher socio-economic status within the community. People engaged in non-agricultural professions and those who were educated, economically well-off and political elites tended to migrate, leaving behind the agricultural workers, the poor and the uneducated Muslims in India (Islam 2012; Basant and Shariff 2010). The overall backwardness of the community in terms of socio-economic development is heavily influenced by this legacy of migration and the absence of elites to provide political and entrepreneurial leadership.

Muslims are the largest minority in India; the total number reached160 million in 2009 (Kulkarni 2010). ${ }^{6}$ The annual growth rate of the Muslims has averaged 2.7 per cent over the period 1960-2001, above the national average of 2.1 per cent. The geographical distribution of Muslims in India is highly dispersed and among twenty-six states, only Jammu and 
Kashmir has a Muslim majority population constituting of 67 per cent of the population while states such as West Bengal, Assam and Kerala have Muslim populations above 20 per cent. Of the total 594 districts in 2001, only twenty had a majority Muslim population and thirty-eight had a substantial, though not a majority, Muslim population. Literacy level of Muslims is estimated at 59 per cent, lower than the national average of 65 per cent according to the 2001 census. Also according to the 2001 census, the sex ratio of Muslims adheres to the national figure of 930 women per thousand men. Child mortality rate and infant mortality rates are slightly lower than the national figures of 57 (infant mortality rate) and 74 (under five mortality rate) according to the 2001 census and stand at 52 and 70 respectively (Kulkarni 2010 and Deolalikar 2010).

The academic as well as policy-level attempts to look at the socio-economic development of Muslims as a distinct religious group is of very recent origin in the Indian context, as most of the literature on Muslims revolved around issues such as identity and communalism. It has been pointed out that colonial rule and the influence of modernisation theory on Indian social sciences and state-led developmental discourses has been significant, forcing upon them an evolutionary view of development where the traditional and primordial affiliations such as caste and religion would vanish at the advent of modern institutions as well as ideologies (Jodhka 2007; Upadhya 2001). This tendency also went hand in hand with a secular notion of development, especially at the formative years of Nehurvian era, refusing to recognise caste and religion as legitimate categories to understand development status of different sections of the population. Though the Indian constitution recognised the precariousness of religious minorities and provided special rights, economists who worked with 'hard data' generated through the 'secular' economic and demographic variables dominated the mainstream development discourse, paying scant attention to the development experience of religious groups (Jodhka 2007:2297).

The distinct socio-economic condition of Muslims as a religious category came to the fore and aroused considerable public debate with the publication of a report popularly known as the Sachar Committee Report ${ }^{7}$ in 2006 (Basant 2007; Basant and Sheriff 2010; Islam 2012; Jodhka 2007; Robinson 2007; Shah 2007). The Report essentially deals with the relative deprivation of Muslims vis-à-vis other socio-religious communities (SRC), thus providing a comparative and comprehensive framework on all important development parameters. The Report shows that 25 per cent of Muslim children in the six to fourteen age group have either never been to school or have dropped out at some stage. Using the 61st round of National Sample Survey, the Report shows that Muslims stand second with 31 per cent of the headcount ratio (HCR) living below poverty line, just behind the SCs/STs with an HCR of 35 per cent. More than half of the Muslim workers are self-employed in household enterprises and concentrated in certain areas such as tobacco and textile products, retail and wholesale trade, repair and maintenance of motor vehicles, electrical machinery and apparatus manufacturing, and so on, and their participation in the informal sector is much higher than most other SRCs.

The Sachar Committee also looked at the representation of Muslims in government employment and demonstrates that they are highly under-represented in proportion to their population; for example only 3 and 4 per cent of the officers of the Indian Administrative Service (IAS) and the Indian Police Service (IPS) in 2006 were Muslims. The Report also shows that the number of Muslim members of major policy making bodies is not only inadequate, but has drastically declined in parliament and state legislative assemblies over the years. ${ }^{8}$ In a nutshell, the Report observes that the socio-economic condition of Muslims in India is somewhat better than that of the SCs/STs but worse than of the Hindu OBCs. 
More important is that while most of the SRCs have received some benefit in the economic development, the position of the Muslims has been somewhat reversed in the past sixty years as their economic opportunities have shrunk and political space has been conspicuously abridged (Shah 2007:839).

One of the significant implications of the Sachar Report is its reformulation and recasting of the category of Muslim as a monolithic, pan-Indian identity. The Report divides Indian Muslims on caste lines into 'general' and 'OBC' categories, recognises the three fold castelike divisions such as ashrafs, ajlafs and arzals and advocates the listing of arzals as scheduled castes along with similar categories from other religions. In that sense, the Report facilitated a shift from a discourse of treating Muslims as a 'community' with specific cultural histories and self-identities with clearly marked out boundaries into a 'population', identified and described through a language that primarily belongs to the state (Jodhka 2007: 2998). This shift, it is argued, will facilitate new forms of mobilisation from within the community in future and the question of citizenship will begin to take priority over the questions of identity and cultural distinctiveness (Jodhka 2007: 2998).

\section{The political dimensions of Muslims in India: questions of citizenship and identity}

The story of Muslims in post-colonial India, especially their political mobilisation and citizenship questions are significant on various counts. There have been intense debates among scholars of Muslim societies regarding the compatibility of Islam with modern institutions and systems such as secularism and democracy. While scholars such as Gellner (1981) and Geertz (1965) point out the inherent features of Islam that prevents it from undergoing secularisation process, Giddens (1999) and Huntington (1996) highlight the essentially anti-democratic and anti-modernist tendencies of Islam. On the other hand, a vast array of scholars have argued, based on ethnographic as well as historic works, and demonstrated the complex processes through which Islamic communities have successfully negotiated with the challenges of modernity (Brenner 1996; Euben 1997a, 1997b; Hefner 1997, 1998; Moaddel 1998; Piscatori 1986; Robinson 2008). Scholarship on Indian Muslim's encounter with electoral democracy and secular state adds many valuable insights to the complexity of these negotiations that are highly contingent on the socio-political and historical contexts of Indian society. The Muslim experience in India also stands testimony to the travails of a secular constitution striving to protect the minority rights in an atmosphere of surging Hindu nationalist politics and communal tension.

The saga of partition and the creation of a Muslim majority nation still hang on the political discourse of Indian society as a testimony to Muslim separatism and their uneasy relation with a secular constitution. With the Muslim League dissolved in north India and its leadership filtered through to Pakistan, the political trajectory of the Muslim community was defined within the democratic and secular framework; its future lay in coming to terms with the broad contours of Indian secularism and rallying round political parties with avowed secular goals (Hasan 1988, 1990). Moreover, a spate of bloody communal violence that followed partition and the assassination of Mahatma Gandhi by a Hindu fanatic closely associated with RSS (Rashtriya Swayamsevak Sangh) discredited the arguments of Hindu nationalism and Muslim separatism and made secularism as the only possible basis for a modern Indian state (Brass 1990: 229). Upholding the principle of secularism, the Indian constitution had incorporated significant provisions for the protection of the sociocultural identity of religious minorities in India. ${ }^{9}$ 
It is evident that Muslims who remained in India failed to emerge as a powerful political force and this is mainly due to their scattered demographic distribution across the country and the internal schism based on sectarian and theological differences. After independence, at least for a couple of decades, the Indian National Congress became the most trusted party of Indian Muslims. Historically too, Jamiyat al-ulama-I Hindi, an influential party of the ulema associated with the Deoband seminary, was a close supporter of the Congress throughout the freedom struggle. Jamiyat's support was based on the tacit understanding with the Congress that a number of key issues dear to the ulemas such as places of worship, religious endowments, Muslim Personal Law, and other institutional aspects of Islamic culture would be protected (Hasan 1990, 1988; Khalidi 1993; Malik 2012). The other major Muslim organisation, Jamaat-e-Islami was in a quandary as it found it impossible to adhere to and openly proclaim the vision of its founder Abul ala Maududi as it would be impractical and suicidal to argue that secularism and democracy are un-Islamic and the real obligation of a true Muslim is to strive for an Islamic state. ${ }^{10}$ Two prominent Muslim political parties which have been successful in sending representatives to the parliament are the Indian Union Muslim League and the Majlis-i Ittihad al-Muslimin. While the former is confined to the northern districts of Kerala the latter has retained its political base in Andhra Pradesh, especially in Hyderabad. The political fortunes of these organisations support the argument of Lloyd and Susanne Rudolph that Muslim voters tend to favour confessional parties where Muslims are in significant numbers, and vote for national parties when in a smaller minority (Rudolph and Rudolph 1987).

From the beginning of the 1980s, the Indian political system began to witness radical changes as political mobilisation based on ascriptive identities such as caste and religion began emphatically to appear on the political front, offsetting the rhetoric of secular democratic politics. Hansen argues that in the field of political discourse, during the 1980s majoritarian and communal themes were becoming ever more accepted and legitimate and the majoritarian notion of the 'rights' of the Hindus was gradually becoming a 'legitimate problematic' (Hansen 2005: 332). This turn in terms of the ascendance of Hindu nationalism and growth of the Bharatiya Janata Party (BJP) posed significant challenges to the citizenship questions of Muslims in India. This is of paramount importance because, fundamentally, Hindu nationalism was conceived and nurtured through various strategies over decades as opposition to the 'Muslim other' who by definition do not belong to the cultural imagination of Indian nationalism, because, their holy land is elsewhere (Varshney 1993). ${ }^{11}$

A reinvigorated Hindutva politics since the 1980s has played a crucial role in the construction of this 'Muslim other' in Indian political discourses, but its genesis goes back to the time of Indian independence and impinges on the ways through which the Indian nation-state was conceived and imagined. Pandey suggests that while the political discourses immediately after partition acknowledged the nationalist credentials of Hindus as given and original, those of the Muslims who remained in India were suspect on account of their being Muslims and this axiomatic view was further strengthened by the agitation for separate Muslim rights (Pandey 1999; Malik 2012). Following Talal Asad, Pandey also argues that the institutionalisation of terms such as 'majority and minority' on the basis of religion resulted in creating a pan-Indian idea that members of some cultures belong to particular politically defined space, but those of others (minority) do not. Hence, the Muslim minority, who originally fought for Pakistan and later constricted to stay back, came under the perpetual burden of demonstrating the sincerity of their choice: they had to prove that they were loyal to India and, hence, worthy of citizenship (Pandey 1999: 610-611). 
This burden of having to demonstrate their patriotism and nationalism on demand gets exacerbated in a political climate dominated by Hindutva discourse that thrives on exclusionary politics and vilification of Muslims. Scholars working on the phenomenal growth of Hindutva organisations since the 1980s that culminated in the formation of the BJP government in 1999 at the centre have dwelt extensively on the carefully drafted ideological and tactical strategies which included the incorporation of selected symbolic and mythological elements from popular Hinduism as well as the systematic vilification of Muslims and Christians (Anderson and Damle 1987; Brass 2003; Breman 2002; Chatterji 1994, 1995; Fox 2007; Fuller 2001; Jafferlot 1996; Ludden 2007; Nandy et al. 1997; Noorani 2000; Pandey 1991,1993; Rajagopal 2001; Van der Veer 1987, 1994; Vanaik 1997). These campaigns have consistently sought to highlight the sense of betrayal and inferiority of the Hindu majority in secular India, and demanded acts of atonement, purification or sacrifice to restore the glories and unity of Hindudom (Corbridge and Harriss 2000: 189).

The Hindutva protagonists are not the advocates of a Hindu theocratic state, and they have thoroughly problematised the Nehruvian version of secularism by casting it as 'pseudo-secularism', which implies that secularism has been distorted and biased in favour of minorities in India. They accuse that secular parties, mainly Congress and the Left, are brainwashed by western-influenced liberals and are practising 'minority appeasement' and engage in 'vote bank politics' to win over minority votes. The Hindutva discourse depicted Islam as inherently intolerant and aggressive, backward and feudal, and a community that enjoys undeserving rights in the guise of secularism in India. The Shah Bano controversy ${ }^{12}$ of 1985 bolstered this view that Indian National Congress, led by its Prime Minister Rajiv Gandhi had meekly given in to the demands of Muslim clergy, overturning the Supreme Court's historic judgment that aimed at upholding the constitutional requirement for a uniform civil code (Jafferlot 1996; Kishwar 1998). The Salman Rushdie controversy of 1989 where the concerted efforts of various Muslim organisations against his book Satanic Verses ultimately resulted in its ban also was played out by the Hindutva discourses as an example of an intolerant and assertive Muslim community coercing the Indian government to toe its line. According to these narratives, the on-going sub-national struggle in Jammu and Kashmir is the manifestation of Muslims' religiously rooted anti-national tendencies that try to divide and sabotage national integrity of India.

The Babri Masjid agitation of the early 1990s and the subsequent demolition of the mosque on 6 December 1992 was the culmination of a protracted ideological and organisational campaign on these lines by Hindutva forces. Hansen points out that Ayodhya was made the central and highly mobile metaphor for a 'something lacking' among the Hindus, and the Babri Masjid was portrayed as a traumatic wound in the nation and in Hindu civilisation - 'something lacking' that could be healed through the removal of the mosque and the construction of the temple (Hansen 2005: 326). The Babri Masjid demolition was widely celebrated by the Hindutva protagonists as the 'awakening of a resurgent Hindu'; as the illustration of reversing a historic wrong, disregarding the constitutional and judicial establishments that has been insensitive to the religious sentiments of the Hindu majority in India.

While the Hindutva discourse disparaged secularism and its practice in India, Muslims have an ambivalent and uneasy relationship with the conceptual and institutional aspects of secularism in India. For Muslims, the destruction of the mosque represented a complete breach of trust in the secular constitution and the judiciary that had ordered the maintenance of the status quo of the mosque. Muslims across the country firmly believed that the entire episode was well orchestrated with the tacit connivance of the Congress government at the 
centre and the BJP government in Uttar Pradesh where the mosque was situated. The sense of betrayal still lingers on as the accused in the demolition, especially those implicated by the Liberhan Commission, are still scot-free and enjoy highly powerful positions within the government and BJP. ${ }^{13}$

For Muslims, the secular constitution and its promise appear ineffective given the grim picture of Hindu-Muslim violence in the country (see the chapter by Vicziany in this book) and the the overriding Hindu majoritarian character of the state apparatus, which could not even ensure their physical security and safety. Wilkinson estimates that the overall number of casualties (dead and injured) since independence in Hindu-Muslim riots is around 40,000 besides causing enormous economic losses running into thousands of crores of rupees (Wilkinson 2005) $\cdot{ }^{14}$ It has been pointed out that the very stature of Muslims as a minority in terms of population and political power results in them bearing the brunt of violence in comparison with their Hindu counterparts, especially given the fact that major communal riots have occurred in towns and cities where they have attained economic success through their traditional artisanal and entrepreneurial skills (Engineer 1983; Hasan 1988). The rise of the BJP in many north Indian states has significantly altered the ways in which the state deals with religious violence, giving rise to the accusation that the state takes a highly partisan stand against Muslims during riots and the most striking example is the 2002 Gujarat pogrom that resulted in the deaths of more than 1,000 Muslims. The Gujarat government, headed by Narendra Modi - the current Prime Minister of India and the then Chief Minister of Gujarat - was at worst highly partisan and at the best inexcusably hesitant in preventing antiMuslim violence and in its willingness to call in central troops and paramilitary forces to do the job for them (Wilkinson 2005:19; Setelvad 2005). Given the recent communal riots in Muzaffarnagar in Uttar Pradesh and in Assam, where Muslims suffered heavily during the riots and the state administration turning ineffective, this trend seems to be the rule rather than the exception in the current political scenario of the country. This in turn contributes to the spiral of a heightened sense of insecurity among the Muslims leading to increased ghettoization in their residential spaces, which further contributes to the sense of alienation and isolation (Breman 2002; Kirmani 2008; Mahadevia 2002).

The growth of fringe groups of extremists who believe in terrorist reprisal from within the community has worsened the precarious situation of Muslims in the contemporary era where the 'war on terrorism' enjoys unquestionable legitimacy. A series of terrorist attacks since the early 1990s - serial bomb explosions in Mumbai and Coimbatore in 1993 and 1998 respectively, the attack on the parliament in 2001, and the 2008 Mumbai attack being the most violent among them - by Muslim radical groups who are suspected of having crossborder connections have brought the Muslim community into the limelight with regard to the question on terrorism. The terrorist attacks that occur with unfailing regularity across the country have only intensified the already existing burden of suspicion and prejudice faced by that community. ${ }^{15}$ There have been widespread accusations of unlawful arrests and illegal detention of Muslim youths by the police on the basis of mere suspicion, and this, further exacerbates the process of alienation that has been well underway for several decades.

On the other hand, observers of Muslim politics have begun to argue that the Hindutva onslaught has helped in the creation of an alternative pan-Indian political consciousness among Muslims and has given rise to a new form of politics. In a decisive departure from the traditional Muslim politics led by elites who were wary of secularism and obsessed with questions of religious identity and cultural factors, the new political discourse is thoroughly democratic, unflinchingly embraces secular language and articulates itself as citizen politics that translates itself through the demands for equality, recognition and equal rights to ensure 
an egalitarian living (Alam 2008; Jodkha 2007). According to this argument, implementation of the Mandal Commission Report following the OBC agitation and the publication of the Sachar Committee Report has already facilitated this process and the possibility of a broadbased political alliance of the backward communities, Dalits and Muslims is highly promising and imminent. On similar lines, Hansen also mentions the emergence of a plebeian politics among Indian Muslims premised on the powerful emotions attached to Muslim identity in contemporary India while it also questions the very notions of a unified Muslim community by expanding into religious and cultural practices previously not politicised, such as sectarian and caste differences (Hansen 2000: 269). These arguments echo the observations regarding the changing character of Muslim politics across the world where there is a decisive adoption of liberal secular language of equality, social justice, human rights and secularism indicating the turn towards post-Islamism and civil Islam (Bayat 2007; Roy 2004). Some of the overzealously optimistic commentators are even celebrating an 'India's Muslim Spring' namely the emergence of a new generation of Muslims who want to rid the community of its insular and sectarian approach by concentrating on things that affect their everyday lives (Suroor 2014).

\section{Conclusion}

The citizenship question of Indian Muslims is quite fascinating given the specificities of its historic legacy and the complex socio-political and ideological contestations that mark present times. Scholars of Indian Muslims have demonstrated beyond doubt the fallacy of treating them as a 'community' with given socio-political dispositions due to their shared religious identity. Yet, the identity of a Muslim minority in a secular Hindu majoritarian country constantly informs their everyday existence and continuously shapes the multiple contours of their citizenship question in India. Scholars have also exhibited the futility of privileging Islamic theological doctrines as determinants of their socio-political positions and instead have demonstrated how these positions are quite contingent on external contexts that often compel theology to reinvent itself. Yet the fatwa issuing ulema who vouch by theological infallibility and command leadership within the community too is a reality for Muslims.

Like any other socio-religious groups, propelled by processes of globalisation and economic reforms, Muslims in India too are undergoing rapid socio-cultural transformations resulting in critical reformulation of their living. Significant advancement in education and the emergence of a new middle class who is benefiting from the opportunities of a globalised era is redefining the character of Indian Muslims. Increasing democratisation of religious authority and the emergence of a vibrant public domain where theological and ideological matters are thoroughly discussed and debated are definitely positive signs for the community. The active involvement in the democratic process of India and the constructive engagement with a secular liberal paradigm to articulate their collective demands and aspirations add to the democratic spirit of the country. Yet, the future of their citizenship question and integration into the collective imagination of Indian nationalism is highly contingent on the present as well as the future prospects of Hindutva ideology in the country.

At present, the most significant development in Indian polity for the Muslims is the usurpation of political power at the centre by BJP in the 2014 election with an overwhelming majority resulting in the virtual decimation of the opposition and the 'secular' parties. Even more significant is the elevation of Narendra Modi, who has been pilloried as the mastermind of the 2002 anti-Muslim pogrom and widely recognised as the mascot of hard- 
line Hindutva as the Prime Minister of the country. It is too premature to guess the specific policy orientations and administrative interventions of the new government in several contentious matters related to the minority question in India and the responses from the community. Yet, it is evident that Muslims in India are passing through some of the most momentous phases of their recent history and only the future will demonstrate how the community negotiated with these challenging times.

\section{Notes}

1 Sunnis are the vast majority among Indian Muslims and Shias constitute roughly 25 per cent. Ahmadiyyas and Bohras are minuscule minorities with less than one million each.

2 Imtiaz Ahmad's seminal anthropological works on Indian Muslims triggered a debate between historians and anthropologists on the nature of Islamisation and syncretism among Muslim communities in the sub-continent. See for details: Ahmad (1973, 1976, 1981), Das (1984), Robinson (2000), Roy (2005) and Madan (2007).

3 See Ahmad and Chakravarti (1981) for a detailed enumeration of Muslim castes in different geographic regions of India

4 For the emergence of the backward class movement in India in the 1990s following the Mandal commission agitation that demanded 27 per cent of reservation for Other Backward Classes in government jobs and educational institutions, see Yadav (1996) and Jafferlot (2000)

5 The term pasmanda means those who are left behind and the Pasmanda movement highlights the plight of Arzals and argues for their mobilization against the upper-caste Ashraf within the community (Alam 2010).

6 The 2001 decennial census shows Muslims constituted roughly 14 per cent of the Indian population amounting to a total of 138 million while other minorities such as Christians, Sikhs, Buddhists and Jains constituted 2.34, 1.87, 0.77 and 0.41 respectively. The following census held in 2011 has not yet released the population statistics of religious groups.

7 The Prime Minister's High Level Committee, headed by justice Rajendra Sachar was appointed on 9 March 2005 and submitted the report titled 'Social, Economic and Educational Status of the Muslim Community' in the last week of November 2006 and tabled it in parliament on 30 November 2006. The committee visited almost all the states and apart from the 578 representations it received on the conditions, grievances and demands from several Muslim groups and organisations, it heavily depended on quantitative data available from the Census, National Sample Surveys, National Family Health Survey and information from banking and financial institutions, government departments, universities, etc.

8 The most recent election held in 2014 that witnessed a Hindutva wave across the country saw an all-time low of only twenty-four Muslim members of parliament, representing a mere 4.4 per cent of the total strength of the house, and the BJP, the ruling party which won an absolute majority with 282 seats, does not have a single Muslim member.

9 The Indian constitution champions the cause of minorities through two significant provisions; that of non-discrimination and provision of minority rights. The Chapter on Fundamental Rights (Article 14-30) ensures that no citizens will be discriminated on the basis of caste, gender, race, religion, sex and place of birth in the country. Article 16 and Clause 2 of Article 29 specifically affirm the principle of non-discrimination in the field of employment by the state and admission to educational institutions maintained by the state or receiving aid from state funds respectively. In terms of minority rights, Article 29(1) guarantees the right of religious minorities to protect and conserve their culture. The right to establish and administer educational institutions of their choice and to receive state grants are guaranteed to minorities through Article 30(1) and Article 30(2). Many of these provisions have been strengthened by a series of innovative court verdicts in favour of minorities, especially in matters relating to educational rights (Alam 2008). The most significant legal provision to protect the distinct cultural identity of Muslims in India is the protection of Muslim Personal Law or Sharia law that governs matters related to 'personal' aspects such as marriage, divorce, adoption, inheritance and succession of Muslims. The commitment of the Indian constitution to the principle of secularism is enshrined in Articles 25, 26, 27 and 28. Article 25 (1) grants 'freedom of conscience' and 'free profession, practice and propagation of religion' to all citizens while Article 26 confers the right upon the members of a religious group to 


\section{R. Santhosh}

'manage religious affairs, establish institutions and acquire movable and immovable property for religious and charitable purposes'. Article 27 prevents the state from levying a tax upon citizens to promote any particular religion while Article 28 prohibits the impartation of any religious instruction in educational institutions supported by state funds.

10 See Ahmad (2006, 2008, and 2010) for a comprehensive account of the dilemma and ideological turnaround of Jamaat-e-Islami in post-independent India, compelled by socio-political circumstances.

11 The central thesis of Hindutva ideology is articulated in the book The Essentials of Hindutva (1922) by V. D. Savarkar and according to him, a true Hindu can be defined as 'a person who regards this land ... from the Indus to the Seas as his fatherland as well as his Holyland'. It is evident that this formulation excludes 'alien' religions like Christianity, Islam and Judaism from the national imagination of 'true Indians' since their holy land lies outside the geographic boundaries of India.

12 In 1985, the Indian Supreme Court overruled a Muslim personal law by granting Shah Bano, a 62 -year-old woman alimony from her divorced husband. This resulted in powerful backlash from Muslims across the country who saw it as an infringement on the Sharia law and successfully pressurised Rajiv Gandhi, the then Congress Prime Minister to bring in a constitutional amendment to overrule the Supreme Court verdict.

13 The Home Ministry appointed retired High Court Judge M. S. Liberhan on 16 December 1992 to look into the circumstances of the Babri Masjid demolition and, though originally mandated to submit the report within three months, the Commission submitted its report after fortyeight extensions and a delay of seventeen years. In the report submitted on 30 June 2009, the Commission holds sixty-eight people culpable including the top leadership of BJP such as Atal Bihari Vajpayee, L. K. Advani, Murali Manohar Joshi etc.

14 For an exhaustive account on communal riots see Wilkinson (2005) and Brass (2003).

15 Investigations into two terrorist attacks, the 2006 Malegaon bomb blast and the Ajmer bomb blast, have revealed the involvement of radical Hindutva groups behind these blasts and hence blunted the argument that all terrorist attacks in India are the work of Muslims.

\section{References}

Ahmad, I. (ed.) (1973) Caste and Social Stratification among Muslims in India, New Delhi: Manohar.

Ahmad, I. (ed.) (1976) Family, Kinship, and Marriage among Muslims in India, New Delhi: Manohar.

Ahmad, I. (ed.) (1981) Ritual and Religion among Muslims in India, New Delhi: Manohar.

Ahmad, I. (2003) 'A different jihad: Dalit Muslims' challenge to Ashraf hegemony', Economic and Political Weekly, 38: 4886-4891.

Ahmad, I. (2006) 'The state in Islamic thought', ISIM Review, 18: 12-13.

Ahmad, I. (2008) 'Cracks in the mightiest fortress; Jamaat-e-Islami's changing discourse on women', Modern Asian Studies, 42: 549-575.

Ahmad, I. (2010a) 'Recognition and entitlement: Muslim castes eligible for inclusion in the category of scheduled castes', in M. Hasan (ed.), Islam in a Global World, New Delhi: ImprintOne.

Ahmad, I. (2010b) Islamism and Democracy in India: The Transformation of Jamaat-e-Islami, New Delhi: Permanent Black.

Ahmad, S. S. and A. K. Chakravarti (1981) 'Some regional characteristics of Muslim caste system in India', GeoJournal Southern Asia-Geography of Contrast, 5: 55-60.

Alam, A. (2010) 'New directions in Indian Muslim politics: The agenda of the All-India Pasmanda Muslim Mahaz', in M. Hasan (ed.), Islam in a Global World, New Delhi: ImprintOne.

Alam, J. (2008) 'The contemporary Muslim situation in India: A long-term view', Economic and Political Weekly, 43: 45-53.

Anderson, W. K. and Damle, S. D. (1987) The Brotherhood of Saffron, the Rashtriya Swayam Sevak Sangh and Hindu Revivalism, New Delhi: Visthar Publications.

Asad, T. (1986) 'The idea of anthropology of Islam', Occasional Paper Series, Centre for Contemporary Arab Studies, Georgetown University.

Basant, R. (2007) 'Social, economic and educational condition of Indian Muslims', Economic and Political Weekly, 42: 828-832.

Basant, R. and A. Shariff (2010) 'The state of Muslims in India: An overview' in R. Basant and A. Shariff (eds), Handbook of Muslims in India; Empirical and Policy Perspectives, New Delhi: Oxford University Press. 
Bayat, A. (2007) Making Islam Democratic: Social Movements and the Post-Islamist Turn, Stanford, CA: Stanford University Press.

Brass, P. R. (1990) The Politics of India Since Independence, Cambridge: Cambridge University Press.

Brass, P. R. (2003) The Production of Hindu-Muslim Violence in Contemporary India, Seattle, WA: University of Washington Press.

Breman, J. (2002) 'Communal upheaval as resurgence of social Darwinism', Economic and Political Weekly, 37: 1485-1488.

Brenner, S. (1996) 'Reconstructing self and society: Javanese Muslim women and the veil', American Ethnologist, 23: 673-697.

Brown, D. (1996) Rethinking Tradition in Modern Islamic Thought, Cambridge: Cambridge University Press.

Chatterji, M. (1994) 'The BJP: Political mobilization for Hindutva', South Asian Bulletin: Comparative Studies of South Asia, Africa and the Middle East, 14: 14-23.

Chatterji, M. (1995) 'Communalism in India: A historical and empirical study', in A. A. Engineer and M. Shakir (eds), Communalism in India, New Delhi: Vikas Publications.

Corbridge, S. and J. Harriss (2000) Reinventing India: Liberalization, Hindu Nationalism and Popular Democracy, New Delhi: Oxford University Press.

Dallal, A. (1993) 'The origins and objectives of Islamic revivalist thought 1750-1850', Journal of the American Oriental Society, 113 (3): 341-359.

Das, V. (1984) 'For a folk-theology and anthropology of Islam', Contributions to Indian Sociology, 18: 293-300.

Deolalikar, A. B. (2010) 'The performance of Muslims on social indicators', in R. Basant and A. Shariff (eds), Handbook of Muslims in India; Empirical and Policy Perspectives, New Delhi: Oxford University Press.

Eaton, R. M. (2000) Essays on Islam and Indian History, New Delhi: Oxford University Press.

Eaton, R. M. (2003) India's Islamic Tradition; 711-1750, New Delhi: Oxford University Press.

Eikelman, D. F. and J. Piscatori (1996) Muslim Politics, Princeton, NJ: Princeton University Press.

Engineer, A. A. (1983) 'Socio-economic basis of communalism', Mainstream, 21: 15-18.

Euben, R. (1997a) 'Comparative political theory: An Islamic fundamentalist critique of rationalism', The Journal of Politics, 59: 28-55.

Euben, R. (1997b) 'Premodern, antimodern, or postmodern? Islamic and western critiques of modernity', The Review of Politics, 59: 429-459.

Fox, R. G. (2007) 'Communalism and modernity' in L. David (ed.), Making India A Hindu: Religion, Community and the Politics of Democracy in India, New Delhi: Oxford University Press.

Fuller, C. J. (2001) 'The Vinayaka Chathurthi festival and Hindutva in Tamil Nadu', Economic and Political Weekly, 36: 1607-1616.

Geertz, C. (1965) 'Modernisation in a Muslim society: The Indonesian case', in R. N. Bellah (ed.), Religion and Progress in Modern Asia, New York: The Free Press.

Gellner, E. (1981) 'Flux and reflux in the faith of men', in E. Gellner (ed.), Muslim Society, Cambridge: Cambridge University Press.

Giddens, A. (1999) Runaway World: How Globalisation is Reshaping Our Lives, London: Profile Books.

Hansen, T. B. (2000) 'Predicaments of secularism: Muslim identities and politics in Mumbai', Journal of the Royal Anthropological Institute, 6: 255-272.

Hansen, T. B. (2005) 'The saffron wave', in W. Steven (ed.), Religious Politics and Communal Violence, New Delhi: Oxford University Press.

Hasan, M. (1988) 'Indian Muslims since independence: In search of integration and identity', Third World Quarterly, 10: 818-842.

Hasan, M. (1990) 'Adjustment and accommodation: Indian Muslims after partition', Social Scientist, 18: $48-65$.

Hefner, R. W. (1997) Islamisation and Democratisation in Indonesia in Islam in the Era of Nation States: Politics and Religious Renewal in Muslim Southeast Asia, Honolulu, HA: University of Hawaii Press.

Hefner, R. W. (1998) 'Multiple modernities; Christianity, Islam and Hinduism in a globalising age', Annual Review of Anthropology, 27: 83-104.

Huntington, S. P. (1996) The Clash of Civilizations and the Remaking of World Order, New York: Simon and Schuster.

Islam, M. (2010) 'Rethinking the Muslim question in post-colonial India', Social Scientist, 40: 61-84.

Islam, M. (2012) 'Rethinking the Muslim question in post-colonial India'. Social Scientist, 40 (7/8): $61-84$. 


\section{R. Santhosh}

Jafferlot, C. (1996) Hindu Nationalist Movement and Indian Politics: 1925 to the 1990s, New Delhi: Viking. Jafferlot, C. (2000) 'The rise of other backward classes in the Hindi belt', Journal of Asian Studies, 59: $86-108$.

Jain, M. S. (2005) Muslim Political Identity, Jaipur: Rawat Publications.

Jodhka, S. S. (2007) 'Perceptions and receptions: Sachar Committee and the secular left', Economic and Political Weekly, 42: 2996-2999.

Khalidi, O. (1993) 'Muslims in Indian political process: Group goals and alternative strategies', Economic and Political Weekly, 28: 43-54.

Kirmani, N. (2008) 'History, memory and localised constructions of insecurity', Economic and Political Weekly, 43 (10): 57-64.

Kishwar, M. (1998) Religion at the Service of Nationalism and Other Essays, New Delhi: Oxford University Press.

Kulkarni, P. M. (2010) 'The Muslim population in India; A demographic portrayal', in R. Basant and A. Shariff (eds), (2010) Handbook of Muslims in India: Empirical and Policy Perspectives, New Delhi: Oxford University Press.

Ludden, D. (ed.) (2007) Making India a Hindu: Religion, Community and the Politics of Democracy in India, New Delhi: Oxford University Press.

Madan, T. N. (1997) Modern Myths Locked Minds, New Delhi: Oxford University Press.

Madan, T. N. (2007) 'One from many: Explorations in the anthropology of Islam', Eastern Anthropologist, 60: $1-26$.

Mahadevia, D. (2002) 'Communal space over life space: Saga of increasing vulnerability in Ahmedabad', Economic and Political Weekly, 37: 4850-4858.

Malik, J. (2012) Islam in South Asia: A Short History, New Delhi: Oxford University Press.

Mayaram, S. (1997) Resisting Regimes: Myth, Memory and the Shaping of a Muslim Identity, New Delhi: Oxford University Press.

Metcalf, B. D. (1982) Islamic Revival in British India: Deoband, 1860-1900, Princeton, NJ: Princeton University Press.

Metcalf, B. D. (1993) 'Living Hadith in the Tablighi Jamaat', Journal of Asian Studies, 52(3): 565-584.

Metcalf, B. D. (2004) Islamic Contestations: Essays on Muslims in India and Pakistan, New Delhi: Oxford University Press.

Moaddel, M. (1998) 'Religion and women: Islamic modernism versus fundamentalism', Journal of the Scientific Study of Religion, 37: 108-130.

Nandy, A. (1990) 'The politics of secularism and the recovery of religious tolerance', in D. Veena (ed.), Mirrors of Violence, Communities, Riots and Survivors in South Asia, New Delhi: Oxford University Press.

Nandy, A., T. Shikha, S. Mayaram and Y. Achyut (1997) Creating a Nationality, Oxford: Oxford University Press.

Noorani, A. G. (2000) The RSS and the BJP: A Division of Labour, New Delhi: Leftworld Publications.

Pandey, G. (1991) 'Hindus and others: The militant Hindu constructions', Economic and Political Weekly, 26: 2997-3009.

Pandey, G. (ed.) (1993) Hindus and Others: The Question of Identity in India Today, New Delhi: Viking.

Pandey, G. (1999) 'Can a Muslim be an Indian?', Comparative Studies in Society and History, 41: 608-629.

Piscatori, J. P. (1986) Islam in a World of Nation-States, Cambridge: Cambridge University Press.

Rajagopal, A. (2001) Politics after Television: Hindu Nationalism and the Reshaping of the Public in India, Cambridge: Cambridge University Press.

Reetz, D. (2004) 'Keeping busy on the path to Allah: The self-organisation (Intizam) to the Tablighi Jamaat', in D. Bredi (ed.), Islam in Contemporary South Asia, Rome: Oriente Moderno.

Reetz, D. (2006) Islam in the Public Sphere; Religious Groups in India, 1900-1947, Oxford: Oxford University Press.

Reetz, D. (2008) 'The "faith bureaucracy" of the Tablighi Jama'at: An insight into their system of selforganisation (Intizam)', in B. Gwilym (ed.), Colonialism, Modernity, and Religious Identities: Religious Reform Movements in South Asia, Delhi: Oxford University Press.

Robinson, F. (2000) Islam and Muslim History in South Asia, New Delhi: Oxford University Press.

Robinson, F. (2008) 'Islamic reform and modernities in South Asia', Modern Asian Studies, 42(2/3): 259-281.

Robinson, R. (2007) 'Indian Muslims: The varied dimensions of marginality', Economic and Political Weekly, 42: 839-841. 
Roy, A. (2005) 'Thinking over popular Islam in South Asia', in M. Hassan and A. Roy (eds), Living Together Separately: Cultural India in History and Politics, New Delhi: Oxford University Press.

Roy, O. (2004) Globalised Islam: The Search for a New Ummah, London: Hurst.

Rudolph, L. I. and S. H. R. Rudolph (1987) In Pursuit of Lakshmi: The Political Economy of the Indian State, Chicago, IL: University of Chicago Press.

Saberwal, S. (2010) 'On the making of Muslims in India historically', in R. Basant, and A. Shariff (eds), Handbook of Muslims in India; Empirical and Policy Perspectives, New Delhi: Oxford University Press.

Sanyal, U. (1996) Devotional Islam and Politics in British India: Ahmad Riza Khan Barelwi and His Movement 1870-1920, New Delhi: Oxford University Press.

Setelvad, T. (2005) 'Godhra: Crime against humanity', in S. Wilkinson (ed.), Religious Politics and Communal Violence, New Delhi: Oxford University Press.

Shah, G. (2007) 'The condition of Muslims', Economic and Political Weekly, 42: 836-839.

Sikand, Y. (1999) 'The emergence of Tablighi Jamaat among the Meos of Mewat' in M. Noor (ed.), Indian Muslims; Percepts and Practice, Jaipur: Rawat Publications.

Sikand, Y. (2002) 'Islamic perspectives on liberation and dialogue in contemporary India: Muslim writings in Dalit voice', Economic and Political Weekly, 37: 3849-3858.

Sikand, Y. (2005) Islam, Caste and Dalit: Muslim Relations in India, New Delhi: Global Media Publication.

Suroor, H. (2014) India's Muslim Spring, New Delhi: Rupa Publications Limited.

Turner, B. S. (2001) 'Cosmopolitan virtue: On religion in a global age', European Journal of Social Theory, 4(2): 131-152.

Upadhya, C. (2001) 'The concept of community in Indian Social Sciences: An anthropological perspective', in S. S. Jodkha (ed.), Community and Identities: Contemporary Discourses on Culture and Politics in India, New Delhi: Sage Publications.

Van der Veer, P. (1987) 'God must be liberated! A Hindu liberation movement in Ayodhya', Modern Asian Studies, 21: 283-302.

Van der Veer, P. (1994) Religious Nationalism: Hindus and Muslims in India, New Delhi: Oxford University Press.

Vanaik, A. (1997) Furies of Indian Communalism, London: Verso.

Varshney, A. (1993) 'Battling a past, forging a future? Ayodhya and beyond', in P. Oldenburg (ed.), Indian Briefing 1993, Boulder, CO: Westview and the Asiatic Society.

Wilkinson, S. (2005) Religious Politics and Communal Violence, New Delhi: Oxford University Press.

Yadav, Y. (1996) 'Reconfiguration in Indian politics: State assembly elections 1993-95', Economic and Political Weekly, 31: 94-105.

Zainuddin, S. (2003) 'Islam, social stratification and empowerment of Muslim OBCs', Economic and Political Weekly, 38: 4898-4901. 
27

\title{
RELIGIOUS VIOLENCE, CRIME STATISTICS AND INDIA'S MUSLIM MINORITY
}

\author{
Marika Vicziany
}

The first part of this chapter asks who is a Hindu. Hindu nationalism (Hindutva) is based on perceived threats to Hindu demographic, cultural and political dominance, so the contours of these fears need to be understood as a starting point for any discussion of religious violence in India. In the second part of this chapter, I examine the nature of that violence and the extent to which the official crime statistics of India can be relied on as a way of understanding the position of India's Muslim minority. I argue that the under-representation of Indian Muslims in India's administrative and security institutions contributes to religious violence and to the unreliability of Indian crime statistics.

\section{Who is a Hindu?}

Religious violence in contemporary India takes many forms but in this chapter I focus on the conflict between Hindus and Muslims, the two largest religious communities in India. In South Asia, this kind of conflict is called 'communalism'. The newly leaked figures for the 2011 Census of India tell us that 78.35 per cent of Indians were Hindus and that Muslims accounted for about 14.2 per cent of the total population of just over 1,210 million (Ghosh and Singh 2015). The proportion of Christians, Sikhs, Buddhists and Jains was much smaller, namely about 2 per cent in all cases except for the Jains whose population remains at about 0.4 per cent of the total. The official Census of India report on the religious composition of India has not been released yet despite the publication of other summary figures in 2013 from the 2011 Census. Some right-wing political groups in India have seen this as a deliberate attempt by the Indian government to suppress sensitive data showing that the proportion of Muslims is growing at the expense of the proportion of Hindus (Dutta 2013). Between 1950 and 2001 the Indian Census figures did show a disparity between trends in the Hindu and Muslim populations: the proportion of Hindus declined from 84.1 to 80.45 per cent while the proportion of Muslims increased from 9.8 to 13.4 per cent. On the other hand, the 2011 Census figures show that the Muslim population of India grew more slowly in the last decade relative to the previous one. Why are these numbers sensitive? 
The controversy about the size and growth of the Hindu and Muslim populations of India is an old one which began in the early twentieth century when plans were being made for the devolution of colonial power to local Indian parliamentary institutions (Mendelsohn and Vicziany 1998). The demographic factors that give rise to these disparities in growth have been routinely ignored because it has suited some politicians to use the higher Muslim population growth rates as the basis for arguing that the Hindu-ness of India is under threat. The higher Muslim population growth rates have been interpreted by the Hindu right as one indicator of the 'assertiveness' of Indian Muslims (see for example Dutta 2013). This assertiveness is said to threaten Hindu nationalism and identity. Research on the historical demography of rapid population growth has been ignored, partly because the Hindu right does not accept the evidence showing that high fertility rates in many countries and communities (not only India) are an indicator of socio-economic disadvantages. Typically, high fertility goes hand in hand with high death rates. Instead, Hindu nationalists stick to a common stereotype about Indian Muslims that the men all have four wives which, in turn, produce 25 children per family (Engineer 1984: 3-4).

The numbers of Hindus and Muslims have been a charged political question in India since Savarkar became involved in definitional issues about the nature of Hindu nationalism in the early decades of the twentieth century. Anxieties about Indian Hindus preceded Savarkar, as the 1909 essay by U. N. Mukherji on A Dying Race, shows. However, the definition that Savarkar gave in 1923 in the first edition of his book Hindutva has become the most influential amongst the Hindu right. Indian Hindus were one nation because both their fatherland (Pitribhumi) and their holy land (Punyabhumi) were India (Savarkar 1966, fifth edition, 115-116). This he contrasted with the alleged, divided allegiance of Indian Muslims whose fatherland was India but whose holy land, he claimed, was Mecca (Savarkar 1966, fifth edition, 135). This assumed, divided loyalty of Indian Muslims, is a recurring theme in attempts by Hindu nationalists to justify their criticisms of and attacks on India's Muslim minority. Sitting on top of the perceived threat of rapid population growth amongst Indian Muslims are the ongoing conversions to Islam and Christianity - the fact that these conversions are so small in number and percentages, does not weaken the perceived threat as seen from the viewpoint of the Hindu right.

A related problem of definition is that 'Hindu-ness' has always been, and remains today, a contested notion partly because many tribal and Dalit populations practise a wide variety of animistic and other customs, some of which have been incorporated into Hinduism and some of which have not. Most important of all, Hindus are born into the Indian caste system. By contrast, Dalits and tribal people were traditionally born outside the fourfold brahmanical caste division of India and they remained outside it in terms of the ritual hierarchies that remain important in the twenty-first century. These ritual hierarchies have also placed tribal and Dalit peoples into disadvantaged socio-economic, labouring groups. As a result, the Indian Constitution of 1950 created special categories which recognised the right of these people to obtain parliamentary seats, government jobs and places in schools, colleges and universities proportionate to their population size: particular tribal groups were named in a list of 'Scheduled Tribes' and similarly particular Dalit groups were named in a list of 'Scheduled Castes'. These two schedules entitle the groups named in the Indian Constitution to reservation or affirmative action proportionate to their population in India: about 8.6 per cent in the case of Scheduled Tribes and 16.7 per cent for Scheduled Castes (Indian Census of 2011, 2013). Together these two groups represent some 25.3 per cent of all Indians who are defined as needing special consideration (or affirmative action) because they were 'outsiders' living beyond the pale of the traditional Indian caste system (Indian Census of 2011, 2013). 
Beginning in the nineteenth century, however, some Hindu reformers have sought to bring these 'outsiders' into Hinduism by means that circumvent the problem of birthing rights. In particular, this has involved various 'purification' or 'conversion' movements led by caste Hindus amongst tribal and Dalit peoples. Hinduisation has even involved 'converting' and 'purifying' Indian Muslims (Sikand and Katju 1994). Various Hindu organisations have played an important role in these conversion/purification movements, one of the oldest being the Arya Samaj. For more than a hundred years, Hindu and Christian organisations in India have clashed in their competition to convert the 'outsiders' of the Indian caste system to their religious and social values (Kanungo 2008). Perhaps the greatest threat to the Hinduisation movement came from the Dalit leader Ambedkar, who in October 1956 took about half a million Dalits with him when he converted to Buddhism. The cry of the Ambedkarite movement was: we are not Hindus and we will not die as Hindus (Mendelsohn and Vicziany 1998: 114-115).

All conversion movements away from Hinduism have been seen as additional threats to Hindutva or the Hindu nation even though most of the religious minorities of India are very small - the Muslim minority being the one exception. Simplistic arithmetic has compelled supporters of Hindutva to see the growth of non-Hindu conversion movements (no matter how minor their impact on the total population of India) as something that weakens Hindu nationalism and anything that does that automatically strengthens the Muslim minority.

In contrast to these threats, Savarkar and the Hindu Mahasabha of which he became President in 1937, looked to those Princely States of India which were predominantly Hindu as future role models of what a hegemonic state based on Hindu-ness would look like and how it might function (Copland 2002: 221). A small group of Indian princes ultimately supported the Hindu Mahasabha and in the ten years up to Indian independence in 1947 abandoned their eclectic political and cultural policies by sacking their Muslim advisors, ministers and other high-ranking public servants in favour of appointing Hindus (Copland 2002: 227). The emergence of Hindu Rashtra (Hindu Rule), or explicitly Hindu oriented states, allowed the Hindu Mahasabha and the RSS ${ }^{1}$ to provoke communal animosity by encouraging Hindus to attack Muslims. Communal riots followed:

During the last five years of the colonial period, Hindu-Muslim clashes not only became more frequent in states like Jaipur which had wrestled with the problem since the 1920s, but began to break out in states which until then had been virtually riot-free, such as Gwalior, Jodhpur, Bikaner, Kotah, Patiala, Rampur, Bhavnagar and Bhopal.

Copland, 2002: 228

The question of who is a 'Hindu' and who is not has been a fraught political question for more than a century. In the contest for political legitimacy in India, various Hindu nationalist political parties have found it essential to their pride and also to their political success to convert and purify as many non-Hindus as possible as a way of augmenting the Hindu vote. In garnering the Hindu vote, many measures have been taken to strengthen Hindu culture by reinterpreting it and asserting it as something that has been pure, ageless and homogenous. $^{2}$

The contested nature of Hindu identity in modern India is an important factor in understanding religious violence and the crime statistics that I discuss in the following section. Why does the Muslim minority of India suffer disproportionately from violence? What are the mechanisms that allow this to happen? 


\section{Crime statistics and religious violence in India}

In 2012, the Government of India decided to collect data about religious violence in India and began to distinguish between 'riots' and 'incidents of tension' between religious communities. Those data are summarised in Table 27.1 below which shows that in the first nine months of 2013 there were 479 communal riots in India, 154 incidents of intercommunity tension, 66 Muslim deaths and 41 Hindu deaths. The figures show that trends in 2013 were well on their way to matching the level of religious violence recorded in 2012: namely 640 riots, 371 incidents and the deaths of 48 Muslims and 44 Hindus (Table 27.1). These data were prepared by the Ministry of Home Affairs and reported to the National Integration Council. Until now, however, I have been unable to locate the original document and so rely on press reports about it.

The data in Table 27.1 are puzzling for two reasons: why was it necessary to collect this data when the annual report called Crime in India was already published by the same Ministry? Second, why does the information in these two reports for 2012 not match up? To begin with, some preliminary observations are needed about any data that purport to capture the nature of violence and crime in India.

Attempts to quantify the extent and severity of religious violence in India are fraught with enormous difficulty and all numbers need to be cited with great caution. Official statistics about violence in India are collected by the local administration and police in each state: typically the reports are biased in favour of the majority Hindu community for the simple reason that the police who investigate the crimes are predominantly Hindu. Before Indian independence, in northern India for example, half of the police force was Muslim, but by the early 1950s this was down to 5 per cent (Brass 1997: 288). The situation had probably worsened by the late 1990s, because the Sachar Report of $2006^{3}$ noted that the proportion of Muslims working in the 'Public Order and Safety Activities' area (a category including workers in addition to police) was only 6 per cent at central level and 7 per cent at the state level despite the proportion of Muslims in the Indian population being about 13.5 per cent as per the 2001 Indian Census. Well over 80 per cent of employees at both levels in the area of policing and related duties were Hindu as Table 27.2 shows.

The lack of empathy that Indian administrations have for Muslims is partly driven by their very low representation in the public services beyond the 'public order and safety activities' noted above. According to the Sachar Report, at the central level a mere 3 per cent of the Indian Administrative Service employees were Muslim and they only represented some 4 per cent of the Indian Police Service. In the case of the highly prestigious Indian Foreign Service, the proportion was dramatically lower, just 1.8 per cent (Sachar 2006: 165).

At the state level the visibility of Muslims in the apparatus of government was not any better. Table 27.3 summarises the data that the Sachar Report eventually extracted from state governments that had been very uncooperative; as a result the data are far from complete, often based on small samples. On average, the proportion of Muslims employed in state level administrations at high and low level positions was about 6 per cent. The table also reveals some surprises: for example, in the state of West Bengal, the proportion of Muslims was well under a fifth of their proportion in the state's population despite a long history of Marxist government in West Bengal. That left-wing regime frequently claimed to deliver greater equality than other regimes, but clearly this did not apply to the employment of Muslims in the government services of West Bengal. In most parts of India, Muslims were greatly under-represented in the government bureaucracy. 


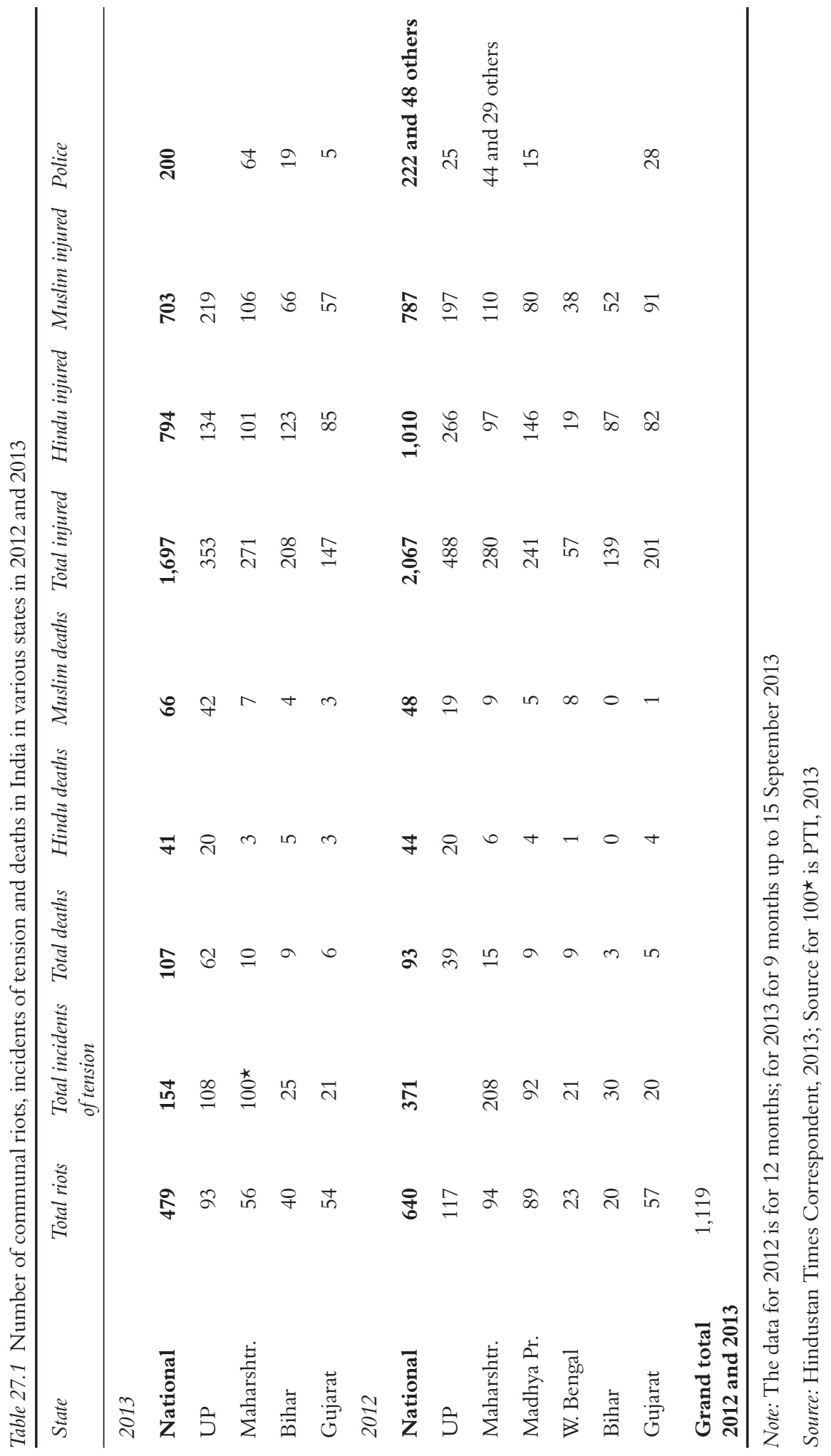


Table 27.2 Proportion of employees in public order and safety activities in India at the Government of India Level and the State Governments Level

\begin{tabular}{lcc}
\hline Community identity & $\begin{array}{l}\text { Central: Government } \\
\text { of India services } \\
\text { Percentages employed }\end{array}$ & $\begin{array}{c}\text { State Level services } \\
\text { Percentages employed }\end{array}$ \\
\hline Muslims & $6(13.5)$ & $7(13.5)$ \\
Hindu UCs (upper castes) & 42 & 37 \\
Hindu SC/ST (scheduled castes and scheduled tribes) & 23 & 21 \\
Hindu OBCs (other backward castes) & 23 & 26 \\
Other & 6 & 9 \\
Total & 100 & 100 \\
\hline
\end{tabular}

Note: Proportion of the Indian Muslim Population as per the 2001 Indian Census in brackets

Source: National Sample Survey data cited in Sachar, 2006, p. 102

Table 27.3 Share of Muslim employees in some State Governments (sample of 4.4 million)

\begin{tabular}{lcccc}
\hline State & $\begin{array}{l}\text { Sample of total } \\
\text { number of employees }\end{array}$ & $\begin{array}{l}\text { Percentage of } \\
\text { Muslims in the state } \\
\text { population }\end{array}$ & $\begin{array}{l}\text { Percentage of } \\
\text { Muslims in higher } \\
\text { positions }\end{array}$ & $\begin{array}{l}\text { Percentage of } \\
\text { Muslims in lower } \\
\text { positions }\end{array}$ \\
\hline West Bengal & 134,972 & 25.2 & 4.7 & 1.8 \\
Kerala & 268,733 & 24.7 & 10.3 & 10.4 \\
Uttar Pradesh & 134,053 & 18.5 & 7.5 & 4.9 \\
Bihar & 78,114 & 16.5 & 7.2 & 7.6 \\
Assam & 81,261 & 30.9 & 10.2 & 11.4 \\
Jharkhand & 15,374 & 13.8 & 3.8 & 7.2 \\
Karnataka & 528,401 & 12.2 & 4.9 & 8.9 \\
Delhi & 135,877 & 11.7 & 2.1 & 3.3 \\
Maharashtra & 915,645 & 10.6 & 3.1 & 4.5 \\
Gujarat & 754,533 & 9.1 & 3.4 & 5.5 \\
Tamil Nadu & 529,597 & 5.6 & 4.2 & 2.9 \\
Sum of states & $4,452,851$ & 16.0 & 5.7 & 5.6 \\
\hline
\end{tabular}

Note: Only the four states marked with an asterisk above provided the Sachar commission with full information. 'Sum of states' includes Andhra Pradesh with 876,291 employees, but no breakdown was given

Source: Data extracted from Sachar, 2006, Table 9.5, p. 170 
The low presence of Muslims in the administrative, police and security services of India at the central and state levels interacts with their lack of political influence. At the state level the impact can be seen more clearly in cities such as Mumbai where the growing rhetoric of Hindu nationalism continues unchecked, partly because right-wing political parties such as the Shiv Sena have close connections with the police, the administration and politicians. By contrast, the political influence of the Muslim communities has been very weak, as it is in most parts of India. The 1998 Srikrishna Report ${ }^{4}$ concluded that a factor in the routine lack of consideration given to Mumbai's Muslims was their inability to:

increase their representation in the Bombay Municipal Corporation or in the Legislative Assembly. This has contributed to the Hindutva idiom gaining ground. Justice Srikrishna 1998: Vol. 1, Chapter 2, para.1.25

Police bias against the Muslim minority in Bombay was acknowledged in the Srikrishna Report to be serious. It manifested itself in the local police frequently refusing to record Muslim complaints. The Srikrishna Report is again worth citing:

The Commission is of the view that there is evidence of police bias against Muslims which has manifested itself in other ways like the harsh treatment given to them, failure to register even cognizable offences by Muslim complainants and the indecent haste shown in classifying offences registered in "A" summary in cases where Muslim complainants had specifically indicated the names and even addresses of the miscreants. That there was a general bias against the Muslims in the minds of the average policemen which was evident in the way they dealt with the Muslims, is accepted by the officer of the rank of Additional Commissioner, V.N. Deshmukh. This general police bias against Muslims crystallizes itself in action during January 1993.

Justice Srikrishna 1998: Vol. 1, Chapter 1, para.1.6

Later in the report more detail was provided about the poor records kept by the police and their lack of investigative professionalism (Justice Srikrishna 1998: Vol.1, Chapter 5, paras 1.3-1.6).

What impact does such police bias have on the data about communal violence in India? More often than not, official police statistics tend to show that the victims of communal riots are more numerous amongst the Muslim communities than amongst the Hindus. More accurate investigations and reporting by Indian police would probably increase the disparity between the number of Muslim and Hindu victims of communal violence by showing that more Muslims suffered than the current records show. ${ }^{5}$ One report into the communal riots of Gujarat in 2002, for example, rejected the official death rate because so many Muslims had been

burnt alive after being hacked, cut, gang raped ... There are no death certificates since no remains were found as bodies were burnt to ashes.

$$
\text { Concerned Citizens Tribunal - Gujarat, 2002, Vol.1, p. } 40^{6}
$$

Second, the police themselves are part of the problem of religious violence. Table 27.1 shows that many police were injured in riots and incidents of tensions. Some police were killed too, but typically their numbers are small because the police are armed while the 
rioters are at best poorly armed. What these figures do not reveal is the role that the police can play by either failing to act against those who perpetrate violence or being complicit in the violence because they identify with the grievances articulated by local Hindus, administrators or politicians. Typically it is Indian Muslims, Dalits, tribal people, women and sexual minorities (Vicziany 2007) that tend to suffer the worst police anger or revenge that might be unleashed during periods of social instability. As a result of these biases, the police cannot be relied upon to accurately report crimes committed against Indian minorities. Again, the Srikrishna Report provided a good example of the scale of the problem of police complicity in riots. Between December 1992 and January 1993 police shootings during the communal riots in Mumbai exceeded all other reasons for death: 356 police shootings compared to 347 stabbings, 91 incidents of arson, 80 deaths due to 'mob action', 22 private shootings and four others. Forty per cent of the 900 people who died were shot by the police (Justice Srikrishna 1998: Vol. 1, Chapter 2, para.1.25). Chapter 4 of the report speaks specifically about the connivance of the police with the rioters:

Police officers and men, particularly at the junior level, appeared to have an in-built bias. The bias of policemen was seen in the active connivance of police constables with the rioting Hindu mobs on occasions, with their adopting the role of passive on-lookers on occasions, and finally, in their lack of enthusiasm in registering offences against Hindus even when the accused were clearly identified and post haste classifying the cases in "A" summary.

Justice Srikrishna 1998: Vol. 1, Chapter 4, para.1.13

The Srikrishna Report's documentation of the communal bias of the Bombay police is not unusual. The Liberhan Commission Report ${ }^{7}$ documented similar biases in the case of the state apparatus in Uttar Pradesh (UP). In this instance, the state government of UP ensured that the local police and civil servants were supportive of the agenda of Hindu nationalists by organising 'mass transfers' of neutral personnel out of positions of authority and replacing them with compliant individuals (Justice Liberhan, 2009, 950, para. 168.7; para. 168.8). The destruction of the mosque in Ayodhya on 6 December 1992 as a result of mob violence orchestrated by the Sangh Parivar depended not only on the frenzy of hatred conjured by Hindu nationalists (Justice Liberhan, 2009, 377 para. 61.33), but also the religious bias of the law enforcers (Liberhan Memo, 2010, para. 2.6), the lack of police and bureaucratic professionalism (Liberhan Memo, 2010, para. 2.12) and the unhealthy collusion between police, civil servants and politicians (Liberhan Memo, 2010, para. 2.2). Justice Liberhan's inquiry into the violence of events in Ayodhya concluded that serious public disorder had occurred because the local police were incapable of and unwilling to act because of their sympathy for the supporters of Hindutva:

What also became painfully obvious was the danger of allowing the guardians of peace to sympathize with miscreants to the extent that they become a part and parcel of the problem instead of the solution.

Liberhan Memo 2010: para 3.6

The public disorder surrounding the destruction of the Babri Masjid in Ayodhya was orchestrated by the RSS but Liberhan named the top leadership of the BJP in a long list of those culpable for the events that threatened peace and democracy of India (Justice Liberhan, pp. 958-962, para. 171.1). 
Another reason for not trusting police data on communal violence is that the minority communities often engage in self-censorship and do not report religious tension or instances of violence. Communities have come to depend on their own interventions. For example, amongst the Koli communities of Mumbai, ${ }^{8}$ we discovered that two of the villages had dargahs or shrines to Sufi saints. In the case of one of these villages, a gang of torch-bearing Hindu hooligans turned up during the riots of December 1992 threatening to burn down the dargah (Vicziany et al. 2013). The Koli residents surrounded the building and protected it by shouting 'You will have to burn us before you burn the shrine'. The hooligans left; no damage was done and nobody was hurt. However this 'incident' was never reported to the police. More significantly, the confrontation would not have fitted into police definitions of religious violence because only a few Muslim Koli families continue to live in the village. It was the other residents, mainly Hindu and Christian Kolis, who formed the protective ring around the shrine. In other words, the hooligans who wanted to destroy the Muslim shrine were Hindu nationalists but the protectors were the whole village, not just the Muslim custodians of the dargah. Moreover, the Koli of Mumbai in general believe in a wide range of gods, goddesses, spirits and gurus - including their own tribal goddesses and water spirits. Typically, they are described by outsiders as 'Hindu' but they may or may not accept that definition depending on their family circumstances. In other words, the realities of religious life amongst India's many communities are complex and do not always lend themselves to simplistic definitions or fixed categories. This means that when we read police reports, we have to ask ourselves how the police decided who was a Hindu and who was a Muslim? How do the police learn about the identity of individuals involved in religious conflict? Can police categories be depended on? The risk of a serious mismatch between police definitions and ground realities is considerable. Most important of all is how do the police apply the categories given to them by administrators seeking to classify the 'motives' for violence and crime? We now turn to the question of motives.

The greatest danger hidden behind the figures in Table 27.1 is the assumption that religious riots and inter-community tensions are actually about religion. Even if the victims have been correctly identified as Muslim, Hindu or other, that says nothing about how the violence began, how it was fuelled, why some incidents of tension died out while others assumed explosive dimensions, and in whose interest it was to fan the flames of conflict in the first place.

An insight into these difficulties is provided by another important and frequently cited source of information about violence in India, namely the annual report on Crime in India by the Ministry of Home Affairs. I use the 2012 report as a benchmark for commenting on the nature of police data about violence and crime. I seek to explain why the category called 'communalism' is not an exclusive motive for murder or culpable homicide.

Table 3.2 of the 2012 report lists various motives for murder and culpable homicide for each Indian state and territory. In addition to 'communalism' which appears on page 331, on pages 329 to 331 statistics are provided for other motives such as gain, property disputes, personal vendettas or enmity, love affairs/sexual causes, dowry, lunacy, witchcraft, political reasons and terrorist/extremist violence, casteism, caste conflict, and other motives (Crime in India 2012).

The number of people reported as having been murdered in 2012 as a result of 'communal' motives was 15 for the whole of India (Crime in India 2012: 331). However, in Table 27.1, based on a special report by the Ministry of Home Affairs as cited by the Hindustan Times, the total number of deaths during communal riots for 2012 was given as 93: 44 Hindus and 49 Muslims. I have been unable to ascertain why this statistical discrepancy exists between the two reports on communal violence in 2012. More importantly, however, 
we gain an insight into the statistical mess surrounding the police reports of crimes and violence in India by carefully studying the motives for murder in the annual Crime in India report.

To begin with, local police have enormous discretion in the classification of crimes. For example, during fieldwork in Belgaum district (Karnataka state) in 1988 on the subject of atrocities against Dalits, we discovered the multi-layered nature of the motives behind crimes (Mendelsohn and Vicziany 1998: 70-71). Four Dalit boys and their Maratha friend were abducted by an unsuccessful Lingayat-caste candidate for the village council election. Another Lingayat candidate had been elected to lead the village council and his success was blamed on the Holeya Dalits in the village. One Holeya candidate also won the reserved seat for Scheduled Castes and his son was amongst the five punished by the failed Lingayat candidate. All three of the successful village candidates belonged to the Janata Party that had stood against candidates from the local peasant party. The boys were caught cutting grass for the family cow on the disgruntled Lingayat member's land. The cow had recently been purchased as part of the asset creation schemes promoted by the Integrated Rural Development Program (IRDP) to assist the economic improvement of Dalits. Night was falling and it began to rain, so the boys were in a hurry. They were caught and punished by being forced to eat human faeces collected from the roadside. Although no murders were committed in this case, the multiple causes for the Lingayat landlord's anger could have led to worse outcomes. Had a murder been committed, the local police would have had the discretion to classify the case as a crime of property or personal enmity or political violence or casteism or class conflict. Exactly how and why the local police decide to classify a crime by placing it into one category rather than another depends entirely on the local situation and police perceptions of this. Given the discretional mobility between the categories, any statistic that claims to be an accurate reflection of murders motivated by religious hatred rather than something else should be regarded as unreliable or at best incomplete.

The Crime in India annual report for 2012 also includes Table 3.1 on the 'Incidence and Rate of Violent Crimes'. On page 328 the category 'Riots' is given, showing that in 2012 there were 74,633 riots throughout India. Table 3.1 also has information about other crimes including murder, attempts to commit murder, culpable homicide, rape, kidnapping and abduction, dacoity, preparation and assembly for dacoity, robbery, arson, and dowry death (Crime in India 2012: 327-328). The crimes are classified according to the particular Indian law under which the criminals were apprehended and charged. What is especially interesting about this table is that there is no disaggregation of the statistics for 'riots' - so we do not know what number were reported as communal. Nevertheless, my basic question remains: when do the police classify an event as a riot? When do they focus on other aspects of violence? Riots, including communal riots, are likely to involve robberies, rapes and arson too. So what determines which criminal event goes into which category? How do the police deal with such enormous overlaps? Or more cynically, does it sometimes suit the police and local administrators to use whatever criminal classifications they think best serves their own interests? My point is the same as argued earlier: the categories under which crimes in India have been classified are not mutually exclusive. The decision about how to classify crimes is in the hands of the local police which can be influenced by local administrations and politicians. Given the under-representation of the Muslims in the policing and governance of India, we cannot be confident that the criminal statistics of India are neutral and reliable.

I am not suggesting that all Indian police are corrupt, prone to communal revenge, submit false returns or ignore the plight of Indian minorities. Certainly there are outstanding policemen such as Suresh Khopade who took an interest in preventing religious violence and 
in the aftermath of the 1984 riots in Bhiwandi set up a new model whereby citizens and the police cooperated in the containment of communal conflict (Khopade 1998). ${ }^{9}$ Khopade's own investigations, however, also suggest that the burning of the bodies of riot victims prevented their identification (Khopade 1998: 39, 42-43, 45, 46). Some burnings were accidental in the sense that people might have been trapped inside burning buildings, given that arson is a common feature of communal riots. But other burnings appear to have been inflicted as a result of deliberate violence against individuals. Khopade notes that the 200 recorded deaths were a 'gross understatement' (Khopade 1998: 50) and that of these 200 'only 66 could be identified' (Khopade 1998: 55). Khopade portrayed the police as overworked, unable to cope with the scale of the violence and so incapable of generating comprehensive or accurate records. While there is some logic to what Khopade has written, his analysis of the communal riots in Bhiwandi remains relatively superficial and incomplete.

A very different analysis of the 1984 communal riots in Bhiwandi was given by Ali Asghar Engineer in a unique study that compared the reporting by the police and press with an independent investigation undertaken by the Committee for Protection of Democratic Rights that Engineer set up and participated in (Engineer 1984, Preface). This inquiry was undertaken not long after the riots which occurred mainly between 18 and 27 May 1984. Engineer cites the official death toll as 278 (Engineer 1984: 154). A summary follows of the 'Figures Reported by Authorities and Press' according to the time and place of the riot incidents (Engineer 1984: 155-159). The table that follows these pages, summarises the findings of Engineer's team. At the bottom of this table the following note appears:

According to a reliable source total number of deaths in Bhiwandi is 500 of which 400 [were] Muslims and 100 Hindus. The total number of persons arrested in Bhiwandi is 1350 of which 400 [were] Hindus and 950 Muslims.

Engineer 1984: 163

A comparison between these two tables - the official and independent summaries - show that the earliest police reports date from 21 May 1984 but the first independent survey reports begin on the 18 May 1984 when in Thane and other localities a total of 201 Muslims were killed (Engineer 1984: 160-162). Engineer's report also adds the following remark in the case of Thane: 'One girl raped; 4 girls missing' (Engineer 1984: 160) and in the case of Chungat Nagar: ‘4 children missing' (Engineer 1984: 161).

The reports by Khopade and Engineer agree on the significant under-reporting of the deaths and injuries that occurred during the Bhiwandi riots. However, Engineer's report goes much further in explaining why such a high death rate amongst Muslims was possible in a Muslim dominated area. One factor was that the Hindus in the villages on the outskirts of Bhiwandi were mobilised and attacked the outlying urban Muslim settlements - they 'came and wrought havoc' (Engineer 1984: 13). Another factor was the police who 'sided openly with the rioters and miscreants' (Engineer 1984: 3). The Muslim riot victims reported that the police even fired on them, looted their houses, released biased reports to journalists and prevented them from identifying their dead (Engineer 1984: 13). Only the arrival of the military brought the situation under control.

I have used the accounts by Khopade and Engineer to illustrate the complex nature of communal conflict and in citing the Bhiwandi example I have tried to show why the crime statistics of India cannot be relied on. The aggregated crime statistics published by the Ministry of Home Affairs in their annual Crime in India reports depend on local police records such as those described by Khopade and Engineer. 


\section{Conclusion}

Almost ten years ago, Paul Brass warned us not to seek explanations of communal violence in India by analysing statistical trends. His warning was incisive and elegantly expressed: abandon the methods of contemporary social science and focus on describing particular events, place them into their full context, continue your inquiries until such time as you have gathered as many representations and misrepresentations as possible, and then stand back and say: 'I find no other logical explanation for this event. I challenge you to find a better one and to provide evidence for it' (Brass 1997: 167). His critique of the use of statistical methods to elucidate communal violence in India is also worth citing in full, because many practitioners of contemporary social science ...

continue to believe that there are certain truths to be found in a multiplicity of discrete events if only we can quantify and categorise precisely our cases. Nor can we take comfort that, if we are persistent enough, apply the appropriate methods of observation, testing and reasoning, we will find our 'way among the facts' to the truth of an event, to that which 'really is'.

Brass 1997: 267

Religious violence in India cannot be understood by studying the country's crime statistics. More generally, police reports need to be treated with much caution not only because the police are overworked but more seriously because, as I have sought to explain, the police form part of a wider governance structure that under-represents the interests of India's Muslim citizens. The dominant Hindu character of India's administrative and security system makes it much easier for Hindu nationalists to co-opt the police and bureaucracy into serving the interests of Hindutva. During communal riots, when the religious consciousness of Hindus and Muslims has been inflamed to abnormal levels and taken on dimensions of extreme paranoia and revenge, it is easy for the police to be overwhelmed by the momentum of events, forget their professional duties and throw their lot in with their fellow Hindus. The absence of countervailing forces, such as stronger Muslim representation in the government, administration and policing of India, makes it harder to contain the influence of interest groups who manipulate religious differences for political ends. As one report noted, the police in India are not a neutral force: they 'too have their biases' and in the absence of proper training to counteract prejudice, the biases of the police are likely to reflect those of the Hindu majority community (Concerned Citizen's Inquiry Report into Malegaon Riots 2001).

\section{Acknowledgements}

I am grateful to a number of scholars and observers for their comments on earlier drafts of this chapter: Oliver Mendelsohn, Maseeh Rahman, Peter Mayer, Ian Copland, Kannan Srinivasan, Smita Gupta, Vivien Seyler, Martin Hribek, Jayant Bapat and the editor of this volume Knut A. Jacobsen.

\section{Notes}

1 The RSS or Rashtriya Svayamsevak Sangh, was formed in 1925 and is the ideological heart of the Hindu right, more commonly known in India as the 'Sangh Parivar'. The Sangh Parivar includes a number of co-related organisations: today the BJP or Bharatiya Janata Party is the political arm of the Hindu nationalist movement; the VHP or Vishva Hindu Parishad extends the work of the 
Sangh Parivar into many different social services and the international arena; and the Bajrang Dal is the youth wing of the movement.

2 The way in which Hindu nationalists have reinterpreted Indian history in a self-serving and communal manner has been the subject of analysis by Romila Thapar for many years (Thapar 2014).

3 The Sachar Commission was established in March 2005 by the Office of the Indian Prime Minister Manmohan Singh to report on the status of India's Muslim minority. The chairperson Justice Rajinder Sachar was assisted by six expert, commission members and, despite many obstacles, submitted its report on 17 November 2006.

4 Justice Srikrishna, a sitting judge of the Bombay High Court, was appointed in late February 1993 to inquire into the events and causes of the Bombay riots of December 1992 to January 1993 in the aftermath of the demolition of the Babri Masjid in Ayodhya (Uttar Pradesh). The work of the commission was assisted by two committees of assessors: one from the Tata Institute of Social Sciences to report on the political, demographic and socio-economic background to the riots and another consisting of senior, retired state and federal police to report on the policing system of Mumbai and how to improve it. Five years later Justice Shrikrishna handed down his findings.

5 For example, the Srikrishna Report on the Bombay riots of December 1992-January 1993 noted that of the 900 people who were killed, 575 were Muslims (or 64 per cent), 275 Hindus, 45 unknown and five 'others' (Justice Srikrishna 1998: Vol. 1, Chapter 2, para. 1.25). The same paragraph also recorded the greater number of Muslims who were injured: 1,105 or 54 per cent out of a total of 2,036, relative to 893 Hindus and 38 others.

6 Many other riot victims were burned alive in Gujarat in February 2002: see for example a new documentary about the violence in Gujarat by Sumaria 2014.

7 Justice Liberhan was appointed as a one-man judicial commission to investigate the 'events, facts and circumstances' leading up to the demolition of the Babri Masjid in Ayodhya on 6 December 1992. The demolition was regarded by Hindu nationalists as the first stage of rebuilding a Hindu temple on soil that they alleged was the birth place of the Hindu god Ram and that they believed existed beneath the foundations of the mosque. That demolition gave rise to communal riots in many parts of India. At the time of his appointment, Justice Liberhan was a sitting judge in Chandigarh. His office of inquiry was established in Lucknow (Uttar Pradesh) where he was given the support of the services of the CBI (Central Bureau of Investigation). The Commission was set up ten days after the demolition of Babri Masjid but the report was not completed until 30 June 2008, after some ' 17 long years and 48 extensions' (Engineer 2009). The report was over 1,000 pages long with many more thousands of pages of supporting documents and evidence.

8 The Koli tribal peoples of Mumbai are one of the original three indigenous tribal groups that have inhabited this area for hundreds, perhaps thousands of years.

9 Perhaps the most famous and highly respected Indian policeman in recent years was Hemant Karkare (1954-2008) who, as the head of Mumbai's anti-terrorist squad, uncovered the role of Hindu extremists in the Malegaon bombings. His death when leading Mumbai's response to the terrorist attack of 26 November 2008 gave rise to rumours about his death having been arranged by Hindu militants.

\section{References}

Brass, P. (1997) Theft of an Idol: Text and Context in the Representation of Collective Violence, Princeton, NJ: Princeton University Press.

Census of India 2001 (2014) http://censusindia.gov.in/Census_And_You/religion.aspx [accessed 23 November 2014].

Census of India of 2011 (2013) Primary Census Abstract Scheduled Castes and Scheduled Tribes for the 2011 Census of India, 14 November: 6, http://www.slideshare.net/geography_monkey/2011indian-census-scheduled-castes-scheduled-tribes [accessed 23 November 2014].

Concerned Citizen's Inquiry Report into Malegaon Riots (2001), November, http://www.pucl.org/ reports/Maharashtra/2001/malegoan-concerned.htm [accessed 25 November 2014].

Concerned Citizens Tribunal - Gujarat (2002), Crime Against Humanity, vols. 1, 2 and 3, November, http://www.sabrang.com/tribunal/ [accessed 21 November 2014].

Copland, I. (2002) 'Crucibles of Hindutva? V.D. Savarkar, the Hindu Mahasabha, and the Indian Princely States', South Asia: Journal of South Asian Studies, 25 (3), 211-234, DOI: 10.1080/00856400208723499 [accessed 24 November 2014]. 
Crime in India (2012) Statistics 2012, National Crime Records Bureau, Ministry of Home Affairs, New Delhi, June, available at http://ncrb.nic.in/CD-CII2012/Statistics2012.pdf [accessed 23 November 2014].

Dutta, P. (2013) 'Why is Census 2011 silent on religious data?', Niticentral, May, http://www.niticentral. com/2013/05/03/why-is-census-2011-silent-on-religious-data-73065.html [accessed 28 August 2014]

Engineer, A. A. (1984) Bhiwandi-Bombay Riots: Analysis and Documentation, Bombay: Institute of Islamic Studies.

Engineer, A. A. (2009) 'Babri Masjid demoliton and Liberhan Commission Report', TwoCircles.no, 24 November, http://twocircles.net/2009nov24/babri_masjid_demolition_and_liberhan_commission_ report.html\#.VHlc02e4YcA [accessed 18 October 2014].

Ghosh, A and V. Singh (2015) 'Census: Hindu share dips below 80\%, Muslim share grows but slower', Indian Express January 24, available at http://indianexpress.com/article/india/india-others/censushindu-share-dips-below-80-muslim-share-grows-but-slower/ [accessed 18 April 2015].

Hindustan Times Correspondent (2013) '107 Killed in Riots this Year: 66 Muslims, 41 Hindus', Hindustantimes.com, 24 September, http://www.hindustantimes.com/india-news/newdelhi/107killed-in-riots-this-year-66-muslims-41-hindus/article1-1126579.aspx [accessed 23 November 2014]

Justice Liberhan (2009) Report of the Liberhan Ayodhya Commission of Inquiry, November, http://www. mha.nic.in/LAC (NB the official website does not provide a date for the report) [accessed 29 November 2014].

Justice B. N. Srikrishna (1998) The Shri Krishna Commission Report, vols. 1 and 2, http://www.sabrang. com/srikrish/sri\%20main.htm [accessed 21 June 2014].

Kanungo, P. (2008) 'Hindutva's Fury against Christians in Orissa', Economic and Political Weekly, 43 (37), September 13-19: 16-19.

Khopade, S. (1998) Bhiwandi Riots 1984, Mumbai: Granthali.

Liberhan Memo (n.d.) Action Taken on the Report of the Liberhan Ayodhya Commission of Inquiry, October,http://www.mha.nic.in/sites/upload_files/mha/files/pdf/ATR-LibComm2009.pdf [accessed 14 May 2014].

Mendelsohn, O. and M. Vicziany (1998) The Untouchables: Subordination, Poverty and the State in India, Cambridge: Cambridge University Press.

PTI (2013) 'Government Releases Data of Riot Victims Identifying Religion', Hindustantimes.com, 24 September, http://www.hindustantimes.com/india-news/newdelhi/government-releases-data-ofriot-victims-identifying-religion/article1-1126537.aspx [accessed 22 November 2014].

Sachar, R. (2006) Social, Economic and Educational Status of the Muslim Community of India: A Report, Prime Minister's High Level Committee (Chaired by Sachar), Cabinet Secretariat, Government of India, New Delhi, November, http://www.minorityaffairs.gov.in/sachar [accessed 21 June 2014].

Savarkar, V. D. (1966) Hindutva, 5th edition, New Delhi: Hindi Sahitya Sadan. [1st edition 1923 published under pseudonym 'A Maratha'.]

Sikand, Y. and M. Katju (1994) 'Mass Conversions to Hinduism among Indian Muslims', Economic and Political Weekly, 29 (34), August 20: 2214-2219 [accessed 25 November 2014].

Sumaria, S. and S. Sumaria (2014) Even the Crows: A Divided Gujarat, London: Guerrera Films.

Thapar, R. (2014) The Past as Present: Forging Contemporary Identities through History, New Delhi: Aleph Books.

Vicziany, M. (2007) 'The Political Economy of HIV/AIDs in India', in Paul Harris and Patricia Siplon (eds), The Politics of HIV/AIDS in Asia, Boulder, CO: Lynne Rienner.

Vicziany, M., J. Bapat and S. Ranade (2013) 'Muslim Saints and the Koli Tribal Fishers of Mumbai in the Context of Hindu Fundamentalism', in A. Weigold and L. Brennan (eds), Rethinking Modern India and its Neighbours, 198-222, New Delhi: Readworthy. 


\title{
28 \\ CHRISTIANS IN INDIA \\ Living on the margins with a diverse and controversial past
}

\author{
John C. B. Webster
}

In 2001 the Census of India recorded just over 24 million Christians. Christians were India's second largest religious minority with 2.3 per cent of the population, well behind the Muslims (12.4 per cent) but ahead of the Sikhs (1.9 per cent), Buddhists ( 0.8 per cent), and Jains (0.4 per cent) (Census of India 2001: xxvii-xxviii). This Christian minority was distributed very unevenly throughout the country. In the hill states of Nagaland, Mizoram, and Meghalaya in northeast India, Christians comprised 90 per cent, 87 per cent, and 70.3 per cent of the population respectively, whereas in each of four north Indian states they were a mere 0.1 per cent of the population. The largest number of Christians was in the south Indian states of Kerala, with over 6 million, and Tamil Nadu, with close to 4 million (Census of India 2001: xxix-xxxiii). While these figures have been contested (Frykenberg 2008: vii), they do show how difficult it is to generalize about Christians in India because their regional histories have been so different. In order to place their present situation in context it is therefore necessary to provide some historical background.

\section{From Christianity's arrival to India's independence}

Christianity came to India by sea and spread inland over the course of the centuries. According to a long-standing tradition, which has neither been proven nor disproven, it was first brought to what is now Kerala in 52 AD by St Thomas, one of Jesus's disciples. Other traditions mention one Thomas of Cana leading a group of Christians from Persia to Malabar in 345. These Christians followed a Syrian rite of worship (hence Syrian Christians) and were ecclesiastically related to the bishop of Edessa. By the time the Portuguese arrived, Christianity in India was still nothing more than either the religion of some inhabitants of foreign enclaves or a high status panth within Hindu society on the southeastern coast.

Once the Portuguese had established themselves in Goa in 1510 Christianity began to spread. In 1514 the Pope gave the kings of Portugal both the right and the responsibility to establish and maintain the Christian Church in the lands under their rule. Under this Padroado (patronage) arrangement several Catholic religious orders came to evangelize India. Francis Xavier, one of the original Jesuits, led two fishing communities on the southern tip of India, the Paravas and Mukkuvars, to convert en masse; others won over entire villages 
around Goa and along the western coast. In 1599 the Archbishop of Goa succeeded in bringing all of the Syrian Christians in Kerala under formal allegiance to Rome.

As Roman Catholic Christianity spread and moved inland during the course of the seventeenth and eighteenth centuries, it incorporated members of castes differently ranked within regional caste hierarchies. Caste distinctions and rivalries thus entered the churches and missionary policy at the time generally favoured maintaining those distinctions and hierarchies (Mosse 2012: 31-46; Bayly 1989: 321-351, 379-419). When Portuguese power and financial support declined, Rome began to play a larger direct role in spreading the Christian faith in India. This led to jurisdictional disputes between Rome and the Portuguese Padroado that were not settled until 1886. Christianity itself also began to diversify. In 1653 a large group of Syrian Christians split off from the Roman Catholic Church and resumed their ecclesiastical connections with the Syrian churches of West Asia. In 1706 the first Protestant missionaries arrived in the Danish settlement of Tranquebar in Tamil Nadu. Thus, as Christianity entered the nineteenth century, there were three branches of the Church present in India instead of just one: a Kerala-centric Syrian Orthodox Church, a very small Protestant presence in Tamil $\mathrm{Nadu}$, and a widely spread but divided Roman Catholicism depleted of its earlier Portuguese resources.

The British East India Company, unlike the Portuguese, was under no mandate to evangelize the people of India. In fact, the Company was suspicious of Christian evangelists as potential disturbers of a profitable status quo and had also taken over the traditional ruler's responsibilities for protecting the holy places of other religions (Frykenberg 2008: 169-205). Only in 1813, in response to Evangelical pressure at home, did it permit British missionaries to enter its territories; other missionaries were not allowed in until 1833. Thereafter, Protestant missionaries came to India from the United Kingdom, the European continent, and North America in increasing numbers.

Historians have written extensively about those missionaries as innovators and modernizers in nineteenth-century India (Webster 2012: 143-55). Their primary aim throughout the century remained evangelistic. They preached a gospel of individual salvation expressed primarily in other-worldly terms (Webster 1976: 30-34, 2007: 48-55) through street preaching, the distribution of Christian scriptures and tracts, the education of young men and women, and medical and other forms of humanitarian work, especially among women. Undergirding these efforts were translation work, the development of Indian languages for these purposes, and the voluntary society as an organizational model for impacting society. The missionaries, sometimes most reluctantly and at other times enthusiastically, critiqued not only rival religious beliefs, but also such religiously sanctioned practices as caste hierarchy and the treatment of widows.

This challenge to the prevailing moral and religious order evoked a variety of responses from local and regional elites. Those individuals and nuclear families who converted were immediately outcasted. Reformers sought to redefine their religious traditions and modernize their social practices to blunt the missionary challenge. Others counter-attacked both verbally and by setting up rival schools, petitioning the law courts, and even by using violence, as was most evident in 1857 (Sherring 1859). However, for the vast majority of people, especially in the villages, such conversions posed no challenge at all.

It was not individual and family conversions so much as large-scale, caste-based, rural conversion movements that both changed the situation of Christianity in India and posed its most serious challenge to the prevailing socio-cultural order. The first of these was the Nadar conversion movement in southern Tamil Nadu and Travancore during the 1840s in which whole villages converted (Hardgrave 1969: 43-70). The next was a movement among the 
Pulayas of Travancore inspired by (successful) missionary agitation for the abolition of slavery (Gladstone 1984: 110-122). Other Dalit castes soon converted in significant numbers, most notably in Tamil Nadu, Andhra Pradesh, western Uttar Pradesh, and the Punjab (Webster 2009: 40-92). In addition, Tribals, first in central India and then in the northeastern hill areas, converted in large numbers starting in the nineteenth century. Not only did these movements add significant numbers to the Christian population and change Protestantism from an urban modernizing community into a predominantly poor and illiterate rural community, but they also provoked reformers to pay attention to the plight of oppressed groups, especially after 1909 when the British instituted communal electorates. Now conversion movements could affect the balance of communal power in the country, since conversion changed not just one's religious affiliation but also one's political constituency.

These conversion movements have been matters of considerable controversy. All of them occurred among subordinate groups within Indian society whose conversion was strongly opposed by dominant groups. Gandhi considered Dalits incapable of discerning, mentally and spiritually, what religion was best for them, a patronizing attitude which has persisted and is embodied in post-independence anti-conversion legislation (Webster 2009: 138-139, 164-165). Historians who have studied these movements in some depth have depicted them as emancipatory movements characterized by Dalit or Tribal agency. In the Dalit case, they were motivated by a desire for greater respect and fuller human rights (Webster 2012: 156162, 182-218), while Tribals found in Christianity a way to modernize without losing their tribal identities (Downs 1992: 154-155).

Politically, Indian Christians were well represented in the early years of the Indian National Congress (Oddie 1968: 53-54; Suntharalingam 1974: 256-264, 306-307; Webster 2007: 350 355, 185-186). They tended to be political moderates suspicious of the extremists' religious nationalism. Both Protestants and Catholics formed their own political organizations, the Protestants taking a non-communal approach to national politics, whereas the Catholics did not (Mallampalli 2004: 108-156). Following World War I, Christians in mission employment were forbidden by government order to participate in politics, lest they jeopardize their mission's continued presence in India (Jeyakumar 1999). Nonetheless by the mid-1930s the government had lifted the ban, Christian opinion had become largely nationalist, and many Christians were active in the struggle against British rule. A much smaller number, most notably in Travancore, played leading roles in the Dalit movement (Gladstone 1984: 343; Oommen 1993: 278-352).

At the same time there was also a nationalist movement against 'missionary raj' within the churches that in many respects paralleled the broader movement. Among Protestants this involved a gradual transfer of power from the foreign missions to the churches until the Indian churches, with their own leadership, became ecclesiastically independent of the missions that had brought them into existence. The Catholics simply replaced foreigners with Indians at the top of the Church hierarchy and religious orders. ${ }^{1}$ The Christian ashram movement and experiments in using Indian religious thought to convey Christian theological convictions were deliberate attempts to give expression to a Christian cultural nationalism after World War I. Christians, however, were already culturally Indian and Indian music, perhaps the most powerful and long-lasting expression of distinctively Indian culture in the form of zaburs, lyrics, and bhajans, had long been an integral part of Christian worship.

Thus, when India became independent in 1947, it had some 7 to 8 million Christians in its population, ${ }^{2}$ drawn mostly from the marginalized rather than 'mainstream' sections of Indian society. The major exceptions were the Syrian Christians in Kerala and the Vellalars in Tamil Nadu, although the Nadars were on the rise. Christianity also had a strong and influential 
institutional presence consisting of schools, colleges, and hospitals, as well as a reputation for service to all regardless of caste, tribe or creed. Christians had a non-communal and progressive public image, especially with regard to the position and roles of women. They were thus well positioned and eager to play a constructive role in Nehru's modernizing India of political democracy, economic development, secularism, and national integration.

\section{The first half century of independence}

The constitution of independent India, adopted in 1950, provided the legal parameters within which Christians and other Indians were to live together. Apart from the adult franchise opening up the vote to all, there were several provisions of the constitution that were of special significance to Christians. Christians gave up the communal electorates they had been granted in the 1935 constitution, both to express their confidence in majority rule within a general electorate and to depoliticize religious conversion (D'Souza 1949). The central Christian concern, however, was religious liberty which included the right not only to profess and practise but also (after intense debate over the right to convert) to propagate the religion of one's choice (Article 25). Along with this went the right for all religious communities to manage their own religious affairs (Article 26) and for religious minorities to establish and administer their own educational institutions (Article 30).

The affirmative action articles of the constitution providing reservations and special benefits $^{3}$ to Dalits and Tribals because of past disabilities (Articles 47, 330-342) proved to be problematic for Christians. All Tribals, regardless of religion, who belonged to a scheduled tribe, were eligible for these benefits and Christian Tribals availed themselves of them to improve their lot. However, the Presidential Constitution (Scheduled Caste) Order of 1950 stated that 'no person who professes a religion different from the Hindu religion shall be deemed to be a member of a Scheduled Caste'. Exclusion met with strong protests of religious discrimination from Christians both inside and outside the Parliament (Webster 2009: 169-172), but the Order was not modified. It was amended in 1956 to include Sikh Dalits and in 1990 to include Buddhist Dalits, but Christian and Muslim Dalits were unable to receive either these benefits or the special protections granted to other Dalits in subsequent legislation. This Presidential Order, in effect, not only punished Dalits for converting but also offered those belonging to religious minorities some powerful incentives to become Hindus.

It was soon followed by another indicator that the Constituent Assembly's debate over conversion had not been fully resolved. In 1954 the government of Madhya Pradesh, where Tribals were not only converting to Christianity in significant numbers but also agitating for a separate Jharkhand state, launched an official inquiry into Christian missionary activities. In its report the Commission depicted Christianity as a foreign religion, and hence inherently unIndian, and as a tool of the neo-colonial, anti-communist United States in undermining India's internal unity and neutrality in the cold war. Conversions among Tribals were seen as due to missionary use of force, fraud or inducements to win over a particularly vulnerable section of the population. Christian Tribals, on the other hand, considered not only the desire for deliverance from exploitation, social degradation, and evil spirits, but also a new sense of dignity as human beings to be the main reasons for both conversion to Christianity and the desire for political autonomy (Thomas and Taylor 1965: 93-121, 164-171, 190-201). ${ }^{4}$ While the Commission's recommendations were rejected by the Central Government, the Commission's view of conversion, especially with regard to the 'weaker sections' of Indian society, was carried over into a series of anti-conversion laws in Orissa (1967), Madhya 
Pradesh (1968), Arunachal Pradesh (1978), Tamil Nadu (2002), Gujarat (2003), Rajasthan (2006), and Himachal Pradesh (2006). ${ }^{5}$ The underlying assumptions in all of them were that conversion is something one person does to another rather than something one chooses to do for oneself and that the 'weaker sections' had to be 'protected' from exercising the same degree of religious liberty that members of other sections of Indian society were granted.

While this inquiry was going on, there were similar conversion and autonomy movements among the largely Christian Nagas who had been led to believe that they could opt out of the Indian republic in 1947. Their peaceful movement turned violent, as did a later movement among the Mizos. In both cases the Indian army took strong measures against the insurgents and any deemed to be aiding them, but both movements were better contained by the grant of statehood in 1963 and 1986 respectively.

Despite these developments, anthropological studies of Christian communities from this period indicate that most Christians were far more concerned about survival and/or social mobility than about evangelism and winning new converts (Campbell 1961, Alter and Jai Singh 1961, Luke and Carman 1968, Godwin 1972). Census statistics indicate that the growth rate of the Christian population at that time was the same as that of the Indian population as a whole, except in the northeastern states of Manipur, Meghalaya, and Nagaland (Census of India 1972: 2-4). Church leaders were preoccupied with administrative responsibilities handed over by foreign missionaries, while Christian elites were concerned about Christian participation in nation-building, inter-faith dialogue, and the 'Indianization' of the churches.

By the mid-1970s there were clear signs that a Christian radicalism was emerging. Not only was the gap between the rich and poor widening, but evidence was also mounting that the 'weaker sections' were being exploited and oppressed to benefit the dominant (Abraham 1974; Indian Social Institute n.d.: 39). In 1974 a National Committee on the Status of Women in India issued a well-documented report showing that the status of women relative to men had actually declined in key respects since independence (Towards Equality 1974). With these changed perceptions of 'Indian reality' came increased Christian demands that the churches act in greater solidarity with the oppressed both inside and outside their own membership. Specifically, this was expressed in terms of giving priority to the needs of Dalits over those of the elites as well as to achieving equality of women and men over maintaining existing hierarchies of gender, caste, and class.

Progress in accepting and implementing these priorities was contested, slow, and very uneven. The churches' involvement with the Dalit struggle is the best documented, one aspect of which was overcoming caste discrimination within the churches. This has been most prevalent in the south where members of several jatis differently placed within regional caste hierarchies have converted in large numbers and brought their caste rivalries with them into the churches. (In the north, where that did not happen, class distinctions have been more significant than caste distinctions.) Local patterns of discrimination have shown up in such forms as separate churches or separate seating, and even separate cemeteries for Dalit Christians; inferior roles in Christian festivals; and discrimination in the allocation of church resources, especially in the areas of education, employment, and financial assistance. Such discrimination has led to protests, to Dalits leaving to form churches of their own, and even to conversion to Islam and Hinduism (Webster 2009: 221-234).

Another aspect of the Dalit Christian struggle focused upon caste discrimination in the wider society, where they have faced the same social stigma, disabilities, and oppression as other Dalits. Here the main target was the 1950 Presidential Order that denied Christian Dalits the same compensatory benefits and protections to which other Dalits are entitled. After their initial protests against the Order failed, church leaders made only sporadic 
attempts to change it until 1975 when they came together to prepare and implement a shared agenda. They then sent petitions and deputations to the Central Government in 1977, 1981, 1985, and 1988, all to no avail. They also brought a case before the Supreme Court which, in 1984, adopted a highly compartmentalized view of Indian society in stating that the petitioners had failed to show that Dalit Christians 'suffer from a comparable depth of social and economic disabilities and cultural and educational backwardness and similar levels of degradation within the Christian community necessitating intervention by the state under the provisions of the Constitution' (Kananaikil 1986: 49). In 1990 there was a huge rally of Dalit Christians in New Delhi, a smaller one in 1994, and a hunger strike in 1996 to back up their petitions, but with no greater success. In 1997 the Bharatiya Janata Party (BJP), which strongly opposed change, came to power and Christians saw that petitions and rallies were pointless (Webster 2009: 168-174, 234-245).

A third aspect was Dalit Christian involvement in the broader Dalit struggle, most often on local issues and through independent, secular non-government organizations. The Dalit Liberation Education Trust, founded in Chennai by Henry Thiagaraj in 1985, was an early example, moving in the course of its history from camps preparing educated Dalit youth for job interviews, to both rural and urban community organization, to human rights education, including training lawyers to fight cases in which Dalit human rights were violated. At a later stage in 1998, the National Campaign for Dalit Human Rights, in which another Dalit Christian, Paul Divarkar, was National Convener, championed a broad range of Dalit concerns at the local, state, national, and international levels.

Growing activism on these three fronts exploded the myth that Christians constituted a community without caste, enhanced the sense of Dalit identity among Dalit Christians, and brought them into an increased solidarity with other Dalits based on an awareness of common grievances and shared struggle. ${ }^{6}$ Underlying all three struggles, and providing them with a rationale as well as a 'spirituality of combat', was Dalit liberation theology, which drew upon both the Bible and Dr B. R. Ambedkar's analysis of Indian society (Webster 2009: 290-312).

Recent Christian involvement in women's struggles followed a similar pattern. While Christians had played a very progressive role in this regard since the nineteenth century, they did so within a patriarchal intellectual and structural framework. Although in 1971 the Christian sex ratio was a very high 986 women for every 1,000 men v. a national average of only 930 (Census of India 1972: 23-24), and women's religious orders as well as women's organizations enjoyed a good measure of autonomy, they remained under the supervision of male-dominated church bodies. After the National Committee's wake-up call in the mid1970s, this began to change. Women demanded a greater voice in the decision-making bodies of their churches and, for Protestants, the ordination of women as pastors and priests. In 1980 the Church of North India and in 1982 the Church of South India voted to ordain women, two great symbolic victories for women. Other, but not all, Protestant churches have done likewise (Webster 1985; Faria 1985).

Christian women have also been involved in the broader women's movement through existing Christian institutions and newer non-government organizations. One, Ruth Manorama, received the prestigious Right Livelihood Award in 2006 for creating and leading several non-government organizations (e.g. the Bangalore-based Women's Voice, the National Alliance of Women and the Federation of Dalit Women), devoted to organizing and empowering poor and Dalit women, especially in the unorganized sector of the economy, in their struggles for better working conditions and full human rights. ${ }^{7}$ These efforts have been undergirded by women's theologies (Gnanadasan 1986, 1994; Manorama 1994). 
As indicated earlier, the major challenge facing Tribals outside the hill areas of the northeast has been resisting encroachments upon their traditional lands, autonomy, and way of life by an assimilative jati society which has looked down upon them as 'primitive'. Christian Tribals have joined and even provided leadership in these struggles. In the hill states of the northeast, the Christian population has grown rapidly since independence and either is in the majority and rules or forms a significant minority. There Christians confront development issues through the separate agencies of Church and state. In both situations during this period Christian intellectuals have made conscious efforts to find a better 'fit' between the Christianity expressed by their foreign missionary predecessors and the cultural traditions of their own people (Vadakumcherry 1994; Minz 1994; Keitzar 1996).

The months following the first BJP victory at the polls saw more anti-Christian violence than in the previous 50 years of Indian independence put together. Between January 1998 and February 1999, 116 cases were reported. The most affected area was the largely tribal Dangs district of Gujarat, where Christians were assaulted, Christian schools and churches destroyed, and Christian meetings disrupted while the police either stood by or joined in the attacks. In a tribal area of Orissa an Australian missionary and his two young sons were burned alive as they slept in their Land Rover. All this violence was justified as a deterrent to conversion (Narula 1999). The furore picked up again in November 1999 when the Pope visited New Delhi to open a synod of Asian bishops. This time the government took strong action and the visit was both peaceful and polite.

\section{The current twenty-first century scene}

At the beginning of the twenty-first century, the Census indicated that the Christian population was just over 24 million, but with a growth rate slightly lower than that of the population as a whole. Thirty-four per cent of the Christian population was urban, slightly above the national average of 27.8 per cent. Its literacy rate of 80.3 per cent was well above the national average of 64.8 per cent, as was its female literacy rate $(76.2$ per cent v. 53.7 per cent). The sex ratio among Christians was an unbelievable 1,009 women for every 1,000 men, whereas the national ratio was a very low 930. These figures give the impression that Christians constitute a relatively advanced and progressive community, especially with regard to the status of women.

However, whereas the literacy rate of the overwhelmingly Dalit Christian population of the Punjab, who are not eligible for scheduled caste benefits, was a mere 45.8 per cent (well below the state average of 60.6 per cent), in the tribal states of Mizoram, Nagaland, and Jharkhand, where Christians are eligible for scheduled tribe benefits, the Christian literacy rates were 78.1 per cent, 56.5 per cent, and 56.9 per cent respectively (Census of India 2001: 1-48). This suggests that while some sections of the Christian community are making genuine progress, others are stagnating and becoming relatively worse off. Recent studies of specific Christian communities confirm the existence of such gaps. Four studies of Dalit Christian churches suggest that while there has been considerable upward mobility among urban Dalit Christians the condition of those who have remained in villages has in recent years been stagnant (Oommen and Webster 2002: 65-129). That picture of rural Dalit Christian stagnation is reinforced by two broader studies of rural Dalit Christians in Karnataka, Andhra Pradesh, and northwest India (Shiri 1997; Dogar 2001).

Another significant demographic feature of the twenty-first century Christian community is its further internal diversification. The last two decades have witnessed a significant growth all over India of charismatic and independent churches, many if not most of indigenous 
origin, which are outside the historic Christian 'mainstream'. These offer more ecstatic forms of worship as well as public meetings in which faith healing of various kinds has been a prominent feature (Webster 2007: 298-301; Hedlund 2000). These charismatic churches have not only attracted members of more traditional churches to either switch or divide their church loyalties but also caused some 'mainstream' churches to incorporate charismatic elements into their regular Sunday worship services. They are also attracting participants and converts from outside the Christian community as their messages and energies are focused on individual problems (e.g. illness, misfortune) rather than on shared caste or tribal problems such as oppression and systemic humiliation. In fact, conversion movements have been rare in the twenty-first century; where conversions do occur, they are generally of individuals and nuclear families. ${ }^{8}$

As indicated earlier, Christianity in India is neither socially nor culturally homogenous. Where significant conversion movements took place within a particular caste or tribe, converts and their descendants have continued to identify with their caste or tribe. Thus the Anthropological Survey of India, using the community defined in terms of endogamy and a corporate existence as its chief characteristics, found that Christians in the Punjab constituted a single community, whereas in Kerala and Tamil Nadu they found multiple Christian communities (e.g. Syrian Christians, Latin Christians, Church of South India Christians, etc.). In Tamil Nadu 25, and in Kerala ten, categories of Christians were identified with caste labels such as Izhava Christians, Nadar Christians, Brahman Christians, Chakkiliyan Christians (Singh 1997a, 1997b, 2003). On the other hand, where converts have entered as individuals or nuclear families, they have identified more with the (generally urban) social class to which they belong by virtue of their education, occupation, and income level.

Christian social practices and cultural preferences have tended to follow from these patterns of conversion and self-identification. Christians generally practise tribe and caste endogamy. Garo and Khasi Christians have maintained their matrilineal system of descent and tribal Christians generally, while eager to retain their traditional culture, have proven to be more open to influences from modern than from 'jati' or 'sanskritic' culture. Elsewhere caste provides the best indicator of socio-cultural adherences. To cite but two examples, in Andhra Pradesh dominant caste Kamma and Reddy Protestants prefer to attend their own assemblies rather than 'mainline' churches where Malas and Madigas worship (Raj 1998: 68-69), while the latter carry on their long-standing caste rivalries and often, while attending and supporting them, refuse to have official connections (through baptism or formal membership) with their churches lest they lose their Scheduled Caste status (Sudarshan 1998). David Mosse, upon returning to a village in Tamil Nadu where caste competition among Catholics for ceremonial honours during Christian festivals was rampant in the 1980s, found that now 'caste distinction is evaded and erased from public space, and yet as a basis of claims to equal rights, caste is more visible than ever' (Mosse 2012: 262).

What is true of caste is also largely true of existing relationships between Christianity and local cultures. There is caste in the churches but it has lost its divine sanction and become more associational in character, while caste hierarchy and discrimination receives little sanction and much criticism. Similarly, other local customs and practices surrounding child-rearing, marriage, kinship, and the like have been retained, modified, or replaced by 'functional equivalents' more in keeping with Christian belief and ethics. The sharpest sociocultural contrasts between Christians and their neighbours are to be found, as might be expected, in the areas of foundational religious beliefs and ritual practices (Robinson 2003: 69-171; Singh 2003, 1997, Robinson and Kujur 2010). 
Even in 'Church politics' Christians follow Indian cultural patterns based on patronclient relationships. The Orthodox Churches, the Roman Catholic Church, the Church of South India, the Church of North India, the Methodist Church in India, and others are hierarchically structured with bishops, or their equivalents, at the top overseeing not only the clergy and local parishes but also a multitude of Christian institutions. Such centralization of power provides great scope for patronage in terms of appointments, employment, admissions, scholarships, and grants. These church structures have been dominated over the decades by men belonging to local or regional educated urban elites whose interests have been safeguarded, while others have received 'leftovers' and token acknowledgement. Progress towards changed priorities within the churches has been uneven, but the fundamental reorientation of the churches sought by advocates of liberation and equality, while much discussed, has yet to take place (Webster 1998; Webster 2007: 332-335).

Christians have also been active in civic life. While as yet there has not been a Christian President or Prime Minister of India, there have been Christian cabinet members, state governors and chief ministers, and speakers of the Parliament. Christians have been appointed to high positions in the civil and military services as well as to the Supreme Court. In the early years of independence, Christians were solid backers of the Congress Party, but in recent years with the rise of regional parties their political loyalties have diversified. The Congress can no longer take the Christian vote for granted.

Two public issues inherited from the past continue to be of special concern to Christians. The struggle to gain scheduled caste status for Dalit Christians took a decisive turn on 22 March 2004 when T. Franklin Caesar and the Centre for Public Interest Litigation filed a petition with the Supreme Court challenging the constitutional validity of paragraph 3 of the 1950 Presidential Order restricting scheduled caste status to Hindus on the grounds that, in violation of the constitution, it discriminates on the basis of religion. In response the (Congress) government sought the recommendation first of the National Commission for Religious and Linguistic Minorities and then the National Commission for Scheduled Castes, both of which supported and became co-respondents with the petitioners. Christians and Muslims organized demonstrations demanding that the government file its counter affidavit so that the case could proceed to a decision, but it did not do so. One such demonstration in December 2013 was met with water cannons, canes, batons, and the arrest of, among others, the Catholic Archbishop of Delhi and the General Secretary of the Church of North India. Following the 2014 elections the new government is expected to file a counter affidavit in July 2014. ${ }^{9}$

The other public issue has been the protection of not only the minority rights but also the very lives of Christians against external threats. The right of Christians to administer their own educational institutions - a major concern of Christian elites - was challenged in at least two cases affecting the prestigious St Stephen's College in Delhi and the Christian Medical College in Ludhiana, Punjab. In 1991 and 2005 respectively, the Supreme Court upheld Christian minority rights (Webster 2007: 308, 314). More serious has been the continued anti-Christian violence, especially in rural areas, averaging over 200 incidents per year. As Bauman and Leech put it, 'Hindu-Christian violence is routine not only in the sense of everyday, but also in the sense of regularized and routinized in the treatment of Christians and in the framing of Christianity as a threatening minority' (Bauman and Leech 2012: 2198). Why the Sangh Pariwar ${ }^{10}$ has singled out the small, scattered Christian minority as such a threat has been the subject of considerable scholarly discussion (Bauman 2013; Bauman and Leech 2012), but one thing seems clear enough. The ancestors of the vast majority of Christians converted in order to escape from the experienced consequences of the kind of 
religio-cultural homogenization that the Sangh Pariwar seeks to impose. The descendants of those converts, while culturally Indian in the ways described above, have also been advocates and beneficiaries of both Christianity and modernity, and so will probably continue to resist homogenization on Hindutva terms.

\section{Conclusions}

India's Christians in the twenty-first century, whether viewed as constituting a community or as simply a religiously defined category of Indian humanity, are very much products of their history. This chapter has emphasized three aspects of that history which have had a strong bearing upon the present. One is the enduring significance of group origins in relation to a social order deemed by others to be sacred as well as of patterns of conversion which have resulted in far greater socio-cultural continuity than discontinuity with not only the preconversion past but also their present neighbours of other faiths. This distinguishes lived Christianity in India from Christianity elsewhere in the world. A second emphasis has been upon religious and social diversity among Christians themselves. This makes generalizations about them difficult and unity among them rather fragile, often only apparent when Christianity as such is being threatened from outside by legal or extra-legal means. A third emphasis has been upon an historical combination of both close cooperation and tension between Christians and other Indians over issues not just of religious belief and practice but also of distributive justice and human well-being.

\section{Notes}

1 This process is documented for the northwest in my A Social History of Christianity (2007), pp. 256-269. Churches in other regions underwent similar changes.

2 This rough estimate is based on the 1941 and 1951 Census figures provided on page 5 of 'Religious Demography of India - Centre for Policy Studies', www.cpsindia.org/d/religious/summary3c.pdf.

3 These included reserved seats in elected bodies from village panchayats to the Parliament; reserved quotas of government jobs; reserved seats and financial aid in educational institutions; welfare and development benefits.

4 The predominantly tribal states of Jharkhand and Chhattisgarh were formed in 2000.

5 Christianity actually spread much more rapidly in Arunachal Pradesh after the passing of this law than before it (Census of India 2001: First Report on Religious Data, p. xxxiii).

6 One organizational expression of this growing unity was the Dalit Solidarity Programme (1992), later Dalit Solidarity Peoples, a prime mover of which was James Massey. It brought Dalits of different faiths together to work on a common agenda.

7 www.rightlivelihood.org/ruth-manorama.html.

8 There have been conversion movements to Buddhism among Dalits in this century, but not to Christianity. The one exception I know of is the continuing Dalit Avatari (so named because they believe Jesus is the Dalit incarnation of God) conversion movement begun in the 1980s among the Bhangis in western Uttar Pradesh (Webster 2010: 110-112).

9 T. Franklin Caesar has provided documentation of this case without commentary in two papers presented at national consultations: 'The Inclusion of Dalit Muslims and Dalit Christians: Constitutional and Social Justice Issues' 1 June 2013 (Centre for the Study of Social Exclusion and Inclusive Policy and National Law School of India University Bangalore: sponsors) and 'Demand of Scheduled Caste Status by the Dalit Christians and Muslims', 19-20 November 2013 (Jama Millia Islamia). His case gained support from the United Nations Human Rights Council, the European Parliament Working Committee on Freedom of Religion or Belief, and the United States Commission on International Religious Freedom as well as many groups and political parties within India. T. Franklin Caesar, correspondence with the author, 25 May 2014.

10 A 'family' of organizations strongly committed to Hindutva ('Hindu-ness') agendas for India. 


\section{References}

Abraham, K. C. (1974) 'Caste and Class in the Context of the Struggle of People in India for Justice', Religion and Society, 21 (3): 82-86.

Alter, J. P. and H. Jai Singh (1961) The Church in Delhi, Nagpur: National Christian Council of India.

Bauman, C. M. (2013) 'Hindu-Christian Conflict in India: Globalization, Conversion, and the Coterminal Castes and Tribes', The Journal of Asian Studies, 72: 633-653.

Bauman, C. and T. Leech (2012) 'Political Competition, Relative Deprivation, and Perceived Threat: A Research Note on Anti-Christian Violence in India', Ethnic and Racial Studies, 35: 2195-2216.

Bayly, S. (1989) Saints, Goddesses and Kings: Muslims and Christians in South Indian Society 1700-1900, Cambridge: Cambridge University Press.

Campbell, E. Y. (1961) The Church in the Punjab: Some Aspects of its Life and Growth, Nagpur: National Christian Council of India.

Census of India. Paper 2 of 1972: Religion, Registrar General and Census Commissioner, India.

Census of India 2001: First Report on Religious Data, New Delhi: Registrar General and Census Commissioner, India.

Dogar, V. S. J. (2001) Rural Christian Community in North West India, Delhi: ISPCK.

Downs, F. S. (1992) History of Christianity in India. Volume 5, Part 5: North East India during the Nineteenth and Twentieth Centuries, Bangalore: Church History Association of India.

D’Souza, J. (1949) 'Constituent Assembly Discussions on Fundamental Rights', Guardian, 2 June, p. 343.

Faria, S. (1985) 'Catholic Women of India', in J. C. B. and E. L. Webster (eds), The Church and Women in the Third World, Philadelphia, PA: The Westminster Press, pp. 74-87.

Frykenberg, R. E. (2008) Christianity in India: From Beginnings to the Present, New York: Oxford University Press.

Gladstone, J. W. (1984) Protestant Christianity and People's Movements in Kerala 1850-1936, Trivandrum: Seminary Publications.

Gnanadasan, A. (ed.) (1986) Towards a Theology of Humanhood: Women's Perspectives, Delhi: ISPCK.

Gnanadasan, A. (1994) 'Dalit Women: The Dalit of the Dalit', in J. Massey (ed.), Indigenous People: Dalits. Dalit Issues in Today's Theological Debate, Delhi: ISPCK, pp. 168-176.

Godwin, C. T. (1972) Change and Continuity: A Study of Two Christian Village Communities in Suburban Bombay, Bombay: Tata McGraw Hill.

Hardgrave, R. L. Jr (1969) The Nadars of Tamilnad: Political Culture of a Community in Change, Bombay: Oxford University Press.

Hedlund, R. E. (ed.) (2000) Christianity is Indian: The Emergence of an Indigenous Community, Delhi: ISPCK.

Indian Social Institute (n.d.) 'Indian Social Institute through the Fifty Years', Indian Social Institute Golden Jubilee.

Jeyakumar, D. A. (1999) Christians and the National Movement: The Memorandum of 1919 and the National Movement with Special Reference to Protestant Christians in Tamil Nadu 1919-1939, Calcutta: Punthic Pustak.

Kananaikil, J. (ed.) (1986) Scheduled Castes in Search of Justice. Part II: The Verdict of the Supreme Court, New Delhi: Indian Social Institute.

Keitzar, R. (1996) 'Developing a Contextual Theology for North East India', in S. K. Chatterji and H. P. Mabry (eds), Culture, Religion and Society: Essays in Honour of Richard W. Taylor, Delhi: ISPCK, pp. 131-153.

Luke, P. Y. and J. B. Carman (1968) Village Christians and Hindu Culture: A Study of a Rural Church in Andhra Pradesh South India, London: Lutterworth Press.

Mallampalli, C. (2004) Christians and Public Life in Colonial South India, 1863-1937: Contending with Marginality, London: RoutledgeCurzon.

Manorama, R. (1994) 'Dalit Women: Downtrodden among the Downtrodden', in J. Massey, (ed.), Indigenous People: Dalits. Dalit Issues in Today's Theological Debate, Delhi: ISPCK, pp. 159-167.

Minz, N. (1994) 'Dalit-Tribal: A Search for a Common Ideology', in J. Massey (ed.) Indigenous People: Dalits. Dalit Issues in Today's Theological Debate, Delhi: ISPCK, pp. 134-142.

Mosse, D. (2012) The Saint in the Banyan Tree: Christianity and Caste Society in India, Berkeley, CA: University of California Press.

Narula, S. (1999) Politics by Other Means: Attacks against Christians in India, Washington: Human Rights Watch. 
Oddie, G. A. (1968) 'Indian Christians and the National Congress, 1885-1910', Indian Church History Review, II: 45-54.

Oommen, G. (1993) 'The Struggle of Anglican Pulaya Christians for Social Improvement in Travancore, 1854-1966', Unpublished PhD Dissertation: University of Sydney.

Oommen, G. and J. C. B. Webster (eds) (2002) Local Dalit Christian History, Delhi: ISPCK.

Raj, P. Solomon (1998) 'Christianity among the Kammas and Reddys of Andhra Pradesh', in F. Hrangkhuma (ed.), Christianity in India: Search for Liberation and Identity, Delhi: ISPCK.

Robinson, R. (2003) Christians of India, New Delhi: Sage.

Robinson, R. and J. M. Kujur (eds) (2010) Margins of Faith: Dalit and Tribal Christianity in India, New Delhi: Sage.

Sherring, M. A. (1859) The Indian Church during the Great Rebellion, London: James Nisbet \& Co.

Shiri, G. (1997) The Plight of Christian Dalits - A South India Case Study, Bangalore: Asian Trading Corp.

Singh, K. S. (gen. ed.) (1997a) People of India. Volume XXVII: Kerala, edited by T. M. Menon, D. Tyagi and B. F. Kulirani, New Delhi: Affiliated East-West Press.

Singh, K. S. (gen. ed.) (1997b) People of India. Volume XL: Tamil Nadu, edited by R. Thirumalai and S. Masnoharan, Madras: Affiliated East-West Press.

Singh, K. S. (gen. ed.) (2003) People of India. Volume XXXVII: Punjab, edited by I. J. S. Bansal and Swaran Singh, New Delhi: Manohar.

Sudarshan, K. J. (1998) 'Christianity among the Mala and Madiga in Andhra Pradesh: Trends and Issues', in F. Hrangkhuma (ed.), Christianity in India: Search for Liberation and Identity, Delhi: ISPCK, pp. 81-91.

Suntharalingam, R. (1974) Politics and National Awakening in South India, 1852-1891, Tucson, AZ: University of Arizona Press.

The Christian College and National Development: The ISS-FERRES Consultation of Principals of Christian Colleges Tambaram 30 December 1966 - 5 January 1967, Madras: Christian Literature Society, 1967.

Thomas, M. M. (compiler) (1960) Christian Participation in Nation-Building: The Summing Up of a Corporate Study on Rapid Social Change, Bangalore: National Christian Council of India and Christian Institute for the Study of Religion and Society.

Thomas, M. M. and R. W. Taylor (eds) (1965) Tribal Awakening: A Group Study, Bangalore: Christian Institute for the Study of Religion and Society.

Towards Equality: Report of the Committee on the Status of Women in India (1974) New Delhi: Government of India.

Vadakumcherry, J. (1994) 'The Original Inhabitants of India: Victims of Written Traditions', in J. Massey (ed.), Indigenous People: Dalits. Dalit Issues in Today's Theological Debate, Delhi: ISPCK, pp. 122-133.

Webster, J. C. B. (1976) The Christian Community and Change in Nineteenth Century North India, Delhi: Macmillan.

Webster, J. C. B. (1985) 'Assumptions about the Indian Woman Underlying Protestant Church Policies and Programs, 1947-1982', in John C. B. and E. L. Webster (eds), The Church and Women in the Third World, Philadelphia, PA: The Westminster Press, pp. 35-47.

Webster, J. C. B. (1998) 'The Church of South India Golden Jubilee', International Bulletin of Missionary Research, 22: 50-54.

Webster, J. C .B. (2007) A Social History of Christianity: North-West India since 1800, New Delhi: Oxford University Press.

Webster, J. C. B. (2009) The Dalit Christians: A History, 3rd edition; Delhi: ISPCK.

Webster, J. C. B. (2010) 'Varieties of Dalit Christianity in North India', in R. Robinson and J. M. Kujur (eds), Margins of Faith: Dalit and Tribal Christianity in India, New Delhi: Sage, pp. 97-118.

Webster, J. C. B. (2012) Historiography of Christianity in India, New Delhi: Oxford University Press.

Zachariah, M. (ed.) (1971) The Indian Church: Identity and Fulfilment, Madras: Christian Literature Society. 

$\because$ Taylor \& Francis http://taylorandfrancis.com 


\section{PART V}

\section{Cultural change and innovations}



$\because$ Taylor \& Francis http://taylorandfrancis.com 


\title{
29 \\ COMBATIVE \\ CONSTRUCTIONS OF \\ FEMININITY IN THE \\ LATE TWENTIETH- \\ CENTURY NARRATIVES \\ OF INDIA
}

\author{
Nandita Ghosh
}

This chapter will scrutinize how gender constructs available in the fiction, journalism, and scholarship of the late twentieth century complicate any discussion of nationhood, modernity, and development because these narrate 'women' as an unstable signifier destabilizing established meanings. In the fiction of the period, authors explore constructions of femininity through a variety of female characters that modify or subvert the roles they are required to play. Often readers are critically distanced from these characters by the movement of the text or by ironic third-person commentary. Such distancing signals the possibility of reading differently the apparently seamless narrative of the nation.

The trajectory by which women were integrated into India is traced back by scholars to nineteenth-century constructs of a new woman for the patriarchy that was gearing itself for independence from the British. ${ }^{1}$ Anti-colonial nationalists confronted British rhetoric, which criticized sub-continental traditions as barbaric, especially regarding women, and justified its colonization of India as a civilizing mission. In counterpoint, these nationalists constructed the idea of a new woman partly influenced by Victorian ideals and partly claiming ancestry with a classical Vedic tradition. They created a fiction of womanhood, which gave partial equality to middle-class women but did not touch other classes. Women were objects of benevolence, recovery, and repatriation. The contradictory aftereffects of this legacy created a nexus of problems that lasted well into the twentieth century. In fact, feminist scholars point to innate contradictions in the Indian Constitution. ${ }^{2}$ While it gave equal rights to women as citizens, it also empowered traditional religious and familial laws that strengthened their subordination. The 1970s and 1980s marked a period of crises of the state with a proliferation of women's groups and grassroots movements, interlinked regionally, locally, and nationally, that battled discriminatory practices in domestic and public domains. ${ }^{3}$ From the 1990s, these groups focused on the gendered impact of free 
market capitalism, religious fundamentalism, changes in democratic culture, and problems of the national economy.

The visibility of women on the political stage in these decades challenged the story of India's emergence as a modern nation-state by calling attention to the invisibility of women in the construction of that story. The works of fiction considered here - In Custody (Chatterjee 1988), Days of the Turban (Desai 1984), English, August (Devi 1995), and Imaginary Maps (Sharma 1986) - present differing female experiences of oppression excluded by the social reforms stemming from nineteenth-century ideas of femininity. The way in which these works of fiction narrate the nation parallels the way a narrative of the nation emerges from a great many scholarly and journalistic discourses of the period. However, the fiction makes visible through its textual ruptures the politics that renders women invisible.

\section{Violence and the female body}

As sites of violence, resistance, and transformation, women's bodies are central to any understanding of unequal gender relations. Recent feminist theorists have pointed to the feminization of the nation, which is narrated on the body of women. Women's bodies are disciplined to adjust to tradition, thus limiting possibilities of resistance and transformation (Thapan 1997). Inevitably, conflict is central to women's lives. These bodies are fluidly situated in space and time and act as repositories of the acquired attributes of femininity the two axes that ground women socio-historically in specific contexts (Niranjana 1997). Women are violated through the prevailing ideologies of the nation as part of the process by which it is created and reinforced (Karlekar 2005; Agnihotri and Mazumdar 2005). These scholars are endorsed by journalists and activists, who list ways in which patriarchal culture brutalizes the female psyche and perpetrate the manifold violence against women. ${ }^{4}$ They indict landlords, police, politicians, and big industry for using mass rape as a political weapon to subdue lower-caste and working-class women. Their critique of patriarchy acquires a new depth of perspective when read in relation to the dialogic form of the novel.

The narrative technique in Days of the Turban presents Fat Aunty's death as not particularly significant in itself but as a catalyst that enables a male character, Dev Singh, to ruminate on his life. Fat Aunty is the local, aging prostitute who falls out of favour because she aids an inter-class and caste friendship between Gulnari and Kumhareya. Kumhareya is a potter's son and an illiterate, impoverished farmhand. Gulnari is from a family of wealthy, educated merchants with social standing in a village in Punjab. Kumhareya helps Gulnari escape from an arranged marriage. However, their running away is construed as a sign of a premarital sexual relationship. Gulnari's family's honour is premised upon the chastity of Gulnari's body. Escaping with an unmarried man jeopardizes her chastity and compromises her family's honour in the eyes of her community. Gulnari's male relatives scapegoat Fat Aunty for desecrating the family honour, which is then retrieved through the violation of the latter's body. Fat Aunty is entirely expendable because she lives outside the borders of bourgeois respectability. She loses her chastity when raped and her marital status when her husband is killed during Partition riots. Being Muslim in a lower-caste colony, she is outside upper-caste Hindu society. As a prostitute, she is the locus for an adulterous male sexuality that can only be expressed outside the kinship relations that are established through codes of honour. Fat Aunty signifies what Spivak terms 'excess', a space where social norms are fluid and which Gulnari's male relatives attempt to control. ${ }^{5}$ However, unlike the journal articles of the 1980s, this incident is not narrated in a direct reportorial style. Her torture recedes into the background of Dev Singh's meditations on his life. Dev Singh, Gulnari's 
uncle and guardian, orders Fat Aunty's torture but he leaves the premises because 'the whole proceeding was repugnant to him. He was a man of some feeling and refinement' (266). Consequently, the violence against Fat Aunty is filtered through his consciousness. Fat Aunty is beaten, kicked, and prodded with staves 'as though she were a wriggling unclean thing, a snake' (279) all the while that she screams for mercy. However, either he hears his wife report the violence or surmises the events from the 'hysteria of voices' (267) in the courtyard. The violence is lessened in many ways. Fat Aunty's bones break 'no louder than the report of a child's firecracker' (267). Dev Singh's thoughts flit from memories of his wife in her younger days, through his deteriorating relations with her, to an uneasy conversation about Gulnari with his brother and distraction at Gulnari's mother's screams. All of these thoughts and reactions take attention away from Fat Aunty's plight. However, the narrative introduces the reader to Fat Aunty's experience of torture through Dev Singh's empathetic reactions:

With each cry that he heard, he rocked back and forth involuntarily and eventually to prevent the nausea from erupting through his mouth. ... No one could see him now - a respected cloth merchant, a respected man - in a consternation of grief. For surely, this old woman could not survive such treatment.

$266-267$

Dev Singh is constantly described as refined and educated, because of which he is unable to participate in the torture. He suffers with Fat Aunty, worries about and grieves with her. Yet her torture 'was being done in his name. In order that there may be respect for his name' (268). The nausea that he feels at the brutality creates the potential for an epiphanic moment in the text where he is on the verge of confronting his own complicity in these events. $\mathrm{He}$ temporarily abdicates control over the situation in order to allow his accomplices to complete what appears undesirable but is necessary. "It has to be done I suppose", he whispered. And even as he said it he was aware that he really had no control over what was being done' (267-268). However, Dev Singh does have control; he stops the torture when he feels it has gone far enough. What Dev Singh does not realize within the framework of the text becomes glaring to the reader; his refinement, sophistication, and power as a bourgeois, male subject are premised upon the subjugation of female desires and actions deemed deviant within patriarchy. Respectability is asserted on the terrain of the sexed female body. However, in making Fat Aunty's torture predominantly a moment for Dev Singh to evaluate his own investment in it, the narrative becomes complicit in the violence and breaks down. It is in the rupture that the reader gets an opportunity to read the text differently in order to reconstruct how the postcolonial nation is constructed. Feminist sociologist Veena Das asserts that the postcolonial nation-state is constructed out of the discourse of family and kinship politics (1995). In incidents of collective violence, such as that of Fat Aunty's torture, Das argues, a woman's body becomes a sign through which men communicate with each other. Gulnari, born into a respectable middle-class family, chooses to step outside marriage and domesticity to interact with men outside her class and conspire against the nation. In helping Gulnari hide from her family, Fat Aunty acts against codes of middle-class respectability upon which the national patriarchy is premised.

The language of honour within kinship relations functions to discipline these errant women through the subjugation of their bodies. Such disciplinary functions are not exclusive to the 1980s. Prem Chowdhry (1998) points to three incidents of violence involving intercaste marriages in North India in the 1990s: in March 1991, Roshni, a Jat woman, was tortured and hanged for eloping with a Yadav man; in April 1991, Poonam, another Jat 
woman, was shot by her uncle in broad daylight for having a boyfriend before marriage; and in 1993 Sarita, a lower-caste woman, was axed to death for marrying her upper-caste husband. Chowdhry elaborates that since intra-caste marriage empowers kinship relations and secures property inheritance, any breach in caste status is treated violently. And so, Dev Singh's ideology of female guardianship in the novel becomes his way of controlling his niece's sexuality and enforcing caste power.

However, what becomes increasingly evident in the 1970s and 1980s is the formation of relatively new female subjectivities that read the nation differently. Women's activist movements unite to organize public opinion against the police gang rapes of Mathura (1972), Maya Tyagi (1980), and Gunaben (1986). These included campaigns against bride burning, dowry, and widow immolation with the burning of Roop Kanwar, a young widow, on the funeral pyre of her husband in 1987. It spread to address issues regarding invasive contraceptives, the denial of healthcare to mothers and children, and gendered violence in private and public arenas. Consequently, there were amendments to the rape law, the law against custodial rape was introduced, and the number of women police officers were increased. However, Butalia (2005), Sangari (1999), and Agnihotri and Mazumdar (2005) point out that these measures were insufficient to counteract violence against women, which became complex due to a number of factors. Hindutva women cadres participated in the violence against Muslim women in Ayodhya. Globalization allowed the entry of multinationals, which projected women as consumers and reproductive beings. The rise of religious fundamentalisms also created a framework for demolishing women's rights to equality. And so, they conclude that, the women's movement and feminism are deeply contested concepts today. By writing on violence to women's bodies, these scholars, journalists, and authors make visible the violence of nation-building that either contains women in fixed spaces or seeks to erase them.

\section{Women, work, and the nation}

In this section, the chapter will examine how the patriarchal management of female sexuality reproduces social inequality by devaluing women's labour within the nation. Feminist scholars, writing at the turn of the century, point out that women's work, though necessary for survival of the family, is unpaid, underpaid, and deemed valueless under capitalist modes of production because only marketable goods and services have value. ${ }^{6}$ Women's work creates surplus value for industry and agriculture and women become part of a reserve army of surplus labour that is used to ensure low wages within a system of production where labourpower is produced as commodity. Consequently, women's work has been largely invisible to development planners. Several journalists ${ }^{7}$ writing at the time endorse these ideas when they assert that if women were paid for domestic work, they would contribute to half the national income. Women do multiple types of work in agriculture and are responsible for 50 per cent of the total food production. Women often control the family-centred village crafts and handloom industries and trade goods in the market. Middle-class women contribute as professionals. Yet, these contributions remain less recognized because historically the lives of Indian women have existed at the interface of caste and class inequalities. They conclude that the economic changes of globalization on women have created unequal opportunities and new forms of oppression away from the traditional family.

In fictional works, there are middle and lower-middle-class women characters that do unpaid domestic work. Regardless of class, caste, or religion none of these women has direct control over resources. They are mostly under- or uneducated and defined by their relations to 
men. Sarla (In Custody) and Renate (Days of the Turban) contribute to the domestic economy by cooking, cleaning, rearing children, budgeting household expenses, and serving houseguests and male family members. Renate is Raskaan's (the Punjabi expatriate entrepreneur in Germany) secretary-wife. She arranges his schedule, monitors his restaurants, safeguards his money, decorates his house, hostesses his parties, and satisfies his sexual urges. "She's a pet," said Raskaan in Punjabi as he replaced the receiver. Satyavan said carefully, "She's just right for you". What he meant was that he thought her a good wife. Raskaan shrugged. "It's a good arrangement"' (Days of the Turban 100). Indeed, Raskaan views his relationship with Renate as a profitable business arrangement in which the returns are more than his initial investment. Being important only as an addition to Raskaan's life, Renate is practically peripheral to the plot. Most of the other female characters share her fate in these novels.

However, there are moments in these novels when women's invisibility regarding their work gets challenged. For example, in In Custody Sarla is dissatisfied with her marriage and tacitly accuses Deven, her husband, of being a bad provider '... she dreamt the magazine dream of marriage: herself stepping out of a car with a plastic shopping bag full of groceries and filling them into the gleaming refrigerator, then rushing to the telephone placed on a lace doily upon a three-legged table and excitedly ringing up her friends to invite them to a picture show with her and her husband who was beaming at her from behind a flowered curtain' (68). As a temporary lecturer at Ram Lal College in Mirpore, Deven is poorly paid and cannot afford the lifestyle advertised in the media. In the late 1970s, most middle- and lower-middle-class families, like Sarla's, were unable to afford refrigerators, telephones, and cars. Much of Deven's income is carefully spent bargaining in markets over grocery prices. The lace doily, three-legged table, and flowered curtain are aesthetic, inessential items requiring surplus income. Similarly, going to the movies with one's girlfriends requires extra income to afford leisure time away from domestic chores. Sarla and Deven do not have the income for any of these commodities or activities. However, media images of the beautifully dressed housewife with two model children living in a modern apartment while cheerfully undertaking all domestic chores became increasingly prevalent from the late 1970s. Such images sold the idea of domestic bliss that would result from increased leisure housewives would enjoy if they purchased the drudgery-reducing kitchen gadgets advertised in the media. These advertisements, coinciding with the expansion of domestic markets and an increased production of consumer goods in the 1980s, appealed to an expanding middle class while creating an image of a desirable lifestyle that only the urban, upper-middle class could afford. Sarla's dreams reveal the vulnerability of lower-middle- and working-class women to such images. Sarla's reality is that she lives in meagre accommodation provided to low-grade college employees. Her surroundings are impoverished. Her house is dirty. Her cooking is tasteless. She and her child are poorly dressed. Sarla is presented scowling, sulking, or playing power games with Deven while performing her duties as wife and mother. She receives no financial or emotional acknowledgement for being house and kitchen-bound. The contrast between the magazine advertisements and her circumstances creates a rupture in the narrative by which Sarla refuses to be rendered invisible. Her irritation at the domestic work she is forced to do haunts Deven, who cannot successfully erase her by escaping to the world of Urdu poetry.

Journalists in the 1980s point to the multiple oppressions women face in respect to their labour. ${ }^{8}$ Women continue to face discrimination regarding inheritance, divorce, alimony, and maintenance. Working women often face sexual harassment and while their earnings may supplement the family income, these do not give them autonomy. Poor women are forced to work long hours for meagre wages, are not represented by trade unions, and are without 
healthcare, maternity benefits, childcare, or legal rights. Those employed in agriculture are exposed to toxic hazards from fertilizers. In the organized sector, women are laid off at every crisis. The plight of women deserted by their husbands is worse because they are left in charge of their families with little or no resources. ${ }^{9}$

The dialogic form of fiction, treating these truth claims as constructs, makes visible the processes at work within patriarchy that render the gendered subaltern invisible. The exploitation of lower-caste/class women takes on a corporeal hue in the stories of Imaginary Maps. In 'Doulati the Bountiful', Doulati is sold into prostitution at 19 years to repay her father's debt of Rs. 300 to their landlord Munabar Chandela. She dies of venereal disease 8 years later after having earned Rs. 40,000 for the brothel owner. She has no control over or access to her earnings and has to borrow money from the brothel owner to buy toiletries and other essentials, all of which further increase her debts. 'Paramanand [the brothel owner] is a sucking fly. Doesn't give them anything ... He'll take the money of the kamiyas' whoring work, will not give a penny and what he lends will be added to the reckoning of the first loan' (67). Latia, one of the clients who makes this statement, can obviously see the exploitation in the system but supports and benefits from it. Doulati has no knowledge of accounting to calculate the accurate amount of her earnings or the interest the brothel owner charges to comprehend exactly how she is being oppressed. Nor does she know her legal rights or have access to law courts for their redress. The system by which she is made a bond slave is usury, practised not only by the upper-caste landlord who sells her to the Brahman brothel owner but also by the upper-caste/class policemen, government officers, and contractors who patronize her brothel. Hence, the system of usury is a part of the local as well as national economy. In fact, one of Doulati's clients, Latia, is contracted by the government to construct roads and office buildings for the forestry department. Latia's money not only funds the brothel but is also behind the national foreign policy, dictating the war effort towards China. Paramanand, the brothel owner, has to bribe the local police, government officers, and politicians to run his profitable business. Contractors like Latia have to bribe government officers with free sex in order to get contracts.

Doulati's name itself means wealth and provides an ironic insight to the title of this story; her body is indeed bountiful for it earns excess profits for her clients and brothel owner. In this inequitable exchange, she gets no medical treatment, very little food, regular physical abuse, minimum rest with ten to thirty clients a day, and minimal clothing. The moment she outlives her usefulness, she is thrown out on the street without money and cannot treat the disease she contracts while prostituting. Doulati dies on Independence Day on the map of India drawn on the ground by the village schoolmaster. 'Filling the entire Indian peninsula from the oceans to the Himalayas, here lies bonded labour spread-eagled, kamiya-whore Doulati Nagesia's tormented corpse, putrefied with venereal disease, having vomited up all the blood in its desiccated lungs' (93). Her body makes visible the untold story of India - how political independence from British rule has only exchanged the empire for conditions of internal colonization. Mahasweta Devi deliberately uses a rough, jagged style interspersed with journalistic diction to break the smooth flow of narration. In the ruptures, it is possible to see the gendered subaltern who is displaced from the official processes of democracy, development, and modernization and yet whose labour makes such processes financially viable for the upper-caste/class male subject who inherits the nation. Bond slaves like Doulati constitute the invisible workforce behind every industry within the nation; their contributions to the national economy are constantly erased in order to maintain the margins of profit. However, for a moment in the text, what becomes visible is the complicity between nation-building efforts, male sexuality, and big capital 
in structures of exploitation. Mahasweta Devi's fiction is part of larger, vociferous, and polarizing debates in the 1980s on the issue of prostitution. It is important to look at the process by which women's reproductive labour is incorporated into the sex service industry. In the case of the prostitute, reproductive labour (or the sexual use of the body as an instrument of labour) is forcefully commercialized and placed in the market and so wage relations dominate. However, a prostitute's labour is not seen as productive and so is invisible and legally and morally isolated - factors that increase capital accumulation (D'Cunha 1997). Under capitalism, large-scale disruptions of kinship and family relations, migration for jobs, and separation of work from home increase capitalist mobility to generate new forms of sexual needs, commoditize sex and the prostitute's body, while increasing the numbers of women who are marginalized, illiterate, and unemployable elsewhere. These factors increase the magnitude of sex trafficking as well as the foreign exchange earned by nation-states. So, feminist scholars point to the collusion between the sex trafficking industry and the state apparatus.

Scrutiny of gender inequality intensified through the 1980s in the media, the arts, and protest movements. As part of these debates, journalists publishing through the 1980s insist that some social change has benefited all classes of women in India. ${ }^{10}$ They point to the legislations passed since independence, safeguarding women's rights regarding marriage, divorce, child custody, domestic violence, inheritance, maternity leave, work conditions, and unionization. They detail the workshops and diploma courses established by the government for training women in various fields. They uphold efforts made by nationalized banks to ensure gender equity. They assert that rural migrations to urban areas have allowed women better access to healthcare. They applaud the media in educating women in socio-economic issues. Non-governmental organizations have done much for women's rights.

In the fictional worlds of Imaginary Maps, these social improvements seem mostly to affect middle-class women, who are all, however, known through male characters. They do not speak for themselves and are not even present during the main narrative action. Hence, in a sense, these women are erased. In 'Pterodactyl, Pirtha, and Puran Sahay' (Imaginary Maps) Harisharan, a civil servant, describes his wife and Surajpratap's wife, Sheila, as ambitious career women to Puran, the male protagonist. Harisharan's wife is a civil servant. Sheila is a political activist who is able to cross class and caste boundaries in marrying her husband. Both Harisharan and Puran respect and admire the work these women do because of their own enlightened gender politics, which then provides a vantage point from which Mahasweta Devi deliberately launches her critique of the corrupt, patriarchal bureaucracy. In contrast with these women, Imtiaz Begum, Nur's second wife, in In Custody, was at one time a poor courtesan and is now a budding poet who would like her contributions to the world of Urdu poetry acknowledged. Imtiaz Begum is resented by Deven, the protagonist, who feels threatened by her ambition: 'who was she? ... How could she claim monopoly of the stage with ... her ... third rate verse ...?' (81-82). 'This woman, this so-called poetess, belonged to that familiar female mafia, he [Deven] thought, looking at her with unconcealed loathing' (83). Perhaps Imtiaz Begum does indeed write inferior verse. However, she attributes its poor quality to the inadequate education she has received as a lower-class woman. She argues for an equal opportunity to explore her innate talents and refuses to be erased by Deven without being relegated to the 'safe world of dementia, termagants, and viragos' (83). These novels are not alike in their evaluation of women's work; situated in the moment of crisis in the 1970s and 1980s, they display differing viewpoints based on the authors' politics.

These narratives of the late twentieth century reveal how attitudes to women's work remain tied to the social reforms of the nineteenth century that valorized domestic work 
and tied women in various capacities to the home as keepers of the national/spiritual inner space. Middle-class women were more affected by these constructions; hence in the novels middle-class female characters like Sarla (In Custody) are confined to and defined by the domestic space. Lower-caste prostitutes existed in tense relations to notions of conjugality. Hence, characters like Doulati serve as the invisible workforce that does indeed build the nation. Moreover scholars like Susan Vishwanathan (1997) ask why, if women are associated with life generating labour, is their labour considered passive? In answer, she examines how patriarchy associates women with nature and corporeality and how women, unlike men, are not considered rational, orderly, or innovative; they are therefore to be tamed and civilized much like animals, colonized subjects, and slaves. These debates draw attention to how such constructions of femininity enable a modernizing development rationale, which then renders women's work invisible.

\section{Goddesses, mothers, and prostitutes: icons of women, sexuality, and the nation}

Questions of gender have always been central to forming national identity. The language of nationalism singles women out as symbolic markers of the respectability and immutability of the nation. George Mosse (1985) traces the roots of this phenomenon to the growth of nationalism with the rise of the middle classes, who defined themselves through the ideal of respectability in eighteenth- and nineteenth-century Europe. They perceived their lives, based upon frugality, duty, and restraint, as superior to those of the 'lazy' lower classes or the 'profligate' aristocracy. Mosse reveals how in England and Germany these values spread to other classes and ultimately controlled gender and sexual differences. It is easy to conclude that these colonial influences also shaped Indian nationalists' control over women's sexuality and gender roles. Proliferating icons of selfless mothers, martial goddesses, or fallen women in Indian culture bear witness to such patriarchal constructions of femininity that render women invisible through their inherent representational logic. The fictional and journalistic texts of the late twentieth century increasingly challenge such constructions through rhetorical strategies, female characters, and ideological utterances that render visible women hitherto excluded from such processes.

The figure of the martial goddess was particularly strong in Bengal because the cult of worshipping the devi or the divine feminine principle had been prevalent for over 600 years. By the nineteenth century, specific forms of devi worship, signifying strength and energy, became aligned with Hindu nationalism. The martial goddess was manifest as Mother India militant about independence from British rule. Feminist scholar Indira Chowdhury (1998) explains how colonized males, who felt emasculated, used myths about heroic women to reclaim their lost manhood and nationhood. She elaborates that the need for constructing a national identity resistant to colonial rule fuelled the contrasting image of the heroic goddess and her weak grovelling male worshipper; the former represented the dormant potential of the colonized male who could repossess his history and refashion his resistance. These icons were articulated by the middle-class Bengali elite and often excluded lower castes and non-Hindus. Icons of the heroic goddess persisted into the decades after independence that devalued women as humans by conflating them with goddesses, eradicating or controlling their sexuality. In the early 1980s the slogan 'Indira is India' by the Congress party likened Indira Gandhi, the then prime minister, to the goddess Durga or Mother India. However, through the late twentieth century, women from other classes, castes, and religions challenged their exclusion from the imagined 
national community. Consequently, the icon of the heroic goddess was also appropriated and changed, as evident in the novels of the time.

Mary Oraon in 'The Hunt' (Imaginary Maps) is a goddess-like creature who possesses strength inaccessible to men in her community. Instead of enabling men to act, she acts to enhance her agency as a gendered subject within a patriarchal nation. Mary is a young, attractive, strong, and intelligent Christian from an impoverished adivasi community. Her mother was raped and abandoned by her father, a white plantation owner. Such a background would not generally allow Mary too many options. Yet, in the story her racial hybridity provides her some autonomy within her tribe. Her anger at her father fuels her self-assertion and resistance to patriarchy. Mary asserts her autonomy in many ways. She intimidates her employers from interfering with her work and gains favourable terms of employment for herself. She retains the profit she earns from selling their orchard produce to save some money as future security. She resists being sexually exploited by men from her tribe and her employers' caste. There is a militant quality about Mary. She is able to transcend the limitations of her environment and gain respect from people surrounding her. She hunts and kills her potential rapist Tehsildar Singh, the urban labour contractor, during a ritual hunt festival. Mahasweta Devi deliberately rewrites the patriarchal narrative to present a radical feminist vision with alternative possibilities. Tehsildar represents mainstream contractors whose illegal deforestation activities are supported by the entire administration. He is willing to rape Mary and exploit her tribe. Just as the inaccessible beauty and frightening sexual energy of the liminal goddess is channelled for anti-colonial resistance, Mary uses her body as a weapon to foil patriarchal rape. As a potential goddess, she enables the men and especially the women of her community to glimpse alternative possibilities through resistance.

Icons of goddesses are closely linked with configurations of the nation as the motherland, mother goddess, or earth mother. Scholars trace this link to nineteenthcentury anti-colonial construction of the new woman who was to safeguard the spiritual qualities, contained within the inner space of the new nation that was preparing to be born. ${ }^{11}$ Mothers became crucial as bearers and nurturers of future citizens and were to be self-sacrificing, chaste, and loyal in order to restore the colonized male's assailed masculinity. Heroic mythical characters famous for their motherly wisdom and wifely devotion, like Sati, Savitri, and Sita, became popular at the time. Chowdhury points out how ideas of motherhood gained strength from Queen Victoria's role as wife and mother; in Bengal, she was seen as the head of the family moulding her children to be the future inheritors of empire. According to Chowdhury, Indian subjects saw themselves being moulded to take over self-governance. By the 1980s, media reports increasingly critiqued the idea of the nation as mother as a metaphor of heterosexual exclusion confining women within spheres of domesticity. ${ }^{12}$ These reports criticize advertisements for perpetuating the mistreatment of barren women, promoting perceptions of female children as unwanted burden, and encouraging intra-caste, -class, -regional, and -religious alliances among the youth. Feminist scholars (Sangari 1999; Tanika Sarkar 1995) point to further complications in the 1990s with the Hindu Right's conflation of the heroic goddess with the nation as mother. They assert that motherhood is vested with political instrumentality; mothers as political creatures are to instil in children habits of obedience to authority and patriotism for the nation. Drawing upon icons of the martial goddesses Durga and Kali, the Hindu Right mobilize and train women in martial arts to transmit an ideology of violent action as evident in the Durga Vahini's (carriers of the goddess Durga) incitement of sons and husbands to communal violence. 
Late twentieth-century fiction also scrutinizes icons of mothers as non-sexual beings at the heart of their families and of the nation; such scrutiny evolves out of the ruptured narrative. None of the mothers have individual names or identities. Puran's (Imaginary Maps) mother takes care of domestic chores and safeguards family interests. She produces children who belong to her husband's family and functions as a caretaker with interim responsibilities. Consequently, Puran's mother is profoundly alienated from her labour and her body under patriarchy, an alienation that is normalized by the codes of motherhood. According to Spivak (1993), traditional Marxist theories of alienation never account for the womb as a place of production in multiple economic systems and the unique alienation that women experience. In all patrilineal societies, the man legally owns the child as the product of the woman's body. The woman merely possesses the place of production - the womb - and is therefore the agent of production. Therefore, it is possible to see how within the Marxist triad of use - exchange - surplus, Puran's mother always produces more than she gets for the man, her husband, who owns her and, through the man, for the capitalist who owns his labour. She has to condition her sons and daughters differently in order to prepare them for very different lives within patriarchy. Such a world decreases her influence and authority over her grown son. She cannot persuade Puran to remarry after the death of his wife and settle down in one place. In creating a gender-enlightened male protagonist such as Puran, Mahasweta Devi creates a contrast between his politics and his mother's ideological beliefs. It is through such a contrast that Devi ironically examines Puran's mother's devaluation of herself as a mother and wife who is unable to fulfil her obligations to the family as well as the system that enables such devaluation. In English, August Agastya's mother occupies a sacred space; Agastya cannot tolerate derogatory comments about her. Unfortunately, the space that she occupies is constantly desacralized by virtue of her having married a Hindu: 'At lunch Mrs. Srivastav said, "Arrey August, you eat fish like a real Bengali. Look his plate is clean." ... "Looks like your mother's side couldn't corrupt you," said Kumar' (107). The question of corruption arises only because in Kumar's eyes, Agastya's identity is compromised in his mother's Goanese Catholic womb, which hybridizes his father's Hindu Bengali maleness. Kumar and Mrs Srivastav participate in the Indian bureaucracy that positions itself as the modernizing agency of governance. This conversation is part of a social event between administrative officials. Yet within the novel, bureaucrats perpetuate patriarchal values, which imprison most women's sexuality within the confines of domesticity. Within patriarchy, as Spivak points out, men own property by virtue of which they define that which is proper. Women become signs of the improper and as unstable spaces they must be controlled by the proper name of the patronymic in order to maintain the status quo. According to this logic, Agastya's mother's womb as the property of her Bengali Hindu husband is to replicate the proper identity of the father in the child. However, as the unstable, improper space, her womb threatens to dilute the name of the father by hybridizing Agastya's identity with her Goanese Catholicism. This instability is feared and demonized by Kumar's threatened laughter.

Female sexuality is a disturbing force that potentially upsets the gender distinctions of patriarchy; it is seen as potentially wild, promiscuous, disruptive, and dangerous (Vishwanath 1997). Coping with and controlling this threat posed by women became a central concern in Hindu texts such as the Manusmriti and the later Vedic tradition (Roy 1998). Nineteenth-century reformers restrained female sexuality by dividing the social space into public and private spheres; lower-caste/class women were allowed public mobility because their labour supported middle-class lifestyles. Such distinctions fostered icons of the loose woman, indecently inhabiting public spaces with an uncontrollable 
sexuality. Poor women abandoned by husbands often become sex workers to support families, exploding myths about family respectability and stability; later the spread of HIV/AIDS thrust the issue of sexuality into public domain and sexual health became a key question (Deshmukh-Ranadive 2005). In the novel English, August, film actresses and porn stars occupy the space given to lower-caste and lower-class women and function outside the domestic sphere of respectability; they have statuses that overlap in specific ways. Their bodies are on display for a price and hence become public property. This nonexclusivity is deemed indecent. But like middle-class respectable women, their sexuality is also controlled because they become mere locations for the expression of aggressive male heterosexuality. Their bodies as sexual objects invite the male gaze that is not allowed to linger openly on domesticated, respectable women. However, the narrative movement within these 1980s texts reverses traditional expectations by gazing at the male gaze to undermine the way it is constituted. Similarly, the narrative structure in English, August forces the reader to scrutinize Agastya's obsession with sex. Agastya focuses on specific body parts of the women that he meets. He notices 'the wonderfully pretty' tribal women with 'tall', 'rigid' bodies, 'large cracked feet' and 'veined forearms'; he watches their '... taut female bodies struggle to extract water out of a well of mud' (258). Their severe poverty provides a context for their eroticization and sexualization. Agastya is thrilled that 'They exist ... outside arty films about tribal exploitation and agrarian reform' (101). None of these women actually exist as people with complex personalities but become fragmented objects of his desire. His desire too is fractured. He is frequently disconnected from his self, unable to establish coherent relationships, and wrapped in sexual thoughts, which create an alternative reality to his daily routine. His discomfort stems from the public/ private divide that he must maintain as a member of the bureaucracy.

In the last few decades of the twentieth century in India, feminists have variously defined icons of goddesses, mothers, and prostitutes. These icons demarcate the attributes comprising the category of woman (Thapan 1997). In fact, female bodies, inserted into a matrix of sexuality, are ensconced in layers of meaning (Niranjana 1997). In other words, sexuality is a tool for studying norms governing caste, class, kinship, and religion; it is also regionally varied (Deshmukh-Ranadive 2005). Hence, the sexual domain is an intersubjective realm in and by which desire is aroused, blocked, and violated (John 1997). Codes of moral conduct regulate women's activities, dress, and speech; women as both agents and subjects confront and are contained by these rules. Vishwanath (1997) traces the development of various women's groups since the 1970s, which focused on enacting legal reform. They agree that the 1990s brought unprecedented changes with increasing numbers of divorced, single, and working women and increasingly circulating images of female bodies. Ghosh (2005) points to problematic collaborations between secular feminist organizations and the Hindu Right in condemning these images with both groups relying on conservative notions of female purity and failing to distinguish between sexual explicitness and sexism. In the fiction, marriages face constant constraints and surveillance. Female sexualities that deviate outside marital relations proliferate but are categorized and incorporated in specific ways in public and private spaces. These fictional examples show a shift in perspective, revealing the sexual politics that make women visible in specific ways through icons of goddesses, mothers, and immoral women. Yet this visibility succeeds in erasing female agency with a violence that intensifies and consolidates patriarchal power. 


\section{Concluding ruminations}

Late twentieth-century narratives reveal the female body to be the site of struggle over which the nation articulated its concerns. Scholars have much to say about the nation, its literature, and women. Feminist scholarship animated literary debates since the 1970s, with women's writing gaining visibility; however, the term 'women writers' may erase differences between women's experiences while rescuing them from isolation (M. Mukherjee 2008). For Sunder Rajan (2008), the categories 'women' and 'nation' signify the gendered private-public divisions, which become sites for contending ideologies of freedom. In such struggles, it is crucial to dynamically represent women through a variety of cultural texts that invite critical interpretation and recuperation. Dutta (2008) connects women's visibility in national discourse to the growing demand among all marginalized subjects for a place at the centre. Any understanding of the relations between literature and nationalism must be cognizant of this demand, she believes. Paranjape (1998) endorses this idea when he asserts that current literary debates place a greater emphasis on the experiences of women who are not part of the mainstream. In so doing, these debates contest the identity and destiny of modern India. Such contestations are unsurprising, says Raveendran (2006); he declares that India as a nation is a stable entity only on the political map of the world; its literary and cultural borders keep changing between writers, readers, and subjects. These critics are influenced by Homi Bhabha's formulation of the nation and its narratives being conceptually indeterminate, transitional, and wavering between vocabularies (1990). Bhabha is influenced by Benedict Anderson's 1983 formulation of the nation as a product of the simultaneous imagination of its disparate groups of citizens who experience themselves as a community while reading its fiction and newspapers. This chapter seeks to situate itself among these debates by juxtaposing images of women in fiction with journalistic and scholarly discourses on the nation in the last three decades of the twentieth century. In the process, it seeks to reveal how literature stages many moments when dominant narratives are unsettled and exposes new possibilities within the discourse of the nation. These possibilities become evident once again in the public outrage over the rape of Nirbhaya in December 2012 when various sections of civil society united to assert the right of women to safely and freely inhabit public spaces within the nation at all times. It is therefore entirely reasonable to assert that this period of the late twentieth century is a time of crucial changes leading up to this present moment in the twenty-first century.

\section{Notes}

1 See Sangari and Vaid (1990), Butalia (2005), P. Chatterjee (1993), Jayawardena (1986).

2 See Desai (1994), Khullar (2005), and Sen (2005).

3 For instance, the Bodhgaya struggle led by the Chhatra Yuva Sangharsh Vahini took on land rights for women. The Chipko movement mobilized women against felling trees commercially. The Shramik Sangathana involved women to uphold the land rights of the dispossessed tribal peasantry of Shahada. The Kerala fishworker's movement took up women's rights to public transport for vending fish.

4 See L. Sarkar (1987), Madhok (1984), Raman (1980), S. P. Gupta (1987), Gnanadasan (1981).

5 See Spivak's use of 'excess' in 'French Feminism Revisited' (1993).

6 See Sangari (1999), Menon (1982), Deshmukh-Ranadive (2005), Mazumdar and Sharma (2005), N. Banerjee (2005), and Jain (2005).

7 Balasubramanyan (1986), D’Souza (1980), R. P. Gupta (1983), P. P. Saxena (1988).

8 Ahuja (1985), Pereira (1980), N. Mukherjee (1984), Grover (1988), Saradamoni (1982), Cinar (1987).

9 Latifi (1986), Haider (1986), Begum (1983), and Iyer (1986) refer to the plight of Shah Bano, a Muslim woman, whose abandonment after 50 years of marriage provided the subject for an 
extremely controversial court case in the 1980s. The government passed the Muslim Women's Bill despite protests by feminist organizations. This bill, according to these journalists, exacerbated the miserable plight of many Muslim women living in poverty and illiteracy. However, not all Muslim women are uniformly oppressed. Educated urban women faced a different reality than their poor, illiterate counterparts in urban slums or villages.

10 Govilkar (1982), B. R. Sharma (1989), and Jahagirdar (1988).

11 Chowdhury (1998), P. Chatterjee (1993), Bose (1998), and Jayawardena (1986)

12 See Krishnan (1984), N. K Singhi (1985), Raheja and Saraswati (1980).

\section{Bibliography}

Agnihotri, I and V. Mazumdar (2005) 'Changing Terms of Political Discourse: Women's Movement in India, 1970s-1990s', in M. Khullar (ed.), Writing the Women's Movement: A Reader, New Delhi: Zubaan (An Imprint of Kali for Women).

Ahuja, R. (1985) 'Political Awareness and Political Participation of Women in Rural Areas', Journal of Sociological Studies, 1(Jan): 14-26.

Anderson, B. (1983) Imagined Communities: Reflections on the Origin and Spread of Nationalism, London: Verson.

Balasubramanyan, V. (1986) 'Invisible, Underpaid, and Unorganized', Mainstream, 24 (50): 25-27.

Bannerjee, N. (2005) 'The Structural Adjustment Programme and Women's Economic Empowerment', in M. Khullar (ed.), Writing the Women's Movement: A Reader, New Delhi: Zubaan (An Imprint of Kali for Women).

Begum, J. (1983) 'Allah! Amader Kandte Dao!', Organiser, 35 (13): 17-19.

Bhabha, H.K. (1990) Nation and Narration, New York: Routledge.

Bose, S. (1998) 'Nation as Mother: Representations and Contestations of "India" in Bengali Literature and Culture', in S. Bose and A. Jalal (eds), Nationalism. Democracy, and Development: State and Politics in India, Delhi: Oxford University Press.

Butalia, U. (2005) 'Confrontation and Negotiation: The Women's Movements Responses to Violence Against Women', in M. Khullar (ed.), Writing the Women's Movement: A Reader. New Delhi: Zubaan (An Imprint of Kali for Women).

Chatterjee, P. (1993) The Nation and its Fragments: Colonial and Postcolonial Histories, Princeton, NJ: Princeton University Press.

Chatterjee, U. (1988) English, August: An Indian Story, London: Faber and Faber.

Chowdhry, P. (1998) 'Enforcing Cultural Codes: Gender and Violence in Northern India', in M. E. John and J. Nair (eds), A Question of Silence: The Sexual Economies of Modern India, 332-367, New Delhi: Kali for Women.

Chowdhury, I. (1998) The Frail Hero and Virile History: Gender and the Politics of Culture in Colonial Bengal, Delhi: Oxford University Press.

Cinar, E.M. (1987) 'Disguised Employment: Female Family Labor', Mainstream, 27 Jun: 32-34.

Das, V. (1995) Critical Events: An Anthropological Perspective on Contemporary India, Delhi: Oxford University Press.

Desai, A. (1984) In Custody, New York: Harper \& Row.

Desai, A. (1994) 'Gender Role in the Constitution', in L. Sarkar and B. Sivaramayya (eds) Women and the Law: Contemporary Problems, 41-49, New Delhi: Vikas.

Deshmukh-Ranadive, J. (2005) 'Controlling Sexuality', in M. Khullar (ed.), Writing the Women's Movement: A Reader, New Delhi: Zubaan (An Imprint of Kali for Women).

Devi, M. (1995) Imaginary Maps, translated by G. Spivak, New York: Routledge.

D'Cunha, J. (1997) 'Prostitution: The Contemporary Feminist Discourse', in M. Thapan (ed.), Embodiment: Essays on Gender and Sexuality, Delhi: Oxford University Press.

D’Souza, E. (1980) 'What is in Store for the Fair Sex in the 1980s?', The Indian Worker, 5 May: 12-16.

Dutta, N. (2008) 'Nationalism and Otherness: Reading Nation in the Literature Classroom', The Global South 2 (1): 71-90.

Ghosh, S. (2005) 'The Troubled Existence of Sex and Sexuality: Feminists Engage with Censorship', in M. Khullar (ed.), Writing the Women's Movement: A Reader, New Delhi: Zubaan (An Imprint of Kali for Women).

Gnanadasan, A. (1981) 'Human Rights and Women's Concerns', Religion and Society, 13 (1): 14-24.

Govilkar, M. (1982) 'Providing Gainful Employment to Rural Women', Kurukshetra, 16 May: 7-10. 
Grover, I. (1988) ‘Occupational Hazards of Rural Working Women’, Social Welfare, 35 (2): 12.

Gupta, R.P. (1983) 'Role of Rural Women in India's Economic Development', Southern Economist, 22 (2): 15-17.

Gupta, S.P. (1987) 'Social Workers on Violence on Women', Social Welfare, 34 (7): 17-19.

Haider, S. (1986) 'Muslim Women's Bill: A Return to the Dark Ages', Link, 16 March: 4-5.

Iyer, V.R.K. (1986) 'The Shahbano Showdown', Manthan, 7 (2): 35-41.

Jahagirdar, M.P. (1988) 'The Status and Role of Women in a Tribal Community', Man in India, 68 (4): 424-430.

Jain, D. (2005) 'The Household Trap: Report on a Field Survey of Household Activity Patterns', in M. Khullar (ed.), Writing the Women's Movement: A Reader, New Delhi: Zubaan (An Imprint of Kali for Women).

Jayawardena, K. (1986) Feminism and Nationalism in the Third World, London: Zed Books.

John, M.E. (1997) 'Globalisation, Sexuality and the Visual Field: Issues and Non-issues for Cultural Critique', in M.E. John and J. Nair (eds), A Question of Silence: The Sexual Economies of Modern India, New Delhi: Kali for Women.

Karlekar, M. (2005) 'Encountering Violence', in M. Khullar (ed.), Writing the Women's Movement: A Reader, New Delhi: Zubaan (An Imprint of Kali for Women).

Katrak, K.H. (1992) 'Indian Nationalism, Gandhian Satyagraha, and Representations of Female Sexuality', in A. Parker, M. Russo, D. Sommer, and P. Yaeger (eds), Nationalisms and Sexualities, New York: Routledge.

Khullar, M. (2005) 'Introduction', in M. Khullar (ed.), Writing the Women's Movement: A Reader, New Delhi: Zubaan (An Imprint of Kali for Women).

Krishnan, P. (1984) 'Hidden Face of Patriarchy', Seminar, 300 (1): 15-18.

Latifi, D. (1986) 'Muslim Women's Bill: The Unfriendly Act', Manthan, 7 (2): 61-62.

Madhok, S. (1984) 'Struggling for Space', Seminar, 300 (1): 29-34.

Mazumdar, V. and K. Sharma (2005) 'Sexual Division of Labour and the Subordination of Women: A Reappraisal', in M. Khullar (ed.), Writing the Women's Movement: A Reader, New Delhi: Zubaan (An Imprint of Kali for Women).

Menon, U. (1982) 'Women and Household Labour', Social Scientist, 10 (7): 30-42.

Mosse, G.L. (1985) Nationalism and Sexuality: Middle Class Morality and Sexual Norms in Modem Europe, Madison, WI: University of Wisconsin Press.

Mukherjee, M. (2008) Elusive Terrain: Culture and Literary Memory, New Delhi: Oxford University Press.

Mukherjee, N. (1984) 'Being Professional and Female', Mainstream, 1 Dec: 22-24.

Niranjana, S. (1997) 'Bodily Matrices', in M. Khullar (ed.), Writing the Women's Movement: A Reader, New Delhi: Zubaan (An Imprint of Kali for Women).

Paranjape, M. (1998) 'Post-Independence Indian English Literature: Towards a New Literary History', Economic and Political Weekly, 33 (18): 1049-1056.

Pereira, O. (1980) 'Indian Women Voiceless and Wordless', Social Welfare, 26 (12): 4-5.

Raheja, S. and T. S. Saraswati (1980) 'Women's Lib: Just a Facade?' Social Welfare, 26 (12): 1-2.

Rajan, R.S. (2008) 'English Literary Studies, Women's Studies and Feminism in India', Economic and Political Weekly, 43 (43): 66-71.

Raman, P.S. (1980) 'Women's Emancipation: Illusion and Reality', Link, 22 (31): 30-32.

Raveendran, P.P. (2006) 'Genealogies of Indian Literature', Economic and Political Weekly, 41 (25): 25582563.

Roy, K. (1998) 'Unveiling the Kamasutra', in M.E. John and J. Nair (eds), A Question of Silence: The Sexual Economies of Modern India, New Delhi: Kali for Women.

Sangari, K. (1999) Politics of the Possible: Essays on Gender, History, Narratives, Colonial English, Delhi: Tulika.

Sangari, K. and S. Vaid (1990) Recasting Women: Essays in Indian Colonial History, New Brunswick, NJ: Rutgers University Press.

Saradamoni, K. (1982) 'Work at Home: What it Means', Mainstream, 20 (48): 29-31.

Sarkar, L. (1987) 'Gender Injustice and the Law', Cochin University Law Review, 11 (3-4): 435-448.

Sarkar, T. (1995) 'Heroic Women and Mother Goddesses: Family and Organisation in Hindutva Politics', in T. Sarkar and U. Butalia (eds), Women and the Hindu Right: A Collection of Essays, 181-215, New Delhi: Kali for Women.

Saxena, P.P. (1988) 'Gender Bias in Inheritance and Property Rights', Religion and Society, 35 (1): 29-37.

Sen, I. (2005) 'A Space Within the Struggle', in M. Khullar (ed.), Writing the Women's Movement: A Reader, New Delhi: Zubaan (An Imprint of Kali for Women). 
Sharma. B.R. (1989) 'Muslim Wife's Right to Maintenance: From Shah Bano to Begum Subanu', Indian Socio-Legal Journal, 15 (1-2): 23-32.

Sharma, P. (1986) Days of the Turban, London: Bodley Head.

Singhi, N.K. (1985) 'Social and Academic Structures and Women's Development', Development Policy and Administration Review, 11 (1): 47-64.

Spivak, G.C. (1993) 'French Feminism Revisited', Outside in the Teaching Machine, New York: Routledge.

Thapan, M. (1997) 'Introduction: Gender and Embodiment in Everyday Life', in M. Thapan (ed.), Embodiment: Essays on Gender and Sexuality, Delhi: Oxford University Press.

Vishwanath, K. (1997) 'Shame and Control: Sexuality and Power in Feminist Discourse in India', in M. Thapan (ed.), Embodiment: Essays on Gender and Sexuality, Delhi: Oxford University Press.

Vishwanathan, S. (1997) 'Women and Work: Housewifization to Androgyny', in M. Thapan (ed.), Embodiment: Essays on Gender and Sexuality, Delhi: Oxford University Press. 


\title{
30 \\ THE NEW INDIAN MALE Muscles, masculinity and middle classness
}

\author{
Michiel Baas
}

\section{Introduction}

The August 2013 edition of Men's Health investigates a pressing matter: 'Why being Indian is good for your health'. The special section opens with a bold statement:

From the spicy food on your plate and the martial blood pumping through your veins to the love lavished by your family and the benefits of advice professed by the Kamasutra - here's why India is the only country on the planet you would want to be in right now.

The first article in the above-mentioned special section takes inspiration from classical Indian sports. Accompanied by five pictures featuring two muscular male models engaged in hand-to-hand combat, their bodies smeared with what looks like mud or soot, they perform various 'traditional' Indian fighting techniques. The first picture introduces the so-called kalari elbow strike, referring to the martial art of kalaripayattu, which has its origin in the southern state of Kerala. ${ }^{1}$ The next set of pictures illustrates how to throw one's opponent on the floor in three comprehensive steps making use of techniques derived from pehlwan wrestling. ${ }^{2}$ Finally the last picture in the article showcases the muki or 'lighting fist', a reference to musti- $y$ uddha, a South Asian form of boxing usually referred to as muki boxing and (now) mainly practised in Varanasi. Other articles that fall under the 'India Issue 2013' header discuss the merits of an Indian diet ('eat Indian for a metabolism spike'), what can be learned from Indian superheroes ('how to gain mental superiority over others') and finally how 'our [Indian] tradition makes us sexy', specifically discussing the workout merits of various positions from the Kamasutra. While the article alludes to 'local' Indian workout techniques, the end result is a body that adheres closely to bodily aesthetic ideals that are inherently 'globalized' in nature. It is a body that could easily don the cover of any of the forty editions of Men's Health that appear in forty-seven different countries on a monthly basis but for the fact that the model 'looks' Indian, which gives the cover a 'local' flavour. Although it could be argued that globalization presents itself in a heterogenized form here ${ }^{3}$ its ambition to insert 'Indianness' actually underlines that the allusion is not a natural one. 
Those familiar with the aforementioned classical sports will also agree that the bodies on display in the article actually do not resemble those that would 'naturally' be the end result of practising these sports.

The cover of the above-mentioned Indian edition of Men's Health features a model who in terms of his body type - lean and muscular ${ }^{4}$ - will be referred to as the 'new Indian male'. Throughout this chapter I will discuss this 'new Indian male' in terms of it being an 'ideal type'. Invoking Weberian typology here serves two purposes: it draws attention to the near impossibility of such bodies and it highlights the process of becoming of which such bodies are imagined to be the end result. This increasingly visible 'ideal type' adorns billboards advertising a whole gamut of products ranging from toothpaste to four-wheel drive cars - and features prominently in TV series (in particular soap operas) and Bollywood movies. It is this new 'visibility' that lies at the heart of what this chapter seeks to explore. Glassner (1989: 183-184) ${ }^{5}$ argues that the way we experience our own bodies is done so within the context of a media environment of repeating images. Furthermore Glassner argues that: 'The physique has become a cardinal sign of the self in a way which add-ons such as fashion and cosmetics (the appearance-enhancer signs of modernity) no longer can' (Glassner 1989: 183-184). Visually processing and meticulously reading our own as well as the bodies of others for social cues about beauty, love, identity and status is something we are trained to do from a very young age, argue Casper and Moore (2009: 3). Bodies are seen and the act of seeing itself is a reflexive activity; we interpret what we observe (Waskul and Vannini 2006: 5). In line with this I propose to make the following questions central: How can we understand this ostensibly new Indian male? Who is he, what is he the product of, how is he produced and what produces him? Principally what I am interested in is the question of what the arrival of this 'ideal type' articulates about contemporary India in relation to socioeconomic developments. I will do so by drawing upon various fields of scholarly research including studies that have engaged with the body in terms of its socio-cultural significance; studies that have discussed the (Indian) male body and its associated masculinity; and finally recent studies that have examined the shape and composition of the Indian middle classes. Besides that, this chapter takes inspiration from ethnographic fieldwork conducted in a small neighbourhood gym in South Delhi over the period of nine months in 2013-2014. In addition to this interviews were conducted with fitness and health professionals, gym members and bodybuilders in four cities: Delhi, Bangalore, Mumbai and Patna. ${ }^{6}$

A glossary excursion through the Indian edition of Men's Health (see Figure 30.1) reveals that it is not just about an 'ideal type' body that is desirable in terms of aesthetics and associated masculinity (denoting masculine strength and fitness) but that this body also stands in direct relation to notions of socio-economic success, cosmopolitanism and even professionalism. This contrasts significantly with the way 'midriff rotundity' used to signify wealth and prosperity among men belonging to the middle classes, something that clearly juxtaposed with the wiry/veiny muscularity of the labour classes. This connection between rotundness, health and prosperity was also reflected in the depiction of male Hindu gods, often sporting a 'healthy belly' and sometimes even being directly associated with particular sweets rich in ghee (clarified butter). More recently, however, some of the iconography of deities such as Ram, Krishna, Shiva, Hanuman and even Ganesha has undergone a process of muscularization as well (see also Anand 2007). While I am well aware that I am taking big steps here, sketching and contrasting without leaving much space for the kind of nuance which always characterizes reality, it helps set the stage for what I wish to unpack further in this chapter: the arrival of an 'ideal type' and its symbolic associations which on the one hand are clearly the product of recent developments yet on the other hand also channel previously 

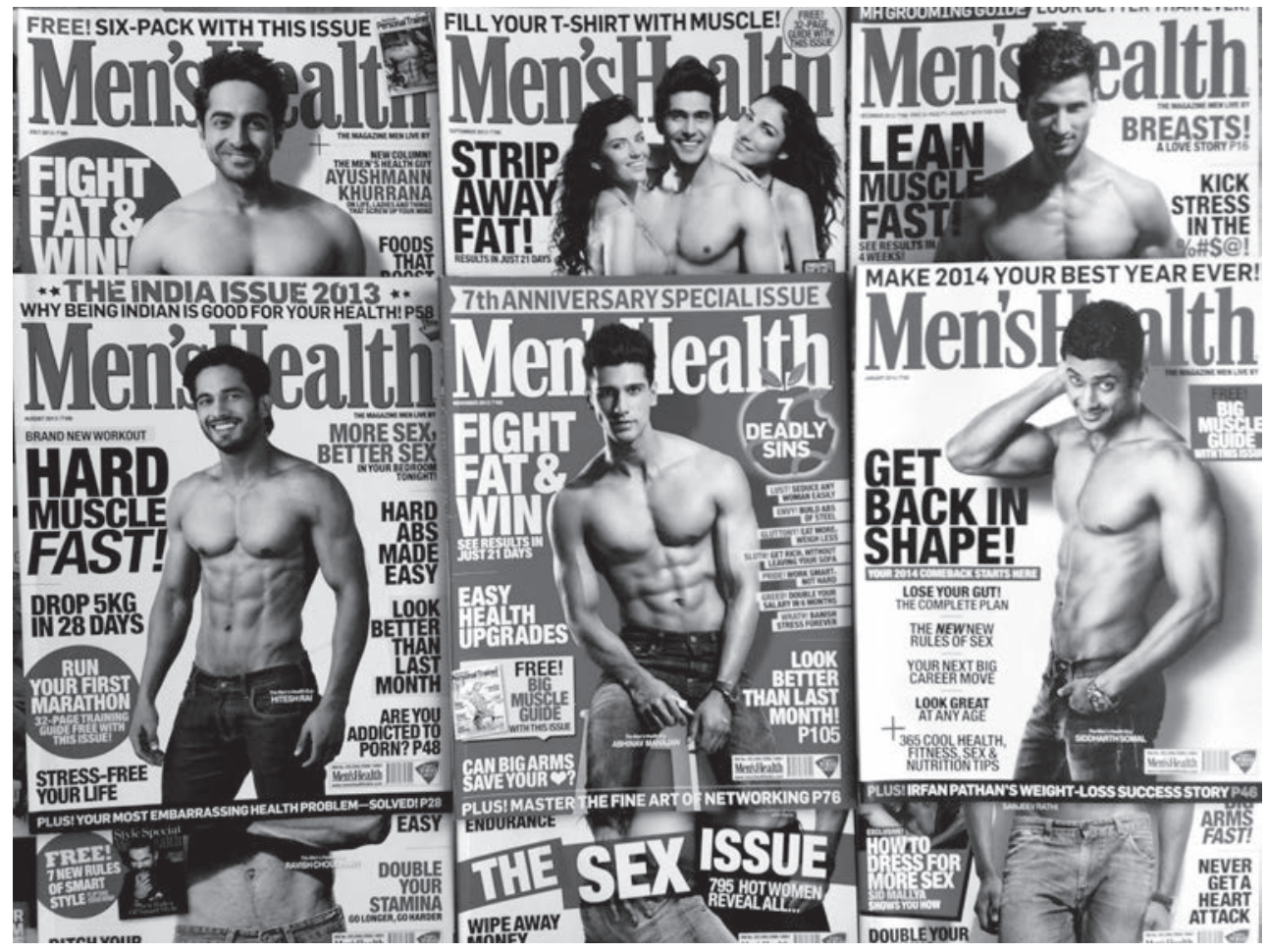

Figure 30.1 The 'new Indian male', lean and muscular on the cover of health magazines

hegemonic associations between body, class and masculinity. India's recent economic growth and the effect this has had on middle-class formation has made an impact on the way Indian (middle-class) men have started to reflect on their own bodies and associated masculinity. This new 'middle-class' masculinity and its associated bodily ideals do not just reflect notions of masculine strength, fitness and health but also narrate a complex array of desires, expectations and anxieties of 'middle-class' life.

\section{Bollywood, Men's Health and the fitness industry}

Men's Health, launched in India in 2006, is now available at virtually every newspaper stand in the country. As such it has become part of an ever-growing group of health and lifestyle oriented magazines specifically targeting English-speaking middle-class men. According to its editorial director Jamal Shaikh the magazine has continued to sell more copies with each new edition than the previous one since its launch in 2006, something that is particularly interesting considering the lack of celebrities on its cover (author's interview 07 February 2014). Instead the magazine relies on unknown male models who purportedly show up in droves on days when the magazine recruits new talent, requiring the presence of security personnel to keep the numbers in check. Sitting in a meeting room with Men's Health magazine covers adorning the walls it is not hard to notice how the cover models all have a similar lean, muscular look, in line with an 'ideal type' informed by what has become an almost globalized standard for which the magazine itself seems to set the tone. In particular Bollywood stars have adopted this look and virtually every mainstream blockbuster movie 
now has one or two scenes which sets the stage for the male hero to take off his shirt and flaunt his chiselled physique often making only marginal adjustments by use of make-up and colour to bring the body in line with a certain mood, period or style. A recent example of this is Goliyon Ki Raasleela Ram-Leela ${ }^{7}$ (2013), a Romeo and Juliet-esque adaptation revolving around two feuding families in provincial Gujarat. In one of the opening scenes, the male hero played by Ranveer Singh goes around town dancing and singing. From the moment he arrives on scene, lying on a white Royal Enfield 'Bullet' motorcycle, his purple shirt unbuttoned revealing washboard abs as if carved out of marble, his 'heroism' is primarily underlined through the body on display. Driving home this point even further, towards the end of the song he even takes off his shirt and strikes a number of classical bodybuilding poses, all while loudly cheered on by the female onlookers of whom one even faints.

The video of the song described above would frequently play on MTV, the channel of choice for the small neighbourhood gym in South Delhi in which I conducted ethnographic fieldwork. Almost all other videos running in a loop similarly revolved around key-moments when the male lead would dance bare-chested; Farhan Akhtar revealing his muscular and distinctly veiny body that gave him the necessary 'athletic' look for his role as sprinter Milkha Singh in Bhagg Milkha Bhaag; Hrithik Roshan flexing his densely muscled physique for his superhero reprisal in Krrish 3; or the more rugged muscular 'working-class' look of Arjun Kapoor who featured alongside earlier mentioned Ranveer Singh in the retro-infused period action crime thriller Gunday. The 'making of' such bodies generates considerable media attention in conjunction with the launch of new blockbuster movies. Popular Englishlanguage magazine India Today, for instance, discussed the 'Making of Milkha' by displaying a bare-chested Farhan Akhtar as Milkha Singh, arrows pointing to various body-parts explaining how the actor had worked on these. About his shoulders the articles explains: 'Farhan's favourite exercise, according to his trainer, was lateral raise which helped him develop round muscled shoulders. Along with that, he did fifteen sets of front raises with dumbbells regularly' (29 July 2013). The same article also dedicates a separate column to his (personal) trainer who was instrumental to developing the necessary workout routines and dietary restrictions. ${ }^{8}$ In that way newspaper and magazine articles frequently discuss the active partnership between actor and trainer. In the case of Hrithik Roshan this even resulted in a workout guide in which he featured and which was authored by his personal trainer Kris Gethin titled: The Bodybuilding.com: Guide to Your Best Body (2013). Bollywood stars are also actively employed in the opening of new fitness centres particularly by brands such as Gold's Gym whose establishments are decorated with pictures in which a famous Bollywood star like John Abraham is seemingly casually working-out alongside 'regular' clients.

It is clear that a highly specific male bodily ideal has taken up an increasingly prominent place in public space and popular media and that this is a relatively recent development in which Bollywood is an important factor. Jamal Shaikh of Men's Health, for instance, claimed that before the magazine was launched in 2006 there was virtually no interest for musclebuilding exercises in popular media. In fact the first line on the first cover of the Indian edition of the magazine was: 'Indians can have abs too!' (Author's interview 07 February 2014). The following year, one of Bollywood's biggest stars Shahrukh Khan was allegedly the first to adhere to what had come to be referred to as the Men's Health standard and flaunted six pack abs as he performed the lead role in blockbuster movie Om Shanti Om ${ }^{9}$ (2007). ${ }^{10}$ However, it was particularly the Hindi remake of the Tamil action movie Ghajini (2008), ${ }^{11}$ which those already active in the fitness industry at the time remember as a turning point. Not only the specific haircut of lead actor Aamir Khan would quickly become fashionable among young men across India, the rapid transformation of Khan's body from that of 'next 
door neighbour' in Taare Zameen Par (2007) ${ }^{12}$ to the hulking muscular physique he sported for the lead role in Ghajini actually led to a surge in new members of fitness clubs everywhere in India.

While there are no official statistics available on the number of gyms in India, the owners and trainers I interviewed agreed that the explosive growth the industry has witnessed is by and large the product of the last five to six years. A report by the IHRSA (International Health, Racquet and Sportsclub Association) (quoted in Andrews et al. 2013) speaks of 765 fitness clubs in India in 2008. However, a search entry for 'gyms' on Just Dial.com ${ }^{13}$ produces already 500 addresses each for cities such as Bangalore, Delhi (NCR) and Mumbai. Although these search results also include a limited number of yoga and dance studios it does provide a snapshot impression of how exponential growth has been. This is further underlined by the recent announcement of a company such as Snap Fitness India, the Indian master franchisee of the US-based company, which was in the process of raising $\$ 10$ million in 2013 to finance its expansion plans. Having entered India in 2008 , the company already operates four company owned and thirty-six franchisees with about 30,000 members. With the sought funding it would be able to fund its mandate of 300 gyms, forty of which it was hoping to open in 2013 alone. The news which appeared in the Indian business daily Business Standard furthermore reported that the 'wellness industry' as they referred to it was now valued at $\$ 3$ billion and that 95 per cent is dominated by the unorganized sector, the rest by brands such as Fitness First (British), Gold's Gym (American), Snap Fitness (American), and Talwalkars (Indian). ${ }^{14}$ Gold's Gym, for instance, now operates eighty-nine gyms in India, the majority of which are located in the state of Maharashtra (twenty-five, mainly in Mumbai and Pune), Karnataka (sixteen, mainly in Bangalore) and Delhi-NCR region (seven).

India's urban landscape is now dotted with gyms, both small ones operating on a neighbourhood-level and larger facilities set-up by nationally or internationally operating brands. Especially in middle-class neighbourhoods, such as the one in which the gym was located where I conducted fieldwork myself, it is often striking how many gyms and health-oriented establishments such as so-called 'fat clinics', providing weight loss solutions, and shops selling protein powder and other supplements, there are. In the near vicinity of my home in CR Park (a traditionally Bengali middle-class neighbourhood) I counted at least seven other gyms within walking distance (under fifteen minutes) besides the one I frequented on a daily basis for fieldwork in nearby neighbourhood GKII. Easily recognizable for what they are and seemingly on an ever-expanding quest it is worth considering the 'visibility' of these gyms themselves as a factor in the way they encourage and/or instil (in the middle class) a sense of inevitability to work out .

\section{Men, masculinity and 'modern' India}

It cannot be ignored that the development whereby Indian men have now become the object of the gaze instead of 'simply' being the bearer of the look (Waskul and Vannini 2006), coincides with a decade of considerable economic growth ${ }^{15}$ and a rapidly expanding middle class. It is this middle class which is specifically targeted by the marketing endeavours of gym chains, the more general product advertisement of brands that make use of lean, muscular models, and who are the targeted audience of health and fitness magazines. What stands out about the Indian middle classes is not just the ensuing rhetoric on economic growth and the way it drives the political agenda on certain matters (Baviskar and Ray 2011) but also how it has become a self-referential category to which many aspire to belong. In describing their sociocultural/family backgrounds I have often observed how informants do not simply explain that 
they are 'middle class' but frequently use words such as old $/$ new $^{16}$ or lower/middle/upper to be more specific in terms of where they consider themselves to belong in relation to others (see also Baas 2009, 2010). Considering the size of the Indian middle classes for which estimates in size vary between 100-350 million it is perhaps not surprising that Jaffrelot and Van der Veer (2008: 11) argue that it is a 'notoriously elusive category'. As a result the 'criteria for drawing boundaries' has become a main focus for studies discussing the Indian middle classes (E. Sridharan 2011: 27), with a particular focus on household income, level of education and the way people are able to profit from recent economic growth (e.g. Fernandes 2006, 2011; Ganguly-Scrase and Scrase 2009; Jeffrey et al. 2008; E. Sridharan 2011). To complicate matters further, besides economic terms the middle classes are furthermore dividable along linguistic/ regional, ethnic, religious and caste lines (Nijman 2006).

Describing the 'new Indian male' as a 'middle-class' phenomenon inspires to ask two important interrelated questions: 1 . Within the context of belonging to the middle class where we can position this 'ideal type' male body? 2. In relation to what this body is imagined or understood to signify to those belonging to the middle classes, how does this resonate with or contradict existing notions of Indian masculinities? It is clear that Indian masculinities have been discussed in relation to a wide variety of issues ranging from the stereotyping of Hindu men during colonial days (Osella and Osella 2006), the 'muscularization' of the Hindu movement (Alter 1994a, 1994b; Hansen 1996; Anand 2005, 2007, 2008; Rogers 2008), to the way masculinities have been depicted in religious and mythological stories (McLain 2009; Srinivas 2010). Although the body features prominently in such studies, it either concerns traditional, culturally specific bodily ideals and/or groups of men who are not well educated, clearly belonging to the working classes (see also De Neve 2004). Of particular relevance here are studies which have examined the role the body plays in traditional Indian sports such as pehlwan wrestling (Alter 1992, 1995, 2011), the south Indian martial arts form kalaripayattu (McDonald 2007; Zarilli 2000), or the Punjabi team sport kabbadi (Mills 2005). While these studies deal with ostensibly 'traditional' sports, 'assumed' to be predecessors of more modern forms - pehlwan wrestling being one of the oldest forms of wrestling, kalaripayattu as ancient form of martial art - what stands out is how they interact and compete with socio-economic change and (associated) globalization.

As modern-day workout routines borrow from those developed for the training of pehlwan wrestlers ${ }^{17}$ and, in the case of the Delhi-NCR region, fitness trainers, especially those from nearby towns and villages, often have a background in this sport, it makes sense to examine in what way practices and associated (masculine) ideals overlap or digress. Joseph Alter's seminal work in this regard is particularly illuminating. Alter uses the term 'integrated selfdevelopment' (1995: 112) to describe the way a pehlwan wrestler develops himself through 'eating, sleeping, resting, walking, talking, defecating, as well as practising moves and countermoves or doing various types of exercises'. His diet, high in fat and calories, not only gives the wrestler the necessary energy he needs to wrestle and exercise (ibid.: 115), but also produces a particular body type which, as informants often assured me, is easily recognizable. As such pehlwan wrestlers clearly distinguish themselves from bodybuilders whose fixation on 'external form' is characterized by a focus on distinct body-parts - something that also comes with its own lingo (bulging biceps, ripped abs, muscular back) - as opposed to the more holistic development of what could be understood as a 'smoother' body, one 'of one colour and uniform texture, through attention to the matter that goes into and comes out of it, and an exercise regime that is inseparable from devotion' (Jain 2001: 206). Joseph Alter even argues that the wrestling akhara or public gymnasium provides a social environment which allows for a certain morality to be performed, particularly with reference to celibacy or 
semen retention, which as a critique of postcolonial desire gets disseminated among village and neighbourhood men. "Thereby a "moral" form of popular culture is pitted against the popular hedonism of modernity' (Alter 2011: 29).

Although Alter's work on pehlwan wrestlers as renunciate or brahmacharya is revealing in its exploration of the moral, material and physical roots of masculinity in India, how to relate these idealized notions of (embodied) masculinity to developments in contemporary 'middle-class' India poses us with a challenge. While it appears as if a definite shift has been made towards the external form, characterizing not just bodybuilding but working-out in general, I will argue that this development comes with a new specifically 'middle-class' type of masculinity, which is not so much 'pitted against' modern life but communicates directly with it. As Ghosh (2009: 38) argues, the shape and beauty of the body is emerging as the marker of modernity for young people in the metropolitan milieu; the body as an entity in the process of becoming and 'open to reconstruction' is linked to self-esteem and personal control (over one's environment). The ubiquitous, highly visible presence of an 'ideal type' male body in public space and popular culture plays a key-role in this, I argue.

\section{Trainers, bouncers, the floor and the land}

When Ratish Khanna (23) stands in front of the mirror flexing his muscles the floor trainers whose focus should be on the gym's clients, making sure they do their exercises properly, shifts to what is on display: heavily pronounced pectoral muscles ('pecs'), sharply defined triceps, bulging biceps and a v-shaped back. Ratish has recently finished his degree in hotel management from an elite institute in Switzerland and has moved back to Delhi to search for a job. Clearly of an upper-middle class background, he is well able to afford topof-the-line supplements and is at liberty to spend his free time - which he has in abundance - in the gym. In the morning we usually catch up briefly basically to discuss 'how things are going', conversations which are eagerly participated in by the floor trainers whose English is often limited and who struggle to follow what the discussion of the day is about. Ratish interlaces his stories with rapid Hindi that generally lacks in the slang that lubricates the bolder tales of the trainers. Hailing from lower or 'new' (generally meaning 'recent') middleclass families, this is generally the first gym they have found employment in. Essentially a 'neighbourhood' kind of place with limited facilities; the majority of its members find their way to the gym from nearby affluent middle-class suburbs such as GKII, ${ }^{18}$ CR Park and Chirag Delhi. Being business owners or employed in professions (e.g. accountant, dentist, IT professional) that require higher education and fluency in the English language, their family histories often reveal that their self-identification as upper-middle class rests on having already been considered 'middle class' for a number of generations. They come in to 'reduce fat levels', 'improve general health', 'become more fit' and in addition to this, a remark which was often accompanied by a hopeful shrug, 'to build some muscle'. While the ideal of a lean, muscular body had coaxed them to the gym, their expectations with respect to their own bodies would generally be more realistic. In that sense they contrasted markedly with the trainers whose bodies had not only landed them this particular job but who also keenly realized that in order to tap into the lucrative personal training market or to work for more prestigious gyms they would have to work even harder in order to bring their bodies as close as possible to the desired ideal.

The situation described above illustrates the complexities that come with locating the 'ideal type' male body within a highly concrete setting such as the gym itself. This is where the 'ideal type' body is produced; under the guidance of trainers, observed through 
its omnipresent mirrors, the Bollywood clips on the TV screens hanging above portraying the 'end result' in various contexts often making specific statements about its associated masculinity. It is here that the muscular body and its associated symbolic capital (Bourdieu 1984, 2001) are on full display. However, instead of being 'semiotically divorced' from its association with physical labour and associated class (Bourdieu 1984), the perceptions of what this body stands for, how it can be interpreted, what it is assumed to communicate, and also what it is imagined to facilitate varies along (middle-)class lines.

In his study on so-called bouncers or doormen, Simon Winlow argues that 'Having large muscles immediately illustrates vibrant maleness; masculinity does not need to be spelled out through complex verbalizing or accepted modes of mutually congratulatory conversation' (Winlow 2001: 98). As such the muscular body can, as Winlow phrases it, 'claim to the spirit of all that is masculine' and accentuates 'differences from all that is feline' (ibid.: 99). Yet while Winlow argues that what bouncers bring with them as 'crude bodily capital' (for which he refers to Wacquant's seminal study on boxing, 2003), offering their bodies as marketable assets, he also cautions that this is not simply a process of use and exchange value. Equally important is what he calls the sign value of a bouncer's body, his speech and body language, facial expressions and demeanour and so on, basically what customers 'understand' (ibid.). Although bouncers can be considered entrepreneurs in bodily capital (Winlow 2001: 103), their bodies carry the kind of symbolic weight that should ideally be enough to deter others from misbehaving. Winlow (2001) and Lee Monaghan's studies (2002a, b) make clear how bouncers' bodies (often the product of bodybuilding) are layered with lower or workingclass connotations.

In discussions I had with floor and personal trainers in terms of the way they utilized their bodies with respect to attracting clients or finding employment in a particular gym, the way they narrated about their bodies and what they hoped to communicate could be placed on an axis where muscularity and masculinity intersects with various notions of middle classness. The bulkier though decidedly muscular body the result of pehlwan wrestling, a sport many had practised in their native villages or towns (often in the near vicinity or even part of the NCR region), was associated with a particular 'lower' middle classness which stereotypically let itself be illustrated by a low level of education, aggressive behaviour and being ill-adjusted to big citylife. ${ }^{19}$ The ideal transformation was envisioned as one where not just the body went through a metamorphosis that brought it increasingly closer to the desired 'ideal type' but also, in tandem to this, that by means of education (English language and various certifications in the field of personal training, diets and new exercise routines) and the daily interaction with clients, a closer match would emerge between the body and what it was imagined to stand for in terms of professionalism and success. However, faced with the high cost of building and maintaining their bodies, trainers would often have to 'make sacrifices' and would be forced to accept jobs outside the gym such as that of bouncer at a club or bar. While still operating in a decidedly middle-class environment, no longer would their muscular bodies be the source of admiration of (and information for) clients, instead their relatively 'lower' middle-class status would be highlighted and associated with an aggressive masculinity which in turn would be informed by presumptions about a provincial/rural background. ${ }^{20}$

\section{Clients, professionalism and changing (urban) India}

Ratish Khanna, one of the gym's clients whom we met earlier, would frequently visit the above-mentioned clubs and bars which for him was part of the lifestyle of a young urban upper-middle class Indian. Now in his twenties he would be quite frank about how overweight 
he had been as a youngster. His immediate goal now was simply 'to get bigger', something to which he would sometimes add: 'huge', and also 'drier', meaning a lower fat content making his muscles and veins more visible, and for which he was considering growth hormones and/or steroids. While he believed a 'fit' body would help him in his search for a suitable managerial position with an international hotel chain, his story also betrayed body image insecurities that were the product of a personal history with obesity. Traditions and customs that once provided a clear route in life - as was the case with for instance arranged marriage (Baas 2009) - can no longer do so in the straightforward manner they once did. As Crossley (2006: 22) argues, drawing upon Anthony Giddens (1991, 1992), individuals increasingly embark on their own identity-making projects in which the body plays a crucial role. I would suggest that Foucault's take on reflexive embodiment could be folded into the notion of (bodily) 'self-making' here. The onslaught of modernity and the dwindling importance of socio-cultural factors and boundaries that shape self-making projects inherently produce the kind of reflexivity and internalization of the gaze of others that is 'powerful' enough to trigger the (bodily) self-policing/disciplining that Foucault $(1978,1979)$ suggests.

The kind of self-making that a magazine like Men's Health promotes revolves around the interplay of, indeed, internalizing the gaze of others (and thus self-disciplining, moulding oneself into the required/desired shape), yet it is also guided by a process which is encrusted with notions of 'newness', in tune and able to deal with a rapidly changing society. The same issue of Men's Health as the one this article opened with also features an article with the header 'Surprising Superphysiques'. Titled 'The Software Engineer With Hardcore Abs', its subtitle reads: 'This Bengaluru-based IT expert proves how focused training and willpower can transform into a chiselled core' (August 2013: 52). Describing his transformation from 120 to $81 \mathrm{~kg}$, Mayank Goswami (31) explains how he works out at Snap Fitness which is open 24-hours per day. 'Even when I get held up in meetings till 10 or 12 at night, I still make it a point to head to the gym' (p. 53). Virtually every edition features one or more comparable narrations of self-transformation in relation to dealing with a demanding job, stress, professionalism, as well as a busy social/family life. ${ }^{21}$ In line with this, the July 2013 issue presents 32-year-old Rakesh Badola who is an associate director with the food and beverages department of the Hyatt Regency in New Delhi. 'In the service industry, you want people to believe in the importance of well-being and fitness. No one takes a pot-bellied associate seriously. You need to be fit and presentable to convey your message,' he explains (p. 61). The February 2014 issue gives the stage to Sandeep Singh, a 28-year-old inspector with the Narcotics Control Bureau who with reference to this job says: 'I know one thing about myself: if I am knocked down by any adversity tomorrow, I am sure getting back up again. This resilience gives me an edge over others' (p. 61).

Aforementioned examples from Men's Health further underline that the objectification of the (Indian) male body in terms of an easily recognizable lean, muscular ideal does not only narrate easily 'quantifiable' notions of health and fitness but is in fact layered with a more complex interplay of associations. While personal and career related ambitions and notions of professionalism are communicated through the 'ideal type' body, this appears to stand in direct relation to ideas of coping with emerging consumer culture, globalization and the manifold challenges rapidly transforming cities bring with them as well. The gym trainer (whether 'floor' or 'personal') could be thought of as a broker in bodily capital in this regard, yet considering the middle-class context in and through which the idealized form is produced it is also clear that this bodily capital cannot completely make up for a lack in social capital. As such the 'ideal type' male body allows for a critical reflection on a number of intersecting debates that all have the question of socio-economic change in urban India at its heart. 


\section{Conclusion}

In the second half of 2013 the Hindustan Times ran a 'Get Healthy, Delhi' campaign in which ostensibly 'ordinary' Delhiites featured who had taken the pledge to get fit. On Saturday 12 October 2013 the paper ran a large article titled 'Kisme Kitna Hai Dum' (roughly: Who Is The Strongest?) on two businessmen who accordingly 'say their biggest weakness is food' and were pitted against each other in a face-off to see whoever could lose more fat. Accompanied by a set of jovial pictures the battle is a good-natured one yet touches upon a fast growing problem in India: obesity and associated problems such as diabetes and hypertension. The two businessmen, one who even hails from Kalkaji, a nearby area in South Delhi, are in many ways interchangeable with many of the male clients who would frequent the gym I conducted fieldwork in. Arriving throughout the morning, the 'valet parking' outside taking care of their vehicles, workouts would regularly be interrupted by calls, which they would answer on one of their multiple cell phones. It was up to the floor trainers to come up with a workout for the day often specifically tuned to one or two body-parts. Life was hectic and time short; most would be in 'construction' and spend the bulk of their day stuck in snailpace traffic from building-site to building-site. It is of course this dilemma that magazines such as Men's Health also tap into when they discuss the benefits of a lean, muscular body. Ultimately, however, this body is an 'ideal type'. For by far the majority of men in urban India the challenge will be exactly as the one so jovially illustrated by the Hindustan Times: reducing fat levels and thus potentially avoiding certain serious ailments.

This article gave the floor to the 'new Indian male', one who is not only synonymous with a lean, muscular 'ideal type' bodily physique but whose body, in tune with a changing socio-economic climate, resonates with notions of success, professionalism and being able to deal with the onslaught of consumerism, materialism and globalization. Ubiquitously present in public space and popular culture this body often gets inserted into typically 'Indian' settings and contexts yet it cannot be denied that through the thin layer of veneer shimmers a globalized ideal. In that sense it is perhaps not surprising that when Men's Health first appeared in India, as Jamal Shaikh explained, people were doubtful if the cover model was actually Indian (author's interview 07 February 2014). While this was partly about the disbelief that 'Indians can have abs too!', it also reveals that for middle-class men in India this was already a widely recognizable 'ideal type'.

However, while the 'new Indian male' with its aesthetically pleasing 'ideal type' body may at first glance simply reflect globalized notions of attractiveness, as an exploration of the Indian edition of Men's Health also revealed this body stands in direct relation to notions of professionalism and success. While the body itself is pitted as a piece of work and as an accomplishment, the result of hard work and dedication, it resonates with ideals of selfmaking which in turn are fuelled by changing ideas of work and education with a focus on merit as opposed to family and community ties (e.g. Baas 2009; Upadhya and Vasavi 2008). As such a new kind of 'ideal type' masculinity emerges which unites bodily ideals with a highly idealized urban lifestyle that the body also inherently reflects. Yet planting this body firmly with his feet on the ground, or the gym floor for that matter, also reveals the impossibilities of the idealized reality this body conjures. For the trainers and clients of the small neighbourhood I conducted fieldwork in the challenge is not just their own body but also very much the wider context in which their lives take shape. 


\section{Notes}

1 Besides, Kerala kalaripayattu is practised in adjoining areas of Tamil Nadu. Originally it was also practised in Tulunadu (a Tulu-speaking region) what is now part of the state of Karnataka.

2 Pehlwani is a form of South Asian wrestling sometimes also referred to as kusti. In order to distinguish it from the western/Olympic variety of wrestling I will refer to this particular type as pehlwan wrestling.

3 For a more extensive discussion on this, see Roland Robertson (1995).

4 'Lean and muscular' should be thought of as a shorthand for a variety of body types which could be grouped under the same header here. Leanness refers most of all to low body-fat, as such not only enhancing the visibility of various muscles but also producing a much desired veininess, making veins clearly visible even when not working-out. Muscularity is not only a question of size but also of proportion. In that sense the ideal clearly builds upon a bodybuilding-ideal yet tends to stay away from the massiveness which is desired to compete in this sport.

5 Glassner takes inspiration from Baudrillard (1987: 70-72) here.

6 This fieldwork was part of a larger project of which the principal aim was to investigate so-called 'new middle class professionals', people who have found employment in professional categories that emerged out of recent economic growth in India. Besides fitness trainers, research was also conducted among coffee baristas and people employed in high-end malls. I thank Nalanda University (Rajgir) for providing me with a fellowship to conduct this research.

7 Colloquially this movie is usually referred to as 'Ram Leela'.

8 The Men's Health edition of September 2013 even dedicated a three-page article to how the actor had built his body for the role of Milkha Singh. However, the article was critical in tone, raising the question 'Should you get a body like Farhan Akhtar?' (p. 53) and cautioning that one should '[b] eware of six-hour training regimes without proper guidance on a daily basis.' (p. 55). As advice the article mainly reflects common sense yet also hints at the problem of how highly specific training routines that actors follow under strict guidance for particular roles have a tendency to gain popularity in a relatively short time. Several fitness trainers I interviewed also mentioned this during interviews and how it worried them what kind of risks especially youngsters were willing to take in terms of diets and 'supplements' in order to achieve a particular bodily ideal portrayed in the movies.

9 A romantic-reincarnation movie set in the 1970s and featuring more than forty-two well-known Bollywood stars.

10 This does not mean that it was the first movie in which an actor had gone bare-chested; Salman Khan had already appeared bare-chested in Maine Pyar Kya, a movie that came out in 1989. Although his body is clearly 'muscular' it does not come close to the sharply defined lean muscular one that Shahrukh Khan would introduce with Om Shanti Om in 2007. Trainers I interviewed would sometimes also refer to older Bollywood stars such as Dara Singh (1928-2012), a pehlwan wrestler who initially started as stunt film actor and then went on to play the lead role in a number of productions.

11 The Tamil movie Ghajini was itself an adaptation of the Hollywood production Mememto (2000). The story centres on a man who is trying to find out who murdered his wife and who suffers from anterograde amnesia, impairing him to store new memories.

12 This movie was reissued as Like Stars on Earth. Aamir Khan plays an art teacher who takes a special interest in a talented eight-year-old boy who excels in art but has poor school results due to dyslexia.

13 Although the website does not say so explicitly, it appears that JustDial.com maximizes its search result to 500 spread over twenty pages of twenty-five results each.

14 'Snap Fitness India to raise \$10 million to fund expansion,' Business Standard, 30 May 2013. Available online.

15 According to figures provided by Index Mundi, India's economic growth shot-up to 8.3 per cent in 2003 from 4.3 per cent the previous year. The following year (2004) witnessed somewhat of a decline in terms of growth (6.2 per cent) but in subsequent years it picked up reaching a high point in 2010 with 10.1 per cent. In more recent years, however, Indian economic growth has stunted: in 2011 it was 6.8 per cent, for 20126.5 per cent was reported, and in 2013 it was only 4.4 per cent. Source: www. indexmundi.com $/ \mathrm{g} / \mathrm{g} \cdot \mathrm{aspx} ? \mathrm{v}=66 \& \mathrm{c}=\mathrm{in} \& \mathrm{l}=\mathrm{en}$ (accessed $17 \mathrm{June} 2014$ ). Disappointing economic figures are generally assumed to have been a major factor in the Congress Party's dramatic electoral loss in 2014, bringing the BJP back in power with a landslide victory.

16 See Upadhya (2011) for a useful discussion of the distinction between old-and-new and its implications.

17 Modern-day workout routines with weights often have their roots in more ancient 'non-western' ones. For instance, kettle bell swinging which has been reintroduced in many modern gyms in the 
last few years draws heavily on techniques used by Russian farmers. Pehlwan wrestlers use a similar technique of swinging or juggling for their training making use of meels or clubs. These meels actually are of Persian origin though they were also used in ancient Egypt.

18 GK=Greater Kailash, though locally never pronounced as such. The same goes for nearby CR Park, which stands for Chitaranjan Park, but which is colloquially referred to as CR Park.

19 For a far more extensive exploration of the transition from small town/village life to the "big city', see Harjant S. Gill's (2012) excellent (unpublished) dissertation titled Becoming Men in a Modern City: Masculinity, Migration and Globalization in North India. Washington, DC: The American University. Press

20 A recent article in British tabloid the Daily Star titled 'Welcome to the small village that is the bodybuilding capital of the world' (29 June 2014) describes a village in North India where 90 per cent of the men between 18 and 55 work as bouncers and security guards in New Delhi. The accompanying photos and video show various workout techniques which, making use of alternative/ limited means (for instance using the tyres of a tractor or a motorcycle for weight lifting), as well as recommended diets (' $[\ldots]$ about 3-4 litres of milk, one dozen bananas and half a kilo of cheeku [...]'), clearly drawing inspiration from pehlwan wrestling.

21 Although for the purpose of this research a more extensive and comparative content analysis of Men's Health magazines around the world was not made, it needs to be noted that in the period of writing this article (June-July 2014) American, British, Dutch and Singaporean editions did not discuss featured models in relation to their jobs and/or issues related to professionalism and career.

\section{References}

Alter, J. S. (1992) The Wrestler's Body. Identity and Ideology in North India, Berkeley, CA: University of California Press.

Alter, J. S. (1994a) 'Somatic Nationalism: Indian Wrestling and Militant Hinduism', Modern Asian Studies, 28 (3): 557-588.

Alter, J. S. (1994b) 'Celibacy, Sexuality, and the Transformation of Gender into Nationalism in North India', The Journal of Asian Studies, 53 (1): 45-66.

Alter, J. S. (1995) 'The Celibate Wrestler: Sexual Chaos, Embodied Balance and Competitive Politics in North India', Contributions to Indian Sociology, 29 (1-2): 109-131.

Alter, J. S. (2011) Moral Materialism. Sex and Masculinity in Modern India, New Delhi: Penguin Books.

Anand, D. (2005) 'The Violence of Security: Hindu Nationalism and the Politics of Representing "the Muslim" as a Danger', The Round Table, 94 (379): 203-215.

Anand, D. (2007) 'Anxious Sexualities: Masculinity, Nationalism and Violence', British Journal of Politics and International Relations, 9: 257-269.

Anand, D. (2008) 'Porno-Nationalism and the Male Subject: An Ethnography of Hindu Nationalist Imagination in India', in J. Parpart and M. Zalewski (eds), Rethinking the 'Man' Question in International Politics, London: Zed.

Andrews, D. L., C. Batts, and M. Silk (2013) 'Sport, Glocalization and the New Indian Middle Class', International Journal of Cultural Studies, 17 (3), 259-276.

Baas, M. (2009) 'The IT Caste: Love and Arranged Marriages in the IT industry', South Asia, 32 (2): 285-307.

Baas, M. (2010) Imagined Mobility. Migration and Transnationalism among Indian Students in Australia. London: Anthem Press.

Baudrillard, J. (1987) The Ecstasy of Communication, New York: Semiotext(e) / Foreign Agents.

Baviskar, A. and R. Ray (eds) (2011) Elite and Everyman. The Cultural Politics of the Indian Middle Classes, New Delhi: Routledge.

Bourdieu, P. (1984) Distinction: A Social Critique of the Judgement of Taste, Cambridge, MA: Harvard University Press.

Bourdieu, P. (2001) Masculine Domination, Cambridge: Polity Press.

Casper, M. J. and L. J. Moore (2009) Missing Bodies: The Politics of Visibility, New York: New York University Press.

Crossley, N. (2006) Reflexive Embodiment in Contemporary Society, Milton Keynes: Open University Press.

De Neve, G. (2004) 'The Workplace and the Neighbourhood: Locating Masculinities in the South Indian Textile Industry', in R. Chopra, C. Osella, and F. Osella (eds), South Asian Masculinities. Context of Change, Sites of Continuity, New Delhi: Women Unlimited, 60-95.

Fernandes, L. (2006) India's New Middle Class. Democratic Politics in an Era of Economic Reform, Minneapolis, MN: University of Minnesota Press. 
Fernandes, L. (2011) 'Hegemony and Inequality: Theoretical Reflections on India's “New” Middle Class', in A. Baviskar, and R. Ray (eds), Elite and Everyman: The Cultural Politics of the Indian Middle Classes, 58-82, New Delhi: Routledge.

Foucault, M. (1978 [2004]) Security, Territory, Population: Lectures at the Collège De France, 1977-1978, New York: Palgrave.

Foucault, M. (1979 [2004]) The Birth of Biopolitics: Lectures at the Collège de France, 1978-1979, New York: Palgrave.

Ganguly-Scrase, R. and T. Scrase (2009) Globalisation and the Middle Classes in India. The Social and Cultural Impact of Neo-liberal Reforms, London and New York: Routledge.

Ghosh, S. (2009) 'Case Study 3. Modern Youth and Embodied Work: A Study of Kolkata', in P. R. DeSouza, S. Kumar, and S. Shastri (eds), Indian Youth in a Transforming World: Attitudes and Perceptions, London: Sage, 38-39.

Giddens, A. (1991) Modernity and Self-Identity. Self and Society in the Late Modern Age, Stanford, CA: Stanford University Press.

Giddens, A. (1992) The Transformation of Intimacy: Sexuality, Love and Eroticism in Modern Societies, Oxford: Polity Press.

Glassner, B. 1988 [1989] Bodies: Why We Look the Way We Do (and How We Feel About It), New York: Putnam.

Hansen, T. B. (1996) 'Recuperating Masculinity: Hindu Nationalism, Violence and the Exorcism of the Muslim “Other”, Critique of Anthropology, 16 (2): 137-172.

Jaffrelot, C. and P. Van der Veer (eds) (2008) Patterns of Middle Class Consumption in India and China, London: Sage.

Jain, K. (2001) 'Muscularity and its Ramifications: Mimetic Male Bodies in Indian Mass Culture', South Asia: Journal of South Asian Studies, 24: 197-224.

Jeffrey, C., P. Jeffery, and R. Jeffery (2008) Degrees without Freedom. Education, Masculinities and Unemployment in North India, Stanford, CA: Stanford University Press.

McDonald, I. (2007) 'Bodily Practice, Performance Art, Competitive Sport: A Critique of Kalarippayattum, the Martial Art of Kerala', Contributions to Indian Sociology, 41: 143-168.

McLain, K. (2009) India's Immortal Comic Books: Gods, Kings and Other Heroes, Bloomington, IN: Indiana University Press.

Mills, J. M. (2005) Subaltern Sports. Politics and Sports in South Asia, London: Anthem Press.

Monaghan, L. F. (2002a) 'Regulating "Unruly" Bodies: Work Tasks, Conflict and Violence in Britain's Night-Time Economy', The British Journal of Sociology, 53 (3): 403-429.

Monaghan, L .F. (2002b) 'Hard Men, Shop Boys and Others: Embodying Competence in a Masculinist Occupation', The Sociological Review 50 (3): 334-355.

Nijman, J. (2006) 'Mumbai’s Mysterious Middle Classes', International Journal of Urban and Regional Research, 30 (4): 758-775.

Osella, C. and F. Osella (2006) Men and Masculinities in South India, London: Anthem Press.

Osella, C., F. Osella, and R. Chopra (2004) 'Introduction: Towards a More Nuanced Approach to Masculinity, Towards a Richer Understanding of South Asian Men', in R. Chopra. C. Osella, and F. Osella (eds) South Asian Masculinities. Context of Change, Sites of Continuity, New Delhi: Women Unlimited, 1-33.

Robertson, R. (1995) 'Glocalization: Time-Space and Homogeneity-Heterogeneity', in M. Featherstone, S. Lash and R. Robertson (eds), Global Modernities, London: Sage Publications.

Rogers, M. (2008) 'Modernity, "Authenticity" and Ambivalence: Subaltern Masculinities on a South Indian College Campus', Journal of the Royal Anthropological Institute, 14 (1): 79-96.

Sridharan, E. (2011) 'The Growth and Sectoral Composition of India's Middle Classes: Their Impact on the Politics of Economic Liberalization', in A. Baviskar and R. Ray (eds), Elite and Everyman. The Cultural Politics of the Indian Middle Classes, 27-57, New Delhi: Routledge.

Srinivas, D. (2010) History, Masculinities and the Amar Chitra Katha, New Delhi: Routledge India.

Upadhya, C. (2011) 'Software and the "New" Middle Class in the "New India", in A. Baviskar and R. Ray (eds) Elite and Everyman: The Cultural Politics of the Indian Middle Class, New Delhi: Routledge, 167-192.

Upadhya, C. and A. R. Vasavi (eds) (2008) In an Outpost of the Global Economy: Work and Workers in India's Information Technology Industry, New Delhi: Routledge.

Wacquant, L. (2003) Body and Soul: Notebooks of an Apprentice Boxer, Oxford: Oxford University Press.

Waskul, D. D. and P. Vannini (2006) Body/Embodiment: Symbolic Interaction and the Sociology of the Body, Aldershot: Ashgate.

Winlow, S. (2001) Badfellas: Crime, Tradition and New Masculinities, London: Bloomsbury Academic.

Zarilli, P. B. (2000) When the Body Becomes All Eyes: Paradigms, Discourses and Practices of Power in Kalarippayattu, a South Indian Martial Art. Oxford: Oxford University Press. 


\title{
31 \\ CHANGING FOOD HABITS IN CONTEMPORARY INDIA Discourses and practices from the middle
classes in Chennai (Tamil Nadu)
}

\author{
Michaël Bruckert
}

\section{Introduction}

In 2014, while campaigning for the general elections, Narendra Modi, the candidate of the Bharatiya Janata Party ${ }^{1}$ (who was elected as the fifteenth Prime Minister of India on 16 May), blamed the ruling Congress Party for having orchestrated a 'pink revolution', namely a boom in meat production epitomised by India's new position as the largest beef exporter in the world. ${ }^{2}$ Such an attack may sound puzzling, uttered by a politician who wants to put India on the tracks of prosperity with the help of private investments and the invisible hand of the market. But Modi is a Hindu nationalist, inspired by an ideological movement well known for its anti-Muslim and anti-cow slaughter rhetoric and activism. ${ }^{3}$

This apparent paradox between a conservative discourse on food and a call for economic modernity sheds light on the complex and negotiated meanings of food in present-day India. Mass production and consumption, brought about by rising incomes, commodification of goods and services and globalisation - namely the worldwide expansion of flows of people, capital, products and imaginaries - are indeed supposed to reconfigure, if not erode the food habits of Indians, especially those who claim to belong to the emerging 'middle classes'. It is for instance alleged by some scholars that, in a process termed 'nutrition transition' (Popkin 1993, Shetty 2002), 'diet transition' (Pingali 2006) or 'food transition' (Bengoa 2001) economic development would result in an increasing consumption of meat. In this context, how will the Holy Cow revered by Modi and millions of Hindus ${ }^{4}$ encounter the 'global steak' allegedly diffused by the forces of this globalisation that India is now increasingly embracing? In the wake of global interconnectedness, urbanisation and economic growth, how will socio-economic changes affect practices and representations related to food in a country where the diet has long been a bio-moral marker of the position in the socio-cosmic order? 
In India, food patterns differ according to region, religion, caste, financial means, habitat (rural or urban) and also to the age and gender of the individuals. Portraying changes on the national scale within such a fragmented mosaic is an arduous, if not an impossible, task. I will therefore address the changing food habits in contemporary India through the particular case of Chennai (formerly Madras). The capital of Tamil Nadu, also the fourth most populated city in India (about 6 million inhabitants in 2011), is characterised by the diversity of its population in terms of religions (Hinduism, Islam and Christianity), castes, occupations (from white-collar to daily workers) and revenues. It therefore allows a comprehensive overview of food change within a circumscribed space. More specifically, the population of the city (mostly the Tamil people) is generally defined as conservative in terms of food habits (Osella and Osella 2008: 196). According to Patricia Caplan (2008: 127), Tamils consume a very small amount of meat and fish, even those who do not claim to be vegetarian. But the people of Chennai are gradually encountering global flows of ideas, people and goods, in a state where social and economic indicators are, in broad terms, higher than those at the national level. Indeed, the development of computer services and other outsourcing industries in the city has triggered the growth of a new middle class of engineers and entrepreneurs, beside an older middle class of bureaucrats, teachers, physicians or lawyers (Fuller and Narasimhan 2007). These middle classes (defined by the National Council of Applied Economic Research as having an annual household income between Rs. 200,000 and $1,000,000^{5}$ ), will be the main focus of this chapter, as their purchasing power and cultural influence may set the trend for food change in the years and decades to come.

This apparent contrast between a cultural conservatism and a socio-economic boom is a factor that makes Chennai a relevant place to study food change. With the empirical findings from my fieldwork in the city in 2012 and 2013 as a base, I will attempt to define the complex ways in which food patterns are reconfigured, neutralising the basic opposition of modernity versus tradition. As my investigations and interviews mainly centred on meat production, distribution and consumption, this chapter will place particular emphasis on the issue of flesh food. The first section explores the notion of food transition. Drawing on statistical data and on second-hand sources, it questions the relevance of this model as many indicators reveal the non-achievement of this transition in the case of India. The second briefly exposes the theoretical ethos of food in the Indian context, relating it to conceptions about the social hierarchy and the individual body. The third section calls for an analysis that goes beyond the mere economic approach, putting forward the need to consider a cultural economy of food: although the (so-called) rational choices are made under financial constraint, they are also always embedded in moral values. This section therefore portrays specific modes of selecting, provisioning, transforming and consuming food that highlight both the persistence of longstanding habits and the emergence of new practices and discourses in the city of Chennai. It also investigates the restrictions limiting meat consumption. The last section argues that, for the urban middle classes, the experience of eating out can pave the way to food change. Although mirroring domestic consumption, it partially recasts notions of purity and commensality.

\section{Discussing food transition in contemporary India}

\section{Definition of food transition}

The notion of 'food transition' (Bengoa 2001) theorises a universal pattern of food change. It derives from the model of 'nutrition transition' that was widely popularised by Barry M. 
Popkin in the early 1990s. In his article entitled 'Nutritional patterns and transitions', the nutritionist argues that 'the pace of dietary change has accelerated to varying degrees in different regions of the world' (Popkin 1993: 138). The author explains later that 'modern societies seem to be converging on a diet high in saturated fats, sugar and refined foods and low in fibre' (Popkin 2003: 581). Drawing on these analyses, the economist Prabhu Pingali specifies that 'rapid economic and income growth, urbanization, and globalization are leading to a dramatic shift of Asian diets away from staples and increasingly towards livestock and dairy products, vegetables and fruit, and fats and oils' (Pingali 2006: 281). It is usually admitted that the transition is threefold: first, a higher purchasing power combined with better agricultural yields prompts a rise in cereal consumption, especially rice and wheat, at the expense of traditional cereals such as millets or sorghum. In a second step, the demand for grains decreases while the consumption of animal products (including meat, fish, eggs and dairy products), oil seeds, sugar, vegetables and fruits is increasing, so that protein and fat intakes are rising. Third, health-related awareness tends to mitigate these trends (Popkin 2003).

\section{Food transition in India: changes that match the definition only partially}

On the Indian scale, some of the mechanisms depicted by nutritionists have been confirmed by economic and statistical studies. Prakash S. Shetty (2002) argues that milk, meat and oil consumption are indeed on the rise in the country. In his paper, he points out a causal link between what he calls an 'inculcation of imbalanced and calorically excessive Western-type diets existing globally' (2002: 181) and the growing prevalence of metabolic disorders such as diabetes, cardiovascular diseases and obesity in the country. The 2009-2010 Nutritional Intake and Household Consumption Reports by the National Sample Survey Office of the Indian Government (NSSO 2012a, 2012b) state that the share of calories derived from cereals is decreasing. It is still higher in rural areas and negatively correlated to the economic status of the households: the upper-income urban sections have a more diversified diet. The NSSO data also shows that the average protein intake per person is the same in the rural and urban areas but that it increases with income. These trends suggest that the country is today going through the second stage of the food transition.

Some recent studies, however, cast doubt upon Shetty's assertions. Angus Deaton and Jean Drèze have argued that, even though there is 'evidence (...) of a sustained decline in per capita calorie consumption during the last 25 years or so' (2009: 62) and an increase in fat consumption, the total intake of proteins (vegetal and animal) and other nutrients is diminishing. Their analyses contradict the model exposed above. Quoting Deaton and Drèze, Frédéric Landy aptly notices that 'the second stage of food transition seems to have started in India before the first stage has been completed' (2009b: 60): per capita cereal consumption is already decreasing while meat, fish and eggs still account for only 6 per cent of protein in rural India and for 8 per cent in urban India. These low animal protein intakes are not compensated by vegetal protein: the NSSO data reveal that, while meat, fish, eggs and dairy products intake is hardly increasing, pulse consumption is declining. Besides, meat consumption is high in states where milk product consumption is low, and vice versa. Due to this low protein intake and despite rising incomes, India still displays one of the highest rates of child malnutrition and anaemia in the world (Sébastia, et al., forthcoming).

There are certainly distinctive features in the way India is experiencing food change today. In spite of globalisation and economic growth, food patterns are not converging towards 
what has sometimes been termed a 'westernisation' of diets, to use Shetty's terminology. With an annual consumption of only $5 \mathrm{~kg}$ of meat per person, whereas the world average comes close to $50 \mathrm{~kg}$, Indians seem to resist the too rapidly predicted modification of their eating habits.

In the state of Tamil Nadu, long-term changes in food habits have been partly documented. The substitution of what is called 'coarse grains' (i.e. finger millet, pearl millet, sorghum, etc.) in favour of rice in Chennai accelerated during the nineteenth century. At that time, highly polished rice imported from Burma by the British flooded the city markets (Sébastia 2013) and in 1900, the parboiling of this cereal was the most thriving industry of the city (Lewandowski 1975: 353). Barbara Harriss-White, in her accounts of public nutrition policies in Tamil Nadu in the late 1970s notices a 'long-term shift in diet against coarse grains and towards rice' (2004: 53). She also argues that in the villages where she carried out her investigations, per capita protein consumption has remained low and almost constant between the late 1970s and the early 2000s (Harriss-White 2004: 59), while calorie consumption has hardly risen (Harriss-White 2004: 66). She concludes that, in Tamil $\mathrm{Nadu}$, 'nutrition transition has resulted in increasingly differentiated nutritional behaviour' (Harriss-White 2004: 66): only better-off households can afford a more diversified diet.

While Harriss-White suggests that revenue inequality is the main reason for this dietary differentiation, one may advocate with Landy that 'cultural density' (2009b: 61) could be another, and perhaps the main factor that makes India an exception to the food transition model. Quantitative data, in terms of economic and nutritional values, do not permit the exploration of the non-market relationships in which people indulge with their food. Incomes not only pertain to purchasing power, but to ways of life as well. Moral values matter as food is always socially and symbolically constructed. What the 'food transition' approach actually neglects in the Indian context is the influence of the local ethos over the representations and practices.

\section{The theoretical ethos of food on India}

Food as a cultural practice or as a 'total social fact' has been thoroughly argued by anthropologists (Douglas 1972; Goody 1982; Lévi-Strauss 1983, Sahlins 1976, to name a few). India is not an exception to this rule. R.S. Khare, who abundantly addressed this issue (1976a, 1976b, 1992), defines food in the Indian context as 'an item that receives a pervasive cultural direction' (Khare and Rao 1986: 160). Arjun Appadurai refers to the 'density, scope, and taxonomic complexity of Hindu symbolic thought in regard to food' (Appadurai 1981: 496).

In India, the dominating ethos of food is set by both Hinduism and a discourse about the physical properties of the food material (including a classification of species). Thus, food practices relate mainly to hierarchy but also to conceptions about the body, these two considerations being intermingled. On the one hand, food practices are embedded in a socio-cosmological dimension: food stands as a marker of caste as it determines and reflects one's relative place in a stratification defined by rules of social and symbolic purity. Food prescriptions and proscriptions operate differently according to the position in this hierarchy: the higher the status, the stricter the observances. To put it briefly, four observances are essential to the maintenance of relative purity: what kind of food is eaten (given that food items are ranked on a purity scale); how it is cooked; who cooks it; with whom it is eaten. On the other hand, food has a medical dimension as it is supposed to prevent, cure or cause diseases. In short, food, which is incorporated as a bio-moral aggregate (Appadurai 1981: 507), 
participates in stabilising the place of the eater within the socio-cosmic order as well as his/ her physical and psychological conditions. However, this food ethos is theoretical and often contradicted by reality. It applies mostly to Hindus ${ }^{6}$ and the rules are more rigid for the orthodox upper castes. Yet, these conceptions pervade and underlie most of the attitudes pertaining to the ways food is handled and consumed in India. They shape the significances bestowed on food and create obstacles to food change. Codifications in terms of purity and health entail a feeling of 'neophobia': food that is symbolically unacceptable and thought of as 'impure' is perceived as a potential danger (Osella and Osella 2008: 192). For orthodox Brahmans, the restrictions with regard to food transactions confine proper food intake to the hearth of the home.

To grasp the complexity which emerges from the Indian food scene, it is necessary to go beyond two reductionisms: the economic and nutritionist approach that considers, through the theory of food transition, that every country goes through a similar pattern of food change, and the essentialist approach that portrays Indian food as totally imbued by its ethos since ancient times. Therefore, I propose here an approach in terms of cultural economy, focused on the ascription of meaning in the acts of buying, transforming, sharing and eating food in present-day India.

\section{A cultural economy of food in Chennai}

\section{Food change in urban India in second-hand sources}

The urban middle classes have concentrated the attention of scholars working on food change in India for the past ten years. The emergence of national, regional and ethnic cuisines (Appadurai 1988; Nandy 2004), the arrival of new products (Baviskar 2012; Dittrich 2009; Donner 2011; Srinivas 2007), the evolution of the retailing sector (Dittrich 2009; Srinivas 2007) and the mushrooming of street food stalls (Mukhopadhyay 2004) and restaurants (Appadurai 1988; Conlon 1995; Quien 2007; Ray and Srinivas 2012; Siegel 2010; Srinivas 2002,2007 ) have been extensively investigated. In a nutshell, food has been mostly described as a marker for middle-class identity (Donner 2011; Srinivas 2007). Some authors emphasise the rapid changes that urban food patterns undergo in contemporary India. Arguing that food choice is increasingly individual, they consider eating as mostly a practice of conspicuous consumption, in a strategy of class distinction (Dittrich 2009; Dolphijn 2006; Mukhopadhyay 2004). Others who are more cautious state that Western or cosmopolitan products or diets are indeed entering the Indian food culture but are still negotiated (appropriated, adapted or discarded), intersecting with vernacular categories (religion, caste, gender, kinship, etc.). Thus, Tulasi Srinivas tries to go beyond the apparent contradiction between 'gastronostalgia' and 'gastro-adventure', analysing these attitudes in Bangalore as two faces of the same 'cosmopolitan narrative' (Srinivas 2007: 100). In the same way, Henrike Donner (2011) explores the articulation between ethnicity and cosmopolitanism in Bengali middle classes, showing how these two values are mediated by mothers within the household.

\section{Chennai: a place of food conservatism?}

At first sight, food patterns in Chennai seem to bare the mark of conservatism. Most of the Chennai people still stick to a Tamil repertoire when eating at home. One Hindu couple told me that '(they) prefer Tamil kind of preparations only', a preference that can be generalised in most of the lower and middle classes. Similarly, a college administrator was proud to 
report that his wife sometimes tries new recipes, but 'only Tamil ones', he added when I asked more details about his wife's experiments. In both urban and rural Tamil Nadu, food intake is still mostly based on cereals: a standard meal cannot be imagined if not dominated by a large amount of white rice, drizzled by a dhal and campar (sambar, tamarind sauce) and accompanied by a pickle. The poor rarely enjoy more than this basic food. The working class may afford a variety of side dishes: stewed vegetables, fried green leaves, deep-fried pulse pancakes (appalam), tamarind gravies (kulampu), 'pepperwater' (racam) and curd or buttermilk (mor) to accompany the rice. For the middle classes, itli (idli, steamed cakes made of fermented rice-and-black gram batter) and tocai (dosa, thin pancakes made of the same batter) can also be cooked for breakfast or dinner. In non-vegetarian families, meat dishes such as spicy fried chicken or stewed lamb are served once or twice a week, mostly on Sundays. In fact, there is no striking difference between urban and rural people regarding the daily diet consumed at home. Rural populations have now adopted the food pattern of urban ones notably as they shifted from coarse grains to highly-valued rice. ${ }^{7}$ Thus, the centrality of rice remains unquestioned by Tamils, except by the elites who have resided abroad and claim a cosmopolitan way of life.

In cities, and particularly in Chennai, a better availability of foodstuffs and probably a certain taste for diversity, however, usually make the food choice wider than in villages. Various chutneys (made of onions, coriander, etc.) and gravies, uppuma (thick semolina porridge), omelettes, tocai stuffed with potatoes, north-Indian chapattis (wheat-made flat bread) and snacks such as chickpea-flour fritters (vatai) are added to the base described above. Milk, curd and ghee ${ }^{8}$ are surprisingly consumed far more in Chennai than in rural Tamil Nadu. Indeed, even though villagers possess cattle, they rarely drink or transform milk: agricultural labourers and farmers sell it to local cooperatives or to middlemen to get a substantial financial surplus.

\section{New equipment, new modes of provisioning, new foodstuffs and new habits}

According to studies conducted in other megacities such as Bangalore (Srinivas 2007), Hyderabad (Dittrich 2009), Kolkata (Donner 2011) or Pune (Baviskar 2012), Tamils from the urban middle classes appear to be particularly conservative. Nonetheless, food change in Chennai is a reality that should not be underestimated, as the city has experienced many evolutions of its foodscape in the recent years. In this regard, Patricia Caplan's accounts are path-breaking $(2001,2006,2008):^{9}$ she thoroughly describes the advent of processed and packaged food in the 1970s, the enlargement of the eating out scene in the 1980s and the development of supermarkets in the late 1990s. Indeed, a weaker connection with agriculture and a more extensive exposure to global material and immaterial flows, make urbanites with higher revenues less reluctant to let their diet evolve. Among other factors that encourage food change, space and time allotted to cooking are slightly less than in villages: kitchens are smaller and, in progressive families, women often work outside (see Sébastia in this volume), which affects cooking practices. Moreover, the urban context tends to erode the model of the joint family, where the husband's mother stands as the official cook and gradually teaches her daughter-in-law. It favours nuclear families where wives, especially those with higher education and outside employment, sometimes lack culinary know-how, while their husbands rarely enter the kitchen. These changes induce a shift and even a break in the transmission of cooking abilities. TV shows, cookbooks, lifestyle magazines, columns in daily papers and internet blogs provide an abundant array of Tamil, Indian or more cosmopolitan recipes, but few women from the middle classes claim to take inspiration from them. Domestic facilities 
have also evolved significantly, as electric grinders, pressure-cookers and refrigerators now equip many homes. Noticeably, ovens and microwave ovens are still confined to upper-class households as no dish from the Tamil repertoire needs baking or roasting. In upper-class and Westernised families, eating behaviour has begun to follow the 'process of civilisation' described by Elias (2000) as spoons tend to substitute for hands. Tables and chairs also tend to edge out mats and the cooking tasks are no longer undertaken on the floor but on an elevated counter top (Baviskar 2012). Whatever the economic background, stainless-steel or plastic plates have taken over from banana leaves.

Furthermore, new food products are entering the domestic space. In middle-class families, three main driving forces may account for this change. First, children, the preferential targets of TV advertisements, are the first actors by which change crosses the threshold of homes. Second, mothers, coping with the fast pace of urban life, more and more cook with ready-made preparations. Third, a growing number of adults are seeking healthy food to prevent or cure diseases caused by a sedentary life and an imbalanced diet. This demand for new foodstuffs is both fostered and met by the soaring of new modes of provisioning on national and international scales: new brands and products are distributed by the supermarkets and retail stores that are mushrooming throughout the city, offering 'a mark of modernity and cultural sophistication' (Osella 2008: 2). Since the economic liberalisation, begun in the 1990s, transnational companies have broken into the market and the national corporate sector has expanded. Products from Maggi, Coca-Cola or Kellogg have been available in Chennai for a long time (Caplan 2001). Indian distributors such as Reliance Fresh, More (Aditya Birla Group), Heritage Fresh, Oceanaa, Big Bazaar (Future Group), Spencer's and Nilgiri's 1905 have conquered the urban foodscape, supplying with a variety of references in two-storied air-conditioned buildings, mostly settled in the main avenues of the city's upmarket neighbourhoods. In these outlets, consumers escape the hardships of the city and make a choice among a broad variety of packaged products that they once considered as stale but now see as hygienic, easy-to-handle and high quality (Dittrich 2009: 273). Apart from this well-organised sector, many small supermarkets, sometimes state-run or owned by cooperatives, are flourishing. International operators such as Walmart, Carrefour, ${ }^{10}$ Tesco or Metro are, however, still not allowed to enter the retailing scene, and are confined to wholesale. As an exception, the France-based Auchan Group is operating in the retailing sector in Chennai under a franchise signed with the Landmark Group. Moreover, despite higher prices, small-scale grocery shops, valued for their proximity, are resisting the assault of these high-capital-input outlets. Besides, local pastry and bakery shops, sometimes borrowing European names ('French Loaf', 'La Chocolaterie', etc.), are thriving in Chennai, selling the usual puffs and English-style sponge cakes (made 'eggless' for vegetarians) with artificial fruit flavours, covered with a layer of cream and topped with shiny colours, and more recently viennoiseries and baguettes have appeared. These places usually sell take-away items but they increasingly put chairs and tables at the disposal of customers. Indeed, if the food eaten at home is only marginally affected by the new consumption patterns, food eaten out is often the frontrunner of modernisation, an issue which I shall get back to in the last section.

The recomposed retailing sector has also contributed to the recent success of products such as breakfast cereals, pastas, dehydrated soups, cake mixes, wholesome grains and flours (varieties of rice, millets, pulses and beans), a wide scope of dairy products (butter, fresh cream, yoghurt, processed cheese, paneer, etc.), 'exotic' condiments (mustard, mayonnaise, soy sauce, Mexican salsa, etc.) or sweet items (chocolate, jams, spreads, etc.). Some of these products escape the vernacular classification of foodstuffs, which actually makes them appear neutral in terms of symbolic purity. Many of them are popularised by TV commercials intended for children or mothers, and praising either their convenience, their novelty or their medical benefits. Indeed, 
the increasing prevalence of metabolic disorders among the middle classes of Chennai has created an interest in 'healthy food'. Whereas the market of organic products remains a very narrow niche, low-fat, low-sugar and wholesome food tend to occupy a growing stretch on the shelves, targeting those suffering from obesity, diabetes or cardiovascular diseases. Many brands available in supermarkets as well play the card of traditional knowledge, for instance selling ayurvedic purifying infusions or plant powders and extracts (from garlic, tulasi, ${ }^{11}$ nellikay, ${ }^{12}$ etc.). Meanwhile, imported olive oil, taking advantage of aggressive marketing and positive conceptions regarding its nutritional properties, is increasingly available but still is prohibitively expensive. Green tea sales are picking up, boosted by its alleged benefits to health. Health consciousness, together with higher purchasing power and advances in horticulture, has also made vegetables and fruits easily available and highly desirable. In Chennai, the socalled 'English' and hill-grown vegetables (carrots, cabbage, peas, etc.), which are profiting from improved transportation, have penetrated the market. The fruits on offer have also diversified. Apart from the common mangoes, bananas, papayas, watermelons and guavas, the consumption of which is on the rise, ${ }^{13}$ grapes have benefited from an increasing local production whereas Kashmir- and Himachal Pradesh-grown apples are still a luxury that many cannot afford. Moreover, strawberries, litchis, pears and mangosteens sometimes appear on the shelves of dedicated store ${ }^{14}$ that also sell freshly made drinks from their surplus fruits. In front of the big supermarkets of the city, the traditional sugar cane juice is now squeezed in neat huts flanked by boards displaying its therapeutic properties. Another newcomer has quickly conquered the appetite of the middle classes: steamed sweet corn, eaten as a gourmandise and for its claimed medicinal values, is sold in small paper cups by street vendors - an ironic turn of fate for maize, which used to be a staple in many regions of central India before the green revolution. The deep-seated belief in a strong relation between food and health is thus reinvested in retailing strategies.

Less healthy products such as snacks, sweets and drinks have experienced sky-rocketing growth as people, and especially the younger generation, become eager for their appealing taste. But it would be misleading to consider that the food sector in Chennai is invaded by faceless globalised capitalism as upmarket retail stores as well as informal vendors source both locally and globally. When returning from work or from school, it is common for men to grab freshlyfried samosas at the tea shop. Drinks and packaged food are manufactured by both foreign and national companies and local cottage industries hiring women on a caste or ethnic basis (Baviskar 2012; Srinivas 2007). Since the liberalisation of the economy, local retail shops have admittedly been flooded by a wide variety of industrial biscuits (Britannia, Oreo, etc.) with flavours referring to the Indian (mango) and the cosmopolitan (chocolate or vanilla) taste. But snacks and biscuits are also produced by hand by family-owned businesses and then sold to shops around the corner. On a single shelf at a grocery store, fussy consumers can for instance choose between banana chips, fried in coconut oil by a neighbouring craftsman, and packets from the US brand Lay's. Another consequence of economic liberalisation is the invasion for the past few decades of the Indian market by sodas (Caplan 2001). Referred to as 'cool drinks', they are served chilled-from-the-fridge to children, presented to guests or drunk with friends on the way back from college. Here again, the broad offer ranges from local to global, from the decades-old sparkling rose water served in returnable bottles to the ubiquitous cans of 7-Up. Transnational beverage companies are selling their own products or developing a new range adapted to local preferences. ${ }^{15}$

Many food items on sale at supermarkets do not actually reach the entire middle classes nor substitute for the daily meals. Breakfast cereals and energy drinks, for long heavily advertised (Caplan 2006: 2.19), are consumed mainly by children. Instant noodles and chicken sausages 
are eaten preferentially as snacks or by students living away from their families. Mostly, the novelties on offer illustrate the 'local refraction of global processes' that characterise the industrialised food chains (Morgan et al. 2006: 10). To save time, urban women from the middle classes rely more and more on ready-made Tamil preparations such as mixed spice powders, ginger-garlic paste and itli (idli) and tocai (dosa) fermented batter. Similarly, murukku (salty and spicy deep-fried dumplings) was usually hand-made, but its production tends to shift from the home to the factory. The demand for new foodstuffs is indeed mediated by local specificities. Some best-sellers in the West barely appear on the shelves in Chennai. Tin boxes, baby food in pots and frozen food do not succeed in the city for reasons of cost and preference mostly given for fresh products. If de-alcoholised wine is to be found in some supermarkets, alcohol production and sales are controlled exclusively by the state government. On each packaged product (even on bottles of water), a label indicates whether it is vegetarian or not, and meat is available only in a minority of Chennai's retail stores as its presence in fridges would deter vegetarians from shopping there.

\section{Meat in Chennai: a heavily regulated consumption}

Despite the changes noticed in the city, Chennai is not only a place of unleashed modernity and Westernisation. One specific feature of the Tamil diet, in both rural and urban contexts, is the very low consumption of meat that accounts for the low levels of protein intake mentioned in the first section. Meat in India is not endowed with the rather positive significances it has in other countries. Although economic and geographical factors obviously play a paramount role in limiting its consumption (more meat is consumed in cities due to higher incomes and availability), its status in Chennai is also defined by conceptions about culture, religion and health.

When served, meat is always a side dish, cereals remaining the staple food. The NSSO data show that, in 2009, more than 70 per cent of the people interviewed in Tamil Nadu declared themselves as having eaten meat during the past 30 days (NSSO 2012a), but all Tamils actually share a common vegetarian food repertoire (Caplan 2008: 127). Many people I met claimed to be 'both veg and non-veg', these two notions not being mutually exclusive for them. Even many of those who pretend to be keen meat-eaters reckon that they would become tired of eating flesh food daily. Moreover, for reasons of penance or purity, many Hindus still refrain from eating meat on 'auspicious days' (as often as two to three days per week for most of them), when visiting a major temple or preparing for a pilgrimage. 'I have something to pray for the god so I abstain from non-veg for the past two years,' a company chairman from Chennai told me, wondering how he would maintain his diet during his next business trip to China. A temporary state of ritual defilement, for instance after the death of a relative or during menstruation, also leads to meat avoidance. On a register of fasting, the majority of Tamil Christians follow a 40-day-Lent before Easter, during which they eschew meat and fish. Moreover, conceptions of the holiness of the cow or merely a family habit deter most of middle- and high-caste Hindus from eating beef, be it from cattle or buffalo. After coming to power in 2014, some leaders of the BJP pushed Modi to implement a total ban on cow slaughter throughout India. ${ }^{16}$ As Paul Robbins puts it, 'meat is a politically- and socially-contentious issue in India' (1994: 11). The taboo on beef has spread over the centuries towards certain Muslim communities that now regard this meat as a low-status food or abstain from it as a sign of respect towards Hindu feelings (Chigateri 2008: 18). Furthermore, health factors are often mentioned to justify a low consumption of animal flesh: meat, especially mutton and beef, is blamed for causing diseases such as 
hypercholesterolemia, diabetes, high blood pressure, and so on (see Sébastia in this volume). Many of my informants, mostly males ranging from lower- to upper-urban classes, reported that they stopped eating meat following their doctor's advice. These Western-influenced medical conceptions of food are articulated with more vernacular representations of its 'thermal qualities' (Eichinger Ferro-Luzzi 1975: 471). For instance, a person considering his/her body to be too hot will avoid chicken or lamb, both classified as heating. Other symbolic properties of meat make high consumption suspected of contributing to the development of peculiar physical and psychological characteristics such as an 'animal spirit', a violent character, a bad smell, pimples, and so on. Last, a new and more individualistic vegetarianism, sometimes claiming a Western influence, is emerging. Although often underpinned by a brahmanical ideology, it intermingles hygienic, moral and ritual concerns (Donner 2008; Quien 2007; Sébastia 2010). In some cases, a fleshless diet is promoted as a panacea against the evils of the modern world, such as metabolic diseases and relentless lust, as well as environmental damage, global warming, harmful behaviours towards animals, over-consumption and Americanisation of society.

Admittedly, there has been a surge in meat consumption over the past few decades (Robbins 1999). Chicken especially has benefited from the integration of its raising and the spatial concentration of its distribution. Broiler shops and non-vegetarian restaurants are spreading across Chennai. In a few supermarkets, marinated or ready-to-cook chilled chicken as well as frozen minced lamb are for sale. Some cosmopolitan young Brahmans move away from the ancestral vegetarianism of their parents. Numerous men indulge in meat-eating - notably when drinking alcohol - as a marker for virility, but practices regarding meat consumption hardly evolve. Meat is mostly bought from the 'wet market' - animals are slaughtered in the morning, carcasses are kept at ambient temperature and the flesh is sold the same day in open-air shops and bazaars. Heavy consumption of meat is still not a daily experience, even for the middle classes. Meat is rarely consumed more than twice a week, in portions usually not exceeding 50 grams. In addition to economic constraints, cultural and individual regulations account for the low level of protein intake evoked in the first section of this chapter and contradict the assumption that meat consumption is alleged to increase mechanically with economic development.

\section{Restaurants in Chennai: venues of food change and mirrors of domestic consumption}

While the domestic context gives a framework to regulate meat consumption, eating out often provides the opportunity to erode, refigure or transgress some of the cultural habits and purity rules. Numerous works have portrayed the specificities of eating in the public sphere, interrogating restaurants as loci for the discovery of new tastes relating to social differentiation and conspicuous consumption (Ashley et al. 2004; Beardsworth and Keil 1997; Bell and Valentine 1997; Warde and Martens 2000). In the specific Indian context, Appadurai has defined restaurants as 'arenas for the transcendence of ethnic difference and for the exploration of the culinary Other' (1988: 9). Arguments about the role of eating out as a main factor in food change in the country have been widely developed by Frank Conlon for Mumbai (Bombay) and Benjamin Siegel for Delhi. These two historians analyse public eating as a marker for class belonging and as a driving force of social change. For Conlon, restaurants 'reflect, permit, and promote the introduction of a wide variety of changes in modern Indian life' (1995: 91). Siegel depicts dining out as a 'primary method by which the city's denizens can embody both wealth and cosmopolitanism' (2010: 73). 


\section{Different places, different foods, different people}

Let me now turn to the public food sphere in Chennai. Venues for eating out actually cover a reality that ranges from 'loosely constrained' to 'highly structured' eating places (Beardsworth and Keil 1997: 121). A basic typology would differentiate several kinds of places:

- Street stalls offer a diversity of food, including north-Indian chaats (snacks) such as bhelpuri (puffed rice served with a sauce) or panipuri (small deep-fried bread), but as well spicy chickpea stew, steamed groundnuts, sliced fruits and fish curry served with itiyappam (steamed rice-made vermicelli cakes) or rice, mutton leg soup, or, more rarely, even fried beef.

- 'Messes', as they are called in Chennai, are basic restaurants open mostly for lunch, catering to the needs of male workers looking for a cheap meal. When they are nonvegetarian, they often serve offal (mutton legs, brain or liver).

- 'Fast-foods' are small restaurants that offer a variety of pre-cooked food, heated up on demand, such as fried rice, fried noodles or chicken 65 (chicken deep-fried in a variety of spices). These outlets sometimes sprawl onto the pavement and serve single dishes such as kebabs or greasy biryani. ${ }^{17}$ They are mostly frequented by students and single men.

- 'High-class restaurants', 'family restaurants' or 'hotels', many of them being 'pure vegetarian' (cuttu caivam), are of higher standard, usually with neatly tiled walls, a number of waiters and sometimes an air-conditioned zone. On the laminated menus, items are listed following a geographical or sometimes culinary classification (south Indian, north Indian, Chinese, Arabian, Chettinadu, ${ }^{18}$ tandoori, etc.). At noon, they are packed with political leaders and office employees, local or travelling on business; in the evening and during weekends, they welcome middle-class families.

- Western chains, advertised on TV, are enjoying increasing popularity among the affluent classes, with Pizza Hut and KFC mostly targeting college students attracted by 'modernity' while McDonald's, as everywhere else, tries to be regarded as a 'family restaurant'.

- Upper-scale 'multi-cuisine' restaurants, mostly attached to star hotels, offer worldwide food (Lebanese, Continental, Italian, Thai ...) to the local upper class, but also to expatriates, tourists and foreign businessmen.

Other places dedicated to public food consumption must quickly be described: ice-cream parlours are more and more alluring, especially for families with children. Air-conditioned cafés, ${ }^{19}$ serving espresso, latte and pastries, are sometimes similar to the previously described bakeries and pastry shops. They attract upper-class single men taking advantage of wireless internet connections and young couples hiding their relationships. Food courts in malls exhibit a concentration of world cuisines, from traditional Tamil to ice-creams, pastas, Chinese and Mexican, allowing both an exotic and extremely individualised experience.

\section{Restaurants: commensality and conviviality}

In Chennai, as elsewhere in India, eating out paves the way to food change. For a long time, the food-related taboos described in the second section have prevented Indians, especially high-caste Hindus, from eating outside. Therefore, the main novelty experienced in the domain of food consumption is the mere fact of eating out; the public space has become an arena for food discovery. 
Discrepancies between domestic and non-domestic food in the Indian context have been argued with salience (Khare 1976b; Caplan 2008). For instance, a significant number of high-caste men, who are pure vegetarians at home, sometimes eat meat outside, usually with colleagues from lower castes and quite often without informing their wives. Some youngsters from families who eschew beef transgress the taboo when accompanying friends to restaurants. More essentially, the pattern of the meal changes with the context: in the house, cereal consumption continues to prevail, while outside, the preference may go to dishes composed of meat (kebab, grilled chicken, etc.). But food eaten outside hardly affects domestic consumption patterns, the main reason being that the first must take the shape of a 'proper meal' (Douglas 1972: 68) - namely, for the Tamils, rice and pulses. Besides, the home is the place where caste purity is constantly being re-activated: to stay pure, the house should not be contaminated by alien products (Khare 1976b). Lastly, many housekeepers lack the equipment and the skills to cook new items such as pizzas or kebabs - foodstuffs that as well often require costly ingredients. When eaten at home, such dishes are actually bought outside and taken away.

As a consequence, food eaten outside paves the way for new patterns of sociability as it potentially emancipates from ethnic, religious or caste rules. Revenue, class, generation and gender prevail in the choices, hence reconfiguring food habits (Staples 2014). While domestic food is still dominated by rules of commensality (food transactions are confined within certain community boundaries), non-domestic food patterns are increasingly shaped by conviviality (the pleasure of discovering and sharing food induces cross-caste gatherings). This contrast makes food prescriptions highly contextual and relative to castes, places or interactions. Indian eaters enjoy a 'simultaneous individual cultural multiplicity' (Heinrich and Landy 1995: 8): they are able to deal with different contexts, by switching from a code referring to commensality and tradition to one referring to conviviality (Strümpell 2008) and cosmopolitanism. The city is exacerbating these interactional and spatial compartmentalisations (Singer 1972: 392). Increasing mobility and obvious diversity make this code switching (Heinrich and Landy 1995) more and more necessary, if not appealing.

Moreover, even the public foodscape has two dimensions: it allows play with both visibility and invisibility. As restaurants are located 'in the space between the public and the domestic' (Ray and Srinivas 2012: 17), eating there implies being seen by one's peers, thus demonstrating social status, but also being protected from the gaze of one's community. This duality is exemplified by beef consumption: when it is ordered in five star hotels, it symbolises cosmopolitanism; when it is eaten by Muslims, Christians or Dalits, it is a defining marker of identity; when it is tasted by other high-caste communities in dark local fast-food outlets, it denotes a transgression of family rules.

\section{A continuum between domestic and non-domestic food}

The dichotomy between eating out and eating in should not be overstressed nor reduced to an opposition of modernity versus tradition. Home and outside food indeed are still articulated together, linked by a continuum. Community rules and references have not faded completely when it comes to going out for lunch or dinner. In Chennai, as in most places in India, all restaurants display whether they are 'pure vegetarian' or 'non-vegetarian'. As well, many vegetarian restaurants have gods' names (Sri Krishna Bhavan, Ganapati Mess) and displays in some bakeries proudly proclaim that the owner is from a high caste, notably from the Brahman Iyengar community. Around the brahmanical temples of the city, restaurants are all pure vegetarian. Ethnicity matters and eating out does not always imply eating 'alien 
food': many successful restaurants serve dishes from the Tamil repertoire. In Chennai (and in other cities of Tamil Nadu), this appetite for what is seen as 'authentic food' is exemplified by the success of the vegetarian chain Saravana Bhavan. Middle- and upper-class people rush to its high-class restaurants for the tasty tocai (dosa) or the sumptuous 'south Indian meals' (rice served with an impressive range of gravies, vegetables and sweets). Even in restaurants, community belonging (be it on an ethnic, caste or national basis) still shapes practices, reflecting what Ian Cook and Peter Crang have named a 'commodification of ethnicities' (1996: 144). Moreover, Western fast-food chains do not impose an 'Americanised' food consumption model. Burgers and chicken wings are eaten more like a snack than like a meal and their taste is often 'Indianised': McDonald's restaurants claim that they serve no beef or pork. KFC includes curry leaves in the bread crumbs and both these chains split their kitchens into a vegetarian and a non-vegetarian sector. New restaurants may permit the discovery of culinary otherness, but their menus do not become Westernised: they conversely give preference to easy-to-locate cuisines, mostly to the above mentioned north Indian, Arabian or Mughal dishes (biryani, kebabs) inspired by the food repertoire of the ancient royal courts of Delhi and Lucknow. People therefore try to accommodate the new food consumption patterns in their local systems of significance (Caplan 2006: 4.4).

Many connections indicate the existence of a strong physical and symbolic link between the domestic and the public food spheres. Numerous people buy parcelled food in restaurants and eat it at home. But if outside food may prompt enthusiasm, it can also provoke reluctance, drawing a 'moral geography of polite public food consumption' (Bell and Valentine 1997: 131). Many people lack the economic resources to eat in restaurants on a regular basis. A lot of workers and students still bring home food in lunch-boxes at their places of work or study as it is still a duty and a pride for many women of the middle classes, and even for those working outside the house, to take time to cook food for the whole family. Noticeably, food served outside is often criticised: it is reported that 'powders' are added to the rice, frying oil is said to be adulterated, kitchens are deemed unhygienic, and so on, thus paradoxically making restaurants 'non-modern' places. In the same way, restaurants should not be regarded only as places of freedom. Many eaters are driven there by their desire but others also by compulsion: single men who do not have use of a kitchen in their lodgings, single workers who lack time and knowledge to cook, and employees away from home.

\section{Conclusion: a segmentation of food consumption patterns}

This chapter has attempted to illustrate the complexity of food change in contemporary India through the specific example of the middle classes in Chennai. Capital-intensive agricultural practices, the rapid growth of the agri-food industry, including the sector of ready-made and packaged products, expanding circuits of supply that more and more source at a global scale, new modes of provisioning and the now well-anchored habit of eating outside, have partly transformed the ways Indians relate to food. It is also hardly deniable that, in some specific contexts and for the upper sections only, mass consumption and a globalised urban way of life turn the act of eating into a demonstration of social status. Adhesion to the consumer society and distinction from the diet of the poor are a way to show middle-class respectability. Outside and new processed food appears as ritually neutral. Places of conviviality such as restaurants question the domestic rules of commensality and contribute to a secularisation of food: revenue, class and generation intersect with ethnicity, religion and caste, blurring the lines of community affiliation and becoming new decisive factors in food decisions. 
However, food change, as obvious as it may seem, is embedded in a deep-rooted system of values to which the analysis in terms of 'food transition', when it concerns India, unfortunately often turns a blind eye. Whereas economic constraints prevent the poorest sections of the society from diversifying their diet, the symbolic meanings of food account for the specificities of the Indian food scenario. In Chennai, food change mostly occurs at the margins: margins of the kitchen (new equipment, ready-made preparations), margins of the plate (take-away snacks and drinks, new side dishes) and margins of the home (new food experienced outside). New food patterns rarely refer to a Western or cosmopolitan repertoire, but rather to regional or national ones. The narratives of authenticity reveal how ethnic identity becomes an increasing concern which is constantly negotiated, commodified and essentialised in the domestic and public arenas. In this way, Indians try to incorporate novelties in a long-lasting and dense cultural matrix. For instance, attitudes to meat are still entrenched in conceptions about status and symbolic pollution. Other vernacular notions about purity and health are not disappearing but they are reconfigured by the middle classes into modern discourses about hygiene and nutrition. The emerging food cosmopolitanism of the middle and upper classes in Chennai continues to mediate moral values and conceptions about what is acceptable and what is not. Conspicuous eating in the public sphere is actually re-asserting the link between diet and hierarchy elaborated in the Hindu cosmology. Food consumption patterns still shape and legitimise the position in society, but for the middle and upper-urban classes, this position is less and less an assigned one but becomes an achieved one. Thus, more than a standardisation of diets, food in contemporary India and in particular in Tamil Nadu displays models of renewed and increasing spatial compartmentalisation and social segmentation.

\section{Notes}

1 Party of the People of India, the political organisation of a nebulous network that seeks to promote Hinduism as the cornerstone of India's identity.

2 According to the Ministry of Food Processing, in 2012-2013 India has exported 1.89 million tonnes of beef (officially only buffalo meat), bringing a revenue of approximately $€ 2.5$ billion.

3 Hindu nationalists often blame Muslims for having introduced meat and beef consumption in India (Robbins 1999: 417).

4 Claiming that the cow is 'holy' in India would be an essentialising discourse, but it is true that religious sentiments towards this animal deter many Hindus (with the notable exception of those from lower castes) from slaughtering cattle and eating beef.

5 Between approximately $€ 2,500$ and $€ 12,500$ in 2014 .

6 For instance, Osella and Osella (2008) have well argued that in Kerala, Muslims' food practices are underpinned by more egalitarian standards.

7 It has been satisfyingly argued that the green revolution movement and Tamil governmental food schemes such as the Public Distribution System (subsidised food grains and commodities) and the Midday Meal (free lunch in schools) have promoted rice at the expense of 'coarse cereals' (Harriss-White 2004; Landy 2009a). Polished rice, as commonly consumed, is blamed for causing type 2 diabetes as well as micronutrient deficiencies (see Chapter 32 in this volume).

8 Ghee (clarified butter) is especially favoured by Brahman households, more numerous in cities than in the countryside of Tamil Nadu.

9 Even though we may argue that what Patricia Caplan calls the 'middle-class' refers more to uppermiddle or upper classes.

10 As Modi did not make any move regarding the opening up of the retail sector, Carrefour announced in July 2014 that it would leave India.

11 Ocimum tenuiflorum.

12 Phyllanthus emblica.

13 Urban fruit consumption has largely outstripped the rural (NSSO 2012a: ii). 
14 In Chennai, Pazhamudir and Reliance Fresh are competing for this booming market.

15 Coca-Cola and PepsiCo share the market in bottled mango juice: the first sells Maaza ${ }^{\circledR}$ and the second Slice ${ }^{\circledR}$.

16 For the time being, the legislation regarding cattle and buffalo slaughter is set by the states, but the Article 48 of the Constitution encourages them to prohibit it (see also Chigateri 2008: 16).

17 Pilaf rice of Mughal origin cooked with meat and specific spices.

18 A region of Tamil Nadu that many Tamils associate with tasty non-vegetarian food.

19 In Chennai, Café Coffee Day and Barista are the main actors in the sector.

\section{Bibliography}

Appadurai, A. (1981) 'Gastro-politics in Hindu South Asia', American Ethnologist, 8 (3): 494-511.

Appadurai, A. (1988) 'How to Make a National Cuisine: Cookbooks in Contemporary India', Comparative Studies in Society and History, 30 (1): 3-24.

Ashley, B., J. Hollows, S. Jones and B. Taylor (2004) Food and Cultural Studies, London and New York: Routledge.

Baviskar, A. (2012) 'Food and Agriculture', in R. Sadana and V. Dalmia (eds), The Cambridge Companion to Modern Indian Culture, 49-66, Cambridge and New York: Cambridge University Press.

Beardsworth, A. and T. Keil (1997) Sociology on the Menu: An Invitation to the Study of Food and Society, London: Routledge.

Bell, D. and G. Valentine (1997) Consuming Geographies: We Are Where We Eat, London and New York: Routledge.

Bengoa, J.M. (2001) 'Food Transitions in the 20th-21st Century', Public Health Nutrition, 4 (6A): 14251427.

Caplan, P. (2001) 'Food in Middle-class Madras Households from the 1970s to the 1990s', in K. Cwiertka and B. Walraven (eds), Asian Food: The Global and the Local, 46-62, Honolulu: University of Hawaii Press.

Caplan, P. (2006) “'Is It Real Food?” Who Benefits from Globalisation in Tanzania and India?' [online], available: http://www.socresonline.org.uk/11/4/caplan.html [accessed 21 July 2014].

Caplan, P. (2008) 'Crossing the Veg/Non-Veg Divide: Commensality and Sociality Among the Middle Classes in Madras/Chennai', South Asia: Journal of South Asian Studies, 31 (1): 118-142.

Chigateri, S. (2008) “'Glory to the Cow": Cultural Difference and Social Justice in the Food Hierarchy in India', South Asia: Journal of South Asian Studies, 31(1): 10-35.

Conlon, F. (1995) 'Dining out in Bombay', in C. Breckenridge (ed.), Consuming Modernity: Public Culture in a South Asian World, 90-127, Minneapolis, MN: University of Minnesota Press.

Cook, I. and P. Crang (1996) 'The World On a Plate: Culinary Culture, Displacement and Geographical Knowledges', Journal of Material Culture, 1 (2): 131-153.

Deaton, A. and J. Drèze (2009) 'Food and Nutrition in India: Facts and Interpretations', Economic and Political Weekly, 44 (7): 42-65.

Dittrich, C. (2009) 'The Changing Food Scenario and the Middle Classes in the Emerging Megacity of Hyderabad, India', in L. Meier and H. Lange (eds), The New Middle Classes, 269-280, Dordrecht: Springer Netherlands, available: http://link.springer.com/chapter/10.1007/978-1-4020-9938-0_15 [accessed 21 July 2014].

Dolphijn, R. (2006) 'Capitalism on a Plate: The Politics of Meat Eating in Bangalore, India', Gastronomica, $6(3): 52-59$.

Donner, H. (2008) 'New Vegetarianism: Food, Gender and Neo-Liberal Regimes in Bengali MiddleClass Families', South Asia: Journal of South Asian Studies, 31 (1): 143-169.

Donner, H. (2011) 'Gendered Bodies, Domestic Work and Perfect Families: New Regimes of Gender and Food in Bengali Middle-class Lifestyles', in H. Donner (ed.), Being Middle-Class in India: A Way of Life, 47-72, Abingdon: Routledge.

Douglas, M. (1972) 'Deciphering a Meal', Daedalus, 101 (1): 61-81.

Eichinger Ferro-Luzzi, G. (1975) 'Temporary Female Food Avoidances in Tamilnad. Interpretations and Parallels', East and West, 25 (3/4): 471-485.

Elias, N. (2000) The Civilizing Process: Sociogenetic and Psychogenetic Investigations, 2nd edition, Oxford: Blackwell.

Fuller, C.J. and H. Narasimhan (2007) 'Information Technology Professionals and the New-Rich Middle Class in Chennai (Madras)', Modern Asian Studies, 41 (1): 121-150. 
Goody, J. (1982) Cooking, Cuisine and Class: A Study in Comparative Sociology, Cambridge: Cambridge University Press.

Harriss-White, B. (2004) 'Nutrition and Its Politics in Tamil Nadu', South Asia Research, 24 (1): 51-71.

Heinrich, S.A. and F. Landy (1995) 'Le Barbier et ses clients: Usages Diversifiés des Codes Culturels et Permanence de l'Inde Rurale', Études rurales, (137): 6-22.

Khare, R.S. (1976a) The Hindu Hearth and Home, New Delhi: Vikas.

Khare, R.S. (1976b) Culture and Reality: Essays on the Hindu System of Managing Foods, Shimla: Indian Institute of Advanced Studies Shimla.

Khare, R.S. (1992) The Eternal Food: Gastronomic Ideas and Experiences of Hindus and Buddhists, Albany, NY: State University of New York Press.

Khare, R.S. and M.S.A. Rao (eds) (1986) Food, Society, and Culture: Aspects in South Asian Food Systems, Durham, NC: Carolina Academic Press.

Landy, F. (2009a) Feeding India: The Spatial Parameters of Food Grain Policy, New Delhi: Manohar.

Landy, F. (2009b) 'India, "Cultural Density” and the Model of Food Transition', Economic and Political Weekly, (20): 59-61.

Lévi-Strauss, C. (1983) The Raw and the Cooked: Mythologiques, Volume 1, Chicago, IL: University of Chicago Press.

Lewandowski, S.J. (1975) 'Urban Growth and Municipal Development in the Colonial City of Madras, 1860-1900', The Journal of Asian Studies, 34 (2): 341-360.

Morgan, K., T. Marsden and J. Murdoch (2006) Worlds of Food: Place, Power, and Provenance in the Food Chain, Oxford: Oxford University Press.

Mukhopadhyay, B. (2004) 'Between Elite Hysteria and Subaltern Carnivalesque: The Politics of StreetFood in the City of Calcutta', South Asia Research, 24 (1): 37-50.

Nandy, A. (2004) 'The Changing Popular Culture of Indian Food: Preliminary Notes', South Asia Research, 24 (1): 9-19.

NSSO (2012a) Household Consumption of Various Goods and Services in India, July 2009-June 2010, New Delhi: Government of India.

NSSO (2012b) Nutritional Intake in India, July 2009-June 2010, New Delhi: Government of India.

Osella, C. (2008) 'Introduction', South Asia: Journal of South Asian Studies, 31 (1): 1-9.

Osella, C. and F. Osella (2008) 'Food, Memory, Community: Kerala as both "Indian Ocean" Zone and as Agricultural Homeland', South Asia: Journal of South Asian Studies, 31 (1): 170-197.

Pingali, P. (2006) 'Westernization of Asian Diets and the Transformation of Food Systems: Implications for Research and Policy', Food Policy, 32 (3): 281-298.

Popkin, B.M. (1993) 'Nutritional Patterns and Transitions', Population and Development Review, 19 (1): 138-157.

Popkin, B.M. (2003) The Nutrition Transition in the Developing World, SSRN Scholarly Paper ID 513432, Social Science Research Network, Rochester, NY, available: http://papers.ssrn.com/abstract $=513432$ [accessed 21 Jul 2014].

Quien, A. (2007) Dans les cuisines de Bombay: Travail au Féminin et Nouvelles Sociabilités en Inde Aujourd'hui, Paris: Karthala.

Ray, K. and T. Srinivas (eds) (2012) Curried Cultures: Globalization, Food, and South Asia, Berkeley, CA: University of California Press.

Robbins, P. (1994) 'Goats and Grasses in Western Rajasthan: Interpreting Change', Pastoral Development Network Papers, 36(a): 6-12.

Robbins, P. (1999) 'Meat Matters: Cultural Politics along the Commodity Chain in India', Cultural Geographies, 6 (4): 399-423.

Sahlins, M. (1976) Culture and Practical Reason, Chicago, IL: University Of Chicago Press.

Sébastia, B. (2010) 'Be a Vegetarian! Discours en Inde sur les Bienfaits du Végétarisme pour un Corps Pur et Sain' [online], available: http://www.lemangeur-ocha.com/fileadmin/images/sciences humaines/Be-a-vegetarian.pdf [accessed 21 July 2014].

Sébastia, B. (2013). 'L'Inde, Impuissante face à la Malnutrition?', Diplomatie. Affaires Stratégiques et Relations Internationales (14): 32-35.

Sébastia, B., P. Balagopal and R. Misra (forthcoming) 'Fighting Food-related Diseases in India. Inadequacy in Indian Food Programmes and Prescriptions: Some Solutions', Diets and Food Patterns. Myths, Realities and Hopes, Bucharest : University of Romania.

Shetty, P.S. (2002) 'Nutrition Transition in India', Public Health Nutrition, 5 (1A): 175-182.

Siegel, B. (2010) 'Learning to Eat in a Capital City Constructing Public Eating Culture in Delhi', Food, Culture and Society: An International Journal of MultidisciplinaryResearch, 13 (1): 71-90. 
Singer, M.B. (1972) When a Great Tradition Modernizes: An Anthropological Approach to Indian Civilization, New York: Praeger Publishers.

Srinivas, T. (2002) 'AA Tryst with Destiny": The Indian Case of Cultural Globalization', in P.L. Berger and S. Huntington (eds), Many Globalizations: Cultural Diversity in the Contemporary World, 89-116, Oxford University Press.

Srinivas, T. (2007) 'Everyday Exotic: Transnational Space, Identity and Contemporary Foodways in Bangalore City', Food, Culture and Society: An International Journal of Multidisciplinary Research, 10 (1): 85-107.

Staples, J. (2014) 'Civilizing Tastes: From Caste to Class in South Indian Foodways', in J.A. Klein and A. Murcott (eds), Food Consumption in Global Perspective: Essays in the Anthropology of Food in Honour of Jack Goody, 65-86, New York: Palgrave Macmillan.

Strümpell, C. (2008) “We Work Together, We Eat Together": Conviviality and Modernity in a Company Settlement in South Orissa', Contributions to Indian Sociology, 42(3): 351-381.

Warde, A. and L. Martens (2000) Eating Out: Social Differentiation, Consumption and Pleasure, Cambridge: Cambridge University Press. 


\title{
32
}

\section{COPING WITH THE DISEASES OF MODERNITY}

\section{The use of siddha medical knowledge and practices to treat diabetics}

\author{
Brigitte Sébastia
}

\section{Introduction: questioning traditional medicines for treating new diseases}

India is well known for its pluralistic medical system which is composed of biomedicine, improperly called 'allopathy' imposed by the British, and then supported by the Indian government, of homeopathy also introduced during British colonization, and of various Indian therapeutic systems, recognized or not by the present government. Ayurveda, yoga (including naturopathy), unani, siddha and homeopathy, ${ }^{1}$ and more recently in 2009, sowarigpa or amchi (Tibetan medicine) are supported by the department of AYUSH (Ayurveda, Yoga and Naturopathy, Unani, Siddha and Homeopathy) of the Ministry of Health and Family Welfare founded in 2003 to replace the Department of Indian Systems of Medicine and Homeopathy. In contrast, a wide range of therapies including bone setting and home remedies used by various communities (tribes, villagers) are not recognized and are denounced by the government as unscientific, even though, it encourages research on them for identifying plants, their usage and medicinal properties, with the goal of developing new formulas for ayurveda and siddha.

Among these medical systems, biomedicine is the most attractive, and that, in spite of the creation of AYUSH, and the boomerang effect from the West which gives high value to traditional medicines, especially ayurveda. The ambivalent attitude of the Indian government to supporting Indian medicines in terms of funding for clinical and pharmaceutical research, and of allocating beds in hospitals and primary health centres as well as chairs in colleges, is a major reason. The government is aware of the high financial profit gained by Indian medicines, from medical tourism and marketing of medicinal plants and drugs. However, it is subjected to pressure from biomedical doctors and pharmaceutical companies, and from directives from international health agencies such as $\mathrm{WHO}$, demanding that traditional medicines meet the same criteria and regulations applied to biomedicine with regard to standardization, innocuity 
and medical validation through scientific tools and clinical trials (WHO 2002). The strong expectation of patients for immediate cure in a context in which an episode of disease may put them at financial risk also favours biomedicine. Compared to biomedical medicaments, traditional ones are perceived as having no side effects (also Nisula 2006), but as working slowly. The choice of the medical system is, however, dependent on the availability of practitioners, biomedicine being mainly present in urban areas, on the particular situation of each of the Indian states ${ }^{2}$ the reputation of the practitioner and the specific disease. Regarding the last criterion, Indian medical practitioners are consulted for joint and bone disorders, digestive and sexual troubles, snake bites, skin diseases, respiratory distress, and so on, a range of ailments for which they are traditionally well renowned and have a great deal of medicinal formulations. However, they are increasingly approached for the treatment of new diseases by patients who, very often, have been unsatisfied with biomedical treatment.

The new disease which the present chapter aims at exploring is type 2 diabetes and some of its allied disorders. These are examined in the field of siddha, the Indian medical system of Tamil Nadu and, more particularly, in the practices of traditional siddha practitioners (paramparaya citta maruntuvarkal), a class of medics who inherited medical knowledge from their ancestors or from well reputed practitioners. Several reasons justify these choices. First, the increase of diabetes over the last thirty years has caused it to become a major public health issue, and thus to examine how traditional medicine may contribute in diabetic care is of the utmost importance, notably when biomedical services are deficient, or when patients have still not been diagnosed and consulted for secondary disorders. Second, as traditional siddha practitioners have not inherited the knowledge of treating diabetes in terms of diagnosis, medicinal formulas and food prescription, how they approach this disease and its allied disorders is relevant in demonstrating their capacity to adapt their knowledge and to convoke different medical systems in order to respond to patients' needs. Third, as an important part of the therapy in Indian medical practice concerns diet, exploring diabetes will allow for examining how food recommendations are prescribed by practitioners and how they are received by patients. Lastly, the choice is to compensate for the scarcity of studies on siddha practice, on the one hand, and on the treatment of diabetes by Indian medicines that has been explored especially from the viewpoint of the anti-glycaemic potentiality of plants, on the other (Chacko 2003; Kaushik et al. 2010).

This ethnographical study is based on the practice of two traditional practitioners, Jeyananda and Rattinammal, whom I have selected, from among the twenty I observed during my five-year research on siddha medicine, because of their high involvement in coping with diabetes that obliged them to innovate, and because of their great difference in approaches to this disease and its treatment. While Jeyananda's approach could be defined in terms of modernity as it blurs the differences between siddha and bio-medicines, Rattinammal's practice is rather close to the siddha tradition, but not in terms of authenticity as it mixes some medical systems and adjusts them in order to treat these 'new diseases' and to fit in with contemporary changes in lifestyle. The chapter is structured according to the diverse aforementioned points: prevalence and causes of diabetes in contemporary India; definition of siddha medicine and its practitioners; approach to diabetes and its treatment by siddha practitioners; and diet and food recommendations in siddha medicine. It will show how Jeyananda and Rattinammal respond to the new demands from their patients and face many obstacles, which may damage the identity of their medicine and weaken its reputation. Their practices question too what is the 'tradition' in the field of medicine since the knowledge on which the practices are based is not just inherited and fixed, but is in constant re-composition and adaptation. 


\section{Diabetes: prevalence and cause}

Type 2 diabetes has increased substantially in India since the 1980s. It appears more and more precociously and, as in developed countries, affects even obese adolescents in cities (Ramachandran et al. 2003; Bhardwaj et al. 2008). Diabetes rarely occurs alone. It is associated with being overweight or obese, having dyslipidemia, high blood pressure, and provokes a range of secondary diseases such as, inflammatory disorders, renal failure, retinopathy and diabetic ulcers. The study of Mohan et al. (2008), assessing the increase in the occurrence of diabetes between 1972 (the first study) and 2003-2005, shows that in thirty years diabetes has increased from 2.1 per cent to 7.3 per cent in urban areas and from 1.5 per cent to 3.1 per cent in rural areas. In Tamil Nadu, Chennai Urban Rural Epidemiology Studies (CURES) reveals a sharp increase in its prevalence: 8.3 per cent in 1989, 11.6 per cent in 1995, 13.5 per cent in 2000 and 14.3 per cent in 2004 (Mohan et al. 2006). It also affects the rural population of Tamil Nadu with a rise of 2.2 per cent in 1989 to 6.36 per cent in 2003 (Ramachandran et al. 2004).

Type 2 diabetes may have an endocrinal origin (hyperthyroidism, syndrome of SteinLeventhal), but its main cause is the rapid change in food and lifestyle. Indians are particularly prone to developing this disease as they are handling a food transitional stage defined by Barker's hypothesis (1995): undernourished at the foetus stage (low birth weight LBW), they develop diabetes when they are exposed to high caloric consumption. According to an estimate by UNICEF and WHO in 2000 (Wardlaw et al. 2004), India accounted for 7.8 million LBW babies per year; Angus Deaton and Jean Drèze (2009) have shown that the consumption of a large part of its population has shifted rapidly to more high-energy foods rich in fat and carbohydrates. As a result, the metabolism, earlier adjusted to store calories to cope with irregular food intake, is struggling to adapt to regular, large supplies of food energy.

The common explanation for diabetes' prevalence in India is the high consumption of junk food and fast food, implicitly assimilated as pizzas or hamburgers, and soft drinks. Western types of fast food are becoming increasingly available in towns, but are consumed mainly by the well-off population who eat them mostly as snacks, shared with friends or family members. In contrast, Indian fast food, quite often fatty and imbalanced (reheated biriyani, fried noodles, fritters, etc.), is cheap and consumed as meals by all socio-economic categories. However, the major cause of food-related diabetes is the daily diet which is imbalanced and little varied. The three daily meals are composed of a large amount of cereal, rice or wheat according to the food pattern of the region, served with some pulses and vegetables, and possibly with small pieces of meat, fish or egg according to both economic means and food pattern. This diet, composed of 65 per cent to 85 per cent of carbohydrates depending on the social-economic status of the family, is too rich in calories compared to the daily needs of people with low levels of physical activity, and too low in micronutrients, notably when polished rice is the staple food, as in the South Indian states. Such a diet induces malnutrition at two levels: metabolic disorders and deficiencies in micronutrients reflected in the fact that 79 per cent of children aged between six and thirty-five months and 55.5 per of women suffer from iron deficiency anaemia (IIPS 2007; Mittal 2007).

The green revolution policy is partly responsible for the change in food. It was initiated to compensate for food shortages, when India faced the threat of an embargo on cereals by the United States, in retaliation for India's position against the Vietnam War. Cultivation of high-yield varieties of wheat and rice and of sugar has been specifically encouraged and their production has allowed the country to be self-sufficient, and wheat, rice and sugar, to be distributed at a subsidized price through the public distribution system. In contrast, cultivation of other cereals such as millets, ${ }^{3}$ pulses, beans, vegetables and fruits, has been 
neglected so that their prices are very volatile, constantly in tension between availability and demand, the strategy of traders and recourse to the international market. Millets, the traditional cereals of South India for thousands of years, ${ }^{4}$ were progressively depreciated when rice became increasingly available, first, during British colonial rule when rice was imported from Burma into the towns, and then, under the pressure of the green revolution. Labelled as 'country food', millets were abandoned for rice, the 'Brahman food', ${ }^{5}$ on plates and progressively in the fields. Let us add that the quantity of legumes in meals is largely dependent on the state food pattern, very poor in Tamil Nadu, where the consumption of vegetables and fruits is very low: vegetables constitute side dishes; fruits are supplementary and festive foods, often associated with medicinal properties.

Development of public and private transport, mechanization of work, increase in incomes and urbanization of society, are factors responsible for the reduction of physical activity and, consequently, for the development of diabetes and obesity. Women are specifically affected by inactivity due to the fact that, in traditional families where financial resources are considered sufficient, they are not expected to take a job or to go out alone after marriage. Apart from cooking, mostly done sitting on the floor, they spend little time on housework. They consider preparation of food as a dull and repetitive task, and are reluctant to experience new dishes, even with the recent development of cookery books, TV food programmes and food websites. Many housewives prefer to spend their spare time watching television, sleeping, talking to neighbours or doing small chores, such as making flower garlands or supervising children's school work. The urbanization of Indian society which spurs the transformation of the family, including the nuclearization process, boosts changes in food. In liberal milieus, women take jobs, and consequently, have less time to prepare meals. This transforms food habits which are stimulated by higher incomes and by media influence. Ready-to-eat or processed foods from supermarkets and specialized shops (pre-fermented dough for idli or dosai), ${ }^{6}$ street vendors entering homes, and eating-out in different types of restaurants are constantly increasing. Children, particularly from the upper and middle classes, participate in the transformation of eating habits; they are more receptive to advertisements in the media and more open to innovation. Compared to urban people, those living in villages are less exposed to the change in foodstuffs and food habits. They have less access to 'new' foods, but they have adapted gradually to the urban model of consumption, notably to eating rice instead of millets and consequently they are developing food-related disorders (Balagopal et al. 2008), and when the disease causes disability, they approach biomedical or Indian medical practitioners, according ease of access, reputation and familiarity.

\section{Siddha medicine and its practitioners}

Siddha medicine is par excellence the traditional medical system of Tamil Nadu as it is used by Tamil communities in India and overseas, and its corpus is written in Tamil. Its medical concepts and pharmacopeia are very close to those of ayurveda; the major differences concern philosophical and spiritual foundations (anti-brahmanical ritualism, Sāktism, ascetism) and its roots in alchemy from which iatrochemical processes have been elaborated to prepare medicines. ${ }^{7}$ Like ayurveda, physiological concepts of siddha medicine are based on the principle that everything in the universe is composed of five elements, ether, air, fire, water and earth. Food and respiration supply the basic elements which, converted into juices, generate successively the seven bodily constituents (tättukkal): chyle, blood, muscle, fat, bone, marrow and semen. The balance of tattukkal and, concomitantly, of the three tōṣakkal: vāta 'air'; pitta 'fire'; kapa 'phlegm', depends on the appropriateness of diet and 
rules of conduct (Uthamaroyan 2005; Wujastyk 2001). Siddha texts are attributed to the cittarkal ${ }^{8}$ (yogis; from Sanskrit siddha 'realized, perfect'), eighteen according to the Tamil tradition, who also developed alchemy, astrology, philosophy, yoga and magic (Ganapathy 1993; Venkataraman 1990). Because of its roots in alchemy and esotericism, siddha has acquired a doubtful reputation which prevented it from being taught during a period when the scientific validity of Indian medicines was being debated (Sébastia 2010; Weiss 2009). This branch of medicine was minimally taught at the School of Indian Medicine at Madras, established in 1923, assimilated to ayurveda, and it was only in 1964 that a siddha college was founded at Palayamkottai (southern Tamil Nadu). This led to siddha medicine being predominantly practised by traditional practitioners as compared to ayurveda. According to the AYUSH report for 2007, the percentages of registered non-qualified (traditional) practitioners of siddha and ayurveda medicines were respectively 54 per cent and 48 per cent. ${ }^{9}$ The statistics do not include the numerous traditional practitioners who are unregistered due to the suspension of the registration process established in 1933, consequent to the notification No.V. 26211/4/1976, dated 10 September 1976, added to the Indian Medicine Central Council Act, 1970 (IMCC) (Sébastia 2010). The number of unregistered traditional practitioners in both branches of medicine is difficult to estimate, but is certainly higher in siddha as its training centres are less numerous, compared to ayurveda that benefits from a large private and governmental sector. Moreover, traditional practitioners do not approve of the training provided in siddha governmental hospital-cum-colleges as they consider their own knowledge as superior and more authentic. Under the continual pressure of students who have demanded that the curriculum of governmental siddha colleges incorporate more biomedical subjects and concepts, the practice and knowledge of siddha medicine have declined; some of its specialities, such as varma therapy ${ }^{10}$, medicine preparation or pulse reading being rarely taught. However, compared to traditional practitioners, those trained in colleges are better prepared to cope with the diseases of modernity. As their curriculum incorporates the study of contemporary diseases, which they study from the point of view of diagnosis using both siddha methods and clinical tests, and the pharmacognosy of siddha material medica, they treat them in the same manner as biomedical doctors: they prescribe medication developed by ayurveda and siddha manufacturers, which patients buy in medical shops specializing in Indian systems and they use the diagnostic tools of biomedicine. In contrast, traditional siddha practitioners have had to adapt to the increasing number of patients with contemporary diseases, notably diabetes.

\section{The recourse to siddha medicine: case of diabetes}

Siddha texts categorize the disease corresponding to diabetes under nīrilivu Tamil, 'faultwater/urine' or matumekam from Sanskrit, 'sweet-disease' for which they provide some description, diagnosis and treatment. Siddha practitioners, however, never use these terms but those of 'sugar disease' or cakkarai uyarvu (sugar-increase/high), non-technical terms with which patients are familiar and which reflect the dominance of biomedical concepts over traditional ones, and the modernity of this disease as those traditionally treated by siddha practitioners continue to be mentioned by their Tamil terms: vātanōy for osteoarthritis or pakkavātam for hemiplegia. Traditional practitioners have not studied these siddha texts and thus, if they were not benefiting from the experience of their ancestors, they would not know how to treat diabetes. How some practitioners are able to cope with this disease and its allied disorders is what I want to show through the case studies of Jeyananda and Rattinammal. 


\section{Jeyananda and Rattinammal's treatment: a combination of medical systems}

Jeyananda is fifty years old. He lives in a small village in Kanniyakumari district where he practises siddha and varma therapy. He studied siddha medicine from the age of fourteen with his father and grandfather, both renowned ācān according to the term used in this region to refer to proficient practitioners. After studying homeopathy for one year, he founded a hospital on land belonging to his family that he runs with his wife Neela who holds a Bachelor of Siddha Medicine and Surgery degree.

The 'Jeyananda Siddha and Ayurveda Hospital', with its waiting room, consultation room, in-patient wards, laboratory, X-ray room, pharmacy and canteen, differs very little from the numerous biomedical hospitals established in the region of Nagercoil. The use of biomedical tools in the practice of traditional medicine has often been mentioned (Nisula 2006). It has been explained in terms of biopolitics, a Foucaultian concept of the power of the rational and scientific knowledge (on the bodies) which has its roots in Indian colonial history, but continues today to undermine traditional medicines (Langford 1995; Wujastyk and Smith 2008). It is the hegemony of biomedicine that Jeyananda tried to thwart when he decided to 'biomedicalize' his practice:

I introduced them [X-ray, lab] to give trust to the patients. Nowadays, patients do not come to us when they are ill or injured. They go directly to allopathy doctors. Only if they do not get any relief they come to us. The two new floors that I am adding to this hospital are for allopathy. My idea is to get more patients interested in siddha. As patients will come for allopathy, they will be able to consult first siddha and then choose.

Despite Jayanenda's lament on the lack of interest in traditional medicines, he and Neela receive eighty to a hundred patients daily from various socio-demographic categories. Among this clientele, patients with diabetes represent 10 to 15 per cent and some of them end up being hospitalized.

Compared to Jeyananda's, the clientele of Rattinammal is very small, less than six patients a day, but half of them are diabetics. Rattinammal is eighty-six years old. She belongs to a raja vaittiyar family, a lineage of highly reputed practitioners who traditionally served a king. She acquired her knowledge from her mother and grandmother, and from another practitioner well versed in alchemy. After practising in a village, she settled down in her daughter's house in Madurai when her husband died. Her practice is not commercially oriented; it aims to give cevai, that is, to help the community, according to the ethics of siddha medicine. Rattinammal has never tried to use biomedical tools. Rather, she practises siddha medicine according to the 'tradition', but by combining it with other medical systems, Bach flower remedies and homeopathy, that she considers to be complementary to siddha medicine. She is also very aware of the decline of interest in siddha medicine. However, she puts her energy into transmitting her knowledge to her patients and to anyone who approaches her to learn about siddha.

\section{Jeyananda medication: juggling with tradition and modernity}

Patients with diabetes approach siddha practitioners either to change their medication from biomedicine to siddha drugs, or to be treated for disorders for which siddha practitioners are traditionally consulted, such as dry itchy skin, nausea, tiredness, frequency of urination, 
foot ulcers, kidney stones and osteoarthritis. Mindful that these symptoms may be those of diabetes, and combining this with knowledge acquired from the media, biomedicine practitioners, pharmaceutical representatives, patients, and so on, Jeyananda prescribes blood and urine sugar tests to patients aged forty and over, to evaluate the level of sugar or to detect an abnormality when the patient has not yet been diagnosed; this is not uncommon as awareness of this disease is weak, and preventive measures deficient (Venkataraman et al. 2009). He also reads the pulse, an important siddha diagnostic method to detect the imbalance of vata-pitta-kapa, and sometimes checks blood pressure with the sphygmomanometer. $\mathrm{He}$ claims to be able to detect high blood pressure through pulse reading, but uses the instrument 'to reinforce the confidence of patients'. Indeed, he uses it often at the request of patients who are not aware of the specificities of bio- and siddha medicine.

Jeyananda's therapy for 'blood sugar' is a combination of tradition and modernity. It takes into account the constitution of the patient and the balance of vatta-pitta-kapa, and aims to purify the blood and improve digestion. For this, Jeyananda prescribes his own medicine. He provides anti-glycaemic tablets that he buys from ayurvedic and siddha pharmaceutical representatives to reduce 'sugar' level, if the patient so wishes. He records on the patient's medical card the pulse reading laboratory results, including sugar level, blood pressure, and medication so that he can check the efficacy of his treatment during follow ups. Aware of the risk associated with diabetes, Jeyananda advises patients treated with biomedical medication not to discontinue it. It will rather be reduced progressively after the efficacy of siddha medicine has been checked. The ayurveda and siddha market for anti-diabetic drugs is well developed so that Jeyananda is able to try different products and analyse their effects according to the constitution of the patients and their health. He argues that siddha drugs work well up to a sugar level of $2.0 \mathrm{~g} / \mathrm{l}$, but not if people are using insulin. In that instance, he refuses to treat them. When secondary disorders caused by diabetes such as, osteroarthritis and hemiplegia or diabetic ulcer are severe, he hospitalizes the patients for forty-eight days (a number auspicious in Hindu tradition) and provides them with therapy including marketed tablets and his own products: medicated oil taken with kaśāyam (highly concentrated decoction), and curranam (powdered dried plants) taken with honey. In addition, patients with osteoarthritis are prescribed two sorts of massage daily; those with hemiplegia, two massages daily and three talankal (poultices of cockerel blood mixed with curranam) during their stay. For diabetic ulcers, Jeyananda treats them with his own products that he uses for applying to affected wounds and for lancing carbuncles: a medicated oil for external wounds and a paste of crushed green leaves for opening ulcers.

Consultations are free of charge, but patients have to pay for expensive medicines. ${ }^{11}$ Medicaments from pharmaceutical companies are removed from their wrapping and put in unmarked packets so that patients cannot differentiate them from those dispensed at the hospital. Jeyananda explains his recourse to the market and his process for selling them:

All formulas of medicines I am producing come from my ancestors. At that time, there were very few patients with sugar. I remember that once my grand-father gave a leaf to a patient that he suspected to have sugar; his tongue turned back and my grand-father told me: he has cakkarai nōy. But I do not know the plant and how he treated this.

Nowadays, there are many patients with sugar but I have no time to develop any formulas. To collect plants in order to prepare medicines is also a problem. Nobody wants to do this job which is too hard. Plants also are disappearing because of urbanization. So, I buy medicines from some pharmacies, I try them, and 
when I observe they work well, I give them to patients. However, patients have no confidence in the medicaments from the market. To be sure that they will take them, I give them in the same way that I give ours.

Patients who turn to traditional siddha practitioners quite often consider marketed medicines as having poor efficacy because they are allegedly made with adulterated ingredients and by machines that overheat them thereby destroying their potency. Conversely, they hold traditional practitioners' medicines in high regard as they are supposed to be produced according to those inherited formulas that made the reputation of practitioner families. By repackaging the commercial drugs under his hospital's name, Jeyananda can retain his clientele and maintain his family's reputation.

\section{Rattinammal's medication: a clever mixing of medical systems}

Unlike Jeyananda, when Rattinammal was confronted twenty years ago by the increase in patients with sugar, she decided to develop formulas. She used oral and textual sources: her hereditary know-how and diverse sources of medical knowledge that she had acquired throughout her life, and texts and manuscripts, especially those attributed to Pōkar, the famous alchemist-cittar. She developed a cüranam which she called cakkarai cüranam, a combination of thirty-one ingredients, among which thirteen are commonly used by practitioners and siddha/ayurveda pharmacies for their anti-glycemic properties. She prescribes this medicine to be taken in the morning and two other drugs: in the evening, a cüranam of two plants for purifying the blood, and at noon, pañcamūlikai cüranam (five medicinal curranam plants) for regulating the function of the 'five king organs'. She explains:

Sugar is due to rise of pitta when the liver fails. Pancreas fails and each of the king organs [kiṇruppācān], lung, heart, liver, pancreas and kidney, are affected. These five organs cooperate with each other so that any disease will not come, but if one organ fails, all will fail. That is the reason I give this medicine, not only for sugar, but also for curing the five organs and purifying the blood. If the patient has BP (blood pressure), cholesterol, kidney problems, he will be cured.

To increase the efficacy of her cüranam, Rattinammal adds muppu. Мирри is a particularly emblematic substance in siddha medicine as it is related to the alchemical knowledge of practitioners. It is comparable to the philosopher's stone of the alchemists. Generally translated as 'three salts' ( $m u-u p p u)$, it is considered as a universal salt containing catalytic power, necessary for the purification of metals and minerals used after calcination in the preparation of drugs against degenerative diseases. It is a panacea (Venkataraman 1990). Its original formula is not known, but some traditional practitioners involved in alchemy are proud to exhibit their muppu as proof of their erudition. This substance is made from pūnir (earth-water), a salt highly valued by siddha practitioners well versed in alchemy, which appears on the full moon nights of April and May in some secret places. In the past, Rattinammal used her mother's recipe to prepare muppu. But she is now too old to collect pūnir and has elaborated her own panacea from the combination of three salts. While she admits that her mother's тирри is more in keeping with tradition as it uses pūnìr, she considers her own formula to be very effective.

In addition, Rattinammal provides her family medicines to treat certain diseases that, after taking the pulse, examining and questioning the patient, she associates with diabetes: 
Sugar disease is often associated with väta or with kapa or with väta-kapa. To treat a sugar patient, I check his condition and I treat sugar disease, vāta and kapa separately. If I treat only sugar without treating vāta and kapa, sugar disease will not be cured. ${ }^{12}$

Ratinammal's explanation reflects the holistic dimension of disease commonly attributed to Indian medicine and the sensibility of its practitioners who deal with it in its complexity in the treatment. The psychological disposition of her patients is another aspect that Ratinammal pays particular attention to. In comparison with her family practice, one of her innovations has been the integration of the Bach flower remedies. She discovered this therapy at the age of twenty, when she attended a lecture by an English disciple of Dr Bach. Bach remedies are supposed to help with mental and emotional disorders. They are given by putting a few drops of flower extract on the tongue. However, Ratinammal uses another technique: associating principles of siddha medicaments favouring the combination of multiple ingredients deemed necessary to enhance efficacy, and of homeopathy based on the action of active principles in infinitesimal dosage, she gives her patients small vials of granules that she has impregnated with four or five different flower essences. Although Ratinammal knows the Western origin of Bach flower therapy, ${ }^{13}$ she considers it as an integral part of siddha medicine, because both systems use flowers and have a holistic approach. Her awareness of psychological impact in treatment is in accordance with the principle of siddha medicine which, like ayurveda, 'frequently frames illness as socio-psychosomatic distress and understands patients as part of an enclosing social, climatic, or cosmic field' (Langford 1995: 330). In contrast, Jeyananda pays less attention to the patient's socio-psychological disposition as the large number of patients who attend his hospital does not allow more than five to ten minutes on each patient. However, he devotes more time to patients when he feels they need to be reassured about the efficacy of his treatment and the prognosis, or to be informed about the disease.

How to heal diabetic ulcers has also been a great challenge for Rattinammal. During one of my visits, she was consulted by a woman with diabetes who had an injured toe. This casual visit gave me the opportunity to follow the entire treatment. The woman explained that the doctor had informed her that only surgery could save her foot. The fear of amputation, or of surgery in general, as I frequently noticed at Jeyananda's hospital and at other siddha clinics, is one of the reasons why patients turn to traditional medicine.

After having removed the bandages, Rattinammal collected some leaves from her garden that she crushed to extract the juice. She washed her hands and the wound with the juice, which is supposed to be antibacterial. She removed the dead skin, opened the wound that she filled with an ointment and bandaged it. The ointment she prepared extemporaneously is a mixture of $\operatorname{nim}$ oil (Azadirachta indica) which is antiseptic, copper sulphite, alum for disintegrating dead skin, and two cüranam for regenerating blood vessels, tendons and nerves and inhibiting pus formation. The dressing was changed daily and, when the wound was becoming less purulent, she replaced nim oil with aloe vera juice, which is also thought to have some antibacterial properties, but fewer than nim oil. After a ten-day treatment, when Rattinammal considered the flesh of the wound to be well irrigated, she applied rana kalimpu, an ointment her mother had used for treating wounds. To adapt rana kalimpu to the treatment of diabetic ulcers, Rattinammal added one plant of the cakkarai curanam. She then gave rana kalimpu to the patient for continuing the treatment at home. During the wound treatment, Rattinammal supplied some medication to complement the patient's insulin treatment and also two vials of Bach remedies: one to remove the fear of amputation, and the other to instill, confidence in the treatment. Every day during the treatment, Rattinammal tirelessly recommended the woman to follow her diet strictly. 
Treatment of patients with diabetes who change to siddha drugs is a heavy responsibility for siddha practitioners. Jeyananda and Rattinammal are confident of the efficiency of their medicines, but they stress that without compliance with food rules the efficiency is reduced. They never advise discontinuation of biomedical treatment unless they are sure that the patient is motivated enough to faithfully follow their recommendations on medication and diet. As Rattinammal explained to me: 'Patients must cooperate with us, without cooperation we cannot treat them'. Confidence in the doctor and his medication and adherence to his recommendations are indeed key factors in the treatment of diseases in general. These factors are even more important in traditional medicines that need a higher resolve on the part of patients, and for treatment of diabetes that requires the patient to follow the therapy strictly. They admit that they cannot compete with biomedicine if patients do not seriously follow their prescriptions. As Rattinammal complains:

Now people have no patience, no faith. They do not want to make any effort to change their habits. They want to eat whatever they like: rice, large amount of rice with meat, fish, oily snacks ... They do not want to change anything. They take some medicines and they continue eating as before. But with our medicines, this is not possible; our medicines work only with appropriate diet.

\section{Diet: a fundamental therapy allied to medication}

Food is intrinsically related to health and disease as is well illustrated by the Indian adage 'food is medicine and medicine is food'. The belief in the link between health and food is particularly strong in India, and more specifically in traditional medicine because of its elaborate taxonomy of foods which is based on the constitution of the body and its metabolism. On the principle that everything in the universe is composed of five basic elements (pañcaputta or kattukkal): ether, air, fire, water and earth, the basic elements of food supplies which, converted into a juice (rasam), produce body constituents (tättukkal). These constituents are essential for the development and maintenance of the human body. However, the ratio of basic elements varies according to the composition of foodstuffs. A diet made up of inappropriate food for the constitution of the body causes an imbalance of tättukkal and, concomitantly, of väta-pittakapa, which results in diseases, whereas a diet that includes foodstuffs capable of compensating for deficiencies and restoring the balance of tattukkal will form part of the treatment of disorders. In addition to the functions of regenerating and balancing tattukkal, food provides the digestive fire which is necessary for the formation of tattukkal. Food, moreover, possesses various qualities that play a role in physiology and digestive metabolism. One of these qualities is tastes, or arucuvaikkal, which are of six categories: sweet, or inippu, sour, or pulippu, salty, or uppu, pungent, or karppu, bitter, or kaippu, and astringent, or tuvarppu. These tastes can act in opposition; regarding the treatment of diabetes, it is worth mentioning that plants with a bitter taste have the property of inhibiting a sweet taste; some of these oppositions are used in ayurveda and siddha formulas. Food is also classified as heavy/light, cold/hot, solid/liquid, soft/hard, minute/gross, and so on. The heavy/light group is particularly important because of its action on digestion. Light foodstuffs may be consumed in large quantities without any damage to health, while heavy foodstuffs are difficult for the digestive fire to metabolize. Another quality of foodstuffs is potency (viriya) which defines their power to act in the body. (Thirunarayanan n.d. Uthamaroyan 2005).

Rattinammal and Jeyananda's dietary advice takes into account both traditional knowledge and contemporary food habits. In the medical text, Patārtta guña cintāmaṇi by C. S. 
Uthamaroyan (2005: 246-247), two meals a day are recommended for good health. However, practitioners provide dietary prescriptions on the basis of four meals a day according to the contemporary food pattern. Advice on mealtimes which have an important place in medical texts is also omitted. However, they advise patients with diabetes to reduce the quantity of food. It is stipulated in siddha medical texts that the stomach must not be full so that there is room for air which, associated with digestive fire, enhances digestion (Uthamaroyan 2005) and that excess food increases vata-pitta-kapa in the body. Jeyananda and Rattinammal know the theoretical corpus that is the foundation of the food taxonomy. Nevertheless, their dietary prescriptions for patients with diabetes that follow the rules of pattiyam/apattiyam 'do/don't', are not individualized. They encourage patients with diabetes to reduce cereal intake, avoid sugar, sweets and oily items and to increase intake of pulses, green leaves and vegetables. They strongly emphasize the consumption of millets, sorghum and whole grain, and of certain Indian vegetables such as bitter gourd and spices used in medicines for their anti-glycemic proprieties (cumin, turmeric, asafoetida). They recommend consumption of dairy products that lower pitta in the body since pitta is considered to increase the likelihood of diabetic conditions, but discourage meat intake that enhances it. To sum up, they strongly encourage their patients to return to traditional food. Their recommendations are relevant because millets, sorghum, pulses and vegetables are rich in micronutrients and fibres that help to prevent or control diabetes as well as combating micronutrient deficiencies that affect a large part of the Indian population regardless of socio-economic status (Singh 2007). Nevertheless, practitioners must explain at length and repetitively in order to convince patients of the beneficial effect of dietary prescriptions on their health, and find arguments to thwart complaints such as 'only rice is available to us (in ration shops); how can I buy kampu or ragi (pearl millet; finger millet)?' 'Doctor, we cannot pay for vegetables, pulses, milk, they are too expensive'. 'It takes too long to prepare ragi and it is difficult to eat it at the office'. 'I have too much work, how can I manage to prepare food for me and food for my children? My children want only rice, they don't like vegetables, they don't want bitter gourd.'

Patients' responses regarding prescriptions are well founded. As I mentioned at the beginning, the cereals available in ration shops are rice; the price of vegetables is very volatile and, according to season, too high for patients who have to face expenditure, not only on food but also on medicine, education, and so on. Indian vegetables and green leaves are cheaper, but they are depreciated compared to 'English vegetables'. The bitter taste of various vegetables is also an obstacle. As some have high anti-glycaemic proprieties, such as the renowned bitter gourd, pharmaceutical companies transform them in cüranam and sell them in capsules. However, unwillingness to change food habits is the main obstacle. A study on biomedicine conducted in 1999, quoted by K. Venkataraman et al. (2009) shows that only 37 per cent of diabetic patients are compliant with dietary prescription. Compared to biomedical practitioners, siddha ones possess a valuable therapy for controlling food-related diseases, as diet is an intrinsic part of the treatment. But the lack of compliance with diet may be a drawback as the efficacy of medication depends on it.

\section{Perspectives and issues}

Jeyananda's and Rattinammal's medical practices mirror the great heterogeneity of knowledge and know-how that I was able to observe during my eight-year research on siddha. Indeed, among the practitioners I visited, four who run large hospitals use biomedical diagnostic tools similar to Jeyananda's (X-ray, laboratory, sphygmomanometer) and have recourse to marketed drugs to supplement their own. In other words, they correspond to the 
class called 'lay practitioners' by Kalpana Ram who 'hope(s) to soften, if not abolish, the invidious distinctions between the polarized and hierarchical categories of "indigenous" and "cosmopolitan"' (2010: 200). Not all practitioners, however, accept that siddha is intertwined with biomedicine as that would weaken its own identity. Like Rattinammal, they are likely to provide medicaments based on iatrochemistry, to elaborate new formulas from texts, and to use other therapies that share some characteristics with siddha, such as homeopathy, naturopathy, Bach flower remedies, magneto-therapy, and so on. They are also very involved in the promotion of their medicine in addition to dealing with patients, students and interested persons. The differences in practice depend largely on the personality and ambitions of the practitioner, and also on his/her knowledge, inherited as well as acquired and experienced, that give him/her the capacity to mobilize different medical sources to treat and adapt to the new context of health and diseases.

The complaints of Jeyananda and Rattinammal about the difficulty of treating patients with siddha medicine are justified. People demand quick relief. They make frequent consultations when their disease is at a very advanced stage or when they have not been cured by biomedicine after a long time. These are the issues often confronted by traditional siddha practitioners. They result from the hegemony of biomedicine, scientificity and rationality, over empiricism, experience and know-how. Patients are not the only issue. Among the obstacles that weaken the position of traditional siddha practitioners are: the difficulty of producing their own medicines as medicinal plants are being reduced due to pressure exerted by urbanization; the decreasing quality of medicinal products from specialized shops; the lack of interest of their children in continuing the family profession; the competition from biomedicine and ayurveda; and the non-recognition by institutionalized siddha practitioners. Nonetheless, during my observations of Jeyananda, Rattinammal and others, I noticed how well they healed diabetic ulcers, in spite of the often advanced stage of the ulcers. They rarely advise their patients to revert to biomedicine, which would probably mean amputation. Patients with joint and back pain, osteoarthritis or hemiplegia are also very satisfied with the results of the treatment. On the other hand, it is impossible for me to judge the efficacy of medications on blood sugar as it is not the role of ethnographical studies to make such evaluations. In my reading of the patients' records at Jeyananda's hospital, I noted a progressive decrease of sugar levels in patients treated with anti-diabetic tablets from ayurveda or siddha pharmacies. Such observations are impossible with Rattinammal as there are no clinical test records. She never pays attention to the laboratory analyses of her patients, and never advises going to the laboratory to check sugar levels. It is worth mentioning that although Jeyananda prescribes blood sugar tests, his interest in the results is limited. Like Rattinammal, he evaluates the efficacy of his treatment by checking the pulse and questioning the patient on his/her symptoms and health. His lack of concern with sugar tests shows that he prescribes them only to 'reinforce the confidence of the patient'. Jeyananda and Rattinammal have no doubt of their ability to treat patients with diabetes, nor of the efficacy of the medicaments provided by them or from pharmaceutical companies. The effectiveness of a medicine, as the World Health Organization demands, are nonsense to them. Their long experience and knowledge of the practice of medicine inherited from several generations has conferred on them the skill necessary to be confident in the treatment. It is noticeable that a large number of the medicinal plants Rattinammal uses for preparing her curanaikal are well known for their anti-diabetic properties and are used in siddha and ayurveda formulas such as Momordica charantia, Aegle marmelos, Phyllanthus emblica, Terminalia chebula, Gymnema sylvestre, Azadirachta indica, Elipta alba, Cassia auriculata, Enicostema axillare, Glycyrrhiza glabra, Myrica nagi, and so on (Canmukavelu 1993; Chacko 2003; Goyal 1998; Grover et al. 2002; Masilamani et al. 2000; 
Pandey et al. 1996; Sood et al. 2005; Veluchamy et al. 2004). Dietary prescriptions of traditional siddha practitioners, influenced by their own consumption pattern that privileges traditional food, are also a useful tool to treat, as well as to prevent, diabetes. Even though the dietary prescriptions meet with reticence from some patients, they are consistent with the advice on medicinal and nutritional properties of plant foods in the treatment of food-related diseases (sugar from the borassus palm, millets, pulses, vegetables) which, today, are profiled in the media and arouse interest among the middle class and patients with diabetes. Therefore, there is no doubt that traditional siddha practitioners contribute to the prevention and detection as well as the treatment of diabetes and its allied diseases. Not only do they complement health services which are deficient in rural as well as in urban areas, but also, they treat patients at affordable prices. Although medication may be expensive at the beginning, as the treatment aims at rectifying the imbalance of vata-pitta-kapa, therapies for treating allied diseases and hospitalization are cheap. Practitioners are also aware of the financial situation of patients so that they adjust the price of the treatment to their means. This is an enormous advantage for the treatment of diabetes whose chronicity and the price of medication often force patients to disrupt their treatment or go untreated.

\section{Notes}

1 Homeopathy was founded by the German, Samuel Hahnemann, but it expanded rapidly in India after its introduction in the first part of the eighteenth century because of its material medica and some of its concepts which echo Indian medicine. Traditional medicines are, in essence, allopathic, and the term allopathy for distinguishing biomedicine from traditional medical systems is incorrect. Unani is a combination of Greco-Arabic and Indian medicine.

2 See the AYUSH 2007 report (retrieved on 23 February 2014): http://indianmedicine.nic.in/ writereaddata/linkimages/2155398780-section3.pdf

3 In India, 'millet' is a generic term used for different varieties of pulses, namely sorghum (Sorghum vulgare), pearl millet (Pennisetum glaucum), finger millet (Eleusine coracana), foxtail millet (Setaria italica), barnyard millet (Echinochloa colona), proso millet (Panicum miliaceum), kodo millet (Paspalum scrobiculatum) and small millet (Panicum sumatrense).

4 Historical studies on cereal consumption in South India are rare. One may consult the archaeological research of Dorian Fuller (2011) and of K. R. Krishna and Kathleen D. Morrison (2010) on the domestication of cereals.

5 This appellation echoes the fact that rice has long been the privileged staple food eaten by Brahmans in South India. Two explanations can be given. First, Brahmans were supported by the rulers who developed irrigation for rice crops in deltaic regions. The epigraphy of many Brahmanical temples shows that paddy (rice with hull) was offered to feed the deities, the Brahmans and the temple servants. Some major temples also stored paddy in the past. Second, the white colour of polished rice corresponds to the sattva guna (Sanskrit: sattva quality), according to Sāṃkhya philosophy which classifies all the elements of nature into three qualities: sattva-rajas-tamas. Sattva refers to purity, perfection and whiteness; it is the quality par excellence of Brahman ethics. In contrast, rajas which refers to vitality, energy and redness corresponds to the Kșatriya ethics and tamas which refers to obscurantism, impurity, wildness and blackness corresponds to the identity of Śudra and Avarna (untouchable).

6 Idli (steamed cake) and docai (a kind of pancake) are southern Indian foods. The dough is prepared by grinding grains (rice or millet with husked horse gram) soaked in water for one night for developing fermentation.

7 Iatrochemistry is the use of chemistry for healing. It is based on the alchemical principle that the body is constituted of chemical elements which intervene in the health of the person.

8 This chapter uses the transliteration rules according to the Tamil Lexicon, University of Madras (1982). In the perspective of homogeneity, the transcription of Sanskrit words is privileged over that of Tamil words.

9 See the document entitled Organization of Health Care in India by Leo S. Vaz on www.whoindia. org/ContentPages/127626072.pdf (retrieved on 23 February 2014). 
10 Varma therapy comprises acupressure on vital points for treating bone and joint pain, muscular dystrophy and neurological disorders, and massages using medicated oils and fresh plants. This therapy is a part of varmakkalai (art of vital points) which consists in two opposite arts: that of causing harm or death by touching the vital points through cilampam (Tamil martial art using long sticks or cilampam and various weapons), and that of healing by pressing injured vital points.

11 Compared with the usual statement that traditional medicaments are cheap, I have noticed that those prescribed are often expensive (400 rupees (around £1.95) or more according to the ailment) because the number of different medicaments is high. The preparation of medicines is certainly expensive, notably when they require manpower and high-cost products

12 Rattinammal's explanation of the relationship between blood sugar and imbalance of väta-pittakapa differs from that given by institutional siddha doctors. Basing their explanation on medical texts, they identify the presence of diabetes by vitiated kapa which results in deterioration of the seven constituents of the body (Masilamani et al. 2000; Shankar and Aggarwal 1986; Shankar and Singhal 1995).

13 Bach flower therapy was developed in the 1930s by Edward Bach, a British homeopath. Bach elaborated his treatment from the fact that flower petals contain all the healing power of the plant. He used it, primarily, for counteracting negative emotions which could cause depression, anxiety, insomnia and stress. According to homeopathy's principles, Bach remedies are based on the 'water memory' so that the flower extracts are highly diluted in water. Ratinammal is able to buy her Bach remedies in Madurai, which means that this treatment is well known. It is used by practitioners involved in alternative medicines such as naturopathy, homeopathy and herbal therapy. In the field of siddha medicine, I met another woman traditional siddha practitioner who used this therapy.

\section{References}

Balagopal, P. N. Kamalamma, T. G. Patel, and R. Misra (2008) 'A Community-Based Diabetes Prevention and Management Education Program in a Rural Village in India', Diabetes Care, 31(6): 1097-1104.

Barker, D. J. (1995) 'Foetal Origins of Coronary Heart Disease', British Medical Journal, 311: 171-174.

Bhardwaj, S., A. C. Misra, L. Khurana, S. Gulati, P. Shah, and N. K. Vikram (2008) 'Childhood Obesity in Asian Indians: A Burgeoning Cause of Insulin Resistance, Diabetes and Sub-clinical Inflammation', Asia Pacific Journal of Clinical Nutrition, 17 (S1): 172-175.

Canmukavelu, M. (1993) Nōykal ukkuc cittaparikāram (Iraṇtām pākam) Chennai: Department of Indian Medicine and Homeopathy (1st publication 1976).

Chacko, E. (2003) 'Culture and Therapy. Complementary Strategies for the Treatment of Type-2 Diabetes in an Urban Setting in Kerala, India', Social Science and Medicine, 56: 1087-1098.

Deaton, A. and J. Drèze (2009) 'Food and Nutrition in India: Facts and Interpretations', Economic and Political Weekly, February 14: 42-64.

Formulary of Siddha Medicines (2000) Madras, IMPCOPS, The Indian Medical Practitioners's Cooperative Pharmacy and Stores LTD (1st publication 1956).

Fuller, D. (2011) 'Finding Plant Domestication in the Indian Subcontinent', Current Anthropology, 52 (S4): 347-362.

Ganapathy, T. N. (1993) The Philosophy of the Tamil Siddhas, New Delhi: Indian Council of Philosophical Research.

Goyal, H. R. (ed.) (1998) Theriyar Kudineer, New Delhi, Central Council for Research in Ayurveda and Siddha, Ministry of Health and Family Welfare, Government of India.

Grover, J. K., S. Yadav, and V. Vats (2002) 'Medicinal Plants of India with Anti-diabetic Potential', Journal of Ethnopharmacology, 81: 81-100.

International Institute for Population Sciences (IIPS) and Macro International (2007) National Family Health Survey (NFHS-3), 2005-06: India: Volume I, Mumbai: IIPS.

Kaushik, G. S. Satya, R. K. Khandelwal, and S. N. Naik (2010) 'Commonly Consumed Indian Plant Food Materials in the Management of Diabetes Mellitus', Diabetes \& Metabolic Syndrome: Clinical Research \& Reviews, 4 (1): 21-40.

Krishna, K. R. and K. D. Morrison (2010) 'History of South Indian Agriculture and Ecosystems', in K. R. Krishna (ed.), Agroecosystems of South India: Nutrient Dynamics, Ecology and Productivity, 1-51, Boca Raton, FL: BrownWalker Press.

Kumar, P. and V. C. Mathur (1996) 'Structural Changes in the Demand for Food in India', Indian Journal of Agricultural Economics, 51 (4): 664-673. 
Kumar, P., D. Mruthyunjaya, and M. M. Deyb (2007) 'Long-term Changes in Indian Food Basket and Nutrition', Economic and Political Weekly, September 1, 3567-3572.

Langford, J. M. (1995) 'Ayurvedic Interiors: Person, Space, and Episteme in Three Medical Practices', Cultural Anthropology, 10 (3): 330-366.

Masilamani, G., V. Ravishankar, U. M. Kansra, and B. Chakravorty (2000) 'Clinical Study on Neerizhivu Noi (Diabetes Mellitus) - A Comparative Study', Journal of Research in Ayurveda and Siddha, 21 (3-4): $126-134$.

Mittal, S. (2007) 'What Effect Changes in Cereal Consumption?' Economic and Political Weekly, February 3: 444-447.

Mohan, V., M. Deepa, R. Deepa, C. S. Shanthirani, S. Farooq, A. Ganesan, and M. Datta (2006) 'Secular Trends in the Prevalence of Diabetes and Impaired Glucose Tolerance in Urban South India - the Chennai Urban Rural Epidemiology Study (CURES-17)', Diabetologia, 49: 1175-1178.

Mohan, V., P. Mathur, R. Deepa, M. Deepa, D. K. Shukla, G. R. Menon, K. Anand, N. G. Desai, P. P. Joshi, J. Mahanta, K. R. Thankappan, and B. Shah (2008) 'Urban Rural Differences in Prevalence of Self-reported Diabetes in India - The WHO-ICMR Indian NCD risk factor surveillance', Diabetes Research and Clinical Practice, 80: 159-168.

Nisula, T. (2006) 'In the Presence of Biomedicine: Ayurveda, Medical Integration and Health Seeking in Mysore, South India', Anthropology and Medicine, 13 (3): 207-224.

Pandey, V. N., S. C. Malhotra, and D. P. Sharma (eds) (1996) Pharmacological Investigations of Certain Medicinal Plants and Compound Formulations Used in Ayurveda and Siddha, New Delhi, Central Council for Research in Ayurveda and Siddha, Ministry of Health and Family Welfare, Government of India.

Pingali, P. and Y. Khwajav (2004) 'Globalisation of Indian Diets and the Transformation of Food Supply Systems', ESA Working Paper No. 04-05 in 17th Annual Conference Indian Society of Agricultural Marketing, Hyderabad, Agricultural and Development Economics Division, FAO.

Ram, K. (2010) 'Class and the Clinic: The Subject of Medical Pluralism and the Transmission of Inequality', South Asian History and Culture, 1 (2): 199-212.

Ramachandran, A., C. Snehalatha, A. D. S. Baskar, S. Mary, C. K. Sathish Kumar, S. Selvam, S. Catherine, and V. Vijay. (2004) 'Temporal Changes in Prevalence of Diabetes and Impaired Glucose Tolerance Associated with Lifestyle Transition Occurring in the Rural Population in India', Diabetologia, 47: 860-865.

Ramachandran A., C. Snehalatha, K. Satyavani, S. Sivasankari, and V. Vijay (2003) 'Type2 Diabetes in Asian-Indian Urban Children', Diabetes Care, 26: 1022-1025.

Sébastia, B. (2010) 'Governmental Institutions versus Associations: The Multifaceted Expression of Siddha Medicine in Tamil Nadu', available at http://rasi.hypotheses.org (retrieved on14 May 2015).

Selvam, S. Catherine and V. Vijay (2004) 'Temporal Changes in Prevalence of Diabetes and Impaired Glucose Tolerance Associated with Lifestyle Transition Occurring in the Rural Population in India', Diabetologia, 47: 860-865.

Shah, B. (2003-2005) Development of Sentinel Health Monitoring Centers for Surveillance of Risk Factors of Noncommunicable Diseases in India (April 2003 to March 2005) Collated Results of 6 Centers, Founded by World Health Organization, New Delhi: Division of Non-communicable Diseases, Indian Council of Medical Research.

Shankar, V. R. and M. P. Aggarwal (1986) 'Clinical Studies of Abraga (Mica) Chendooram in the Management of Diabetes Millitus (Neerzhivu)', Journal of Research in Ayurveda and Siddha, 9 (1-2): $38-45$.

Shankar, R. and R. K. Singhal (1995) 'Clinical Studies of the Effect of Abraga (Mica) Chendooram in the Treatment of Diabetes Mellitus (Neerzhivu)', Journal of Research in Ayurveda and Siddha, 16 (3-4): $108-117$.

Singh, P. (2007) 'Micronutrients Deficiencies in India', Journal of the Indian Society of Agricultural Statistics, 61 (2): 128-131.

Sood, S. K., R. Bhardwaj, and T. N. Lakhanpal (2005) Ethnic Indian Plants in Cure of Diabetes, Jodhpur: Scientific Publishers.

Thirunarayanan, T. (n.d.) An Introduction to Siddha Medicine, Tiruchendur: Thirukumaran Publishers.

Uthamaroyan, C.S. (2005) A Compendium of Siddha Doctrine, translated by R. Anaivaari Anandan, Chennai: Department of Indian Medicine and Homeopathy.

Veluchamy, G., S. Raja Rattinamma, S. Jega Jothi Pandian, and M. Sundaramoorthy (2004) A Hand Book of Common Remedies in Siddha System of Medicine (3rd Revised Edition), New Delhi: Central Council for Research in Ayurveda and Siddha, CCRAS - Pub. 13 (1st published 1975).

Venkataraman, R. (1990) A History of The Tamil Siddha Cult, Madurai: NS Ennes Publications. 
Venkataraman, K., A. T. Kannan, and V. Mohan (2009) 'Challenges in Diabetes Management with Particular Reference to India', International Journal of Diabetes in Developing Countries, 29 (3): 103-109.

Wardlaw, T., A. Blanc, J. Zupan, and E. Åhman (2004) Low Birth Weight. Country: Regional and Global Estimates, United Nations Children's Fund and World Health Organization, New York: UNICEF.

Weiss, R. S. (2009) Recipes for Immortality. Medicine, Religion and Community in South India, New York: Oxford University Press.

WHO (2002) Traditional Medicine Strategy 2002-2005, Geneva: World Health Organization.

Wujastyk, D. (2001) The Roots of Ayurveda. Selection from the Ayurvedic Classics, New Delhi: Penguin Books.

Wujastyk D. and F. M. Smith (eds) (2008) Modern and Global Ayurveda. Pluralisms and Paradigms, Albany, NY: State University of New York Press. 


\section{INDEX}

Endnotes are indicated with 'n'. For example, 46 n17 indicates endnote 17 on page 46.

Aam Aadmi Party 46n17, 256

Abe, Shinzo 132

Adani, Gautam 279

Adani group 279

Ad Dharm 14, 169, 373-6, 380, 382n13

Ad Dharm Report 376

Addlakha, Renu 292

Adigurus: festivals of 376

adivasi communities: and the capitalist economy 303-5; and Christian missionaries 301; definitions of 297-8, 305; exists only in Schedule V areas 298; fissured along the lines of class, gender and generation 300, 305; identity of 297; and indigeneity activists 12, 298, 302-3; and the Maoist movement 302; misrepresented as noble 'eco-savages' 303; and non-state actors 301-3; politics of 297-305; and right-wing Hindu organizations 301-2; and sarna (sacred grove) activism 301; and the state 299-301

Ad Prakash (The Original Light) 376, 382n17

affirmative action 5, 91, 93, 123, 401, 417

Afghanistan 8, 43, 130, 139, 147, 150, 152

Africa $147,149,150,151$

Agnes, Flavia 293n6

Agnihotri, I. 432

agrarian reform: blocked by rich farmers 204; failure by the state to implement 127

Agrawal, S. 149

agriculture 6-7, 10, 67, 68, 73-4, 99-114; alternatives in development of 104-7; 'basis of all development' of 101-2; bears the burden of structural unemployment 107; bureaucratic strangleholds on 112; centralisation of 102; changing land use patterns of 102; development of defined as technological modernisation 103; disillusionment of modernisation of 104; diversity of not acknowledged by the state 111; growth rate 107; increasing subsidies of 103; the intermediate regime imposes its articulation of development on 99; left largely untouched by economic reforms 206; modernisation for development of 103-4; rainfed 111; supply driven 103; three phases of development articulation101-7; under-employed work force in 107

Ahl-e-Sunnat 386

Ahlstrom, Sydney 179

Ahluwalia, Montek Singh 212

Ahmadabad 272, 273, 274, 275

Ahmed, Imtiaz 387, 395n2

ajlaf 387,390

akhara 449

Akhtar, Farhan 447, 454n8

alchemy 477, 478, 479, 481

Ali, Ahmed 163

Ali, Cajzoran 180

Ali, Justice Fazl 51

Allahabad 349, 356, 357

All Assam Student Union (AASU ) 125

All India Ayurveda Mahasammelan 187

All India Ayurvedic Congress 187, 189

All India Pasmanda Muslim Mahaz 388

Alter, Joseph 176, 449-50

Amarnath 349

Ambedkar, Bhimrao Ramji 13-14, 39, 372; all India service of 366; conversion 366-7; and Dalit liberation theology 419; diaspora influence 169; drafting the 
Hindu Code Bill 294n13; first encounter with Buddhism 361; four problems in the teaching of Buddhism 368; giving Indian democracy a strong foundation 2; 'messiah of the downtrodden' 372; Navayana Buddhism and 3, 361-70, 378; oaths taken at the time of conversion 367; portraits of 377; sacred symbol 168; and Sants of Ravidass Deras 378; satyagrahas of $363-5$; statues of $169,263,357$; threat to the Hinduisation movement 402

Ambedkar International Mission 169

Amritsar 26, 27, 32, 33n2, 125, 167

ancestral homelands: memory of 22

Anderson, Benedict 440

Andhra Pradesh 58, 60, 76, 258, 349-51, 391, 421

Andrew, C. F. 164

Anjaria, J. S. and C. McFarlane 222-3

anti-Christian violence 420, 422

anti-colonialism 256

anti-conversion legislation 301, 416, 417-18

anti-corruption 11, 27, 28, 44, 238, 256-69;

appeals to a lost political morality

264; BJP traditionally dominated by

an ideology of 263; committees 260;

critiques of the colonialism system 257;

middle class privilege 267; movements

appearing at moments of state transition

267; reports 261

anti-cow slaughter rhetoric 457

anti-globalization 261

anti-Hindi agitation 125

anti-Maoist operations 128

anti-Muslim pogroms 302, 393, 394

anti-Muslim rhetoric 457

anti-Muslim riots 126, 302, 393, 394-5

anti-Sikh riots 125

Antony, A.K. 130, 131, 132, 142

Appadurai, Arjun 460, 466

arcāvatāra 334, 335

Arunima, G. 287-8

Arya Samaj 402

arzal 387, 390

Asad, Talal 391

äsana (the physical postures of yoga) 172-9

ashraf 387, 390

Association of Southeast Asian Nations

(ASEAN) 138

Australia 132

autobiography 168, 178, 284, 369

Ayodhya 126, 163, 348, 357-8, 392, 407, $412 \mathrm{n} 7,432$

ayudhapūjā 342, 343

Ayurveda 3, 9, 17n9, 185-97, 474, 477-8, 480, 481, 482, 483, 485; Anglophone 195-6; and biomedicine 185, 187, 189, 190, 192, 193, 194, 195, 196, 197; borrows from the paradigms and methods of biomedicine 193; in contemporary India 192-4; as a global health tradition 194-6; inclusive approach of popular writers in the West 195; in independent India 18992; as an indigenous tradition 189-90; integrationists 190; modern/modernised 185; national system of health care 189; pre-modern 185; purists 190; revivalist movement 186-7, 193, 188; status of inferiority 192; transnational Anglophone manifestations of 196

Ayurveda Mahasammelan, 187

Ayurvedic branded products 191

Ayurvedic hospitals 191, 192

Ayurvedic pharmaceutical industry 193

Ayurvedic practitioners 186; aligned with the nationalist struggle 186; attempted to align with science 187 ; borrowed from Orientalist perspectives 186; came together to revive Ayurveda 186; cooperation with Western biomedicine 187; emphasized the need to establish Ayurveda as India's national medicine 186; felt increasingly marginalized 186 ; sought support in religion 187; tried to showcase the scientific achievements of ancient India 187

AYUSH see Department of AYUSH

Baba Ramdev 173

Babri Masjid 56, 126, 206, 207, 357-8, 392, 396n13, 407, 412n4, 412n7

Babu Mangu Ram Mugowalia, 373; see Mangu Ram

Bach, D. C. 148

Bach flower remedies 479, 482, 487n13

Bahadur, Nripendra Narayan Bhup 286

Bahujan Samaj Party 357, 369

Bailey, F. G. 147

Bakreshwar 355

Balakrishnan, Justice 57

Balasarasvati 339-40

Bali 339, 344

Bandyopadhyay, Sibaji 290-1

Banerjee, A. and T. Piketty 208

Banerjee, M. 191

Banerjee-Guha, S. 220

Bangalore 172, 225, 342, 368, 419, 448, 461, 462

Baptiste, Walt 179

Bardhan, Pranab 204

Barelwi, Maulana Ahmad Raza Khan 386

Basham, A. L. 326

Bansode, Kisan Fagoji 362

Basu, Srimati 283, 289

Bauman, C, 422

Baxi, Pratiksha 289 
Begum Sombre of Sardhana 285-6, 290

Beidelman, T. O. 247

Belarus 150

Belgaum district (Karnataka state) 409

Benjamin, S. 223

Berreman, G. 245, 246

Bhaag Milkha Bhaag 447

Bhaartiya Buddhist Cultural Association 169

Bhabha, Homi 440

bhagat 378

Bhagavadgītā 334, 335

bhagidari 226, 227

Bhagwati, J. 205

Bhagwati, Justice 52

Bhaktavatsala, Justice 283

Bharatiya Janata Party (BJP) 40, 42, 46n17, 124, 391, 411-12n1; and 1992 violence

357; and 2002 violence 126, 271; ability to capitalize on the political and socioeconomic contradictions within the middle classes 239; Ayodhya campaign of 357; blaming Congress for having orchestrated a 'pink revolution' 457; boost to India's quest to play the role of a major power in Asia 142; Dalit struggle and 419; and Deepa Mehta's film Fire 290; and Gujarat as 'showcase' of the Hindu right 271; ideology of a homogeneous Hindu nation of 357; rise of rested in part on an urban-middleclass backlash against a Congress government 237; seen as party of business and industry 39 ; situation of religious minorities worsened under 271; and statue of Sardar Vallabhai Patel 357; traditionally been dominated by an antireservation ideology 263; and traditions of salvific space $357-8$

Bhardwaj, A. 30

Bhattacharya, R. and K. Sanyal 220

Bhils 299, 300

Bhiwandi riots 410

Bhutan 136, 147, 148

binary medical model 192

biomedicine 3, 9, 185, 187, 188, 189, 190, 192, 193, 194, 195, 196, 197, 474-5, 478, 479-80, 483, 484, 485

biopolitics 479

Biswas, Ranjita 289

BJP see Bharatiya Janata Party

Bode, M. 192

bodily capital 451-2

body 14-15; of brahman 332, 334, 345; carries aspects of Hindu cosmologies 338; dancer creates the temple within the 340 ; 'deviant' 293; elaborate taxonomy of foods based on the 483; female 429-41; fluid and permeable 194; and food habits and hierarchies 16, 460-1; gendered 291, 292; increasingly circulating images of female 439; male 15-16, 444-55; and notions of success, professionalism and being able to deal with consumerism, materialism and globalization 453; obesity 452, 453, 477, 459; prostitute's 435; shape and beauty of as a marker of modernity 450-1; struggle over which the nation articulated its concerns 440; vāta-pitta-kapa in the 484; violence and the female 430-2; of Viṣnu 334-5; as a weapon to foil patriarchal rape 437; women's 429-40; yoga dedicated to the $3,172-82$

bodybuilders 176, 179, 445, 449

The Bodybuilding.com: Guide to Your Best Body 447

Bofors scandal 257

Bollywood 15, 288, 445, 446-8, 451

Bombay 53, 124, 275, 276, 361, 363, 364, $365,367,369,374,406,407$

book-fairs 337

Bougle, Celestin 245

boundaries of federal states 42

Bourdieu, P. and J.-C. Passeron 83

Brahmā/Brahma 323, 367

Brahmachari, Dhirendra 173

brahman 13, 16, 331, 332, 334, 335, 344, 345

Brahman food 477, 486n5

Brahmans 167, 243, 245, 247, 252, 272, 273, $274,275,278,319,348,353,354,355$, $364,365,371,468,486 n 5$

Brass, Paul, 23, 264, 411

Brautigam, Deborah 149

Breman, Jan 221, 276

Brereton, Bridget 164

Bretton Woods institutions 205-6

British Raj 2, 136, 186, 359n9

broad-based political coalitions 41

Brown, W. Norman 313, 314

Bt genes 106

Buddha 14, 169, 333, 344, 348, 357, 361, 362, 367, 368, 369, 370

The Buddha and His Dhamma 368

Buddhism 3, 13-14, 325, 347, 348, 361-70, $378,382 \mathrm{n} 15,402,423 \mathrm{n} 8$

Burma 136, 143n7, 149, 162, 368, 460, 477

Butalia, U. 432

Butler, Judith 291-2

Caesar, T. Franklin 422

cakra system 181

Calcutta 186, 189, 287, 290; see also Kolkata

The Cambridge History of India 319

Cāmuṇụī 343

Canada 164-5, 166, 169, 322

Caplan, Patricia 458, 462, 470n9

Carrin, M. and H. Tambs-Lyche 301

Cārvākas 331 
Casper, M. J. 445

casta 243

caste: alliances and caste consciousness, and modern election 39; all India schema 248; among Indian Muslims 387-8; changes in the traditional order 248-50; changing realities of 248-50; conceptualisations of 244-8; declining hierarchy 250-2; dominant 247; hierarchy 249, 250, 252, $371,372,381 \mathrm{n} 3$, 415, 421; horizontal mobilization 252;and kinship networks 251; mobilization from the margins 249; Muslim mobilization around 388; and old diaspora 163; overlaps with newer forms of inequalities 253; persistence of 252; persisting inequality 250-2; and reservation policy 249; system 244; violence and 250; works to block those located at the lower end 252

Castes of Mind 246

Census of India 26, 110, 122, 123, 235, 400, $414,418,419,420$

centralization of power 59,422

Centre for Public Interest Litigation 422

cevai 479; see also seva

Chamar 169, 362, 375, 377, 378, 379

Chandrachud, Justice 55

Chandramani, Mahastavir 366

Chatterjee, Partha 212, 256, 267

Chaudhuri, Buddhadeb 355

Chennai 16, 258, 337, 342, 419, 457-71, 476

Chester, Lucy 24, 26

Chhattisgarh 86, 111, 127, 128, 289, 301, $423 n 4$

child malnutrition rates 211

China 1, 68, 75, 130, 136, 137-8, 140, 141, 142, 146, 154, 160, 166, 175, 180, 205, 208, 210, 217; border dispute with 121; invasion in 1962 129; providing Pakistan with weapons-grade uranium for two atomic bombs 138

Chitnis, Suma 88

Chopra, Deepak 195

Choudhary, Bikram 179

Chowdhry, Prem 287, 289, 431-2

Christian missionaries 301, 332; first arrival of Protestant 415; and the Hindu right 303; permit British missionaries to enter 415; primary aim of evangelistic 415; Protestant 415

Christians 414-23; internal diversification of $415,420,422,423$; right to administer own educational institutions 422 ; struggle to gain scheduled caste status 418-19, 420, 422

Church of North India 419, 422

Church of South India 419, 421, 422

CII see Confederation of Indian Industry cinema 290, 337, 338, 339, 340-1

citizenship question 390-4

city 216-29; development 219-22; governance 223-6; large and small 217-19; privatized 226-8; reimagined as a site of private fulfilment 228

civil society organisations (CSOs) 94, 155, 226

class identity 232, 236, 239

class politics 227, 232, 234, 238

class warfare 121

Coochbihar marriage 286-7, 293n5

Coelho, K. et al. 225

Cohen, Joel E. 92

Cohn, Bernard 246

Collingwood, R. C. 315, 316

'commodification of ethnicities' 469

communalism 14, 23, 93, 259, 264, 389, 400, 408

communal riots 23, 402, 403, 404, 408; after the demolition of the Babri Masjid in Ayodhya 357, 412n7; in Assam 393; in Bhiwandi 410, 411; deaths during 403-12; in Gujarat in 2002 406; in Mumbai 407; in Muzaffarnagar in Uttar Pradesh 393; and 'vote bank' politics 126

Communist Party of India (Marxist) 207, 300

composite culture 26, 30, 358

Confederation of Indian Industry (CII) 149, 212, 279

Congress party, 38, 39, 40, 49, 52, 55, 124, $125,128,233,262,263,275,278,279$, 422, 436, 454n15, 457; see also Indian National Congress

Conlon, Frank 466

conspicuous consumption: as a strategy of class distinction 461, 466

The Constituent Assembly 24, 48, 49, 58, 59, 366, 417

constitutional self-preservation 60

Constitution of India 42, 43, 48-65, 123, 125, 126, 132, 223, 248, 297, 301, 344, 361, 366, 389, 390, 393, 395-6n9, 401, 417, 419, 422, 429; federal structure of 54-60; rights based discourse of 49-54, selfpreservation of 60-3

contribution to international development $146-55$

conversion: to Buddhism of Ambedkar 366-7; to escape religio-cultural homogenization 422-3; movements led by caste Hindus 402; Nagpur field of 368; oaths taken by Ambedkar at the time of conversion 367; to seek upward mobility 372

Cook, Ian 469

Coordination Committee of Maoist Parties and Organisations of South Asia 127 
Corbridge, S. and J. Harriss 208

corruption 11, 38, 112, 152, 238, 256-69, 279; accusations based on political competition 265-8; as an alternative political economy 267; and bureaucracy 265-6; and failing tradition of political integrity and morality 262; non-routine scandals 257; politics of 258-9, popular views on 261; represented as a total failure of governance 262 ; routine forms of 258 ; symptom of antimodernity 261

corruption-free governance, right to 53

cosmopolitanism 319, 445, 461, 466, 468, 470

cotton hybrids 106

cow, holiness of 457, 465, 470n4

Crang, Peter 469

Crime in India 403, 408, 409, 410

crime statistics 14-15, 400, 403-12

Crooke, William 160

CSOs see civil society organisations

cultural capital 13, 236, 251, 333, 345

Dalai Lama 137

Dalit identity 361-70, 371-82; among Dalit Christians 419; based on a distinct Dalit religion 14, 361-70, 371-82; common adopted in the diaspora 169 ; concretization of a separate $373,376,378$; distinct markers of a separate $364,366-7$, 379-80, 383n13

Dalit Liberation Education Trust 419

Dalit liberation theology 419

Dalit literature 369-70

Dalit Panthers 366, 374, 381n5

Dalit religion 361-70, 373-82, 416

Dalit religious space $372,377-80$

Dalits 123, 132n1, 237, 381n5, 468; affirmative action and Christian 417, 41820; affirmative action and Muslim 417; affirmative action and Sikh 417; churches' involvement with the struggle of 418-19; conversion of 416, 418; forming a distinct identity of 373 , 376, 378, 379-80, 383n13; increasing assertions of $249,250,373$, 376, 378, 379-80; literature of 369-70; mobilisation of Muslim 388; move to urban areas 250-1; rich cultural heritage of 369-70, 373; violence against 250; violent clashes between dominant castes and 378

Dalit Voice 378

Dalton, G. T. 286

Daman, Ustad 21, 22

dance 179, 288, 337-40

dargāh/dargah 348, 358, 408

Darji, Jinabhai 279

darśan (seeing, looking) 338, 349

Das, Taranath 165
Das, Veena 431

Dave, Narmadashankar Lalshankar 280

Days of the Turban 15, 430, 433

Deaton, Angus 459, 476

decentralised knowledge 100, 113

decentralised location-specific programmes 106, 111

decentralised planning, demand for 111

decentralised regional production systems 113

decolonisation, legacy of 31

deglobalisation 67

Delhi 226

Delsarte, François 177, 179

De Michelis, E. 176

democracy 2, 3, 5, 6, 7, 35-46, 92, 121, 124, 126, 170, 203, 204, 207, 249, 253, 256, 384. $386,390,391,407,417,434$

demography 292, 401

Denotified and Nomadic Tribes (DNT) 268

Deobandi School 386

Department of AYUSH: Ayurveda, Yoga and Naturopathy, Unani, Siddha and Homeopathy 17n9, 191, 474, 478

Dera Ballan 373, 375, 378, 381n9, 381n12

Dera Chak Hakim 375

Desai, Amit 302

Desai, Morarji 280

Deshpande, Madhav 323-4, 325

Deśika, Vedānta 334, 335, 345n8

Devee, Maharani Sunity 286-7

development: agenda suiting accumulation by the intermediate class 100 ; and agriculture 99-114; engagement of the diaspora in 161; India's role as development actor 146-55; multilateral organizations 150; uneven social and economic consequences glossed over 153; violence and contradictions of 147

development cooperation 146-55, acceleration of 147; claims expertise to derive from direct experience of 148; does not impose India's own agenda in 148, 152; focused on India's South Asian neighbours 148; framed around shared experience 151; insistence on win-win outcomes 151 ; language in speeches of 152 ; noninterference as principle of 153 ; rejection of hierarchical relations 151; right to define on India's own terms 148

Development Partnership Administration (DPA) 150

Dharmapala, Anagarika 361

Dhawan, Nandita 289

diabetes 453, 459, 464, 466, 470n7, 474-87; caused by rapid change in food and lifestyle 476-7; green revolution partly responsible for 470n2; and siddha medicine 474-87

diachronic ontology, 324-5 
diaspora 1, 8-9, 17n5, 32, 121, 159-70, 340, 378,382 n22; caste discrimination in 169 ; Dalit 169, 382n22; diversity in 159-61, 167; history of 162-7; old 162-4, 166; role of religion in 167-9; temples in 168, 330, 332,333

diet transition 457

'differential' mobilization of voters 41

Dirks, Nicholas 246

disability movement 291-2

Divarkar, Paul 419

Divine Posture Influence Upon Endocrine Glands 180

Djalal, Dino 344

DNT see Denotified and Nomadic Tribes

Doniger, Wendy 318, 319

Donner, Henrike 461

Dravida Munnetra Kazhagam (DMK) party 124-5

Dreze, Jean 211, 459, 476

Duff, Alexander 232

Dumont, Louis, 245-6, 247, 293n12

Durgā/Durga 331, 336, 341, 342, 343, 368, 436, 437

Dutta, N. 440

A Dying Race 401

East Punjab 24, 27, 29, 30

Eaton, R. M. 385

ecological feedback loops 7, 112

ecological movements 106

economic growth 68; regional 75-6

economic liberalisation 129, 131, 135, 203-13, 216, 217, 222, 259, 261, 463, 464; elite groups winners of 204, 208-12; as elite revolt 208; failure of poverty reduction 209-11; jobs for the educated elites 208-9; and state subsidies for the wealthy citizens 209

economic policies 68-9; abandonment of a state centric model 203; embracement of a market oriented model 203; failure of poverty reduction 209-11; financial sector policy $72-3$; industrial policy $71-2$; jobs for the educated elites 208-9; lack of spending on health and education 209; macroeconomic policy 69-70; neglect of agricultural sector 209; state subsidies for the wealthy citizens 209; trade policy 70-1 economic reforms see economic liberalisation economic sectors: agriculture 73-4, 211-12; industrial sector $74-5$; service sector 75 , 208

economy, structural change 68 education 78-97; access to quality 86-8; attention paid to higher education only 88; consequences of competitive language politics for 89
Election Commission 35, 37, 38, 41, 44 ; and fight for equity 86 ; learning outcomes of 93; parallel structures of 91; political debates on 93 ; of the poor 93

elections, parliamentary $38,232,271$; central example of the political complexities of India's middle classes 239; and corruption 257, 260, 262, 264-5, 268; and political parties 38; see also national elections

electoral democracy, the sustainability of 42 electoral dynamics, power of 42-3

Elias, N. 463

Elwin, Verrier 299

emergency: the Centre's power to declare in any particular State 49, 55-7; the National 2, 51-2, 55, 124; at the regional level 42

Encyclopedia of Indian Physical Culture 175, 177

Engineer, Ali Asghar 410

English August 15, 430, 438, 439

entrepreneurialism (jugaad) 259

The Essence of Buddhism 361

The Essentials of Hindutva 396n11

ethnic violence 121

ex-untouchables 132n1, 249, 250, 374, 375, 376, 381n5, 388; see Dalit

family 283-94, history of 285-8; imposition of values of 287; upsurge in iconizing values of 284

family studies: dichotomy between tradition and modernity 284; historiography of 284

farmers: decreasing availability of institutional credit to 209; discontent among poor 127; the large benefitting from the state-led model of development 204, 209; marginal and small 110; the rich able to prevent reforms 211; suffering from declining public investments 212 ; suicides of 10, 111, 209, 211, 212; used for development agenda 100

Faulkner, William 313

federalisation 42

federalism 49, 54-60; asymmetric 58-60

Federation of Ambedkarite and Buddhist Organisations, UK 169

Ferozpur 26

Fiji 163, 166, 275

Fire 290

fiscal policy 69

Fisher, Michael H. 285

fitness industry 446-8

food 4; changing habits of 457-71; codification of in terms of purity and 
impurity 460-1; eaten out as forerunner of modernisation 463; 'healthy' 464; intrinsically related to health and disease 483-4; and maintenance of purity 460; marker of caste 460; marker of class 461, 462-3, 466, 469, 470; medical dimension of 460, 466; new 463-5; and obesity 453 ; practices embedded in a sociocosmological dimension 460; public sphere of 466-9; recommendations 483-4; ritually neutral of new and outside 469; secularisation of 469; taxonomy 484; theoretical ethos of 458, 460-1; transition of 458-60

food change 457-71; experience of eating out paving the way to $458,466-8$

food patterns 16, 458, 459, 461, 468, 470

foodscape 462, 463; public 468

food transition 16, 457, 458-60, 461, 470, 476; definition of 458-9, threefold 459

foreign direct investment (FDI) 75, 107

Foreign Exchange Regulation Act (FERA) 71,105

foreign policy 129-32, 135-43, 154

Forest Rights Act (2006) 304

Foucaultian concept 479

Foucault, M. 285, 452

Fox, R.G. 299

Froerer, Peggy 302

Fuller, C. J. 246, 288

Fürer-Haimendorf, Christoph von 299

Ganapati 367, 368; see also Ganeśa

Gandhian moral norms of austerity 234

Gandhian political integrity, notion of a lost 267

Gandhian utopia 263

Gandhi, Indira 2, 51, 61-2, 124, 125, 167, 206, 208, 321, 436

Gandhi, M. K./Mahatma 2, 14, 25, 36, 39 , $88,151,161,165,169,216,263,329,363$, 374,390

Gandhi, Rajiv 2, 70, 204, 236, 257, 392, 396n12

Ganeśa/Ganesh 336, 340, 445; see also Ganapati

Gasset, Ortega y 316

general elections see elections

Genetic Engineering Approvals Committee (GEAC) 106

genetically modified (GM) crops 105

Geertz, C. 289

Geetha, V. 289

Gellner, E. 390

Ghadr Movement 165

Ghai, Anita 293

Ghajini 447-8, 454n11

Ghertner, D. A. 223, 227
Ghosh, A. 450

Ghosh, B. C. 178, 179

Ghosh, Kaushik 302

Ghosh, Sananda Lal 178

Ghurye, G. S. 244, 298

GIDC see Gujarat Industrial Development Corporation

Giddens, A. 390, 452

Glassner, B. 445, 454n5

global diaspora 8-9, 17n5, 121, 159-70

global Hindu traditions 229-3, 329-46

globalization $6,16,17 \mathrm{n} 5,151,164,211,218$, 234, 277, 281, 284, 432, 394, 444, 449, 452, 453, 457, 459

global power 216

global superpower, emergence of India as 8, 60,121

Goa 122, 414, 415

Godbhole, Waman 367

Godhra fire 126

Gold's Gym 447, 448

Goliyon Ki Raasleela Ram-Leela 447

Government of India Act of 1919297

Government of India Act of 1935 38, 48, 49, $54,248,297$

Govinden, Devarakshnam 163

Grand Trunk Road 27, 30

granthis 168

Green Revolution 72, 105, 106, 112, 204, 210 , 464, 470n7; alternatives to the paradigm of, 106, 113; constituencies excluded in 113; definition of 109; double 105; in Gujarat 278; have also provided new opportunities for employment outside the older economic order 249; have made many of the traditional caste occupations redundant 249; intensification of 105; launching of 102; led to abandonment of millet for rice 477; paradigm has outlived its potential 112; partly responsible for diabetes' prevalence in India 2, 4, 7, 476; post-green revolution stagnation 105; Punjab in the forefront of 22; technologies 105

Grover, Shalini 289

Guha, Ramachandra 318, 319, 320-1, 322

Gujarat 11, 40, 106, 122, 124, 126, 142, 210, 259, 263, 271-81, 300, 301-2, 321, 351-2, $362,393,406,420,447$; caste in 274 ; in the colonial period 274-5; economy of 276-7; geographical factors in the history of 272; government of 271; Hindu-Muslim relations in 273-4;

Hindutva-isation of 281; political dimension of the history of 273; political illiberalism in 282; politics of identity in 280-1; schisms in regional identity in 280; tradition of bourgeois hegemony in 276 
Gujarati-Hindu chauvinism 282

Gujarat Industrial Development

$$
\text { Corporation (GIDC) } 276
$$

Gulf region 166

guṇa (constituent, quality) 335, 336, 486n5

Gunday 447

Gupta, Akhil 261-2, 266

Gupta, C. B. 265-6

Gupta, Dipankar 356

Gupta, Nagendra Nath Sen 187

Gupta, Ram Ratan 265

Gurdaspur 26

gurdwaras 30, 168, 348, 371, 372, 377, 378, $379,382 \mathrm{n} 25$

guru 177, 195, 375, 378, 379

gurughar 377

Guruparamparāprabhāvam 337

Guru Ravidass see Ravidass

Gutsmuth, J. F. C. 174

Guyana 163, 164, 275

gyms 448, 450

Hallup, O. 163

Haṃsasvarūpa, Swāmī 181

Hansen, T. B. 391, 392, 394

Hanumān 4, 333, 357, 445

Hardayal, Lala 165

Hardwar 349, 351, 353, 354

harijans 366, 374

Harimandir Sahib 125

Harit Pradesh 124

harmonial gymnastics 179

Harrison, Selig $45 n 4$

Harriss-White, Barbara 251, 266, 267, 460

Harvey, David 224

Haryana 29, 75, 124, 287, 289, 292

hațhayoga 9, 172, 173, 174, 178, 179

Hatha Yoga (gymnastics) 9, 178, 179, 180

Hasan, Mushirul 31

Hazare, Anna 46n17, 238, 264, 267

Hedrick, Brian 131

Himachal Pradesh 29, 122, 124, 418

Hinduism 3, 4, 13, 243, 244, 329-45, 347-59, 364, 367, 371, 386, 392, 401, $402,418,460,470 \mathrm{n} 1$

hinduisation 3, 353, 402

Hindu Mahasabha 402

Hindu-Muslim: composite culture 358; conflict 44, 390-5, 400-12; relations $273-4,390-5,400-12$; riots 142,393 , 402; unity 363 ; violence 393 , 403-12

Hindu nationalism 125; based on perceived threats to Hindu demographic, cultural and political dominance 14, 400; citizenship questions of Muslims and the ascendency of 391; definition of 281, 401; homophobia within the discourse of 290; ideological and tactical strategies of 392; influence of sharpened the potential conflict between Hindu and Muslim groups in Gujarat 274; longdistance 168; threat of pushed the parties of the left to support the reforms 207; using traditions of pilgrimage to mobilize Hindus politically 357

Hindu Rashtra 280, 302, 402

The Hindus: An Alternative History 318

Hindustan Times 408, 453

Hindutva 401

Hindutva 3, 11, 14, 15, 29, 125, 173, 281, 357, 385, 391, 392, 393, 394, 395n8, 396n11, 396n15, 400, 401, 402, 406, 407, $411,423,423 \mathrm{n} 10,432$

Hindutva-isation 281

Hindu upper-caste groups 38, 40, 281

historical inequalities of caste and religion 237

historiography: endogenous 321-3; exogenous 321-2

history 3, 4; cyclical and linear views of 317-18; divided 21; as 'myth' 316-17; notion of 315-16; rewriting of 30

Hodges, Sarah 285

Holy Cow and the 'global steak' 457, 465-6

homeopathy 474, 479, 482, 486n1

homogeneous Hindu nation: ideology of 357,358

homogeneous religious community: stereotypical image of 384

homophobia 290, 291

homosexuality: Supreme Court affirming the criminalisation of 54

Hum Apke Hain Kaun 284

Hume, Sir Alan Octavian 36

hungry and malnourished /undernourished 99, 100; home of a quarter of world total 100,109 ; home of a third of children 109; reduction of 102

Huntington, S. P. 390

Hyderabad 60, 391, 462

hysterectomies 292

IAS see Indian Administrative Service iconography $372,377,445$

identities, 29; communalisation of 31 ; emotions attached to 394; ethnic and regional 123; fragmentation of religious 384,385 ; in an increasingly polarised society 92 ; middle-class 236; political mobilisation based on 391; politicise 126; preservation of multicultural 66; problem of in-between 168; protection of 38; religious 2, 8, 349, 358; 'vote bank' politics sharpened communal 126 identity politics, 206, 207, 259, 390-3 Ikramullah, Shaista 26 
Illyas, M. Muhammad 386

Imaginary Maps 15, 430, 434, 435, 437, 438

Imagining Karma 322

import-substitution industrialization 139

In Custody 15, 430, 433, 435, 436

Inden, Ronald 244

India After Gandhi: The History of the World's Largest Democracy 318, 320-1

India and India Missions: Including Sketches of the Gigantic System of Hinduism Both in Theory and in Practice 332

India-Pakistan War: 1947-1948 136; 1965 138

'India's Muslim Spring' 394

Indian Administrative Service (IAS) 389, 403

Indian Council of Agricultural Research (ICAR) 102

Indian Council of Cultural Relations (ICCR) 149

Indian independence movement 54

Indian National Congress 23, 25, 36, 38, 39, 123, 187, 188, 391, 392, 416; see also Congress party

'Indian-ness' 54, 275

Indian Police Service (IPS) 383, 403

Indian Technical and Economic Cooperation (ITEC) scheme 149-50, 154

Indian Union Muslim League 391

Indic worldview 322, 323, 325, 326

Indo-China: active diplomatic role in 136-7

Indira doctrine 139

Indonesia 136, 138, 140, 143n7, 162, 217 , $329,341,344$

Indo-Pak relations 22, 23, 126

industrial licensing system 71-2, 74; see also licence-Raj

Industrial Policy Resolution of 195671

Industries (Development and Regulation) Act of 195171

insurgency and counterinsurgency 7, 36, 41, $42,44,302$

intermediate regime 104; development agenda of 105; developments norms of 103-4; emergence of 99; forecloses the opportunities for decentralised location-specific alternatives to the green revolution approach 112; Nehruvian approach to creating and nurturing an 101; nurtures the multi-nationals and domestic businesses and works against the rural poor 99-100; transfers income to agri-business and industry from the shrinking share of the economic pie that agriculture generates 109

Internet 161, 165, 235, 351-2, 462, 467

invoking the threat of terrorism 282

IPS see Indian Police Service

Islam 163, 384-96, 401, 418, 458
Islamabad-Pyongyang nuclear proliferation axis 141

Islamic militants 130

Islamic public spheres 387

'Islamic' Urduised identity 29

Jacobsen, Knut A. 334-5

Jaffrelot, C. 449

Jahn, F. L.'Turnvater' 174

Jainism 167, 325, 348

jajmānī/jajmani 36, 249, 250, 355

jajmans 247

Jalal, Ayesha 45n4

Jamaat-e-Islami 386, 391, 396n10

Jamiyat al-ulama-I Hindi 391

Jammu 124; see also Jammu and Kashmir

Jammu and Kashmir 36, 42, 58, 121, 122, 392

Jan Lokpal (Ombudsman) Bill 259, 264

Japan 131-2, 137, 139, 140-1, 142, 175, 277 , 364,368

jati $243,420,421$

Jat Sikhs 371, 372, 378, 381n3, 381n7

Jawaharlal Nehru National Urban Renewal Mission (JNNURM) 216, 218, 219-21; mission statement of 224

Jayadev, A. et al. 208

Jeffrey, Craig 266, 267

Jenkins, Rob 207-8

Jews 122

Jeyananda 475, 478, 479-81, 482, 483, 485

Jeyananda Siddha and Ayurveda Hospital 479

Jharkhand 86, 122, 124, 127, 128, 297, 417, 420

Jindall, Bobby 165

Jinnah, Muhammad Ali 22, 24, 25, 165

Jìyar, Pinpalakiya Perumāl 337

JNNURM see Jawaharlal Nehru National Urban Renewal Mission

Jung, C. G. 181

kabbadi 449

Kaivalyadhama 172, 177

Kalam, Abul 170

kala pani ('black waters') 160, 162

kalarippayattu 444, 449

Kāmasūtra/Kamasutra 444

Kamble, Shivram Janba 362

kangani system 162, 169, 170n2

Kannabiran, Kalpana 284-5

Kanpur 265

Kapil Mandir 352

Kapil muni 351

Kapoor, Arjun 447

karma (karman) 13, 244, 322, 324, 325, 326, 335, 368

Karma, Mahendra 128 
'karmic eschatologies' 322, 326

Karnataka 7, 40, 75, 97n10, 111, 122, 123, 127, 225, 290, 293n1, 333, 341, 342, 343, 409, 420, 448, 454n1

Kashmir: violence in 125-6; see also Jammu and Kashmir

Kashyap, Jagdish 366

Kausalyayan, Anand 366, 367

Kejriwal, Arvind 256, 259, 260, 262, 264

Kerala 75, 122, 188, 194, 197n5, 218, 356, 363, 389, 391, 414, 415, 416, 421, 444

'Kerala Ayurveda' 194

Khalistan 29

Khalistan movement 2, 31, 125

KHAM see Kshatriyas-Harijans-AdivasiMuslims

Khan, Aamir 447-8, 454n12

Khan, Ghazanfar Ali 25

Khan, Shahrukh 447, 454n10

Khan, Sir Sayyid Ahmad 386

Khare, R. S. 460

Khopade, Suresh 409-10

kinship networks 12, 251, 305

Kirpal, Prem 28

Koli communities of Mumbai 408, 412n8

Kolkata 217, 253, 289, 355; see also Calcutta

kolu (tableaux of steps) 341-3

Komagata Maru 165

Kopf, David 286

Korea 136, 137

Kosambi, D. D. 365

Kosambi, Dharmanand 365, 368

Krrish 3447

Krș̣na 334, 335, 339

Kshatriyas-Harijans-Adivasi-Muslims (KHAM) 279, 281

Kudaisya, G. 31

Kulkarni, A. R. 365

Kundu, Debolina 226

Kuriyama, Shigehisa 180, 181

Kuvalayananda 172, 177, 178, 183n12

labour laws 72, 203

Lahore 21, 25, 26, 27, 28

Lakṣmī 331, 335, 337, 341, 342, 343, 344, 345n8

Land Alienation Act of 1900372

Landy, Frédéric 459, 460

langar 377

The Language of the Gods in the World of Men: Sanskrit, Culture, and Power in Premodern India 318, 319

Leech, T. 422

lesbianism 290-1

'liberalization lobby' 205

Liberhan Commission Report 393, 396n13, $407,412 \mathrm{n} 7$

licence Raj 76, 203, 204, 212, 258, 264; definition of $213 \mathrm{n} 1$
Line of Control (LOC) in Jammu and

Kashmir 121

Lines of Credit (LoC) 147, 148, 149-50, 154

linga 334, 349

Lingayat 409

Ling gymnastics 175-6; see also 'Swedish gymnastics'

Ling, P. H. 175, 182n8

literature 160, 166, 168, 392, 429-41

'little Indias' 167

Lokācārya, Pilḷai 334, 335

Lok Sabha 38, 123, 268n8

long distance Hindu nationalism 168

long distance Punjabi regionalism 168

'Look East' policy 135, 140, 141, 142

love 288-90, 293n7, 293n9; same sex 290-1, $294 n 18$

Ludhiana 26

Lum, Kathryn 380

Lutgendorf, P. 333, 338, 340

Lyallpur 25, 26, 27, 30

MacFadden, Bernarr 177

Madhvadasji, Shri 177

Madhya Pradesh 65n54, 75, 97n10, 111, 122, $123,124,127,210,218,301,302,333$, $362,369,417$

mafia: construction mafia in Rae Bareli 258; groupings in UP 258; involved in the gold quadrilateral project linking Delhi, Calcutta, Mumbai and Chennai 258

Maha Bodhi Society 13, 361, 366

Mahākumbhamelā 349, 355, 356

Mahar caste 362-3

Maharaj, Brij 164

Maharashtra 124, 125, 127, 210, 264, 276, 292, 301, 302, 362, 373, 448

Maharishi Ayurveda 194, 195

Maharishi Mahesh Yogi 194, 195

Mahatma Gandhi National Rural Employment Guarantee Act 43, 100, 209

Mahn, Churnjeet 30

Majhail, Sardar Ishar Singh 27

Majlis-I Ittihad al-Muslimin 391

Make in India Campaign 277

Malhotra, A. 30, 31

management of religious institutions and practices 43

Mandal Commission Report 206, 263, 394, 395n4

'mandalisation' of India's politics 206

Mangu Ram 169, 373, 375, 376

Manorama, Ruth 419

Manor, James 206, 249

Manto, Saadat Hason 25

Manusmriti 243, 364, 376, 438

Maoist Co-ordination Committee 127

Maoist insurgency 7, 121, 127-8 
Maoist movement 302

Maoists 127-8, 302

marriage 283-94; civil/court 289; inter-caste 289,294 n13; laws of $288-9$; and love 288-90; polyandrous customary 287 ; 'runaway' 289; system 289

Marriot, McKim 324

Marx, Karl 233, 244, 303

masculinities: middle class 444-54; new ideals of 4; notions of 449; in sports 446-55

Massey, James 423n6

materiality 3, 13, 331, 332, 333, 338, 340, 345, 357

matter, plural understanding of 332

Maududi, Abul ala 386, 391

Mayawati 263, 269

Mazumdar, V. 432

McDermott, Rachel 169

meat: attitudes to entrenched in conceptions about status and symbolic pollution 470 ; consumption of 462, 465-6, 47n3; defining identity 468 ; denotes transgression of family rules 468 ; symbolises cosmopolitanism 468 medical systems 185-97, 474-87

Meer, Fatima 161

megacities 217, 219, 462

mega-statues 4, 333, 336, 345n3, 357

Meghalaya 58, 122, 124, 59, 414, 418

Mehrotra, Nilika 292

Mehta, Deepa 290

Mehta, Jivraj 280

Mencher, Joan 246

Mendelsohn, Oliver 249

Menon, K. P. S. 137

Men's Health 444, 445, 446-7, 452, 453, $454 \mathrm{n} 8,455 \mathrm{n} 21$

Mere Brother ki Dulhan 288

metabolic disorders: consequences of polished rice being the staple food 476; growing prevalence of 459, 464

middle classes: antipathy towards democratic governmental institutions 238; backlash and revanchism 223, 237-8; and caste 248; changing food habits of 457-71; colonial 234; consumer-based identity of 235-6; contradictions within 239; definition of 213n7, 233-4, 236, 288; food as a marker of 461; frustration with failure of governance 238; high degree of internal differentiation of 232, 237; internal change of 221; muscularization of 446-55; new entrants 237, 240; notoriously elusive category of 449; politization of 238-9, 240; post-liberalization 234-8; product of politics of classification 236; self-classification 238; sense of cultural superiority 238; upper tiers of 237; wrath against the poor 221

migration $25,31,159-70,275,304-5,388$, 435; of adivasis to cities $304-5$; and the notion of an Indian diaspora 159-70; to towns among high income groups in search of economic mobility 217; to towns caused by decline in agriculture 217

militant nativist movements 7,124

military development 129-32

military power, $121,129-32$

Mir, F. 30, 31

Mirajkar, Balasaheb 176

Mizo National Front (MNF) 125

Mizoram 38, 59, 122, 125, 414, 420

mobile phones $235,351-2$

mobilization: differential 41, 45-6n8; horizontal 41, 45-6n8; vertical 41, 45-6n8

Modi government 155, 279

Modi, Narendra 11, 17n9, 142, 232, 239, 256, 259, 263, 271, 276, 277, 279, 280, 393, 394, 457, 465

Mody, Perveez 288-9

mokșa 173, 326, 331, 338, 339, 347, 355, 358

Monaghan, Lee 451

Mongolia 150

Monopolies and Restrictive Trade Practices (MRTP) 71, 72, 106

mono-religious 30

Monsanto 106

Montagu-Chelmsford Report 188

Moore, Barrington 45n4

Moore, L. J. 445

Mosse, David 421

Mosse, George 436

Mountbatten, Louis 23, 24

movement politics 44

MP see Madhya Pradesh

Mugowali, Babu Mangu Ram 373; see Mangu Ram

Mujumdar, D. C. 175, 176, 177

Mukherjea, Justice 50

Mukherjee, Pranab 141, 357

Mukherji, U. N. 401

Müller, J. P. 177

multiculturalism 54, 57, 60

Mumbai 53, 121, 122, 126, 130, 217, 221, 222, 226, 227, 253, 258, 305, 393, 406, 407, 408, 412n4, 412n8, 412n9, 448, 466; see also Bombay

Murti, Srinivasa 188-9

'Muscular Christianity' 174

muscularity $445,451,454 \mathrm{n} 4$

muscularization 445, 449

music: in the Hindu traditions 337-40; most powerful and long-lasting expression of 
distinctively Indian culture 416; therapy 195

Muslim-Hindu-Sikh mix 29

Muslim League 22, 23, 24, 32n2, 39, 233, 390

Muslim Punjabi 29

Muslim societies: constituting the 'other' of Hindu cultural nationalism 385; emergence of caste consciousness among 387-8; emergence of religious diversity within 385-7; extraordinary diversity within 384; main concentrations of 122 ; political dimension of 390-4; reformist/ revivalist moments within 385-7; social stratification among $387-8$; socioeconomic development 388-90

musti-yuddha 444

Muzaffarnagar 393

'myth': as 'history' 316-17; notion of 314-15

Nagaland 38, 124, 125, 414, 418

Nagpur 362, 365, 366, 367, 368

Naidu, Chandrababu 76

Naipaul, V. S. 160, 161, 166

Nair, Neeta 23

Nandy, Ashis 22, 267

Nanotwi, Muhammad Quasim 386

Narasimhan, H. 288

Narasu, Lakshmi 14, 361, 368

Narayan, Jayaprakash 263

Narayanan, K. R. 368

Narmada anti-dam movement 300

Narmada Bachao Andolan (NBA) 300

Narmada project 276

National Agriculture Policy (NAP) 2000100

National Campaign for Dalit Human Rights 419

National Commission for Religious and Linguistic Minorities 422

National Commission for Scheduled Castes 422

National Committee on the Status of Women 418

National Council of Applied Economic Research (NCAER) 234-6

national elections 124, 128, 238; see also elections

National Integration Council 403

nationalist gymnastics systems 174-5

National Policy on Farmers (NPF) 2007 100

National Seeds Act of 2004105

'Native Medical Institution' in Calcutta 186

Natyasaāstra 338

Navarātri 331, 341-3

Navayana Buddhism 361-70, 378; and pilgrimage $368-9$

Navnirman movement 279
Naxalbari 7, 127

Naxalites 7, 302

NBA see Narmada Bachao Andolan

NCAER see National Council of Applied Economic Research

Nehru, Jawaharlal 13, 23, 24, 25, 27, 49, 101, 136, 137, 141, 151, 165, 262, 369

Nehruvian approach to creating and nurturing an intermediate class 101

Nehruvian state socialist ideologies 234

Nehruvian version of secularism 392

Nehruvian vision 189

Nehruvian worldview of development 101

Nel, Philippe 153

neoliberalism 222, 223

neoliberal urbanism 220, 222, 223

neo-Buddhism, 378; see Navayana

Buddhism

'neo-middle class' 232, 239

'Neo-Orientalist' bias 322

Nepal 127, 137, 139, 147, 148, 211, 357

Nevile, Prem 28

'new Indian male' 444-55

new social elites 37

new states: creation of 57-8; follow the principle that ethno-linguistic groups ought to have separate states within the Indian Union 123; key form of ethnic conflict centred on 124

NGOs see non-governmental organisations

Nirbhaya: public outrage over the rape of 4 , $15,238,440$

nirguna 374

Nirmohi Akhāṛā 357

non-governmental organisations (NGOs) 150, 223, 224, 225, 226, 263, 304

North Korean nuclear issue 141

NPF see National Policy on Farmers

Obeyesekere, Gananath 313, 322

Objectives Resolution 49, 50

Om Shanti Om 447

Operation Blue Star 125, 167

Other Backward Classes (OBCs) 40, 84, 85, 206, 252, 388, 389-90, 394, 405

Pakistan 22-33, 37, 45n4, 121, 126, 130-2, 135, 136, 138-41, 142n1, 143n11, 165, 273, 275, 277, 281, 385, 388, 390, 391; and China, strategic ties between 129 ; nuclear doctrine of 130; support of Sikh insurgency 130

Pakistani Punjab 22

Pal, Judge Radhabinod 137

panchayat 59, 89, 218, 289

pandāas 353, 354; see also pilgrimage

Pandey, G. 391

Pandey, Sandeep 266 
Panikkar, Raimundo 315, 316

Pant, G. B. 261

Pant, Pratinidhi 176

pāpa/papa (impurity): removal of 354

Paranjape, M. 440

Parivar, Asha 268

Parliament 389, 391, 393, 395n8; see also Lok Sabha

Parry, Jonathan 261, 289-90

Parsis 122, 275

'participolis' 225

Partition, 2, 3, 4-5, 21-33, 35, 39, 126, 136, $273,385,388,390,391,430$

partition violence 5, 21-5, 31, 32, 32n2, 35

Pārvatì/Parvati 339, 364

The Past Before Us: Historical Traditions of Early North India 318, 319-20

Pātañjala Yoga 322; see also Sāṃkhya-Yoga

Patārtta guña cintāmaṇi by C. S. Uthamaroyan 483

Patel, Sardar Vallabhai 273, 278, 280: statue of 263,357

Patidars 273, 274, 275, 278, 279, 281

Patnaik, P. and C. P. Chandrasekhar 205

patronage politics 11,256

Pawar, Daya 370

Pax Britannica 274

performing arts in the Hindu traditions 337-41

pehlwan wrestling 444, 449-50, 451, 454n2, 454n10, 455n17, 455n20

People's Ware Group 127

Philippines 136, 140

Phule, Jyotirao 13, 362, 373

Piccio, L. 147, 148

Pierce, Steven 257

pilgrimage 13, 161, 333, 347-59, 465; Buddhist 354, 368, 369; centres of Dalit 380 ; and conflicts 356-8; and economy 352-6; and identity and infrastructure 349-52; priests $348,351,352,353$, 354; procession 357; Purānization of traditions of 354

Pingali, Prabhu 459

'pink revolution' 457

pir (religious guide) 387

Plate, S. B. 340-1

Plato 317

politics from below 223

politics of identity $276,280-1$

politics of regional and religious identity 280

Pollock, Sheldon 318, 319, 321

'poly-alignment' policy 131

Poona Pact 39

Popkin, Barry M. 458-9

poor, the: aid as 'charity' to 152 ; attend government schools 87; Christianity has increasingly become a religion of 3 ; city development at the cost of 10 ; considered a burden and a drag on urban economies 221; considered responsible for jeopardizing urban regeneration and economic growth 221; court judgements and 221-2; democratic electoral participation of 223; distinction from the diet of a way to show middleclass respectability 469; economic reforms not particularly beneficent for 209; intermediaries and interlocutors between the state and 226; lack of public spending on health and education for 209; Maoists collecting money to 128; marginalising of 216, 225; mass displacement of from urban land 216, 220, 221, 223, 227; medical needs of 192; middle class defined by a demarcation from 236; and 'occupancy urbanism' 223; policing and 222; pushed into schools with poor learning environment 91; spatial segregation from 87; state elites unwilling to address state capacities to deliver services to 107 ; state support for 102; tended not to migrate to Pakistan at partition 388; threat to public health 221 , 234; as 'vote banks' 221, 223

post-green revolution 104

Potter, David 261

poverty 3, 110, 209-11

Poynting, Jeremy 163

prakrti/prakrti 196, 332, 334-6, 344-5, 345n8

Prasad, N. P. 192

Pravasi Bharatiya Divas 161

preamble to the constitution $48,49,51$

precessional transformation 325-6

Presidential Constitution (Scheduled Caste) Order 417, 418

procession 342, 343, 357, 379

Princely States, accession of 22

private residential enclaves 216

'pseudo-secularism' 392

public interest litigation (PIL) of the

Supreme Court 53-4

punarjanman see rebirth

Punjab: caste hierarchy in 371-2; Dalits in 371-81; and mutiny 22; and partition 21-33

Punjabi: culture 21-33, 168; diaspora 167; identity 5, 29; language 21, 28, 29-30, 433; long-distance regionalism 168; politics 22; society 23,29

Punjabis 164, 165

Purānas 322, 340, 341, 348, 354

purușa 334,335

Quigley, Declan 244 
Radcliffe Boundary Commission 22

Radcliffe, Sir Cyril 24

ragi jatha 168

Raheja, Gloria Goodwin 247

rajas (energy) 323, 335, 336, 486n5

Raja Yoga 176

Raj, Satya 27

Rajshekar, V. T. 378

Ram, Kalpana 485

Ram, Kanshi 369

Rāma/Rama 163, 334, 335, 340, 341, 357, 367

Rāmānuja 332, 334, 335

Rāmāyaṇa/Ramayana 163, 319, 340

Ranganathan M. 225

Rao, Narasimha 139, 140, 203, 206, 207

Rao, P. V. Hanumantha 350

Rao, Rajaratna Manick 177

Rashtriya Krishi Vikas Yojana (RKVY) 106, 111, 112

Rashtriya Svayamsevak Sangh (RSS) 173, 390, 402, 407, 411n1

Rattinammal 475, 478, 479, 481-3, 484, 485

Raveendran, P. P. 440

Ravidass/Ravidas/Raidas 14, 169, 373, 374-7, $378,379,380,382 \mathrm{n} 24,382 \mathrm{n} 28$

Ravidass Deras 377-80

Ravidassia Deras Dalit movement 378; see Ravidassia Deras

Ravidassia Dharm 373-82

Ravidassia movement, 378; see Ravidassia Deras

Rawalpindi 23, 24, 32

Raza, Ahmad 386

Reader, Ian 354

Reardon, S. F. 83

rebirth (punarjanman) 13, 322, 324, 325, 326, $347,349,355,368$,

're-conversion to Hinduism' 301

Reddy, P. C. $350-1$

regional parties 40, 42, 124, 268, 422

regional power across the Indian Ocean Region 131

Rehman, Tariq 30

religious conversion $14,15,286,301,364$, $365,366-7,368,369,372,373,380$, 381n6, 382n15, 402, 415, 416, 417, 418, 421, 423, 423n8; see also conversion

remittances 1, 17n6, 69, 166, 218

'Representation of People Act' of 1947, 39

reservation of seats 39

Reserve bank of India (RBI) 72

Residents' Welfare Associations (RWAs) 216, 225-7

Resurgent Group of Gujarat 279

Right to Information Act of 2005 259, 263 , 266

Right to Information Movement 259, 268 rights-based discourse of the Constitution $49,50-4$

rights discourse 48

RKVY see Rashtriya Krishi Vikas Yojana

Roman Catholic Christianity 348, 415, 422

Roshan, Hrithik 447

Rowlands, Dane 152

Roy, A. 223

Roy, Rammohun 286

RSS see Rashtriya Svayamsevak Sangh

RTI 268; see Right to Information Movement

Rudolph, Lloyd and Susanne 40, 391

Runi, Raza 28

Rushdie, Salman: controversy of 1989392

Russia 129, strategic relations with 131

RWAs see Residents' Welfare Associations

Sachar Committee Report 14, 385, 389, 390, 394, 395n7, 403, 405, 412n3

Sahni, Balraj 32

Said, Edward 244

'salvific space' 347

Sāṃkhya 322, 323, 332, 334, 335, 486n5

Sāṃkhya-Yoga 334, 335; see also Pātañjala Yoga

Sanderson, Alexis 181

Sandow, Eugen 176, 177

Sangari, K. 432

Sangharakshita, Ven. 366

Sangh Parivar 15, 166, 411-12n1

Sankrityayan, Rahul 366

Santhanam Committee Report 261

Sant Hiran Dass of Dera Chak Hakim 375, 376

Sant Isher Dass 376

Sant Pipal Dass of Dera Ballan 375

Sarasvatī/Saraswati 329-45; Embassy Row 329, 330, 333, 336, 338, 341, 343, 344, 345

Sarkar, Tanika 285

sarna (sacred grove): indigenous revivalism centred on 301

Sastri, Justice Patanjali 51

Satanic Verses 392

sattva ('purity') 323, 335, 336, 486n5

Saurashtra 273, 275, 276, 278, 280, 281

Savarkar, V. D. 396n11, 401, 402

Sawhney, Simona 173

Schechner, Richard 338

Schedule V areas 297-8, 300, 301, 302, 303, 304, 305

Schedule V states 86

scheduled castes $79,80,123,248,251-2,253$, 366, 374, 378, 381n5, 390, 401, 405, 409, 422; see also Dalits

scheduled tribes 12, 59, 122-3, 248, 297-8, 300, 301, 366, 367, 401, 405; see also adivasis, Dalits

School of Indian Medicine in Madras 189 
schools: abandonment by middle class of government 91; absence of science and commerce in girls-only 91; attendance rates $82-4$; dropout rates 79,82 ; decline of quality of teachers in 92 ; government and government aided 87; gross enrolment ration (GER), 78, 80-1; 'hierarchies' of access to 91 ; high poverty 87; malaise in 79; movement of the rich and middle class from government to private 89; spatial segregation due to income inequality leads to different kinds of 87 ; teachers absence rates 90 ; unequal access to 87

secularism 56, 123, 126, 321, 384, 386, 390, 391, 392, 393, 394, 395n9, 417

seed industry 105, 106

Sen, A. 211

Sen, Keshab Chandra 286, 293n5

Sen, M. M. Gananath 187, 188

Sen, Samita 287, 289, 290

Senegal 150, 152

Sengupta, M. 205, 206

service sector 208

seva 377 ; see also cevai

SEZ see Special Economic Zones

sexuality: female 438; and the film Fire 290; Indian nationalists' and 436; normative 291, 292; patriarchal management of female 432-6, 438; of persons with disabilities 291-2; regulation of female 284,287 ; tool for studying norms governing caste, class, kinship, and religion 439

Shah, Alpa 303

Shah Bano 392, 396n11, 440n9

Shaikh, Jamal 446, 447, 453

Sharma, Balkrishna 265-6

Sharma, Kalpana 219

Sharma, Shiv 187

Shatkin, G. and S. Vidyarthi 223

Shetty, Prakash S. 459

Shinde, Vital Ramji 13, 362

Shiva 445; see also Siva

Shiv Sena 42, 125, 126, 290, 406

Shri Sailam 349-51

shuddhi 301

Shulman, David 176

siddha medicine 474-87

Siddhpur 351-2

Siegel, Benjamin 466

Sikand, Y. 357, 358

Sikhism 30, 348, 371, 376, 381n6

Sikh militancy in Punjab 31, 125

Sikhs 5, 14, 23, 24, 26, 29, 30, 32, 122, 125 , 164

Sikkim 106, 122, 137, 142n2

Singapore 138, 140, 162
Singh, Chaudhuri Charan 264

Singh, Manmohan 127, 130, 131-2, 139, 141, 142, 147, 170, 203, 205, 206, 239

Singh, Milkha 447, 454n8

Singh, Ranveer 447

Singh, Sardar Baldev 23

Singh, Sherry-Ann 163

Singh, Toba Tek 25

Singh, V. P., government of 206

Singhvi, Hon. L. M. 161

Sino-Indian War 135, 137-8

Siva 4, 334, 339, 355, 357

Sivananda 177, 178, 179

slum dwellers 221, 226, 227

Smith, Stephen 132

Snap Fitness India 448

social activists, a social class of mediators 44 social capital 236, 251, 252

social mobility $14,163,252,275,300,301$, $302,303,305,372,373,376,380,388$, 418

social movements 44, 155, 252, 297, 300-1

Solanki, Madhavsinh 279

South Africa 146, 275, 321, 340

South Korea 140, 141, 142

South-South Development Cooperation (SSDC) 147,149, 151, 152, 154; based on shared experience 151; not to be mistaken for foreign aid 148

South-South discourse 153

'South-South' partners 146

Soviet Union 7, 129, 137, 138, 140

SPARC (The Society for the Promotion of Area Resource Centers, Mumbai) 226

Special Economic Zones (SEZ) 277

spirituality: cosmopolitan and individualistic forms of 197; India as land of 190; India as teacher of the West 3; India superior to the West in 3; inherent in images 332; new emphasis on 197

Spivak, G. C. 291, 303, 430, 438, 440n5

śrāddha 351-2, 353

Sri Guru Granth Sahib 14, 168, 375, 378

Srikrishna Report 406, 407, 412n5

Sri Lanka 2, 37, 43, 45n6, 127, 139 167, 194, $361,366,368$

Srinivas, M. N. 249-50, 272

Srinivas, Tulasi 461

Śrī Vaișnava 332, 334, 336, 337, 345n8

Srivastava S. 227-8

Stack, Mollie Bagot 180

States Reorganisation Act 123

States Reorganisation Commission 123

Statesman 317

Stebbins, Genevieve 179

stūpa/stupa 348, 357, 368, 369

śuddhasattva 335, 336

Sunder Rajan, Rajeswari 12, 284, 292, 440 
Supreme Court 41, 48- 65, 396n12, 419, 422 ; judicial independence of 61 ; selfpreservation of the independence of 60-3 sūryanamaskār 176-7, 182-3n12

'Swedish gymnastics' 175-6; see also Ling gymnastics

synchronic phylogeny, 323-4

syncretism 189, 274, 395n2

Syrian Christians 414, 415, 416, 421

Taare Zameen Par 448

Tablighi Jamaat 386

tamas ('darkness') 323, 335, 336, 486n5

Tamil Eelam diaspora 167

Tamil Nadu 7, 16, 75, 123, 124, 218, 222, 226, 288, 290, 341, 342, 343, 348, 414, 415-16, 418, 421, 454.n1, 457-71, 475, 476, 477,478

Tan, T.Y. 34

Tauseef, Afzal 28-9

Telangana 58

terrorist violence $36,41,44,121,127,130$, 141, 143n11, 166, 393, 396n15, 408, $412 \mathrm{n} 9$

Thapar, Romila 315, 317, 318, 319-20, 321, $412 \mathrm{n} 2$

Tharoor, Shashi 151

There Comes Papa 288

Thiagaraj, Henry 419

Thimayya, General K. S. 137

Thorat, Major General S. P. P. 137

Tibet 129, 137, 364, 366, 474

Tilak, Jandhyala B. G. 88

Tiruchengode, Tamil Nadu 218, 222

Topalove, P. 210, 211

towns: census towns 218; emerging as new centres of dynamism 219; statuary towns 218

trade reforms 70-1

Trailokya Bauddha Mahasangha Sahayaka Gana (TBMSG) 366

transnational and transcultural encounters 3

Transparency International 257

Trass, Pandit Iyothee 13, 361

trauma of partition 22, 31, 126

Trinidad 161, 162, 163, 164, 275, 333, 340

Twice Migrants 166

Uberoi, Patricia 174, 284, 288

Unani (Greco-Arabic medicine) 185, 188, 486n1

Unionist Part (Punjab) 23

United Kingdom 161, 165-6, 415

United Liberation Front of Assam (ULFA) 125

United States: alliance with China 138; Constitution influenced by ideas offered by the rights discourse in 48 ; Dalit
Panthers named after the Black Panthers in 366, 374; diaspora in 169; diplomatic interlocutor during the Korean War between China and 137; early Dalit leaders had lived in 169; early Indian Yoga teachers in 177; green revolution was initiated to compensate for food shortages, when India faced the threat of an embargo on cereals by 476; Hindu display temples in 168; improved military and defence ties with 131: migration from India to 165; Pakistan important partner for 139, 141; Sarasvatî in 329-30; teachers of Yoga in 178; yoga practitioners in 179 untouchables 361-70, 371-82

UP see Uttar Pradesh

Upanișads 332, 334, 343-4

urban class differences 221

urban development policies 223-6

urban economic dualism 220-1

urban foodscape 463

urban governance 223-6

urbanisation 216; development 219-22; disappearing of medicine plants due to 480, 485; governance 223-6; large and small towns 217-19; subaltern 222-3

urbanism: neoliberal 220, 222, 223; occupancy 223

Urban Land Ceiling Act of 1976220

urban middle class environmentalism 221

urban middle class youth 237

urban poverty $210,217,218$

urban transformation 220, 222, 228

Usman Committee report 188

Usman, Muhammad 188

Uttar Pradesh 7, 90, 122, 123, 124, 162, $289,290,300,356,357,362,369,381 \mathrm{n} 9$, 382n13, 393, 407, 412n 4, 416, 423n8

Valisinha, Devipriya 366

Van der Veer, P. 449

Vanita, Ruth 291

'vanvasis' 298, 301, 302

Varanasi 356, 359n7, 377, 444

Varier, P. S. 188

Varma, Raja Ravi 288

varma therapy $479,487 \mathrm{n} 10$

varna 243

Varshney, Ashutosh 206, 207

vāta-pitta-kapa, balance of 480; imbalance of 483 ; increase in the body by excess food 484 ; rectifying the imbalance of 486

vegetarianism 275, 280-1, 466

Verma, Justice 62

Vibrant Gujarat summits 279

Vidarbha 124

Vietnam 131, 136, 138, 140

Vijayanagara empire 341, 342, 343 
violence: anti-Christian 420, 422; Bharatiya Janata Party and 1992 357; Bharatiya Janata Party and 2002 126, 271; and caste 250; communal 14-15, 23, 31, 400-11; against Dalits 250; and the ethnic 121; female body 430-2; Hindu-Muslim 393, 403-12; in Kashmir 125-6; partition 5, 21-5, 31, 32, 32n2, 35; terrorist 36, 41, 44, 121, 127, 130, 141, 143n11, 166, 393, 396n15, 408, 412n9

Vishva Hindu Parishad 166, 280, 411n1

Vishwanathan, Susan 436

Vișnu/Vishnu 331, 332, 334, 335, 367

Vișnupurāna 322, 331

Vivekananda 3, 172, 176, 178, 179, 182n10

Vivekananda Kendra 173

Vivekananda Yoga Kendra 172

'vote banks' 41, 221, 223, 264, 392

Wacquant, L. 451

Wade, Robert 267

Wali-Ullah, Shah 386

Weber, Max 233, 244

Weisskopf, Thomas 88

Wertheimer, Linda 344

West Bengal 7, 76, 124, 127, 207, 289, 290, $300,342,355,403$

'westernisation' of diets 460

widow-remarriage 287

Winlow, Simon 451

women: anti-colonial construction of the new 437; devaluing the labour of 432-6; increased number of divorced, single and working 439; new visibility of on the political stage 4, 430, 440; as symbolic markers of the nation 436-9; violence to the bodies of 430-2

women's movement 283-4, 292-3, 432; reforms and backlashes in 284; unite to organize public opinion 432

working class 104, 113n1, 290, 430, 433, 449, 462

world's largest democracy 2, 99, 320, 321 Wujastyk, Dominik 187-8

Xavier, Francis 414

Yew, Lee Kuan 138

yoga $3,9,17 \mathrm{n} 9,172-83,191,193,195,322$, 448, 474, 478; and bodybuilding 175-6, 179; and creative dialogue with global physical culture movements 174; and the global physical culture movement 174-6; and harmonial gymnastics 179-80; and physical culture in India 176-9; as an Indian method of holistic fitness 174

Yoga Institute 172

Yoga Journal 173

Yogananda, Paramahamsa 178, 179

Yogasūtra 322

Yogendra, Shri 177, 178

yugas ('world periods') 323, 325-6; theory of declining 323 